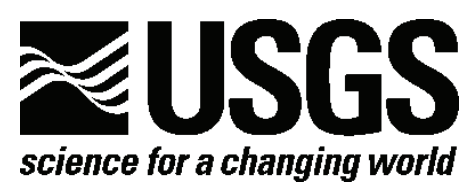

In cooperation with the Los Angeles County Department of Public Works and the Water Replenishment District of Southern California

\title{
Paleontology and Geochronology of the Long Beach Core Sites and Monitoring Wells, Long Beach, California
}

By Kristin McDougall, John Hillhouse, Charles Powell, II, Shannon Mahan, Elmira Wan, and Andrei M. Sarna-Wojcicki

Open-File Report 2011-1274 


\section{U.S. Department of the Interior \\ KEN SALAZAR, Secretary}

\section{U.S. Geological Survey \\ Marcia K. McNutt, Director}

U.S. Geological Survey, Reston, Virginia: 2012

For product and ordering information:

World Wide Web: http://www.usgs.gov/pubprod

Telephone: 1-888-ASK-USGS

For more information on the USGS-the Federal source for science about the Earth, its natural and living resources, natural hazards, and the environment:

World Wide Web: http://www.usgs.gov

Telephone: 1-888-ASK-USGS

Suggested citation:

McDougall, K., Hillhouse, J., Powell, C., II, Mahan, S., Wan, E., and Sarna-Wojcicki, A.M., 2012, Paleontology and geochronology of the Long Beach core sites and monitoring wells, Long Beach, California: U.S. Geological Survey Open-File Report 2011-1274.

Any use of trade, product, or firm names is for descriptive purposes only and does not imply endorsement by the U.S. Government.

Although this report is in the public domain, permission must be secured from the individual copyright owners to reproduce any copyrighted material contained within this report. 


\section{Contents}

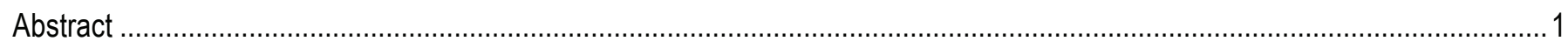

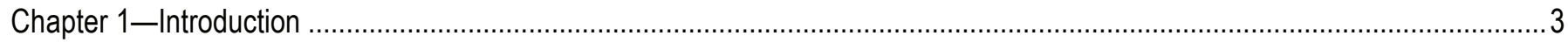

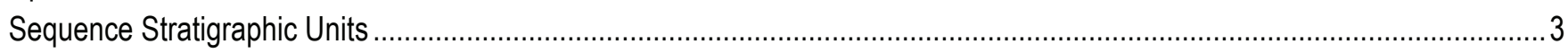

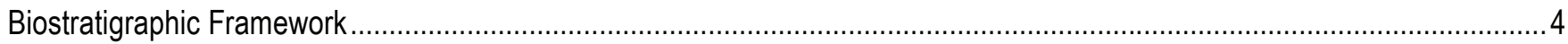

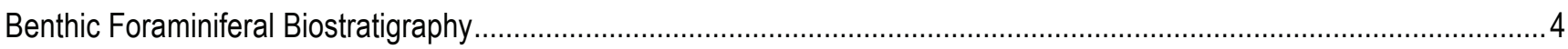

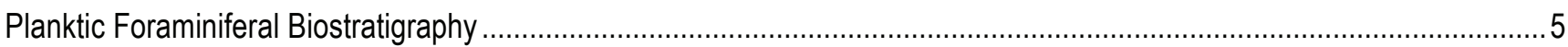

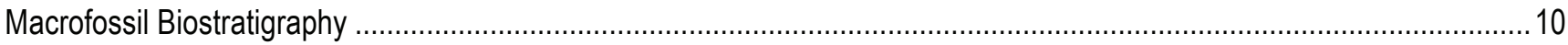

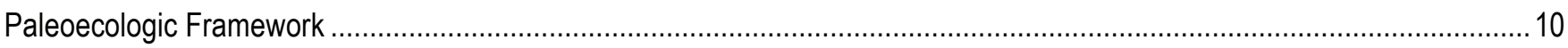

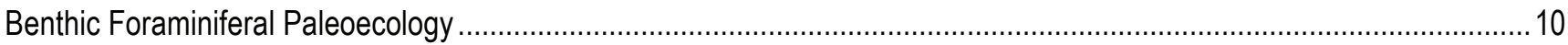

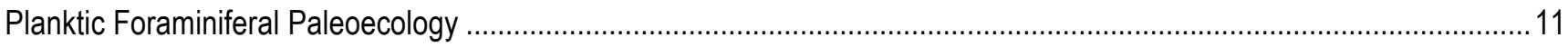

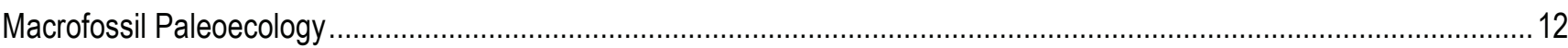

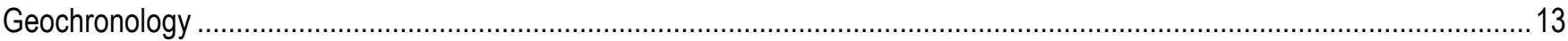

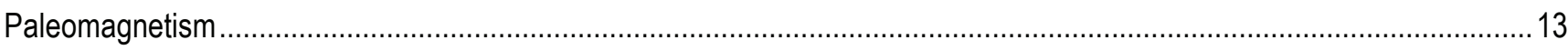

Chapter 2-Long Beach Pier F Core Site and Monitoring Well, Long Beach, California .................................................... 15

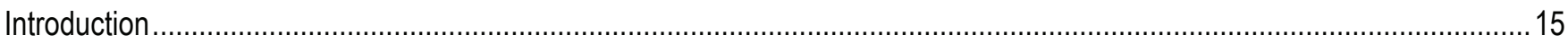

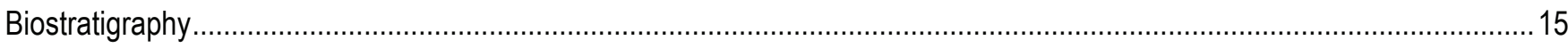

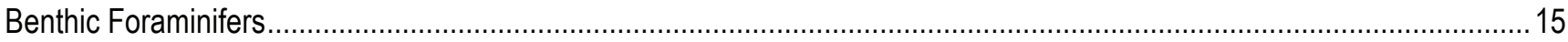

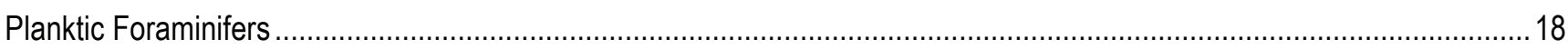

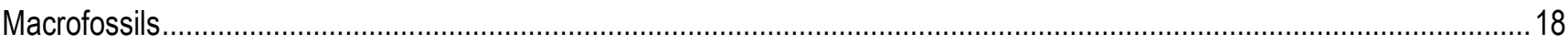

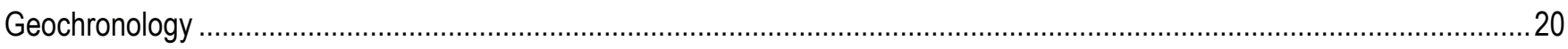

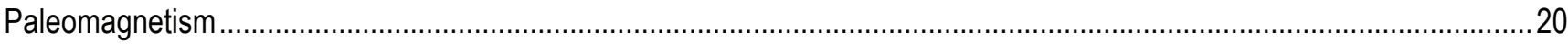

Optically Stimulated Luminescence and Thermal Luminescence Dating ..................................................................26

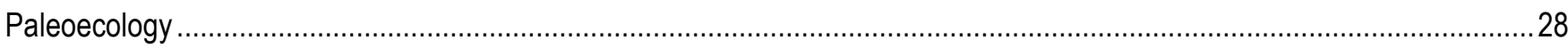

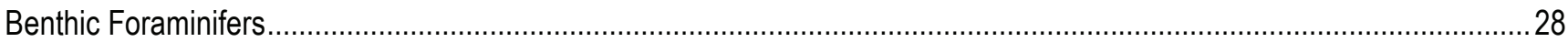

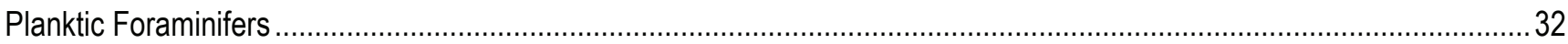

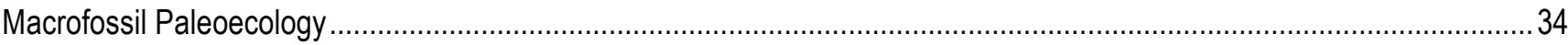

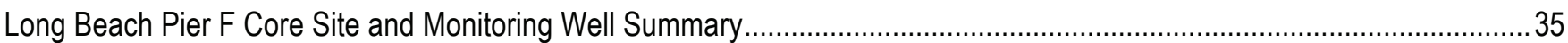

Chapter 3-Long Beach Pier C Core Site and Monitoring Well, Long Beach, California ............................................................39

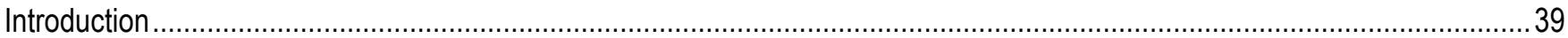

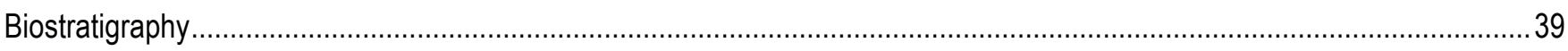

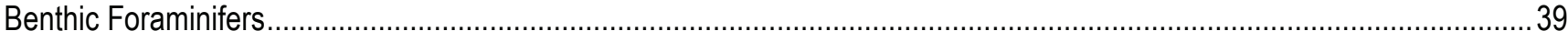

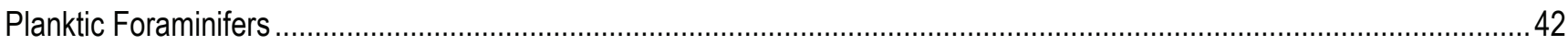

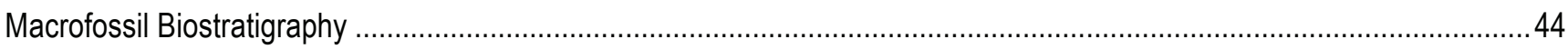

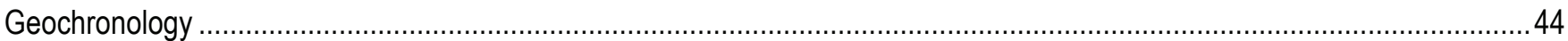

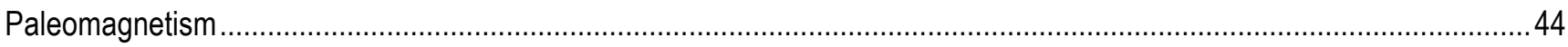

Optically Stimulated Luminescence and Thermal Luminescence Dating .................................................................50

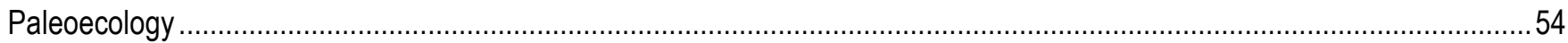

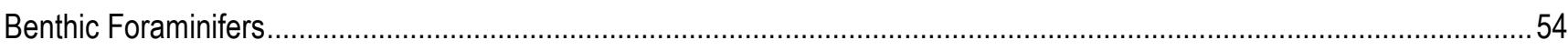

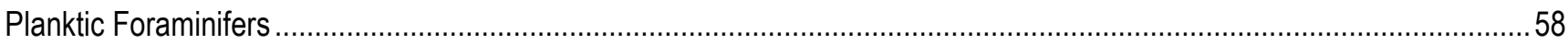

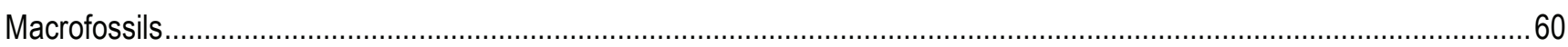

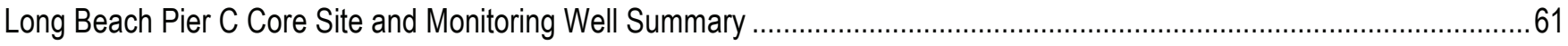

Chapter 4-Long Beach Cabrillo High School Core Site and Monitoring Well, Long Beach, California ......................................65

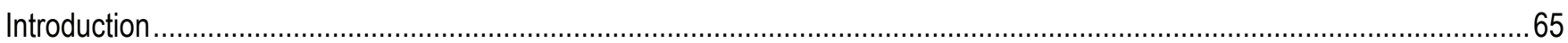




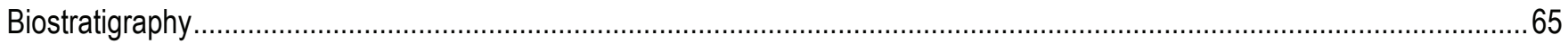

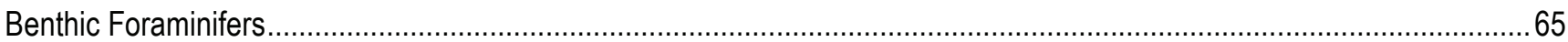

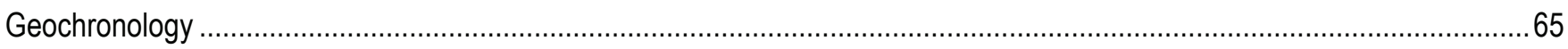

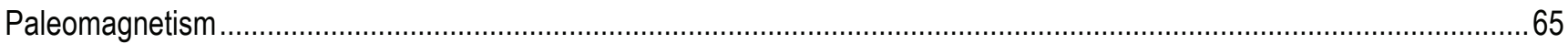

Optically Stimulated Luminescence and Thermal Luminescence Dating ....................................................................68

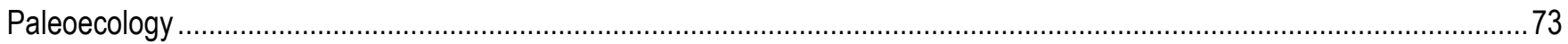

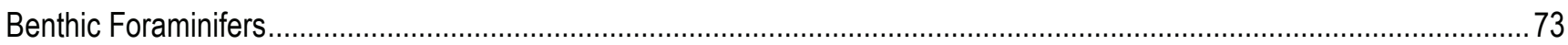

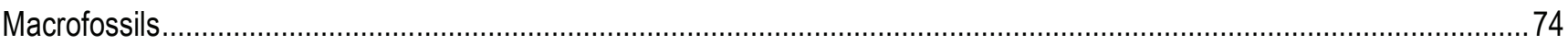

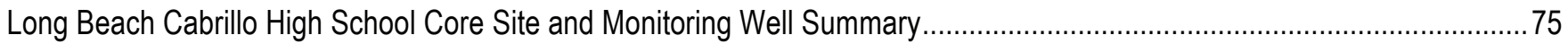

Chapter 5-Long Beach Webster School Core Site and Monitoring Well, Long Beach, California ...........................................79

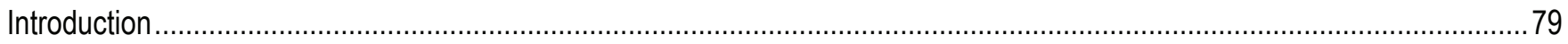

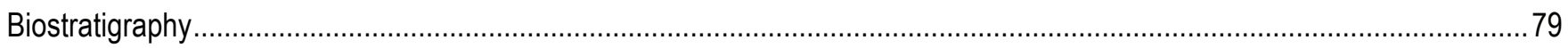

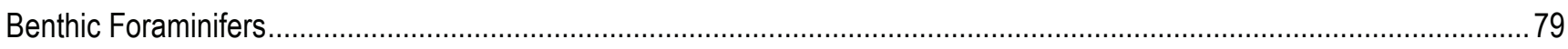

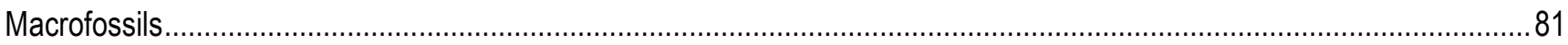

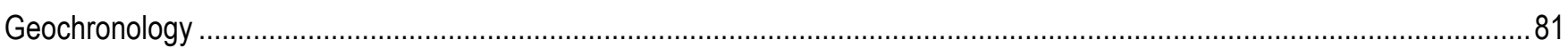

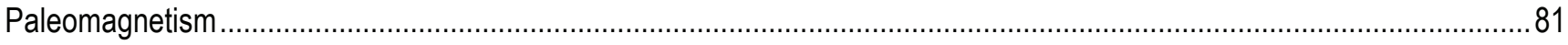

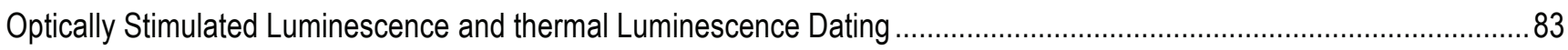

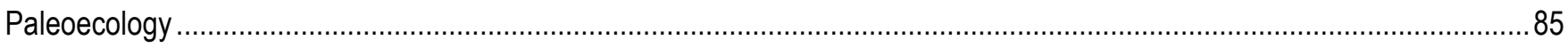

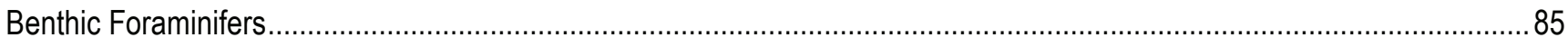

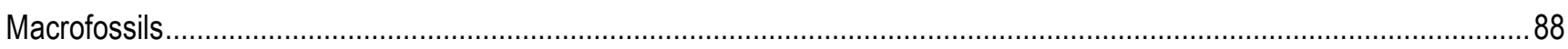

Long Beach Webster School Core Site and Monitoring Well Summary .....................................................................92

Chapter 6-Long Beach City College Core Site and Monitoring Well, Long Beach, California .............................................95

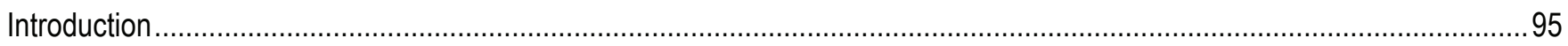

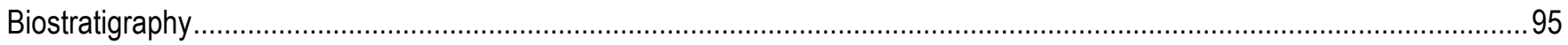

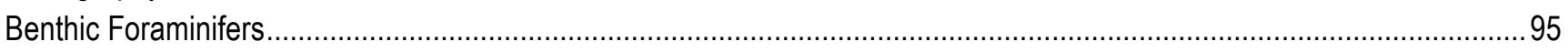

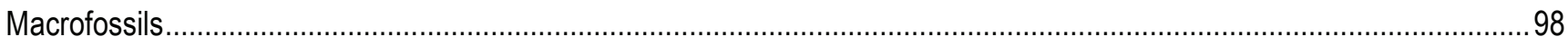

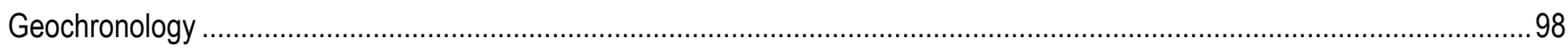

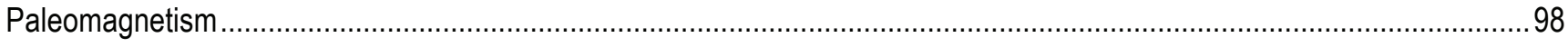

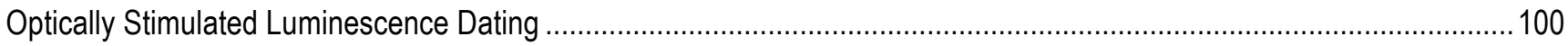

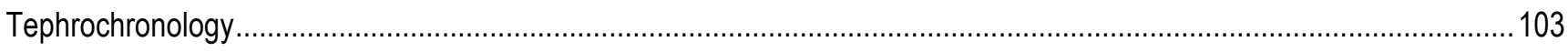

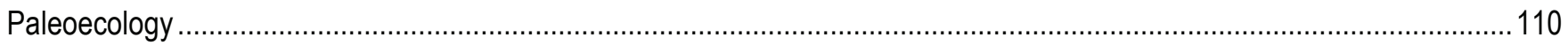

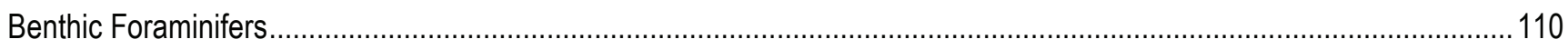

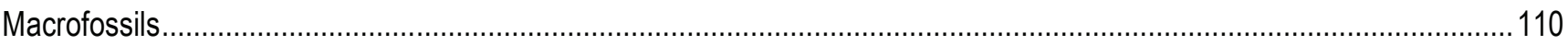

Long Beach City College Core Site and Monitoring Well Summary ......................................................................113

Chapter 7-Long Beach Water Treatment Plant Core Site and Monitoring Well, Long Beach, California...............................117

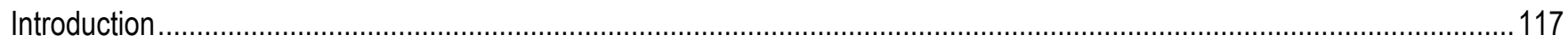

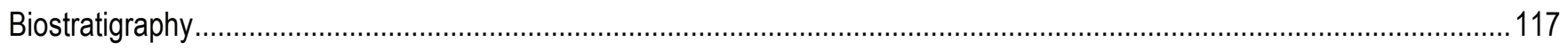

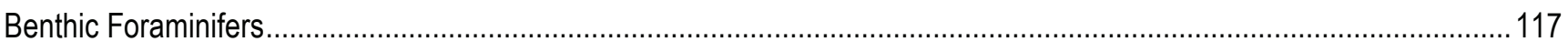

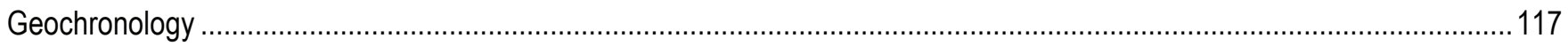

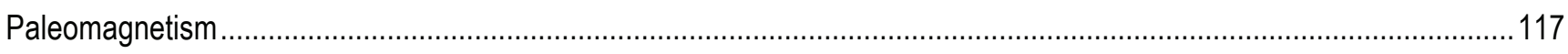

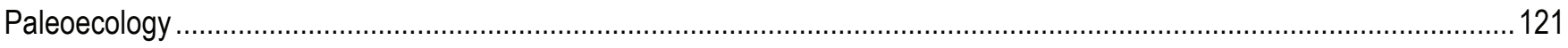

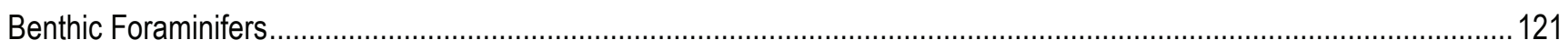

Long Beach Water Treatment Plant Core Site and Water Monitoring Well Summary .................................................... 121

Chapter 8-Long Beach Water \# 1 Core Site and Monitoring Well, Long Beach, California ..................................................124

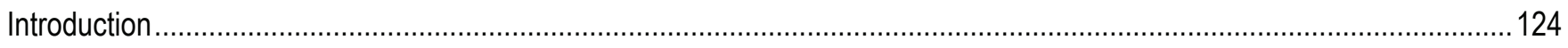




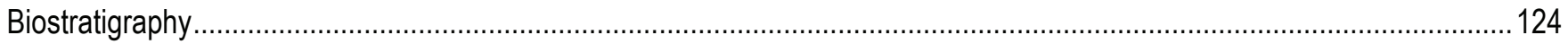

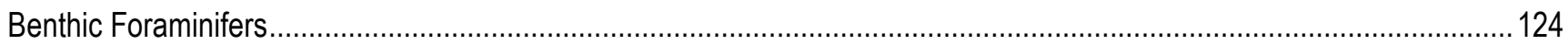

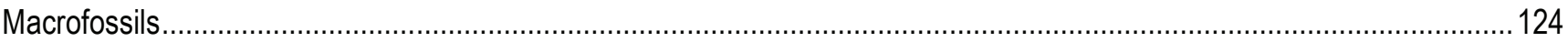

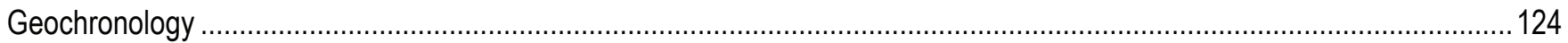

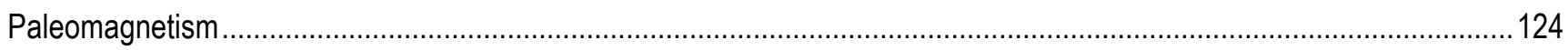

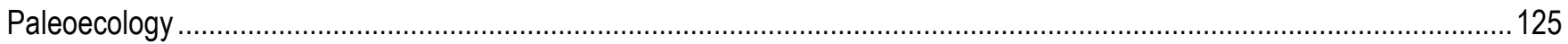

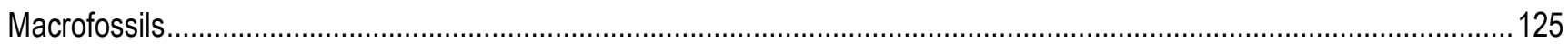

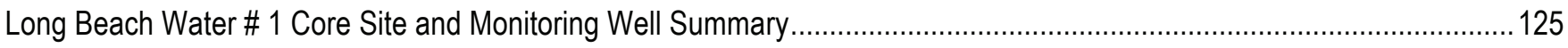

Chapter 9-Westchester Core Site and Monitoring Well, Westchester, California ............................................................129

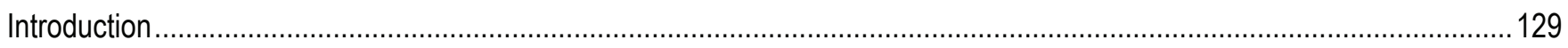

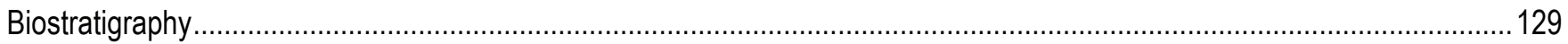

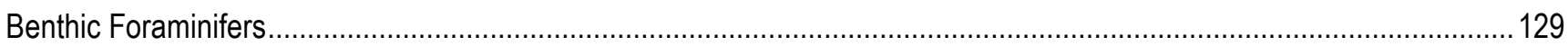

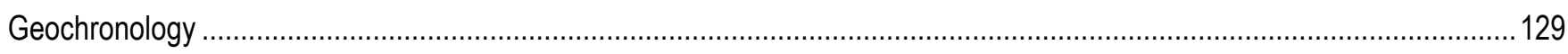

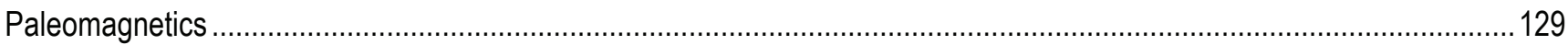

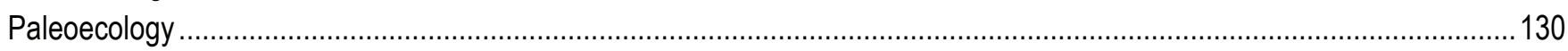

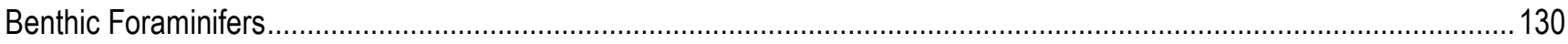

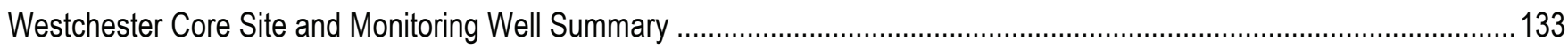

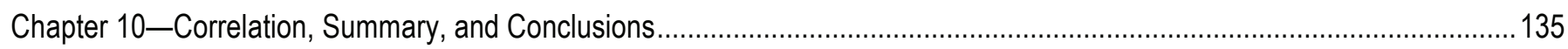

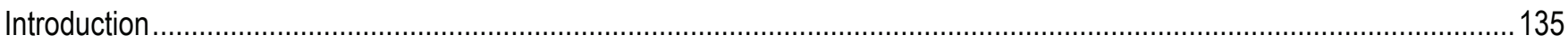

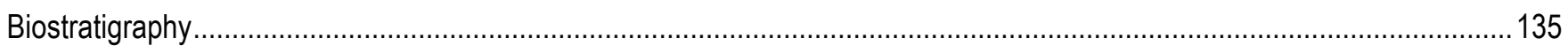

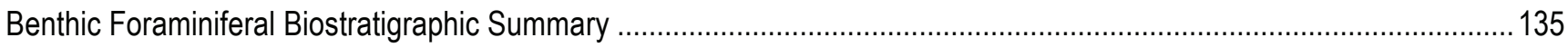

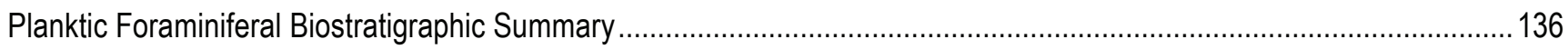

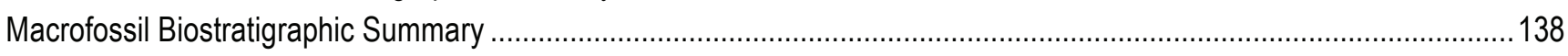

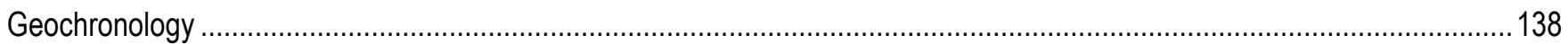

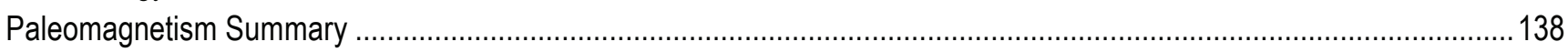

Optically Stimulated Luminescence and Thermal Luminescence Summary .............................................................. 140

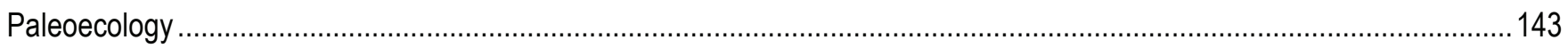

Age, Correlation, and Paleoecology of the Sequence Stratigraphic Units ............................................................. 143

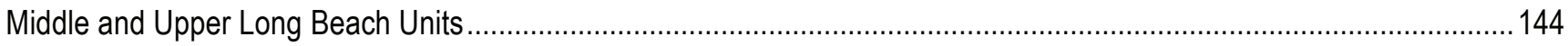

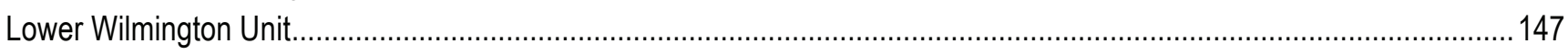

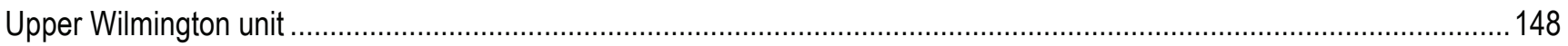

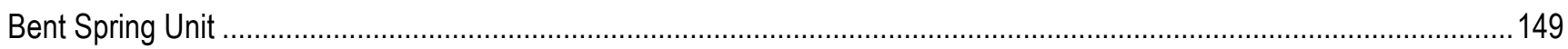

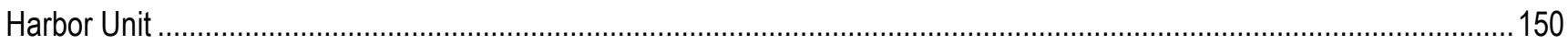

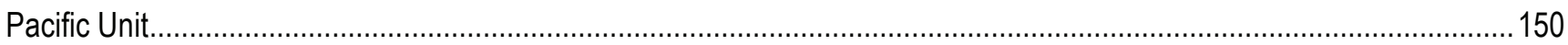

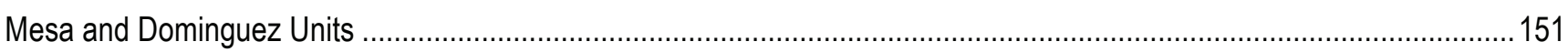

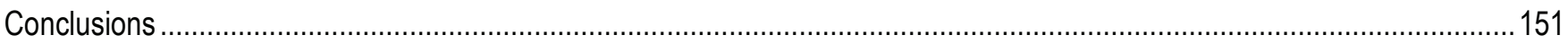

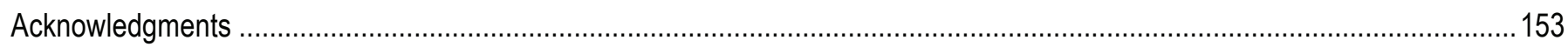

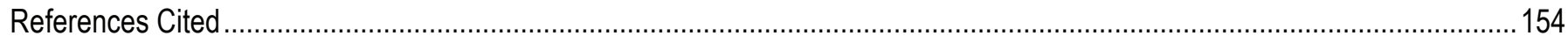

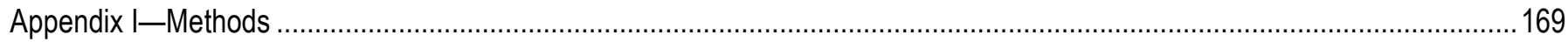

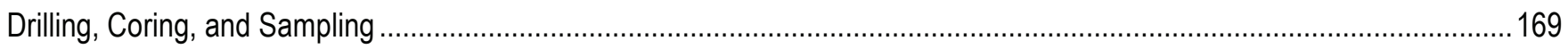

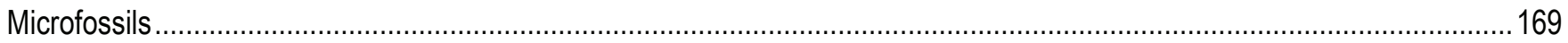

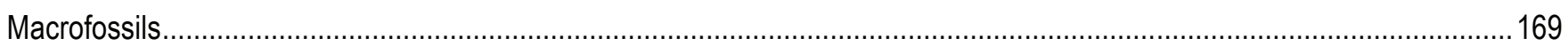

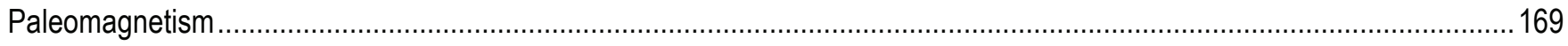

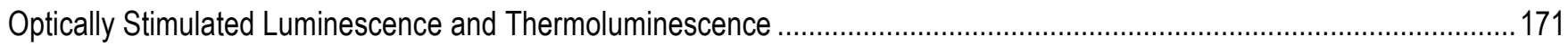

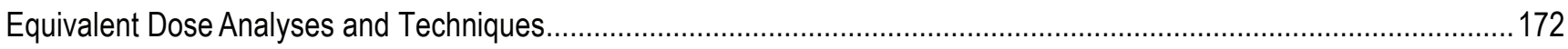


Dosimetry

Tephrochronology

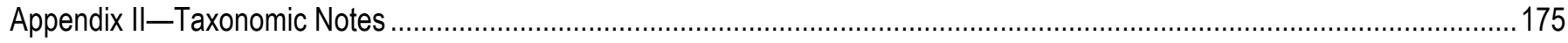

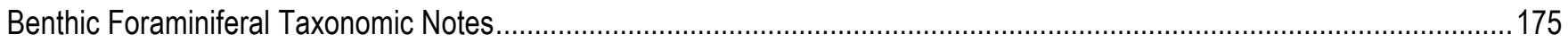

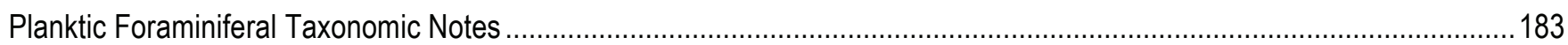

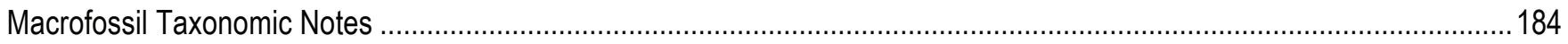

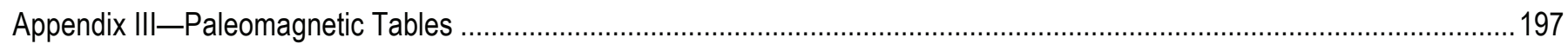

\section{Figures}

Figure 1. Map of the Los Angeles Basin, California, showing geographic distribution of the wells used in this study .............4

Figure 2. Age estimates of Pleistocene sequences in the Los Angeles Basin, California.................................................. 6

Figure 3. Correlation of late Cenozoic benthic foraminiferal stages with chronostratigraphic frameworks based on other

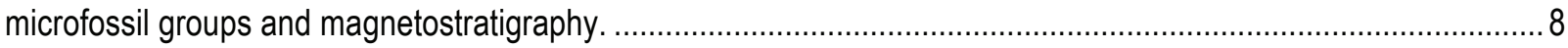

Figure 4. Key benthic foraminifers used to recognize the Pliocene and Pleistocene stages of Natland............................... 8

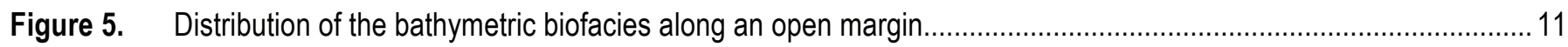

Figure 6. Distribution of benthic foraminiferal biofacies in a continental borderland setting............................................ 12

Figure 7. Dissolved-oxygen facies and associated benthic foraminiferal species............................................................. 13

Figure 8. Correlation of geologic epochs and ages with the Geomagnetic Polarity Timescale for Pliocene and Pleistocene

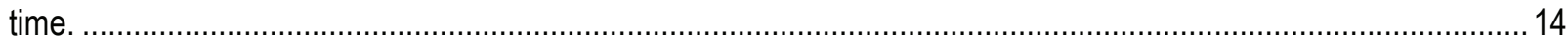

Figure 9. Abundance and diversity of the foraminiferal fauna in Long Beach Pier F core site and monitoring well, Long Beach, California...

Figure 10. Stratigraphic distribution of age-diagnostic benthic foraminifers in Long Beach Pier $F$ core site and monitoring

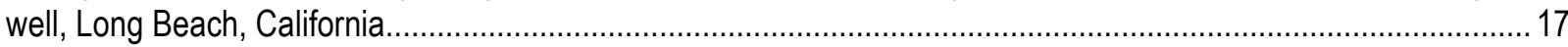

Figure 11. Stratigraphic distribution of age-diagnostic planktic foraminifers in Long Beach Pier F core site and monitoring well, Long Beach, California..

Figure 12. Remanent magnetization intensity and magnetic susceptibility of Long Beach Pier F core site and monitoring well, Long Beach, California.

Figure 13. Resistance of remanence to alternating-field demagnetization of the Long Beach Pier $\mathrm{F}$ core site and monitoring well, Long Beach, California...

Figure 14. Inclination of remanent magnetization with depth in Long Beach Pier F core site and monitoring well, Long Beach, California.

Figure 15. Electron-microprobe scan of magnetic grain from LBPF 55/1 showing thin iron-sulfide rim surrounding a

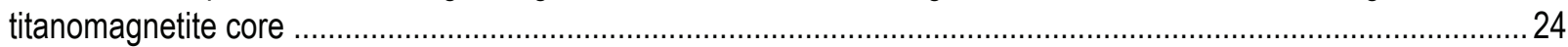

Figure 16. Electron-microprobe scan of magnetic grain from LBPF 221/1 showing titanomagnetite with ilmenite lamellae ..... 25

Figure 17. Electron-microprobe scan of magnetic grain from LBPF 51/1 showing convoluted internal structure commonly associated with titanohematite in high-grade metamorphic rocks

Figure 18. A, Optically stimulated luminescence decay curve for LBPF-13C $(36.5 \mathrm{~m})$. B, LBPF-13C growth curve ...............29

Figure 19. Growth curve of IRSL-OSL in the sample at $59.2 \mathrm{~m}$ (LBPF-28C) obtained using multi-aliquot additive dose method

Figure 20. Paleoecological benthic foraminiferal biofacies analyses of the Long Beach Pier F core site and monitoring well, Long Beach, California......

Figure 21. Distribution of Neogloboquadrina pachyderma in Long Beach Pier F core site and monitoring well, Long Beach, California.

Figure 22. Summary of geochronology of Long Beach Pier F core site and monitoring well, Long Beach, California .......

Figure 23. Summary of ecological interpretations of the Long Beach Pier F core site and monitoring well, Long Beach, 
Figure 24. Abundance and diversity of the foraminiferal fauna in the Long Beach Pier C core site and monitoring well, Long Beach, California.

Figure 25. Stratigraphic distribution of age-diagnostic benthic foraminifers in Long Beach Pier $\mathrm{C}$ core site and monitoring well, Long Beach, California..

Figure 26. Stratigraphic distribution of age-diagnostic planktic foraminifers in the Long Beach Pier C core site and monitoring well, Long Beach, California.

Figure 27. Intensity of natural remanent magnetization and the lithologic $\log$ of the Long Beach Pier $\mathrm{C}$ core site and monitoring well, Long Beach, California.

Figure 28. Magnetic susceptibility from the whole-core logger and lithology of the Long Beach Pier C core site and monitoring well, Long Beach, California...

Figure 29. Ratio of partially demagnetized magnetization to natural remanent magnetization for the $15 \mathrm{mT}(\mathrm{J} 15)$ and $30 \mathrm{mT}$ (J30) treatment steps for Long Beach Pier C core site and monitoring well, Long Beach, California.....

Figure 30. Magnetic inclination with depth in Long Beach Pier $\mathrm{C}$ core site and monitoring well, Long Beach, California ......... 49

Figure 31. Magnetic inclination of the resampled interval shown in figure 30 for Long Beach Pier $\mathrm{C}$ core site and monitoring well, Long Beach, California...

Figure 32. Magnetic inclinations screened for maximum angle of deviation less than 10.0 degrees for Long Beach Pier $\mathrm{C}$ core site and monitoring well, Long Beach, California

Figure 33. Electron-microprobe scan of a titanomagnetite grain containing ilmenite lamellae ...........................................52

Figure 34. Electron-microprobe scan of an ilmenohematite grain in the Long Beach Pier C core site and monitoring well,

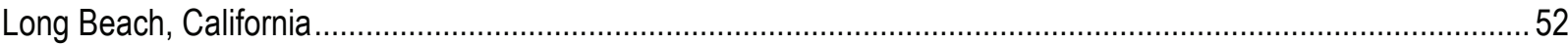

Figure 35. Electron-microprobe scan of a magnetite grain with a thin iron-sulfide rim, LBPC 234C-2 ..............................53

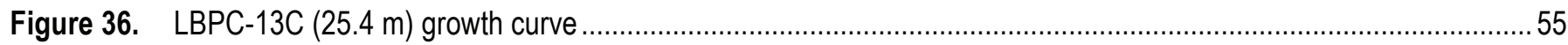

Figure 37. Growth curve of IRSL-OSL in the sample at $80.4 \mathrm{~m}$ (LBPC-61C) obtained using multi-aliquot additive dose method

Figure 38. Paleoecological benthic foraminiferal biofacies analysis of Long Beach Pier C core site and monitoring well, Long Beach, California

Figure 39. Distribution of Neogloboquadrina pachyderma in Long Beach Pier C core site and monitoring well, Long

Beach, California.

Figure 40. Summary of geochronology of Long Beach Pier $C$ core site and monitoring well, Long Beach, California

Figure 41. Summary of ecological interpretations for Long Beach Pier C core site and monitoring well, Long Beach,

California

Figure 42. Abundance and diversity of the foraminiferal fauna in Long Beach Cabrillo High School core site and monitoring well, Long Beach, California..

Figure 43. Stratigraphic distribution of age-diagnostic benthic foraminifers in Long Beach Cabrillo High School core site and monitoring well, Long Beach, California.

Figure 44. Remanent magnetization properties and magnetic susceptibility of Long Beach Cabrillo High School core site and monitoring well, Long Beach, California.

Figure 45. A. Optically stimulated luminescence (OSL) decay curve for LBCH-42C (41.6 m). B. LBCH-42C growth curve .....70

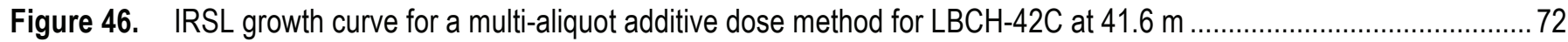

Figure 47. Paleoecological benthic foraminiferal biofacies analysis of Long Beach Cabrillo High School core site and monitoring well, Long Beach, California.....

Figure 48. Distribution and paleoecologic interpretation of macrofossil samples in the Long Beach Cabrillo High School core site and monitoring well, Long Beach, California .....

Figure 49. Summary of geochronology of Long Beach Cabrillo High School core site and monitoring well, Long Beach, California

Figure 50. Summary of ecological interpretations on Long Beach Cabrillo High School core site and monitoring well, Long Beach, California. 
Figure 51. Stratigraphic distribution of age-diagnostic benthic foraminifers in Long Beach Webster School core site and monitoring well, Long Beach, California......

Figure 52. Magnetic inclination versus depth in Long Beach Webster School core site and monitoring well, Long Beach, California.

Figure 53. Histogram showing distribution of inclinations relative to the expected inclination at the Long Beach Webster

School core site and monitoring well, Long Beach, California

Figure 54. Expanded view of inclinations from the upper $180 \mathrm{~m}$ of the Long Beach Webster School core site and monitoring well, Long Beach, California.

Figure 55. Sensitivity-corrected optically stimulated luminescence growth curve for an single aliquot run of sample LWEB-5C

Figure 56. IRSL growth curve for a multi-aliquot run of sample LWEB-5C at $7.3 \mathrm{~m}$ in the Long Beach Webster School core site and monitoring well, Long Beach, California

Figure 57. Growth curve of TL in sample LWEB-5C, taken at $7.3 \mathrm{~m}$ in the well, using multi-aliquot additive dose techniques

Figure 58. Paleoecological benthic foraminiferal biofacies analysis of Long Beach Webster School core site and monitoring well, Long Beach, California.....

Figure 59. Distribution and paleoecologic interpretation of macrofossils in Long Beach Webster School core site and monitoring well, Long Beach, California

Figure 60. Summary of geochronology of Long Beach Webster School core site and monitoring well, Long Beach, California.

Figure 61. Summary of paleoecological interpretations of Long Beach Webster School core site and monitoring well, Long Beach, California.

Figure 62. Abundance and diversity of the foraminiferal fauna in Long Beach City College core site and monitoring well, Long Beach, California

Figure 63. Stratigraphic distribution of age-diagnostic benthic foraminifers in Long Beach City College core site and monitoring well, Long Beach, California.

Figure 64. Remanent-magnetization properties and magnetic susceptibility of Long Beach City College core site and monitoring well, Long Beach, California.

Figure 65. A. Optically stimulated luminescence decay curve for LBCC-15C $(22.7 \mathrm{~m})$. B. LBCC-15C growth curve ............ 101

Figure 66. A. Optically stimulated luminescence decay curve for LBCC-52C (105.0 m). B. LBCC-52C growth curve ............102

Figure 67. IRSL growth curve for a multi-aliquot additive dose method of sample at 22.7 (LBCC 15) ................................103

Figure 68. Scanning electron microscope pictures of bubble-wall junction shards and glass-encased spherical bubble walls on flanks from Lava Creek B ash collected from Long Beach City College core site and monitoring well, Long Beach, California.

Figure 69. $\mathrm{Fe}_{2} \mathrm{O}_{3}$ versus $\mathrm{CaO}$ scatter-plot showing graphic geochemical fingerprint of sample at $378 \mathrm{~m}$ (LBCC 108, C-1, $45-51 \mathrm{~cm}$ ), a rhyolitic volcanic glass with intermediate and low concentrations, respectively, of $\mathrm{Fe}_{2} \mathrm{O}_{3}$ and $\mathrm{CaO}$

Figure 70. Composite $\mathrm{Fe}_{2} \mathrm{O}_{3}$ versus $\mathrm{CaO}$ scatter-plot of sample at $378 \mathrm{~m}$ (LBCC 108, C-1, 45-51 cm) and JRK-DV-70 illustrating good overlap of analyzed points and few outliers

Figure 71. Map showing relative locations of sample at $378 \mathrm{~m}$ (LBCC 108, C-1, 45-51 cm) and JRK-DV-70, areal distribution of $\left(639 \pm 2 \mathrm{ka},{ }^{40} \mathrm{Ar} /{ }^{39} \mathrm{Ar}\right)$ Lava Creek B ash deposits, and eruptive source (star) in the Yellowstone area of Wyoming and Idaho

Figure 72. Paleoecological benthic foraminiferal biofacies analysis of Long Beach City College core site and monitoring well, Long Beach, California.

Figure 73. Distribution and paleoecologic interpretation of macrofossils from the Long Beach City College core site and monitoring well, Long Beach, California

Figure 74. Summary of geochronology of Long Beach City College based on the microfossils, macrofossils, paleomagnetics, luminescence, and radiocarbon... 
Figure 75. Summary of paleoecologic interpretations of Long Beach City College core site and monitoring well, Long

Beach, California...

Figure 76. Abundance and diversity of the foraminiferal fauna in Long Beach Water Treatment Plant core site and monitoring well, Long Beach, California...

Figure 77. Stratigraphic distribution of age-diagnostic benthic foraminifers in Long Beach Water Treatment Plant core site and monitoring well, Long Beach, California

Figure 78. Remanent-magnetization properties of the Long Beach Water Treatment Plant core site and monitoring well, Long Beach, California

Figure 79. Paleoecological benthic foraminiferal biofacies analysis of Long Beach Water Treatment Plant core site and monitoring well, Long Beach, California

Figure 80. Summary of geochronology of Long Beach Water Treatment Plant core site and monitoring well, Long Beach, California.

Figure 81. Inclination after alternating-field treatment and intensity of natural remanent magnetization of specimens from Long Beach Water \# 1 core site and monitoring well, Long Beach, California

Figure 82. Distribution and paleoecologic interpretation of macrofossil samples in Long Beach Water \# 1 core site and monitoring well, Long Beach, California.....

Figure 83. Abundance and diversity of the foraminiferal fauna in Westchester core site and monitoring well, Westchester,

California.

Figure 84. Stratigraphic distribution of age-diagnostic benthic foraminifers in the Westchester core site and monitoring well, Westchester, California.

Figure 85. Remanent-magnetization properties and magnetic susceptibility of the Westchester core site and monitoring well, Westchester, California.

Figure 86. Paleoecological benthic foraminiferal biofacies analysis of the Westchester core site and monitoring well, Westchester, California

Figure 87. Summary of geochronology of the Westchester core site and monitoring well, Westchester, California

Figure 88. Detailed summary of the planktic foraminiferal-age interpretation of the Long Beach Pier $\mathrm{F}$ and Pier $\mathrm{C}$ core site and monitoring wells, Long Beach, California

Figure 89. Summary of paleomagnetic inclination data

Figure 90. Ages obtained as a result of quartz optically stimulated luminescence, feldspar infrared stimulated luminescence, thermal luminescence, and radiocarbon analysis are plotted in each well

Figure 91. Distribution of the sequence stratigraphic units of Ponti and others (2007) encountered in the FOQUS-LA wells with respect to the chronostratigraphic and biostratigraphic time scales, marine oxygen-isotope paleoclimate curve, and the coastal onlap curve

Figure 92. Cross-sectional view of a generalized core, showing location of specimen for paleomagnetic analysis

\section{Tables}

Table 1. Well location and depth used in this study.

Table 2. Correlation table relating sequence stratigraphic units to nomenclature in the Long Beach/Dominquez Gap region, California, and age criteria

Table 3. Planktic foraminiferal zonation scheme used as biostratigraphic framework for nearshore USGS FOQUS-LA wells, Long Beach, California.

Table 4. Paleomagnetic results from Long Beach Pier F core site and monitoring well, Long Beach, California.

Table 5. Thermoluminescence feldspar infrared stimulated luminescence, and quartz optically stimulated luminescence ages for Long Beach Pier F core site and monitoring well, Long Beach, California

Table 6. Elemental concentrations and associated dosimetry for the Long Beach Pier F core site and monitoring well, Long Beach, California, optically stimulated luminescence samples

Table 7. Paleomagnetic results from Long Beach Pier $\mathrm{C}$ core site and monitoring well, Long Beach, California 
Table 8. Thermoluminescence, feldspar infrared stimulated luminescence and quartz blue-light optically stimulated luminescence ages for the Long Beach Pier $\mathrm{C}$ core site and monitoring well, Long Beach, California.....

Table 9. Elemental concentrations and associated dosimetry for the Long Beach Pier $\mathrm{C}$ core site and monitoring well, Long Beach, California, optically stimulated luminescence samples

Table 10. Intensity of remanent magnetization and magnetic susceptibility of Long Beach Cabrillo High School core site and monitoring well, Long Beach, California, samples

Table 11. Paleomagnetic results for Long Beach Cabrillo High School core site and monitoring well, Long Beach, California .

Table 12. Thermoluminescence, feldspar infrared stimulated luminescence and quartz blue-light optically stimulated luminescence ages for the Long Beach Cabrillo High School core site and monitoring well Long Beach,

California

Table 13. Elemental concentrations and associated dosimetry for Long Beach Cabrillo High School core site and monitoring well, Long Beach, California, optically stimulated luminescence samples.....

Table 14. Paleomagnetic results for the Long Beach Webster School core site and monitoring well, Long Beach, California

Table 15. Thermoluminescence, feldspar infrared stimulated luminescence and quartz blue-light optically stimulated luminescence ages for Long Beach Webster School, Long Beach, California

Table 16. Elemental concentrations and associated dosimetry for Long Beach Webster School core site and monitoring well, Long Beach, California, optically stimulated luminescence samples.

Table 17. Intensity of remanent magnetization and magnetic susceptibility of the Long Beach City College core site and monitoring well samples

Table 18. Paleomagnetic results from the Long Beach City College core site and monitoring well, Long Beach, California ...98

Table 19. Feldspar infrared stimulated luminescence and quartz optically stimulated luminescence ages for the Long Beach City College core site and monitoring well, Long Beach, California. 104

Table 20. Elemental concentrations and associated dosimetry for Long Beach City College core site and monitoring well, Long Beach, California, optically stimulated luminescence samples

Table 21. Electron microprobe analytical data for LBCC108, C-1 (378 m), Long Beach City College core site and monitoring well, Long Beach, California. 107

Table 22. Similarity coefficient list with normalized geochemical data including six major and three minor oxides for LBCC 108, C-1 (378 m), Long Beach City College core site and monitoring well, Long Beach, California, and comparative data of closest chemical correlations.

Table 23. Paleomagnetic results from the Long Beach Water Treatment core site and monitoring well Long Beach, California .

Table 24. Paleomagnetic results from the Long Beach Water well \# 1 core site and monitoring well, Long Beach,

California

Table 25. Paleomagnetic results from the Westchester core site and monitoring well, Westchester, California 129

Table 26. Correlation of sequence stratigraphic units to age criteria for selected Long Beach wells, Long Beach, California

\section{Plates}

Plate 1. Distribution of benthic foraminifers in the Long Beach Pier F core site and monitoring well, Long Beach, California

Plate 2. Distribution of planktic foraminifers in the Long Beach Pier F core site and monitoring well, Long Beach, California

Plate 3. Distribution of macrofossils in the Long Beach Pier F core site and monitoring well, Long Beach, California

Plate 4. Distribution of benthic foraminifers in the Long Beach Pier $\mathrm{C}$ core site and monitoring well, Long Beach, California 
Plate 5. Distribution of planktic foraminifers in the Long Beach Pier C core site and monitoring well, Long Beach, California

Plate 6. Distribution of macrofossils in the Long Beach Pier C core site and monitoring well, Long Beach, California

Plate 7. Distribution of benthic foraminifers in the Long Beach Cabrillo High School core site and monitoring well, Long Beach, California

Plate 8. Distribution of macrofossils in the Long Beach Cabrillo High School core site and monitoring well, Long Beach, California

Plate 9. Distribution of benthic foraminifers in the Long Beach Webster School core site and monitoring well, Long Beach, California

Plate 10. Distribution of macrofossils in the Long Beach Webster School core site and monitoring well, Long Beach, California

Plate 11. Distribution of benthic foraminifers in the Long Beach City College core site and monitoring well, Long Beach, California

Plate 12. Distribution of macrofossils in the Long Beach City College core site and monitoring well, Long Beach, California

Plate 13. Distribution of benthic foraminifers in the Long Beach Water Treatment Plant core hole and monitoring well, Long Beach, California

Plate 14. Distribution of macrofossils in the Long Beach \#1 core site and monitoring well, Long Beach, California

Plate 15. Distribution of benthic foraminifers in the Westchester core site and monitoring well, Westchester, California

Plate 16. Summary of biostratigraphic ages of the FOQUS-LA wells obtained from the micro- and macrofossil analysis

Plate 17. Summary of the paleoecologic interpretations of the FOQUS-LA wells obtained from the micro- and macrofossil analysis

Plate 18. Paleoecological benthic foraminiferal biofacies analyses of the Long Beach core sites and monitoring wells 
This page intentionally left blank 


\title{
Paleontology and Geochronology of the Long Beach Core Sites and Monitoring Wells, Long Beach, California
}

\author{
By Kristin McDougall, John Hillhouse, Charles Powell, II, Shannon Mahan, Elmira Wan, and
} Andrei M. Sarna-Wojcicki

\section{Abstract}

The U.S. Geological Survey Focus on Quaternary Stratigraphy in Los Angeles (FOQUSLA) project was a cooperative coring program between Federal, State, and local agencies. It was designed to provide a better understanding of earthquake potentials and to develop a stratigraphic model of the western Los Angeles Basin in California. The biostratigraphic, geochronologic, and paleoecologic analyses of eight wells drilled during the FOQUS-LA project are presented. These analyses are based on microfossils (benthic and planktic foraminifers), macrofossils, paleomagnetic stratigraphy, optically stimulated luminescence (OSL), thermoluminescence (TL), radiocarbon dating, and tephrochronology. These analyses also augment the preliminary biostratigraphic, chronostratigraphic, and paleoecologic interpretations of five key wells published by Ponti and others (2007, USGS Open-File Report 2007-1013).

The results of this study show that (1) the offshore California margin (CM) zones can be used in a nearshore setting, and (2) the CM zonal scheme refines the chronostratigraphic resolution of the benthic foraminiferal biostratigraphic framework for the Pacific Coast. Benthic foraminiferal stages are modified by the recognition of an early Hallian substage, which is a faunal change recognized throughout the Los Angeles Basin. The age of the Hallian/Wheelerian Stage boundary is between 0.60 and $0.78 \mathrm{Ma}$, and the Wheelerian/Venturian Stage boundary occurs between 1.80 and $1.95 \mathrm{Ma}$. The benthic foraminiferal stages are correlated to the CM zones: the Hallian Stage correlates with CM1, the Wheelerian Stage correlates with CM2 through CM4, and the Venturian Stage correlates with CM5 through CM6. Although no detailed macrofossil zonations exist for the Quaternary of southern California, several species, whose distribution is regulated by the climatic conditions, are useful as secondary marker species in the shallower water deposits of the Los Angeles Basin.

A geochronologic framework (incorporating paleomagnetism, luminescence, and tephrochronology) was used to calibrate the sequence stratigraphic units in the FOQUS-LA wells and also was used to calibrate the ages of the microfossil stage and zonal boundaries. Paleomagnetic analyses of well samples identified the Laschamp ( 40 ka), Blake ( $\sim 117 \mathrm{ka})$, and Pringle Falls (200 ka) events throughout the basin, as well as the Brunhes and Matuyama Chrons. Optically Stimulated luminescence (OSL) and thermal luminescence (TL) were used to date younger sediments (OSL to about $80 \mathrm{ka}$ and TL to about $175 \mathrm{ka}$ ). The two techniques tracked with each other and, with few exceptions, correlated with the paleomagnetic excursions.

Tephrochronologic analysis resulted in the identification of the Lava Creek B ash (639 $\pm 2 \mathrm{ka})$ in the Long Beach City College well.

The age ranges of the sequence stratigraphic units proposed by Ponti and others (2007) were modified to reflect the improved chronologies and ecological interpretations. The oldest Pliocene sediments are identified as the middle Long Beach unit in Long Beach Pier F well (LBPF) and are coeval with the early Pliocene warm interval and later the onset of Northern Hemisphere 
glaciation $(\sim 3.5-2.5 \mathrm{Ma})$. The next period of deposition is represented by the upper Long Beach unit in LBPF and middle Long Beach unit of Long Beach Pier C core site and monitoring well (LBPC). This period is coeval with the end of northern Hemisphere glaciation and an early Pleistocene warm interval ( 2.0 Ma). The youngest deposition is represented by the upper Long Beach unit in LBPC which was deposited during an early Pleistocene warm and early Pleistocene cold event (1.78 -1.95 Ma). The upper, middle, and lower Long Beach units are separated from the younger units by a basinwide unconformity of nearly $1 \mathrm{~m}$.y. duration. The Pleistocene units range in age from approximately $0.78 \mathrm{Ma}$ to the present. The Los Angeles Basin was separated into two smaller basins during the deposition of the upper Wilmington sequence stratigraphic unit of Ponti and others (2007, USGS Open-File Report 2007-1013) but it acted as a single basin again by the time the Mesa sequence stratigraphic unit was deposited. Shallow-water deposition began much earlier north of the Pacific Coast Highway Fault than to the south. 


\section{Chapter 1-Introduction}

The FOQUS-LA (Focus on Quaternary Stratigraphy in Los Angeles) coring program was a collaborative study by the U.S. Geological Survey (USGS) in cooperation with the Water Replenishment District of Southern California (WRD), the Los Angeles County Department of Public Works (LACDPW), several State and local agencies, and municipalities in the Los Angeles Basin, California. One goal of this program was to provide land-use and emergency-management agencies with a better understanding of earthquake potentials in the Los Angeles Basin and the distribution of earthquake effects, such as surface faulting, ground failure, and amplified ground motions. Another goal was to aid in the development of new, detailed stratigraphic models that define in three dimensions the geometry and physical properties of water-bearing sediments in the greater Los Angeles Basin for regional water agencies.

A thick sedimentary section of both marine and nonmarine sediments blankets the Los Angeles Basin. Sand and gravel beds within these sedimentary units are aquifers and serve as major sources of water for domestic and industrial use in the metropolitan area. The distribution of these aquifers is controlled by coastline migration in response to sea-level change and tectonism throughout the late Tertiary and Quaternary. The geologic structure is complicated by syndepositional folding along the Wilmington anticline and by young faulting concealed by Holocene deposits.

Prior to the FOQUS-LA coring program, our understanding of this region was based on hydrogeologic studies completed more than 50 years ago (Poland and others, 1956); therefore, a more recent, detailed biostratigraphic and geochronologic framework for the late Tertiary and Quaternary deposits of the southwestern Los Angeles Basin was needed. In this report we develop a refined paleontologic, geochronologic, and paleoecologic framework that provides new insights into the basin's late Tertiary and Quaternary evolution.

This report is based on the study of eight wells, most of which are located in Long Beach, California (fig. 1; table 1). Two wells were drilled at the Port of Long Beach within San Pedro Bay (LBPC and LBPF). Another two wells were drilled to the north along the Los Angeles River (LBCH and LWEB) and three wells were drilled to the east - one on the Long Beach plain (LBCC) and two farther east (LBWT and LB1). The final well is north of Inglewood (WEST). Five of the wells (LBPF, LBPC, LBCH, LWEB, and LBCC) provided particularly useful and abundant biostratigraphic, geochronologic, and paleoecologic data and interpretations for testing and augmenting a three-dimensional sequence stratigraphy that was modeled from seismic imaging, geophysics, and lithologic and electric logs from numerous wells in the Dominguez Gap region (Ponti and others, 2007). This report documents the biostratigraphy, geochronology and paleoecology of the FOQUS-LA wells.

Geoscientific investigations completed during this study involved several disciplines, including micro- and macrofossil biostratigraphy, paleomagnetism, luminescence dating, tephrochronology, and paleoecology. The methods of study are described in appendix I.

\section{Sequence Stratigraphic Units}

Ponti and others (2007) divided sediments in the Long Beach area into ten informal sequence stratigraphic units (from oldest to youngest): lower, middle, and upper Long Beach (renamed from Pliocene C, B, and A, respectively, of Ponti and others, 2007; Ponti, oral commun., 2008), lower Wilmington, upper Wilmington, Bent Spring, Harbor, Pacific, Mesa, and Dominguez. These sequence stratigraphic units are defined by their bounding discontinuities and not by their lithologic characteristics. Many of these names are derived from Ponti (1989) who defined a geochronologic framework for the southwest Los Angeles Basin based on amino acid racemization 


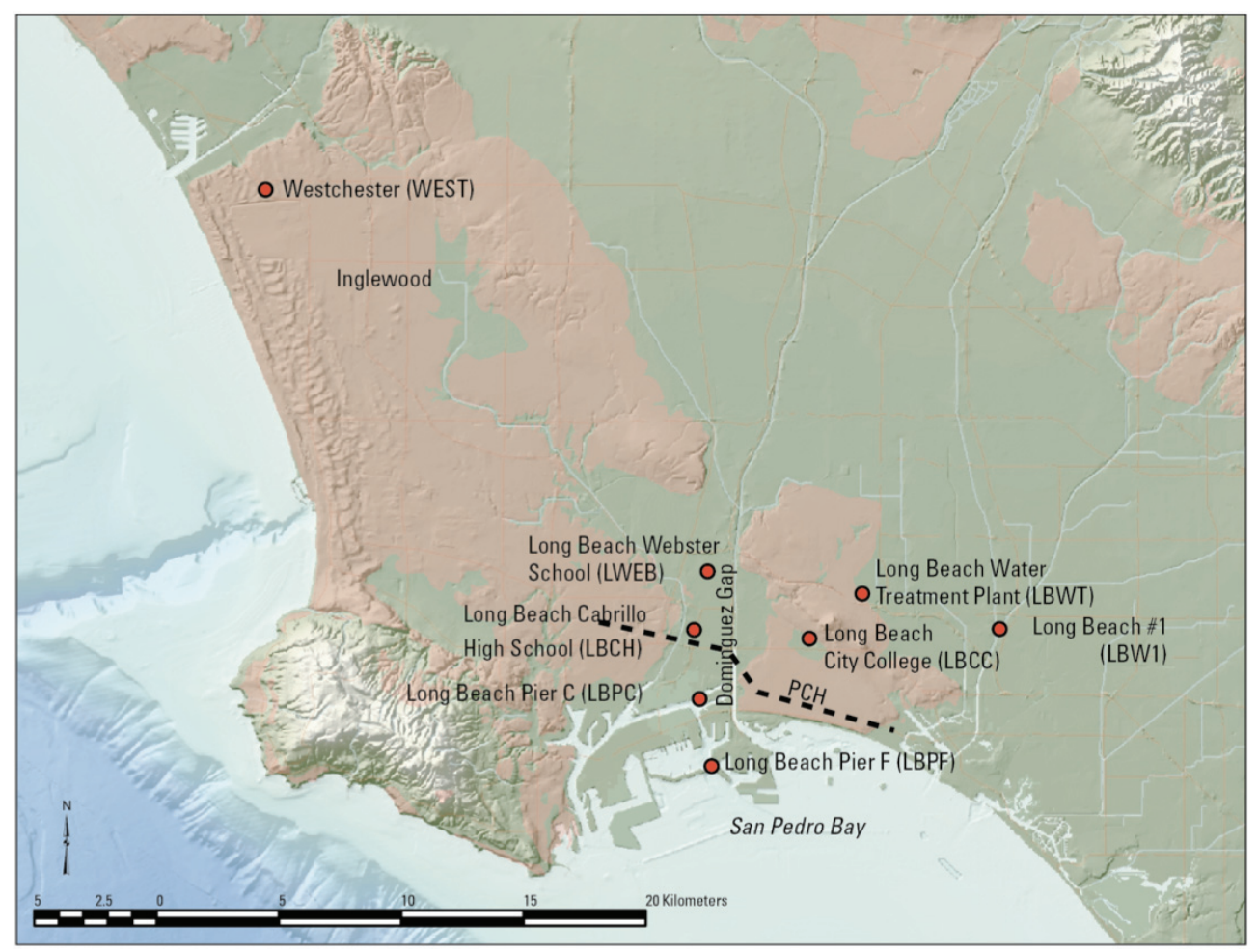

Figure 1. Map of the Los Angeles Basin, California, showing geographic distribution of the wells used in this study (from Ponti and others, 2007). Wells are indicated by red dots. PCH, Pacific Coast Highway Fault.

dates of marine mollusks. Ponti and others (2007) correlated these units to previous aquifer or stratigraphic nomenclature and to the paleomagnetic and marine oxygen isotope records (fig. 2). Ages assigned to these stratigraphic sequences by Ponti and others (2007; table 2) were based on limited radiocarbon data, luminescence dating, and paleontology, except for the lower Long Beach unit, which was identified only from seismic- and electric-log records.

\section{Biostratigraphic Framework}

\section{Benthic Foraminiferal Biostratigraphy}

California Pliocene and Pleistocene benthic foraminiferal stages were defined by Natland $(1952,1957)$ for the Los Angeles and Ventura Basins. The four stages that subdivide the Pliocene and Pleistocene include (in ascending order): Repettian, Venturian, Wheelerian, and Hallian Stages (fig. 3). These provincial stages are recognized by the presence or absence and relative abundance of key benthic foraminiferal species (fig. 4). These criteria primarily reflect local environmental conditions, rather than an evolutionary progression through time (Blake, 1991). The use of planktic microfossil groups (Ingle, 1967, 1980; Lagoe, 1987; Lagoe and Thompson, 1988; Blake, 1991), as well as fission-track ages (Boellstorff and Steineck, 1975), radiometric dates, magnetostratigraphy (Blackie and Yeats, 1976), and tephrochronology (Sarna-Wojcicki and others, 1984) allows calibration of these benthic foraminiferal stages. Blake (1991) cites the ages of the stages as early to late Pliocene ( $\pm 4.8-2.5 \mathrm{Ma})$ for the Repettian Stage, late Pliocene $( \pm 2.5-1.88 \mathrm{Ma})$ for the Venturian Stage, latest Pliocene to early Pleistocene $(\sim 1.88-<1.6 \mathrm{Ma}$, possibly as young as 0.8 $\mathrm{Ma})$ for the Wheelerian Stage, and middle to late Pleistocene $(\leq 0.8 \mathrm{Ma})$ for the Hallian Stage, based on the presence of planktic foraminiferal and siliceous microfossil datums in the Newport Beach section. Modification of these ages based on the time scales of Gradstein and Ogg (2005) 
Table 1. Well location and depth used in this study.

\begin{tabular}{|l|l|c|c|c|c|c|c|}
\hline $\begin{array}{c}\text { Names used in this } \\
\text { report }\end{array}$ & $\begin{array}{c}\text { Abbreviations } \\
\text { used in this } \\
\text { report }\end{array}$ & $\begin{array}{c}\text { Easting (UTM } \\
\text { Zone 11, } \\
\text { meters) }\end{array}$ & $\begin{array}{c}\text { Northing (UTM } \\
\text { Zone 11, } \\
\text { meters) }\end{array}$ & $\begin{array}{c}\text { Land } \\
\text { surface } \\
\text { altitude, in } \\
\text { feet }\end{array}$ & $\begin{array}{c}\text { Land } \\
\text { surface } \\
\text { altitude, } \\
\text { meters }\end{array}$ & $\begin{array}{c}\text { Hole depth, } \\
\text { in feet }\end{array}$ & $\begin{array}{c}\text { Hole depth, } \\
\text { in meters }\end{array}$ \\
\hline Long Beach Pier F & LBPF & 387471.75 & 3734680.73 & 12.17 & 3.71 & $1,203.00$ & 366.67 \\
\hline Long Beach Pier C & LBPC & 386981.98 & 3737428.43 & 12.17 & 3.71 & $1,401.00$ & 427.02 \\
\hline $\begin{array}{l}\text { Long Beach Cabrillo } \\
\text { High School }\end{array}$ & LBCH & 386760.86 & 3740255.91 & 18.59 & 5.67 & $1,412.00$ & 430.38 \\
\hline $\begin{array}{l}\text { Long Beach Webster } \\
\text { School }\end{array}$ & LWEB & 387316.37 & 3742645.99 & 25.64 & 7.82 & $1,404.00$ & 427.94 \\
\hline $\begin{array}{l}\text { Long Beach City } \\
\text { College }\end{array}$ & LBCC & 391748.79 & 3739896.08 & 19.56 & 5.96 & $1,515.00$ & 461.77 \\
\hline $\begin{array}{l}\text { Long Beach Water } \\
\text { Treatment Plant }\end{array}$ & LBWT & 393636.50 & 3741732.36 & 36.50 & 11.13 & $1,550.00$ & 472.44 \\
\hline Long Beach \#1 & LBW1 & 399250.03 & 3740291.33 & 33.40 & 10.18 & $1,498.00$ & 456.59 \\
\hline Westchester & WEST & 369229.26 & 3758142.63 & 127.50 & 38.85 & 898.00 & 273.71 \\
\hline
\end{tabular}

and Gradstein and others (2004) suggests that the Repettian Stage ranges from 2.9 to 2.2 Ma and that the Venturian Stage ranges from 2.2 to 1.9 Ma. Formal ratification of the Quaternary System/Period and the Pleistocene Series/Epoch places the base of the Quaternary and Pleistocene at $2.58 \mathrm{Ma}$ (Gibbard and others, 2010). Therefore, the Venturian Stage is now considered early Pleistocene, the Wheelerian Stage is middle to late Pleistocene, and the Hallian Stage is late Pleistocene to Holocene.

Faunas of the Hallian, Wheelerian, Venturian, and Repettian Stages are characterized by species that indicate decreasing water depths. Repettian faunas, which include Bulimina rostrata, Melonis pompilioides, and Plectofrondicularia californica, indicate lower bathyal depths $(\geq 2,000$ $\mathrm{m})$. Middle and lower bathyal depths $(500-2,000 \mathrm{~m})$ are indicated for the Venturian owing to the presence of Gyroidina rotundimargo and B. subaccuminata, whereas upper to middle bathyal depths $(150-1,500 \mathrm{~m})$ are indicated for the Wheelerian Stage owing to the presence of Bolivina interjuncta, B. spissa, Epistominella pacifica, and Uvigerina peregrina. The Hallian Stage, which is characterized by Ammonia beccarii, Cassidulina limbata, Cassidulina tortuosa, and several species of Elphidium, represents neritic depths $(<150 \mathrm{~m})$.

\section{Planktic Foraminiferal Biostratigraphy}

Since the 1960s, various Neogene and Quaternary planktic foraminiferal zonation schemes have been used to standardize biostratigraphic correlations between marine sedimentary sequences (Kennett and others, 2000). The codified Neogene or N-zone schemes of Banner and Blow (1965), and Blow (1969) are two of the most commonly used zonations. The N-zones are based on the stratigraphic ranges, or the first and last occurrences of low latitude, tropical and subtropical, openocean marker species as proxies for age. More recent zonal schemes (Stainforth and others, 1975; Kennett and Srinivasen, 1983) also incorporated temperate planktic species and associated evolutionary events, increasing spatial, and temporal resolution. Datums calibrated to radiometrically and magnetically dated horizons are especially useful in biochronologic studies.

Although the standardized schemes are a useful correlation tool at open-ocean sites, extending the correlations to near-shore environments at comparable latitudes is problematic (Kennett and others, 2000, Kucera and Kennett, 2000). The N-zones of Blow (1969) are more applicable to low-latitude, subtropical to tropical deep-sea species. However, open-ocean tropical 


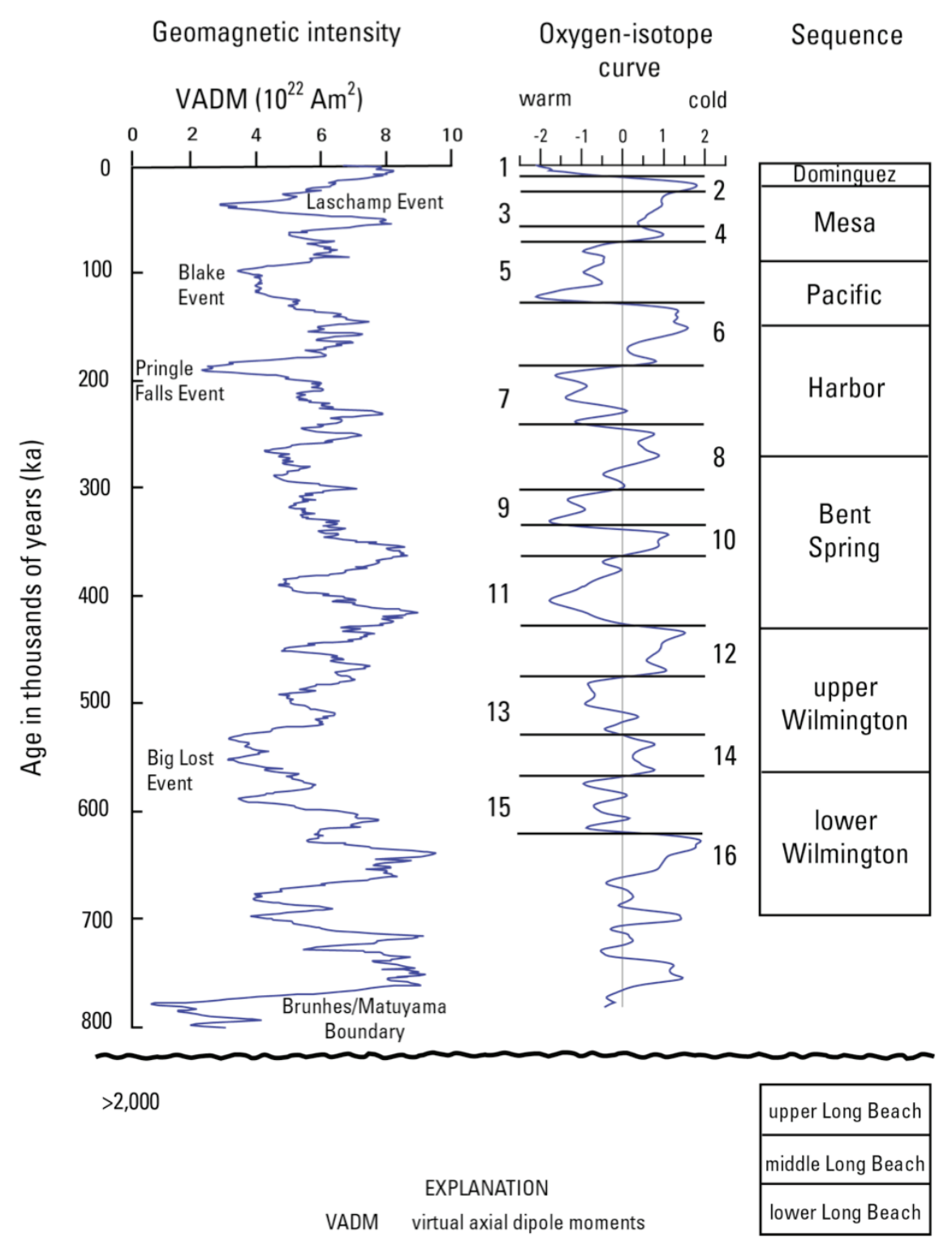

Figure 2. Age estimates of Pleistocene sequences in the Los Angeles Basin, California, based on existing geochronologic data and correlation with the oxygen-isotope curve (Imbrie and others, 1984; Bassinot and others, 1994) and geomagnetic-intensity records (Guyodo and Valet, 1999). Named paleomagnetic events and numbered oxygen-isotope stages are shown. Sequence boundaries generally correspond to relative glacio-eustatic sea-level low-stands (cool), whereas most sediment accumulates during sea-level high-stands (warm) when the largest amount of sediment accommodation is available. Modified from Ponti and others (2007).

index species often are missing from near-shore, mostly temperate assemblages. The planktic species found in sediments along the California margin also are typically provincial, owing to the influence of the California Current and associated upwelling since the late Miocene (Kucera and Kennett, 2000). Consequently, correlating deep-sea zonation schemes to regional sedimentary sequences with local and transitional assemblages has been difficult, and only provides coarse biostratigraphic resolution.

A modern planktic foraminiferal zonation scheme was developed by Kennett and others (2000) and Kucera and Kennett (2000) using cores from Ocean Drilling Program Leg 167 along the California margin (fig. 3). Broadly speaking, the California margin (CM) zonation scheme 
Table 2. Correlation table relating sequence stratigraphic units to nomenclature in the Long Beach/Dominquez Gap region, California, and age criteria.

[Formation designations north and south of Pacific Coast Highway fault (PCH) are from California Department of Water Resources (1961). Stratigraphic units, age estimates, biostratigraphic correlation, and comments are summarized from Ponti and others (2007). PF, Planktic foraminifer; BF, benthic foraminifers; MIS, Marine Isotope Stage; LBPF, Long Beach Pier F core site and monitoring well; LBPF, Long Beach Pier C core site and monitoring well; LBCC, Long Beach City College core site and monitoring well; LWEB, Long Beach Webster School core site and monitoring well, Long Beach, California]

\begin{tabular}{|c|c|c|c|c|}
\hline Stratigraphic unit & Age estimate & PF zones & BF stages & Comment \\
\hline Dominquez & $<18 \mathrm{ka}$ & & Hallian & $\begin{array}{l}\text { Late Pleistocene to Holocene; coincides with climatic amelioration, } \\
\text { which began } 18 \text { ky ago; sea-level rise; tidal marsh peat deposit at base of } \\
\text { sequence in LWEB dated at 1,800-2,390 years (radiocarbon date). }\end{array}$ \\
\hline Pacific & $\begin{array}{l}\sim 40-117 \mathrm{ka} \text { (south of the PCH fault); } \\
117-160 \mathrm{ka} \text { (north of the PCH fault); } \\
\text { coeval with MIS } 5\end{array}$ & & Hallian & Blake event (117 ka) recognized in LBCC, LWEB, and LBPF. \\
\hline Bent Spring & $\begin{array}{l}0.5-0.2 \mathrm{Ma} \text { (south of PCH fault); } 0.5- \\
0.3 \text { (north of PCH fault) coeval with } \\
\text { MIS 13-MIS } 7\end{array}$ & CM1 & $\begin{array}{l}\text { Hallian- } \\
\text { Wheelerian }\end{array}$ & $\begin{array}{l}\text { Abrupt change in water depth in the upper part of the unit which may } \\
\text { correspond to the MIS11/MIS10 boundary }\end{array}$ \\
\hline upper Wilmington & $0.57-0.53$ Ma coeval with MIS 14 & $\mathrm{CM} 1 ; \mathrm{CM} 2$ & $\begin{array}{l}\text { Hallian- } \\
\text { Wheelerian }\end{array}$ & $\begin{array}{l}\text { Barren intervals owing to large sand input in LBCH and LWEB; } \\
\text { environments variable suggesting separation of Los Angeles and Palos } \\
\text { Verde Basins. }\end{array}$ \\
\hline $\begin{array}{l}\text { upper Long Beach } \\
\text { (LBPF) and middle } \\
\text { Long Beach (LBPC) }\end{array}$ & $\sim 2.0 \mathrm{Ma}$ & CM5 & Venturian & $\begin{array}{l}\text { Early Pleistocene; onset of Northern Hemisphere glaciation; declining } \\
\text { sea levels; water depths } 950-1,500 \text { m, shallowing to } 500-950 \text { m; surface } \\
\text { waters primarily cold; Olduvai Normal Polarity Subchron. }\end{array}$ \\
\hline $\begin{array}{l}\text { middle Long Beach } \\
\text { (LBPF) }\end{array}$ & $2.6-3.6 \mathrm{Ma}$ & $\mathrm{CM} 6, \mathrm{CM} 7$ & Venturian & $\begin{array}{l}\text { Early to late Pliocene; deposited during early Pliocene warm and } \\
\text { declining sea levels; water depths 1,200-1,900 m; warm surface waters } \\
\text { at base cool near top; Gauss Normal Polarity Chron. }\end{array}$ \\
\hline
\end{tabular}




\begin{tabular}{|c|c|c|c|c|c|c|c|c|c|c|c|}
\hline \multirow{3}{*}{ 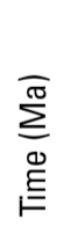 } & \multirow{3}{*}{$\begin{array}{l}\text { 号 } \\
\text { 은 } \\
\text { c }\end{array}$} & \multirow{3}{*}{$\begin{array}{l}\frac{\vec{t}}{\mathbf{t}} \\
\frac{\pi}{0} \\
0\end{array}$} & \multirow{3}{*}{\multicolumn{2}{|c|}{$\begin{array}{l}\text { 등 } \\
\text { 음 }\end{array}$}} & \multirow{2}{*}{\multicolumn{2}{|c|}{$\begin{array}{c}\text { Calcareous } \\
\text { nannnoplankton } \\
\text { zones }\end{array}$}} & \multicolumn{4}{|c|}{ Foraminiferal stages and zones } & \multirow{2}{*}{$\begin{array}{l}\text { Coastal-onlap } \\
\text { in meters } \\
\text { (Johnson and Bloch, } \\
\text { 2005) }\end{array}$} \\
\hline & & & & & & & Planktic & Planktic & Benthic & Benthic zones & \\
\hline & & & & & $\begin{array}{c}\text { Martini } \\
\text { (1971) }\end{array}$ & $\begin{array}{c}\text { Bukry } \\
(1973,1975)\end{array}$ & (Blow, 1969) & $\begin{array}{l}\text { Kennett and } \\
\text { others, 2000) }\end{array}$ & $\begin{array}{l}\text { (Blake, 1991; } \\
\text { this study) }\end{array}$ & & $50 \quad 100 \mathrm{~m}$ \\
\hline \multirow{2}{*}{1} & \multirow[b]{2}{*}{ C1 } & & \multirow{3}{*}{ 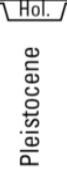 } & $\frac{\mathrm{Llate}}{\mathrm{m}}$ & $\frac{\mathrm{NN} 21}{\mathrm{NN20}}$ & $\mathrm{CN15}$ & \multirow[b]{2}{*}{ N22 } & CM1 & Hallian & C. tortuosa & \\
\hline & & & & \multirow{2}{*}{ 彥 } & NN19 & CN13 & & $\begin{array}{l}\text { CIVI2 } \\
\text { CM3 } \\
\end{array}$ & Wheelerian & $\begin{array}{l}\text { Uvigerina } \\
\text { pergrina }\end{array}$ & \\
\hline \multirow[b]{2}{*}{3} & $\mathrm{C} 2$ & & & & NN18 & \multirow[b]{2}{*}{ CN12 } & \multirow{3}{*}{$\mathrm{N} 20 / 21$} & CM5 & Venturian & B. subacumminata & \\
\hline & \multirow{2}{*}{ C2A } & & \multirow{3}{*}{ 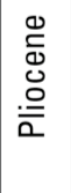 } & $\underset{\mathbb{I}}{\mathbb{I}}$ & & & & CM6 & \multirow{3}{*}{ Repettian } & P. calif-.M. pomp. ${ }^{*}$ & \\
\hline & & & & & & CN11 & & CM7 & & K. milleri & \\
\hline \multirow{3}{*}{6} & \multirow{2}{*}{ C3 } & & & \multirow[t]{2}{*}{ 空 } & NN13 & \multirow{2}{*}{ CN10 } & \multirow{2}{*}{ N18 } & CM8 & & L.pliocenica & \\
\hline & & & & & NN12 & & & & \multirow{3}{*}{ Delmontian } & $\begin{array}{l}\text { Bolivina } \\
\text { obliqua }\end{array}$ & \\
\hline & C3A & & \multirow{3}{*}{ 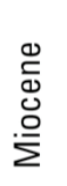 } & \multirow{3}{*}{ 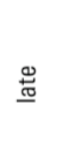 } & \multirow{3}{*}{$\begin{array}{l}\text { alt. } \\
\text { NN11 }\end{array}$} & \multirow{3}{*}{ CN9 } & N17b & & & & \\
\hline 1 & C3B & & & & & & N17 & & & & \\
\hline & C4 & & & & & & & & Mohnian & Bolivina hughesi & \\
\hline
\end{tabular}

*Plectofrondicularia california-Melonis pompilioides

EXPLANATION

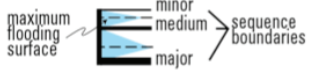

Figure 3. Correlation of late Cenozoic benthic foraminiferal stages with chronostratigraphic frameworks based on other microfossil groups and magnetostratigraphy. Cenozoic benthic foraminiferal stages and zones (Kleinpell, 1938; Natland, 1952; 1957; Blake, 1991) are correlated with the international timescale and magnetostratigraphy (Gradstein and Ogg, 2005; Gradstein and others, 2004; Gibbard and others, 2010), planktic foraminiferal zones (Blow, 1969; Kennett and others, 2000), calcareous nannofossil zones (Martini, 1971; Bukry, 1973, 1975), and coastal onlap curves (Johnson and Bloch, 2005).

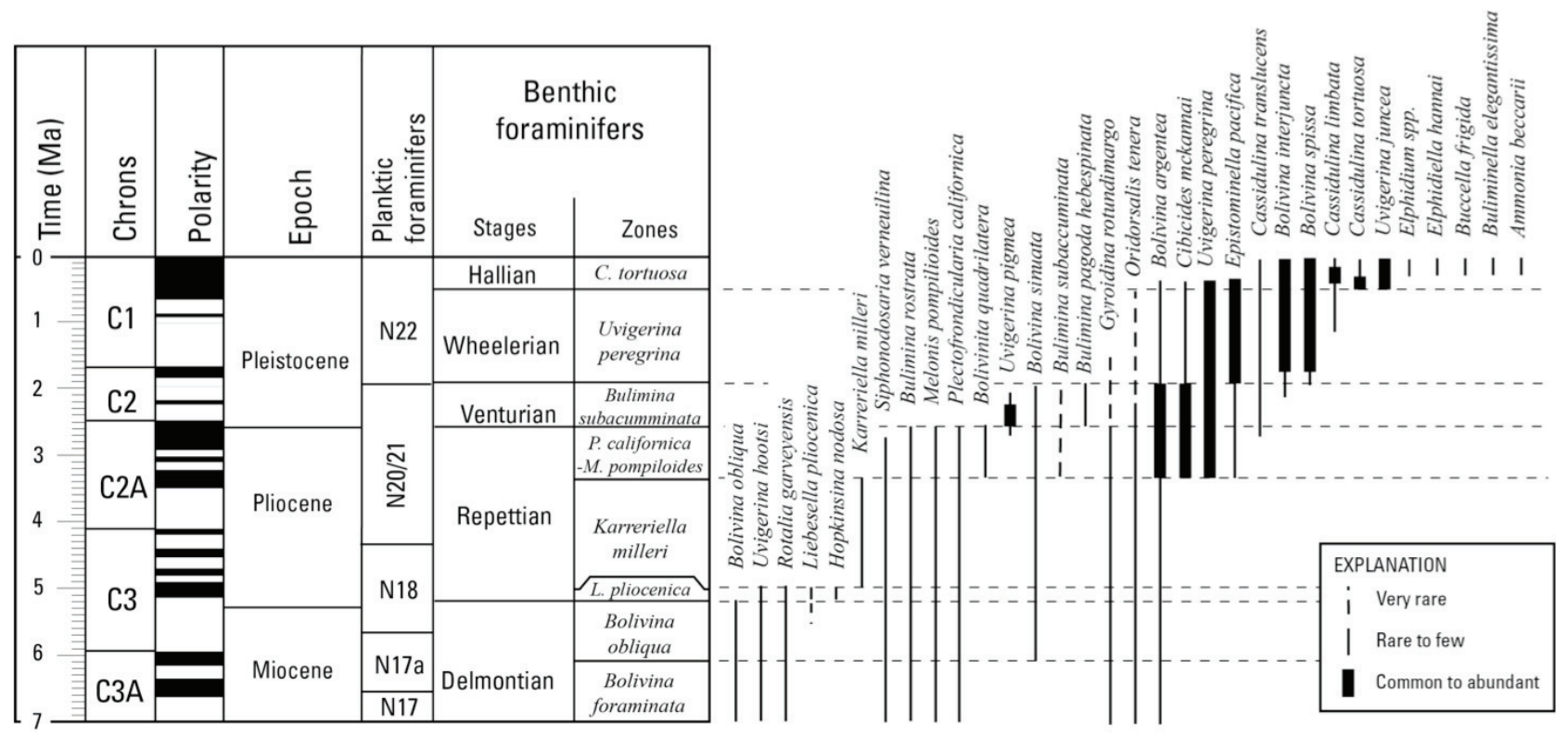

Figure 4. Key benthic foraminifers used to recognize the Pliocene and Pleistocene stages of Natland (1952, 1957). 
Table 3. Planktic foraminiferal zonation scheme used as biostratigraphic framework for nearshore USGS FOQUS-LA wells, Long Beach, California.

[Definitions of zones based on first and last occurrence (FO and LO) events of stratigraphically useful planktic species, and estimated mean, minimum, and maximum basal ages for zones CM7-CM1. Also included (in italics) are several of Lagoe and Thompson's (1988) magnetostratigraphically calibrated Neogloboquadrina pachyderma coiling dominance (CD) zones, which were recognized at California margin study sites]

\begin{tabular}{|c|c|c|c|c|c|c|c|}
\hline \multirow{2}{*}{\multicolumn{2}{|c|}{$\dot{s}_{<}^{\infty}$}} & \multirow{2}{*}{ 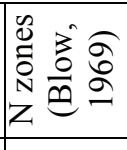 } & \multirow{2}{*}{ 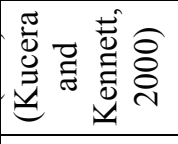 } & \multirow{2}{*}{$\begin{array}{l}\text { First (FO) and last occurrence (LO) } \\
\text { events defining the bases of the CM } \\
\text { zones }\end{array}$} & \multicolumn{3}{|c|}{ Age (Ma) } \\
\hline & & & & & Mean & Minimum & Maximum \\
\hline \multirow{7}{*}{ 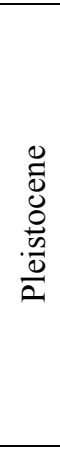 } & 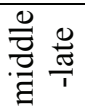 & \multirow{4}{*}{$\tilde{Z}$} & CM1 & LO N. inglei (N. pachyderma sp. A) & 0.712 & 0.569 & 0.774 \\
\hline & \multirow{6}{*}{ 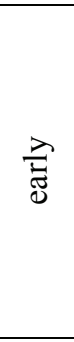 } & & CM2 & FO N. pachyderma sp. B (CD 10) & 1.232 & 1.163 & 1.278 \\
\hline & & & \multirow{2}{*}{ CM3 } & \multirow{2}{*}{$\begin{array}{l}\text { FO N. inglei (N. pachyderma sp. A) } \\
\text { LO N. pachyderma sp. C (CD 11) }\end{array}$} & 1.543 & 1.24 & 1.945 \\
\hline & & & & & 1.881 & 1.704 & 1.984 \\
\hline & & \multirow{4}{*}{$\overline{\mathrm{Z}}$} & CM4 & LO N. kagaensis & 1.915 & 1.813 & 2.003 \\
\hline & & & & LO N. asanoi & 2.216 & 1.98 & 2.39 \\
\hline & & & CMIS & FO N. pachyderma sp. C (CD 14) & 2.362 & 2.23 & 2.475 \\
\hline \multirow{3}{*}{ 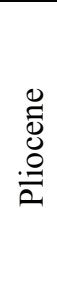 } & 䒿 & & CM6 & FO N. asanoi & 3.583 & 3.284 & 3.897 \\
\hline & \multirow{2}{*}{$\overrightarrow{\bar{\Xi}}$} & \multirow{2}{*}{ 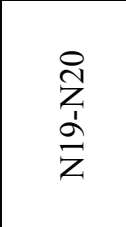 } & CM7 & $\begin{array}{l}\text { LO Globorotalia ikebei } \\
\text { LO Globigerina decoraperta }\end{array}$ & $\begin{array}{l}>3.583 \text { or } \\
\text { late early } \\
\text { Pliocene }\end{array}$ & $>3.284$ & $>3.897$ \\
\hline & & & CM8 & $\begin{array}{l}\text { Base of zone CM } 8 \text { is presently } \\
\text { undefined }\end{array}$ & $\begin{array}{c}\text { early } \\
\text { Pliocene }\end{array}$ & - & - \\
\hline
\end{tabular}

(Kennett and others, 2000; Kucera and Kennett, 2000) is based on calibrated evolutionary events associated with the lineages of select temperate planktic foraminifers, with a focus on provincial species from offshore California. The CM scheme includes low- to high-latitude, deep-marine, and coastal species. Use of this scheme in the development of a biostratigraphic framework for Pacific margin and California borderland sites allows better temporal resolution. The CM scheme subdivides the Pliocene and Quaternary into eight zones, CM8 to CM1 (table 3). The zonal boundaries are based on first occurrence (FO, first occurrence is the oldest occurrence) datums and last occurrence ( $\mathrm{LO}$, last occurrence is the youngest occurrence) datums within the Neogloboquadrina plexus (Kennett and others, 2000). Other species support this lineage of morphotypes. There are two early Pliocene zones, CM8 and CM7. One zone, CM6, comprises the late Pliocene. The Pleistocene also is subdivided into five zones: CM5 to CM1. The estimated ages for the bases of six of the zones, CM6 through CM1, are derived from age models by Lyle and others (2000) based on magnetostratigraphy, calcareous nannofossils, and radiolarian data. Kucera and Kennett (2000) identified several of the Neogloboquadrina pachyderma coiling dominance (CD) zones of Lagoe and Thompson (1988) in the ODP Leg 167 sites. The CD zones further refine the $\mathrm{CM}$ biochronologic framework.

The CM scheme has two limitations: (1) three of the eight events are diachronous owing to latitudinal migrations, environmental change, and (or) evolutionary adaptation (Kucera and Kennett, 2000); and (2) the CM zones were developed using cores from deep waters (1,100-3,000 m) with apparently continuous sedimentation. Due to the above constraints, ages derived from using this scheme at the Los Angeles Basin FOQUS-LA wells were extrapolated with caution. Ages for FO, LO, and zonal boundaries are given as a range from the minimum to maximum age. 
Nevertheless, use of the CM zonation has resulted in a higher-resolution, preliminary biochronology for the Los Angeles Basin wells than was previously available.

\section{Macrofossil Biostratigraphy}

There is no detailed macrofossil biostratigraphy for the Quaternary of southern California. Some mollusks have stratigraphic ranges beginning or ending in the Pleistocene, but these are not well documented, and the precise age ranges of most species remain uncertain. However, the occasional presence of species or genera ranging south or north of their modern distribution indicates that water temperatures were warmer or cooler during certain periods in the past. Correlation of known climatic conditions with latitudinal ranges of species or genera allows speculation on the age of the sediments in which the fossil remains are found. Among the genera that proved extremely useful in the FOQUS-LA wells are Chione, Donax, and Patinopecten.

The occurrence of the bivalves Chione and Donax are biostratigraphically significant in the Pleistocene of the Los Angeles Basin. Both these genera are not known from deposits between Marine Isotope Stage (MIS) 5e and the Holocene ( 116 to $\sim 12 \mathrm{ka})$ in coastal Los Angeles County (Ponti, 1989; Powell and others, 2000). Today these genera are found as far north as Point Conception, California (Coan and others, 2000). Therefore, their presence in the Los Angeles Basin indicates an age $\geq 116 \mathrm{ka}$ or $\leq 12 \mathrm{ka}$.

Although common during the Tertiary, the genus Patinopecten is restricted to one species, P. caurinus, during the Quaternary (Arnold, 1906; Moore, 1983), whose modern occurrence is north of Point Conception in Santa Barbara County. The Pleistocene fossil record of Patinopecten in southern California is from the middle Pleistocene Lomita Marl, Timms Point Silt, and San Pedro Formation in the San Pedro area (Woodring and others, 1946). The minimum age of the San Pedro Group is $<300 \mathrm{ka}$ (Lajoie and others, 1991). The presence of Patinopecten in the Los Angeles Basin, therefore, indicates an age of $\leq 300 \mathrm{ka}$.

\section{Paleoecologic Framework}

\section{Benthic Foraminiferal Paleoecology}

Quaternary environmental interpretations are based on an overview of California benthic foraminifers by Ingle (1980), Ingle and Keller (1980), Blake (1991), and Douglas and Heitman (1979). Along a continental margin, these environmental interpretations primarily indicate depth, but also can suggest water-mass, or various physical properties, such as temperature, salinity, or oxygen content. Depths associated with the bathymetric biofacies follow Ingle (1980) for an open continental margin: inner neritic $(0-50 \mathrm{~m})$, outer neritic $(50-150 \mathrm{~m})$, upper bathyal $(150-500 \mathrm{~m})$, upper middle bathyal (500-1,500 m), lower middle bathyal (1,500-2,000 m), lower bathyal $(2,000-4,000 \mathrm{~m})$, and abyssal $(\geq 4,000 \mathrm{~m})$ (fig. 5). This analysis does not account for the problems associated with sill depths and basins in a borderland setting, so a borderland biofacies analysis was used following the work of Douglas and Heitman (1979) in the southern California borderland. They examined the distribution of benthic foraminiferal species within the borderland setting and described assemblages, which are found in association with various water-masses and at various depths for nearshore and offshore basins: outer shelf (50-200 m), bank (50-200 m or 20-400 m), upper slope $(85-450 \mathrm{~m})$, lower slope $(400-900 \mathrm{~m}$ or $300-1,900 \mathrm{~m})$ and basin floor $(550-950 \mathrm{~m}$ or 1,200-1,900 m) (fig. 6). The third analysis considers oxygen conditions of silled basins in a borderland setting following the work of Cannariato and Kennett (1999). The abundance of various species representing oxygen conditions from oxic to dysoxic is noted in the assemblages (fig. 7). Other analyses used to interpret the environmental conditions in this study include the abundance 


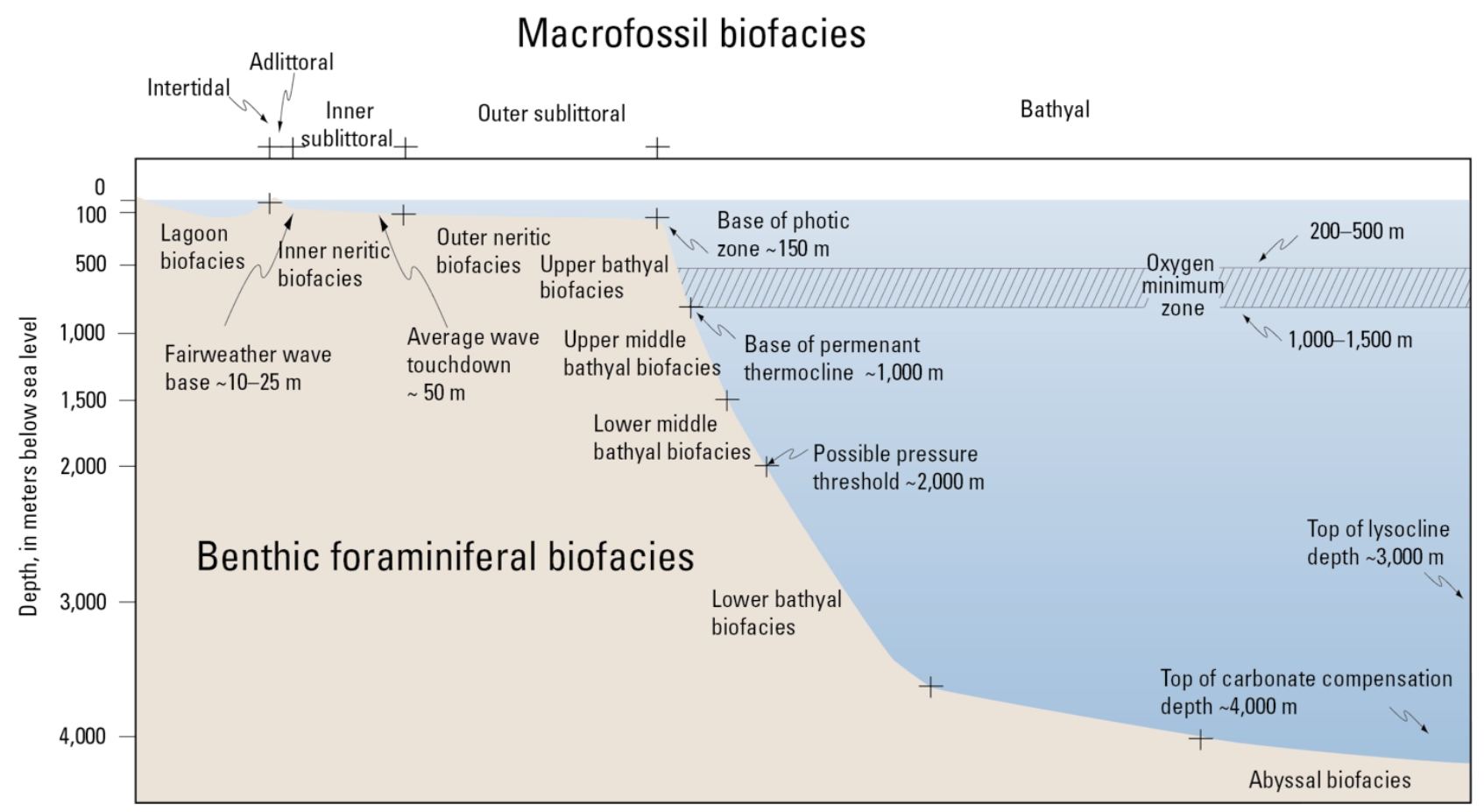

Figure 5. Distribution of the bathymetric biofacies along an open margin. Benthic foraminiferal biofacies are modified from Ingle (1980). Macrofossil biofacies (Valentine, 1961) are indicated across the top of the figure.

of epifauna and infauna species in a sample. Infaunal species are common when oxygen conditions are reduced, whereas epifaunal species are common when oxygen values are higher.

\section{Planktic Foraminiferal Paleoecology}

Paleoceanographic reconstructions and modern studies (Ingle, 1967, 1973a, 1973b; Ravelo and others, 1997) of the northeast Pacific demonstrate that due to interaction of the California Current and southern California Countercurrent, transitional-water masses have existed along the California margin since the Miocene. As a result, tropical to subpolar, and even polar species commonly are observed in the planktic foraminiferal assemblages of the Long Beach wells.

One cosmopolitan species, Neogloboquadrina pachyderma, is particularly useful in paleoecologic reconstructions. Neogloboquadrina pachyderma exhibits a plexus of highly variable coiling morphotypes that appear to be linked to shifts in water-mass temperatures over time (Keller, 1978; Kennett, 1968, 1973; Darling and others, 2006). In lower latitude, warmer water masses, N. pachyderma forms tend to be large, more globose, and lobulate. At increasingly higher latitudes and in cooler water masses, $N$. pachyderma forms become smaller and more compact with thicker, more encrusted tests. Changes also occur in apertural position and shape. Moreover, the coiling direction of the morphologic variants appears to be tied to sea-surface temperatures. Dextral or right-coiling forms tend to dominate warm-water assemblages, whereas sinistral or left-coiling variants dominate cool waters. Populations of N. pachyderma from transitional-water masses exhibit mixed coiling-direction ratios (Keller, 1978; Kennett, 1968; Kennett and Srinivasen, 1980, 1983).

Whether the coiling morphotypes are ecophenotypic variants or are distinct genotypes that reflect evolutionary events is being debated. Modern research (Darling and others, 2000, 2006; Kucera and Kennett, 2002) uses DNA to suggest that the coiling morphotypes are separate genotypes rather than environmentally controlled ecophenotypes. Regardless of the causal 


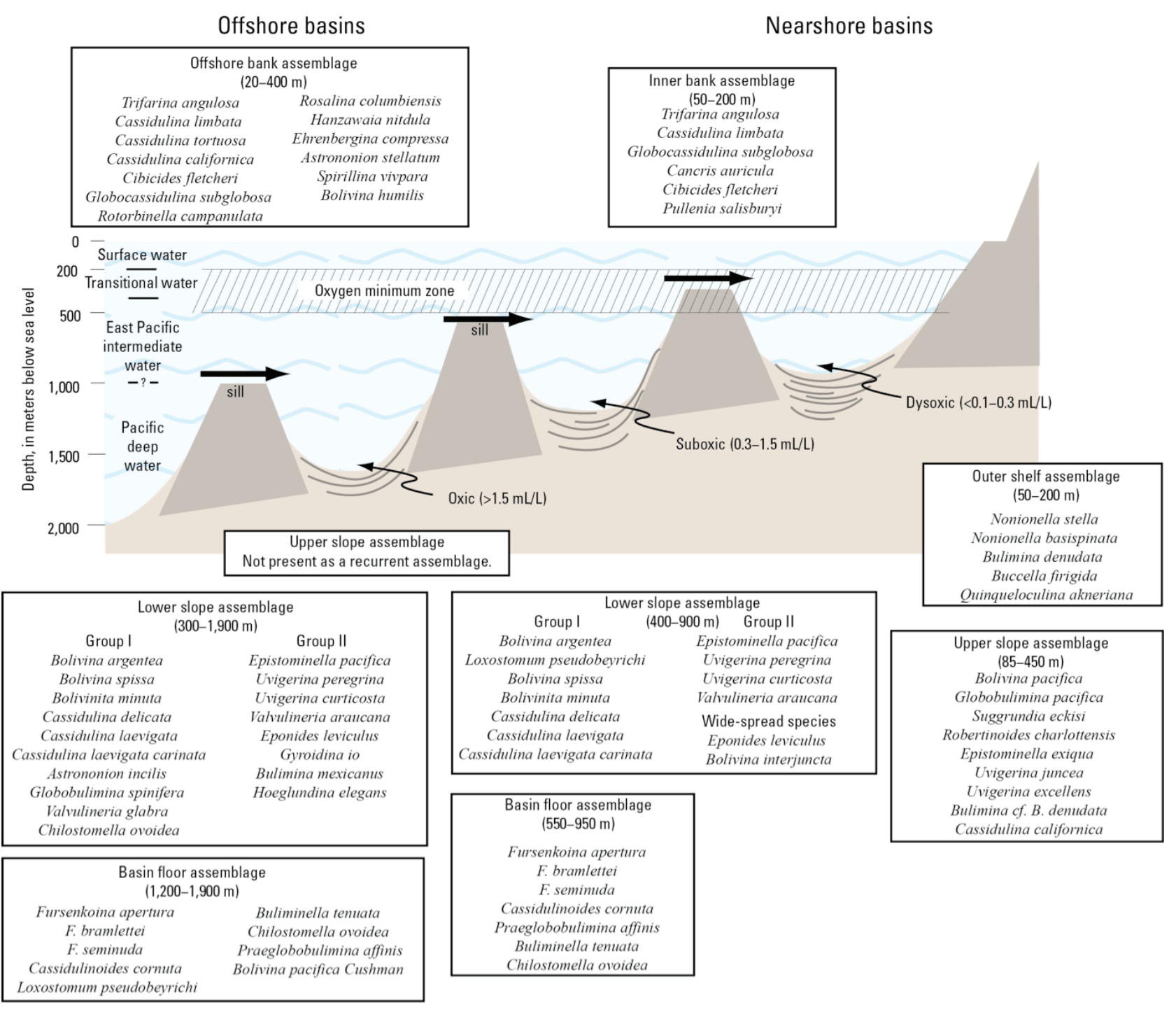

Figure 6. Distribution of benthic foraminiferal biofacies in a continental borderland setting; modified from Douglas and Heitman (1979) and Gorsline and Emery (1959).

mechanism for the wide range of $N$. pachyderma forms, the morphotypes and coiling-direction ratios of this species have been used extensively as paleotemperature proxies. This study uses these morpholotypes and ratios to reconstruct the paleoecology of FOQUS-LA wells. Other paleoenvironmentally sensitive planktic foraminiferal species also are employed to support the reconstructed environmental history of the wells.

\section{Macrofossil Paleoecology}

Ecological interpretations for the macrofossils are based on modern depth and latitudinal ranges for extant species. Classification of marine environments follows Valentine (1961): (1) intertidal - between high water and low water (littoral); (2) adlittoral — between low water and 9.1 $\mathrm{m}$ (5 fathoms) on exposed coasts; (3) inner sublittoral-between $9.1 \mathrm{~m}$ (5 fathoms) and $45.7 \mathrm{~m} \mathrm{(25}$ fathoms); (4) outer sublittoral — between $45.7 \mathrm{~m}$ (25 fathoms) and $182.7 \mathrm{~m}$ (100 fathoms); and 5) bathyal—below $187.2 \mathrm{~m}$ (100 fathoms) (fig. 5).

Many Quaternary fossil molluscan assemblages contain a few species that are extinct locally and now live only north or south of the latitude of the fossil locality. These locally extinct 


\begin{tabular}{|c|c|}
\hline Oxic \\
(>1.5 $\mathrm{mL} / \mathrm{L})$ \\
Epistominella pacifica \\
E. smithi \\
E. bradyi \\
\hline Suboxic II & Suboxic I \\
$(0.3-1.5 \mathrm{~mL} / \mathrm{L})$ & $(0.3-1.5 \mathrm{~mL} / \mathrm{L})$ \\
Cassidulina tortuosa & Bolivina seminuda \\
Valvulineria araucana & Uvigerina peregrina \\
Nonionella stella & \\
\hline \multicolumn{2}{|c|}{ Dysoxic } \\
(0.1-0.3 $\mathrm{mL} / \mathrm{L})$ \\
Bolivina argentea \\
Buliminella tenuata \\
\hline
\end{tabular}

Figure 7. Dissolved-oxygen facies and associated benthic foraminiferal species (after Cannariato and Kennett, 1999).

species are termed extralimital. Some of these extralimital species are reworked (Ponti, 1989), but others reflect latitudinal shifts in marine isotherms (Valentine, 1955, 1961; Addicott, 1966). Basin deposits with cool-water extralimital species (species that occur today only north of the fossil locality), are correlated with glacial lowstands in the Pleistocene (Clark, 1931; Rodda, 1957). Emergent and basinal deposits containing warm extralimital species (species that occur today only south of the fossil locality), were correlated with high-stand deposits (Lajoie and others, 1991). Multiple high- and low-stands are known during the Quaternary (Shackleton and Opdyke, 1973). Recent work by Kennedy and others (1982), Lajoie and others (1991), and Powell and others (2000) has integrated the sea-level curve with strandline and basinal deposits in southern California, showing warm-water species reflect high-stand deposits usually higher than modern, and cool-water species reflect high-stand deposits lower than modern, or basinal deposits correlative with low stands of sea-level.

\section{Geochronology}

\section{Paleomagnetism}

Paleomagnetism, the study of ancient magnetism preserved in rocks, sediment, and ceramics, is a useful tool for dating geologic materials and heat-treated artifacts. The dating method involves correlation of magnetic polarity, directions, and(or) intensities with time-calibrated reference curves. In sediment, these magnetic measures require material with the original fabric and magnetization remaining intact, a condition not satisfied by the cuttings typically retrieved during drilling projects. The most widely used reference for magnetostratigraphy is the Geomagnetic Polarity Reversal Timescale (fig. 8), which provides a pattern of polarity banding to be matched by polarity determinations in a given stratigraphic section (Opdyke and Channell, 1996). By measuring magnetic inclination, which is the plunge of the magnetic vector relative to horizontal, polarity can be determined.

The application of paleomagnetism to correlation of sedimentary rocks will be successful provided the following conditions are met: (1) magnetic detrital grains, most commonly consisting 


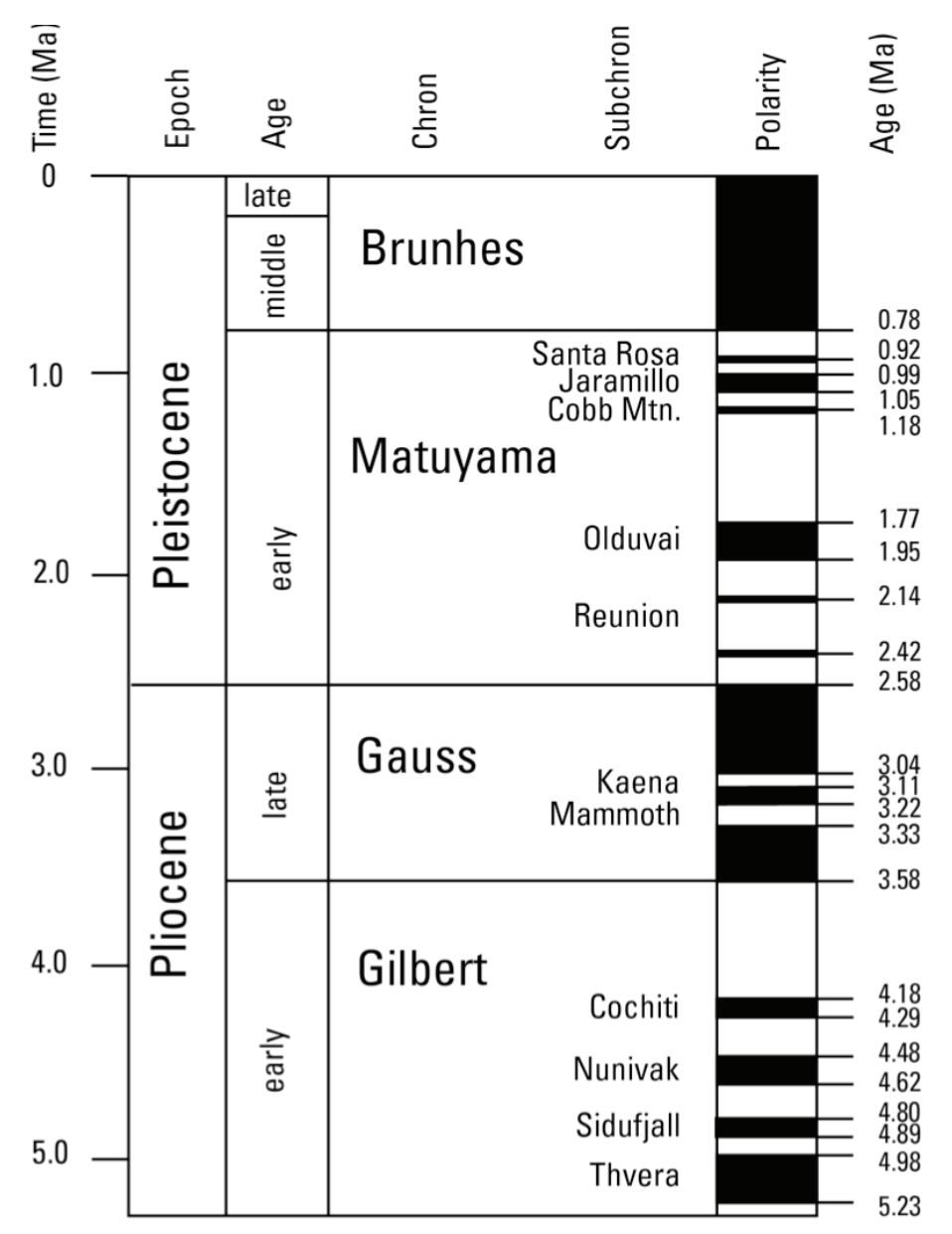

Figure 8. Correlation of geologic epochs and ages with the Geomagnetic Polarity Timescale (Berggren and others, 1995) for Pliocene and Pleistocene time. Polarity zones (black, normal polarity; white, reversed polarity) are calibrated according to Singer and others (1999) and Cande and Kent (1995).

of magnetite, are sufficiently abundant ( $>0.01$ percent by weight) and are silt-sized or finer to acquire a stable remanent magnetization parallel to the geomagnetic field; (2) after burial and sufficient dewatering, the magnetic alignment of grains is locked in, and original depositional fabrics are preserved; and (3) the chemical environment during deposition and subsequent burial does not substantially alter the original remanent magnetization by destroying or creating magnetic minerals.

The strategy of the paleomagnetic study was to measure magnetic inclination at suitable intervals down the full length of the well. A primary objective was to locate the first prominent occurrence of reversed-polarity magnetization, which is the Matuyama-Brunhes transition $(0.78$ Ma). This critical timeline would provide a starting point to search for identifiable volcanic deposits, such as the Bishop Ash (0.76 Ma; Sarna-Wojcicki and others, 2000), and would be a key marker for extending the correlation of sedimentary beds to subsequent coring projects. The secondary objective was to search for thin intervals of anomalous inclination, such as the Blake event (Tucholka and others, 1987), to provide additional timelines within the Brunhes Normal Polarity Chron (fig. 2). The Blake event and other excursions appear to correlate with periods of very low intensity of the geomagnetic dipole, as inferred from relative magnetic-intensity variations since $800 \mathrm{ka}$ in deep-sea cores (Guyodo and Valet, 1999; SINT800 model). Only excursions known from the North American region are listed in figure 2. (Merrill and McFadden, 2005). 


\section{Chapter 2-Long Beach Pier F Core Site and Monitoring Well, Long Beach, California}

\section{Introduction}

The Long Beach Pier F core hole and monitoring well (LBPF) is located on Pier F across from the Navy Mole, Port of Long Beach, Long Beach, California (lat 3344'46.4" N., long $118^{\circ} 12^{\prime} 53.6^{\prime \prime}$ W.) (fig. 1). The well is approximately 15.24 meters east of a small Edison substation adjacent to Jacobsen Pilot Station. Total depth of the well is $366.7 \mathrm{~m}$ (table 1). The biostratigraphic, chronostratigraphic, and paleoecologic data collected at LBPF are summarized in this chapter. Samples taken from LBPF were examined for benthic foraminifers (Kristin McDougall), planktic foraminifers (Elmira Wan), macrofossils (Charles Powell, II), paleomagnetism (John Hillhouse), and luminescence (Shannon Mahan). The middle Long Beach (366.7-351.2 m), upper Long Beach (351.2-294.2 m), lower Wilmington (294.2-230.0 m), upper Wilmington (230.0-205.1 m), Bent Spring (205.1-91.9 m), Harbor (91.9-65.0 m), Pacific (65.0$44.0 \mathrm{~m})$, Mesa (44.0-19.1 m), and Dominguez (19.1-14.6 m) units were recognized in this well (Ponti and others, 2007).

\section{Biostratigraphy}

\section{Benthic Foraminifers}

Of the 201 samples examined for benthic foraminifers, 82 were barren (plate 1). In the upper $170 \mathrm{~m}$ of sediment, only seven of 57 samples contained foraminifers. The proportion of fossiliferous samples increases with depth in the well and the proportion of barren samples decreases with depth (fig. 9). Using the age criteria established for the Quaternary of the Los Angeles basin (fig. 3), the Venturian, questionable Wheelerian, Wheelerian, early Hallian, and Hallian Stages are recognized (fig. 10).

Microfossil samples at the base of LBPF (365.4-298.7 m; Mf10746-Mf10704) are assigned to the Venturian Stage, and samples from 297.2 to 287.7 m (Mf10703-Mf10697) are questionably assigned to the Wheelerian Stage. Species diagnostic of the Venturian Stage found at the base of the well up to $359.7 \mathrm{~m}$ (Mf10704) include Bolivina argentea, Cibicides mckannai suppressa, Epistominella pacifica, and Uvigerina peregrina. Oridorsalis subtenera, O. umbonatus, Gyroidina altiformis, and G. multilobata occur sporadically in this interval, which is characteristic of the Venturian Stage. Cassidulina transluscens appears infrequently at the base, but it becomes more abundant near the top of this interval.

Changes in this dominance pattern are noted at approximately $300 \mathrm{~m}$ (Mf10705), where $C$. mckannai appears. Epistominella pacifica, C. mckannai, and B. argentea disappear between 298.7 and 297.2 m (Mf10704-Mf10703). Between 297.2 and $287.7 \mathrm{~m}$, several shallow-water species (Ammonia beccarii, Buccella frigida, and Elphidium transluscens), which typically characterize the Hallian Stage, appear and in some samples are abundant. Cassidulina transluscens and $U$. peregrina are the only age-diagnostic species that continue into this interval, but even they disappear from the assemblages at 291.1 $\mathrm{m}$ (Mf10700). An unconformity is proposed at approximately $294.2 \mathrm{~m}$ between the upper Long Beach and lower Wilmington units (D. Ponti, oral commun., 2008). Reworked sediments above and below this unconformity explain the foraminiferal distribution observed in this interval.

Age-diagnostic Wheelerian benthic foraminiferal species, which reappear at $283.5 \mathrm{~m}$ (Mf10969) and become dominant are B. interjuncta, C. mckannai, and U. peregrina. Epistominella pacifica (269.8 m, Mf10687) and C. mckannai suppressa (253.0 m, Mf 10677) rejoin the 


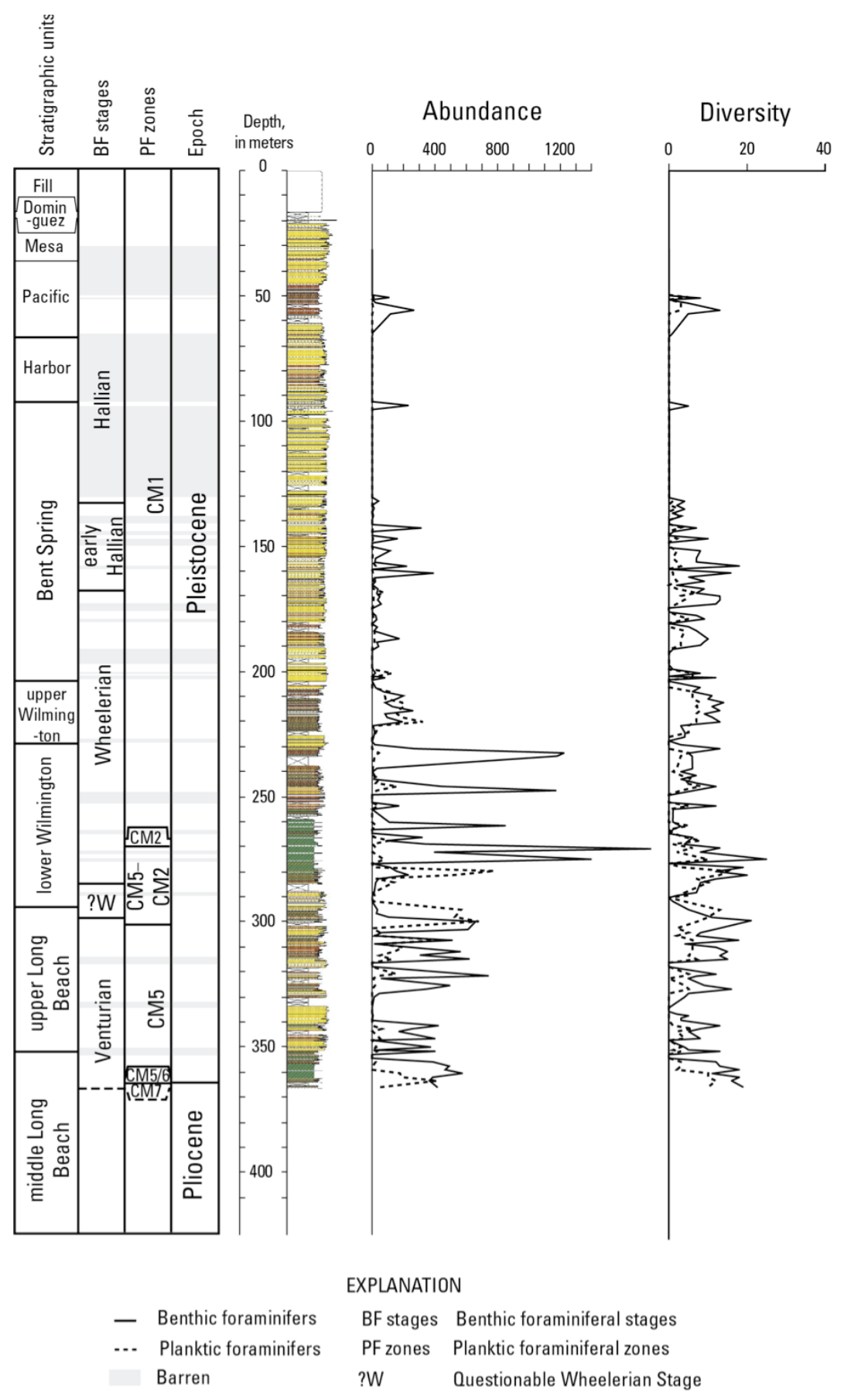

Figure 9. Abundance and diversity of the foraminiferal fauna in Long Beach Pier F core site and monitoring well, Long Beach, California. Abundance of the foraminifers is based on the number of foraminiferal specimens present in the sample. Diversity is the number of species identified in the sample. Stratigraphic units are identified in the left column, and lithologies are indicated on the stratigraphic column by color (clay, green; silt, brown; sand, yellow) (Ponti and others, 2007).

assemblages above the base of the Wheelerian Stage $(283.5 \mathrm{~m})$. The last appearance of these species places the Wheelerian/early Hallian boundary at $167.6 \mathrm{~m}$ (Mf10625) at the last abundant appearance of E. pacifica. In addition, species which first appear in the Wheelerian, but are most abundant in the Hallian, begin appearing within the Wheelerian interval and become dominate species above the boundary: Cassidulina limbata (189.0 m, Mf10639), C. tortuosa (283.5 m, 


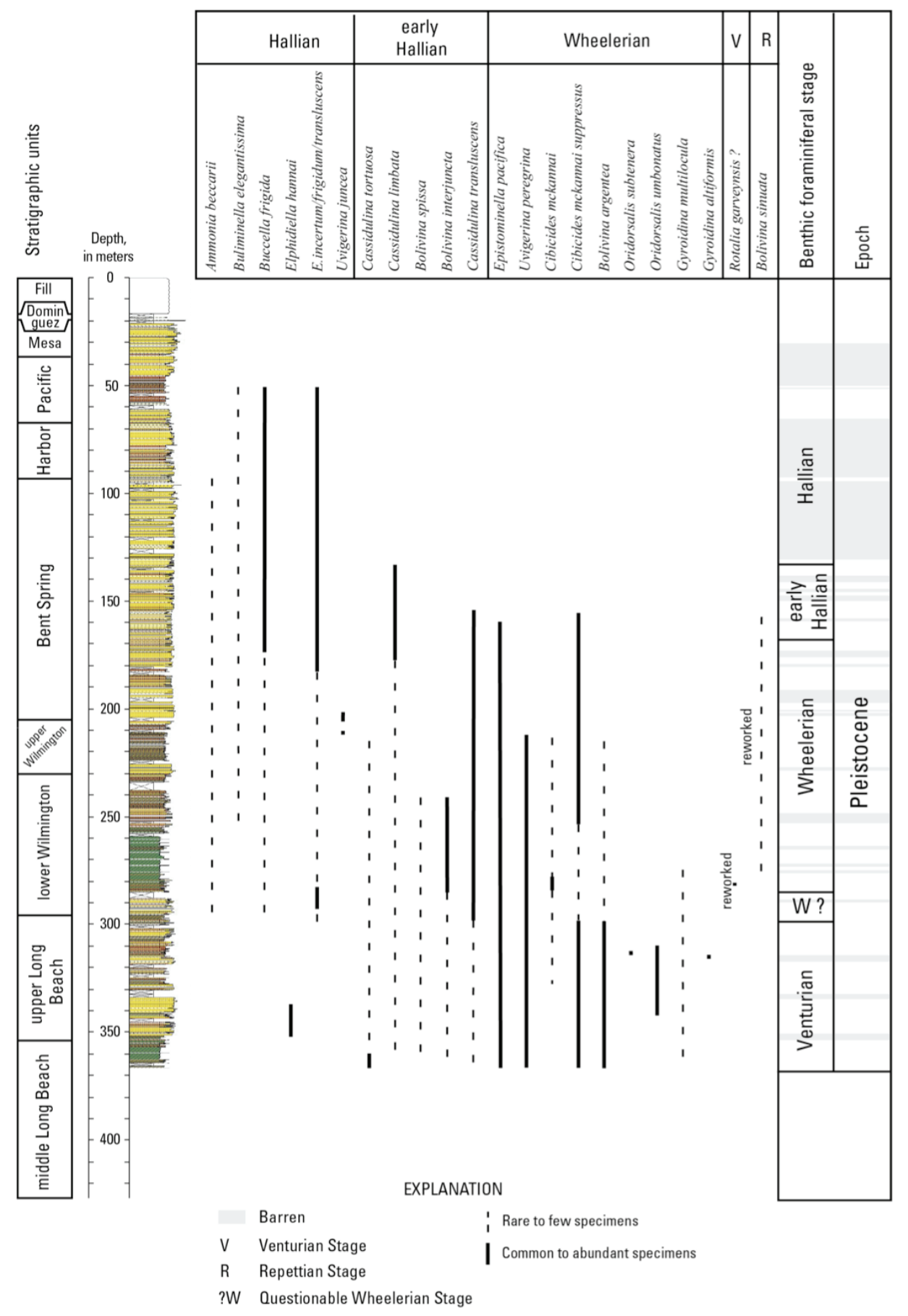

Figure 10. Stratigraphic distribution of age-diagnostic benthic foraminifers in Long Beach Pier $F$ core site and monitoring well, Long Beach, California. Stratigraphic units are identified in the left column, and lithologies are indicated on the stratigraphic column by color (clay, green; silt, brown; sand, yellow) (Ponti and others, 2007).

Mf10696), and C. transluscens (266.7 m, Mf10685). The interval from 168.2 to $132.6 \mathrm{~m}$ (Mf10603-Mf10624) is assigned to the early Hallian.

The few fossiliferous samples in the upper part of LBPF, from 131.1 to $30.5 \mathrm{~m}$ (Mf10546Mf10602), are dominated by various species of Elphidium, Buccella frigida, Nonionella basispinata, and N. stella, suggesting that this interval is Hallian in age. 


\section{Planktic Foraminifers}

In LBPF, 96 microfossil samples contained low to moderate abundances of planktic foraminifers (fig. 9; plate 2). Synthesis of a high-resolution planktic foraminiferal biostratigraphy for LBPF was difficult because (1) samples were widely spaced and (or) discontinuous; (2) marker species were relatively sparse; (3) LBPF was drilled in a complex, tectonically active, nearshore environment making the usefulness of these open-ocean zonal schemes less than optimal; and (4) there is some inherent diachroneity in the CM zonal scheme (Kucera and Kennett, 2000) because zonal boundary ages extrapolated from the first and last evolutionary occurrences of planktic index species were estimated. Nevertheless, Pliocene zones CM7, CM5/6, and CM5, and Pleistocene zones CM2-CM4, CM2, and CM1 are recognized in LBPF (fig. 11).

The oldest sample with planktic foraminifers at $365.4 \mathrm{~m}$ (Mf10746) contains the FO of Neogloboquadrina kagaensis, which indicates this sample may be as old as early Pliocene, zone N19-20 or California Margin, zone CM7. The LO of a primitive form of Globorotalia inflata and the FO of G. inflata s.s. also place this sample proximal to the early-late Pliocene boundary.

The only occurrence of Sphaeroidinellopsis seminulina at $362.7 \mathrm{~m}$ (Mf10745) places this sample in the late Pliocene, zone N21 and zones CM5/6. This age is based on a magnetostratigraphic-age assignment of $3.12 \mathrm{Ma}$ for the LO of S. seminulina (Berggren and others, 1995). The first appearance of $N$. pachyderma C, a small, compressed, and sinistrally coiled form of this plexus, with $S$. seminulina further indicates assignment to zones CM5/6 because the FO of $N$. pachyderma $\mathrm{C}$ is a secondary age datum for CM5 (Kucera and Kennett, 2000). An estimated maximum age of $2.475 \mathrm{Ma}$ is assigned to this evolutionary event based on age models (Kucera and Kennett, 2000). However, Kucera and Kennett (2000) also indicate that there is an uncertainty regarding the timing of the first occurrence of $N$. pachyderma $\mathrm{C}$. Thus, the age determination for the sample at $362.7 \mathrm{~m}$ (Mf10745) is late Pliocene, zone N21, and provisionally CM5/6. The sample directly above this (358.1 m, Mf10742), contains the first occurrence of $N$. dutertrei, which confirms the interval is late Pliocene and falls within zones N21 and CM5.

The interval from 298.7 through 269.8 m (Mf10687-Mf10704) appears to be reworked; the first and last appearances of zones CM2 through CM4 planktic foraminiferal species are stratigraphically out of order. The reworking makes placement of zones difficult. For example, the LO of $N$. pachyderma $\mathrm{C}$ is observed at $298.7 \mathrm{~m}$ (Mf10704), and it defines the base of Pleistocene zone CM3; but only one meter higher, $297.2 \mathrm{~m}$ (MF10703), the FO of N. pachyderma $\mathrm{B}$ indicates the base of Pleistocene zone CM2 (Kucera and Kennett, 2000), and 3 meters higher (294.13 m, Mf10701) the FO of Globigerina umbilicata suggests assignment to the late Pliocene zone N21. Farther up the well (269.75 m, Mf10687), the LO of N. kagaensis marks the base of Pleistocene zone CM4. However, the first evolutionary appearance of N. inglei (N. pachyderma A) occurs below this at $283.5 \mathrm{~m}$ (Mf10696) and constrains the base of Pleistocene zone CM3 (fig. 11). Reworked benthic foraminiferal species also are noted between 280.4 and 271.3 m (Mf10694Mf10688) and are only questionably assigned to the Pleistocene, Wheelerian Stage because of the fluctuating abundances and lack of diagnostic species. An unconformity is suggested at approximately $294.2 \mathrm{~m}$ between the upper Long Beach and lower Wilmington units (Ponti, oral commun., 2008).

The LO of $N$. inglei ( $N$. pachyderma A) occurs at $266.7 \mathrm{~m}$ (Mf10685) and marks the top of zone CM2 and the base of zone CM1, suggesting a Pleistocene age. Above this occurrence, no agediagnostic planktic foraminifers are present.

\section{Macrofossils}

Fifty-three samples containing remains of mollusks, arthropods, and echinoids obtained from LBPF well were examined (plate 3). Six samples are from the shaker table, and 47 samples 


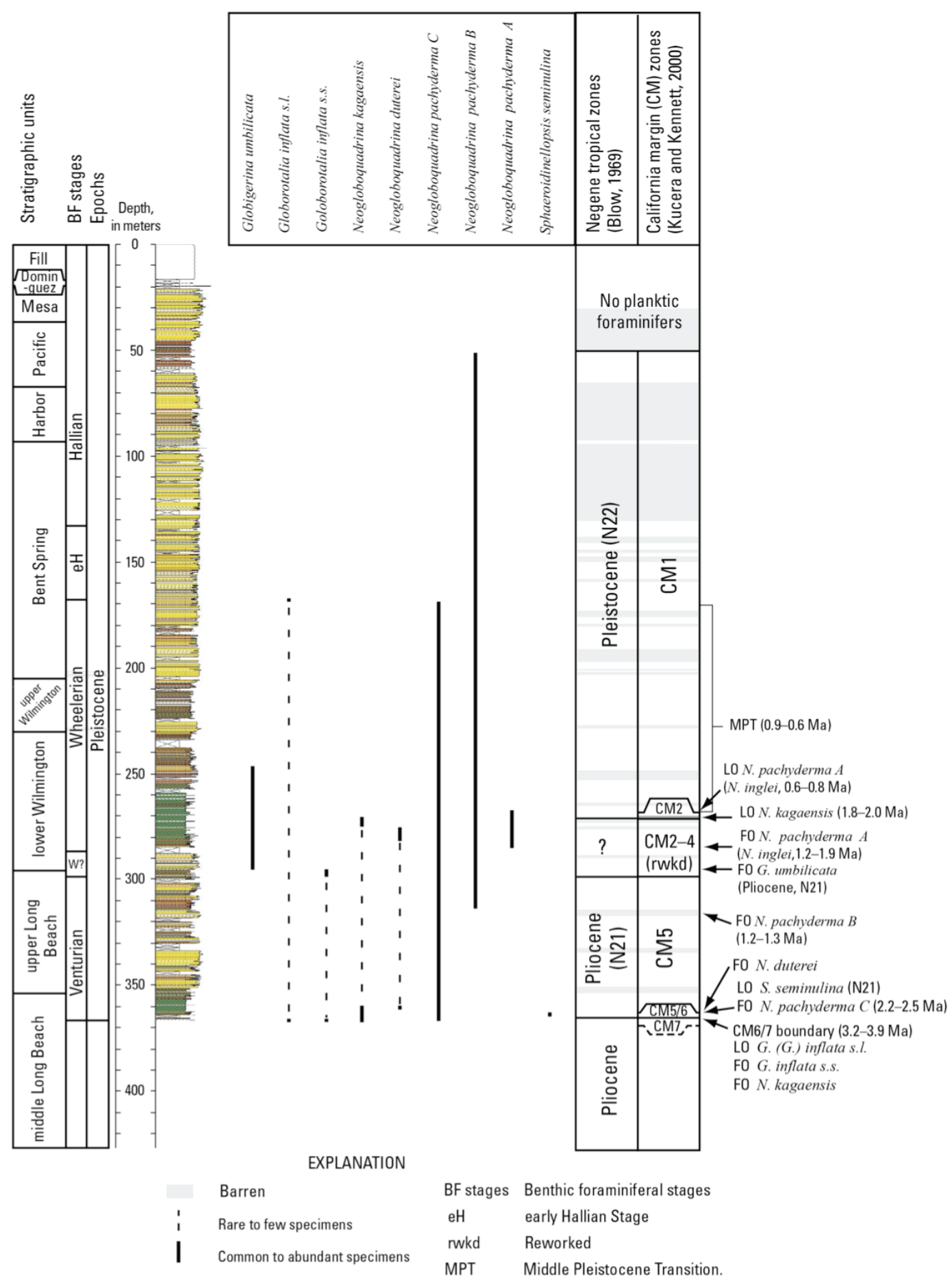

Figure 11. Stratigraphic distribution of age-diagnostic planktic foraminifers in Long Beach Pier F core site and monitoring well, Long Beach, California. Planktic foraminiferal-ages are calibrated to magnetostratigraphy and biostratigraphy (Berggren and others, 1995; Fornaciari, 2000; Kennett and others, 2000; Lyle, and others, 2000; Kucera and Kennett, 2000). Stratigraphic units are identified in the left column, and lithologies are indicated on the stratigraphic column by color (clay, green; silt, brown; sand, yellow) (Ponti and others, 2007).

are from cores. Samples contain 124 mollusk taxa (indeterminate fragments, 60 bivalves, 56 gastropods, one chiton, and six scaphopods), three arthropods, and two echinoids. The occurrence 
of the bivalves Chione and Donax are biostratigraphically significant in the Pleistocene of the Los Angeles Basin. Chione occurs approximately from 61 to $64 \mathrm{~m}$ and at $19.9 \mathrm{~m}$, whereas Donax occurs at approximately $315 \mathrm{~m}$ and from 32 to $38 \mathrm{~m}$ in LBPF. Therefore, the occurrence of Chione at $19.9 \mathrm{~m}$ indicates an age of $\leq 12 \mathrm{ka}$ and the occurrence at $61-64 \mathrm{~m}$ indicates an age of $\geq 116 \mathrm{ka}$. The presence of Donax at 32-38 m probably is reworked because the paleomagnetics, TL, and radiocarbon suggest an age of 35-41 ka for this interval.

\section{Geochronology}

\section{Paleomagnetism}

Intensities of remanent magnetization measured before and after demagnetization treatments are presented in appendix III, table 4 for 171 specimens from LBPF. The natural remanent magnetization (NRM) ranges from $0.24 \mathrm{milliA} / \mathrm{m}\left(10^{-3}\right.$ Ampere/meter $)$ to $0.16 \mathrm{~A} / \mathrm{m}$, with a median value of approximately $10 \mathrm{milliA} / \mathrm{m}$. Very low intensities in two or more specimens are found at depths of 318-364, 245-277, 200-217, and 12-14 m (fig. 12). Comparison of the NRM and susceptibility logs shows that most of the intensity lows correlate with susceptibility lows. This correlation is an indication that the concentration of magnetic minerals is the main influence on intensity of magnetization, rather than variation of the past geomagnetic-field strength.

Table 4. Paleomagnetic results from Long Beach Pier F core site and monitoring well (LBPF), Long Beach, California. [Title of table is included here for continuity; complete table is in appendix III.]

Alternating-field treatments to $50 \mathrm{mT}$ successfully isolated a stable magnetization direction in 77 percent of the specimens (maximum angle of deviation, $\mathrm{MAD}, \leq 10^{\circ}$ ). Optimum cleaning and stabilization of the magnetic direction typically was achieved by alternating-field treatment of 15$30 \mathrm{mT}$. To investigate alternating-field resistance as a function of depth, the ratio of partially demagnetized remanence to the original natural remanence for the $15 \mathrm{mT}$ and $30 \mathrm{mT}$ alternatingfield steps is graphed (fig. 13). The $\mathrm{J}_{15} / \mathrm{J}_{\text {nrm }}$ ratio shows much variation with depth with distinct lows at 169-180, 100-104, 86-91, and 63-73 m. High resistance characterized the intervals at 208-250 m. Intervals of high alternating-field resistance might indicate an increasing percentage of single-domain magnetite grains ( $\sim 0.1$ microns diameter), or a mineralogical change from magnetite to hematite, goethite, or pyrrhotite. Low resistance to alternating-field demagnetization typically indicates preponderance of large, multidomain grains of magnetite in the sediment (diameter $>60$ microns). The coarser sands in the upper part of the core tend to show low resistance to alternatingfield demagnetization.

Inclinations measured in LBPF generally are consistent with a geocentric, axial dipole field of normal polarity (fig. 14). Seven intervals (labeled A through G) yielded negative inclination values, suggesting the possibility of geomagnetic excursions to be examined by more detailed sampling. In January 2006, some of the cores were retrieved from refrigerated storage and resampled in the sections where negative inclinations were previously measured. The new samples confirmed excursions: $\mathrm{A},-35.7^{\circ}$ at $40.1 \mathrm{~m} ; \mathrm{B},-39.5^{\circ}$ at $58.9 \mathrm{~m}$ near the base of the Pacific unit; and $\mathrm{D},-56.8^{\circ}$ at $125.5 \mathrm{~m}$. Anomaly $\mathrm{C}$, at $61-64 \mathrm{~m}$, occurs in friable, medium-grained sand that failed to withstand the tumbling of the demagnetization treatments. Therefore, this anomaly was not confirmed. Inclination anomalies $\mathrm{E}$ and $\mathrm{F}$, represented by single specimens in the original sampling, were not resampled.

The thermal stability of magnetization remanence was tested in the interval of low inclination $(\mathrm{G})$ near the base of the lower Wilmington unit. Thermal demagnetization was applied to eight specimens that had dried during storage in a magnetically shielded room. These specimens 


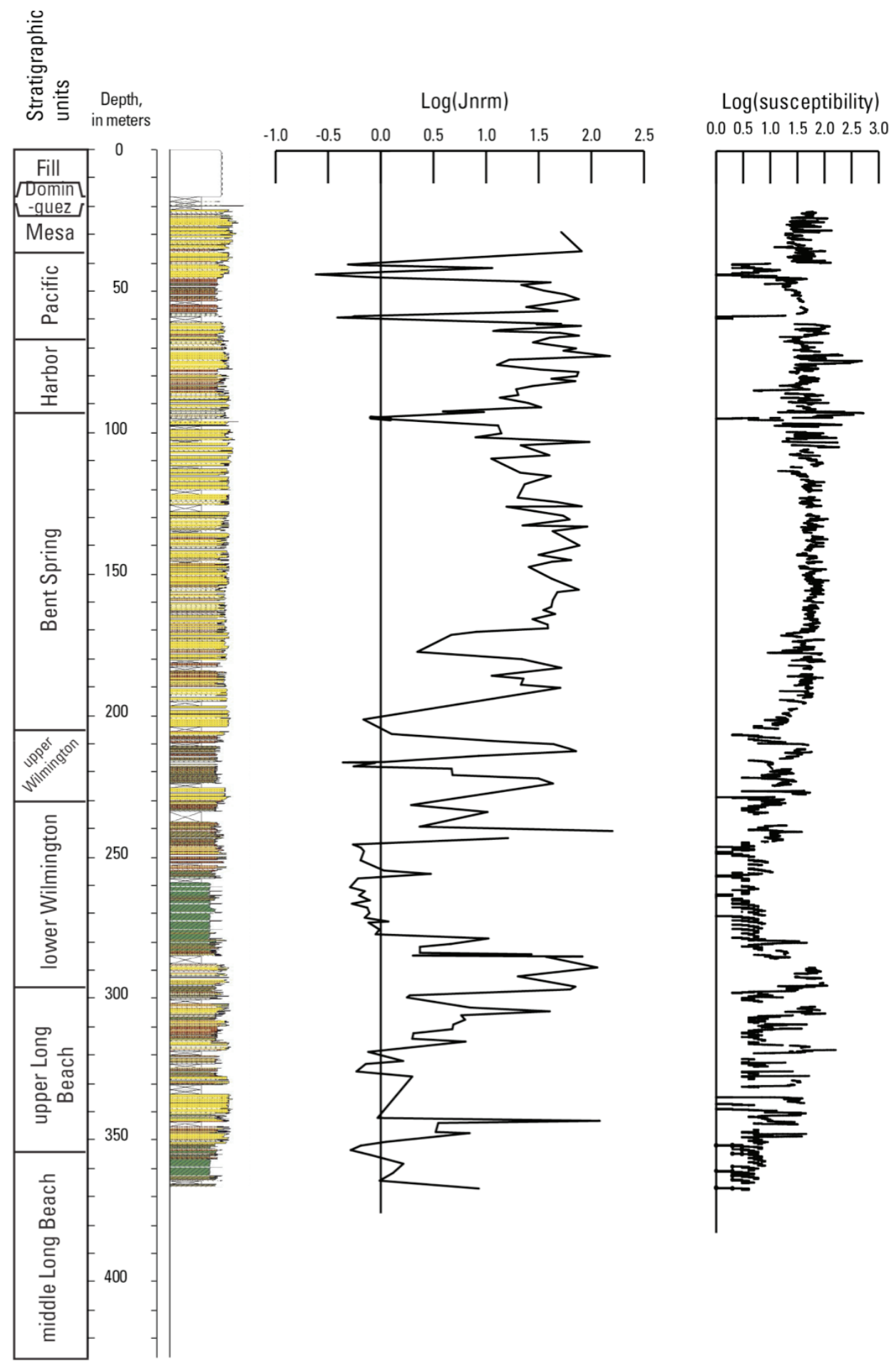

Figure 12. Remanent magnetization intensity (Jnrm) and magnetic susceptibility of Long Beach Pier F core site and monitoring well, Long Beach, California, (logarithmic scale: intensity, $0.0=1 \mathrm{milli} / \mathrm{m}$; susceptibility, $0.0-6=1 \times 10 \mathrm{SI}$ ). Stratigraphic units are identified in the left column, and lithologies are indicated on the stratigraphic column by color (clay, green; silt, brown; sand, yellow) (Ponti and others, 2007).

were previously subjected to alternating-field demagnetization to $40 \mathrm{mT}$, so the natural remanent magnetization was reduced substantially from the initial state. In general, the magnetization was reduced to the point of instability in nearly all the specimens after heating progressed above $350^{\circ} \mathrm{C}$. 


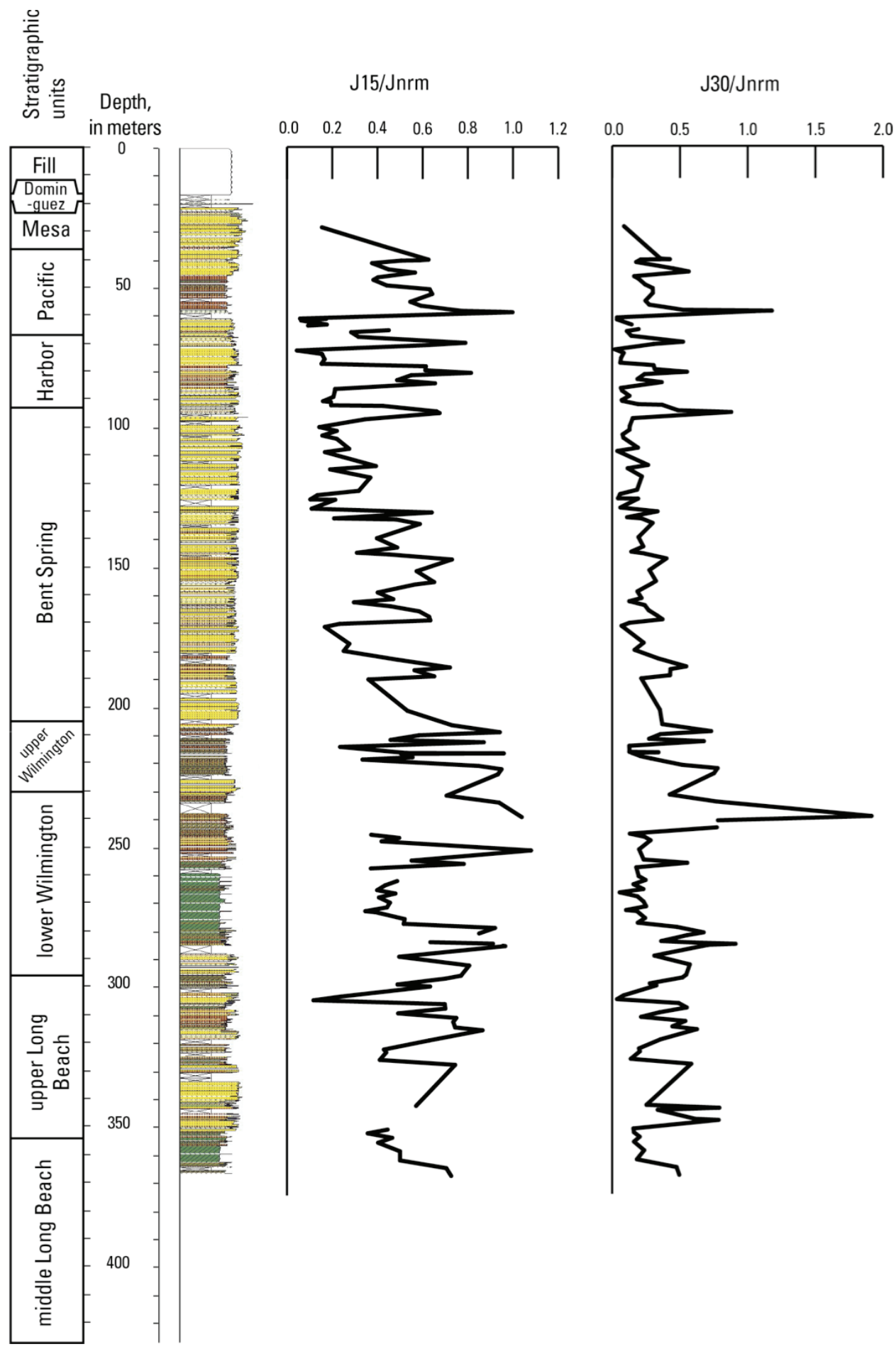

Figure 13. Resistance of remanence to alternating-field demagnetization of the Long Beach Pier $F$ core site and monitoring well, Long Beach, California. Ratio of magnetization intensity after the 15 milliTesla step (J15) to the natural remanent magnetization (Jnrm) is shown. Stratigraphic units are identified in the left column, and lithologies are indicated on the stratigraphic column by color (clay, green; silt, brown; sand, yellow) (Ponti and others, 2007).

One specimen $(1 \mathrm{H} 210-1$ at $283.1 \mathrm{~m})$ retained a normal-polarity inclination below $453^{\circ} \mathrm{C}$ and moved to reversed polarity $\left(-30.0^{\circ}\right.$ inclination) when the heating reached $564^{\circ} \mathrm{C}$. This result, which strengthened evidence that a geomagnetic excursion or polarity reversal occurred during deposition 

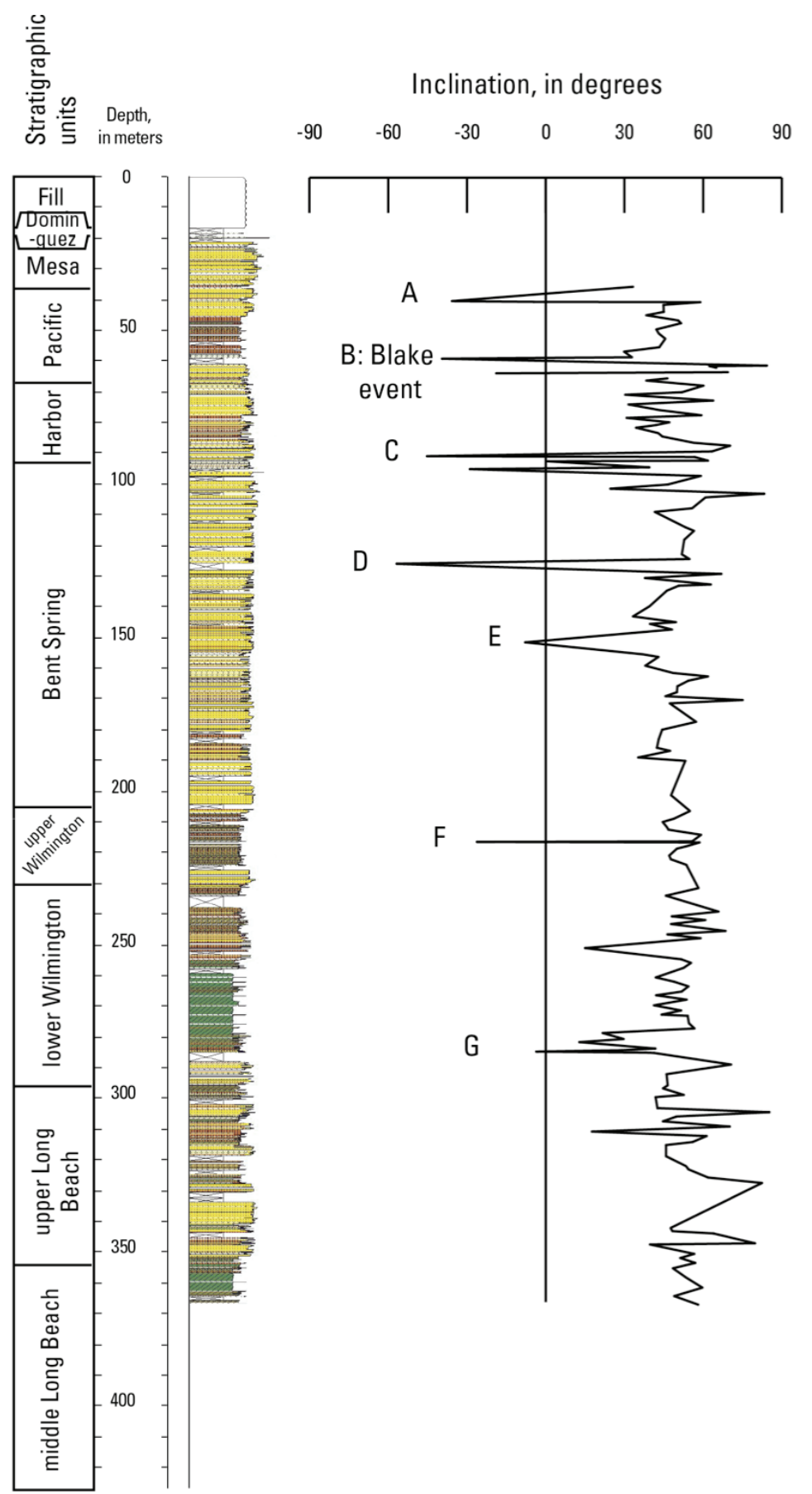

Figure 14. Inclination of remanent magnetization with depth in Long Beach Pier $F$ core site and monitoring well, Long Beach, California. Letters A through $\mathrm{G}$ identify locations of seven negative excursions discussed in the text. Stratigraphic units are identified in the left column, and lithologies are indicated on the stratigraphic column by color (clay, green; silt, brown; sand, yellow) (Ponti and others, 2007).

of the lower Wilmington unit, prompted additional sampling of the interval. The new samples yielded low inclinations $\left(29^{\circ}-41^{\circ}\right)$, but reversed polarity was not confirmed.

Electron Microprobe scans were obtained from magnetic minerals in sandy beds at depths of $343.2 \mathrm{~m}$ (middle Long Beach unit), $96.9 \mathrm{~m}$ (Bent Spring unit), and $90.5 \mathrm{~m}$ (Harbor unit). In general, the elemental compositions indicate iron oxides with very thin iron-sulfide rims (fig. 15). The dominant oxide is magnetite at the three sampled levels. These grains typically have solid, 
unfractured cores, and the sulfide rims, presumably products of anoxic bacterial reduction (Canfield and Berner, 1987, Leslie and others, 1990a,b), are less than a micrometer thick. Less common were titanohematite and titanomagnetite grains, as indicated by the scans for titanium. The example of a titanomagnetite grain at $343.2 \mathrm{~m}(221 \mathrm{C} / 1)$ shows ilmenite lamellae within the magnetite matrix, a crystal form that is typical of extrusive volcanic rocks (fig. 16). The titaniumrich grain at $90.8 \mathrm{~m}(51 \mathrm{C} / 1)$ has convoluted internal structure commonly associated with titanohematite in high-grade metamorphic rocks (fig. 17).

The magnetic grains that were analyzed in LBPF appear to be fresh detrital grains with minor developments of authigenic sulfide coatings. In marine environments, iron-sulfides form under conditions of low oxygen and high organic carbon (Canfield and Berner, 1987). Bacteria reduce sulfate in seawater to produce $\mathrm{H}_{2} \mathrm{~S}$, which in turn reacts with iron-bearing minerals.

Prolonged exposure of magnetite to $\mathrm{H}_{2} \mathrm{~S}$ leads to the formation of pyrite, a form of iron-sulfide that does not acquire remanent magnetization. However, the sulfidization reaction can progress through intermediate products, such as greigite, a form of iron-sulfide that does acquire remanence. The microprobe images show crystal forms consistent with pyrite, but the tests cannot rule out the presence of greigite or pyrrhotite.

The LBPF inclination record exhibits no sustained interval of reversed polarity, suggesting absence of the Brunhes-Matuyama boundary (fig. 8). This result would imply that the entire well represents sediment no older than $0.78 \mathrm{Ma}$. However, planktic foraminifers from samples below the lower Wilmington unit are early Pleistocene in age and are thought to be at least $1.8 \mathrm{Ma}$. An erosional unconformity separates the lower Wilmington unit from the underlying upper Long Beach unit, which may explain the absence of the Brunhes-Matuyama boundary. The erosional gap would be a hiatus in deposition spanning a minimum of approximately one million years, representing the interval between the Olduvai Normal-Polarity Subchron and the beginning of the

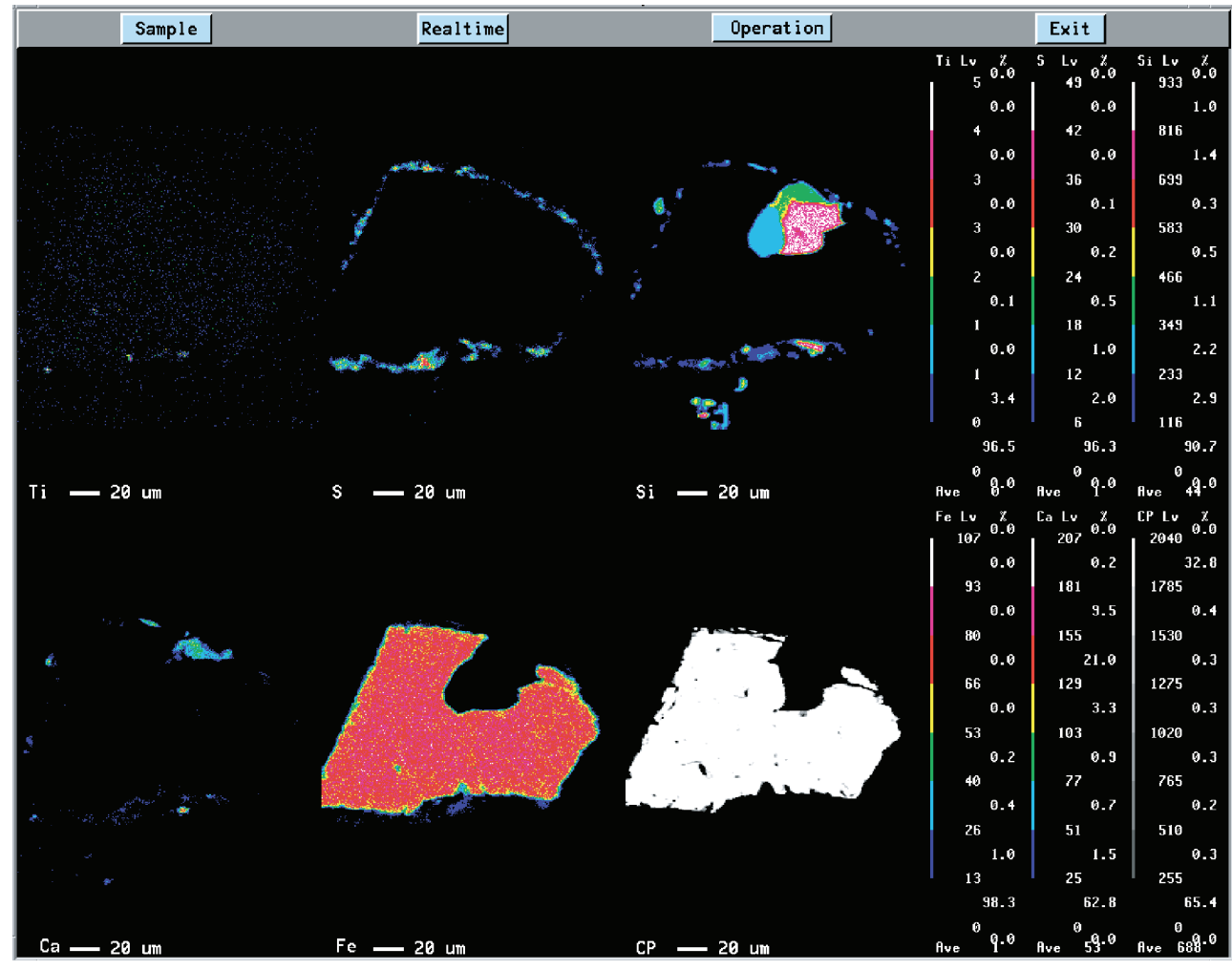

Figure 15. Electron-microprobe scan of magnetic grain from LBPF 55/1 showing thin iron-sulfide rim surrounding a titanomagnetite core. 


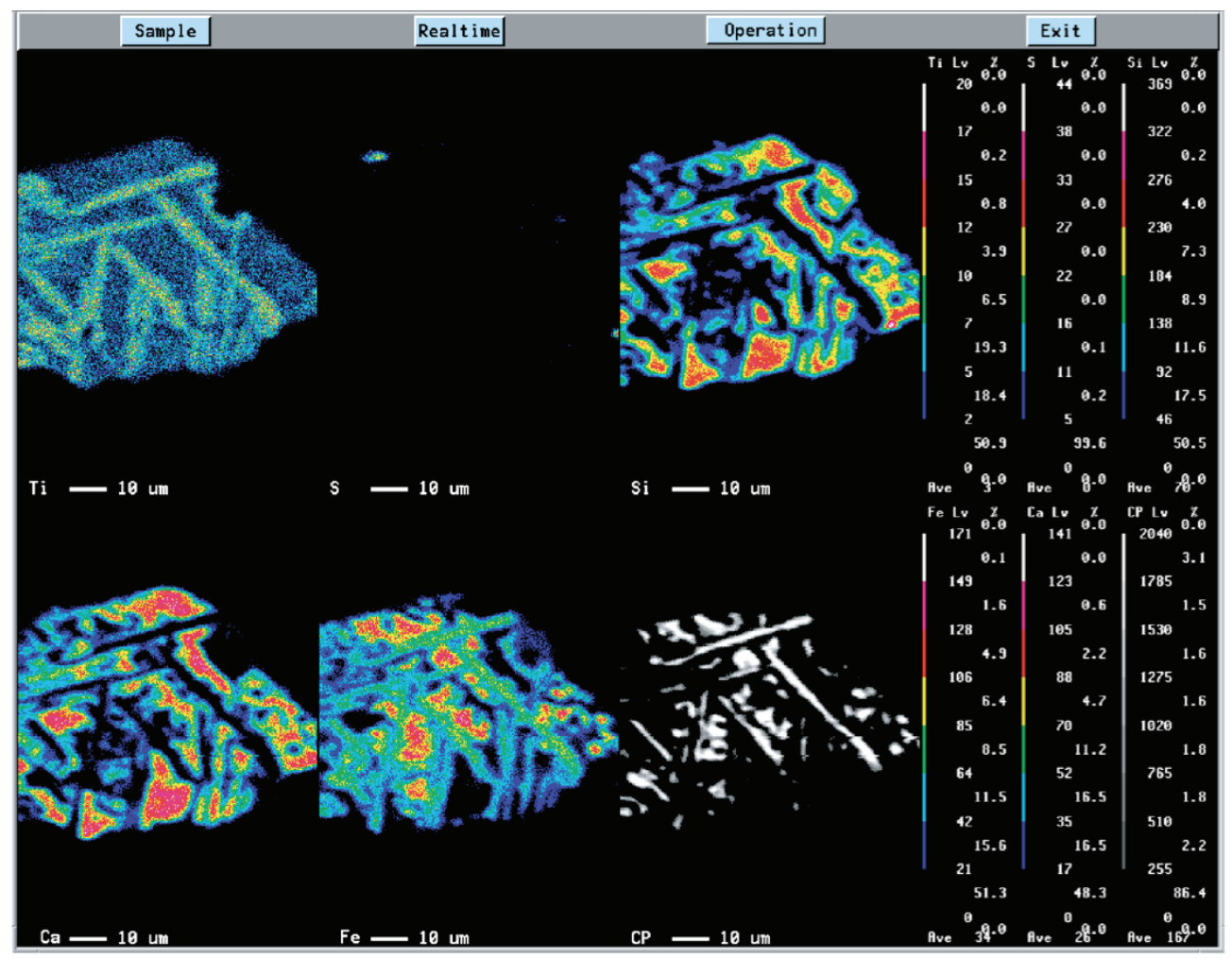

Figure 16. Electron-microprobe scan of magnetic grain from LBPF 221/1 showing titanomagnetite with ilmenite lamellae. This lattice structure is commonly found in extrusive volcanic rocks.

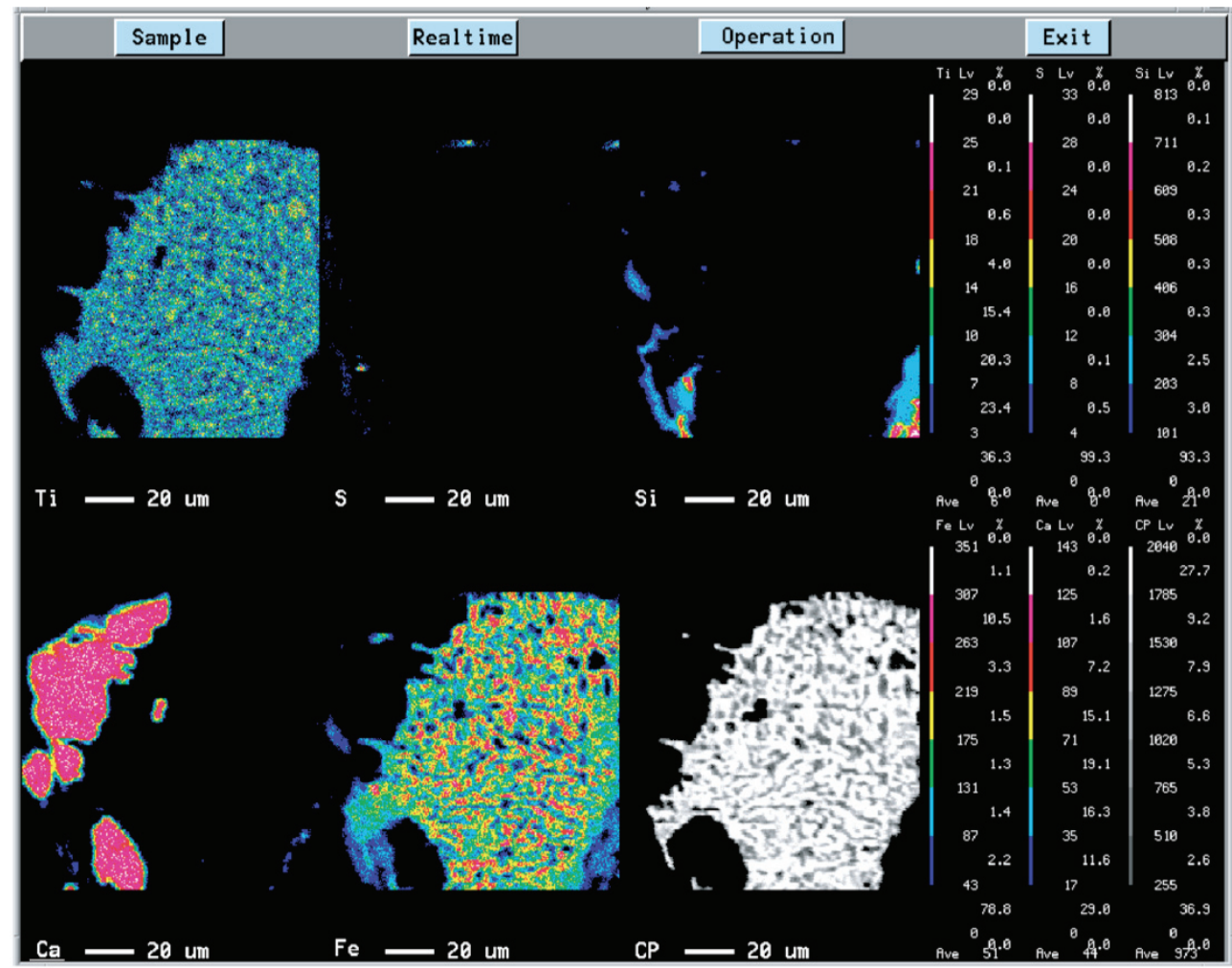

Figure 17. Electron-microprobe scan of magnetic grain from LBPF 51/1 showing convoluted internal structure commonly associated with titanohematite in high-grade metamorphic rocks. 
Brunhes Normal Polarity Chron or Gauss Normal Polarity Chron (2.58-3.58 Ma). Anomalously low inclinations that were measured near the base of the lower Wilmington unit are perhaps a record of geomagnetic instability during the early stages of the Brunhes Normal Polarity Chron.

The interval of anomalous negative inclinations near the base of the Pacific unit (anomaly B, $58.9 \mathrm{~m}$ ) possibly correlates with the Blake event (fig. 2), a global geomagnetic instability that occurred during MIS 5e ( 117 ka). TL dating at $59.2 \mathrm{~m}$ (LBPF-28C), which is within the zone of anomalous inclination, yielded ages of $93.2 \pm 7.8 \mathrm{ka}$ and $95.9 \pm 19.5 \mathrm{ka}$; and at $67.0 \mathrm{~m}$ (LBPF-33C) below this interval, TL dating yields ages of $131 \pm 9.83$ and $149 \pm 17.7$ ka supporting this correlation. Inclination anomaly A $(40.1 \mathrm{~m})$ in the Mesa unit is possibly correlative with the Laschamp event with an age of $40 \mathrm{ka}$ (Scaillet and others, 2004). Correlation with the Laschamp event is supported by a radiocarbon date on a shell in core $13(\sim 35.5 \mathrm{~m})$, approximately $5 \mathrm{~m}$ above anomaly A (40.1 $\mathrm{m})$, which yielded an age of 41,430 $\pm 1130 \mathrm{yr}$ BP and the TL date at $36.5 \mathrm{~m}$ (LBPF-13C) which yielded ages of $26.8 \pm 4.3$ and $35.2 \pm 2.6 \mathrm{ka}$ (IRSL ages were $31.4 \pm 0.9$ and $23.9 \pm 0.8 \mathrm{ka}$ ). The inclination anomaly at $\mathrm{D}$ is in a stratigraphic position consistent with the Pringle Falls event near $200 \mathrm{ka}$ but there is no independent dating information to strengthen the correlation.

\section{Optically Stimulated Luminescence and Thermal Luminescence Dating}

Twelve samples were collected for luminescence dating from this well, but only six were processed and analyzed for equivalent-dose data within the dark lab (table 5), although the elemental concentrations and dosimetry are shown for twelve samples (table 6). The other six samples were not dated because the luminescence began to show saturation behavior owing to the older (middle Pleistocene to Pliocene) age of the sediment. The samples ranged in depth from 27.2 to $94.4 \mathrm{~m}$ and were dated using TL, IRSL on potassium feldspars, and quartz OSL. TL was used because the sediment is sometimes older than what can be dated using OSL. TL is used to date the younger samples even though the technique is prone to overestimating ages owing to the insensitivity to light of the TL centers. Comparisons can be made of how closely either the IRSL or quartz OSL ages track the TL ages.

Feldspar IRSL-OSL ages are reported for six samples, and then the technique was discontinued because the saturation of these particular systems kept returning age underestimates. Table 5 lists two ages using IRSL for the samples (except where it is apparent that the ages are badly underestimated). Most ages are within error of each other and the feldspar IRSL-OSL is older than the quartz by 5,000 years or more. Figure 19 shows the feldspar IRSL-OSL growth curve for sample LBPF-28C (59.2 m). This growth curve is nonlinear in the equivalent dose ranges of 200-220 Gy.

No IRSL-OSL ages older than about 75,000 years were obtained (due to continued saturation), even though the deeper well sediments were clearly trending toward older fossil assemblages. All sample ages below the $59 \mathrm{~m}$ level (LBPF-28C, $59.2 \mathrm{~m}$ ) are considered as minima, sometimes with severe underestimates. Again, elemental data analyses did not indicate large dose rates that were likely to cause the creation of large amounts of unstable luminescence in a short amount of time (table 6), and normal ratios of $U: T h$ are present (that is, 1:2, 1:3, or 1:4). These findings do not indicate substantial problems with disequilibrium issues. However, the dose rate generally is increasing downward, probably owing to the increased fine-grained properties of sediments lower in the well (table 6).

TL was attempted on all the samples and, unlike the OSL, the saturation level was not attained until sample LBPF-53C (94 m). The TL ages are much older than the quartz OSL ages, but track the IRSL-OSL feldspar ages very closely (table 5). TL does not reset as quickly as OSL does (Wallinga, 2002) and often requires many hours of exposure ( $>6$ hours) to sunlight to "zero"; 
Table 5. Thermoluminescence (TL), feldspar infrared stimulated luminescence (IRSL), and quartz optically stimulated luminescence (OSL) ages for Long Beach Pier F core site and monitoring well, Long Beach, California.

[ka, thousands of years; Gy, Grays; >, greater than; -, no data]

\begin{tabular}{|c|c|c|c|c|c|c|c|c|c|}
\hline $\begin{array}{c}\text { Sample } \\
\text { information } \\
\text { core depth: } \\
\text { material }\end{array}$ & $\begin{array}{l}\text { Moisture } \\
\qquad(\%)^{a}\end{array}$ & $\begin{array}{c}\text { TL age } \\
\text { (ka)b }\end{array}$ & $\begin{array}{c}\text { IRSL } \\
\text { dose rate } \\
\text { (Gy/ka) }\end{array}$ & $\begin{array}{c}\text { Equivalent } \\
\text { dose } \\
\text { (Gy) }\end{array}$ & $\begin{array}{l}\text { IRSL age } \\
\qquad(\mathrm{ka})^{\mathrm{b}}\end{array}$ & $\mathrm{n}^{\mathrm{c}}$ & $\begin{array}{c}\text { Quartz } \\
\text { dose rate } \\
\left(10^{-3}\right. \\
\text { Gy/yr }) \\
\end{array}$ & $\begin{array}{c}\text { Equivalent } \\
\text { dose } \\
\text { (Gy) }\end{array}$ & $\begin{array}{c}\text { Quartz } \\
\text { age } \\
\text { (ka) }\end{array}$ \\
\hline LBPF-4C & $3.0 \pm 0.5$ & $26.6 \pm 14.0$ & $3.53 \pm 0.07$ & $59.5 \pm 1.42$ & $17.8 \pm 1.10$ & $\begin{array}{l}24 \\
(30)\end{array}$ & $2.54 \pm 0.05$ & $32.5 \pm 2.11$ & $12.8 \pm 1.02$ \\
\hline $\begin{array}{l}22.7 \mathrm{~m}: \\
\text { Sandy Silt }\end{array}$ & & $27.4 \pm 2.44$ & & $79.0 \pm 0.52$ & $23.6 \pm 0.99$ & & & & \\
\hline LBPF-13C & $16 \pm 2$ & $26.8 \pm 4.31$ & $3.84 \pm 0.05$ & $120 \pm 0.41$ & $31.2 \pm 0.90$ & $\begin{array}{l}28 \\
(30)\end{array}$ & $2.62 \pm 0.04$ & $57.6 \pm 3.17$ & $22.0 \pm 1.49$ \\
\hline $\begin{array}{l}36.5 \mathrm{~m}: \\
\text { Sand }\end{array}$ & & $35.2 \pm 2.62$ & & $91.2 \pm 0.87$ & $23.7 \pm 0.80$ & & & & \\
\hline LBPF-26C & $29 \pm 3$ & $78.0 \pm 8.84$ & $4.17 \pm 0.02$ & $312 \pm 25.9$ & $74.7 \pm 12.7$ & - & - & - & - \\
\hline $\begin{array}{l}56.2 \mathrm{m:} \\
\text { Sand }\end{array}$ & & $66.1 \pm 9.48$ & & $308 \pm 2.12$ & $73.8 \pm 10.5$ & & & & \\
\hline LBPF-28C & $32 \pm 3$ & $93.1 \pm 7.78$ & $3.21 \pm 0.07$ & $>218 \pm 28.9$ & $>67.9 \pm 18.3$ & - & - & - & - \\
\hline $\begin{array}{l}59.2 \mathrm{~m}: \\
\text { Sand }\end{array}$ & & $95.8 \pm 19.5$ & & $>220 \pm 4.49$ & $>68.6 \pm 4.21$ & & & & \\
\hline LBPF-33C & $29 \pm 3$ & $131 \pm 9.83$ & $3.36 \pm 0.07$ & $>254 \pm 21.5$ & $>75.7 \pm 13.2$ & - & - & - & - \\
\hline $\begin{array}{l}67.0 \mathrm{~m} \text { : Silty } \\
\text { Sand }\end{array}$ & & $149 \pm 17.7$ & & $>253 \pm 3.99$ & $>75.3 \pm 3.96$ & & & & \\
\hline $\begin{array}{l}\text { LBPF-53C } \\
94.4 \text { m: } \\
\text { Sandy Silt }\end{array}$ & $31 \pm 3$ & $>68.3 \pm 26.1$ & $3.69 \pm 0.07$ & $>183 \pm 18.4$ & $>49.6 \pm 10.2$ & - & - & - & - \\
\hline
\end{tabular}

${ }^{a}$ Field moisture, ages based on 40-35 percent moisture content through time as an average between field and saturation moisture

${ }^{\mathrm{b}}$ Silt fraction (4-11 micron size) for IRSL as multiple aliquot additive dose technique (MAAD).

${ }^{\mathrm{C}}$ Number of replicated equivalent dose (De) estimates used to calculate the mean. Figures in parentheses indicate the total number of measurements made, including failed runs with unusable data.

${ }^{\mathrm{d}}$ Lab used fine sand grains (125-90 micron size) for quartz OSL as single aliquot regeneration technique (SAR). Fitted to a linear regression. Errors on equivalent dose and dose rate data at one sigma. Errors on ages at two sigma were calculated before rounding.

apparently, the depositional periods associated with this well involved shallower or clearer water or sample grains that had been zeroed well before washing into the basin.

Although the TL ages from LBPF appear to bracket the Blake event (117 ka) between sample LBPF-28C (59.2 m) at about $95 \mathrm{ka}$ and LBPF-33C (67.0 m) at about $140 \mathrm{ka}$, this event occurs at $58.9 \mathrm{~m}$, about $1 \mathrm{~m}$ above the TL samples based on paleomagnetic analysis. There is a sharp drop in sensitivity to luminescence in the next sample (LBPF-53C, $94 \mathrm{~m}$ ), and the TL also begins to return severe age underestimates. Our preferred ages are the quartz OSL ages, then the IRSL and TL ages. The IRSL and TL ages track closely until IRSL saturates at $59.2 \mathrm{~m}$ and the TL is the preferred age.

Radiocarbon dating of a shell at $36.5 \mathrm{~m}$ gave a date of 41,430 $\pm 1,130 \mathrm{yr}$ BP (Beta Analytic Radiocarbon Laboratory, Miami, Fla., oral commun., 2003), which is older than the quartz OSL age of $22.0 \pm 1.49 \mathrm{ka}$ at the same depth. The radiocarbon ages agree better with the IRSL and TL ages $(23-37 \mathrm{ka})$, but cannot be correlated with any of the luminescence ages from the same depth. 
Table 6. Elemental concentrations and associated dosimetry for the Long Beach Pier $\mathrm{F}$ core site and monitoring well, Long Beach, California, optically stimulated luminescence (OSL) samples.

$\left[\%\right.$, percent; ppm, parts per million; $m$, meter; $\mathrm{D}_{\mathrm{r}}$, dose rate; $\mathrm{K}$, Potassium; $\mathrm{U}$, Uranium; Th, Thorium; Rb, Rubidium; -, no data]

\begin{tabular}{|c|c|c|c|c|c|c|c|c|c|c|c|c|}
\hline Sample number & $(\%)$ & (ppm) & (ppm) & Depth & Water & $\begin{array}{c}D_{r} \\
\text { fine } \\
\text { grain }\end{array}$ & $\begin{array}{c}D_{r} \\
\text { coarse } \\
\text { graina }\end{array}$ & $\begin{array}{c}D_{r} \\
\text { for K }\end{array}$ & $\begin{array}{c}D_{r} \\
\text { for } U\end{array}$ & $\begin{array}{c}D_{r} \\
\text { for Th }\end{array}$ & $\begin{array}{c}D_{r} \\
\text { for } R b\end{array}$ & $\begin{array}{c}D_{r} \\
\text { for } \\
\text { cosmic } \\
\text { ray }\end{array}$ \\
\hline LBPF-4C & 2.36 & 1.99 & 9.30 & 22.70 & 35 & 3.51 & 2.54 & 1.759 & 0.722 & 0.971 & 0.033 & 0.025 \\
\hline LBPF-13C & 2.11 & 2.42 & 12.65 & 36.50 & 35 & 3.82 & 2.62 & 1.580 & 0.884 & 1.329 & 0.029 & 0.018 \\
\hline LBPF-26C & 2.44 & 2.91 & 13.16 & 56.20 & 40 & 4.13 & - & 1.752 & 1.017 & 1.323 & 0.033 & 0.006 \\
\hline LBPF-28C & 2.32 & 1.93 & 7.77 & 59.20 & 40 & 3.16 & - & 1.666 & 0.674 & 0.781 & 0.031 & 0.004 \\
\hline LBPF-33C & 2.33 & 1.78 & 7.55 & 67.00 & 35 & 3.22 & - & 1.745 & 0.650 & 0.793 & 0.032 & 0.002 \\
\hline LBPF-53C & 2.34 & 2.43 & 9.14 & 94.40 & 40 & 3.48 & - & 1.681 & 0.849 & 0.919 & 0.031 & 0.002 \\
\hline LBPF-90C & 2.47 & 1.56 & 7.87 & 151.00 & 30 & 3.43 & - & 1.933 & 0.597 & 0.866 & 0.036 & 0.001 \\
\hline LBPF-111C & 2.51 & 2.51 & 12.78 & 183.00 & 40 & 4.00 & - & 1.803 & 0.877 & 1.286 & 0.034 & 0.001 \\
\hline LBPF-128C & 2.53 & 2.47 & 11.70 & 208.00 & 35 & 4.06 & - & 1.895 & 0.902 & 1.224 & 0.035 & 0.001 \\
\hline LBPF-203C & 2.67 & 3.84 & 15.50 & 323.00 & 35 & 4.85 & - & 1.918 & 1.342 & 1.560 & 0.036 & 0.000 \\
\hline
\end{tabular}

${ }^{a}$ Coarse grains used for quartz OSL have the alpha component and about $10 \%$ beta component of the dosimetry etched away

\section{Paleoecology}

\section{Benthic Foraminifers}

The highest and most consistent abundances and diversities of benthic foraminifers occur in the Venturian interval (fig. 9). Biofacies analysis suggests that the lower Venturian interval from 365.4 to $356.6 \mathrm{~m}$ (Mf10746-Mf10741) was deposited in lower middle bathyal biofacies (1,500$2,000 \mathrm{~m}$ ) (fig. 20). On average, 11 percent of the benthic foraminiferal fauna has upper depth limits (UDLs) in the upper middle bathyal biofacies $(500-1,500 \mathrm{~m})$ and $<3$ percent of the fauna has UDLs in the lower middle bathyal biofacies $(1,500-2,000 \mathrm{~m})$. Borderland biofacies analysis indicates that the bulk of the species are common to the lower slope facies ( 38 percent) and $<3$ percent of the fauna represents the basin floor facies $(1,200-1,900 \mathrm{~m})$. The overlapping depth range suggested by these analyses is 1,200-1,900 $\mathrm{m}$. The abundance of dysoxic species (Bolivina, Loxostomum, and Praeglobobulimina), as well as species common to the oxygen-minimum zone (Buliminella basispinata and Uvigerina peregrina) and the dominance of infaunal species ( 80 percent), indicate that oxygen conditions were low $(<1.0 \mathrm{ml} / \mathrm{l})$. Epistominella pacifica and other species characteristic of higher oxygen levels are poorly represented in these assemblages.

Biofacies analysis of the upper Venturian interval, 355.1-298.7 m (Mf10740-Mf10704), indicates deposition occurred in the upper middle bathyal or lower slope biofacies at depths of 500 to $950 \mathrm{~m}$ (fig. 20). Oxygen levels are variable; no well-developed dysoxic fauna is recognized, although Bolivina argentea, several species of Loxostomum, and Praeglobobulimina are present. Epistominella pacifica dominates most of this interval, indicating higher oxygen conditions. Cassidulina californica, Cibicides mckannai suppressa, and Trifarina angulosa also are abundant in this interval and represent a transported assemblage. Uvigerina peregrina is abundant between 355.1 and $349.0 \mathrm{~m}$ (Mf10740-Mf10737). Typically, Uvigerina peregrina and its variants are most abundant during glacial periods (Douglas and Heitman, 1979; Boersma, 1984), however, in LBPF, $U$. peregrina tends to be common in the warm intervals (interglacials), as determined by the coiling direction of Neogloboquadrina pachyderma. The interglacials may be the only time interval during 

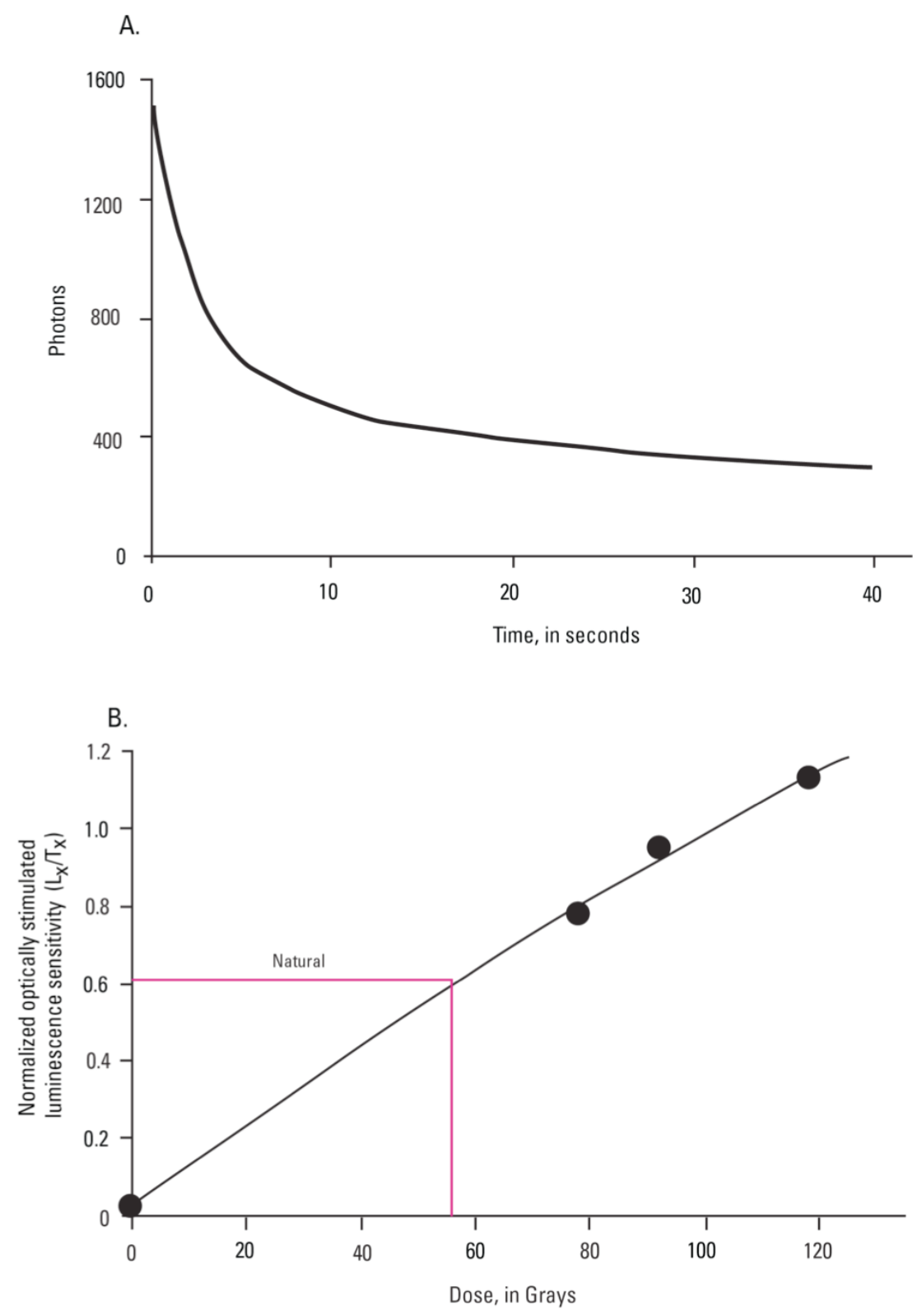

Figure 18. A, Optically stimulated luminescence (OSL) decay curve for LBPF-13C $(36.5 \mathrm{~m})$ showing the quartz signal as measured with blue-light wavelength emitting diodes. Time is measured in seconds (s), and OSL is measured in photon counts for a total time of $40 \mathrm{~s}$. B, LBPF-13C growth curve, with the natural plotted on the $L x / T x$ axis. Regeneration proceeded "optimally" with a recycle within 1 percent of the first measurement, and circles indicate increases in response to increasing beta radiation. Fit is to an exponential and linear function. Dose is measured in Grays (Gy, absorbed radiation), and OSL is measured in unitless normalized OSL-sensitivity measurements (Lx/Tx).

which the older oxygen-deficient water can reach the more nearshore basins. Water depths decrease between the upper and lower Venturian interval and this decrease, as well as other ecological changes, suggests an unconformity or hiatus is present in core 232.

Uvigerina peregrina dominates the questionably Wheelerian and lower Wheelerian interval from 297.2 through $281.9 \mathrm{~m}$ (Mf10703-Mf10695). Transported shelf species such as Ammonia beccarii, Elphidium transluscens, and Nonionella stella also are dominant in the questionably Wheelerian or reworked interval. Occasionally, the bank species, Cassidulina californica appears. 


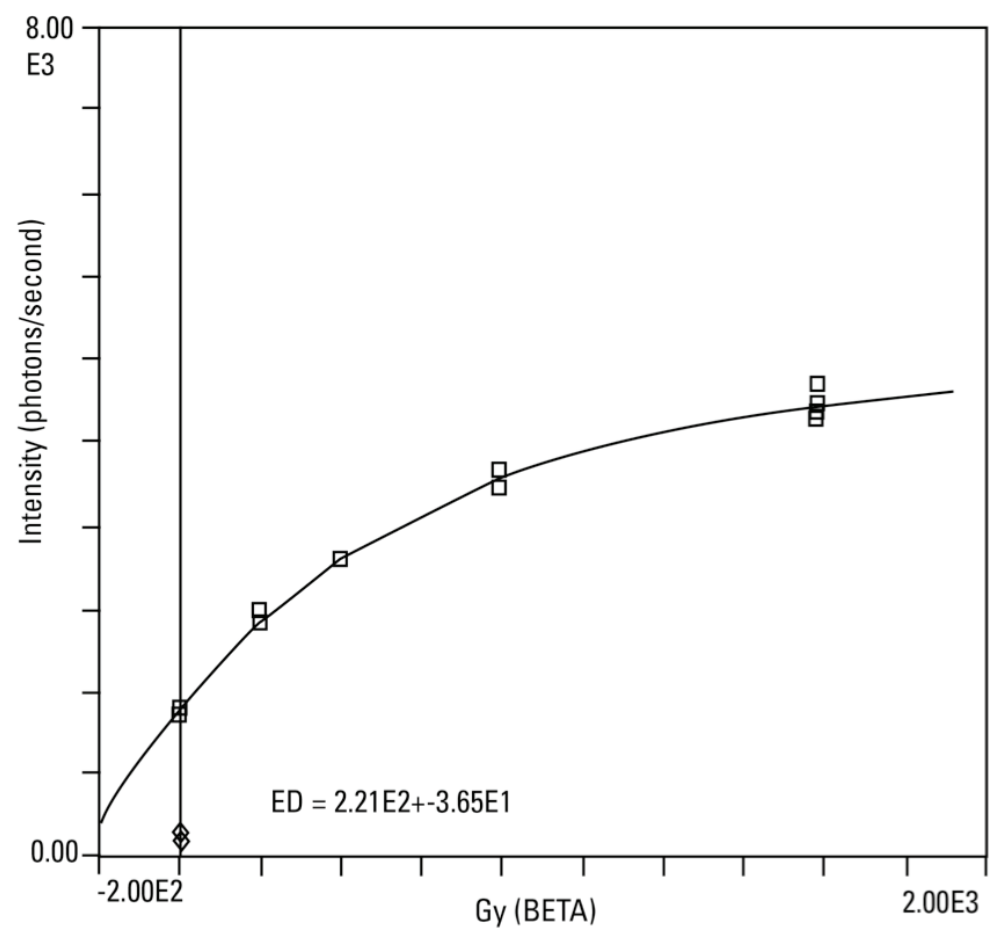

Figure 19. Growth curve of IRSL-OSL in the sample at $59.2 \mathrm{~m}$ (LBPF-28C) obtained using multi-aliquot additive dose method (MAAD). Bleaches are denoted by diamonds, naturals sit on vertical axis, and increasing beta-radiated aliquots are shown on an exponentially fitted growth line. The $\mathrm{X}$ axis shows the measured equivalent dose in Grays (Gy) when compared to calibrated Grays generated by exposure to a beta source. The $Y$ axis shows the intensity of light emitted from the aliquots and is measured in photons/second.

Although deposition continued in the upper middle bathyal or lower slope biofacies, these species suggest considerable transport from the shelf. Suboxic and dysoxic species are mixed in this interval, also indicating transport or reworking of faunas.

Near the base of the Wheelerian interval, Epistominella pacifica and Cibicides mckannai suppressa increase in abundance and become dominant between 265.2 and $214.9 \mathrm{~m}$ (Mf10684Mf10655). Although deposition is still in the upper middle bathyal (500-1,500 m) or lower slope (400-950 m) biofacies, species tolerant of low-oxygen conditions, such as Bolivina interjuncta, $B$. subadvena, Bulimina denudata, and Uvigerina peregrina, become the dominant species.

In the upper part of the Wheelerian interval, from 207.3 through $167.6 \mathrm{~m}$ (Mf10636Mf10625), the faunal composition fluctuates between species diagnostic of the upper bathyal and upper middle bathyal biofacies (500-1,500 and 1,500-2,000 m, respectively). Dominant upper bathyal species in this interval include Cassidulina transluscens and Trifarina angulosa, but the abundances of Epistominella pacific and Praeglobobulimina affinis suggest deposition is occurring in the upper middle bathyal biofacies $(500-1,500 \mathrm{~m})$ or lower slope biofacies $(400-950 \mathrm{~m})$. Water depths probably were greatest at the base of this interval. The abundance of Cassidulina transluscens and several shelf species, such as Nonionella miocenica, N. stella, Quinqueloculina lamarkiana, and Valvulineria araucana, near the base of this interval (213.4-199.6 m, Mf10654Mf10645), indicates transport from the shelf and cooler surface-water temperatures.

Cassidulina limbata and Nonionella basispinata dominate the early Hallian samples between 166.1 and $153.9 \mathrm{~m}$ (Mf10624-Mf10616). Nonionella basispinata, which has a UDL on the shelf, is common in the Wheelerian through Hallian interval either as part of the in situ or transported fauna. The appearance of $C$. limbata suggests, however, that deposition is occurring at 


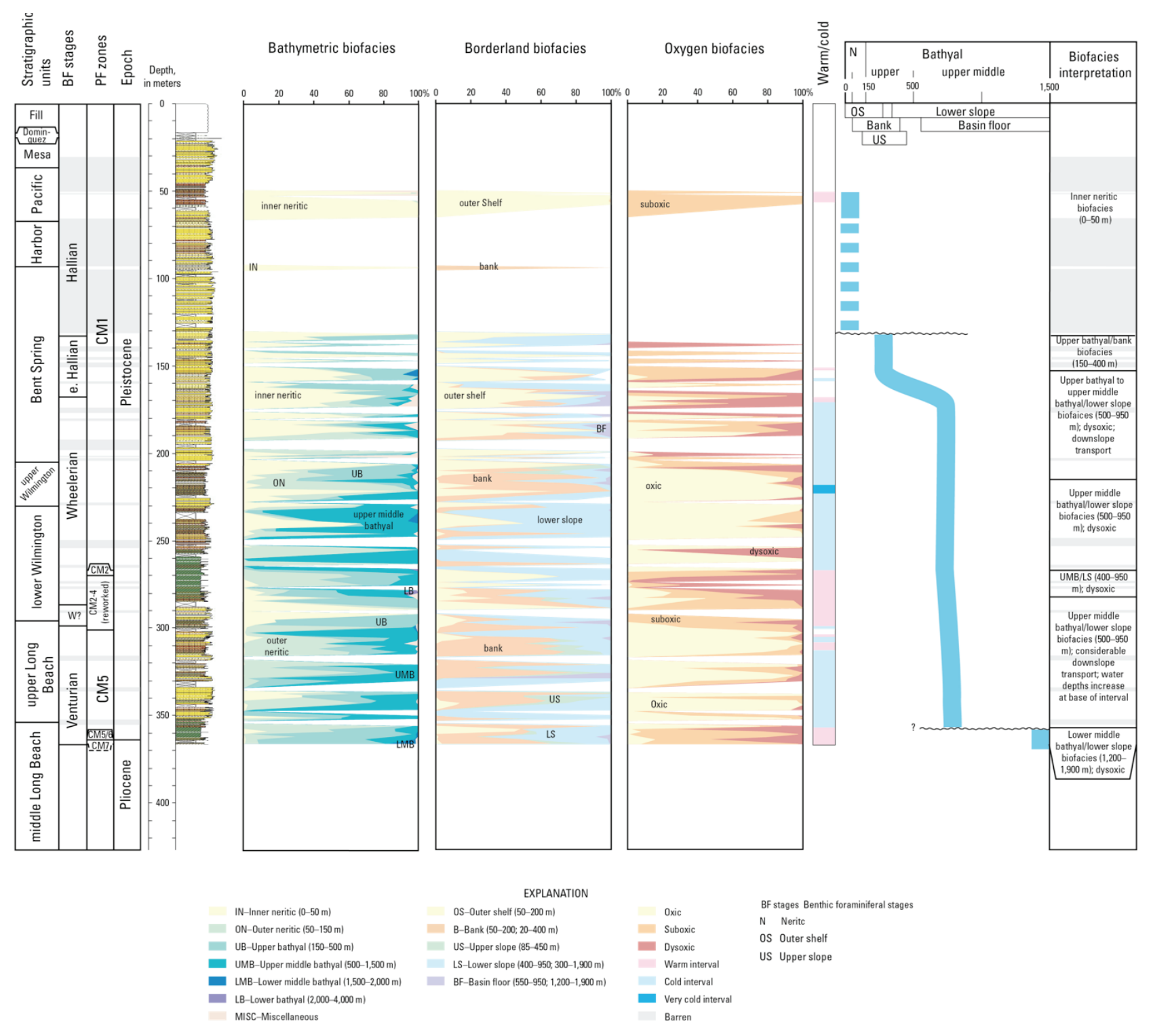

Figure 20. Paleoecological benthic foraminiferal biofacies analyses of the Long Beach Pier $\mathrm{F}$ core site and monitoring well, Long Beach, California. The three biofacies analyses shown are discussed in the text and are based on the abundance of benthic foraminifers in the samples. The bathymetric curve represents the most probable depth at which the samples were deposited. Stratigraphic units are identified in the left column, and lithologies are indicated on the stratigraphic column by color (clay, green; silt, brown; sand, yellow) (Ponti and others, 2007). [Reduced-size figure is shown here for continuity; full-size figure is included on plate 18.]

upper bathyal depths (150-500 $\mathrm{m})$ and in the bank biofacies (20-400 m). Other species occurring in this interval which supports upper bathyal depths are Praeglobobulimina affinis and Trifarina angulosa. A similar fauna is found between 150.9 and $132.6 \mathrm{~m}$ (Mf10603-Mf10615). Rare occurrences of Epistominella pacifica and Bolivina sinuata indicate the presence of a deeper watermass (E. pacifica) and reworking of Miocene sediments (B. sinuata). The faunal change and rapid increase in water depth between the early Hallian and Hallian suggests a possible unconformity or hiatus at approximately $131 \mathrm{~m}$.

Biofacies analysis indicates that the Hallian samples between 131.1 and $30.5 \mathrm{~m}$ (Mf10602Mf10546) were deposited at inner neritic biofacies at depths of 0-50 m. Abundance and diversity 
of the Hallian samples is low, and most of the samples are barren of foraminifers (fig. 9). These assemblages are dominated by species of Ammonia, Buccella, Elphidium, and Nonionella. Analysis based on the borderland geography also suggests that deposition occurred at outer shelf depths (50$200 \mathrm{~m}$; Douglas and Heitman, 1979). Because the borderland model does not consider inner shelf depths $(0-50 \mathrm{~m})$ and characteristic outer shelf species are not present, water depths in this interval are interpreted as $0-50 \mathrm{~m}$.

\section{Planktic Foraminifers}

The planktic assemblages between 365.4 and 356.6 m (Mf10741-Mf10746) contain increased numbers of species that thrived in subtropical marine conditions. Globigerinoides and right-coiling neogloboquadrinid species (for example, Neogloboquadrina kagaensis, N. dutertrei, and $N$. pachyderma s.s. dextral) indicate that the depositional environment was warm during the Pliocene (fig. 21). In this interval, the highest planktic foraminiferal diversity and abundance is found at $362.7 \mathrm{~m}$ (Mf10745). This is also the warmest interval, as indicated by the presence of tropical to warm-subtropical species Sphaeroidinellopsis seminulina.

In the overlying interval, 355.1-312.4 m (Mf10740-Mf10712), the sea-surface temperature (SST) proxies indicate a shift to cold marine conditions. Diversity is further reduced (minimum is 1 species), and abundances of $N$. pachyderma $\mathrm{C}$, the early Pleistocene, small, compact, sinistral form of this species, range from 22 to 93 percent (mean is 44 percent) of the total planktic foraminiferal counts. SST proxies indicate a shift to transitional environmental conditions between 310.9 and $304.8 \mathrm{~m}$ (Mf10711-Mf10707). Reduced diversities continue, and N. pachyderma coiling ratios fluctuate between cold- and warm-water forms.

Reworking and mixing of Pliocene and Pleistocene species was noted between 303.3 and $269.8 \mathrm{~m}$ (Mf10706-Mf10687). Other notable differences in this interval are major increases in the numbers of planktic foraminifers (up to 782 specimens/sample), species diversity (up to 15 species/sample), and the presence of subtropical species. Warm-water species include Globigerina umbilicata, Globigerinella calida, Globigerinoides obliquus, Gs. ruber, Neogloboquadrina dutertrei, N. inglei (N. pachyderma A), and N. pachyderma s.s. dextral. The high abundances (up to 70 percent) of right-coiling $N$. pachyderma morphotypes reinforces the belief that this interval was deposited during a warm climatic period.

Planktic foraminiferal faunas suggest a brief pulse of transitional water at $266.7 \mathrm{~m}$ (Mf10685), based on an increase in the abundance of warm-water variants of N. pachyderma. This gives way to the prevalence of modern, cold-water, sinistral forms of $N$. pachyderma in samples between 265.2 and $170.7 \mathrm{~m}$ (Mf10627-Mf10684) (fig. 21) and suggests a cool interval interrupted at $214.9 \mathrm{~m}$ (Mf10655) by a brief shift to transitional marine conditions; the abundance of $N$. pachyderma dextral increases to $\sim 54$ percent. Some of the highest percent abundances (up to 78 percent) of $N$. pachyderma B occur between 219.5 and 199.5 m (Mf10645-Mf10658). The overall number of planktic foraminifers also greatly increases in these intervals (mean is 152 specimens/sample). This sinistral, coiled variant dominates planktic foraminiferal assemblages in the northern hemisphere during the middle part of the Pleistocene (Kucera and Kennett, 2002; Darling and others, 2000, 2006). This cold interval, called the mid-Pleistocene transition (MPT), reflects the shift from $41 \mathrm{ka}$ climatic cycles of nearly continuous expansion of Northern Hemispheric ice sheets between 0.92 and $0.64 \mathrm{Ma}$ to the $100 \mathrm{ka}$ climatic cycles at $\sim 0.54 \mathrm{Ma}$ (Schmeider and others, 2000). This cold interval in LBPF indicates that not only were SSTs colder, but that sea level was higher.

The few microfossiliferous samples between 169.2 and $50.3 \mathrm{~m}$ (Mf10553--Mf10626) contain rare $(<5$ percent) planktic foraminiferal tests. Diversity and abundance are low in this interval, averaging 3 species and 9 specimens per sample. Planktic foraminiferal assemblages are 


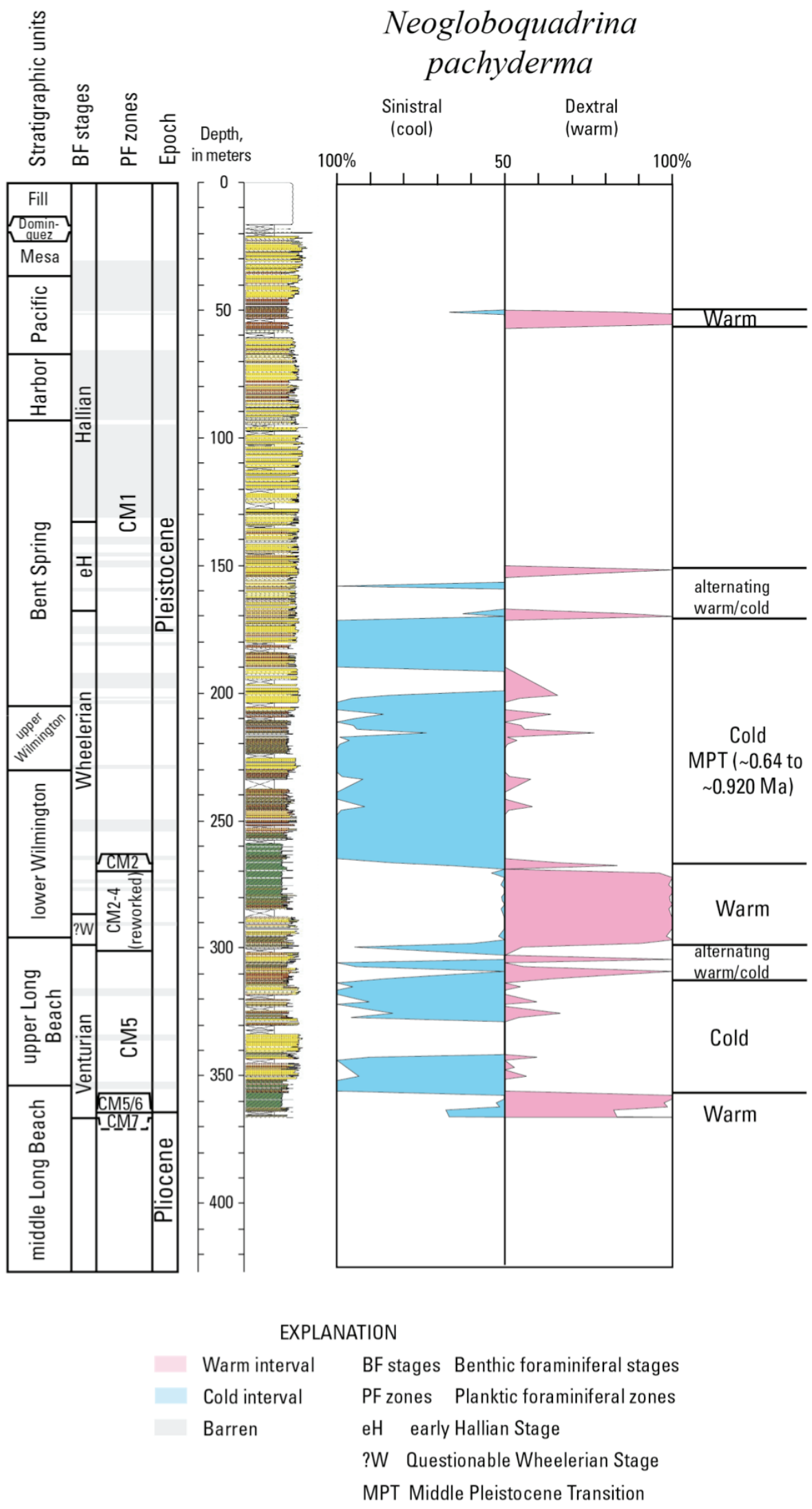

Figure 21. Distribution of Neogloboquadrina pachyderma in Long Beach Pier $\mathrm{F}$ core site and monitoring well, Long Beach, California. Stratigraphic units are identified in the left column, and lithologies are indicated on the stratigraphic column by color (clay, green; silt, brown; sand, yellow) (Ponti and others, 2007). 
composed mostly of small, cosmopolitan species, such as Globigerina bulloides, G. quinqueloba, and Globigerinita glutinata. Right-coiling N. pachyderma s.s., which also has been used as a temperature proxy (Keller, 1978; Kucera and Kennett, 2002; Darling and others, 2006), also is commonly seen in these assemblages. Despite the low diversity and abundance, the nearly ubiquitous presence of $N$. pachyderma s.s., dextral in this interval suggests that SSTs were moderate and warm in this part of the northeastern Pacific Ocean.

The warmest reconstructed paleoenvironment is identified at $167.64 \mathrm{~m}$ (Mf10625). In this sample, Globigerinella calida, a subtropical- to -temperate water species, makes up approximately 33percent of the assemblage. This abundance, and the abundance of planktic foraminiferal specimens in this sample (fig. 9), suggests water depths were greater.

\section{Macrofossil Paleoecology}

Environmental interpretation of the macrofossils suggests shallow water depths, with the occasional occurrence of species that indicate bathyal depths. In most cases, depths indicated by the macrofossil assemblages are considerably shallower than depths indicated by the microfossils, indicating that the macrofossils were transported.

The oldest core sample occurs at $310.1 \mathrm{~m}$ and contains an indeterminate neogastropod, indicating marine conditions but little else. The six shaker samples collected between 310.1 and $285.0 \mathrm{~m}$ are characterized by fairly large faunas that suggest water depths of $25-50 \mathrm{~m}$. Samples between 262.6 and $169.5 \mathrm{~m}$ contain few species, but the species present suggest outer sublittoral (45-183 m) or shallower water depths. Two occurrences within this interval which suggest deeper waters are a questionably identified specimen of Lirobittium paganicum at about $262 \mathrm{~m}$ and Fusinus barbarensis at $169.5 \mathrm{~m}$. Living L. paganicum are reported from water depths between 360 and $650 \mathrm{~m}$, and modern $F$. barbarensis live at water depths between 50 and $350 \mathrm{~m}$ (McLean and Gosliner, 1996).

Most samples recovered between 169.5 and $67.5 \mathrm{~m}$ contain species consistent with shallowwater conditions, probably adlittoral (low water to $9 \mathrm{~m}$ ) or shallower. The sample at about $67.5 \mathrm{~m}$ contains the bivalve Ostrea conchaphila and a gastropod identified as Littorina cf. L. planaxis. Although these species are not restricted to the littoral zone, they do indicate depths, most likely less than $10 \mathrm{~m}$.

In the interval from 65.1 to $44.2 \mathrm{~m}$, recovered mollusks indicate an open marine environment at inner to outer sublittoral water depths, with no littoral or adlittoral restricted species present. The occurrences of the bivalve Chione between 65.1 and $61.0 \mathrm{~m}$ indicates water depths between 10 and $20 \mathrm{~m}$ and water temperatures similar to or warmer than today. The fragment questionably identified as Mya, at approximately $62 \mathrm{~m}$, is believed to be reworked or misidentified.

Between 38.5 and $32.0 \mathrm{~m}$ the occurrence of the bivalves Donax gouldii and Tivela stultorum indicates shallow water depths, probably less than $5 \mathrm{~m}$, although they are associated with the bivalve Lucinisca nuttalli and scaphopod Dentalium neohexagonum, which do not live shallower than about $9 \mathrm{~m}$. Therefore, a water depth of $10 \mathrm{~m}$ or shallower is indicated, and reworking is likely. The occurrence of Amiantis callosa and Tivela stultorum in this interval indicates a sandy, open-coast environment.

The well is barren of megafossils between 32.0 and $19.9 \mathrm{~m}$, but Chione is present again at $19.9 \mathrm{~m}$, suggesting water temperatures similar to or warmer than today. The shallowest megafossil sample, at about $18.5 \mathrm{~m}$, contains indeterminate bivalve fragments, an indeterminate pectinid, and possibly a Nuculana valve (plate 3 ) indicating marine conditions. 


\section{Long Beach Pier F Core Site and Monitoring Well Summary}

Sediments from LBPF range from Pliocene to Holocene in age (fig. 22). Benthic foraminiferal assemblages identified the Venturian, Wheelerian, and Hallian Stages of the Pleistocene. Venturian assemblages are recognized from 365.4 to $298.7 \mathrm{~m}$. Foraminiferal assemblages in the overlying samples (283.7-297.2 $\mathrm{m}$ ) are questionably assigned to the Wheelerian Stage, but this interval contains a mixture of Venturian and Wheelerian species and appears to be reworked. Wheelerian benthic foraminiferal assemblages, without mixing from other stages, first appear at $283.5 \mathrm{~m}$ and continue through $167.6 \mathrm{~m}$. The early Hallian is recognized from 166.1 to $132.6 \mathrm{~m}$, where a hiatus or unconformity separates the early Hallian from the Hallian assemblages. The Hallian Stage contains only sparsely fossiliferous samples and was sampled between 131.1 and $30.48 \mathrm{~m}$.

Planktic foraminifers identified the Pleistocene N22 and Pliocene to Pleistocene N21 zones (Blow, 1969), as well as the California Margin, zones CM7, CM5/6 undifferentiated, CM5, CM2-4 undifferentiated, CM2, and CM1 of Kucera and others (2000). The California Margin zonal boundaries, and FO and LO of various planktic foraminiferal species indicate that LBPF is early Pliocene at the base.

The radiocarbon, TL, and OSL ages indicate that the Harbor, Pacific, and Mesa units are younger than those predicted by Ponti and others (2007). Dates in the Harbor unit ages range from 149 to $131 \mathrm{ka}$, again, younger than the predicted 1,600-300 ka (Ponti and others, 2007). Ages in the Pacific unit range from 66 to $95 \mathrm{ka}$, instead of the predicted 130-110 ka, and in the Mesa unit, ages range from 30-12.8 ka. Although the bulk of the ages are between 35 and $22 \mathrm{ka}$, they are still younger than the 80-30 ka age predicted for the Mesa unit (Ponti and others, 2007).

Inclinations determined from the LBPF are predominantly of normal polarity with six short intervals having very shallow or negative values. The uppermost inclination, anomaly A, is correlated with the Laschamp event (40 ka) and supported by a radiocarbon date of a shell within the Mesa unit (41,430 $\pm 1,130$ yr BP). Inclination anomaly B within the Pacific unit correlates with the Blake event $(\sim 117 \mathrm{ka})$ and is consistent with TL dating of the surrounding sediment and the appearance of the macrofossil Chione which suggests an age of $\geq 116 \mathrm{ka}$. Low magnetic inclinations near the base of the lower Wilmington unit at $281.9 \mathrm{~m}$ may signal recovery of the normal-polarity field after the Brunhes-Matuyama transition (0.78 Ma). However, an erosional gap just below the Wilmington leaves the polarity record incomplete. The upper and middle Long Beach units, which are below the Wilmington unit, have uniform normal polarity and contain planktic foraminifers inferred to be early Pleistocene in age, except for the oldest planktic assemblage which is late Pliocene in age. The Olduvai subchron (1.77-1.95 Ma) is the best option for correlating the normal-polarity Long Beach units with the Geomagnetic Polarity Time Scale. If this correlation is correct, the unconformity represents a gap in deposition of approximately one million years.

Paleoecologic analysis of LBPF indicates that this well was deposited at bathyal depths during the Venturian through early Hallian, but at shallow depths during the Hallian (fig. 23). Lower middle bathyal or lower slope benthic foraminiferal biofacies suggests water depths of 1,200-1,900 $\mathrm{m}$ at the base of the well. Water depths shallowed to the upper bathyal or lower slope biofacies (500-950 m) at $355.1 \mathrm{~m}$ and remained at these depths through about $167.6 \mathrm{~m}$ before shallowing to upper bathyal or bank biofacies depths of 150-400 m. Although macrofossil assemblages generally indicate sublittoral water depths, species found between 262.6 and $262.7 \mathrm{~m}$ indicate deeper, bathyal water depths. At $132.6 \mathrm{~m}$, benthic foraminiferal and macrofossil assemblages indicate water depths abruptly shallow to inner neritic depths of $10-50 \mathrm{~m}$. The macrofauna indicates inner sublittoral or shallower water depths from $38.5 \mathrm{~m}$ up to the youngest in situ macrofossils at $18.5 \mathrm{~m}$. Downslope transport is common through this well and accounts for the 


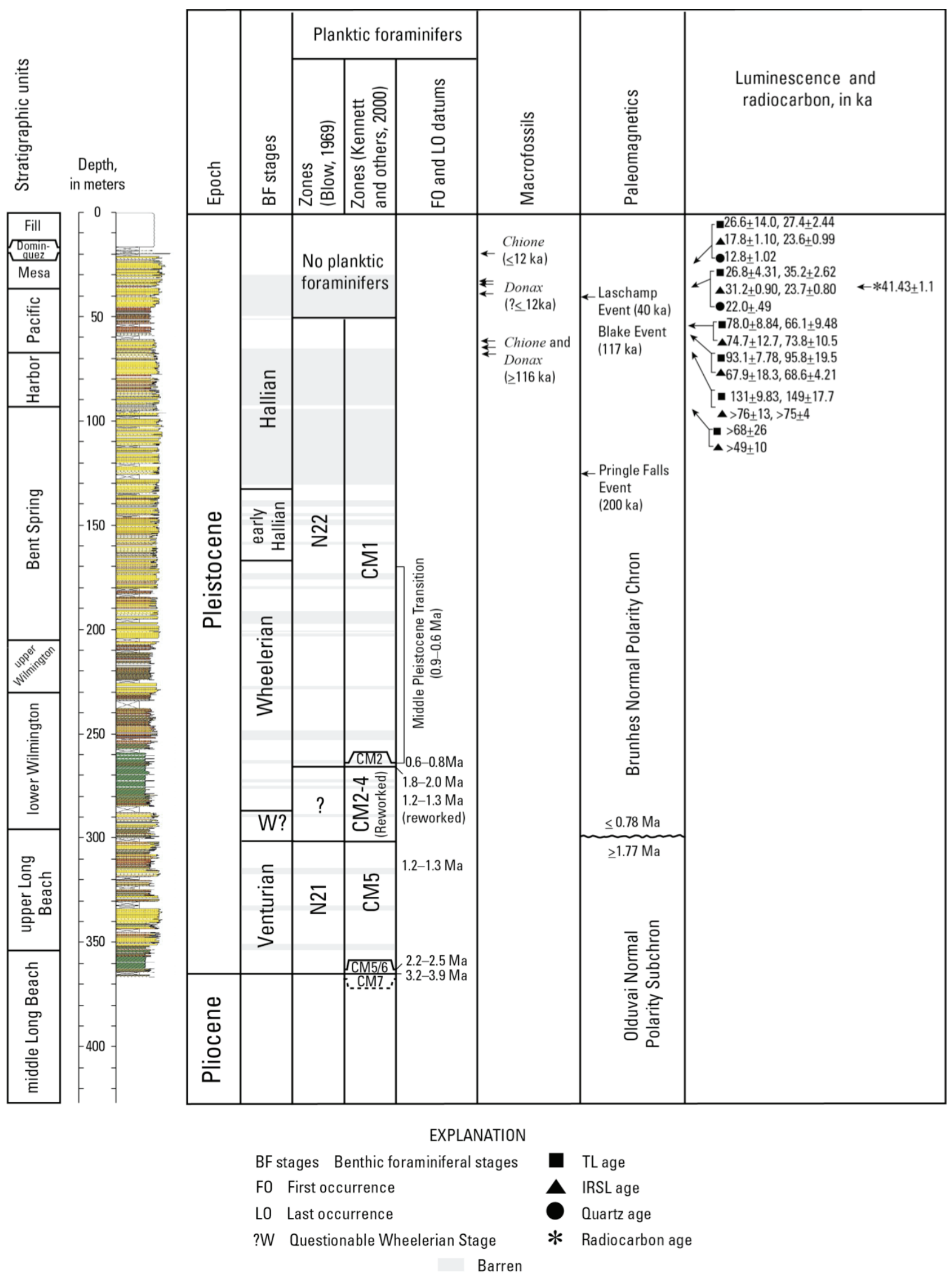

Figure 22. Summary of geochronology of Long Beach Pier F core site and monitoring well, Long Beach, California, based on the microfossils, macrofossils, paleomagnetics, luminescence, and radiocarbon. Stratigraphic units are identified in the left column, and lithologies are indicated on the stratigraphic column by color (clay, green; silt, brown; sand, yellow) (Ponti and others, 2007). 

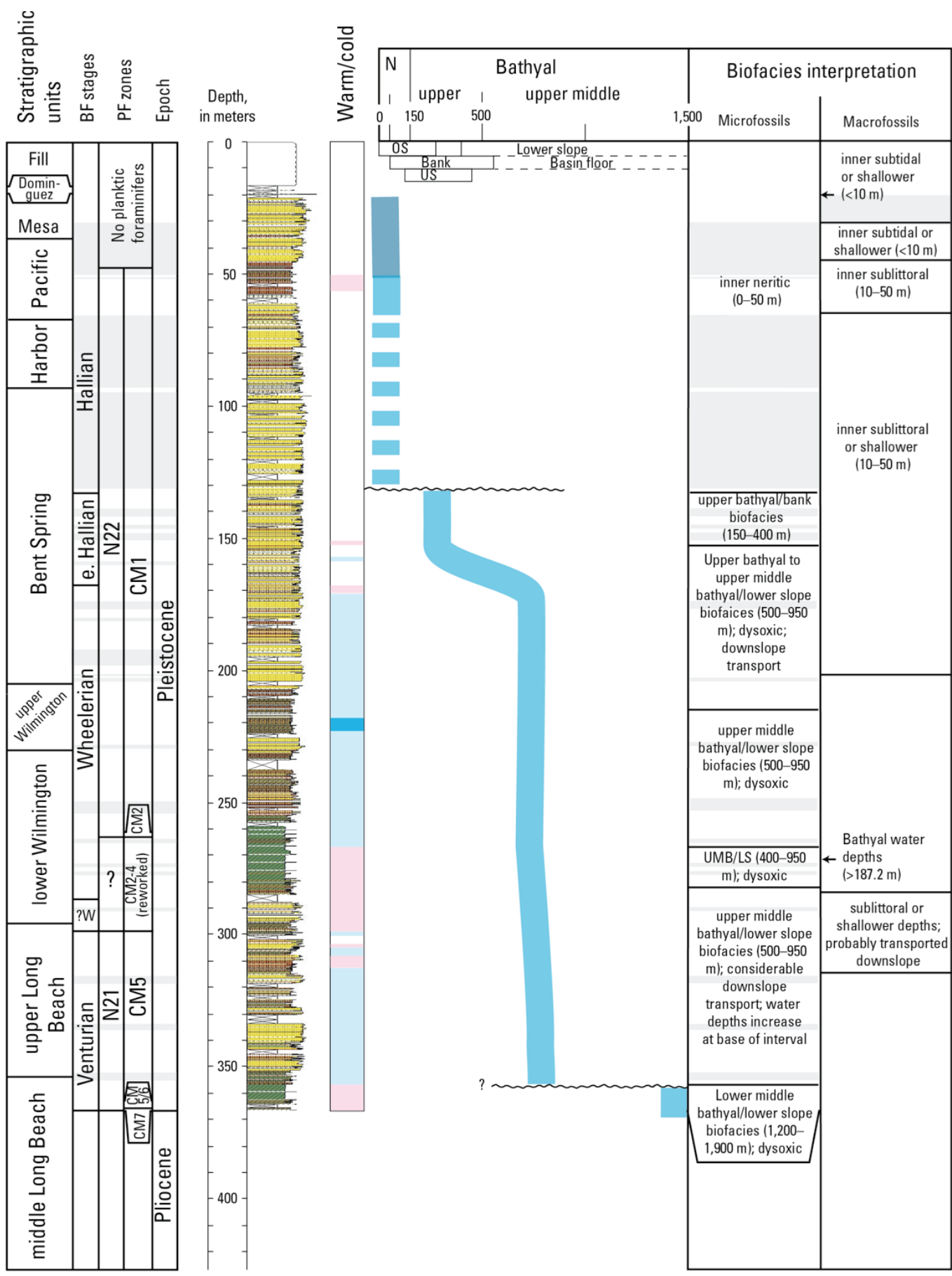

EXPLANATION

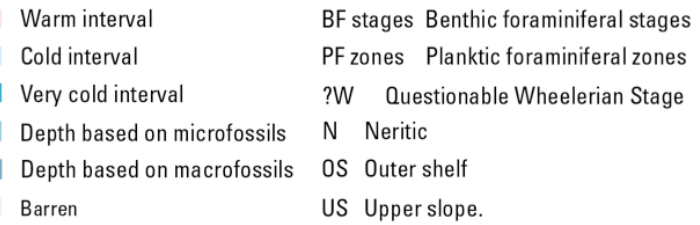

UMB/LS Upper middle bathyal/lower slope

Figure 23. Summary of ecological interpretations of the Long Beach Pier $F$ core site and monitoring well, Long Beach, California, based on benthic foraminifers and macrofossils. Stratigraphic units are identified in the left column, and lithologies are indicated on the stratigraphic column by color (clay, green; silt, brown; sand, yellow) (Ponti and others, 2007). 
presence of the shallow-water macrofossils and abundant shelf and upper slope benthic foraminiferal species. The two intervals with rapid changes of water depth between cores 78 and 79 and between cores 230 and 231 suggest a hiatus or unconformity may be present.

Shifts in the coiling directions of $N$. pachyderma in the lower part of LBPF identify four major climatic changes that account for a glacial period in the early Pleistocene (MPT), two additional interglacials, and one glacial in the Pliocene. The occurrence of Chione at 60-62 m and $19.8 \mathrm{~m}$, as well as the presence of dextral coiling N. pachyderma, indicate water temperatures were warmer than at present during deposition of the upper part of LBPF. 


\section{Chapter 3-Long Beach Pier C Core Site and Monitoring Well, Long Beach, California}

\section{Introduction}

The Long Beach Pier C core hole and monitoring well (LBPC) is located on Pier C in Long Beach Harbor, Los Angeles County, California (lat 3346'15.4"N; long 118¹3'13.9"W) (fig. 1). Total depth of the well is $427.0 \mathrm{~m}$ (table 1). The biostratigraphic, chronostratigraphic, and paleoecologic data collected at LBPC are summarized in this chapter. Core samples taken from LBPC were examined for benthic foraminifers (Kristin McDougall), planktic foraminifers (Elmira Wan), macrofossils (Charles Powell, II), paleomagnetism (John Hillhouse), and OSL and TL dating (Shannon Mahan). The middle Long Beach (427.00-252.68 m), upper Long Beach (252.68-206.84 m), lower Wilmington (206.84-132.59 m), upper Wilmington (132.59-89.15 m), Bent Spring (89.15-68.83 m), Harbor (68.83-48.71 m), and Dominguez (48.71-7.5 m) units were recognized in this well (Ponti and others, 2007). The boundary between the upper and lower Wilmington units was modified from the original interpretation based on discussions with Dan Ponti and John Tinsley in 2008.

\section{Biostratigraphy}

\section{Benthic Foraminifers}

Eighty-seven samples were examined for foraminifers (plate 4). Only seven samples were examined in the upper $78 \mathrm{~m}$ of the LBPC because sands dominate; two of these samples are barren (Mf10329 and Mf10332, 54.1 and $65.7 \mathrm{~m}$, respectively). Sampling was more consistent in the remainder of the well, except for the sands between approximately 253 and $170 \mathrm{~m}$, where few microfossils were taken. Using the age criteria established for the Quaternary of the Los Angeles Basin (fig. 4), the Hallian, Wheelerian, and Venturian Stages are recognized in this wellVenturian from 420.5 to $276.1 \mathrm{~m}$ (Mf10497-Mf10362); Wheelerian from 274.7 to $79.5 \mathrm{~m}$ (Mf10361-Mf10333); and Hallian from 78 to 12.9 m (Mf 10303-Mf10301) (figs. 24 and 25).

Benthic foraminiferal recognized between 420.5 and 276.1 m (Mf10497-Mf10362) are assigned to the Venturian Stage. Age-diagnostic species, which are present at the base of LBPC, include Bolivina argentea, Cibicides mckannai, C. mckannai suppressa, Epistominella pacifica, and Uvigerina peregrina. The abundance of $B$. argentea is sporadic in this interval, whereas $E$. pacifica, C. mckannai, and C. mckannai suppressa are common up to $276.1 \mathrm{~m}$ (Mf10362). Uvigerina peregrina occurs commonly from 420.5 to $329.0 \mathrm{~m}$ (Mf10497-Mf10484) and sporadically up to $297.4 \mathrm{~m}$ (Mf10376). This distribution of critical species suggests that the Wheelerian/Venturian boundary occurs between 276.1 and 274.7 m (Mf10362-Mf10361). Supporting this interpretation is the presence of common Venturian species, Bulimina subaccuminata in Mf10375 (296.56 m) and Cassidulina delicata in Mf10365 (280.71 m), in this interval. Oridorsalis umbonatus, O. subtenera, and Gyroidina altiformis also occur in this interval and are consistent components of the fauna between 420.5 and 375.8 m (Mf10497-Mf10495). Rare occurrences of the Repettian species Rotalia garveyensis and Karreriella milleri and the Miocene species Bolivina woodringi and B. obliqua from 348.3 to 281.9 m (Mf10489-Mf19366) suggests reworking of older sediments.

Benthic foraminiferal faunas between 274.7 and 242.2 m (Mf10361-Mf10349) are only questionably assigned to the Wheelerian Stage. A faunal change occurs at 274.7 m (Mf10361). There are subtle changes in the dominant species. Although still present, the abundance of $E$. pacifica, C. mckannai, C. mckannai suppressa, and Cassidulina transluscens decline, whereas the 


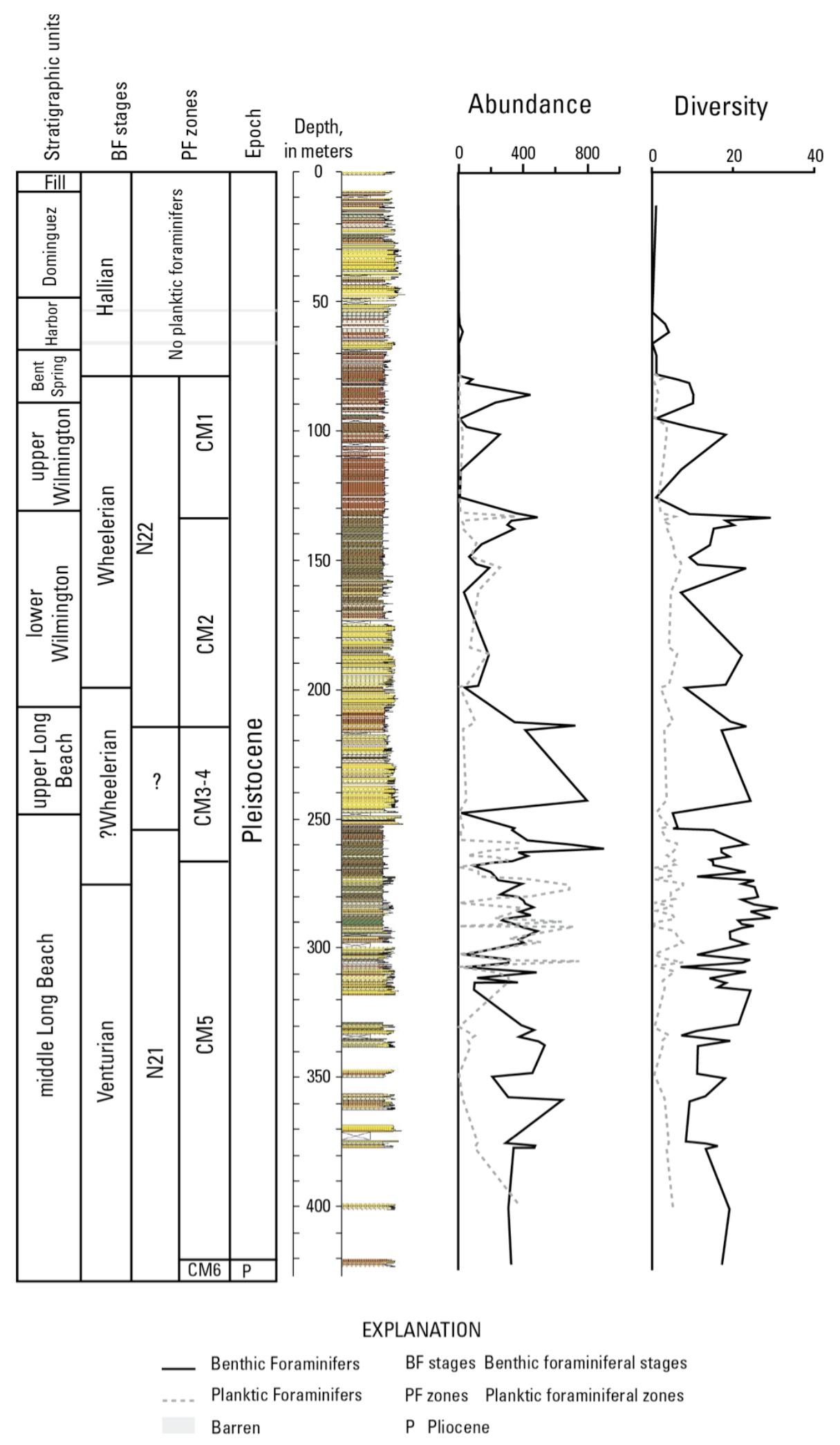

Figure 24. Abundance and diversity of the foraminiferal fauna in the Long Beach Pier $\mathrm{C}$ core site and monitoring well, Long Beach, California. Abundance of the foraminifers is based on the number of foraminiferal specimens present in the sample. Diversity is the number of species identified in the sample. Stratigraphic units are identified in the left column, and lithologies are indicated on the stratigraphic column by color (clay, green; silt, brown; sand, yellow) (Ponti and others, 2007). 


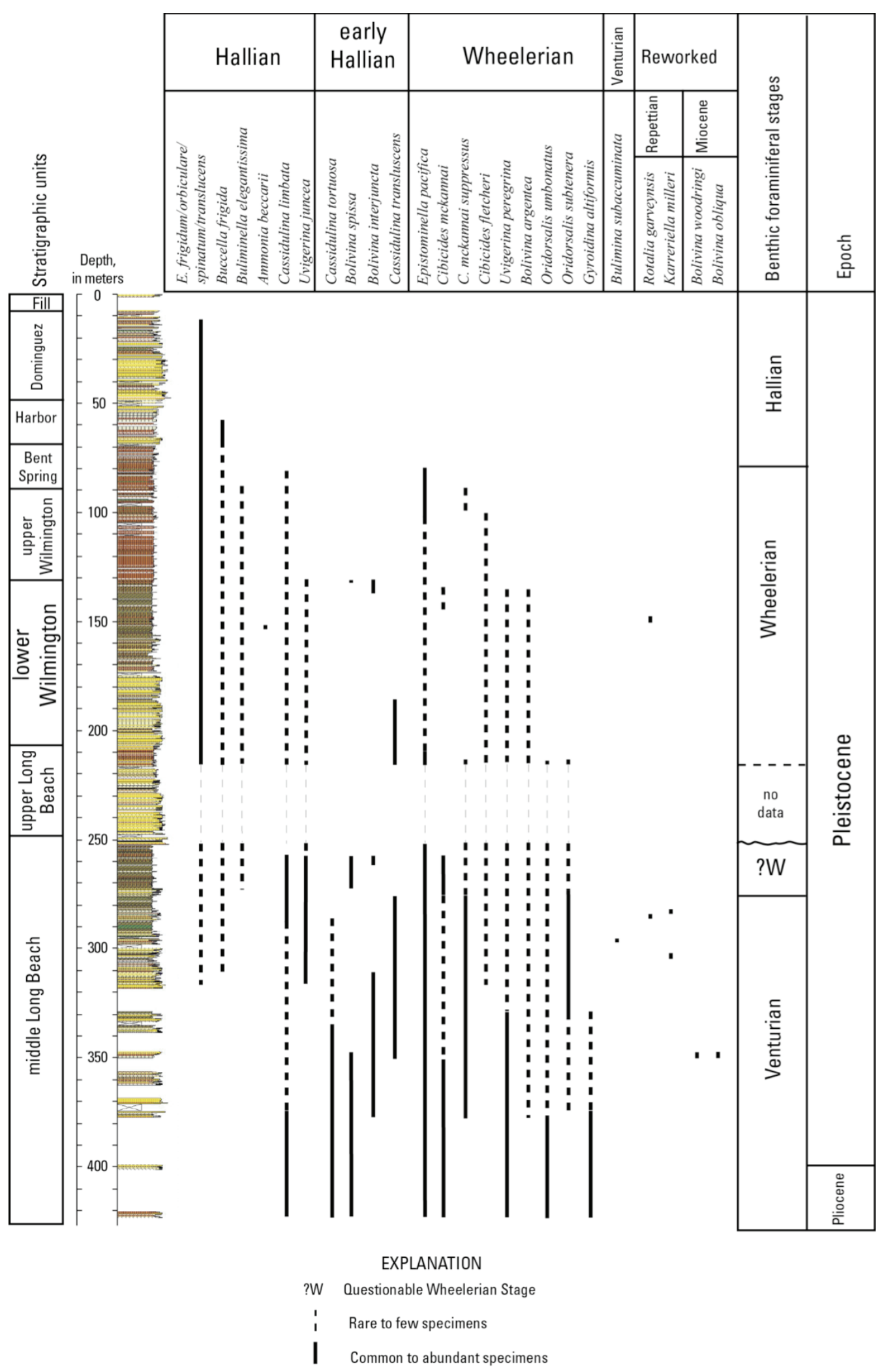

Figure 25. Stratigraphic distribution of age-diagnostic benthic foraminifers in Long Beach Pier $\mathrm{C}$ core site and monitoring well, Long Beach, California. Stratigraphic units are identified in the left column, and lithologies are indicated on the stratigraphic column by color (clay, green; silt, brown; sand, yellow) (Ponti and others, 2007). 
abundance of Cassidulina limbata and Uvigerina juncea increases. This continues up to $242.2 \mathrm{~m}$ (Mf10339). Between 242.2 and $215.1 \mathrm{~m}$, no microfossil samples were taken due to the preponderance of sand and shallow-water macrofossils. An unconformity is assumed at the base of this interval, although it is probably at the base of the sands $(\sim 252 \mathrm{~m})$ and the adjacent microfaunas probably are reworked.

Epistominella pacifica, C. mckannai, C. mckannai suppressa, and Cassidulina transluscens are abundant in $215.1 \mathrm{~m}$ (Mf10312) and mark the lowest occurrence of the Wheelerian Stage. Agediagnostic Wheelerian species appear from 215.1 to $79.5 \mathrm{~m}$ (Mf10312-Mf10333). The benthic foraminiferal fauna at $79.5 \mathrm{~m}$ (Mf10333) includes the last abundant appearance of E. pacifica. Other Wheelerian species that last appear near $79.5 \mathrm{~m}$ (Mf10333) include Cassidulina limbata (Mf10304, $81.72 \mathrm{~m}$ ), Cibicides mckannai suppressus (Mf10335, 88.40 m), and C. fletcheri (Mf10337, 100.56 m). The abrupt faunal change between the sample $79.5 \mathrm{~m}$ (Mf10333) and $78.1 \mathrm{~m}$ (Mf10303) suggests an unconformity.

The sparse benthic foraminiferal assemblages recognized in the upper $78 \mathrm{~m}$ of LBPC contain few diagnostic benthic foraminiferal species. Various species of Elphidium (predominately E. transluscens) and Buccella frigida indicate that these upper assemblages are Hallian (fig. 25). The only other benthic foraminiferal species occurring in this interval are Buliminella elegantissima and Nonionella basispinata, which are not age-diagnostic. An early Hallian interval cannot be identified in this well because species characteristic of the early Hallian (that is, abundant Cassidulina limbata, C. tortuosa, and Uvigerina juncea) do not appear prior to the last abundant and consistent occurrence of E. pacifica at $79.5 \mathrm{~m}$ (Mf10333).

\section{Planktic Foraminifers}

Seventy-two planktic foraminiferal samples from LBPC were examined for age-diagnostic species (plate 5, fig. 26). In the analyzed sample intervals, planktic foraminiferal assemblages were moderately diverse, having rare to highly abundant, moderately to well-preserved specimens (fig. 24). Open-ocean, tropical to subtropical marker species were sparse throughout the samples. Consequently, the N-zone biostratigraphy for LBPC was of low resolution; only tropical zones N21 (late Pliocene-early Pleistocene) and N22 (Pleistocene) were identified, whereas the California Margin temperate zonation scheme (Kucera and Kennett, 2000) allowed the recognition of zones CM6, CM5, CM4-3, CM2, and CM1.

Samples occurring stratigraphically below 398.9 m (Mf10496) are assigned to zone CM6; the base of CM6 is not observed in LBPC. The base of zone CM5 is placed below $398.9 \mathrm{~m}$ (Mf10496) based on the FO of Neogloboquadrina pachyderma C, which has a maximum age of $2.475 \mathrm{Ma}$ (Kucera and Kennett, 2000). Above the base of CM5 is the FO of Globorotalia inflata s.s. (313.9 m, Mf10483), and the LO of Globorotalia puncticulata (2.41 Ma; Berggren and others, 1995; Gradstein and others, 2004) at $273.2 \mathrm{~m}$ (Mf10360). Together these species indicate that the sediments are early Pleistocene, and that the interval from 398.9 to $273.2 \mathrm{~m}$ should be assigned to zone CM5.

The FO of $N$. pachyderma B (approximate age is $1.232 \mathrm{Ma}$ ) and $N$. inglei ( $N$. pachyderma A, 1.240 Ma minimum age) at 211.6 m (Mf10307) constrains the base of Pleistocene zone CM2. Therefore, planktic foraminifers in 211.6 through $134.8 \mathrm{~m}$ (Mf10307-Mf10342) are assigned to zone CM2. The LO of $N$. humerosa praehumerosa at $150.8 \mathrm{~m}$ (Mf10346) indicates middle Pleistocene and reinforces the age determination of CM2 for this interval.

The LO of $N$. inglei ( $N$. pachyderma A; $0.712 \mathrm{Ma}$ ) occurs at $132.6 \mathrm{~m}$ (Mf10341). This planktic foraminiferal datum marks the base of zone CM1 (Kennett and others, 2000). Thus, planktic foraminiferal faunas in the interval from 132.6 to $79.5 \mathrm{~m}$ (Mf10341-Mf10333) are 


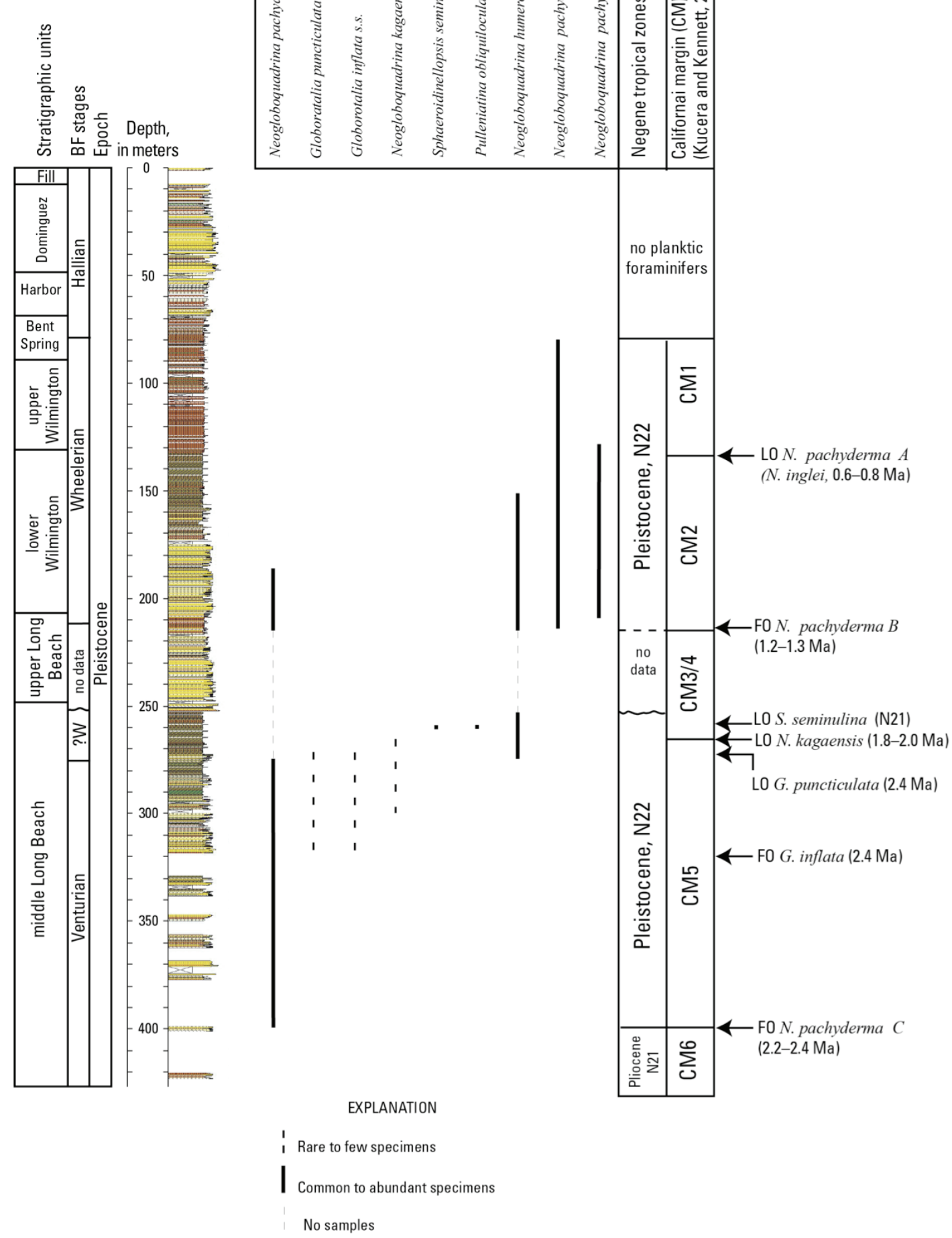

Figure 26. Stratigraphic distribution of age-diagnostic planktic foraminifers in the Long Beach Pier $\mathrm{C}$ core site and monitoring well, Long Beach, California. Planktic foraminiferal-ages are calibrated to magnetostratigraphy and biostratigraphy (Berggren and others, 1995; Fornaciari, 2000; Kennett and others, 2000; Lyle and others, 2000; Kucera and Kennett, 2000). Stratigraphic units are identified in the left column, and lithologies are indicated on the stratigraphic column by color (clay, green; silt, brown; sand, yellow) (Ponti and others, 2007). 
assigned to zone CM1. The highest stratigraphic occurrence of planktic foraminifers is at $79.5 \mathrm{~m}$ (Mf10333). All samples above $78 \mathrm{~m}$ do not contain planktic foraminifers.

\section{Macrofossil Biostratigraphy}

Ninety-one samples containing remains of mollusks and arthropods obtained from coring LBPC were examined (plate 6). Eight of these samples are from the shaker table, and 73 samples are from the core. In the lower part of LBPC $(\sim 279.2 \mathrm{~m})$, a gastropod questionably identified as Boreotrophon raymondi was recovered. This species was described from the late Pliocene sediments in downtown Los Angeles (Moody, 1916). Boreotrophon raymondi is not known from the Pleistocene, but is found living from British Columbia to southern California (McLean and Gosliner, 1996). The bivalve Tivela stultorum was found at $347.4 \mathrm{~m}$ and is consistent with a Pliocene age as its oldest occurrence is in the late Pliocene (Hertlein and Grant, 1972).

Near the top of LBPC, three age-diagnostic macrofossils are present. A poorly preserved specimen identified as Patinopecten was found at $56.0 \mathrm{~m}$, which suggests an age of $<300 \mathrm{ka}$ in the Los Angeles Basin. The bivalves Donax and Chione occur between 46.9 and $14.1 \mathrm{~m}$ (Donax) and between 16.9 and $14.1 \mathrm{~m}$ (Chione). The occurrences of Chione suggest an age of $\geq 116 \mathrm{ka}$ or $\leq 12$ ka.

\section{Geochronology}

\section{Paleomagnetism}

Coring at LBPC was nearly continuous down to $420 \mathrm{~m}$ and yielded a collection of intact sedimentary cores suitable for a comprehensive paleomagnetic analysis. The interval from about 320.1 to $423.7 \mathrm{~m}$ was spot-cored at 6 levels, 6-15 $\mathrm{m}$ apart, and yielded good material for the paleomagnetic study. Magnetic intensity, magnetization direction, and AF-cleaning parameters were measured for 224 samples representing the full length of the LBPC (appendix III, table 7). Intensities of the NRM range over two orders of magnitude with a median value of about 10-2 $\mathrm{A} / \mathrm{m}$. The larger intensity values occur in three intervals: 289.6-332.2, 149.4-170.7, and 0-100.6 $\mathrm{m}$. Very low intensities occur at 126.8-134.4 and 52.1-54.9 m (fig. 27). Measurements of magnetic susceptibility from the whole-core logger show down-core variations that correlate with the intensity variation (fig. 28). The stronger intensities of NRM and larger susceptibilities tend to occur in the sandstone intervals, although one strongly magnetized section of claystone and siltstone from $149.4-170.7 \mathrm{~m}$ is the notable exception.

Table 7. Paleomagnetic results from Long Beach Pier C core site and monitoring well (LBPC), Long Beach, California. [Title of table is included here for continuity; complete table is in appendix III.]

The LO of N. kagaensis at $265.8 \mathrm{~m}$ (Mf10355) defines the base of early Pleistocene zone CM4, which has been assigned an age of $1.915 \mathrm{Ma}$ (Kucera and Kennett, 2000). A dramatic faunal shift is observed in the planktic faunas between 260.1 and 253.7 m (Mf10351-Mf10315). There is a sudden change in the assemblages from tropical-subtropical species (260.1 m, Mf10351), such as Sphaeroidinellopsis seminulina (LO is N21) and Pulleniatina obliquiloculata (FO is N19) to temperate species at $253.7 \mathrm{~m}$ (Mf10315). This shift also is marked by the change from predominantly dextral-coiling $N$. pachyderma pachyderma to predominantly sinistral $N$. pachyderma $\mathrm{C}$, which is indicative of much cooler conditions. In the northeastern Pacific and in central and southern California borderland basins, high abundances of this cool-water variant occur in sediments near 1.89 Ma (former Pliocene/Pleistocene boundary, now early Pleistocene) (Lagoe 


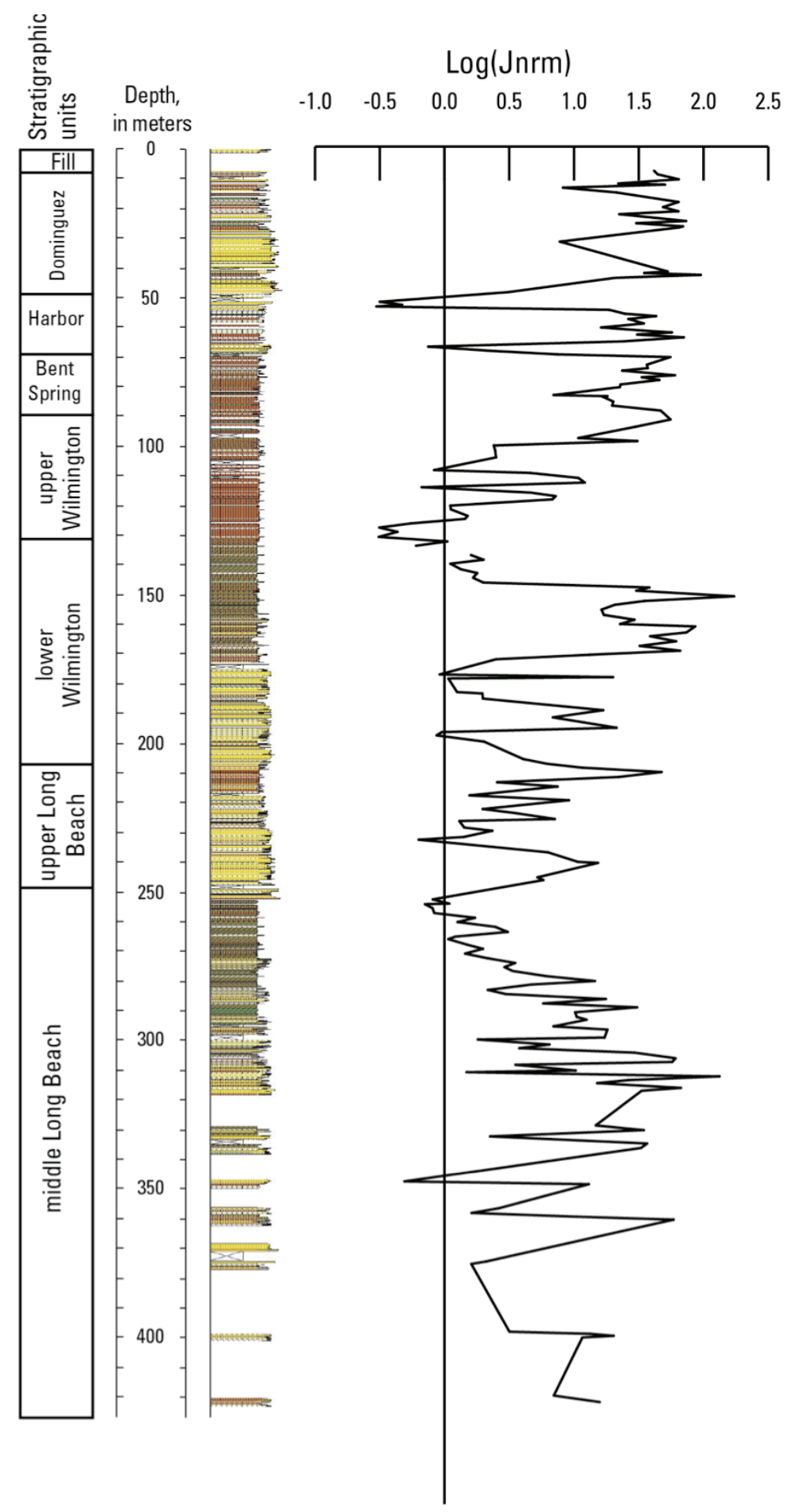

Figure 27. Intensity of natural remanent magnetization (Jnrm) and the lithologic log of the Long Beach Pier C core site and monitoring well, Long Beach, California. Logarithmic scale: 0.0 equals $1.0 \mathrm{~mA} / \mathrm{m}$.

Stratigraphic units are identified in the left column, and lithologies are indicated on the stratigraphic column by color (clay, green; silt, brown; sand, yellow) (Ponti and others, 2007).

and Thompson, 1988). No age-diagnostic planktic species defining the base of zone CM3 were observed in the discontinuously sampled interval between 265.8 and $215.1 \mathrm{~m}$ (Mf10355Mf10315). Thus, at LBPC, the interval between 265.78 and 215.1 m (Mf10355-Mf10312) is designated as zones CM3/4. Note also that no microfossil samples were recovered between 242.2 


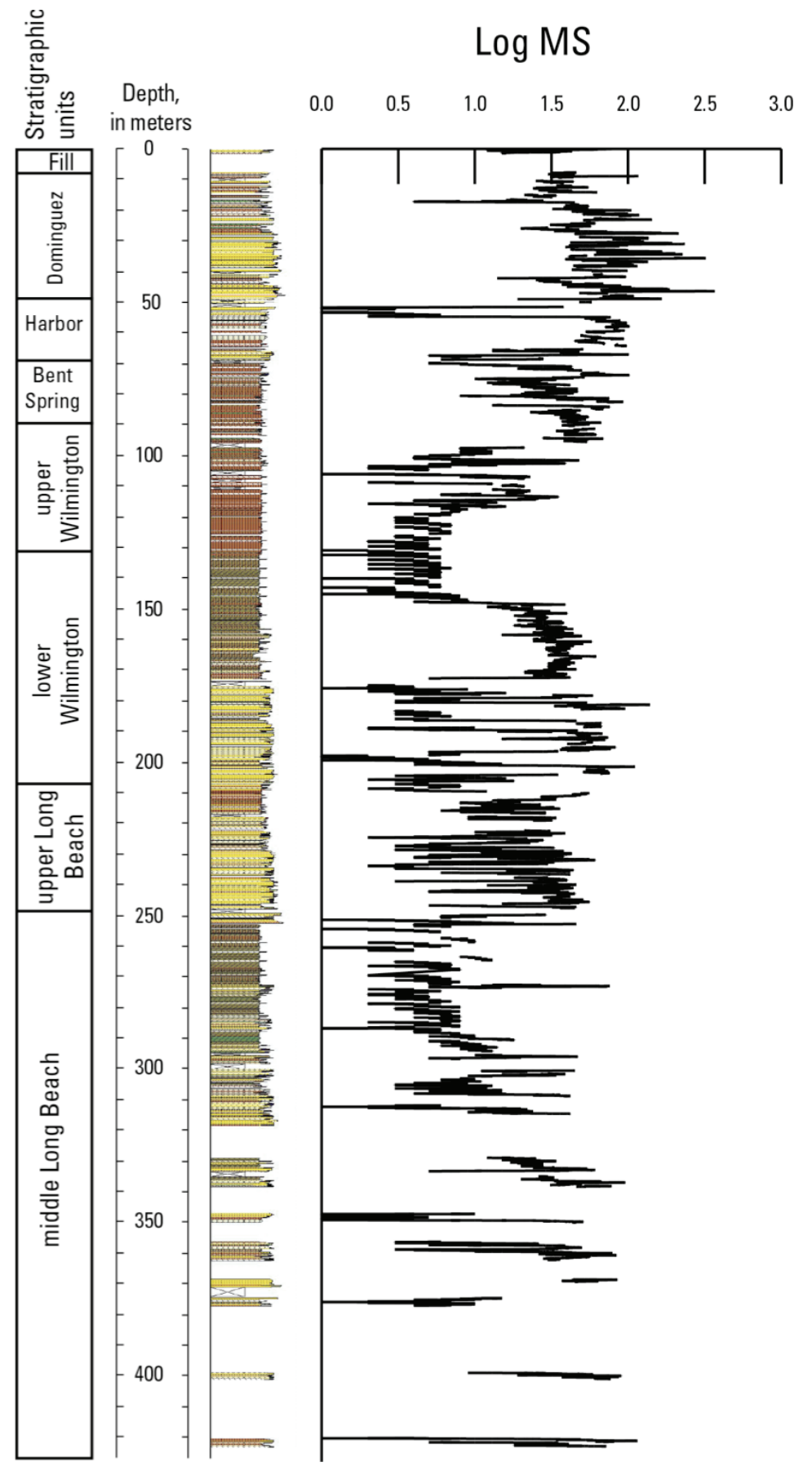

Figure 28. Magnetic susceptibility (MS) from the whole-core logger and lithology of the Long Beach Pier C core site and monitoring well, Long Beach, California. Logarithmic scale: 0.0 equals 10-6 (cgs). Stratigraphic units are identified in the left column, and lithologies are indicated on the stratigraphic column by color (clay, green; silt, brown; sand, yellow) (Ponti and others, 2007).

and 215.1 m (Mf10349-Mf10312) because of the sands and shallow-water macrofossils. An unconformity is assumed to occur at approximately $252 \mathrm{~m}$.

Alternating-field treatments to $40 \mathrm{mT}$ successfully isolated a stable magnetization direction in 75 percent of the specimens $\left(\mathrm{MAD} \leq 10^{\circ}\right)$. Optimum cleaning and stabilization of the magnetic direction was typically achieved by alternating-field treatment of 10-30 mT. As would be expected, the poorer determinations $\left(\mathrm{MAD} \geq 15^{\circ}\right)$ are from weakly magnetized specimens with 
NRM less than $3 \times 10^{-4} \mathrm{~A} / \mathrm{m}$. To investigate alternating-field resistance as a function of depth, the ratio of partially demagnetized remanence to the original natural remanence for the $15 \mathrm{mT}$ and 30 $\mathrm{mT}$ alternating-field steps is graphed (fig. 29). The $\mathrm{J}_{15} / \mathrm{J}_{\mathrm{nrm}}$ ratio shows much variation with depth with distinct lows at 400.8-321.6, 241.0-237.7, 195.7-189.6, 113.1-111.6, and 61.0-54.9. High resistance characterized the intervals at 317.9-274.3 and 100.6-62.5 m. Intervals of high alternating-field resistance might indicate an increasing percentage of single-domain magnetite grains ( $\sim 0.1$ micron diameter), or a mineralogical change from magnetite to hematite, goethite, or pyrrhotite. Low resistance to alternating-field demagnetization typically indicates preponderance of large, multidomain grains of magnetite in the sediment (diameter $>60$ microns).

All but one sample at $12.8 \mathrm{~m}$ yielded positive magnetic inclinations after alternating-field treatment (fig. 30). Slumped bedding was noted at $12.8 \mathrm{~m}$, so the negative inclination should not be interpreted as indicating an excursion of the geomagnetic field. However, two intervals 198.1195.7 and 134.4-126.8 $\mathrm{m}$ have inclinations low enough to be considered possible excursions. Although the upper interval has low inclination and low intensity, it also has very low magnetic susceptibility and poor MADs. The low inclination might be an artifact of the measurements rather than a true indication of anomalous geomagnetic-field behavior. The interval from 137.2 to 123.4 m was resampled to confirm the pattern of low inclinations (fig. 31, appendix III, table 7). After AF cleaning, the new samples have inclinations of $30^{\circ}$ or greater, with the exception of one sample (inclination is $15.6^{\circ}$ ) at $135.8 \mathrm{~m}$. Therefore, the initial evidence for anomalous-field behavior is not confirmed for the interval of 134.4-126.8 $\mathrm{m}$. Subsequent inspection of the magnetometer records indicated that a significant magnetic effect of the sample holder was not removed on the day when the measurements were taken.

The lower inclination anomaly (198.1-195.7 m) corresponds to an interval having low susceptibility and poor MADs. Screening the inclination data for MADs less than $10.0^{\circ}$ eliminated this inclination anomaly as a possible excursion of the geomagnetic field (fig. 32).

Polished grain mounts from magnetic separates were scanned with a JEOL electron microprobe to map the abundance of five elements (Fe, S, Ca, Si, and Ti). To obtain the magnetic separates, sediment was scraped from the split-face surface of four core samples at 65.6, 197.1, 206.2, and $422.8 \mathrm{~m}$, and a hand magnet was used to extract magnetic grains. This method extracts the larger grains, most being 50-100 microns in diameter. The grains were set in epoxy, ground, and polished. Elemental maps and back-scattered electron images of 4-6 grains were produced for each core by scanning the polished surface with a focused beam. The scans show that all grains are composed of iron-oxide cores surrounded by rims of iron-sulfide (figs. 33-35). The majority of grains show etching and dissolution of the core material. Comparing iron abundance between the core and rim, the iron is diminished by approximately one-third. The sulfide rims, up to 20 microns thick, appear in two forms: as a clustering of microspheres on the grain surface and as deep replacement of partially dissolved iron-oxide grains.

The sample at $65.6 \mathrm{~m}$ yielded three types of magnetic grains. The more common type is a titanium-poor titanomagnetite, typical of plutonic rocks. One grain consisted of titanomagnetite with ilmenite lamellae, a typical constituent of subaerially deposited volcanic rocks (fig. 33). This grain was deeply etched and penetrated with iron-sulfide. Another grain showed only minor sulfur replacement; it was a titanium-rich iron-oxide with the characteristic texture of an ilmenohematite common in metamorphic rocks (fig. 34).The samples at 206.2 and $197.1 \mathrm{~m}$ contained roughly equal numbers of titanium-poor titanomagnetites and ilmenite-magnetite grains. A few grains were composed of magnetite inclusions surrounded by silicate crystals. Sulfide replacement deep within the magnetite-ilmenite crystals is common. The lowest degree of sulfide replacement was found in the deepest sample at $422.8 \mathrm{~m}$. Here, the sulfide rims are thin ( $\sim 3$ microns $)$ and appear as coatings of microcrystals on the magnetite-grain surface (fig. 35). 


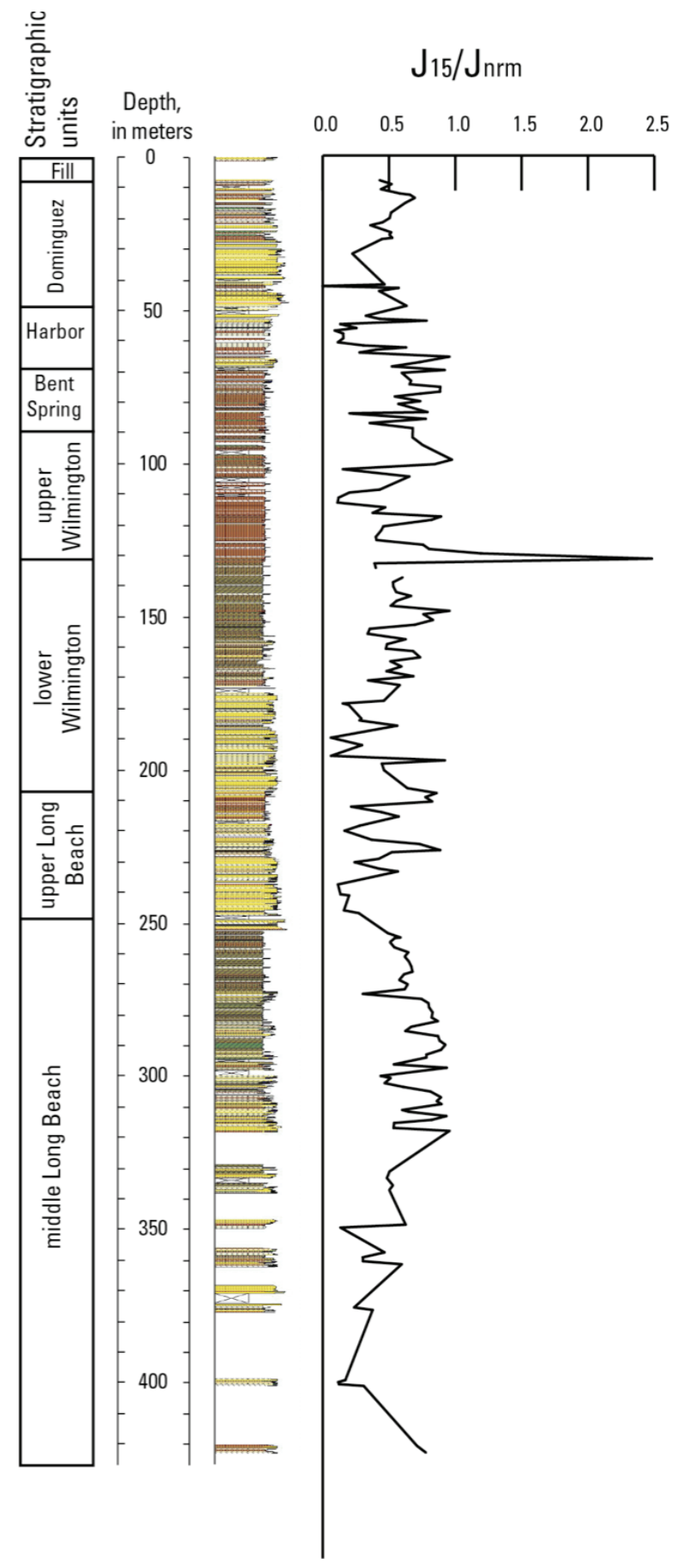

$\mathrm{J}_{30} / \mathrm{J}_{\mathrm{nrm}}$

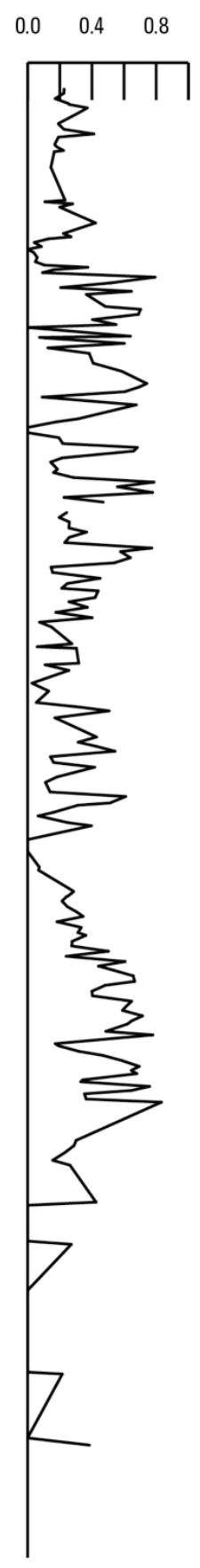

Figure 29. Ratio of partially demagnetized magnetization to natural remanent magnetization (Jnrm) for the 15 $\mathrm{mT}$ (J15) and $30 \mathrm{mT}$ (J30) treatment steps for Long Beach Pier C core site and monitoring well, Long Beach, California. Stratigraphic units are identified in the left column, and lithologies are indicated on the stratigraphic column by color (clay, green; silt, brown; sand, yellow) (Ponti and others, 2007).

The ubiquitous presence of authigenic sulfides the LBPC samples raises a possibility that the original depositional-remanent magnetization has been altered chemically. At the very least, the original magnetization has decreased in intensity as magnetite grains were dissolved and replaced by iron-sulfide. Dissolution could explain very low magnetizations noted in some intervals of the 


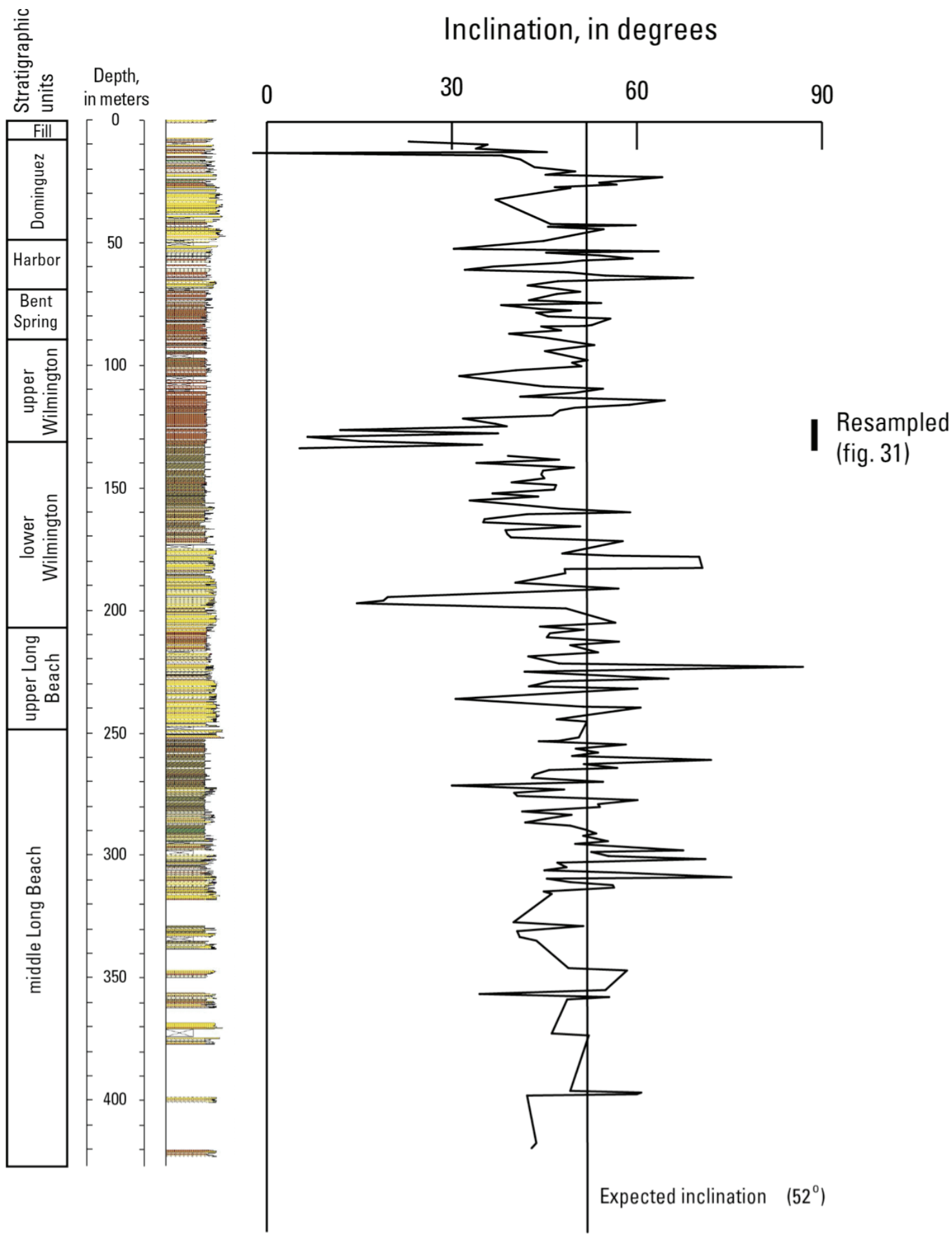

Figure 30. Magnetic inclination with depth in Long Beach Pier $\mathrm{C}$ core site and monitoring well, Long Beach, California. Stratigraphic units are identified in the left column, and lithologies are indicated on the stratigraphic column by color (clay, green; silt, brown; sand, yellow) (Ponti and others, 2007).

LBPC. It is reasonable to assume that the smaller magnetite grains that are critical for preserving a stable paleomagnetic signal are severely depleted, given that thick rims of sulfide were observed on the larger grains. Moreover, spurious secondary magnetizations could be present if magnetic species of authigenic iron-sulfide (pyrrhotite or greigite) developed long after deposition. 


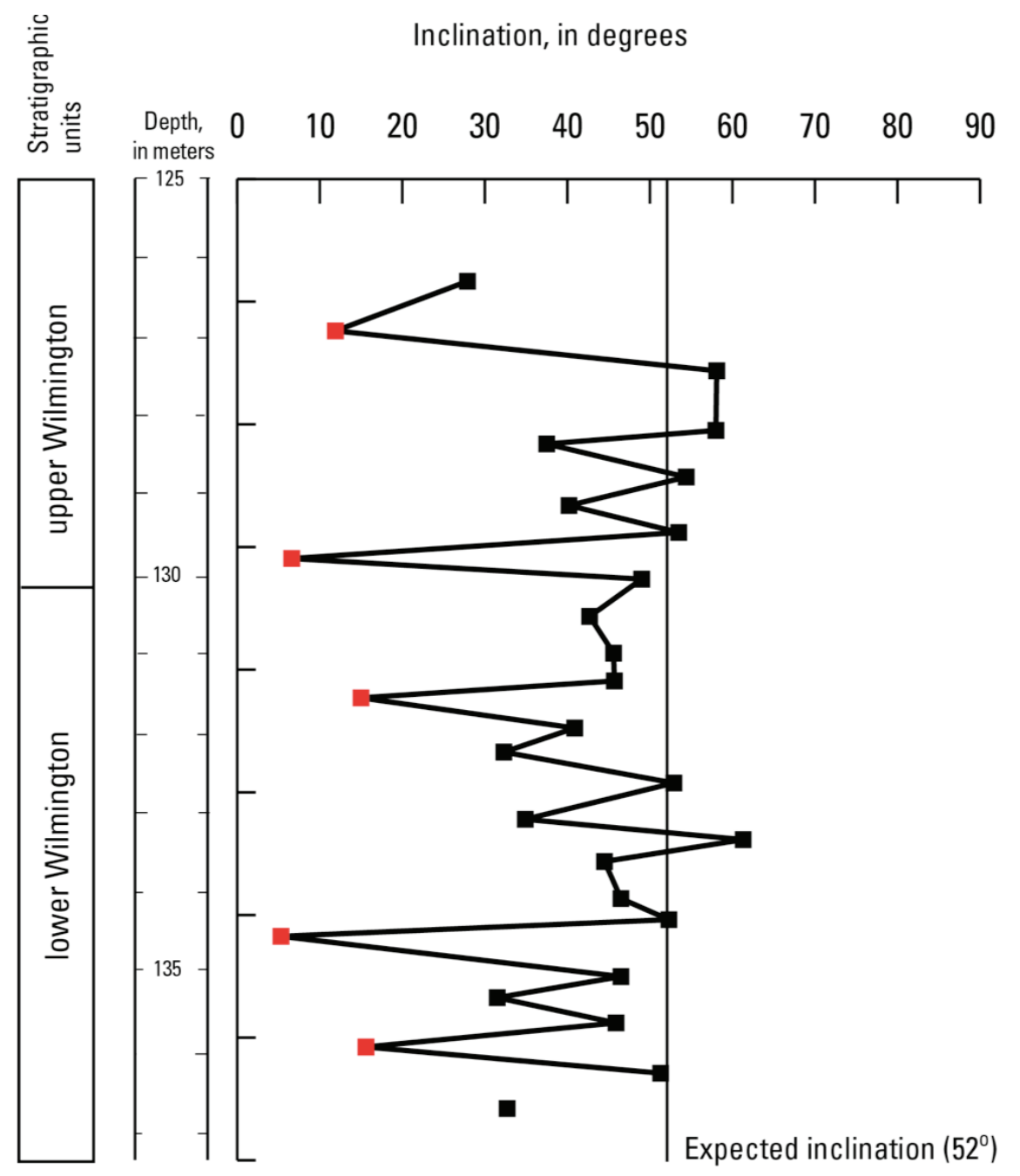

Figure 31. Magnetic inclination of the resampled interval shown in figure 30 for Long Beach Pier $\mathrm{C}$ core site and monitoring well, Long Beach, California. Red squares indicate results from the first round of sampling without removal of sample-holder remanence. Stratigraphic units are identified in the left column (Ponti and others, 2007).

\section{Optically Stimulated Luminescence and Thermal Luminescence Dating}

Six samples were collected for luminescence dating from LBPC, in approximately $20 \mathrm{~m}$ intervals, starting above $90 \mathrm{~m}$ and ending at $25 \mathrm{~m}$ (table 8). Suitable fine-grained material (finegrained sand to silt) was not found continuously in this well and thus, large gaps exist between samples (table 8).

A typical sensitivity-corrected quartz OSL growth curve for the young sample at $25.4 \mathrm{~m}$ (LBPC-13C) is shown in figure 36. The corrected OSL growth curve is linear in the dose range from 0 to about 30 Gray (Gy). The quartz OSL age obtained at $43.5 \mathrm{~m}$ (LBPC-33C) of $12.3 \pm 0.35$ $\mathrm{ka}$ is similar to the radiocarbon ages obtained from wood (not charcoal) at approximately the same core interval. The wood was dated at $12.0 \pm 0.05 \mathrm{ka}$ from $44.2 \mathrm{~m}$ and another at $12.19 \pm 0.40 \mathrm{ka}$ from $45.4 \mathrm{~m}$ (S. Sellars and T. Safford, Stafford Research Laboratories, Boulder Colo., oral commun., 2003). Therefore, the two quartz OSL ages from the upper part of the well are considered reliable. No quartz OSL ages were obtained for the lower four samples. Most of the samples quickly reached saturation for any type of luminescence dating somewhere between 46 and $90 \mathrm{~m}$, and after $90 \mathrm{~m}$ only minimum ages are reported. 


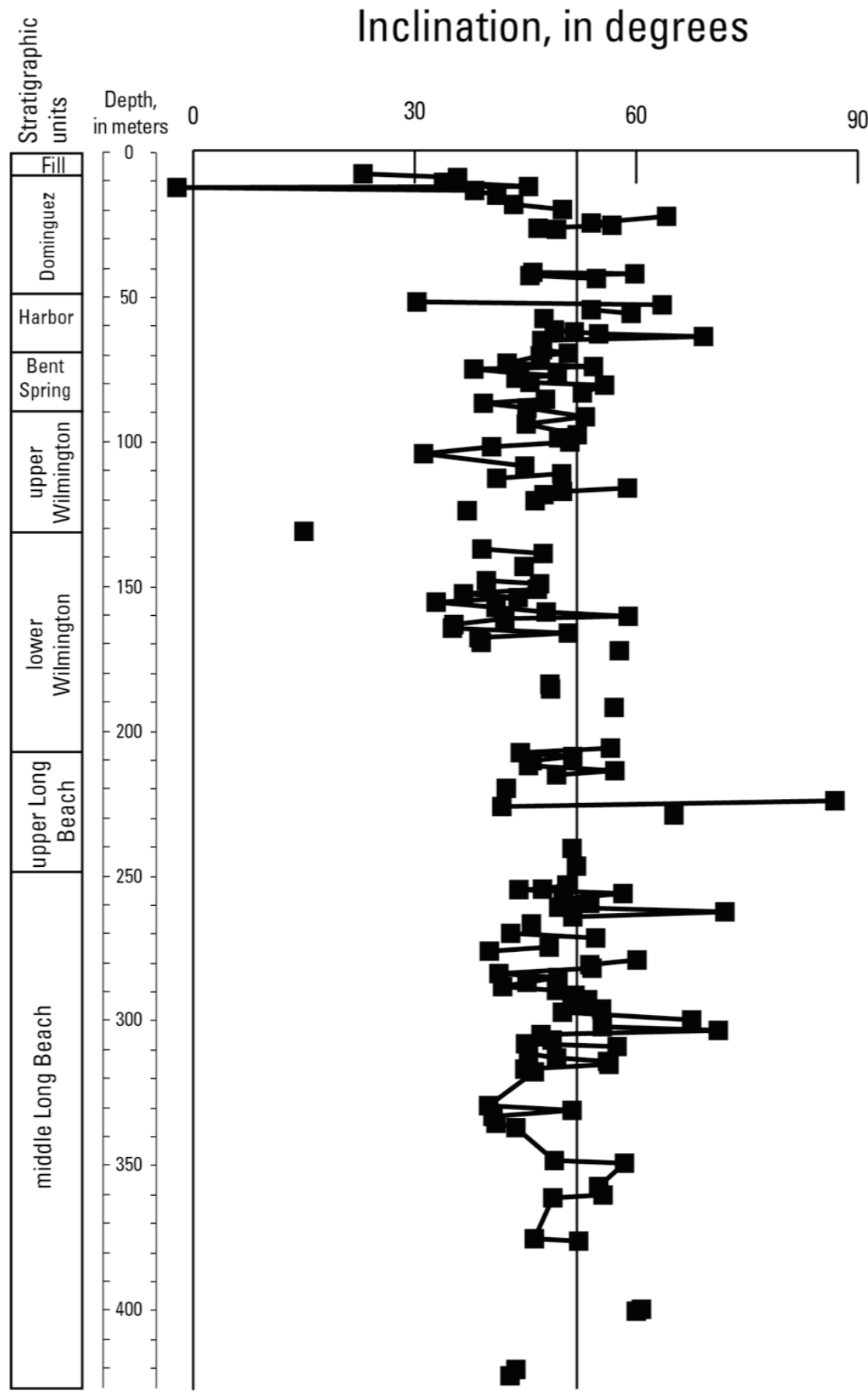

Expected inclination $\left(52^{\circ}\right)$

Figure 32. Magnetic inclinations screened for maximum angle of deviation (MAD) less than 10.0 degrees for Long Beach Pier C core site and monitoring well, Long Beach, California (Kirschvink, 1980). Stratigraphic units are identified in the left column (Ponti and others, 2007).

The feldspar IRSL-OSL growth curve for the sample at $80.4 \mathrm{~m}$ (LBPC-61C) is shown in figure 37. This growth curve is nonlinear in the equivalent dose ranges of 200-300 Gy and upwards. Two ages using IRSL are listed for most samples, except where it is apparent that ages are badly underestimated, and all are within error of each other (table 8). In all cases, the feldspar 


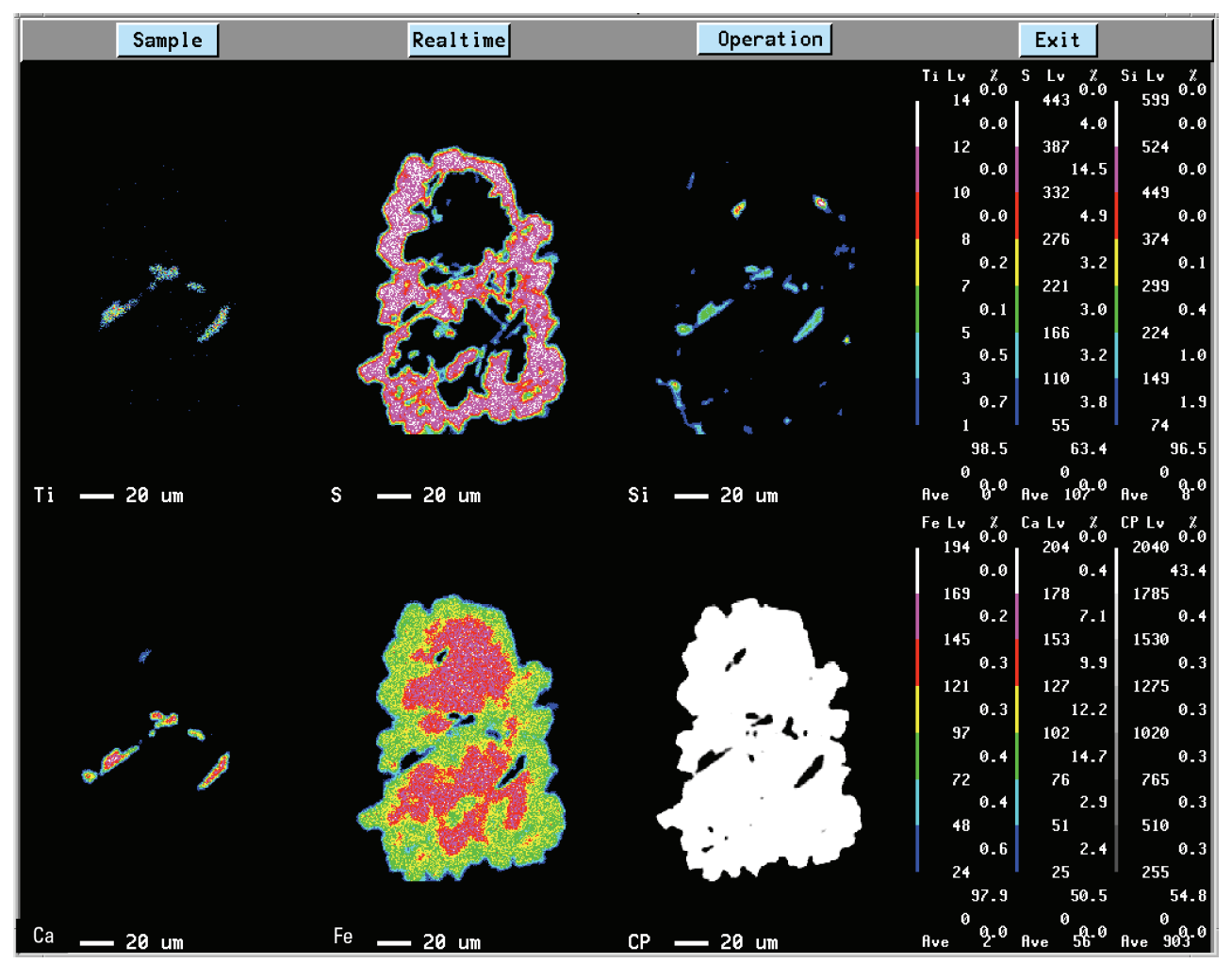

Figure 33. Electron-microprobe scan of a titanomagnetite grain containing ilmenite lamellae. Authigenic ironsulfide coats and replaces part of the original detrital grain in Long Beach Pier $\mathrm{C}$ core site and monitoring well, Long Beach, California.

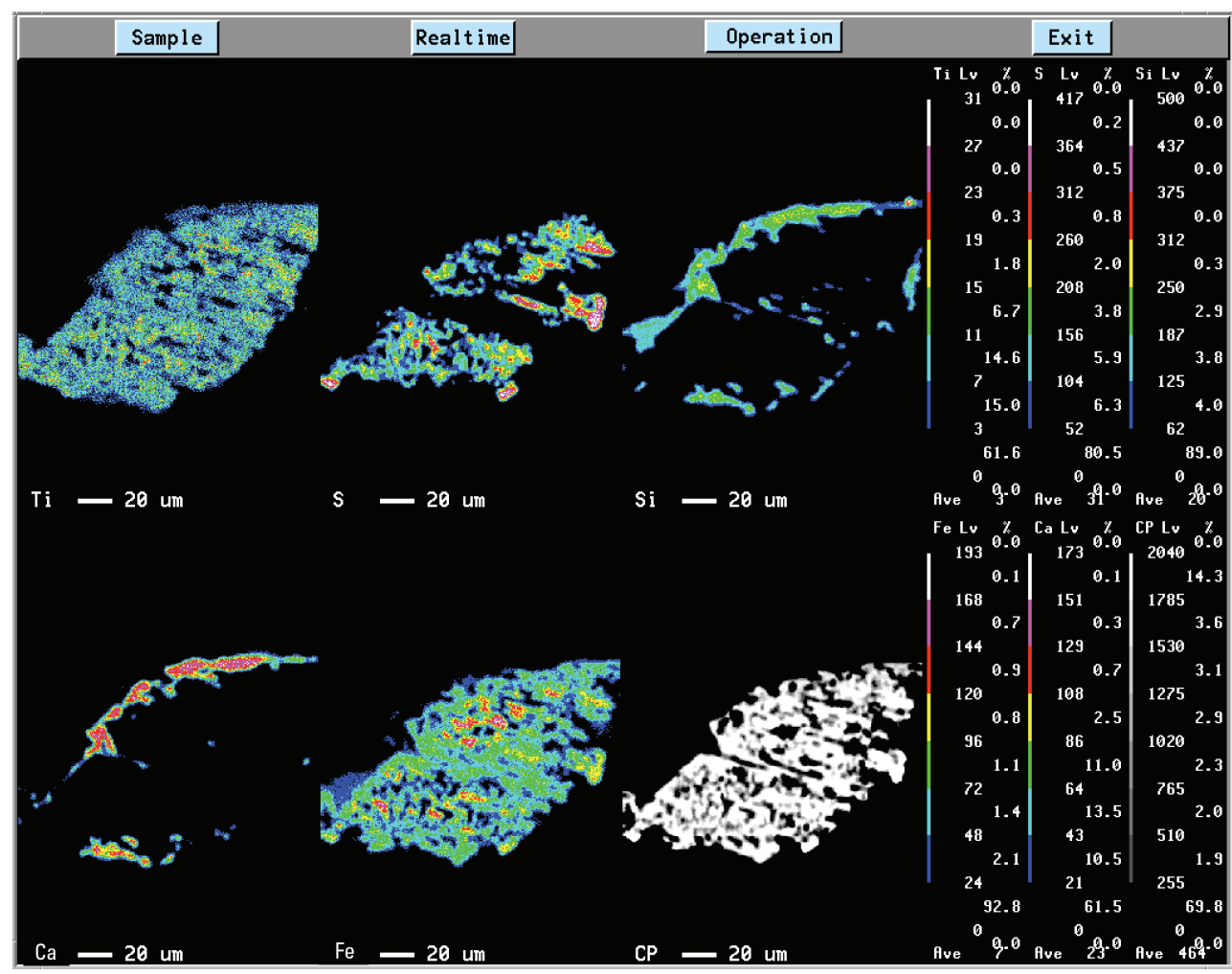

Figure 34. Electron-microprobe scan of an ilmenohematite grain in the Long Beach Pier $\mathrm{C}$ core site and monitoring well, Long Beach, California. 


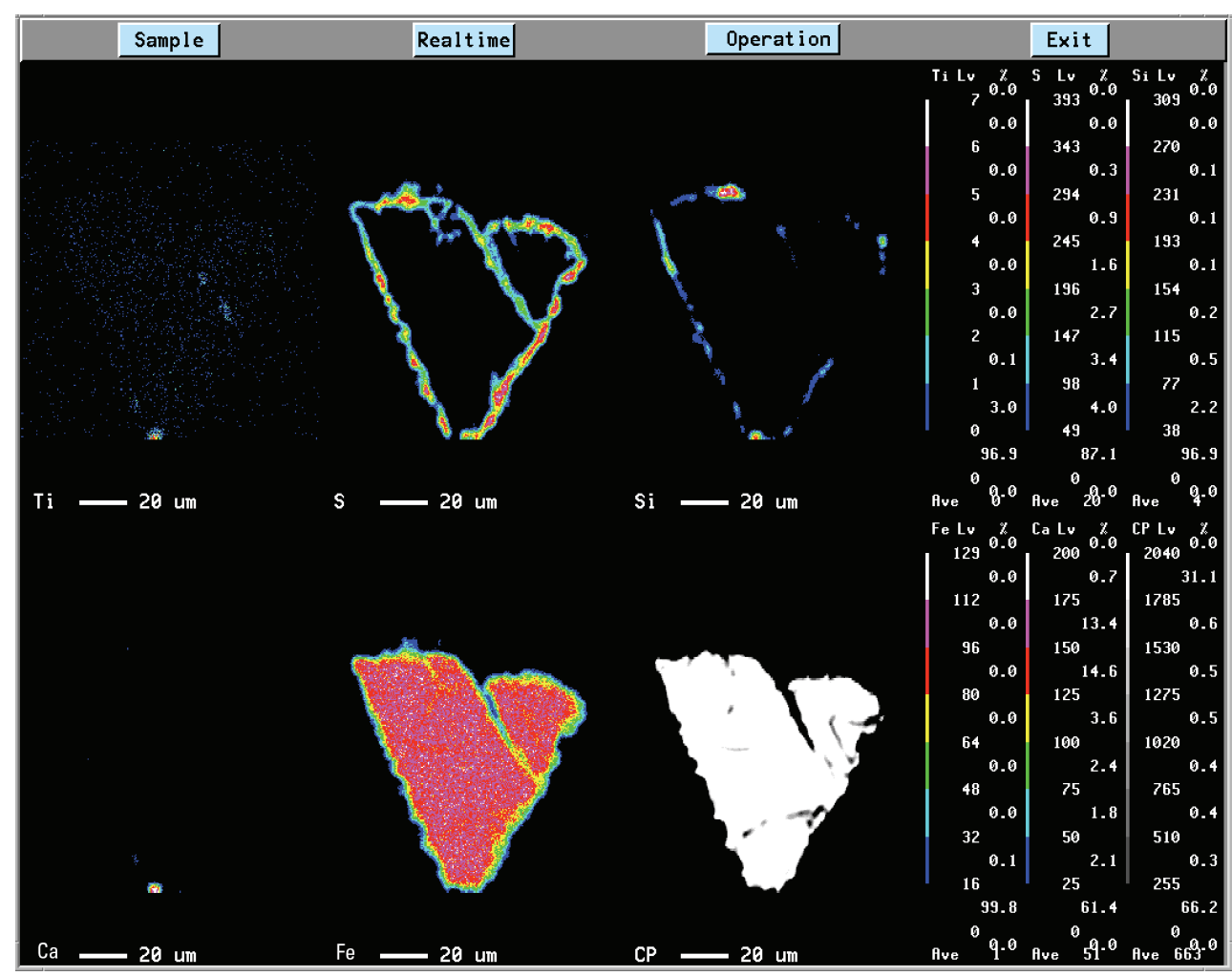

Figure 35. Electron-microprobe scan of a magnetite grain with a thin iron-sulfide rim, LBPC 234C-2.

IRSL-OSL is older than the quartz by 3 to $5 \mathrm{ka}$. The IRSL ages are reported for all samples, even though saturation of these particular systems seems to begin with the sample at $63.6 \mathrm{~m}$ (LBPC49C).

All sample ages below the $90-\mathrm{m}$ level are considered to be minimum ages, sometimes even severe age underestimates, because it was not possible to obtain an IRSL-OSL age older than about $85 \mathrm{ka}$ (owing to saturation) even though the core was clearly trending toward older fossil assemblages. Again, elemental data analyses did not indicate large dose rates that were likely to cause the creation of large amounts of unstable luminescence in a short amount of time (table 9), and normal ratios of $U: T h$ are present (that is, $1: 2,1: 3$, or 1:4). These findings do not indicate substantial problems with disequilibrium issues.

The TL ages from LBPC decrease up section and do not saturate out even at old responses (the oldest age reported is around $425 \mathrm{ka}$ ). Although reported as minimum ages owing to their large equivalent dose and uncertainty over the correct method for fitting (that is, exponential versus "Australian slide" versus exponential plus linear; Berger 1990; Guibert and others, 1996), the TL ages probably represent the maximum age for younger sediment, especially when compared with OSL ages from the same interval.

The $\geq 425 \mathrm{ka}$ old TL age obtained at $88.8 \mathrm{~m}$ (LBPC-67C) from the top of the upper Wilmington unit generally correlates with MIS 14-13 transgression (Ponti and others, 2007). The $\geq 309 \mathrm{ka}$ TL age at $80.4 \mathrm{~m}$ (LBPC-61C) and the $372 \pm 37 \mathrm{ka}$ TL age at $69.9 \mathrm{~m}$ (LBPC-54C) both record an abbreviated section of the Bent Spring unit and correlate with MIS 9 and(or) 11 (301$427 \mathrm{ka}$ ) (Ponti and others, 2007). The very young ages, from both OSL and TL, obtained in the upper $50 \mathrm{~m}$ of the well are similar to the macrofossil ages. The preferred ages are from the quartz OSL and IRSL. These two techniques track each other unusually well and indicate that the sediments were well-bleached at deposition. The TL ages are much too old for the first two samples, but may represent a better fit on the deeper four samples. 
Table 8. Thermoluminescence (TL), feldspar infrared stimulated luminescence (IRSL) and quartz blue-light optically stimulated luminescence (OSL) ages for the Long Beach Pier $\mathrm{C}$ core site and monitoring well (LBPC), Long Beach, California.

[\%, percent; ka, thousands of years; Gy, Grays; >, greater than; -, no data]

\begin{tabular}{|c|c|c|c|c|c|c|c|c|c|}
\hline $\begin{array}{c}\text { Sample } \\
\text { information } \\
\text { core depth: } \\
\text { material }\end{array}$ & $\begin{array}{c}\text { Moisture } \\
(\%)^{\mathrm{a}}\end{array}$ & $\begin{array}{l}\text { TL age } \\
(k a)^{b}\end{array}$ & $\begin{array}{l}\text { IRSL dose } \\
\text { rate } \\
\text { (Gy/ka) }\end{array}$ & $\begin{array}{c}\text { Equivalent } \\
\text { dose } \\
\text { (Gy) }\end{array}$ & $\begin{array}{c}\text { IRSL age } \\
\left(k^{2}\right)^{b}\end{array}$ & $\mathrm{n}^{\mathrm{c}}$ & $\begin{array}{c}\text { Quartz dose } \\
\text { rate } \\
\text { (Gy/ka) }\end{array}$ & $\begin{array}{l}\text { Equivalent } \\
\text { dose } \\
\text { (Gy) }\end{array}$ & $\begin{array}{c}\text { Quartz age } \\
\text { (ka) }\end{array}$ \\
\hline $\begin{array}{l}\text { LBPC-13C } \\
25.4 \text { m: Silt }\end{array}$ & $27 \pm 3$ & $28.0 \pm 1.31$ & $3.51 \pm 0.06$ & $\begin{array}{l}37.6 \pm 0.45 \\
39.4 \pm 0.35\end{array}$ & $\begin{array}{l}10.7 \pm 0.43 \\
11.2 \pm 0.41\end{array}$ & $\begin{array}{l}46 \\
(48)\end{array}$ & $2.58 \pm 0.03$ & $29.2 \pm 1.00$ & $1011.3 \pm 0.84$ \\
\hline $\begin{array}{l}\text { LBPC-33C } \\
43.5 \text { m: Silty } \\
\text { Sand }\end{array}$ & $22 \pm 2$ & $42.1 \pm 2.88$ & $3.46 \pm 0.04$ & $\begin{array}{l}55.1 \pm 6.12 \\
64.3 \pm 0.55\end{array}$ & $\begin{array}{l}15.9 \pm 3.56 \\
18.6 \pm 0.58\end{array}$ & $\begin{array}{l}32 \\
(40)\end{array}$ & $2.60 \pm 0.04$ & $32.1 \pm 0.34$ & $12.3 \pm 0.35$ \\
\hline $\begin{array}{l}\text { LBPC-49C } \\
63.6 \text { m: } \\
\text { Sandy Silt }\end{array}$ & $28 \pm 3$ & $\begin{array}{l}>174 \pm 50.7 \\
>156 \pm 14.4\end{array}$ & $4.12 \pm 0.07$ & $\begin{array}{l}>269 \pm 16.0 \\
>312 \pm 7.90\end{array}$ & $\begin{array}{l}>65.2 \pm 7.90 \\
>75.8 \pm 4.60\end{array}$ & - & - & - & - \\
\hline $\begin{array}{l}\text { LBPC-54C } \\
69.9 \text { m: Silty } \\
\text { Clay }\end{array}$ & $27 \pm 3$ & $\begin{array}{l}>282 \pm 24.5 \\
372 \pm 37.2\end{array}$ & $4.20 \pm 0.06$ & $>362 \pm 2.20$ & $>86.3 \pm 2.80$ & - & - & - & - \\
\hline $\begin{array}{l}\text { LBPC-61C } \\
80.4 \mathrm{~m}: \text { Silt }\end{array}$ & $26 \pm 3$ & $>309 \pm 24.4$ & $4.21 \pm 0.08$ & $>300 \pm 11.6$ & $>71.2 \pm 6.13$ & - & - & - & - \\
\hline $\begin{array}{l}\text { LBPC-67C } \\
88.8 \mathrm{~m}: \text { Silt }\end{array}$ & $19 \pm 2$ & $>425 \pm 54.9$ & $4.01 \pm 0.08$ & $>292 \pm 9.30$ & $>72.7 \pm 5.50$ & - & - & - & - \\
\hline
\end{tabular}

${ }^{a}$ Field moisture, ages based on $40-35 \%$ moisture content through time as an average between field and saturation moisture values.

${ }^{\mathrm{b}}$ Silt fraction (4-11 micron size) for IRSL as multiple aliquot additive dose technique (MAAD).

${ }^{\mathrm{c}}$ Number of replicated equivalent dose (De) estimates used to calculate the mean. Figures in parentheses indicate total number of measurements made including failed runs with unusable data.

${ }^{\mathrm{d}}$ Lab used fine sand grains (125-90 micron size) for quartz OSL as single aliquot regeneration technique (SAR). Fitted to a linear regression. Errors on equivalent dose and dose rate data at one sigma. Errors on ages at two sigma, calculated before rounding.

\section{Paleoecology}

\section{Benthic Foraminifers}

The abundance and diversity of the foraminiferal assemblages in the Venturian interval, 420.5-276.1 m (Mf10362-Mf10497) is moderate with benthic foraminiferal abundances exceeding 100 specimens/sample and diversity averaging 16 species/sample (fig. 24). Biofacies analysis of the Venturian interval suggests that deposition occurred in the upper middle bathyal biofacies (500-1,500 m) and the lower slope biofacies (400-950 m) (fig. 38). Water depths decrease slightly in the upper Venturian, despite an apparent increase in lower bathyal specimens in the upper Venturian. This increase is due entirely to the abundance of Uvigerina senticosa, which can be found rarely at depths as shallow as $100 \mathrm{~m}$ under areas of upwelling and eastern boundary currents (Boersma, 1984) and accounts for less than 1percent of the total benthic foraminiferal fauna except in the sample at $307.8 \mathrm{~m}$ (Mf10481), which contains only 36 specimens. The decrease in water depths is supported by the borderland biofacies analysis, which shows a decrease in lower slope specimens, accompanied by an increase in upper slope and basin floor species up section. Water depths in the upper Venturian interval are interpreted as being less than 1,000 $\mathrm{m}$. Transport of 


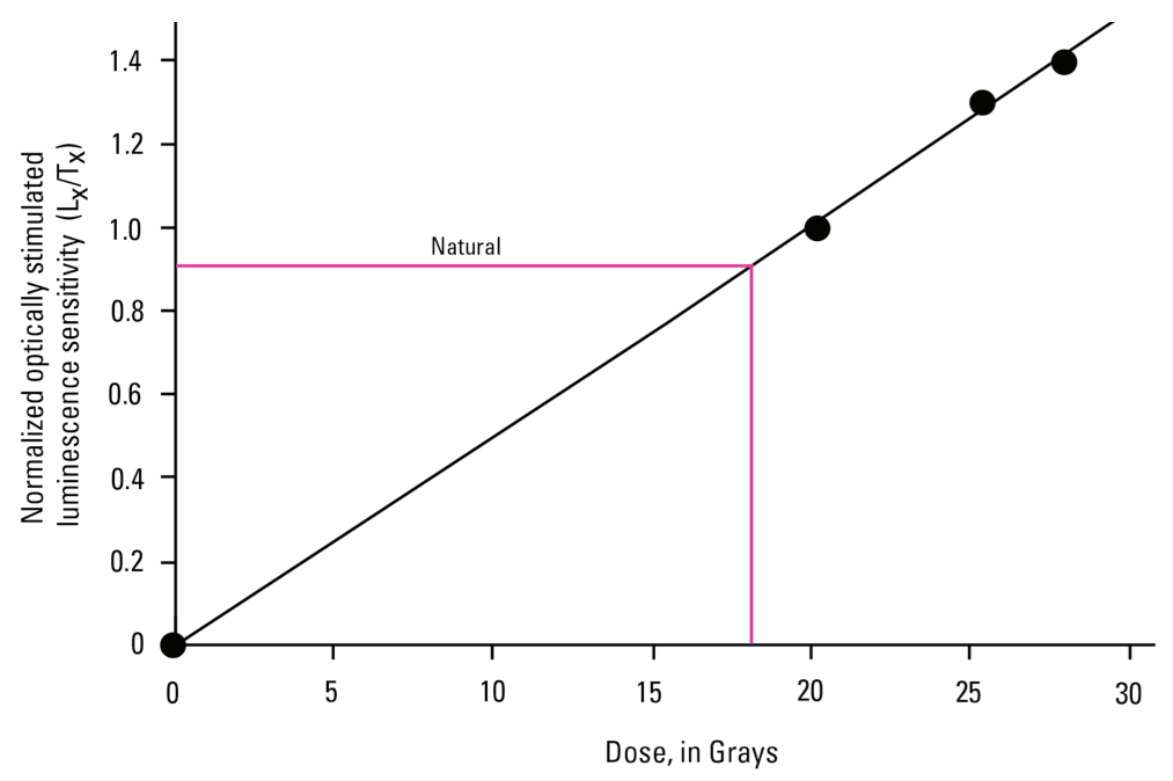

Figure 36. LBPC-13C $(25.4 \mathrm{~m})$ growth curve, with the natural plotted on the $X$ axis. Regeneration proceeded "optimally" with a recycle duplicating the first measurement; circles indicate increases in response to increasing beta radiation. Fit is to an exponential and linear function. Dose is measured in Grays (Gy, absorbed radiation) and optically stimulated luminescence (OSL) is measured in unitless normalized OSL sensitivity measurements $(\mathrm{Lx} / \mathrm{TX})$.

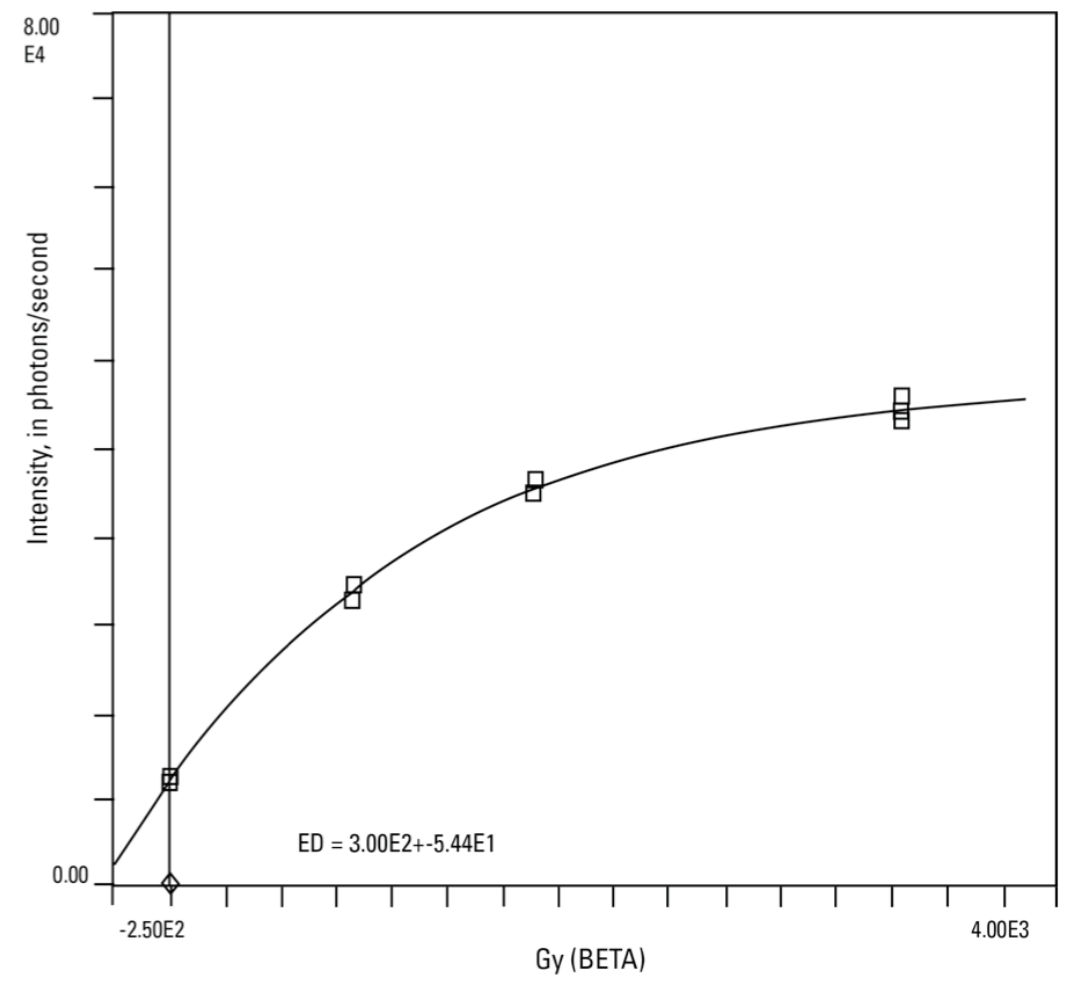

Figure 37. Growth curve of IRSL-OSL in the sample at $80.4 \mathrm{~m}$ (LBPC-61C) obtained using multi-aliquot additive dose method (MAAD). Bleaches are denoted with diamonds, naturals sit on the $X$ axis and increasing beta radiated aliquots are shown on exponentially fitted growth line. The $X$ axis shows the measured equivalent dose in Grays (Gy) when compared to calibrated Grays generated by exposure to a beta source. The $Y$ axis shows the intensity of light emitted from the aliquots and is measured in photons/second. 
Table 9. Elemental concentrations and associated dosimetry for the Long Beach Pier $\mathrm{C}$ core site and monitoring well, Long Beach, California, optically stimulated luminescence (OSL) samples.

$\left[\%\right.$, percent; ppm, parts per million; $m$, meter; $\mathrm{D}_{\mathrm{r}}$, dose rate; $\mathrm{K}$, Potassium; $\mathrm{U}$, Uranium; Th, Thorium; Rb, Rubidium; -, no data]

\begin{tabular}{|c|c|c|c|c|c|c|c|c|c|c|c|c|}
\hline $\begin{array}{l}\text { Sample } \\
\text { number }\end{array}$ & $(\%)$ & (ppm) & Th & $\begin{array}{l}\text { Depth } \\
(\mathrm{m})\end{array}$ & $\begin{array}{l}\text { Water } \\
(\%)\end{array}$ & $\begin{array}{c}D_{r} \\
\text { fine } \\
\text { grain }\end{array}$ & $\begin{array}{c}D_{r} \\
\text { coarse } \\
\text { grain }^{\mathrm{a}}\end{array}$ & $\begin{array}{c}D_{r} \\
\text { for } K\end{array}$ & $\begin{array}{c}D_{r} \\
\text { for } U\end{array}$ & $\begin{array}{c}D_{r} \\
\text { for Th }\end{array}$ & $\begin{array}{c}D_{r} \\
\text { for } R b\end{array}$ & $\begin{array}{c}D_{r} \\
\text { for cosmic } \\
\text { ray }\end{array}$ \\
\hline LBPC-13C & 2.45 & 2.49 & 9.98 & 25.40 & 40.00 & 3.51 & 2.58 & 1.76 & 0.87 & 1.04 & 0.03 & 0.02 \\
\hline LBPC-33C & 2.23 & 2.15 & 8.92 & 43.50 & 35.00 & 3.46 & 2.60 & 1.67 & 0.79 & 0.94 & 0.03 & 0.02 \\
\hline LBPC-49C & 2.28 & 2.83 & 12.77 & 63.60 & 40.00 & 4.12 & - & 1.71 & 1.03 & 1.34 & 0.03 & 0.01 \\
\hline LBPC-54C & 2.42 & 3.08 & 13.45 & 69.90 & 40.00 & 4.20 & - & 1.73 & 1.08 & 1.35 & 0.03 & 0.01 \\
\hline LBPC-61C & 2.65 & 2.87 & 14.80 & 80.40 & 40.00 & 4.21 & - & 1.90 & 0.90 & 1.34 & 0.04 & 0.01 \\
\hline LBPC-67C & 2.62 & 2.69 & 11.46 & 88.80 & 40.00 & 4.01 & - & 1.88 & 0.94 & 1.15 & 0.03 & 0.00 \\
\hline LBPC-97C & 1.55 & 2.10 & 6.24 & 131.40 & 40.00 & 2.50 & - & 1.11 & 0.73 & 0.63 & 0.02 & 0.00 \\
\hline
\end{tabular}

${ }^{a}$ Coarse grains used for quartz OSL have the alpha component and about 10 percent beta component of the dosimetry etched away before analyses.

specimens from the upper bathyal biofacies (420.1-357.5 m), outer shelf (beginning at $357.5 \mathrm{~m}$ ), and inner neritic (beginning at $313.9 \mathrm{~m}$ ) complicate the faunal interpretations in this interval.

Biofacies analysis of the questionable Wheelerian interval between 274.7 and $211.6 \mathrm{~m}$ (Mf10361-Mf10307) suggests a continuation of the upper middle bathyal/lower slope biofacies conditions of the Venturian (fig. 38). Above $261.3 \mathrm{~m}$ (Mf10353) biofacies analysis suggests that water depths shallow slightly, although deposition continues in the upper middle bathyal/lower slope biofacies. Dissolved-oxygen conditions improve and epifaunal species are more common.

No microfossil samples were taken between 242.2 and $215.1 \mathrm{~m}$. Sediments and macrofossils indicate very shallow water depths. The microfossil sample taken at $215.1 \mathrm{~m}$ contains a fauna very similar to the underlying assemblages. Biofacies analysis suggests that deposition is occurring in the upper middle bathyal/basin floor biofacies $(500-1,500 \mathrm{~m})$. Water depths increase rapidly from about $500 \mathrm{~m}$ at base of interval to $1,000-1,500 \mathrm{~m}$ by the sample at $186.1 \mathrm{~m}$ (Mf10308). This increase in water depth is based on the abundant occurrence of Uvigerina senticosa, which has a UDL in the lower bathyal biofacies. In these samples, there are no other species which have UDLs in the lower bathyal or lower middle bathyal biofacies, therefore, $U$. senticosa is assumed to have a shallower UDL as suggested by Boersma (1984). No increase in water depths can be documented for this interval. Dysoxic conditions prevail through the interval.

The next microfossil sample occurs at $161.7 \mathrm{~m}$ (Mf10348). Biofacies analysis suggests this sample was deposited in the upper bathyal/bank biofacies (150-500, and 50-200 m, respectively). Faunas typical of the upper bathyal/basin floor biofacies begin replacing the upper bathyal/bank species by the next sample (153.2 m, Mf10347). Praeglobobulimina affinis, Loxostomum bradyi, and L. pseudobeyrichi, along with Bolivina argentea, B. interjuncta, B. subadvena serrata, Nonionella stella, and $N$. labradorica indicate dysoxic conditions. The numerous bank and outer shelf species present in these assemblages reflected downslope transport from the shelf and bank biofacies. Deposition continues in the upper bathyal/basin floor biofacies throughout the rest of the Wheelerian interval (up to $79.5 \mathrm{~m}$, Mf10333) and is terminated by an unconformity which separates the Wheelerian and Hallian Stages.

Biofacies analysis of Hallian samples indicates deposition occurred at inner neritic water depths $(\leq 50 \mathrm{~m})$, whereas the borderland biofacies analysis indicates the presence of outer shelf $(50-200 \mathrm{~m})$ or basin floor $(550-950 \mathrm{~m})$ biofacies (fig. 38). The borderland biofacies does not 

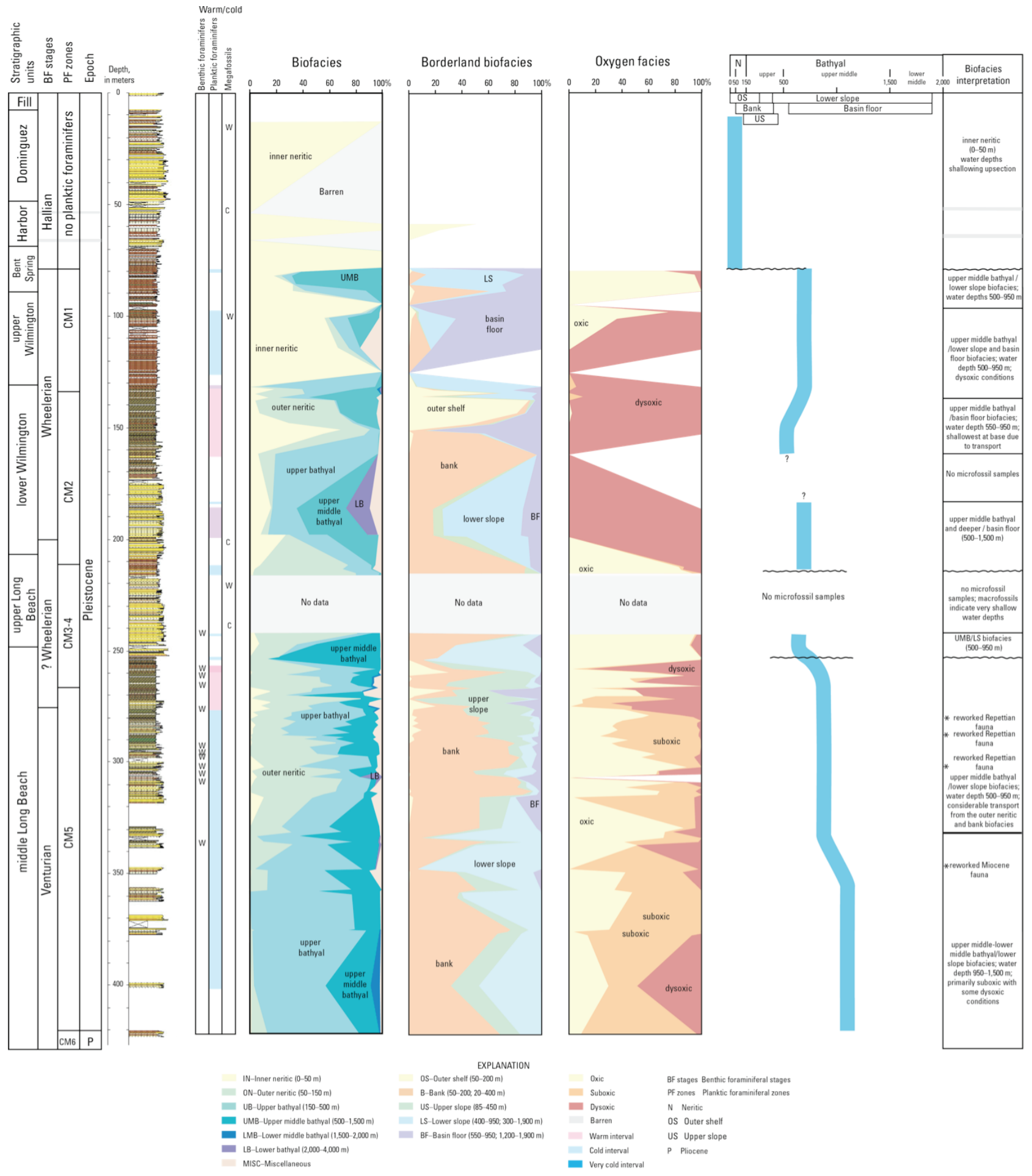

Figure 38. Paleoecological benthic foraminiferal biofacies analysis of Long Beach Pier $C$ core site and monitoring well, Long Beach, California. The three biofacies analyses shown are discussed in the text and are based on the abundance of benthic foraminifers in the samples. The bathymetric curve represents the most probable depth at which the samples were deposited. Stratigraphic units are identified in the left column, and lithologies are indicated on the stratigraphic column by color (clay, green; silt, brown; sand, yellow) (Ponti and others, 2007). [Reduced-size figure is shown here for continuity; full-size figure is included on plate 18.] 
recognize biofacies on the inner shelf at depths of $\leq 50 \mathrm{~m}$. Also, the benthic foraminiferal assemblages in this interval are dominated by abundant Nonionella which dominates either the inner shelf or low oxygen environments such as the basin floor biofacies, and accounts for the disparity in the two analyses. Deposition at inner shelf depths of $\leq 50 \mathrm{~m}$ is considered most probable for this interval.

\section{Planktic Foraminifers}

The strong dominance of $N$. pachyderma $\mathrm{C}$ in the lowermost sample $398.9 \mathrm{~m}$ (Mf10496) indicates subarctic-to-arctic water temperatures (fig. 39). Cooler surface-water temperatures are suggested up to $276.1 \mathrm{~m}$ (Mf10362) by (1) the dominance of left-coiling $N$. pachyderma (most notably the polar to subpolar form $N$. pachyderma $\mathrm{C}$ ), (2) abundances of temperate-to-subpolar planktic foraminifers, and (3) a gradual decrease in the numbers of specimens/sample. A warm pulse may have occurred during this cool period. In sample Mf10490 (348.3 m), tropical-tosubtropical marker, Pulleniatina obliquiloculata, appears. However, this is the only warm-water species in an interval dominated by large populations of $N$. pachyderma $\mathrm{C}$. Nevertheless, the presence of $P$. obliquiloculata could signify a short-lived early late Pliocene warm pulse or simply a mixing of water masses owing to increased influence by the Southern California Countercurrent.

Increases in the diversity and abundances of the planktic foraminifers between 274.7 and $260.1 \mathrm{~m}$ (Mf10361-Mf10351) provide evidence of deeper water. In this interval, a maximum of 17 species and a maximum of 689 planktic foraminifers were counted in a single sample, although the abundance averages 247 specimens per sample and diversity averages 10 species per sample. Microfaunal paleotemperature proxies also shift to warm environmental conditions during this interval. Dextral-coiling $N$. pachyderma comprise an average of 51percent of the planktic foraminiferal assemblages between 274.7 and 258.2 m (Mf10361-Mf10350). The higher abundances of subtropical globigerinids and globorotaliids indicate that there was a warming trend during this interval. The appearances of tropical-to-warm subtropical species, such as Sphaeroidinellopsis seminulina (258.2 m, Mf10350) and Pulleniatina obliquiloculata $(260.1 \mathrm{~m}$, Mf10351), demonstrate that the sediments at the top of this interval were deposited during a period of particularly elevated sea-surface temperatures.

Planktic foraminiferal faunas from 258.2 to $183.5 \mathrm{~m}$ (Mf10350-Mf10308) include gradually decreasing numbers of sinistral N. pachyderma. Despite the low abundances of sinistral coiling $N$. pachyderma, the FO occurrence of $N$. pachyderma B at 213.1 m (Mf10307), suggests possible correlation with the Middle Pleistocene Transition (MPT).

A shift to much warmer marine conditions in the section between 161.7 and $131.5 \mathrm{~m}$ (Mf10348-Mf10340) is noted by the increased specimen numbers, diversity, and presence of tropical to subtropical planktic foraminiferal species, such as Globigerinoides obliquus, G. ruber, Globorotalia truncatulinoides, $N$. dutertrei, dextral-coiling N. pachyderma s.s, and N. pachyderma A. These right-coiling morphotypes of $N$. pachyderma comprise 34-57 percent of the total assemblages supporting the observation that the marine environment was warmer during this period.

Planktic foraminifers are very rare to sparse from 124.9 to 79.5 m (Mf10339-Mf10333). Assemblages in this interval are composed primarily of cosmopolitan and long-ranging coolerwater species, such as Globigerina bulloides, G. quinqueloba, and Globigerinita glutinata. Sinistral coiling $N$. pachyderma B also were observed in the assemblages. This species makes up, on average, 28 percent of the total planktic foraminiferal population and its dominance in these samples indicates temperate-to-cool paleoenvironmental conditions. 


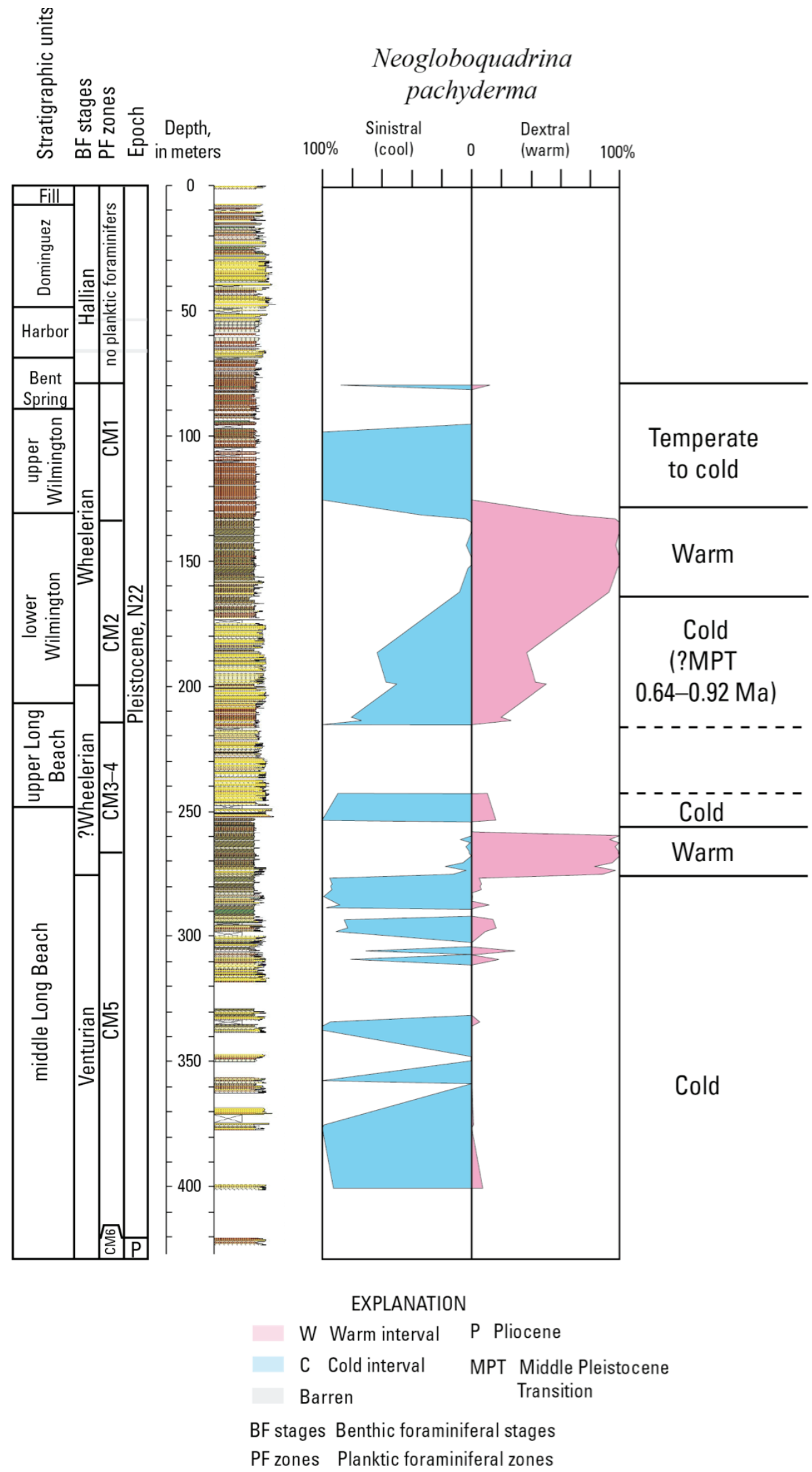

Figure 39. Distribution of Neogloboquadrina pachyderma in Long Beach Pier $\mathrm{C}$ core site and monitoring well, Long Beach, California. Stratigraphic units are identified in the left column, and lithologies are indicated on the stratigraphic column by color (clay, green; silt, brown; sand, yellow) (Ponti and others, 2007). 


\section{Macrofossils}

Environmental interpretation of the macrofossils throughout LBPC suggests shallow water with occasional species that suggest deeper water. The upper part of the well contains species indicative of a bay. In most cases, depths indicated by the macrofossil assemblages are considerably shallower than depths indicated by the microfossils, indicating that the macrofossils were transported.

Samples below 347.4 m contain few identifiable mollusks and are not environmentally significant (plate 6). However, the occurrence of the bivalve Tivela stultorum in samples below $346.4 \mathrm{~m}$ indicates shallow water, $\geq 30 \mathrm{~m}$ (Coan and others, 2000), near a sandy beach exposed to strong surf based on the environmental parameters where modern Pismo clams are found. Samples between 338.3-285.9 and 273.0-244.3 m contain only a few species of poorly preserved shells or shell fragments which are consistent with subtidal water depths. A gastropod questionably identified as Boreotrophon raymondi was recovered at about $279.2 \mathrm{~m}$. Modern counterparts of this species live at water depths between 80 and $440 \mathrm{~m}$ (McLean and Gosliner, 1996), thus the presence of this species indicates deeper water depths in this interval of LBPC.

A 10-cm-thick bed of shells with oysters and mussels between 241.7 and $231.7 \mathrm{~m}$ and Ostrea conchaphila between 242.5 and $239.0 \mathrm{~m}$ indicates very shallow water depths. Modern Ostrea conchaphila generally occur at water depths between the intertidal zone and $10 \mathrm{~m}$ (Coan and others, 2000). Patinopecten is present at $239.0 \mathrm{~m}$, and indicates cooler water conditions than along the adjacent coast today. The faunas found between 230.7 and $223.5 \mathrm{~m}$, along with a specimen of Chione at $223.4 \mathrm{~m}$, are too small for accurate environmental interpretation, but generally suggest subtidal shelf depths and warmer water temperatures. The reappearance of Patinopecten at $203.0 \mathrm{~m}$ indicates a return to cooler water conditions.

Between 203.0 and $102.1 \mathrm{~m}$, the faunas are small and consistent with a subtidal, shallowshelf water depths ( $\sim 10$ to $\sim 50 \mathrm{~m})$. At $101.5 \mathrm{~m}$, the faunas also represents subtidal water depths, but slightly deeper depths between 25 and $30 \mathrm{~m}$, and there is no indication of cooler- or warmer-thanpresent water temperatures. Chione is found at $100.3 \mathrm{~m}$ and suggests water temperatures that are similar to, or warmer than, present.

The few samples collected between 95.6 and $64.0 \mathrm{~m}$ contain a small number of species and are not adequate for ecologic interpretation, but are consistent with the present conditions of the continental shelf off San Pedro. A poorly preserved specimen of Patinopecten found at $56.0 \mathrm{~m}$ indicates a return to cooler water temperatures.

Between 55.3 and $53.9 \mathrm{~m}$, species recovered are characteristic of a subtidal shelf environment along an open coast. The occurrence of the bivalve Mysella pedroana and gastropods Alvinia oldroydae, Lirobittium rugatum, and Scabrotrophon cerritensis (all questionably identified) indicate water depths probably between 30 and $110 \mathrm{~m}$. No southern or northern extralimital taxa are present, thus, the faunas are similar to that which exists today off San Pedro today.

Recovered mollusks from 46.9 to $14.1 \mathrm{~m}$ indicate a bay to open coast environment at intertidal to shallow, subtidal water depths. The bay environment is indicated by the presence of the gastropod Cerithidae californica $(31.0 \mathrm{~m})$. The bivalves Chione $(16.9$ and $14.1 \mathrm{~m})$ and Donax (46.9 and $14.1 \mathrm{~m}$ ) generally are characteristic of open coasts, but are sometimes found in bays. Both bivalves are near the northern end of their latitudinal range so their presence indicates water temperatures as warm as, or possibly warmer than, waters off the adjacent coast today. At 5.5 and $11.9 \mathrm{~m}$ shelly remains of mollusks indicate a bay environment and probably represent modern fill. 


\section{Long Beach Pier C Core Site and Monitoring Well Summary}

LBPC ranges from Pliocene to Holocene in age (fig. 40). Radiocarbon, TL, and OSL dates in the upper part of LBPC identify sediments ranging in age from $11.3 \pm 0.84 \mathrm{ka}$ (quartz OSL) to $>425 \pm 54.9 \mathrm{ka}$ (TL). LBPC is uniformly of normal magnetic polarity and is correlated with the Brunhes Normal Polarity Chron and the Olduvai Polarity Subchron, assuming an unconformity at $252 \mathrm{~m}$ as identified by the foraminifers. Sediments below $252 \mathrm{~m}$ are correlated with the Olduvai Polarity Subchron and are $\geq 1.77 \mathrm{Ma}$, whereas the sediments above $252 \mathrm{~m}$ are correlated with the Brunhes Normal Polarity Chron and are $\leq 0.78 \mathrm{Ma}$. Benthic and planktic foraminifers indicate the presence of the Pleistocene zones and stages, and the presence of a zone of reworking between the Venturian and Wheelerian Stages and in zone CM3/4.

Benthic foraminifers suggest the presence of the Pleistocene, Venturian through Hallian Stages-Venturian Stage from 420.5 to $276.1 \mathrm{~m}$; Wheelerian Stage from 274.7 to $79.5 \mathrm{~m}$; and Hallian from 78.1 to $0 \mathrm{~m}$. Planktic foraminifers indicate the presence of zones N21 and N22 of Blow (1969), as well as the California margin zones of Kucera and Kennett (2000) - CM6, CM5, CM3-4, CM2, and CM1. The FO of $N$. pachyderma C (2.41 Ma; Kucera and Kennett, 2000) at $398.9 \mathrm{~m}$ (Mf10496) indicates the base of the well is still Pleistocene in age.

Despite the age indicated by microfossils, there were no intervals of reversed geomagnetic polarity in LBPC, so the Brunhes-Matuyama polarity transition was not recognized. The fact that no reversed-polarity magnetizations were found may indicate that (1) erosion and (or) nondeposition left no record of the Matuyama Reversed Polarity Chron, (2) sulfide authigenesis remagnetized the sediment during the Brunhes Normal Polarity Chron, or (3) foraminifers from older deposits were reworked into the sediment during the Brunhes Chron, and none of the sediment is older than $0.78 \mathrm{Ma}$ (Brunhes-Matuyama boundary). If the first option is the correct, then a hiatus in deposition or erosion is required to prevent the upper Matuyama Reversed Polarity Chron (0.78-1.77 Ma) from appearing in LBPC. Option 2 would be unlikely if further tests identify pyrite to be the iron-sulfide. Option 3 also is not favored because the microfossils are abundant and unabraided.

Intervals of low magnetic intensity of remanence occur at depths of 134.4-126.8 m, and 54.9-53.1 m. However, these low-field intervals are not associated with anomalous inclinations when the data are screened for quality factors (MAD of Kirschvink, 1980) of less than $10^{\circ}$.

Polished grain mounts from magnetic separates were scanned with an electron microprobe to map the abundance of 5 elements $(\mathrm{Fe}, \mathrm{S}, \mathrm{Ca}, \mathrm{Si}$, and $\mathrm{Ti}$ ). The scans show that all grains are composed of iron-oxide cores surrounded by rims of iron-sulfide, which formed by dissolution and replacement of the original titanomagnetite and hematite grains. Dissolution and sulfidization could explain very low magnetizations noted in some intervals of the LBPC cores.

Ages based on luminescence in LBPC samples range from middle Pleistocene to late Holocene (fig. 40, table 8). The quartz OSL ages saturate out quickly, and only minimum ages of IRSL and TL are recorded below $40 \mathrm{~m}$. Holocene sedimentation exists down to approximately 40 $\mathrm{m}$. The Harbor unit was not dated in this well, and the Pacific and Mesa units are missing. The Bent Spring unit is abbreviated in the LBPC, but likely was deposited during MIS 9 and (or) 11 $(301-427 \mathrm{ka}$ ) based on a TL age of $>309 \pm 24 \mathrm{ka}$. A TL date of $>425 \pm 55 \mathrm{ka}$ comes from the top of the upper Wilmington unit and seems to indicate that the unit might have ended deposition around MIS 13-14 transgression (474-568 ka). This was the oldest unit to be dated using luminescence.

Microfossil interpretations indicate that during the Venturian, ?Wheelerian, and Wheelerian Stages, water depths fluctuated within the upper middle biofacies (500-1,500 m); they become increasingly dysoxic up section (fig. 41). Sea-surface temperatures also fluctuated between cool and warm during this interval. Cooler surface-water temperatures are suggested between 398.9 and $276.1 \mathrm{~m} ; 258.2$ and $183.5 \mathrm{~m}$; and 124.9 and $79.5 \mathrm{~m}$, whereas warm subtropical temperatures are 


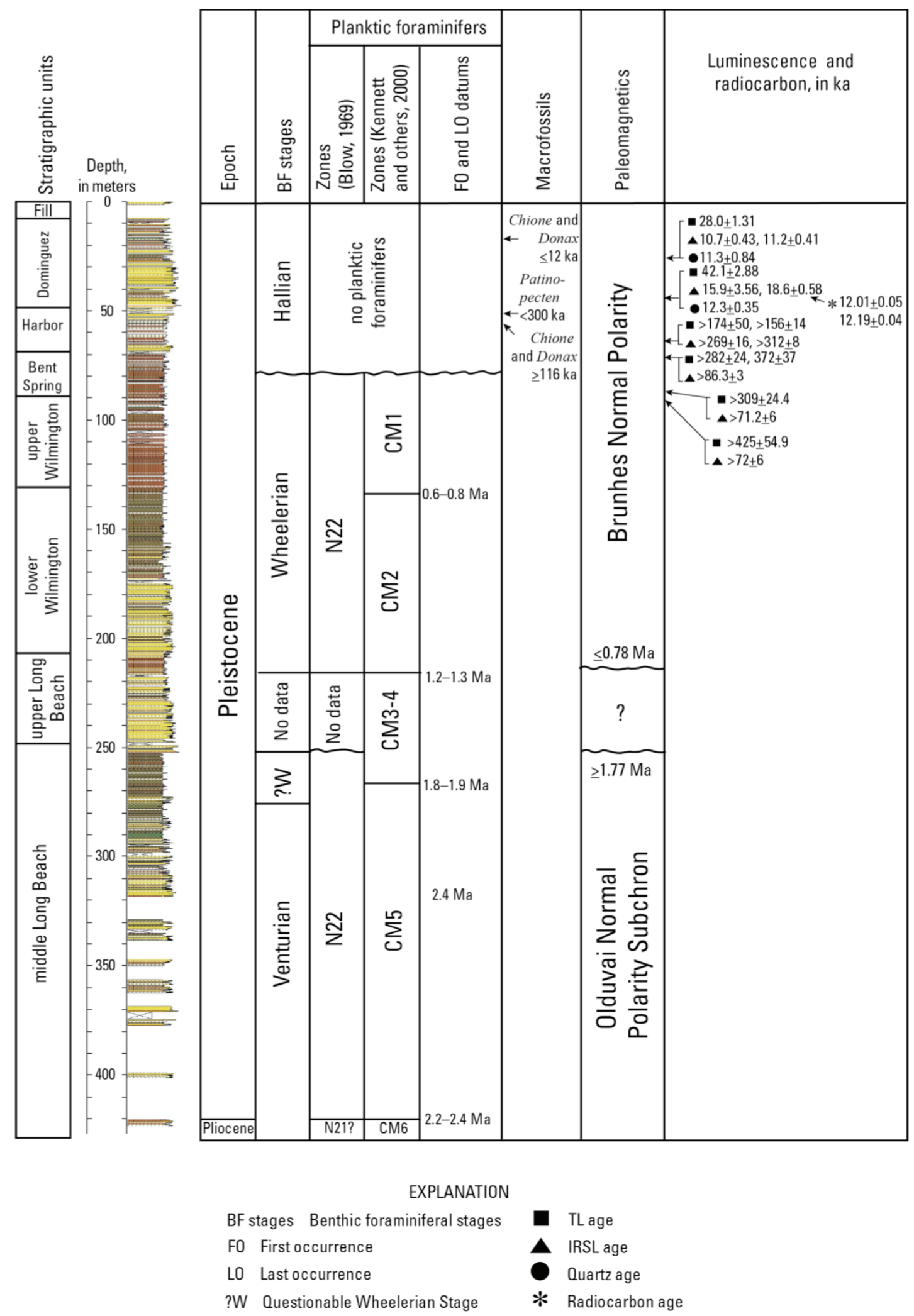

Figure 40. Summary of geochronology of Long Beach Pier $C$ core site and monitoring well, Long Beach, California, based on the microfossils, macrofossils, paleomagnetics, luminescence, and radiocarbon. Stratigraphic units are identified in the left column, and lithologies are indicated on the stratigraphic column by color (clay, green; silt, brown; sand, yellow) (Ponti and others, 2007). 

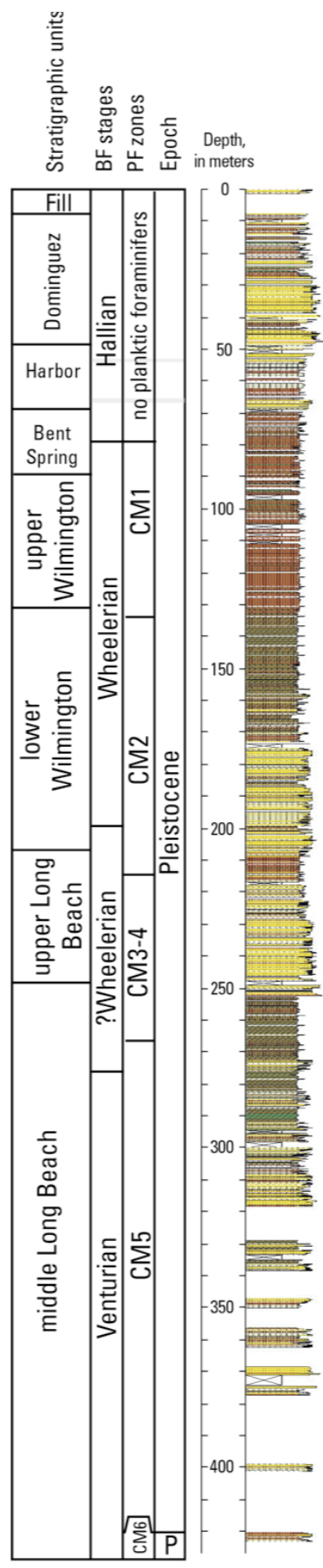

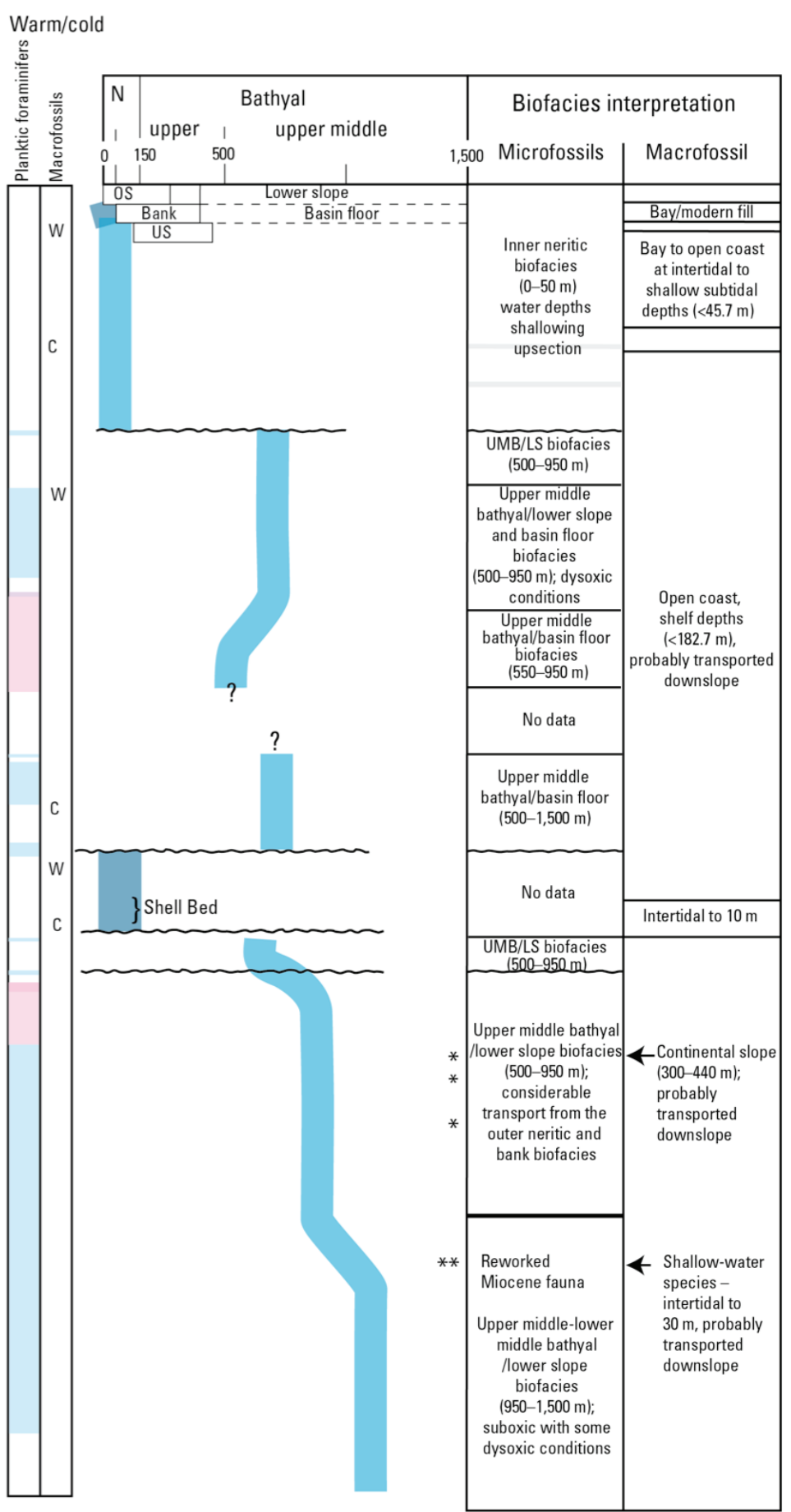

EXPLANATION

$\begin{array}{ll}\text { W Warm interval } & \text { BF stages Benthic foraminiferal stages } \\ \text { C Cold interval } & \text { PF zones Planktic foraminiferal zones } \\ \text { Depth based on microfossils } & \text { N Neritic } \\ \text { Depth based on macrofossils } & \text { OS Outer shelf } \\ \text { Barren } & \text { US Upper slope. } \\ \text { * Reworked Repettian fauna } & \text { UMB/LS Upper middle bathyal/lower slope } \\ \text { * Reworked Miocene fauna } & \end{array}$

Figure 41. Summary of ecological interpretations for Long Beach Pier $\mathrm{C}$ core site and monitoring well, Long Beach, California, based on microfossils and macrofossils. Stratigraphic units are identified in the left column, and lithologies are indicated on the stratigraphic column by color (clay, green; silt, brown; sand, yellow) (Ponti and others, 2007). 
indicated between 274.7 and $260.1 \mathrm{~m}$; and 161.7 and $131.5 \mathrm{~m}$. Warm subtropical to tropical seasurface temperatures are suggested for the interval between 260.1 and $258.2 \mathrm{~m}$.

Two intervals were not sampled for microfossils. The youngest sample gap is between 161.7 and 153.2 m (Mf10348-Mf10347), and water depths do not appear to change above or below this interval. The oldest of these sample gaps is delineated by abrupt changes in interpreted water depths, and unconformities are suggested at 242 and $215 \mathrm{~m}$. The intervening interval (242-215 m) contains a shell layer with macrofossils diagnostic of intertidal depths $(0-10 \mathrm{~m})$. Within this shallow-water interval, both warmer and cooler water conditions are suggested by the macrofauna. The boundary between the Wheelerian and Hallian Stages at $79.5 \mathrm{~m}$ is marked by a dramatic change in water depth from upper middle bathyal $(500-1,500 \mathrm{~m})$ to inner neritic $(0-50 \mathrm{~m})$ according to benthic foraminifers. Macrofossils in this interval indicate shelf depths $(<182.7 \mathrm{~m})$ on an open coast from 79.5 to $64.0 \mathrm{~m}$; intertidal to shallow, subtidal depths $(<45.7 \mathrm{~m})$ in a bay to open coast at from 55.3 to $14.1 \mathrm{~m}$; and modern fill from 11.9 to $5.5 \mathrm{~m}$. 


\section{Chapter 4-Long Beach Cabrillo High School Core Site and Monitoring Well, Long Beach, California}

\section{Introduction}

The Long Beach Cabrillo High School core site and water monitoring well (LBCH) is located on the east side of Terminal Island Freeway, approximately $60 \mathrm{~m}$ south of the westward projection of Hill Street, Long Beach, California (lat 334ㄱ'47.1"N., long 118 13'23.8"W.) (fig. 1). Total depth of the well is $430.4 \mathrm{~m}$ (table 1). The biostratigraphic, chronostratigraphic, and paleoecologic data collected from $\mathrm{LBCH}$ are summarized in this chapter. Core samples taken from the LBCH were examined for benthic foraminifers (Kristin McDougall), macrofossils (Charles Powell, II), paleomagnetics (John Hillhouse), and OSL and TL (Shannon Mahan). The middle Long Beach (430.4-402.3 m), upper Long Beach (402.3-373.3 m), lower Wilmington (373.3$294.0 \mathrm{~m}$ ), upper Wilmington (294.0-127.0 m), Bent Spring (127.0-101.3 m), Harbor (101.3-39.1 $\mathrm{m})$, and Dominguez (39.1-0 m) units were recognized in this well (Ponti and others, 2007). The Mesa and Pacific units are missing due to erosion on the crest of the Wilmington anticline.

\section{Biostratigraphy}

\section{Benthic Foraminifers}

Microfossils were sampled only sporadically in LBCH. The lower 99 cores contain common to abundant foraminifers, whereas the upper 90 cores contain few foraminifers (fig. 42). Barren samples are common in the upper part of the well. Sixty-one samples were analyzed for foraminifers (plate 7).

Samples recovered from $\mathrm{LBCH}$ are Pleistocene in age, and portions of the Wheelerian and Hallian Stages are present (fig. 43). Faunas diagnostic of the Wheelerian Stage were identified between 352.5 and $285.5 \mathrm{~m}$ (Mf1 1061-Mf11042). The fauna in this interval is dominated by Cibicides mckannai suppressus, Epistominella pacifica, various species of Cassidulina, and Uvigerina juncea. Species common to the early Hallian also are present, but are not abundant. The Hallian/Wheelerian Stage boundary is between 282.7 and 274.4 m (Mf1 1041-Mf1 1042) based on the LO of Cibicides mckannai suppressus. The last abundant occurrence of Epistominella pacifica, which typically identifies this boundary, occurs slightly lower at $285.5 \mathrm{~m}$ (Mf1 1044). The last abundant occurrence of Cassidulina limbata and C. tortuosa at $165.3 \mathrm{~m}$ (Mf1 1038) marks the top of the early Hallian Stage (fig. 43). Praeglobobulimina affinis, Trifarina angulosa, and Uvigerina juncea are consistent components of the fauna in this interval.

The upper part of $\mathrm{LBCH}$ is dominated by sands that yield only sparse benthic foraminiferal faunas. The interval from 132.3 to $41.0 \mathrm{~m}$ (Mf 11036-Mf11008) is assigned to the Hallian Stage (fig. 43). This interval is dominated by shallow-water species, Buliminella elegantissima, Buccella frigida, and various Elphidium and Nonionella species. Rare occurrences of Epistominella pacifica, Cibicides fletcheri, and Uvigerina peregrina in this interval suggest reworking of older material.

\section{Geochronology}

\section{Paleomagnetism}

Samples for paleomagnetic stratigraphy were collected to a maximum depth of $352.6 \mathrm{~m}$. Sampling was concentrated in the fine-grained deposits of the Dominguez, Harbor, Bent Spring, and lower Wilmington units. Coarse sands comprise much of the upper Wilmington unit, which was sampled sparsely. The Mesa and Pacific units are absent owing to erosion at the crest of the 

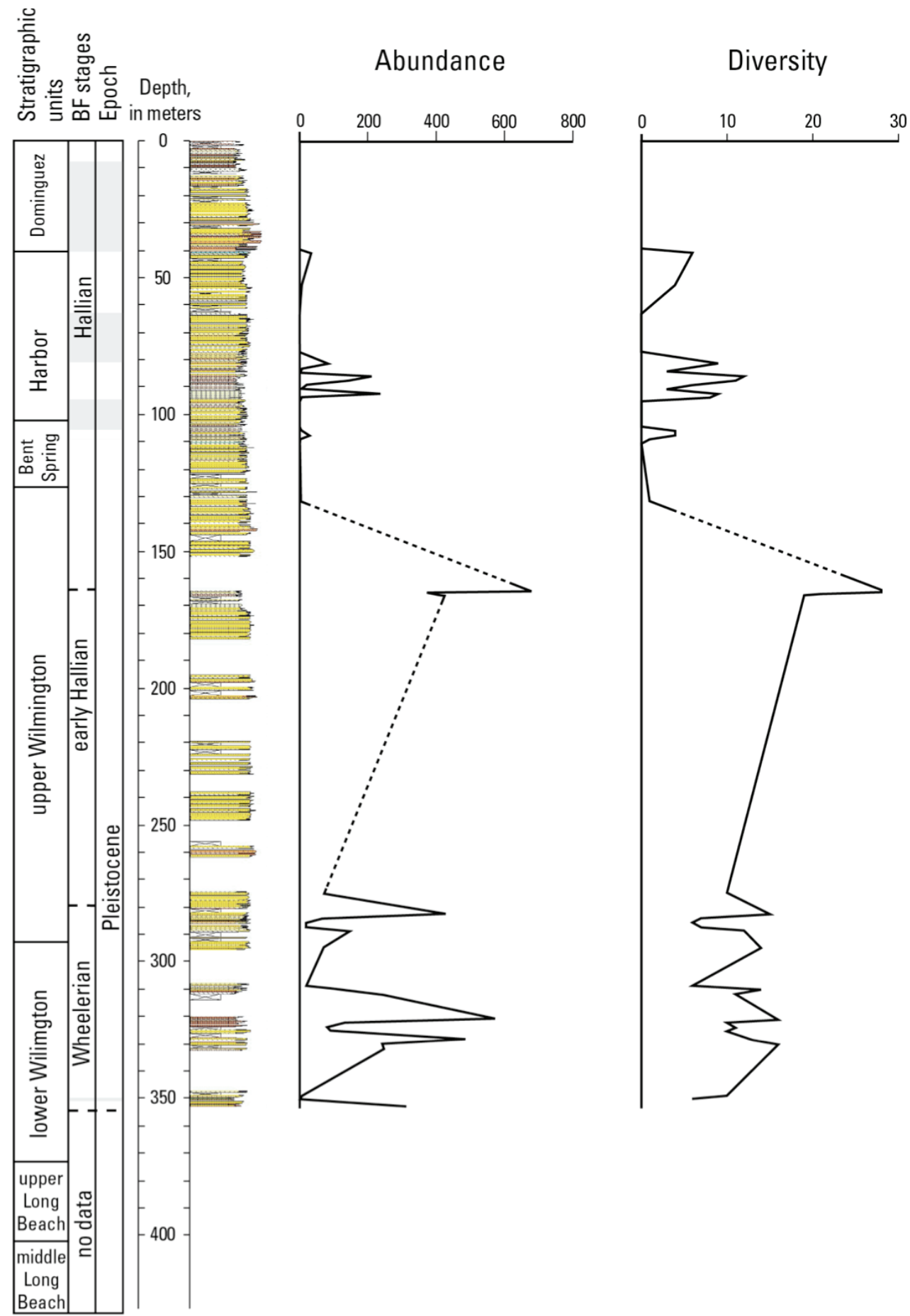

EXPLANATION

Barren

BF stages Benthic foraminiferal stages

Figure 42. Abundance and diversity of the foraminiferal fauna in Long Beach Cabrillo High School core site and monitoring well, Long Beach, California. Abundance of the foraminifers is based on the number of foraminiferal specimens present in the sample. Diversity is the number of species identified in the sample. Stratigraphic units are identified in the left column, and lithologies are indicated on the stratigraphic column by color (clay, green; silt, brown; sand, yellow) (Ponti and others, 2007). Foraminiferal-age interpretations are discussed in the text. 


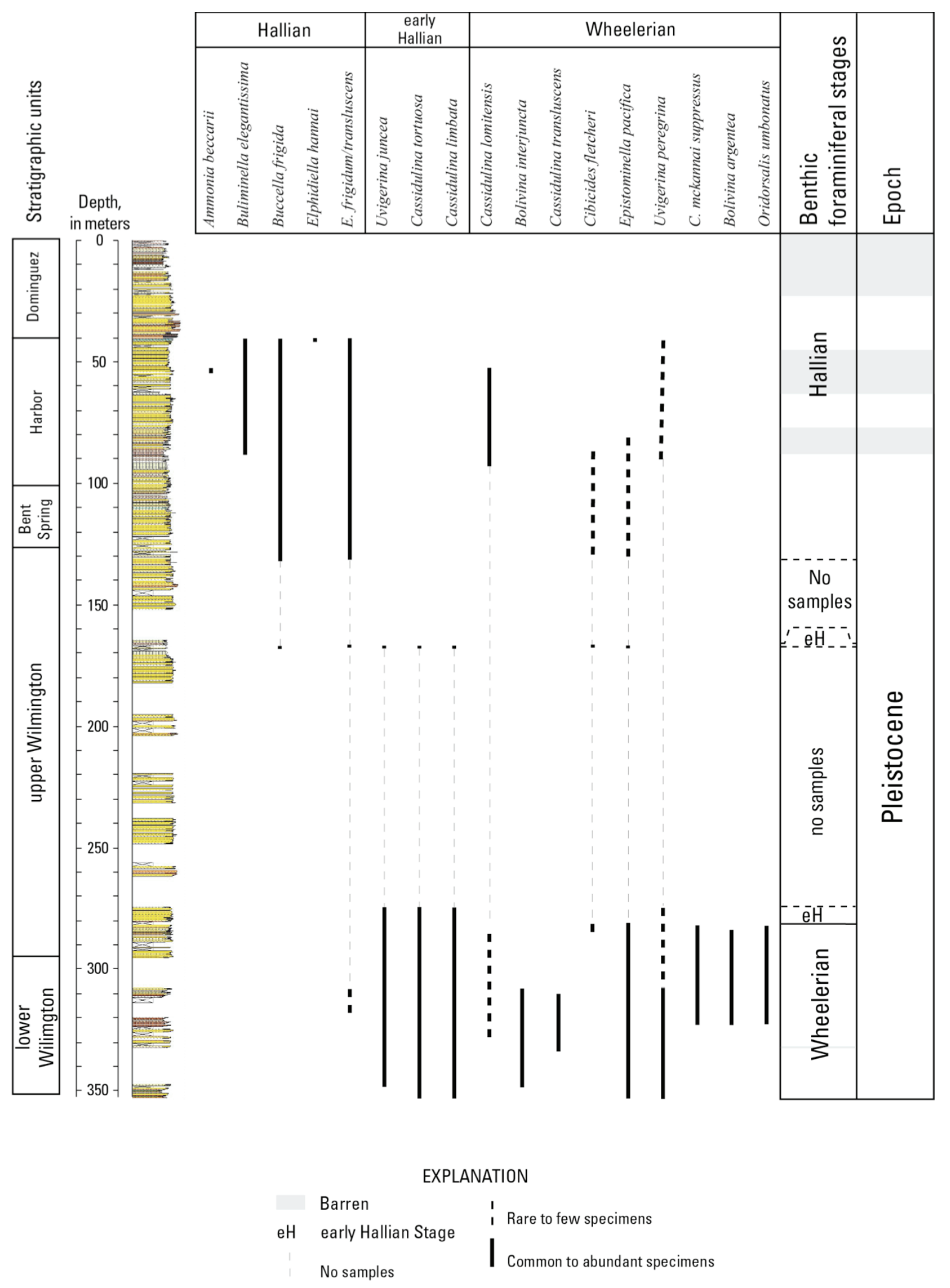

Figure 43. Stratigraphic distribution of age-diagnostic benthic foraminifers in Long Beach Cabrillo High School core site and monitoring well, Long Beach, California. Stratigraphic units are identified in the left column, and lithologies are indicated on the stratigraphic column by color (clay, green; silt, brown; sand, yellow) (Ponti and others, 2007). 
Wilmington anticline. Intensity of NRM, resistance to alternating-field demagnetization, and magnetic susceptibility are listed in appendix III, table 10. The low intensity that occurs in the lower Harbor and upper Bent Spring units correlates with low magnetic susceptibility (Carkin and Edwards, oral commun., 2006) (fig. 44). This correlation indicates that reduced magnetic-mineral concentration, rather than a past interval of decreased geomagnetic-field strength, occurs in the Harbor-Bent Spring interval.

Table 10. Intensity of remanent magnetization and magnetic susceptibility of Long Beach Cabrillo High School core site and monitoring well (LBCH), Long Beach, California, samples. [Title of table is included here for continuity; complete table is in appendix III.]

Alternating-field demagnetization of the $\mathrm{LBCH}$ specimens was carried to a maximum setting of $50 \mathrm{mT}$, with optimum treatment typically occurring between 10 and $30 \mathrm{mT}$. High-quality results, as defined by good isolation of stable magnetization $\left(\mathrm{MAD}<10^{\circ}\right.$ ), were obtained from 56 percent of the specimens. The resultant inclinations from all specimens are listed in appendix III, table 11. Inclinations generally are positive (normal polarity), with the exceptions of three thin intervals having negative inclinations (fig. 44). The Harbor unit contains two of these negative inclination excursions - $(\mathrm{H})$ at 65-70 $\mathrm{m}$ and (D) at $96 \mathrm{~m}$. The third reversed-polarity horizon occurs at $247.9 \mathrm{~m}$ (labeled F, fig. 44) in the lower part of the upper Wilmington unit. Validity of excursion $(F)$ is questionable because the demagnetization path of specimen $2 \mathrm{H} 121$ shows removal of a negative-inclination component rather than the expected positive inclination of the recent magnetic field. Therefore, excursion (F) likely is an artifact of orientation error. Upper excursions (H) and (D) appear to be valid manifestations of geomagnetic-field behavior, based on examination of the demagnetization paths.

Table 11. Paleomagnetic results for Long Beach Cabrillo High School core site and monitoring well (LBCH), Long Beach, California. [Title of table is included here for continuity; complete table is in appendix III.]

The dominantly normal-polarity $\mathrm{LBCH}$ inclination record is consistent with deposition of Brunhes age (fig. 8). We see no evidence of the Matuyama chron, the most recent sustained interval of reversed geomagnetic polarity that ended $0.78 \mathrm{Ma}$. Excursion (D), just above the Bent Spring-Harbor contact at $96 \mathrm{~m}$ is matched by a similar feature in LBPF. This inclination anomaly is in a stratigraphic position compatible with the Pringle Falls event near $200 \mathrm{ka}$ (fig. 8). Excursion $(\mathrm{H})$, which occurs in the middle of the Harbor unit, was not found in the other Long Beach cores.

\section{Optically Stimulated Luminescence and Thermal Luminescence Dating}

Seven samples were initially chosen for TL dating, but the last sample, at $321.4 \mathrm{~m}$ (LBCH176), was considered too deep or old for reliable TL or OSL ages to be obtained (table 12). Depths of the samples that were dated ranged from 3.6 to $170.6 \mathrm{~m}$ and both OSL and TL were attempted for every sample, except the top sample. Sample LBCH-3C (3.6 m) was not analyzed for TL.

Figure 45 shows a sensitivity-corrected quarts OSL growth curve for the sample at $41.6 \mathrm{~m}$ (LBCH-42), as well as a decay curve. The corrected OSL growth curve is linear in the dose range 0 to about 25 Gray (Gy) (in the figure as mid-way between the 0 and 400 seconds), and then becomes increasingly nonlinear to $50 \mathrm{~Gy}$ and can be best fitted with an exponential function. The observation that the OSL can be fitted with an exponential function suggests that the OSL signal might be reaching saturation for the luminescence centers earlier than seen in previous wells. Because the sample at $41.6 \mathrm{~m}(\mathrm{LBCH}-42)$ represents the end of late Pleistocene fill, and the next sample (LBCH-58, $63.6 \mathrm{~m}$ ) lies within the much older Harbor unit (Ponti and others, 2007), other 


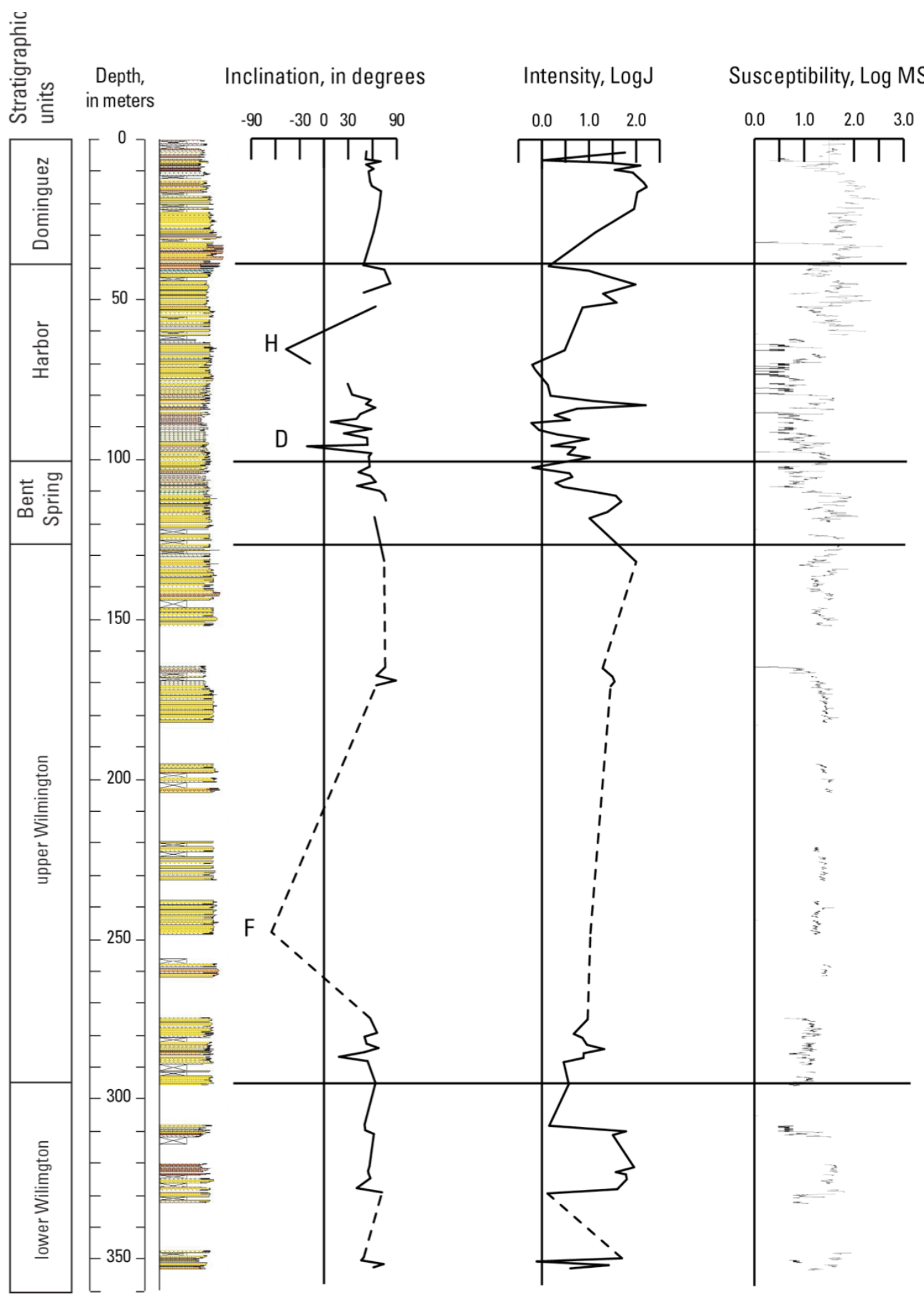

Figure 44. Remanent magnetization (inclination and intensity) properties and magnetic susceptibility of Long Beach Cabrillo High School core site and monitoring well, Long Beach, California. Inclination is measured in degrees. Intensity is depicted with a logarithmic scale where 0.0 equals 1 milliAmpere $/ \mathrm{m}$. Magnetic susceptibility also is given with a logarithmic scale, where 0.0 equals 10-6 SI. Magnetic excursions are marked H, D, and F. Stratigraphic units are identified in the left column, and lithologies are indicated on the stratigraphic column by color (clay, green; silt, brown; sand, yellow) (Ponti and others, 2007).

quartz OSL (LBCH-77 and LBCH-124, 91.0 and $170.6 \mathrm{~m}$, respectively) should be considered severe age underestimations (table 12). The ages given for the top three samples in this well (LBCH-3, LBCH-17, and LBCH-42) are deemed to be reliable, however, and agree well with feldspar IRSL ages (table 12). 


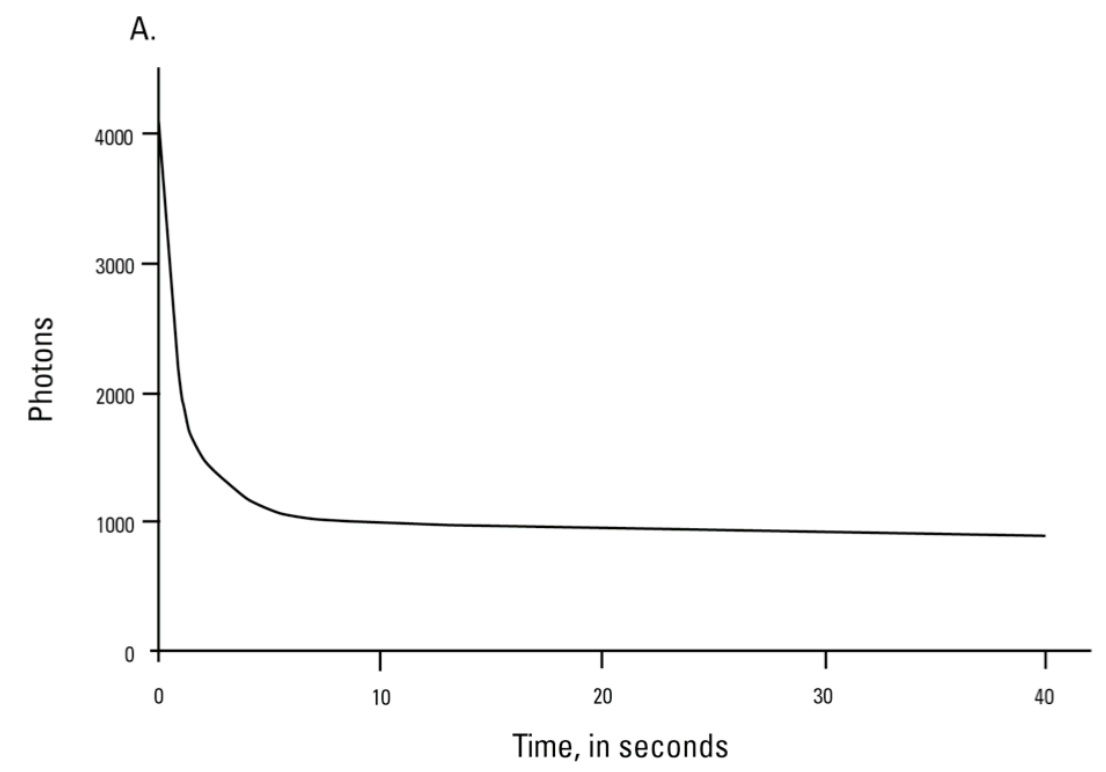

B.

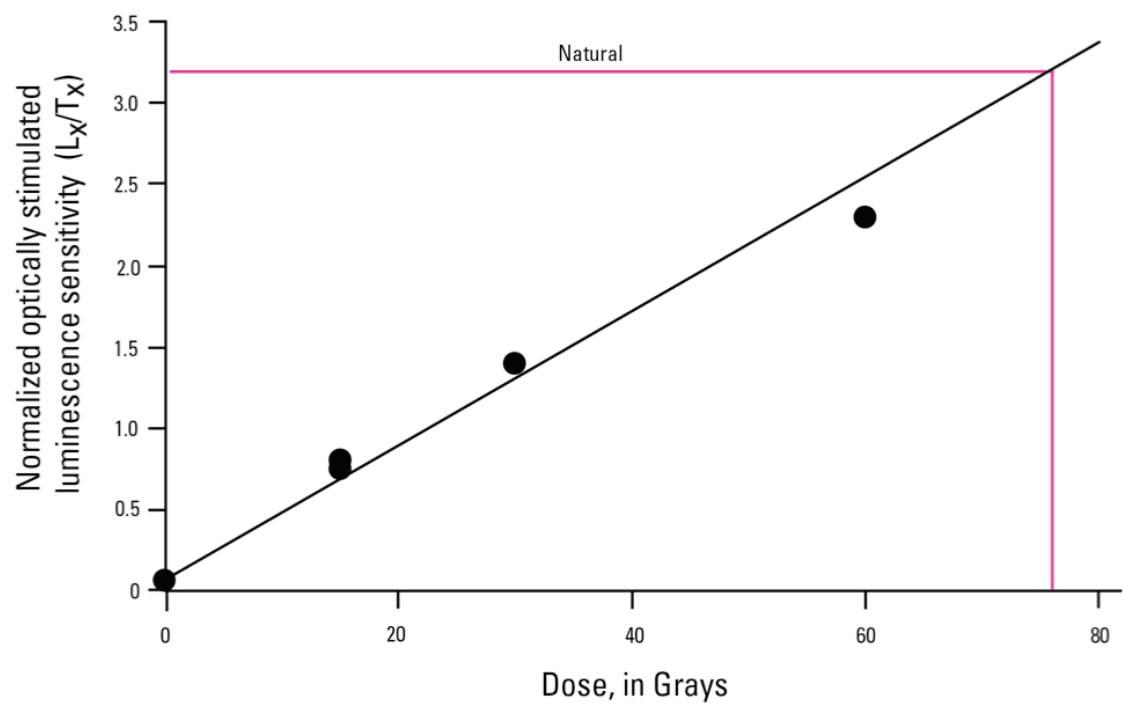

Figure 45. A. Optically stimulated luminescence (OSL) decay curve for LBCH-42C (41.6 m) showing the quartz signal as measured with blue-light wavelength emitting diodes. Time is measured in seconds (s) and OSL is measured in photon counts for a total time of $40 \mathrm{~s}$. B. LBCH-42C growth curve, with the natural plotted on the $\mathrm{Y}$ axis. Regeneration proceeded "optimally" with a recycle within 2 percent of the first measurement; circles indicate increases in response to increasing beta radiation. Fit is to a linear function. Dose is measured in Grays (Gy, absorbed radiation), and OSL is measured in unitless normalized OSL sensitivity measurements (Lx/Tx).

Figure 46 shows the feldspar IRSL-OSL growth curve for the sample at $41.6 \mathrm{~m}$ (LBCH-42). Unlike the quartz OSL, this growth curve is linear to the dose range 0 to about $200 \mathrm{~Gy}$, and the TL analysis for the same sample is within error of the IRSL analysis. The feldspar ages are, again, slightly older than the quartz ages for the sample at $41.6 \mathrm{~m}$ ( $\mathrm{LBCH}-42)$ (table 13), but replicate ages for the sample at $15.1 \mathrm{~m}$ (LBCH-17). The deeper, older samples have only feldspar IRSL and TL ages. While the quartz OSL displayed considerable age underestimation for other samples within the Harbor unit (see LBPF and LBPC), the IRSL ages appear to be correctly estimating the age of deposition. 
Table 12. Thermoluminescence (TL), feldspar infrared stimulated luminescence (IRSL) and quartz blue-light optically stimulated luminescence (OSL) ages for the Long Beach Cabrillo High School core site and monitoring well (LBCH), Long Beach, California.

$[\%$, percent; ka, thousands of years; Gy, Grays; >, greater than; -, no data]

\begin{tabular}{|c|c|c|c|c|c|c|c|c|}
\hline $\begin{array}{c}\text { Sample } \\
\text { information } \\
\text { core depth }(\mathrm{m}) \text { : } \\
\text { material }\end{array}$ & $\begin{array}{c}\text { Moisture } \\
(\%)^{\mathrm{a}}\end{array}$ & $\begin{array}{c}\text { TL/IRSL } \\
\text { dose rate } \\
\text { (Gy/ka) }\end{array}$ & $\begin{array}{l}\text { Equivalent } \\
\text { dose } \\
\text { (Gy) }\end{array}$ & $\begin{array}{c}\text { TL/IRSL age } \\
\text { (ka) }\end{array}$ & $\mathrm{n}^{\mathrm{c}}$ & $\begin{array}{c}\text { Quartz dose } \\
\text { rate } \\
\text { (Gy/ka) }\end{array}$ & $\begin{array}{l}\text { Equivalent } \\
\text { dose } \\
\text { (Gy) }\end{array}$ & $\begin{array}{c}\text { Quartz age } \\
\text { (ka) }\end{array}$ \\
\hline $\begin{array}{l}\text { LBCH-3 } \\
\text { 3.6: Silt }\end{array}$ & $22(48)$ & $3.96 \pm 0.09$ & $5.74 \pm 0.60$ & $1.45 \pm 0.15$ & $\begin{array}{l}13 \\
(28)\end{array}$ & $2.84 \pm 0.07$ & $2.65 \pm 0.29$ & $0.93 \pm 0.21$ \\
\hline $\begin{array}{l}\text { LBCH-17 } \\
\text { 15.1: Silt }\end{array}$ & $26(47)$ & $3.31 \pm 0.07$ & $\begin{array}{l}8.61 \pm 0.59 \\
10.8 \pm 2.59 \\
(\mathrm{TL}) \\
\end{array}$ & $\begin{array}{l}2.60 \pm 0.19 \\
3.27 \pm 0.79 \\
(\mathrm{TL}) \\
\end{array}$ & $5(25)$ & $2.44 \pm 0.05$ & $7.92 \pm 0.48$ & $3.25 \pm 0.21$ \\
\hline $\begin{array}{l}\text { LBCH-42 } \\
\text { 41.6: Fine } \\
\text { sand }\end{array}$ & $19(34)$ & $4.23 \pm 0.10$ & $\begin{array}{l}156 \pm 2.56 \\
164 \pm 5.92 \\
(\mathrm{TL})\end{array}$ & $\begin{array}{l}36.9 \pm 0.99 \\
53.7 \pm 2.17 \\
(\mathrm{TL})\end{array}$ & $\begin{array}{l}22 \\
(36)\end{array}$ & $3.06 \pm 0.08$ & $84.7 \pm 7.08$ & $27.7 \pm 2.22$ \\
\hline $\begin{array}{l}\text { LBCH-58 } \\
\text { 63.6: Sand }\end{array}$ & $14(23)$ & $3.39 \pm 0.06$ & $\begin{array}{l}852 \pm 43.6 \\
939 \pm 105 \\
(\mathrm{TL})\end{array}$ & $\begin{array}{l}251 \pm 13.6 \\
279 \pm 63.3 \\
(\mathrm{TL})\end{array}$ & - & $2.66 \pm 0.05$ & - & - \\
\hline $\begin{array}{l}\text { LBCH-77 } \\
\text { 91: Sandy Silt }\end{array}$ & $24(41)$ & $4.51 \pm 0.09$ & $\begin{array}{l}1,236 \pm 161 \\
(\mathrm{TL})\end{array}$ & $\begin{array}{l}274 \pm 36 \\
(\mathrm{TL})\end{array}$ & $\begin{array}{l}25 \\
(25)\end{array}$ & $3.00 \pm 0.06$ & $>>164 \pm 8.20$ & $>>54.6 \pm 2.98$ \\
\hline $\begin{array}{l}\text { LBCH-124 } \\
\text { 170.6: Sand }\end{array}$ & $23(40)$ & $2.97 \pm 0.05$ & $\begin{array}{l}>1,500 \pm 225 \\
(\mathrm{TL})\end{array}$ & $\begin{array}{l}>505 \pm 90 \\
(\mathrm{TL})\end{array}$ & $9(10)$ & $2.27 \pm 0.04$ & $>>133 \pm 33.3$ & $>>58.3 \pm 15.8$ \\
\hline
\end{tabular}

${ }^{a}$ Field moisture, possible saturated moisture content in parentheses; ages based on 20-40 percent moisture content through time.

${ }^{\mathrm{b}}$ Silt fraction (4-11 micron size) for TL and IRSL as multiple aliquot additive dose technique (MAAD). Fitted with an exponential function.

${ }^{\mathrm{c}}$ Number of replicated equivalent dose (De) estimates used to calculate the mean. Figures in parentheses indicate total number of measurements made including failed runs with unusable data.

${ }^{\mathrm{d}}$ Lab used fine sand grains (125-90 micron size) for quartz OSL as single aliquot regeneration technique (SAR). Fitted to a linear regression. Errors on equivalent dose and dose rate data at one sigma. Errors on ages at two sigma were calculated before rounding.

Dose rates for these samples ranged from 2.97 to $4.51 \mathrm{~Gy}$ (TL/IRSL) and from 2.27 to 3.00 Gy (Quartz OSL). These dose rates are not considered to be especially large and should not be the cause for large amounts of unstable luminescence. The dose rates, as calculated from elementaldata analyses, closely track other dose rates obtained for other well samples (that is, LWEB, LBPC, LBPF, and LBCC). The IRSL curves were fit with a single saturating exponential function, but probably still underestimate the value of the equivalent dose when attempting to project beyond $500 \mathrm{~Gy}$ (or for samples older/deeper than LBCH-58 at $63.6 \mathrm{~m}$ ). Our lack of success with other well samples, owing to saturation of the luminescence signal after about $160 \mathrm{~Gy}$ for the quartz OSL and $300 \mathrm{~Gy}$ for the feldspar IRSL, led us to believe only TL dating on the samples deeper in the well than LBCH-58 $(163.6 \mathrm{~m})$ would yield acceptable results. No further speculation for this OSL saturation is given here, except that inadequate preheating of the samples does not seem to be a cause for sublinearity (Richardson and others, 1997) or age shortfalls. At ages greater than $100 \mathrm{ka}$, 


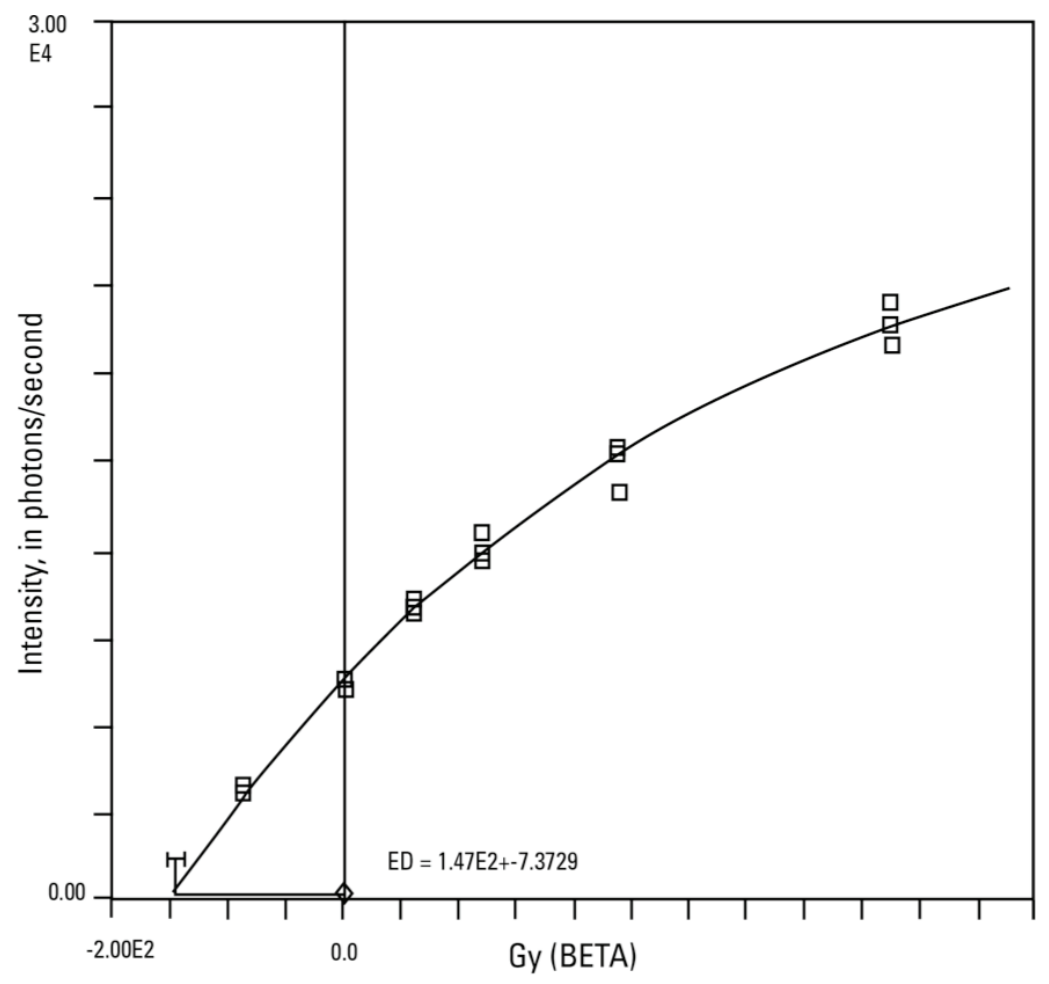

Figure 46. IRSL growth curve for a multi-aliquot additive dose method (MAAD) for LBCH-42C at $41.6 \mathrm{~m}$. Bleaches are denoted with diamonds (near bottom of the figure), naturals sit on the $\mathrm{X}$ axis as squares, and increasing beta-radiated aliquots (four sets of four squares) are shown fitted to an exponential curve, which passes through the naturals and an intercept of the bleaches to obtain the equivalent dose calculation. The $X$ axis shows the measured equivalent dose in Grays (Gy) when compared to calibrated Grays generated by exposure to a beta source. The $Y$ axis shows the intensity of light emitted from the aliquots and is measured in photons/second.

it is probably not possible to date these sediments accurately using OSL, and it is possible that the feldspar ages for $\mathrm{LBCH}-58(63.6 \mathrm{~m})$ and $\mathrm{LBCH}-77(91.0 \mathrm{~m})$ are also underestimates.

TL dating was attempted on all the well samples, except for the very young LBCH-3C (3.6 $\mathrm{m})$. The saturation level for TL was not clearly attained until LBCH-124, which was at a depth of $170.6 \mathrm{~m}$. Further work using TL was abandoned, and LBCH-176 records only a gross minimum age of $>505 \mathrm{ka}$. Unlike other sediment ages, the TL ages closely track the quartz OSL and the feldspar IRSL ages (table 13), at least for the first three samples. Although we know that TL does not reset as quickly as OSL does (Wallinga, 2002) and often requires many hours of exposure (>6 hours) to sunlight to "zero", the erosional-sediment fill of the late Pleistocene unit was thoroughly exposed to sunlight before being redeposited, as evidenced by the matching quartz OSL, IRSL, and TL data.

The TL ages from samples at 91.0 and $63.6 \mathrm{~m}$ (LBCH-77 and LBCH-58) are within error of each other, even though they are separated by almost $27 \mathrm{~m}$ of sediment ( $279 \pm 63 \mathrm{ka}$ versus $274 \pm 36$ $\mathrm{ka})$. The TL age for the sample at $63.6 \mathrm{~m}$ ( $\mathrm{LBCH}-58)$ has a large error (almost 25 percent), while the sample at $91 \mathrm{~m}$ (LBCH-77) has a smaller error (almost 15 percent), so the TL may simply be recording a minimum age and reaching a saturation level or 2) the TL age at $63.6 \mathrm{~m}(\mathrm{LBCH}-58)$ is at the younger end of the error ( 250 to $230 \mathrm{ka}$ ), which would match the IRSL age (table 12), and the TL age at $91 \mathrm{~m}$ ( $\mathrm{LBCH}-77)$ is at the older end of the error range ( $\sim 300 \mathrm{ka})$. The Pringle Falls event (200 ka) was recorded at $96 \mathrm{~m}$ (just below the ages), and the last appearance of the macrofossil, Chione $(\geq 116 \mathrm{ka})$ occurs at $62.5 \mathrm{~m}$, complicating these explanations. 
Table 13. Elemental concentrations and associated dosimetry for Long Beach Cabrillo High School core site and monitoring well (LBCH), Long Beach, California, optically stimulated luminescence (OSL) samples.

[\%, percent; ppm, parts per million; $\mathrm{m}$, meter; $\mathrm{D}_{\mathrm{r}}$, dose rate; $\mathrm{K}$, Potassium; $\mathrm{U}$, Uranium; Th, Thorium; Rb, Rubidium; -, no data]

\begin{tabular}{|c|c|c|c|c|c|c|c|c|c|c|c|c|}
\hline $\begin{array}{l}\text { Sample } \\
\text { number }\end{array}$ & $\begin{array}{l}\mathrm{K} \\
(\%)\end{array}$ & $\begin{array}{c}\mathrm{U} \\
\text { (ppm) }\end{array}$ & $\begin{array}{c}\text { Th } \\
\text { (ppm) }\end{array}$ & $\begin{array}{c}\text { Depth } \\
(\mathrm{m})\end{array}$ & $\begin{array}{c}\text { Water } \\
(\%)\end{array}$ & $\begin{array}{c}D_{r} \\
\text { fine } \\
\text { grain }\end{array}$ & $\begin{array}{c}\mathrm{D}_{\mathrm{r}} \\
\text { coarse } \\
\text { grain }^{\mathrm{a}}\end{array}$ & $\begin{array}{c}D_{r} \\
\text { for } K\end{array}$ & $\begin{array}{c}D_{r} \\
\text { for U }\end{array}$ & $\begin{array}{l}D_{r} \\
\text { for } \\
\text { Th }\end{array}$ & $\begin{array}{l}D_{r} \\
\text { for } \\
R b\end{array}$ & $\begin{array}{c}D_{r} \\
\text { for } \\
\text { cosmic } \\
\text { ray } \\
\end{array}$ \\
\hline LBCH-3C & 2.57 & 2.46 & 10.80 & 3.6 & 40 & 3.96 & 2.84 & 1.846 & 0.859 & 1.087 & 0.034 & 0.131 \\
\hline LBCH-17C & 2.46 & 1.88 & 8.26 & 15.1 & 40 & 3.31 & 2.44 & 1.767 & 0.657 & 0.831 & 0.033 & 0.027 \\
\hline LBCH-42C & 2.51 & 1.92 & 9.60 & 41.6 & 20 & 4.23 & 3.06 & 2.190 & 0.813 & 1.167 & 0.040 & 0.019 \\
\hline LBCH-58C & 2.48 & 0.98 & 5.91 & 63.6 & 20 & 3.39 & 2.66 & 2.144 & 0.436 & 0.749 & 0.040 & 0.010 \\
\hline LBCH-77C & 2.35 & 3.41 & 15.70 & 91.0 & 30 & 4.51 & 3.00 & 1.688 & 1.191 & 1.580 & 0.031 & 0.010 \\
\hline LBCC-124C & 2.09 & 1.67 & 7.2 & 171 & 35 & 2.97 & 2.27 & 1.565 & 0.610 & 0.751 & 0.029 & 0.005 \\
\hline LBCC-176C & 1.96 & 1.01 & 5.83 & 322 & 40 & 2.39 & 1.59 & 1.418 & 0.353 & 0.585 & 0.026 & 0.001 \\
\hline
\end{tabular}

${ }^{a}$ Coarse grains used for quartz OSL have the alpha component and about 10 percent beta component of the dosimetry etched away before analyses.

\section{Paleoecology}

\section{Benthic Foraminifers}

The LBCH well records a gradual decrease in water depths from the late Wheelerian upper middle bathyal or lower slope depths near $500 \mathrm{~m}$ to the late Hallian inner neritic depths of less than $50 \mathrm{~m}$ (fig. 47). Sparse sampling does not permit recognition of unconformities, which are evident in the other wells.

Bathymetric biofacies analysis indicates that the Wheelerian faunas $(352.5-282.7 \mathrm{~m}$, Mf1 1061-Mf1 1042) were deposited at upper middle bathyal biofacies depths (water depths of $500-1,500 \mathrm{~m})$ at the base and shallowed to the upper bathyal biofacies depths $(150-500 \mathrm{~m})$ near the top of the interval. Borderland biofacies analysis indicates that upper slope $(85-450 \mathrm{~m})$ and lower slope (400-950 m) biofacies species are more common at the base of the Wheelerian interval, but the bank facies (50-200 m) dominate the upper part of this interval. The occurrence of Epistominella pacifica and Uvigerina senticosa in several samples in this interval indicate that Pacific Intermediate water entered this basin. Faunas indicate dissolved-oxygen levels were high.

Biofacies analysis of the early Hallian, 274.4-165.3 m (Mf11041-Mf11038), indicates deposition occurs in the outer neritic/bank biofacies but water depths shallow up section. The oldest samples in the early Hallian were deposited in the upper bathyal/bank biofacies (150-200 m) based on the common occurrences of Cassidulina tortuosa, C. transluscens, and Uvigerina peregrina. Many of the samples in this interval contain low oxygen species, such as Praeglobobulimina affinis and Loxostomum bradyi, which suggest that at least the bottom water was dysoxic.

Biofacies analyses suggests that the base of the Hallian Stage interval, 132.3 to $41.0 \mathrm{~m}$ (Mf 11036-Mf1 1008) was deposited in the outer neritic biofacies (50-150 m) based on the presence of Cassidulina lomitensis from 132.3 to $52.6 \mathrm{~m}$ (Mf11036-Mf1 1009), and Praeglobobulimina affinis and Trifarina angulosa from 132.3 to $81.6 \mathrm{~m}$ (Mf11036-Mf11016). Inner neritic biofacies (0-50 $\mathrm{m}$ ) is indicated by $41.0 \mathrm{~m}$ (Mf1 1008). Borderland biofacies analysis does not recognize an inner shelf facies but it does suggest that deposition of these samples was in the outer shelf or bank biofacies $(50-200 \mathrm{~m})$. 

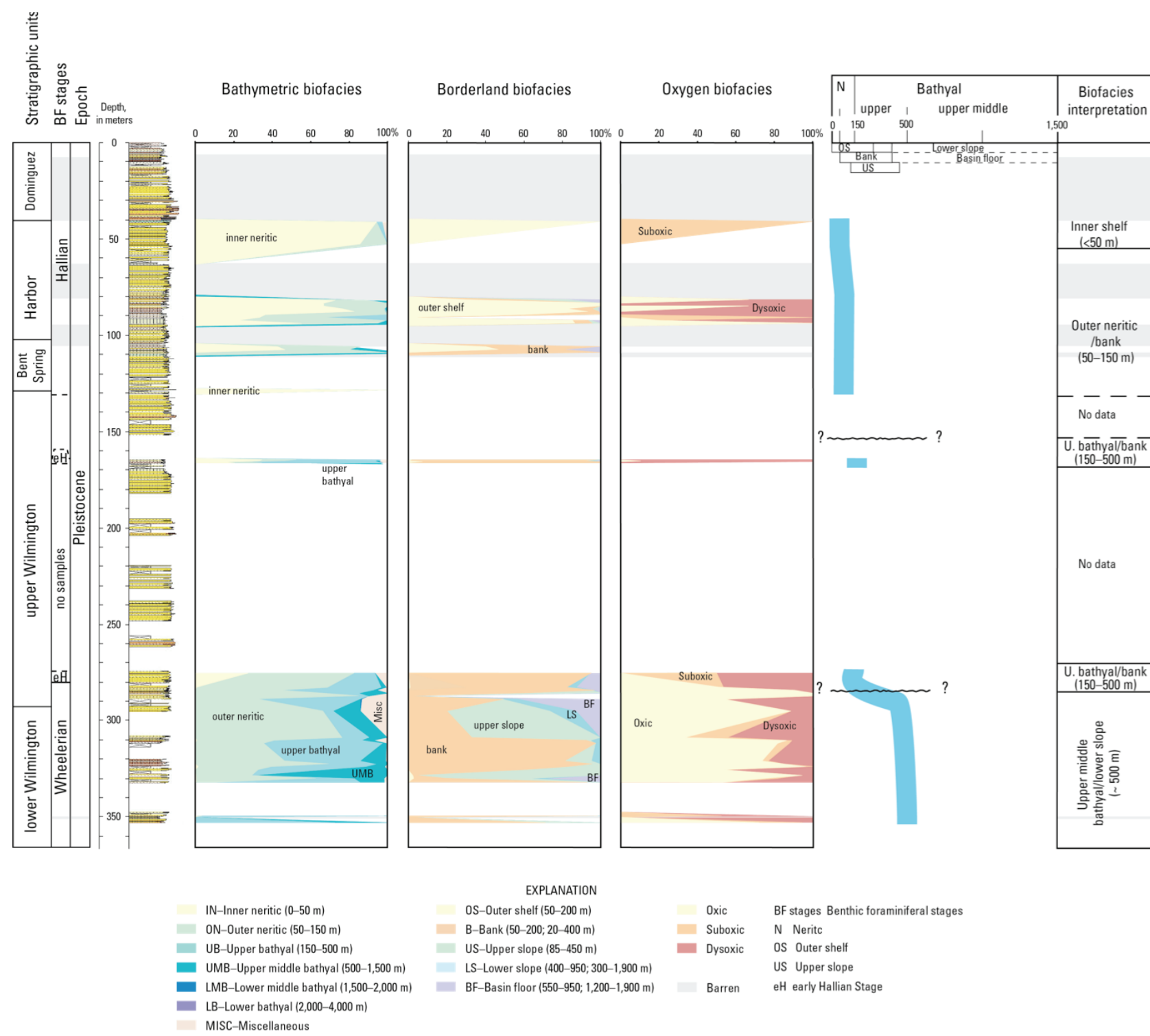

Figure 47. Paleoecological benthic foraminiferal biofacies analysis of Long Beach Cabrillo High School core site and monitoring well, Long Beach, California. The three biofacies analyses discussed in the text are based on the abundance of benthic foraminifers in the samples. The bathymetric curve represents the most probable depth at which the samples were deposited. Stratigraphic units are identified in the left column, and lithologies are indicated on the stratigraphic column by color (clay, green; silt, brown; sand, yellow) (Ponti and others, 2007). [Reduced-size figure is shown here for continuity; full-size figure is included on plate 18.]

\section{Macrofossils}

Forty-one samples containing remains of mollusks, arthropods, and echinoids were obtained from LBCH . All but four of the samples were found in situ. Samples from LBCH contain 41 mollusk taxa (indeterminate fragments, 24 bivalves, 16 gastropods, and one scaphopod) two arthropods, and two echinoids, and two vertebrate remains (plate 8). Extinct species are not present in this well.

The assemblage of mollusks at $110.4 \mathrm{~m}$ (LBCH 90, C-1, 67-78 m) and $87.6 \mathrm{~m}$ (LBCH 75, $\mathrm{C}-1,74-76 \mathrm{~cm}$ ) has overlapping depth-range zones between the intertidal zone and $30 \mathrm{~m}$ (limited by Mysella pedroana, which in both cases is not confidently identified). In addition, the 
assemblage at $87.4 \mathrm{~m}(\mathrm{LBCH} 75, \mathrm{C}-1,52-56 \mathrm{~cm})$ has overlapping depth-range zones from the intertidal zone and $80 \mathrm{~m}$. Further, Lyonsia californica, found at $83.9 \mathrm{~m}$, and Solen cf. $S$.

rostriformis, found at $86.63 \mathrm{~m}$, suggest water depths in the intertidal zone to about $50 \mathrm{~m}$ (Coan and others, 2000). These assemblages are overlain by an assemblage containing the bivalve, Chione, $(62.5 \mathrm{~m})$ which suggests water depths are shallower than about $50 \mathrm{~m}$ (Bernard, 1983) and water temperatures similar to or warmer than today. At $41.1 \mathrm{~m}$, the presence of the gastropod Turritella cooperi, which has a modern depth range from 25 to $100 \mathrm{~m}$, indicates continental-shelf water depths of $100 \mathrm{~m}$ or less.

All the macrofossil samples collected in this well are consistent with continental-shelf water depths, which are here somewhat arbitrarily cited as $\leq 100 \mathrm{~m}$. There is no indication of deeper water depths, although the depth range of some shallow-water mollusks extends into deeper depths. Most macrofauns in $\mathrm{LBCH}$ contain undifferentiated marine species, although key species supporting the shallow-water depths occur throughout this well (fig. 48).

\section{Long Beach Cabrillo High School Core Site and Monitoring Well Summary}

LBCH is Pleistocene in age (fig. 49). Paleomagnetic analysis places the entire section in the Brunhes Normal Polarity Chron and recognizes the Pringle Falls Event (200 ka) at $96 \mathrm{~m}$. Luminescence dates in the upper part of LBCH identify sediments ranging in age from $0.93 \pm 0.21$ ka to $53.7 \pm 2.17 \mathrm{ka}$. Benthic foraminifers indicate the presence of the Hallian, early Hallian, and Wheelerian Stages of the Pleistocene.

Benthic foraminiferal species diagnostic of the Wheelerian Stage last appear at $282.7 \mathrm{~m}$ (Mf11042). Cibicides mckannai suppressa occurs abundantly at the early Hallian/Wheelerian boundary and Epistominella pacifca occurs in abundance below this boundary. The early Hallian is recognized between 274.4 and $165.31 \mathrm{~m}$ (Mf 11041-Mf11038) by the abundance of Cassidulina tortuosa and C. limbata. The Hallian Stage is recognized from 132.32 to $41.0 \mathrm{~m}$ (Mf11036Mf11008).

Magnetic inclination, intensity of remanent magnetization, and magnetic susceptibility were measured in LBCH to a total depth of $353 \mathrm{~m}$. Intensity of remanent magnetization and susceptibility diminish in the upper Bent Spring and Harbor units, which reflects lower concentrations of magnetic minerals either from the source material or chemical dissolution. Paleomagnetic inclinations are generally of normal polarity in $\mathrm{LBCH}$, indicating Brunhes-age sedimentation (younger than $0.78 \mathrm{Ma}$ ). Two inclination anomalies within the Harbor unit are viable indications of geomagnetic-field excursions, the lower of which may correlate with the Pringle Falls Event at $200 \mathrm{ka}$.

The top three samples were selected for luminescence dating based on the assumption that these would all record a Holocene to Late Pleistocene age. The ages returned were indeed very young (top sample LBCH-3 at about 1 to $1.5 \mathrm{ka}$ ) and only as old as about 30 or $40 \mathrm{ka}$ (LBCH-42). Because the TL, quartz, and feldspar OSL ages closely track each other for the three samples, these ages are considered reliable.

Three deeper samples (LBCH-58, LBCH-77, and LBCH-124) produced severe age underestimates for the quartz OSL (table 12), and these OSL ages are not an accurate reflection of depositional history. In comparison, the TL and feldspar IRSL systemstics can and will record longer periods of time since deposition, thus these luminescence methods appear to be returning reasonable age estimates. The IRSL probably is beginning to saturate out for LBCH-58 (63.6 m) (around 800 to $850 \mathrm{~Gy}$ ), based on results obtained for the other wells, and the TL method was used exclusively for the deepest two samples. Even the TL saturated out at the deep sample of LBCH$124(170.6 \mathrm{~m})$ and returned a minimum age of about $505 \mathrm{ka}$. Ponti and others (2007) place this sample within the upper Wilmington unit (tentatively dated between 610-760 ka) and, therefore, 


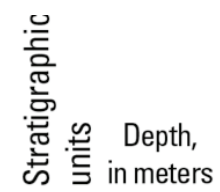

$$
\begin{array}{|l}
\hline \\
\hline
\end{array}
$$
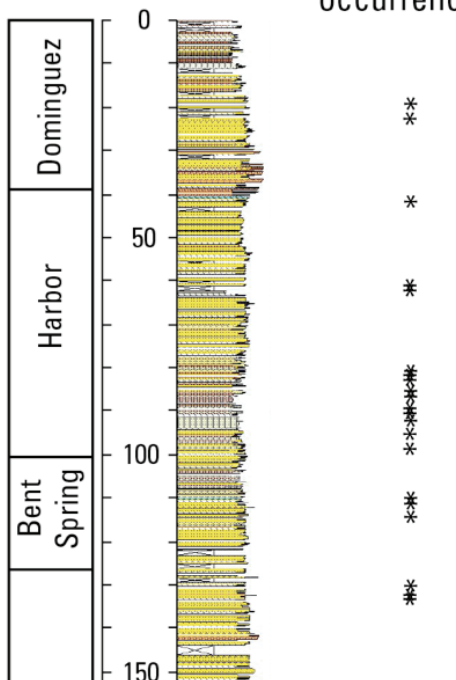

Fossil occurrences

Open marine, inner sublittoral to outer sublittoral water depths

Chione present indicating water temperatures as warm or warmer than modern

Figure 48. Distribution and paleoecologic interpretation of macrofossil samples in the Long Beach Cabrillo High School core site and monitoring well, Long Beach, California. Stratigraphic units are identified in the left column, and lithologies are indicated on the stratigraphic column by color (clay, green; silt, brown; sand, yellow) (Ponti and others, 2007).

this result is not unexpected. The true age for LBCH-58 (63.6 m, upper Harbor unit) probably lies closer to $250 \mathrm{ka}$, and the true age for LBCH-77 (91 m, lower Harbor unit) is more likely to be around $300 \mathrm{ka}$.

The presence of the macrofossil Chione at $62.5 \mathrm{~m}$ indicates an age of $\geq 116 \mathrm{ka}$, and the assignment of the Pringle Falls event at 96 m suggests an age of $200 \mathrm{ka}$. Both these ages are younger than the luminescence ages predicted for LBCH-58 (63.6 m) and LBCH-77 (91 m). 


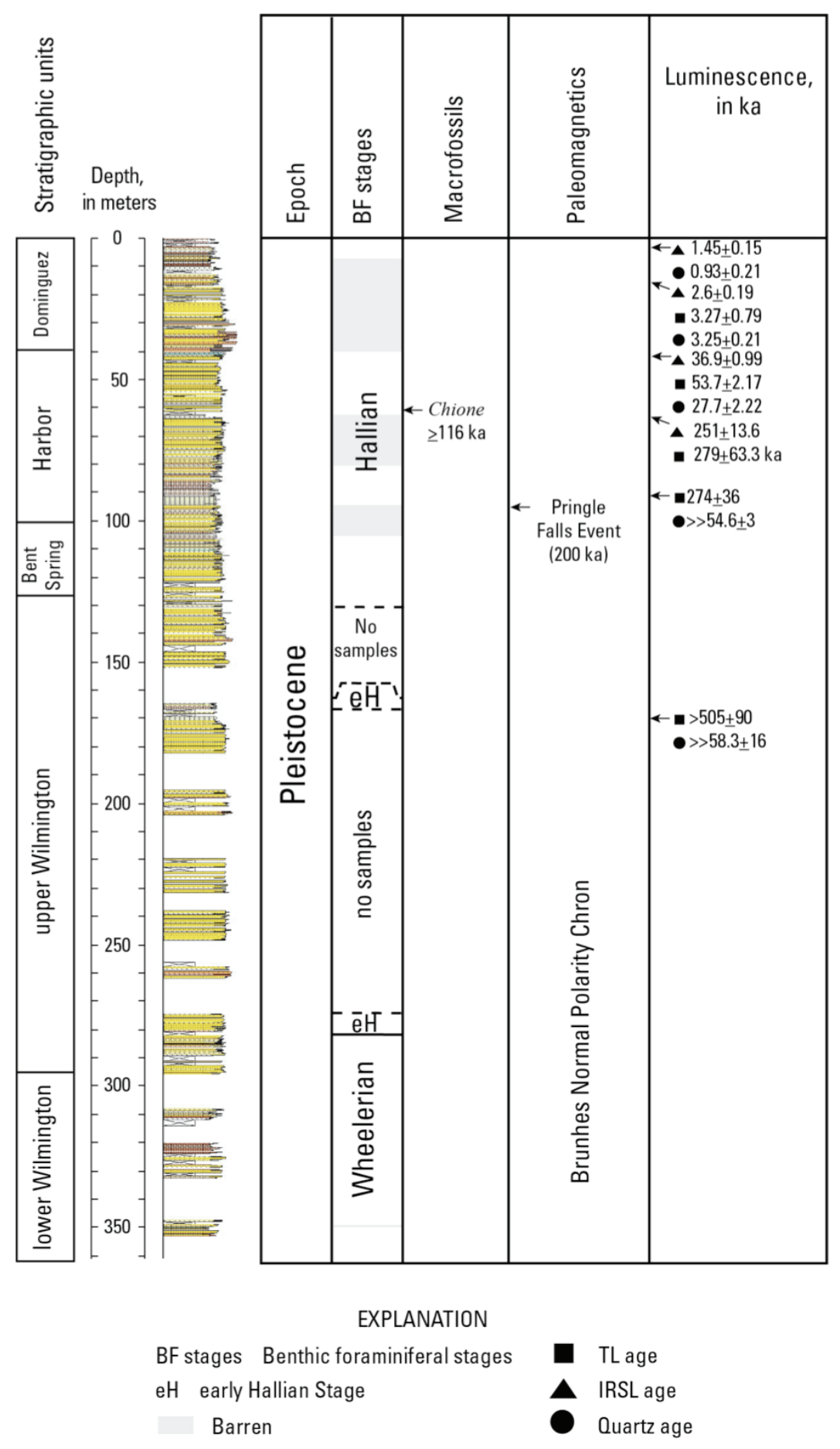

Figure 49. Summary of geochronology of Long Beach Cabrillo High School core site and monitoring well, Long Beach, California, based on the microfossils, macrofossils, paleomagnetics, and luminescence. Stratigraphic units are identified in the left column, and lithologies are indicated on the stratigraphic column by color (clay, green; silt, brown; sand, yellow) (Ponti and others, 2007).

Paleoecologic interpretation of LBCH (fig. 50) indicates deposition of the lower Wheelerian faunas occurred at upper middle bathyal/lower slope biofacies $(500-1,500 \mathrm{~m})$ and shallowed up section to the shallow inner neritic depths $(<50 \mathrm{~m})$ of the Hallian. The bivalve genus Chione, at $62.5 \mathrm{~m}$, indicates water temperatures similar to today, or possibly warmer. 


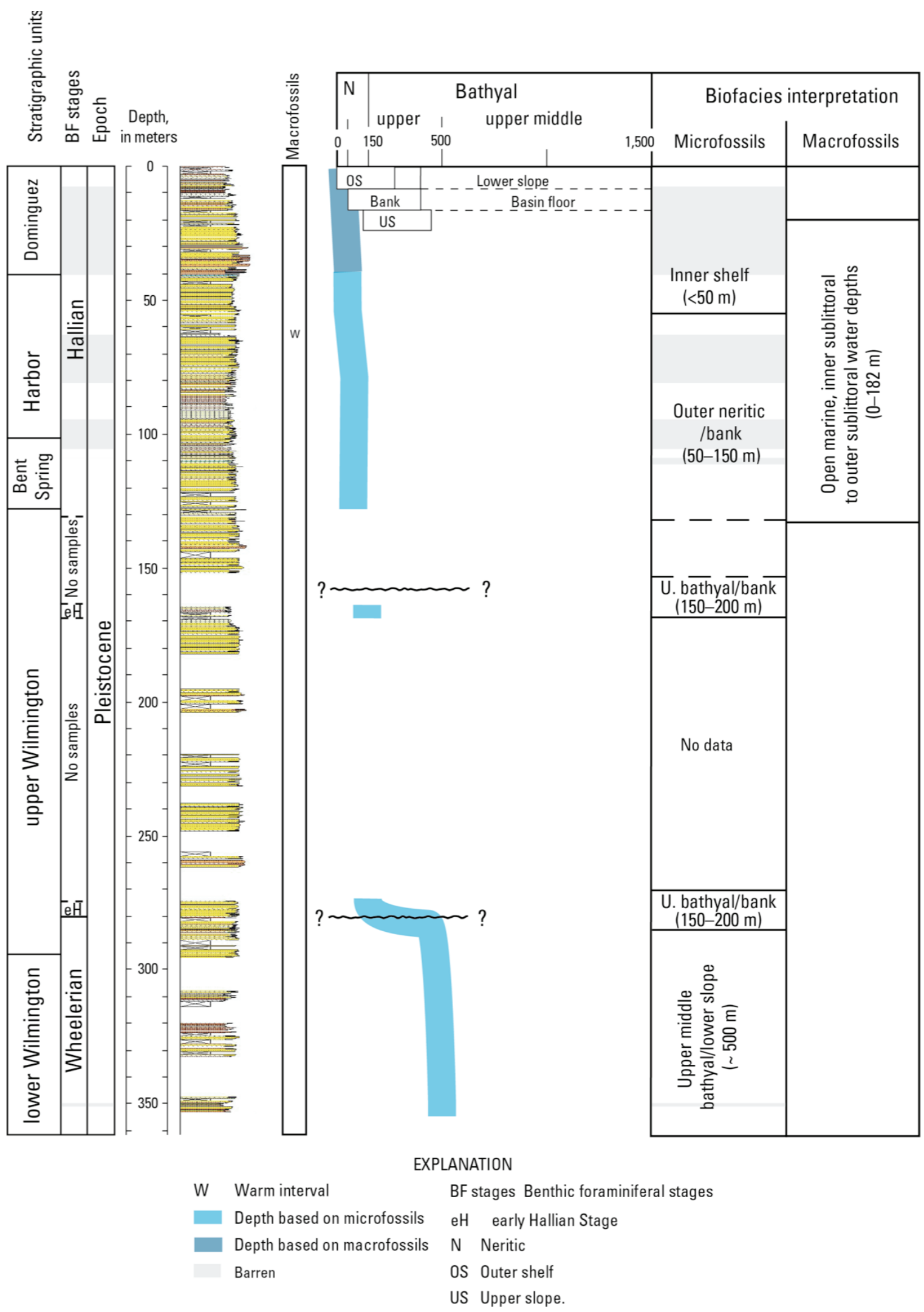

Figure 50. Summary of ecological interpretations on Long Beach Cabrillo High School core site and monitoring well, Long Beach, California, based on benthic foraminifers and macrofossils. Stratigraphic units are identified in the left column, and lithologies are indicated on the stratigraphic column by color (clay, green; silt, brown; sand, yellow) (Ponti and others, 2007). 


\section{Chapter 5-Long Beach Webster School Core Site and Monitoring Well, Long Beach, California}

\section{Introduction}

The Long Beach Webster School core site and monitoring well (LWEB) is located on the Edison easement off Woodland Road, adjacent to Webster Elementary School at 1755 W. 32nd

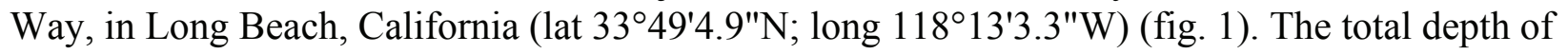
the well is $427.9 \mathrm{~m}$ (table 1). The biostratigraphic, chronostratigraphic, and paleoecologic data collected from LWEB are summarized in this chapter. Core samples taken from LWEB were examined for benthic foraminifers (Kristin McDougall), macrofossils (Charles Powell, II), paleomagnetics (John Hillhouse), and OSL and TL (Shannon Mahan). The upper Long Beach (427.9-407.4 m), lower Wilmington (407.4-319.8 m), upper Wilmington (319.8-169.96 m), Bent Spring (167.0-140.4 m), Harbor (140.4-72.0 m), Pacific (72.0-39.4 m), Mesa (39.4-30.6 m), and Dominguez $(30.6-0 \mathrm{~m})$ units were identified in this well. The boundary between the Harbor and Bent Spring units was modified from the original interpretation (Ponti and others, 2007) based on discussions with Daniel Ponti and John Tinsley in 2006.

\section{Biostratigraphy}

\section{Benthic Foraminifers}

Benthic foraminifers were analyzed from 21 samples in LWEB. Microfossil samples were broadly spaced throughout the well because sands dominate in LWEB. Eight of the 21 samples did not contain foraminiferal remains; six samples contained fewer than 100 specimens, and the remaining seven samples contained more than 300 specimens with an average diversity of 18 species/sample (plate 9). Microfossiliferous samples are from the upper part of the well in cores 250-245 (387.5-171.7 m) and 137-133 (148.5-143.0 m). No microfossils were found in the intervening cores although only limited sampling was done.

Pleistocene Wheelerian and early Hallian stages are recognized in LWEB (fig. 51). Wheelerian faunas occur from 387.5 to 331.05 m (Mf10300-Mf10295). Early Hallian faunas are noted between 148.8 and $143.8 \mathrm{~m}$ (Mf10292-Mf10287). No shallow water, middle to late Hallian assemblages were observed in the microfossil samples examined. Samples between 305.9 and $171.7 \mathrm{~m}$ (Mf10869-Mf10293) and at $143.04 \mathrm{~m}$ (Mf10286) are barren of foraminifers.

Diagnostic Wheelerian species appear commonly between 387.5 and $331.0 \mathrm{~m}$ (Mf10300Mf10295). These include Bolivina argentea, Cibicides mckannai, C. mckannai suppressa, Epistominella pacifica, and Uvigerina peregrina. With the exception of rare Elphidium from 361.9 to $386.8 \mathrm{~m}$ (Mf10299-Mf10298), Hallian species are not present. Sample Mf10295 (331.0 m), from immediately below the sands, contains a single specimen of Uvigerina senticosa adiposa, which is Pliocene in age and occurs primarily in the Capistrano Formation of Southern California. This specimen probably is reworked from older sediments.

Samples at 305.9 m (Mf10869), $200.8 \mathrm{~m}$ (Mf10868), $200.0 \mathrm{~m}$ (Mf10867), $179.0 \mathrm{~m}$ (Mf10866), 172.84 m (Mf10294), and $171.7 \mathrm{~m}$ (Mf10293) are barren of foraminifers. The barren interval that extends from approximately 320 to $160 \mathrm{~m}$ is dominated by sands. Samples at approximately $325 \mathrm{~m}$ (Mf10871 and Mf10870) slightly below the sand, contain sparse foraminifers ( $\leq 5$ specimens/sample). The only age-diagnostic species present is Cibicides mckannai, which indicates a Wheelerian Stage assignment.

Samples from 148.5 to $143.0 \mathrm{~m}$ (Mf10292-Mf10286) are dominated by Cassidulina $(C$. limbata and C. laevigata carinata) and Uvigerina juncea, which indicate the early Hallian Stage. 


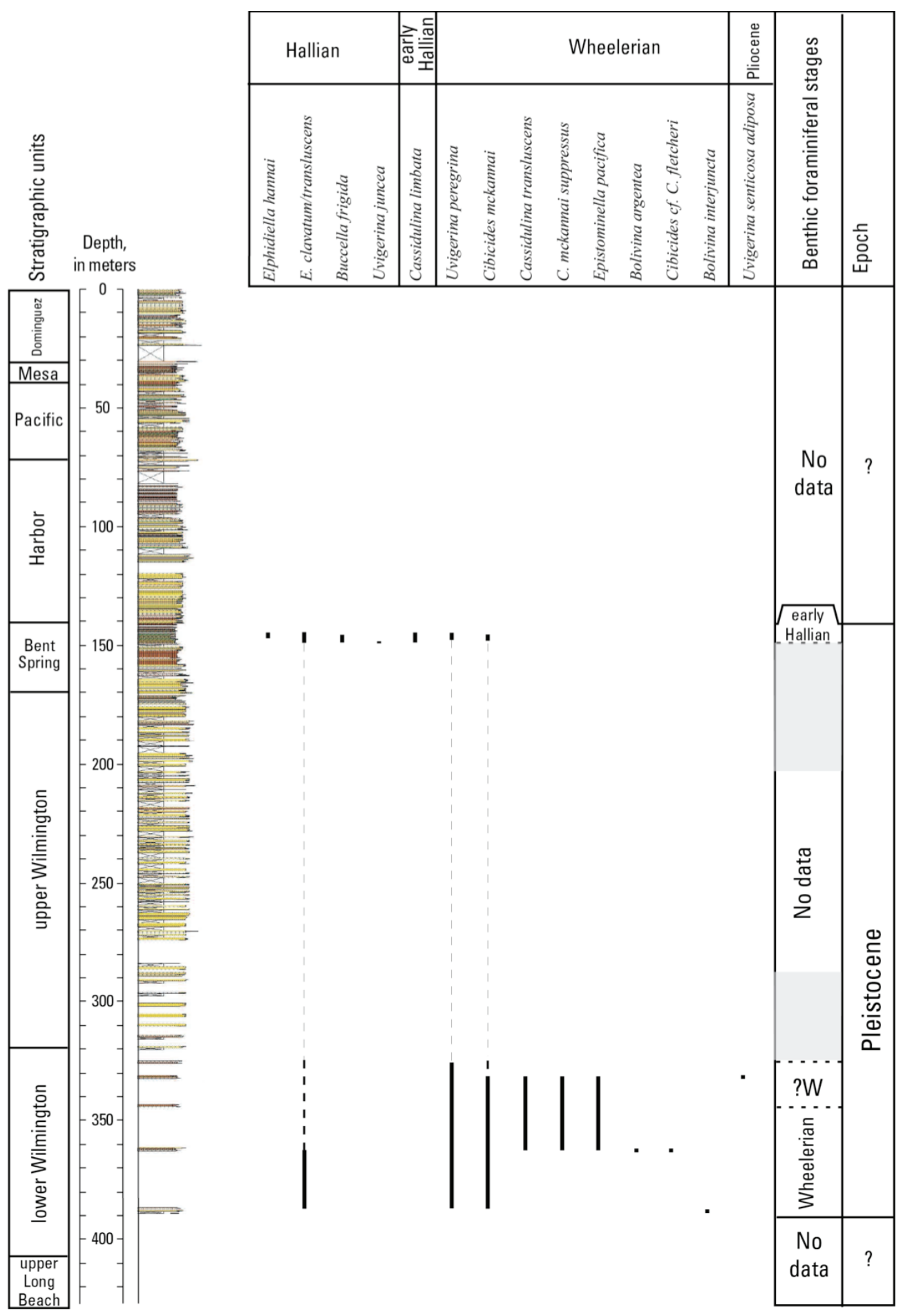

EXPLANATION

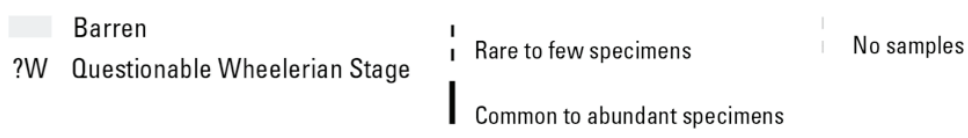

Figure 51. Stratigraphic distribution of age-diagnostic benthic foraminifers in Long Beach Webster School core site and monitoring well, Long Beach, California. Stratigraphic units are identified in the left column, and lithologies are indicated on the stratigraphic column by color (clay, green; silt, brown; sand, yellow) (Ponti and others, 2007). Abundances are given in plate 9. 
Praeglobobulimina affinis, Trifarina angulosa, and Uvigerina senticosa also appear in these samples. Although not diagnostic of age, these species indicate increased water depths and the presence of a deeper water mass. The Hallian species Buccella frigida, Elphidiella hannai, Elphidium clavatum, and E. transluscens, also appear in these assemblages.

\section{Macrofossils}

One hundred eleven samples containing remains of mollusks and arthropods were collected from LWEB (plate 10). Vertebrate remains were noted in a few samples. Eighty-four of the samples collected are from the shaker table and were washed up the drill hole from depth. These samples may include contaminants from shallower parts of the well. The remaining 27 samples were collected from cores. The genus Chione last appears in LWEB at $49.1 \mathrm{~m}$ indicating an age of $\geq 116 \mathrm{ka}$.

\section{Geochronology}

\section{Paleomagnetism}

The remanent magnetization intensity of LWEB sediments typically started near $10^{-2} \mathrm{~A} / \mathrm{m}$ and diminished to $5 \times 10^{-4} \mathrm{~A} / \mathrm{m}$ at the end of the demagnetization treatments. In general, the 5 and $10 \mathrm{mT}$ treatments removed stray magnetizations, and the magnetic direction then stabilized in the range of steps from 10 to $40 \mathrm{mT}$. Appendix III, table 14 lists the inclination values resulting from the AF demagnetization and line-fitting analysis of the demagnetization data for each specimen. Attesting to the overall good quality of the results, 62 percent of the specimens gave MADs less than $10^{\circ}$. The higher MAD values, none of which exceeded $30^{\circ}$, were usually associated with weakly magnetized, fine-grained sandy lithologies. Several thick, sandy layers were not sampled, leaving a few prominent gaps in the inclination record. The largest gap was from the interval between 270 and $180 \mathrm{~m}$ within the coarse-grained upper Wilmington unit (fig. 52).

Table 14. Paleomagnetic results for the Long Beach Webster School (LWEB), Long Beach, California. [Title of table is included here for continuity; complete table is in appendix III.]

Inspection of the inclination log shows that all samples have downward inclinations indicating normal geomagnetic polarity. The histogram of inclinations (fig. 53) shows a range of variation from $10^{\circ}$ to $90^{\circ}$, with 88 percent of the values falling between $30^{\circ}$ and $80^{\circ}$. The inclination data are consistent with the expected natural secular variation of the geomagnetic field (Merrill and others, 1998), and the peak of the histogram is close to the inclination $\left(52^{\circ}\right)$ that would be produced by a geocentric, axial dipole field at the latitude of the coring site. We see no evidence of systematic inclination flattening that is known to result from compaction in some depositional settings. In fact, the LWEB inclination record shows a trend toward steeper inclinations, particularly at depths below $270 \mathrm{~m}$.

A prominent swing in inclination from $13.9^{\circ}$ to $87.6^{\circ}$ at $35.0-40.5 \mathrm{~m}$ was recognized in LWEB (fig. 54). The lower part of this feature, at approximately $40.5 \mathrm{~m}$, was sampled in more detail after initial results were obtained. Examination of the fine-scale bedding in this core showed no obvious cracking or deformation, suggesting that the inclination feature is not an artifact of the coring process.

LWEB is uniformly of normal magnetic polarity. The simplest correlation with the Geomagnetic Polarity Timescale would be to place the cored interval within the Brunhes Normal Polarity Chron (fig. 8). This placement implies that the lowermost sample at $390 \mathrm{~m}$ is younger than $0.78 \mathrm{Ma}$. If substantial intervals of nondeposition or erosion occurred within the sampled section, 


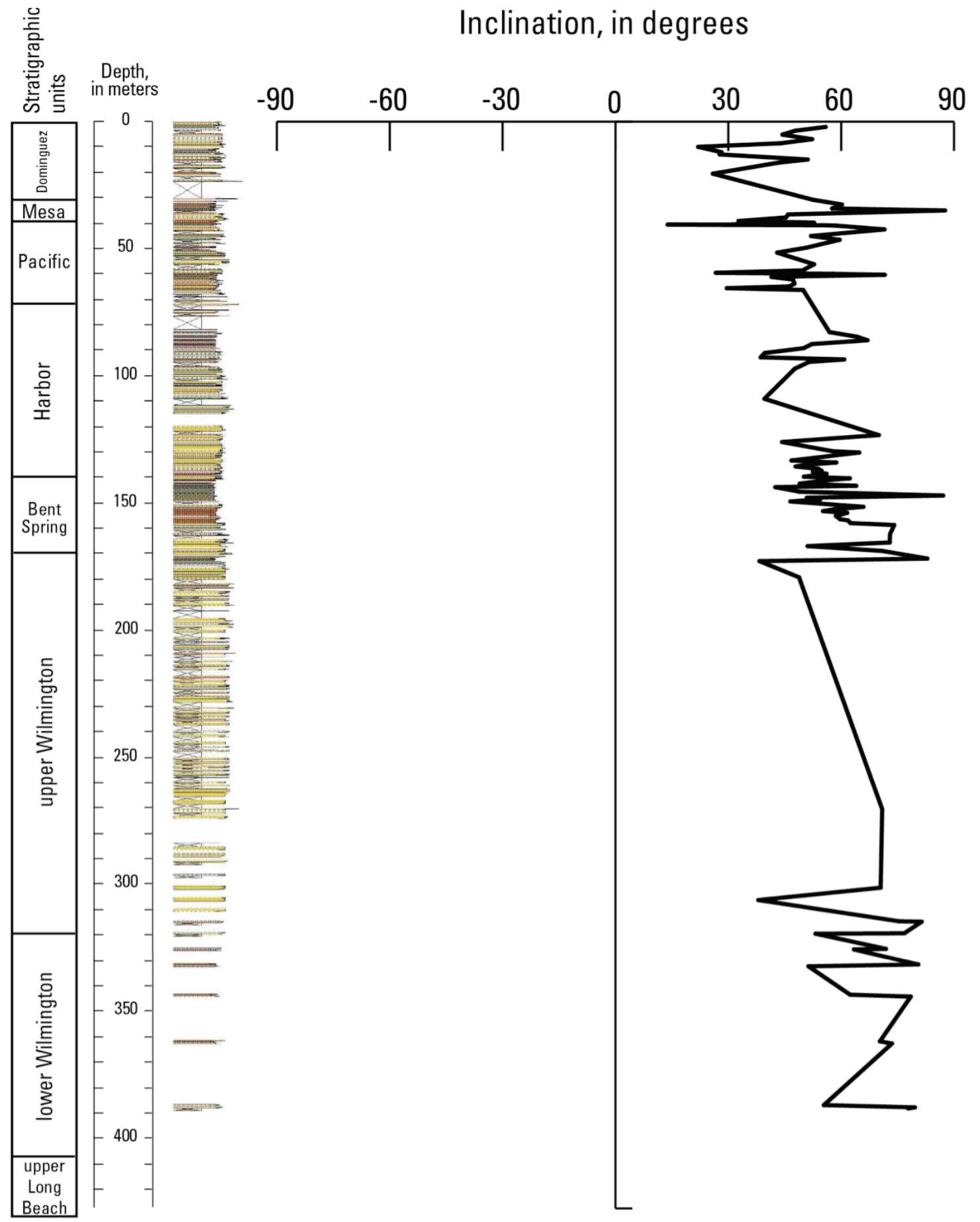

Figure 52. Magnetic inclination versus depth in Long Beach Webster School core site and monitoring well, Long Beach, California. The large gap in sampling in the lower part of the well is due to the presence of coarse sand and gravel. Stratigraphic units are identified in the left column, and lithologies are indicated on the stratigraphic column by color (clay, green; silt, brown; sand, yellow) (Ponti and others, 2007).

then it is possible that reversed-polarity sediment is missing and the deposits might be older than Brunhes age. Therefore, age-confirmation from either an identified volcanic ash or from biostratigraphy is needed. Assuming the proposed correlation is correct, the mean rate of deposition is greater than $0.5 \mathrm{~m} / 1,000$ years. 


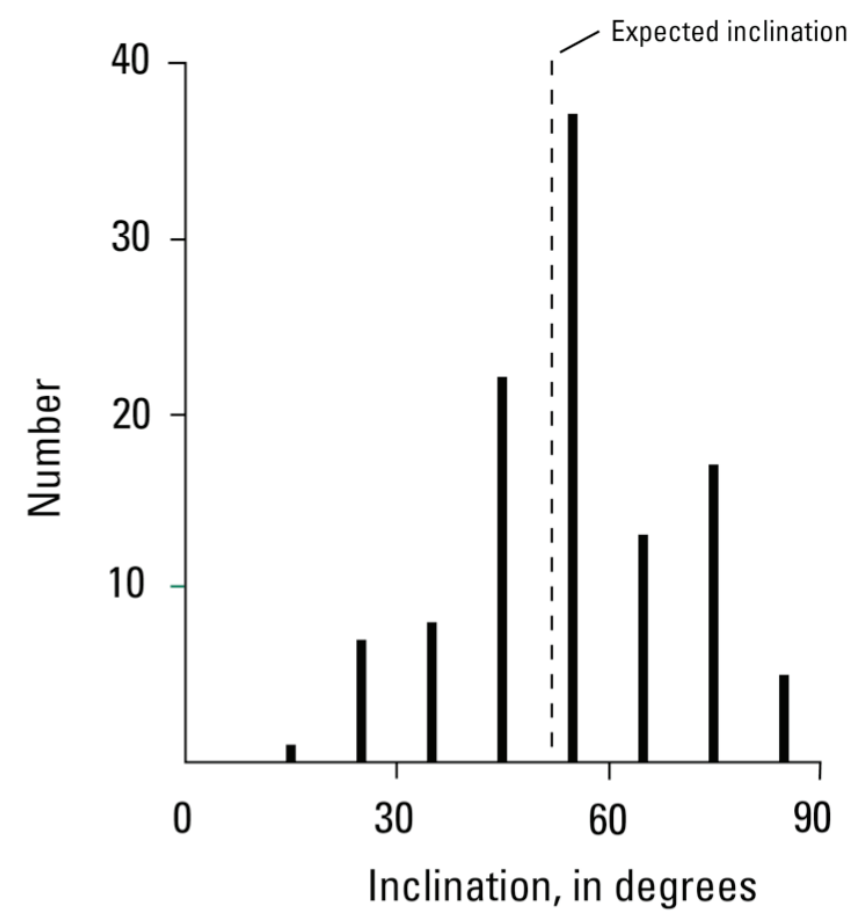

Figure 53. Histogram showing distribution of inclinations relative to the expected inclination at the Long Beach Webster School core site and monitoring well, Long Beach, California.

Luminescence dating of a sample at $42 \mathrm{~m}$ (LWEB-32C) gave an IRSL-OSL age of $70 \mathrm{ka}$ and a TL age of $123 \mathrm{ka}$. The inclination anomaly, a swing from $13.9^{\circ}$ to $87^{\circ}$, starts $2 \mathrm{~m}$ above the dated horizon. Based on the ages, this inclination anomaly probably represents the Blake event, which occurred at about $117 \mathrm{ka}$ (Tucholka and others, 1987).

Optically Stimulated Luminescence and thermal Luminescence Dating

Three analyses were done on the samples at 7.32 (LWEB-5C) and $42.9 \mathrm{~m}$ (LWEB-32C) using TL, IRSL-OSL, and quartz OSL (table 15). Two deeper samples (56.5 and $97.6 \mathrm{~m}$ ) had IRSL and TL analyses performed on them because the quartz OSL saturated and did not return reliable ages.

The corrected quartz OSL growth curve for LWEB-5C is linear in the dose range from 0 to about 4 Gy (fig. 55). The observation that the OSL can be fitted linearly suggests that the OSL signal almost entirely originates from a single luminescence center. The largest observable dose is about $5 \mathrm{~Gy}$ and the mean value is $2.6 \mathrm{~Gy}$ with a standard deviation of $1.2 \mathrm{~Gy}$. The resulting age of approximately $1.5 \mathrm{ka}$ agrees well with the ages obtained from the IRSL-OSL at $1.3 \mathrm{ka}$ and $1.6 \mathrm{ka}$ (table 15).

Like the quartz OSL, the IRSL-OSL growth curve for the sample at $7.32 \mathrm{~m}$ (LWEB-5C) is linear to the dose range 0-6 Gy (fig. 56). Table 15 lists two replicate IRSL runs, where it is apparent the two feldspar ages are not within error. Although the two IRSL-OSL feldspar ages just miss overlapping each other, the older age of $1.6 \mathrm{ka}$ does overlap the quartz OSL age of $1.48 \mathrm{ka}$. The quartz OSL age is also within error of the younger IRSL-OSL age, and given the associated errors, a probable age of 1.7 to $1.1 \mathrm{ka}$ is assigned to the interval. The quartz OSL age for the sample at $42.9 \mathrm{~m}$ is incorrect, for reasons that will be discussed below.

The other three samples that were analyzed using the feldspar IRSL multi-aliquot additive dose method (MAAD) were considerably older in age, between 60 and $\geq 100 \mathrm{ka}$ (fig. 56). While the quartz OSL displayed considerable age underestimation at $46 \mathrm{ka}$, the IRSL ages were almost 


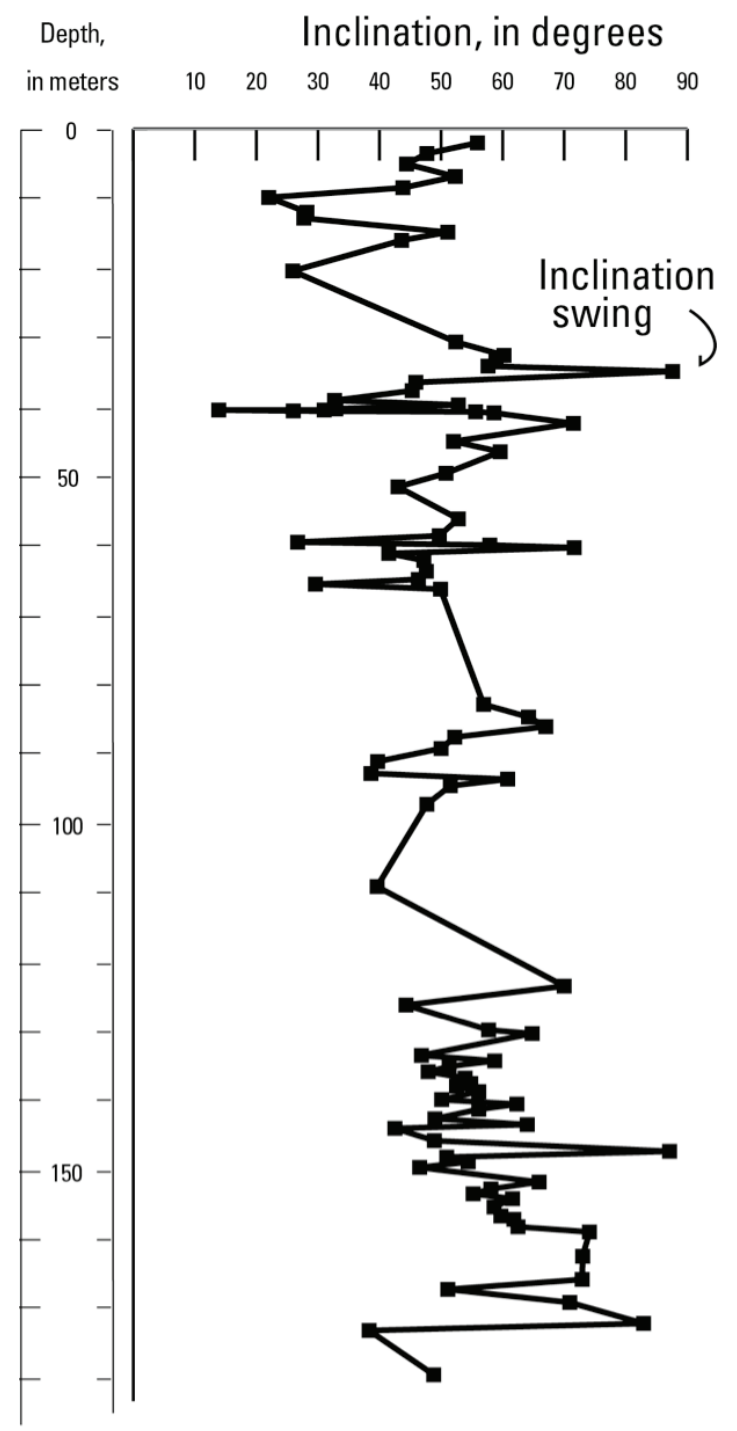

(Top part of well above sand)

Figure 54. Expanded view of inclinations from the upper $180 \mathrm{~m}$ of the Long Beach Webster School core site and monitoring well, Long Beach, California, showing details of the anomalous variation in inclination.

certainly underestimating the true depositional age, at least for samples at $56.5 \mathrm{~m}$ (LWEB-43C) and $97.6 \mathrm{~m}$ (LWEB-80C). Elemental data analyses did not indicate large dose rates that were likely to cause the creation of large amounts of unstable luminescence in a short amount of time (table 16). The IRSL curves were fitted with a single saturating exponential function, but probably still underestimate the value of the equivalent dose owing to sublinearity. Sublinearity is defined as the rate of increase of growth that falls off as the applied dose increases (Aitken, 1998). No firm reasoning for this shortfall is given here, except that inadequate preheating of the samples does not seem to be a cause for the sublinearity (Richardson and others, 1997).

Figure 57 shows the growth curve of LWEB-5C (7.32 m) for a TL MAAD technique that is exponential in growth. The "plateau" or equivalent dose distribution is not shown. LWEB-5C shows much larger TL equivalent doses (and thus, older ages) than either OSL method. The TL appears to show the same overestimation in equivalent dose and age throughout the well, until saturation is approached somewhere after LWEB-43C $(56.6 \mathrm{~m})$ and before LWEB-80C $(97.6 \mathrm{~m})$. The age overestimation is almost certainly linked to the sediment not being exposed to sunlight 


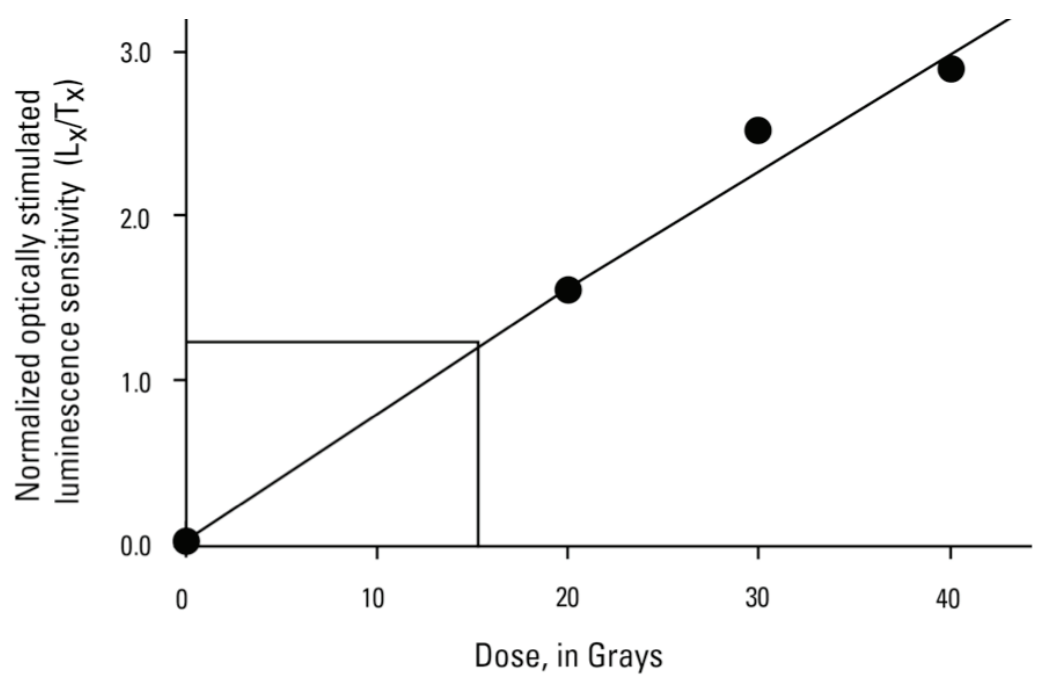

Figure 55. Sensitivity-corrected optically stimulated luminescence (OSL) growth curve for an single aliquot run of sample LWEB-5C. The generation on the sensitivity-corrected OSL signals for the first and the final regeneration doses (as indicated by overlapping circles) overlie each other, indicating that the sensitivitycorrection procedure is working accurately. Dose is measured in seconds times 100 and OSL is measured in normalized OSL sensitivity measurements (Lx/Tx).

during the processes of deposition for the LWEB-5C sample. This means the sediment is deposited carrying a residual signal, resulting in spurious older ages that do not reflect the true depositional age. When saturation (electron traps filling completely) is detected the systematic reverse and age underestimates result, in contrast to previous overestimates, as seen in sample LWEB-80C. The underestimates are caused by the lack of any space in which to fit additional electrons, thus the electrons are lost and cannot be counted.

The sample at $7 \mathrm{~m}$ is very young whereas the sample at about $42.9 \mathrm{~m}$ is much older $(123.3 \pm 8.2 \mathrm{ka})$. This means that assuredly the quartz OSL, and possibly the IRSL-OSL, are underestimating the age of the sediment at $42.9 \mathrm{~m}$ owing to saturation of their systematic. Since the TL age at $42.9 \mathrm{~m}$ (LWEB-32C) of $123.3 \pm 8.2 \mathrm{ka}$ (table 15) is close in age to the Blake event ( 117 $\mathrm{ka}$ ), which was identified between 35.0 and $40.0 \mathrm{~m}$, TL yields a more reliable age for samples at 56.6 and $42.9 \mathrm{~m}$ (LWEB-43C and LWEB-32C) than expected. The IRSL ages begin to reverse themselves at $56 \mathrm{~m}$, and it is probable that at some unknown age "cutoff" the IRSL-OSL does not return a valid equivalent-dose estimate (the 70-80 ka limit seen in other cores). The IRSL-OSL estimates are all invalid in LWEB-80C $(97.6 \mathrm{~m})$, so it is likely that the IRSL-OSL is returning invalid equivalent doses in LWEB-43C $(56.5 \mathrm{~m})$ and LWEB-32C $(42.9 \mathrm{~m})$, as well.

Two samples in LWEB were analyzed for radiocarbon: (1) a peat layer at $11.9 \mathrm{~m}$ (LWEB8), and (2) a macrofossil (shell?) at $12.1 \mathrm{~m}$ (S. Sellars and T. Stafford, Stafford Research Laboratories, Boulder, Colo., oral commun., 2003). The peat was dated to $2,390 \pm 40 \mathrm{cal}$ yrs BP, and the macrofossil was dated at $1,760 \pm 40 \mathrm{cal}$ yrs BP. For comparison, the OSL ages at $7.3 \mathrm{~m}$ (LWEB-5) were $1.48 \pm 0.09 \mathrm{ka}, 1.28 \pm 0.16 \mathrm{ka}$, and $1.60 \pm 0.13 \mathrm{ka}$.

\section{Paleoecology}

\section{Benthic Foraminifers}

The results of the biofacies analyses indicate that deposition of the Wheelerian benthic foraminiferal fauna represents upper bathyal/upper slope biofacies and that the early Hallian benthic foraminiferal faunas represent upper bathyal/bank biofacies (fig. 58). Water depths 
Table 15. Thermoluminescence (TL), feldspar infrared stimulated luminescence (IRSL) and quartz blue-light OSL ages for Long Beach Webster School (LWEB), Long Beach, California.

$[\%$, percent; ka, thousands of years; Gy, Grays; >, greater than; -, no data]

\begin{tabular}{|c|c|c|c|c|c|c|c|c|c|}
\hline $\begin{array}{c}\text { Sample } \\
\text { information } \\
\text { core depth: } \\
\text { material }\end{array}$ & $\begin{array}{c}\text { Moisture } \\
(\%)^{a}\end{array}$ & $\begin{array}{l}\text { TL age } \\
(\mathrm{ka})^{\mathrm{b}}\end{array}$ & $\begin{array}{l}\text { IRSL dose } \\
\text { rate } \\
\left(10^{-3} \mathrm{~Gy} / \mathrm{yr}\right)\end{array}$ & $\begin{array}{c}\text { Equivalent } \\
\text { dose } \\
\text { (Gy) }\end{array}$ & $\begin{array}{l}\text { IRSL age } \\
\text { (ka)b }^{\text {b }}\end{array}$ & $\mathrm{n}^{\mathrm{c}}$ & $\begin{array}{l}\text { Quartz dose } \\
\text { rate } \\
\left(10^{-3} \mathrm{~Gy} / \mathrm{yr}\right)\end{array}$ & $\begin{array}{l}\text { Equivalent } \\
\text { dose } \\
\text { (Gy) }\end{array}$ & $\begin{array}{c}\text { Quartz age } \\
\text { (ka) }\end{array}$ \\
\hline $\begin{array}{l}\text { LWEB-5c } \\
7.32 \mathrm{~m} \text {, silty } \\
\text { sand }\end{array}$ & $31 \pm 1$ & $6.14 \pm 0.42$ & $2.54 \pm 0.05$ & $3.25 \pm 0.19$ & $\begin{array}{l}1.28 \pm 0.156 \\
1.60 \pm 0.130\end{array}$ & $\begin{array}{l}25 \\
(35)\end{array}$ & $1.80 \pm 0.03$ & $2.66 \pm 0.07$ & $1.48 \pm 0.09$ \\
\hline $\begin{array}{l}\text { LWEB-32c } \\
42.9 \mathrm{~m} \text {, sand }\end{array}$ & $27 \pm 1$ & $123 \pm 8.18$ & $3.27 \pm 0.05$ & $230 \pm 1.67$ & $70.3 \pm 2.21$ & $\begin{array}{l}27 \\
(35)\end{array}$ & $2.32 \pm 0.03$ & $108 \pm 0.86$ & $46.4 \pm 1.33$ \\
\hline $\begin{array}{l}\text { LWEB-43c } \\
56.5 \mathrm{~m} \text {, silt }\end{array}$ & $36 \pm 1$ & $\begin{array}{l}141 \pm 10.2 \\
160 \pm 11.8\end{array}$ & $3.54 \pm 0.05$ & $\begin{array}{l}169 \pm 4.24 \\
173 \pm 12.7\end{array}$ & $\begin{array}{l}59.4 \pm 3.25 \\
60.6 \pm 8.98\end{array}$ & - & - & - & - \\
\hline $\begin{array}{l}\text { LWEB-80c } \\
97.6 \mathrm{~m} \text {, sand }\end{array}$ & $19 \pm 1$ & $>101 \pm 67.1$ & $3.30 \pm 0.04$ & $>250 \pm 27.2$ & $>98.6 \pm 21.4$ & - & - & - & - \\
\hline
\end{tabular}

${ }^{a}$ Field moisture, ages based on 35--40 percent (sand-silt) moisture content through time as an average between fieldand saturation-moisture values.

${ }^{\mathrm{b}}$ Silt fraction (4-11 micron size) for IRSL as multiple aliquot additive dose technique (MAAD).

${ }^{c}$ Silt fraction (4-11 micron size) for IRSL as MAAD, with correction of $\mathrm{g}=3.06$ percent fade/decade.

${ }^{\mathrm{d}}$ Number of replicated equivalent dose (De) estimates used to calculate the mean. Figures in parentheses indicate the total number of measurements made, including failed runs with unusable data.

${ }^{\mathrm{e}} \mathrm{Lab}$ used 90-125 micron size for quartz OSL with single aliquot regeneration technique (SAR). Quoted errors are two sigma on age and one sigma on dose rate and equivalent dose.

decrease gradually from a maximum slightly greater than $300 \mathrm{~m}$ in the oldest Wheelerian samples to about 50-150 m for the youngest early Hallian samples. Although the sands between 320 and $160 \mathrm{~m}$ are assumed to be nonmarine or shallow marine, this interval may very likely have been deposited at water depths similar to the adjacent strata since there is no microfaunal evidence of a change in water depth on either side of the sandy interval.

In Wheelerian samples (Mf10300-Mf10295; 387-331 m), benthic foraminifers characteristic of upper bathyal (150-500 m), and lower slope (400-950 m) and basin floor (550$950 \mathrm{~m}$ ) biofacies dominate. Species with UDLs in the upper bathyal biofacies include various species of Cassidulina, Epistominella pacifica, Bolivina interjuncta, and Uvigerina peregrina. Samples Mf10298 (361 m), Mf10299 (386 m), and Mf102300 (387 m), are dominated by $B$. argentea, $B$. interjuncta, Loxostomum bradyi, and Uvigerina peregrina, which suggests deposition occurred on the lower slope (400-950 m), and Nonionella, which suggests low oxygen and basin floor biofacies (550-950 m). Water depths are therefore, believed to be around $500 \mathrm{~m}$ where the three biofacies fauna would overlap. The decline of upper middle bathyal and lower slope species in the upper three samples of the Wheelerian interval indicates that water depths have decreased, and that deposition probably occurred at depths between 400-500 $\mathrm{m}$.

Sparse, questionable Wheelerian assemblages in samples Mf10871 (325.71 m) and Mf10870 (325.01 m, contain only eight benthic foraminiferal specimens and three species. Bathymetric analyses of foraminifers in this interval indicate mixing. Quinqueloculina akneriana has a UDL in the inner neritic, but is easily transported, whereas Cibicides mckannai and Pyrgo murrhina have UDLs in the upper bathyal biofacies. Therefore, deposition is interpreted as 


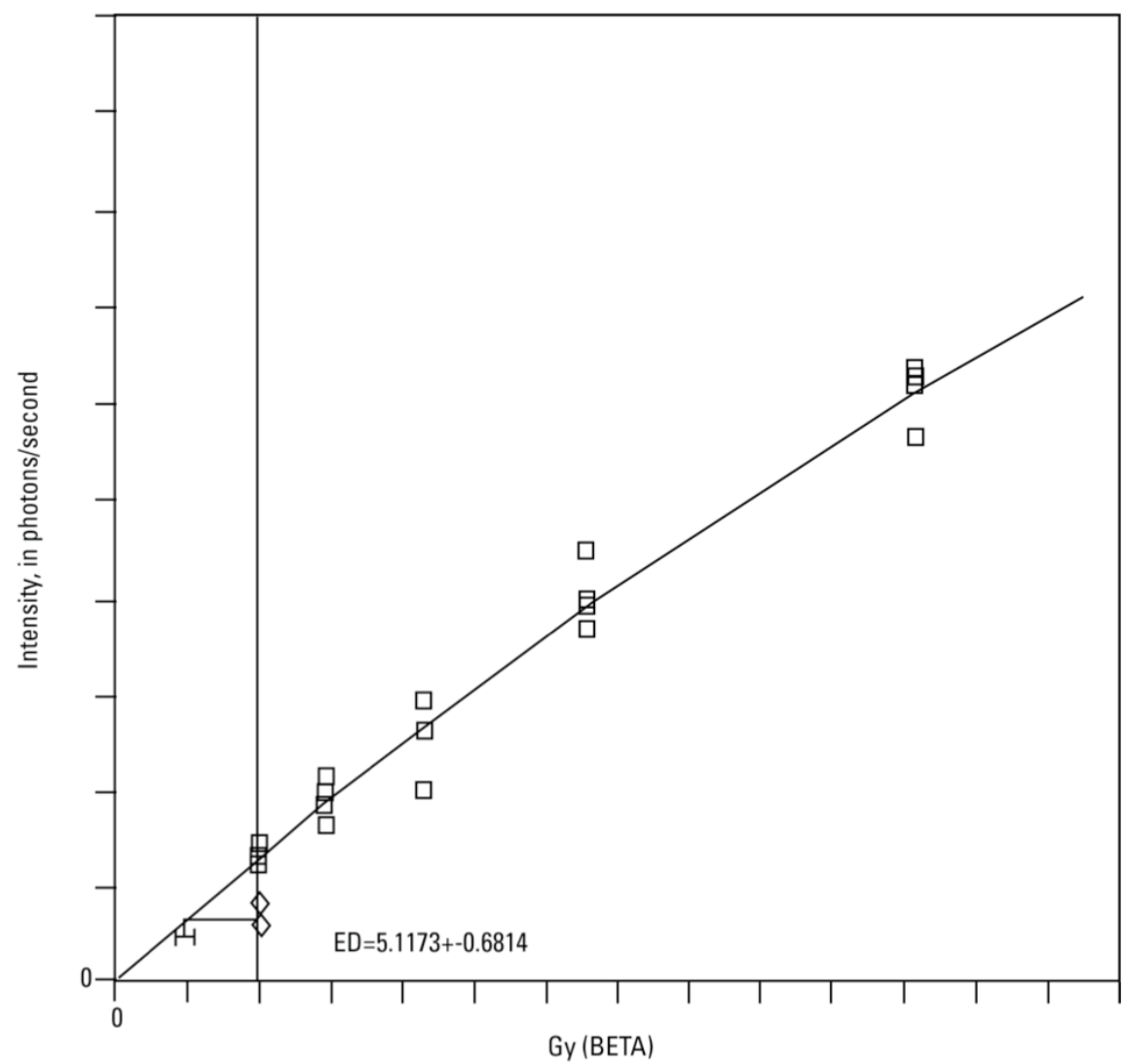

Figure 56. IRSL growth curve for a multi-aliquot run of sample LWEB-5C at $7.3 \mathrm{~m}$ in the Long Beach Webster School core site and monitoring well, Long Beach, California. Bleaches are denoted with diamonds, naturals sit on the vertical axis and increasing beta-radiated aliquots are shown on the slanted line. The $X$ axis shows the measured equivalent dose in Grays (Gy) when compared to calibrated Grays generated by exposure to a beta source. The $Y$ axis shows the intensity of light emitted from the aliquots and is measured in photon/seconds.

occurring in the upper bathyal biofacies, probably near the shelf/slope edge $( \pm 150 \mathrm{~m})$. The faunas are too sparse and not diagnostic of any California borderland biofacies or oxygen conditions.

The early Hallian assemblages include species transported from the neritic biofacies and species indicative of glacial and interglacial conditions. Species with UDLs in the inner neritic biofacies average less than 30 percent of the assemblage and include Buccella frigida, various elphidiums, and Elphidiella. Species indicative of glacial and interglacial cycles are rare and include Elphidiella hannai, Lenticulina cushmani, and Uvigerina peregrina. Elphidiella hannai, which is now found from Point Conception north, migrated south with the California Current during cooler periods. During Pleistocene glacials, Uvigerina peregrina and variants are associated with higher surface productivity, increased carbonate sedimentation, and decreased oxygen (Boersma, 1984); thus, this species also supports glacial conditions. Conversely, Lenticulina cushmani, which is now found off Central America and Baja California, migrated into the California borderland during warmer climatic intervals (Blake, 1976). These species indicate that glacial conditions existed in samples Mf10290 (146 m) and Mf10287 (343 m). The dominance of Lenticulina cushmani in Mf10288 (145.2 m) suggests the presence of interglacial conditions, or that material from a warm interval is being reworked in this interval.

Benthic foraminiferal assemblages in the early Hallian interval (Mf10287-Mf10292; $143.78-148.48 \mathrm{~m})$ are characteristic of upper bathyal $(150-500 \mathrm{~m})$ and bank $(50-200 \mathrm{~m})$ biofacies. 


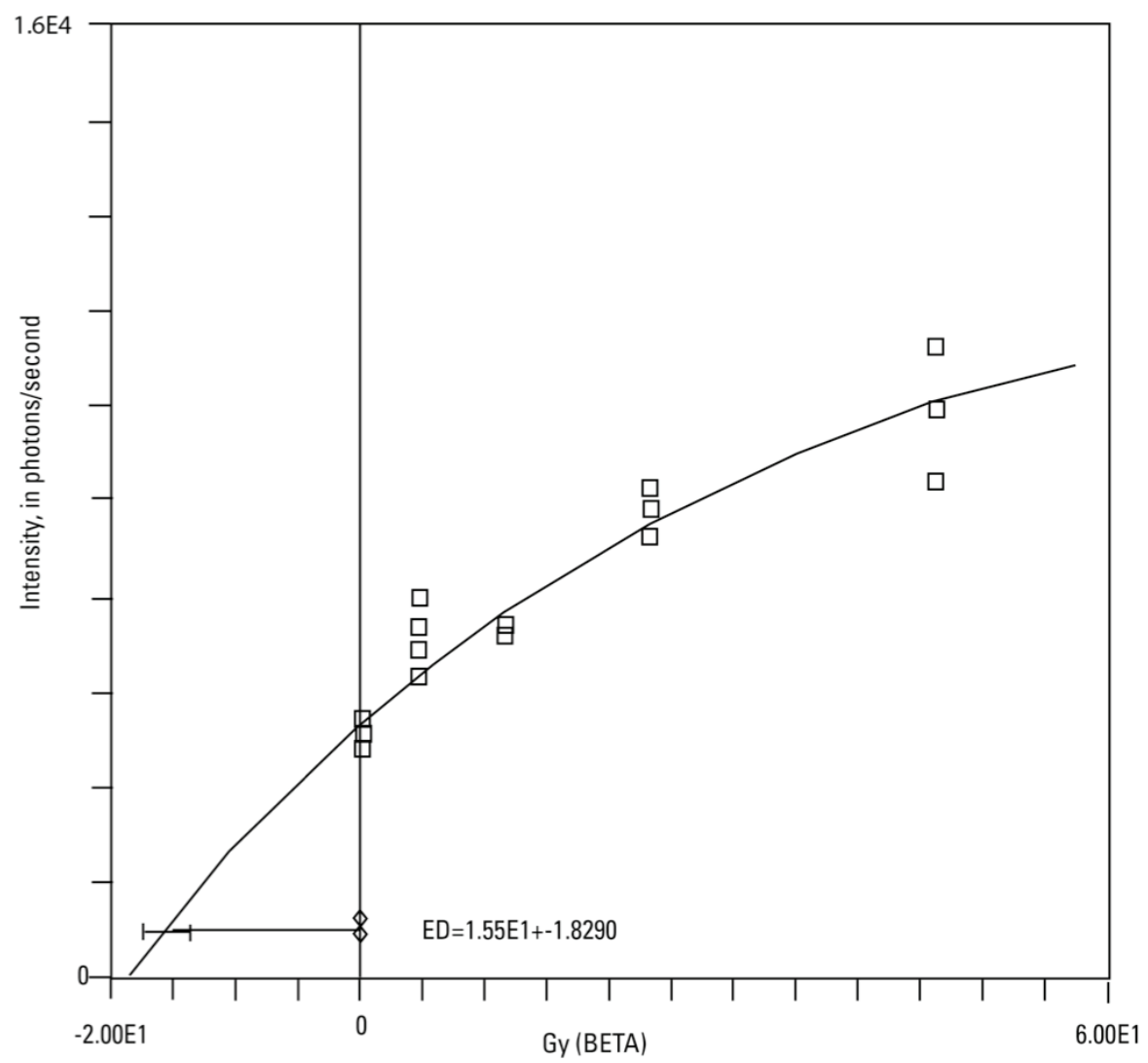

Figure 57. Growth curve of TL in sample LWEB-5C, taken at $7.3 \mathrm{~m}$ in the well, using multi-aliquot additive dose techniques. Bleaches are denoted with triangles, naturals sit on the $X$ axis, and increasing betaradiation treated aliquots are shown on the slanted line. The $X$ axis shows the measured equivalent dose in Grays (Gy) when compared to calibrated Grays generated by exposure to a beta source. The $Y$ axis shows the intensity of light emitted from the aliquots and is measured in photon/seconds.

The upper bathyal interpretation is based on the abundance of Cassidulina species, Trifarina angulosa, and Uvigerina peregrina, which have UDLs within the upper bathyal biofacies. The bank biofacies interpretation is based on the dominance of Cassidulina limbata, as well as on the presence of Astrononion stellatum, Cibicides fletcheri, Cassidulina californica, Galvinopsis campanula, Pullenia salisburyi, and Trifarina angulosa. The bank biofacies occupied much of the mainland shelf during the early Holocene and late Pleistocene, usually in areas of carbonate-rich substrates (bioclastic sediments or relict foraminiferal sands) or clastic sediments (Douglas and Heitman, 1979). Analysis of the oxygen biofacies suggests that the dysoxic conditions persisted in this interval.

\section{Macrofossils}

Macrofossils in LWEB suggest depths of outer sublittoral $(45-183 \mathrm{~m})$ and then inner sublittoral (9-45 $\mathrm{m}$ ) followed by bay conditions. The sediments are nonmarine in the upper part of the well (fig. 59). Generally, macrofossil assemblages are transported, but in LWEB, the macrofossil assemblages probably represent the in situ fauna.

The interval from 288.6-222.8 m contains primarily indeterminate shell fragments from which little ecologic information can be deduced. However, single, articulate specimens of the bivalve Axinopsida cf. A. serricata were found at $\leq 288.6$ to $\leq 283.8 \mathrm{~m}$ (shaker samples $124 \mathrm{~K}$ and $123 \mathrm{~K})$. These specimens, because of their small size and because they are articulate, are unlikely to 
Table 16. Elemental concentrations and associated dosimetry for Long Beach Webster School core site and monitoring well (LWEB), Long Beach, California, optically stimulated luminescence (OSL) samples.

$\left[\%\right.$, percent; ppm, parts per million; $m$, meter; $\mathrm{D}_{\mathrm{r}}$, dose rate; $\mathrm{K}$, Potassium; $\mathrm{U}$, Uranium; Th, Thorium; Rb, Rubidium; - , no data]

\begin{tabular}{|c|c|c|c|c|c|c|c|c|c|c|c|c|}
\hline $\begin{array}{l}\text { Sample } \\
\text { number }\end{array}$ & $(\%)$ & (ppm) & Th & $\begin{array}{r}\text { Depth } \\
(\mathrm{m})\end{array}$ & $\begin{array}{c}\text { Water } \\
(\%)\end{array}$ & $\begin{array}{c}D_{r} \\
\text { fine } \\
\text { grain }\end{array}$ & $\begin{array}{c}D_{r} \\
\text { coarse } \\
\text { grain }^{a}\end{array}$ & $\begin{array}{c}D_{r} \\
\text { for } K\end{array}$ & $\begin{array}{c}D_{r} \\
\text { for U }\end{array}$ & $\begin{array}{c}D_{r} \\
\text { for Th }\end{array}$ & $\begin{array}{c}D_{r} \\
\text { for Rb }\end{array}$ & $\begin{array}{c}D_{r} \\
\text { for } \\
\text { cosmic } \\
\text { ray }\end{array}$ \\
\hline LWEB-5C & 1.78 & 1.40 & 5.61 & 0.73 & 35 & 2.54 & 1.69 & 1.33 & 0.51 & 0.59 & 0.03 & 0.08 \\
\hline LWEB-32C & 2.24 & 1.69 & 8.79 & 42.80 & 35 & 3.27 & 2.25 & 1.68 & 0.62 & 0.92 & 0.03 & 0.02 \\
\hline LWEB-43C & 2.34 & 2.16 & 10.70 & 55.50 & 40 & 3.54 & 2.52 & 1.68 & 0.75 & 1.08 & 0.03 & 0.00 \\
\hline LWEB-80C & 2.37 & 1.40 & 6.59 & 96.00 & 25 & 3.30 & 2.51 & 1.94 & 0.56 & 0.76 & 0.04 & 0.00 \\
\hline
\end{tabular}

${ }^{a}$ Coarse grains used for quartz OSL have the alpha component and about $10 \%$ beta component of the dosimetry etched away

have been transported far and indicate marine conditions. Modern A. serricata occurs from the intertidal zone to $275 \mathrm{~m}$ (Coan and others, 2000), so the depth of deposition cannot be refined for this part of the well. Indeterminate shell fragments, oysters, pectens, and barnacles occur from 283.8-239.6 m (Shaker 122K and 103K) indicating marine conditions, but little else. A sample from 224.3-222.8 m (Shaker 96K) contains the bivalve genera Chione and Cyclocardia, which generally do not occur together. Cyclocardia is common offshore and may indicate cooler water temperatures, whereas Chione is commonly found at shallower water depths and indicates water temperatures similar to those off Long Beach today, or warmer. These taxa are not mutually exclusive, but one of the species probably is reworked.

The overlying interval 222.8-172.5 m contains species that indicate inner to middle sublittoral depths. The base of the interval from 222.8 to $192.3 \mathrm{~m}$ (Shaker $95 \mathrm{~K}$ and $82 \mathrm{~K}$ ) contains only indeterminate mollusk fragments and barnacle fragments which may be reworked, or are from small in situ shell beds in the well, but the quantity of the material in the shaker samples is in excess of that seen in the cores. Faunas from 192.3 to $172.5 \mathrm{~m}$ (Shaker $81 \mathrm{bK}$ to Shaker $71 \mathrm{~K}$ ) continue to indicate inner to outer sublittoral depths with occasional shallow-water taxa. At 172.5 $\mathrm{m}$ (Shaker $71 \mathrm{~K}$ ) deeper water taxa become more prominent, indicating inner to outer sublittoral depths, but some shallow-water taxa continue to be present, although they could have washed in from shallow depths in the well.

Shallow-water faunas appear at $171.1 \mathrm{~m}$ (LWEB 159, C-1, 10-20 cm) and continue up to $143.8 \mathrm{~m}$ (LWEB 133, C-1, 21.5-29 cm). Argopecten ventricosus is present from 162.8 to $162.6 \mathrm{~m}$ (LWEB 151, C-1, 211.5-24 cm to LWEB 151, C-1, 3-11 cm). Argopecten ventricosus suggests warm water, similar to today or warmer off the adjacent coast (Coan and others 2000; Powell and others, 2000) as its modern range does not regularly extend north of Santa Barbara (Coan and others, 2000). A break is indicated by the faunas at $162.6 \mathrm{~m}$ (LWEB 115, C-1, 3-11 cm), which represent shallow-water depths, probably less than $5 \mathrm{~m}$, based on the occurrence of articulate Donax gouldii. Mollusks between 151.2 to 146.9 m (LWEB 137, C-1, 486-491, shoe, and shaker 66K) indicate an increase in water depths. The samples at 148.9-148.7 m (LWEB137, C-1, 66-78 $\mathrm{cm}$ and 137, C-1, 62.5-72 cm) contain three gastropods, Amphissa reticulata, Antiplanes catalensis, and Turritella cooperi, which together indicate a depth between 90 and $100 \mathrm{~m}$ (McLean and Gosliner, 1996). Species in the overlying samples contain faunas, which commonly are found at inner sublittoral depths $(9-45 \mathrm{~m})$. These gradually transition to faunas that suggests outer sublittoral depths, probably between 30 and $90 \mathrm{~m}$. 


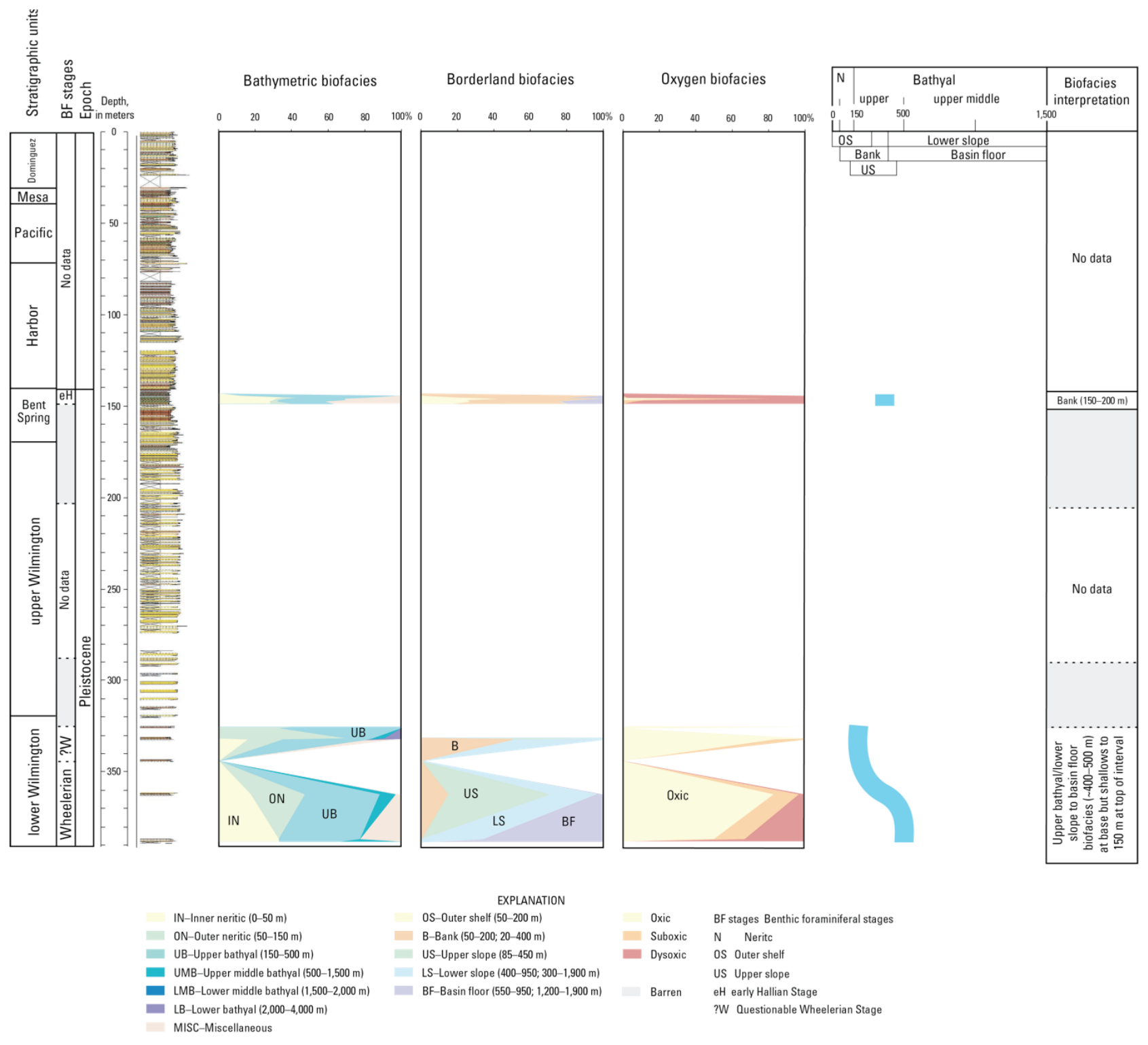

Figure 58. Paleoecological benthic foraminiferal biofacies analysis of Long Beach Webster School core site and monitoring well, Long Beach, California. The three benthic foraminiferal biofacies analyses discussed in the text, are based on the abundance of benthic foraminifers in the samples. The bathymetric curve represents the most probable depth at which the samples were deposited. Stratigraphic units are identified in the left column, and lithologies are indicated on the stratigraphic column by color (clay, green; silt, brown; sand, yellow) (Ponti and others, 2007). [Reduced-size figure is shown here for continuity; fullsize figure is included on plate 18.]

Scattered indeterminate mollusk fragments are present between 143.6 and $110 \mathrm{~m}$ ( shaker samples 63K-54K). Donax and Ostrea conchaphila commonly occur between 110.0 and $100.1 \mathrm{~m}$ (shaker samples 53K-52K, and LWEB92, C-1, $12 \mathrm{~cm}$ ) and have modern occurrences in shallow water, generally less than $10 \mathrm{~m}$ (Coan and others, 2000).

From shaker $43 \mathrm{~K}$ to $46 \mathrm{~K}$ ( 72.5 to $78 \mathrm{~m}$ ), only indeterminate fragments were collected. A few taxa suggesting slightly deeper water are present between 94.0 and $90.5 \mathrm{~m}$ (shaker $51 \mathrm{~K}$ and LWEB 74, C-1, 24-29 cm) and again between 59.7 and $61.3 \mathrm{~m}$ (shaker samples 33K-35 K). Samples at 51.4 and $47.5 \mathrm{~m}$ (shaker samples $26 \mathrm{~K}$ and $25 \mathrm{~K}$ ) contain a mixed-depth assemblage with 


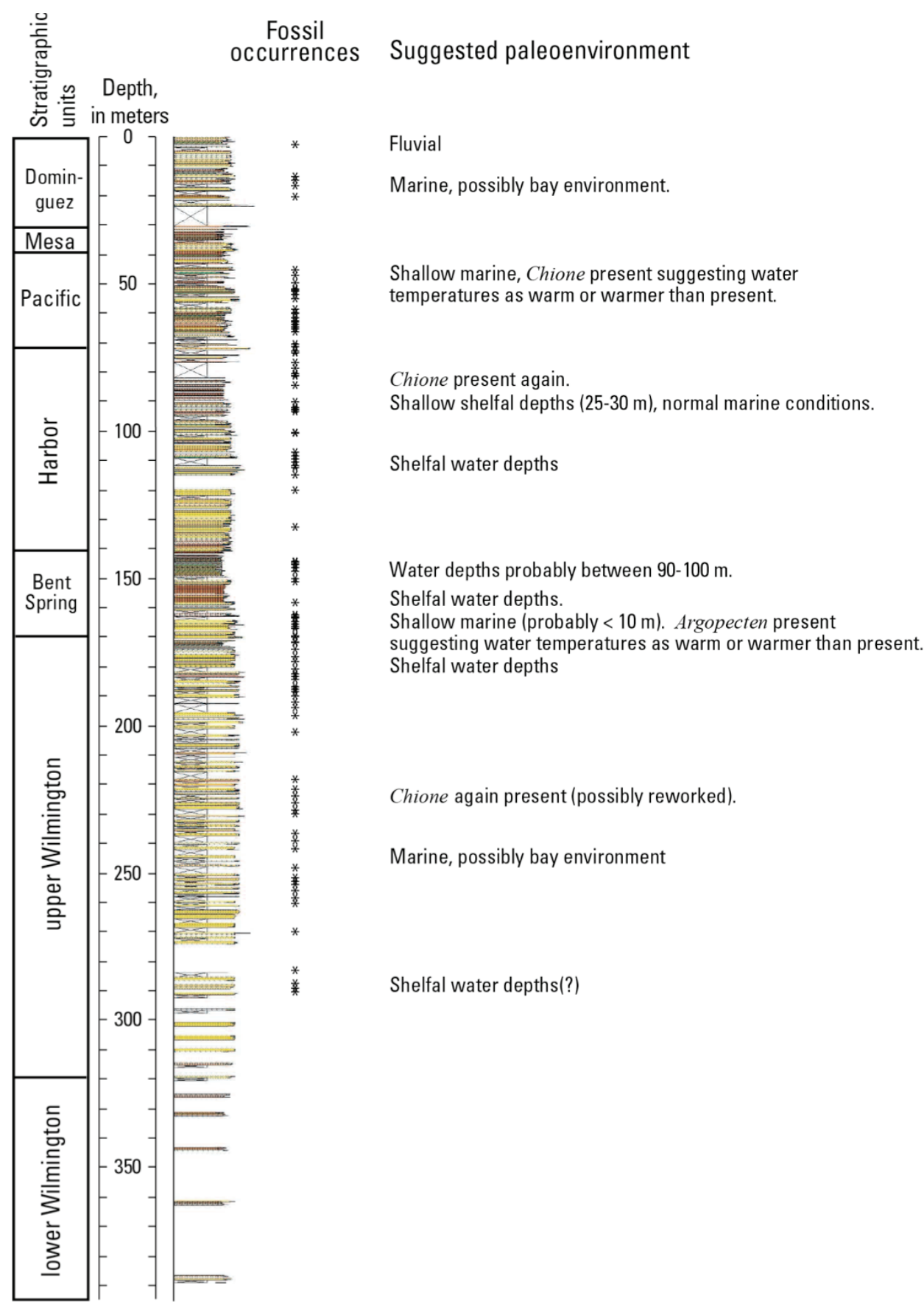

Figure 59. Distribution and paleoecologic interpretation of macrofossils in Long Beach Webster School core site and monitoring well, Long Beach, California. Blank intervals represent no core recovery . Stratigraphic units are identified in the left column, and lithologies are indicated on the stratigraphic column by color; clay, green; silt, brown; sand, yellow) (Ponti and others, 2007).

some taxa suggesting intertidal to shallow, subtidal water depths, while others suggest slightly deeper water, along an open coast. The occurrence of abundant oysters, pectinids, and Anomia between 46.0 and $20.1 \mathrm{~m}$ (shaker samples $24 \mathrm{~K}-6 \mathrm{~K}$ ) indicates a shallow bay environment, but only scattered, indeterminate shelly remains occur between 12.5 and $20.1 \mathrm{~m}$. Marine fossils disappear above $20.1 \mathrm{~m}$. The shallowest, stratigraphically highest sample from this well, from 1.8 to $3.3 \mathrm{~m}$, contains fresh-water mollusks and rodent bones indicating a lacustrine or fluvial environment. 


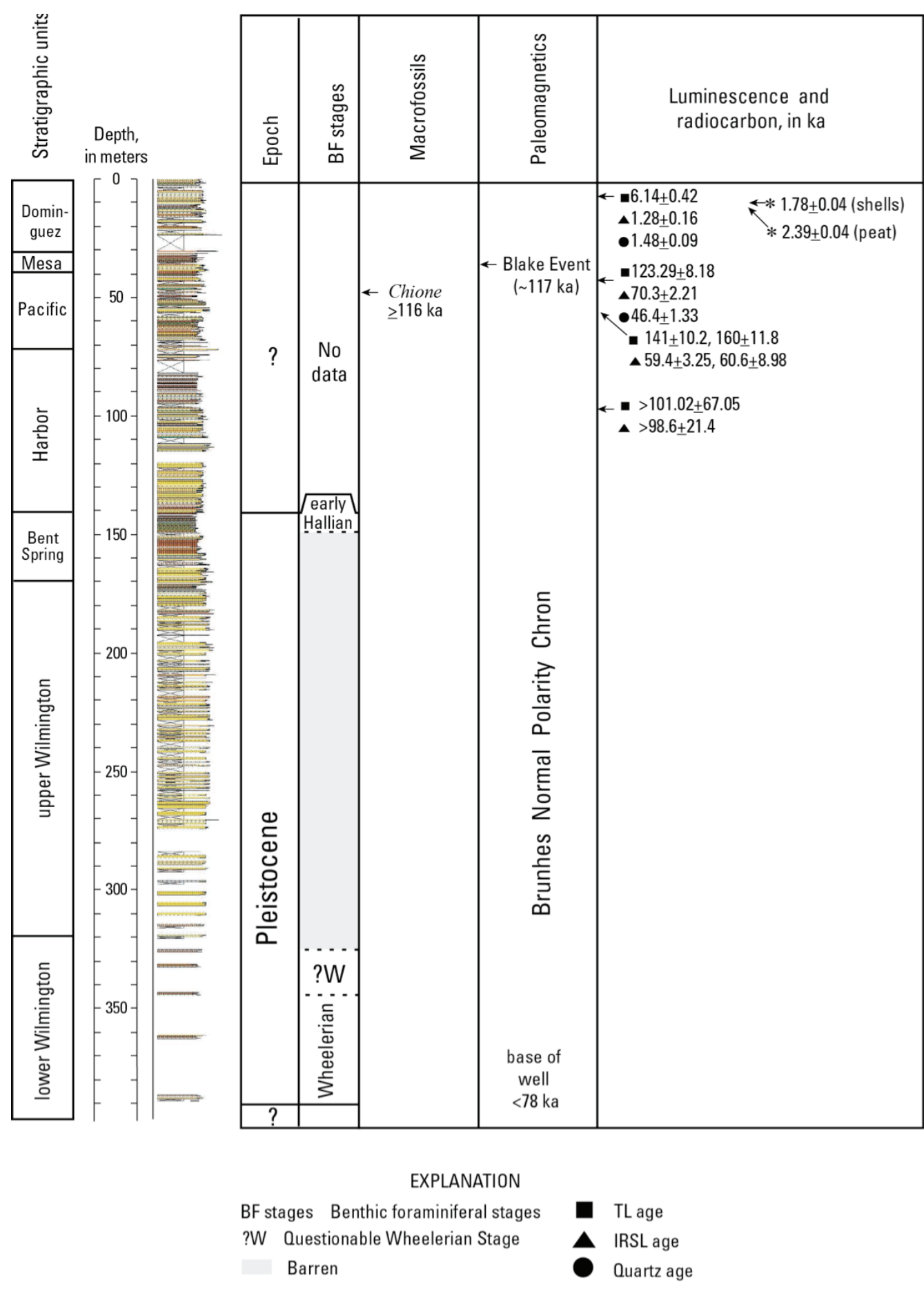

Figure 60. Summary of geochronology of Long Beach Webster School core site and monitoring well, Long Beach, California, based on the microfossils, macrofossils, paleomagnetics, luminescence, and radiocarbon. Stratigraphic units are identified in the left column, and lithologies are indicated on the stratigraphic column by color (clay, green; silt, brown; sand, yellow) (Ponti and others, 2007).

\section{Long Beach Webster School Core Site and Monitoring Well Summary}

LWEB ranges from Pleistocene to Holocene in age (fig. 60). Benthic foraminifers are diagnostic of the Pleistocene - early Hallian (148.47-143.77 m), questionably Wheelerian (331.32-325.01 m), and Wheelerian (387.54-361.91 m) stages. LWEB is uniformly of normal 
magnetic polarity. The cored interval is correlated with the Brunhes Normal Polarity Chron, which implies that the lowermost sample at $390 \mathrm{~m}$ is younger than $0.78 \mathrm{Ma}$, assuming no unconformities or hiatuses. Recognition of Wheelerian microfossils in the lower part of the well indicates that the age is most likely in the older part of the Brunhes Normal Polarity Chron.

A magnetic-inclination anomaly, a swing from $13.9^{\circ}$ to $87^{\circ}$ at $35.0-40.5 \mathrm{~m}$ is identified as the Blake event $(\sim 117 \mathrm{ka})$. This interpretation is supported by a TL date of $123 \mathrm{ka}$ in core 32 (42 $\mathrm{m}$ ), approximately $2 \mathrm{~m}$ below this anomaly and the presence of the macrofossil Chione at $49.1 \mathrm{~m}$, which is $\geq 116 \mathrm{ka}$ (end of MIS5e), or $\leq 12 \mathrm{ka}$ in the Los Angeles Basin.

Sedimentation rates based on paleomagnetic ages indicate a mean rate of deposition is greater than $0.5 \mathrm{~m} / 1,000$ years. The OSL ages suggest that rapid deposition occurred in the top $8 \mathrm{~m}$ of well, probably occurring in less than 1,500 years; the rate of sedimentation would have approached $1 \mathrm{~m}$ every 190 years. Between 43 and $8 \mathrm{~m}$, the age of sediment burial is $100 \mathrm{ka}$ (probably older) and the rate of sedimentation slowed to $1 \mathrm{~m}$ every $2.5 \mathrm{ka}$. If the TL is returning more reliable ages in the older core (when compared with other geochronology), the rate of sedimentation in the core between 43 and $56 \mathrm{~m}$ is $1 \mathrm{~m}$ every $2.7 \mathrm{ka}$.

Paleoecological analyses of LWEB based on both micro- and macrofossils indicate deposition gradually shallowed from upper slope depths at the base of the well to shallow inner neritic depths at $20.6 \mathrm{~m}$ (shaker 6K) and finally lacustrine or fluvial deposition at the top (fig. 61). Paleoecologic analyses of the faunas assigned to the Wheelerian Stage, 387.5-325.0 m, indicate that deposition occurred in the upper bathyal biofacies $(150-500 \mathrm{~m})$, but the older Wheelerian assemblages were deposited at depths slightly greater than $300 \mathrm{~m}$, whereas deposition of the younger Wheelerian samples occurred at depths of less than $300 \mathrm{~m}$. Although faunas in the overlying questionably Wheelerian samples $(325.7$ and $325.0 \mathrm{~m})$ continue to suggest the upper bathyal biofacies, deposition probably occurred near the shelf/slope break $( \pm 150 \mathrm{~m})$.

Although macrofaunas in the sandy middle portion of LWEB (289-148 m) frequently are represented by shell fragments, the faunas generally indicate deposition occurred at outer sublittoral depths shallowing up section to subtidal depths. Outer sublittoral mollusks become evident starting at $192 \mathrm{~m}$ and are present to $172 \mathrm{~m}$. Mollusks from 171 to $163 \mathrm{~m}$ indicate intertidal to shallow, subtidal water depths, and at $163 \mathrm{~m}$ the bivalve Argopecten indicates water temperatures similar to today or warmer. At approximately $149 \mathrm{~m}$, the molluscan fauna suggests water depths between 30 and $90 \mathrm{~m}$.

Benthic foraminifers from the oldest early Hallian sample at $148 \mathrm{~m}$ suggest water depths were within the upper bathyal biofacies $(150-300 \mathrm{~m})$ and gradually shallowed to outer neritic depths by the stratigraphically highest early Hallian sample at $143 \mathrm{~m}$. This interpretation is corroborated by the molluscan fauna that indicate shelf depths. An intertidal to shallow water fauna is present between 110 and $81 \mathrm{~m}$ and is intermittently found between 72 and $20 \mathrm{~m}$. Megafossils found in the well at $2 \mathrm{~m}$ are lacustrine, and (or) fluvial, and are associated with a few vertebrates. 


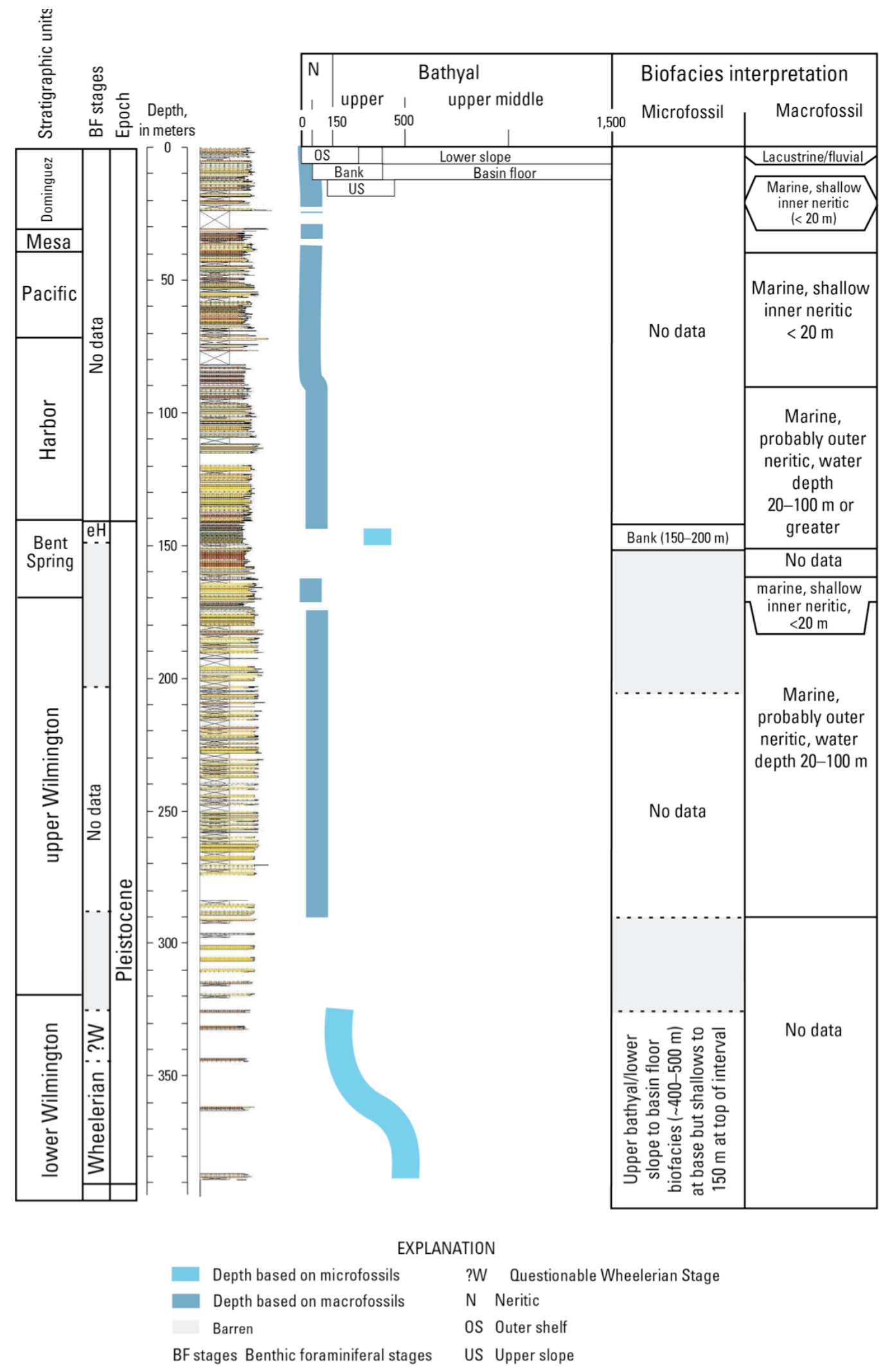

Figure 61. Summary of paleoecological interpretations of Long Beach Webster School core site and monitoring well, Long Beach, California, based on benthic foraminifers and macrofossils. Stratigraphic units are identified in the left column, and lithologies are indicated on the stratigraphic column by color (clay, green; silt, brown; sand, yellow) (Ponti and others, 2007). 


\section{Chapter 6-Long Beach City College Core Site and Monitoring Well, Long Beach, California}

\section{Introduction}

The Long Beach City College core site and monitoring well (LBCC) is located on the Long Beach City College Pacific Coast campus near the corner of Walnut and 20th Streets in Long Beach, California (lat 334' $37.3^{\prime \prime} \mathrm{N}$; long $118^{\circ} 10^{\prime} 9.7^{\prime \prime} \mathrm{W}$ ) (fig. 1). Total depth of the well is 461.8 $\mathrm{m}$ (table 1). Samples collected at LBCC were examined for benthic foraminifers (Kristin McDougall), macrofossils (Charles Powell, II), paleomagnetism (John Hillhouse), tephra (Elmira Wan and Andrei Sarna-Wojcicki), and OSL and TL (Shannon Mahan). The middle Long Beach (461.8-428.2 m), upper Long Beach (428.2-405.4 m), lower Wilmington (405.4-277.4 m), upper Wilmington (277.4-141.7 m), Bent Spring (141.7-115.8 m), Harbor (115.8-64.0 m), Pacific (64.0-33.5 m), Mesa (33.5-9.7 m), and Dominquez $(9.8-0 \mathrm{~m})$ units were recognized in this well (Ponti and others, 2007; Ponti, oral commun., 2011).

\section{Biostratigraphy}

\section{Benthic Foraminifers}

Benthic foraminifers appear throughout LBCC and are most prevalent in the lower part of the well (plate 11). Of the 83 microfossil samples examined from LBCC, 44 contained no foraminifers. Most of the barren samples were found in the upper part of the well (fig. 62). Benthic foraminiferal assemblages in LBCC indicate that this well is Pleistocene in age and contains species representative of the Venturian, Wheelerian, and Hallian Stages (fig. 63).

The interval from 462.1 to 457.6 m (Mf11576-Mf11573) is questionably assigned to the Venturian Stage based on the abundance of Bolivina spissa, Gyroidina altiformis, and Oridorsalis umbonatus. Both G. altiformis and O. umbonatus are common in the Venturian Stage, but appear rarely in the Wheelerian. The Venturian/Wheelerian boundary is placed between $457.6 \mathrm{~m} \mathrm{(Mf}$ 11573) and $396.8 \mathrm{~m}$ (Mf11146). Two barren samples, Mf11571 and Mf11572, occur in this interval.

Above the Venturian/Wheelerian boundary, Cibicides mckannai suppressa, Epistominella pacifica, Uvigerina juncea, and U. peregrina appear more commonly, whereas the abundance of Bolivina interjuncta, B. spissa, Gyroidina altiformis, and Oridorsalis umbonatus declines, or they disappear from the faunas. Various species of Cassidulina appear and dominate some samples. Cibicides mckannai, C. mckannai suppressa, and E. pacifica last appear at about $226.2 \mathrm{~m}$ (Mf 11116), so the Wheelerian/early Hallian boundary is placed between 226.2 and $200.0 \mathrm{~m}$ (Mf11116-Mf11115).

Cassidulina tortuosa and C. limbata dominate the microfauna between 175.5 and $171.4 \mathrm{~m}$ (Mf11113-Mf11110), which suggests the early Hallian Stage. The presence of the shallow-water Hallian species, Elphidium, and the appearance of Praeglobobulimina affinis, Uvigerina juncea, and Trifarina angulosa, supports this interpretation. Cassidulina transluscens and Cibicides fletcheri, which also first appear in the early Hallian, dominate the sample at 200.0 m (Mf11114). The Hallian/early Hallian boundary falls within the $23 \mathrm{~m}$ interval between 171.4 and $149.1 \mathrm{~m}$. The five fossiliferous samples in the upper 65 cores (Mf11088, Mf11103, Mf11106, Mf11107, and Mf11109) contain a shallow-water Hallian Stage assemblage dominated by Ammonia beccarii and various Elphidium species. 


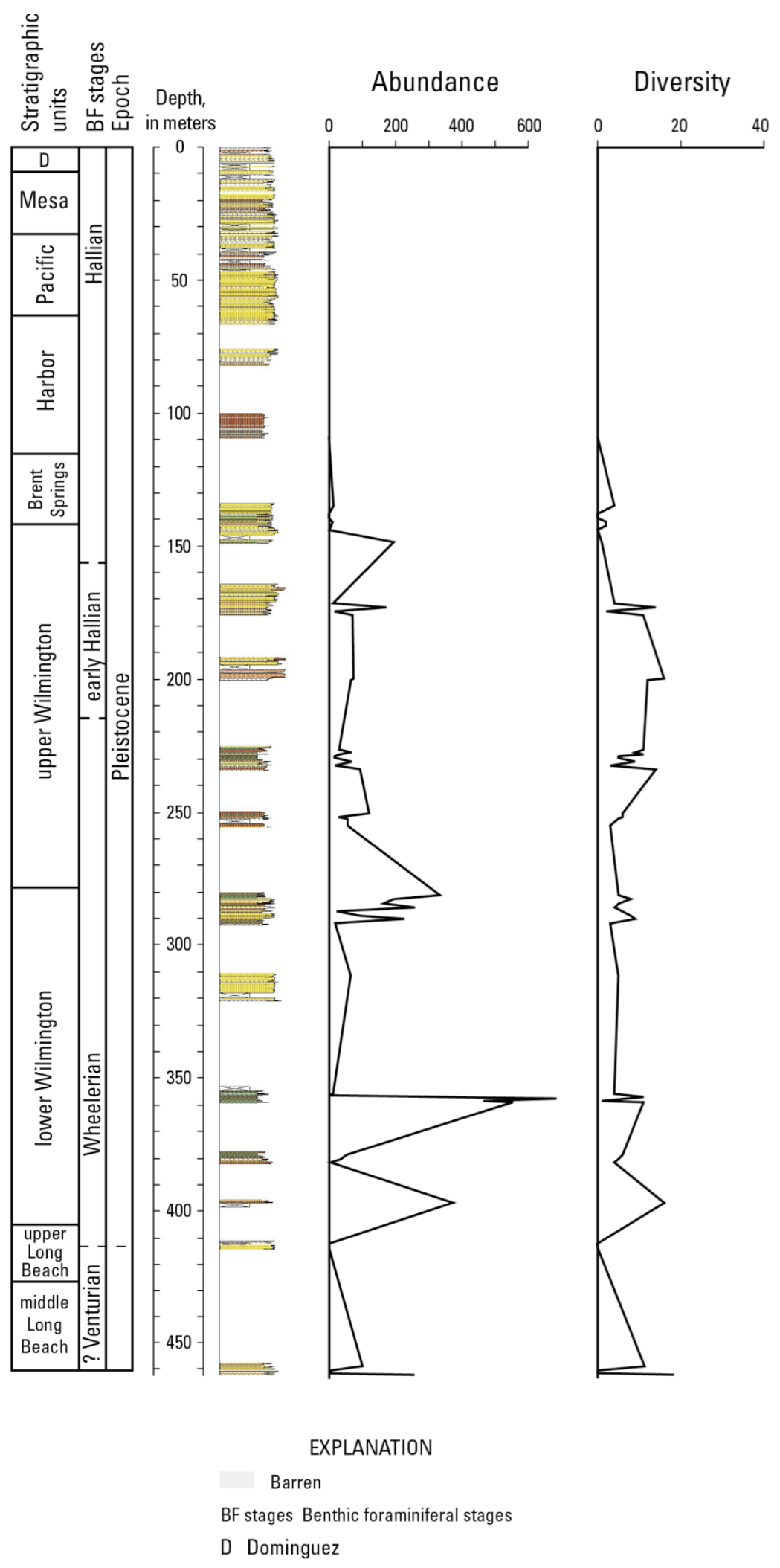

Figure 62. Abundance and diversity of the foraminiferal fauna in Long Beach City College core site and monitoring well, Long Beach, California. Abundance of the foraminifers is based on the number of foraminiferal specimens present in the sample. Diversity is the number of species identified in the sample. Stratigraphic units are identified in the left column, and lithologies are indicated on the stratigraphic column by color (clay, green; silt, brown; sand, yellow) (Ponti and others, 2007). 


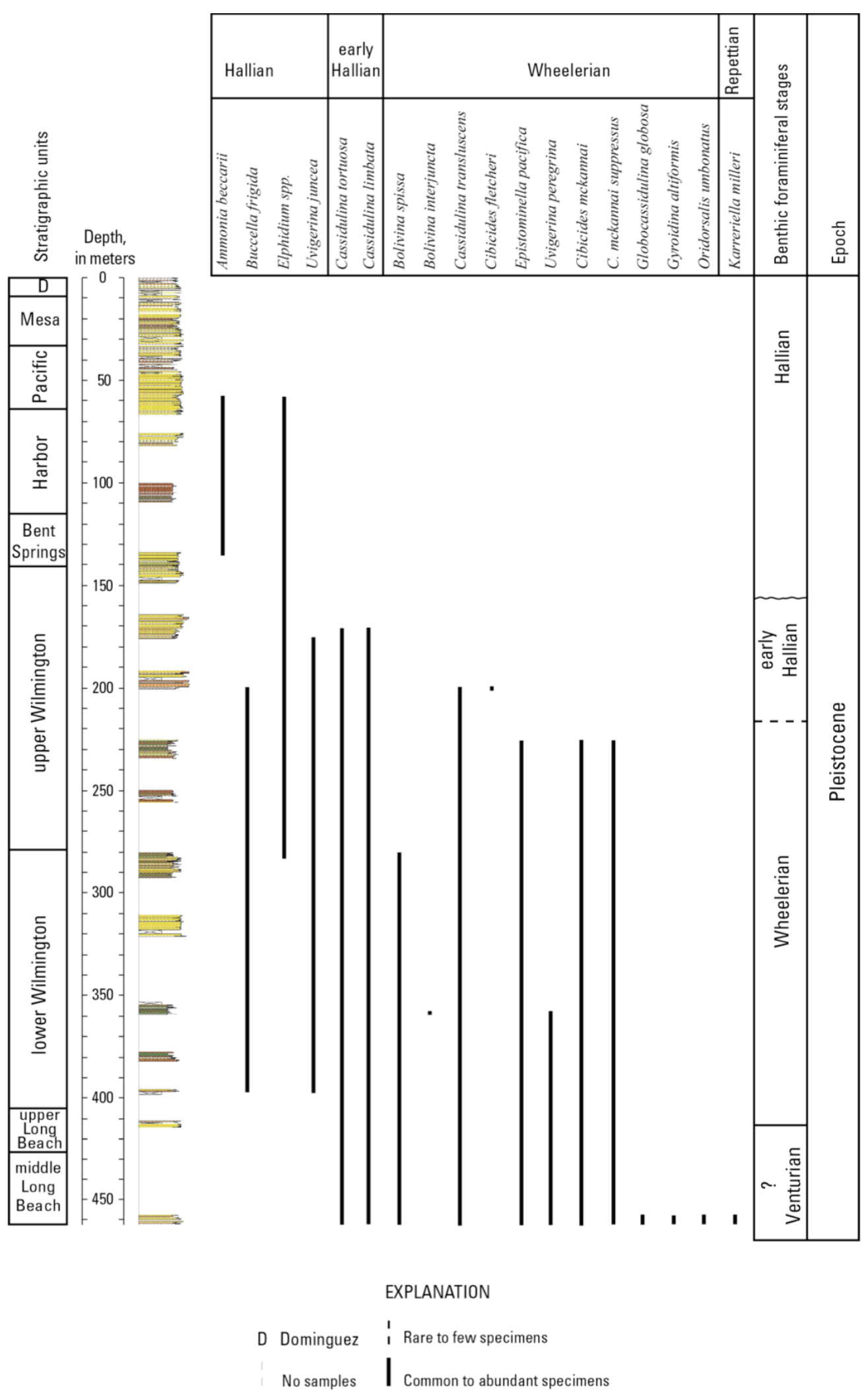

Figure 63. Stratigraphic distribution of age-diagnostic benthic foraminifers in Long Beach City College core site and monitoring well, Long Beach, California. Abundances are given in plate 11. Stratigraphic units are identified in the left column, and lithologies are indicated on the stratigraphic column by color (clay, green; silt, brown; sand, yellow) (Ponti and others, 2007). 


\section{Macrofossils}

Between 354.0 and 10.7 m, 107 samples containing remains of mollusks, arthropods, and echinoids were obtained from LBCC (plate 12). These samples contain 59 mollusk taxa (indeterminate fragments, 31 bivalves, 26 gastropods, and two scaphopods), three arthropods, one echinoid, fish, and mammal remains. Of the 107 samples collected, 67 were from the shaker table. In situ fossils are rare and constitute less than 27 percent of the samples collected. Many, if not all, of the in situ samples are composed partially of disarticulate bivalves, and many specimens are worn and(or) broken, indicating they were not living when buried and are likely transported. The only extinct species present is possibly Calicantharus fortis, questionably identified from fragments.

Two age-diagnostic occurrences of megafossils were encountered in LBCC. The first is the presence of the genus Chione between 20.4 and $<30 \mathrm{~m}$ (LBCC17, C-1, 50-57 cm and shaker 95100). In Los Angeles County Chione is found in deposits older than MIS 5e ( $\geq 116 \mathrm{ka}$ ) (Ponti, 1989; Powell and others, 2007) and in the Holocene $\leq 12 \mathrm{ka}$ (Powell, unpublished data; Coan and others, 2000). Its occurrence here suggests an age of $\geq 116 \mathrm{ka}$. The second is the presence of shell fragments attributed to the extinct gastropod Calicantharus fortis between 143.8 and $142.1 \mathrm{~m}$ (LBCC62, C1, 43-56 cm and LBCC61, C1, 20-40 cm). Calicantharus fortis is known in southern and central California in possibly late Miocene, or early Pliocene to Late Pleistocene deposits. Discounting the late Pleistocene occurrences as being reworked (Woodring and others, 1946), the youngest age of this species is middle Pleistocene (about 300-400 ka), giving a minimum age estimate for the part of the well where it occurs.

\section{Geochronology}

\section{Paleomagnetism}

The intensities of remanent magnetization from LBCC are listed for the natural state and after the 15 and $30 \mathrm{mT}$ treatments in appendix III, table 17. The median value (logarithmic distribution) of NRM is approximately $10 \mathrm{milliA} / \mathrm{m}$ (10-3 Ampere/meter). Very low values of NRM occur at four depths: (1) the middle of lower Wilmington unit, (2) the Bent Spring/Harbor boundary, (3) the Harbor-Pacific boundary, and (4) the top of the Pacific unit (fig. 64). The NRM variation is mimicked by the magnetic-susceptibility record. This correlation indicates that concentration of magnetic minerals (primarily magnetite) is the main influence on intensity of magnetization, rather than variation of the past geomagnetic-field strength.

Table 17. Intensity of remanent magnetization and magnetic susceptibility of the Long Beach City College core site and monitoring well (LBCC) samples. [Title of table is included here for continuity; complete table is in appendix III.]

Alternating-field treatments to $50 \mathrm{mT}$ successfully isolated a stable-magnetization direction in 77 percent of the specimens $\left(\mathrm{MAD} \leq 10^{\circ}\right)$. Optimum cleaning and stabilization of the magnetic direction typically was achieved by alternating field treatment of 15-30 mT. Best-fit inclinations obtained from the demagnetization treatments are listed in appendix III, table 18. With the exception of two short intervals of negative inclination near the top of the well, positive (downward) inclinations consistent with a normal-polarity geomagnetic field were found down to the lowest sample at $461.19 \mathrm{~m}$ (fig. 64). The upper inclination anomaly (A) occurs in two adjacent

Table 18. Paleomagnetic results from the Long Beach City College core site and monitoring well (LBCC), Long Beach, California. [Title of table is included here for continuity; complete table is in appendix III.] 


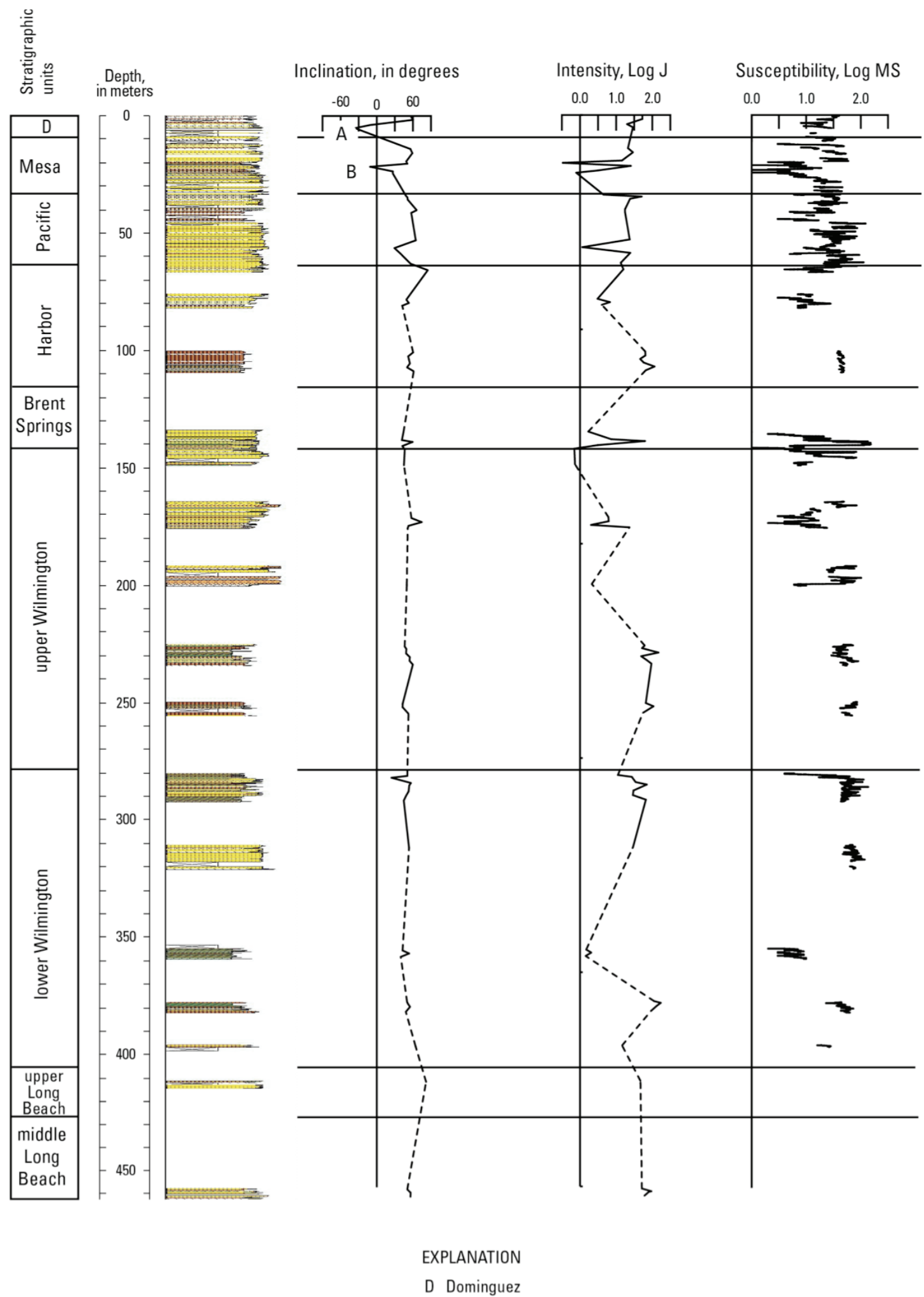

Figure 64. Remanent-magnetization (inclination and intensity) properties and magnetic susceptibility of Long Beach City College core site and monitoring well, Long Beach, California. Inclination is measured in degrees. Intensity is depicted with a logarithmic scale, where 0.0 equals 1 milliAmpere $/ \mathrm{m}$. Magnetic susceptibility also is given with a logarithmic scale, where 0.0 equals 10-6 SI. Magnetic excursions are marked A and B. Stratigraphic units are identified in the left column, and lithologies are indicated on the stratigraphic column by color (clay, green; silt, brown; sand, yellow) (Ponti and others, 2007). 
cores at 3.87 and $5.21 \mathrm{~m}$ in the Dominguez unit reaching a reversed-polarity inclination $\left(-36.4^{\circ}\right)$. At a depth of $21.7 \mathrm{~m}$ near the top of the Pacific unit, the inclination is $-11.0^{\circ}$. This anomaly (B) occurs within an interval of very low NRM intensity and low magnetic susceptibility. In both cases the inclination anomalies are within fine- to medium-grained sand intervals, while the surrounding normal-polarity inclination zones are in silts and clays.

The presence of the Lava Creek B ash at $378 \mathrm{~m}$ in LBCC (see Tephrochronology) indicates that the middle lower Wilmington unit was deposited by $639 \pm 2$ ka during the Brunhes Normal Polarity Chron. The normal-polarity LBCC inclination record is consistent with deposition of Brunhes age. LBCC inclinations from the base of the lower Wilmington unit and from the lowest paleomagnetic samples at $461.2 \mathrm{~m}$ show normal polarity, and we see no evidence of the Matuyama Chron, the most recent sustained interval of reversed geomagnetic polarity that ended $0.78 \mathrm{Ma}$. However, benthic foraminifers suggest that deposits immediately below the lower Wilmington are Pleistocene in age $(\geq 1.8 \mathrm{Ma})$. A major unconformity separates the lower Wilmington from the underlying upper Long Beach unit, and absence of reversed polarity and the foraminiferal evidence imply that the upper part of the Matuyama Reversed-Polarity Chron (1.78-0.78 Ma) is missing (Ogg and Smith, 2004). The youngest possible correlation of the normal-polarity inclination in the middle Long Beach unit is with the Olduvai subchron (1.95-1.78 Ma).

Near the top of LBCC, inclination anomaly (B) in the Pacific unit is correlated with the Blake excursion, a global geomagnetic instability that occurred during MIS 5e ( $\sim 117 \mathrm{ka}$; Tucholka and others, 1987). Anomaly (A) in the Mesa unit is a possible match for the Laschamp event (40 ka). Both anomalies occur within medium-to-fine sandy beds, which are prone to disturbance during drilling. Slightly above the anomaly identified as the Blake event is the youngest occurrence of the bivalve mollusk Chione in this well. Chione last appears in the Los Angeles Basin at $\geq 116$ $\mathrm{ka}$ and reappears in the Holocene $(\leq 12 \mathrm{ka})$.

\section{Optically Stimulated Luminescence Dating}

Four samples were taken for luminescence dating between 5.6 and $380.7 \mathrm{~m}$. The sample, at $380.7 \mathrm{~m}$ (LBCC-109), was considered to be too deep for reliable OSL ages to be obtained, and thus was not run for any form of luminescence dating. TL dating was not obtained on these samples owing to the unexpected extended time needed for machine repairs.

A sensitivity-corrected quartz OSL growth curve for the sample at $22.7 \mathrm{~m}$ (LBCC-15) is linear in the dose range 0 to about $40 \mathrm{~Gy}$; it then becomes increasingly nonlinear to $160 \mathrm{~Gy}$ and can be best fitted with an exponential function (fig. 65). The observation that the OSL can be fitted with an exponential function suggests that the OSL signal might be reaching saturation for the luminescence centers. This suggestion is seen more clearly in figure 66 for the sample at $105 \mathrm{~m}$ (LBCC-52C), which shows saturation at about $175 \mathrm{~Gy}$ (on figure as 2,200 seconds of beta). The age given for this sample is thus considered to be a minimum at $45 \mathrm{ka}$.

Equivalent-dose distributions generally were symmetrical for samples at 5.6 and $105 \mathrm{~m}$ (LBCC-52C and LBCC-4C), whereas the sample at $22.7 \mathrm{~m}$ (LBCC-15C) was positively skewed, with two grain populations, one between 0 and $40 \mathrm{~Gy}$, the other between 60 and $180 \mathrm{~Gy}$. The largest observable dose, however, is about $80 \mathrm{~Gy}$.

Unlike the quartz OSL, the IRSL-OSL growth curve for the sample at $22.7 \mathrm{~m}$ (LBCC-15C) is linear to the dose range from 0 to $160 \mathrm{~Gy}$, and the two replicate IRSL runs for this sample are within error (fig. 67). The feldspar ages are slightly older than the quartz ages for the first two samples (table 19), but for the deeper, older sample the feldspar ages are considerably older than the quartz. While the quartz OSL displayed considerable age underestimation at $45 \mathrm{ka}$, the IRSL ages appear to be correctly estimating the age of deposition, at least for the sample at $105 \mathrm{~m}$ (LBCC-52C). 

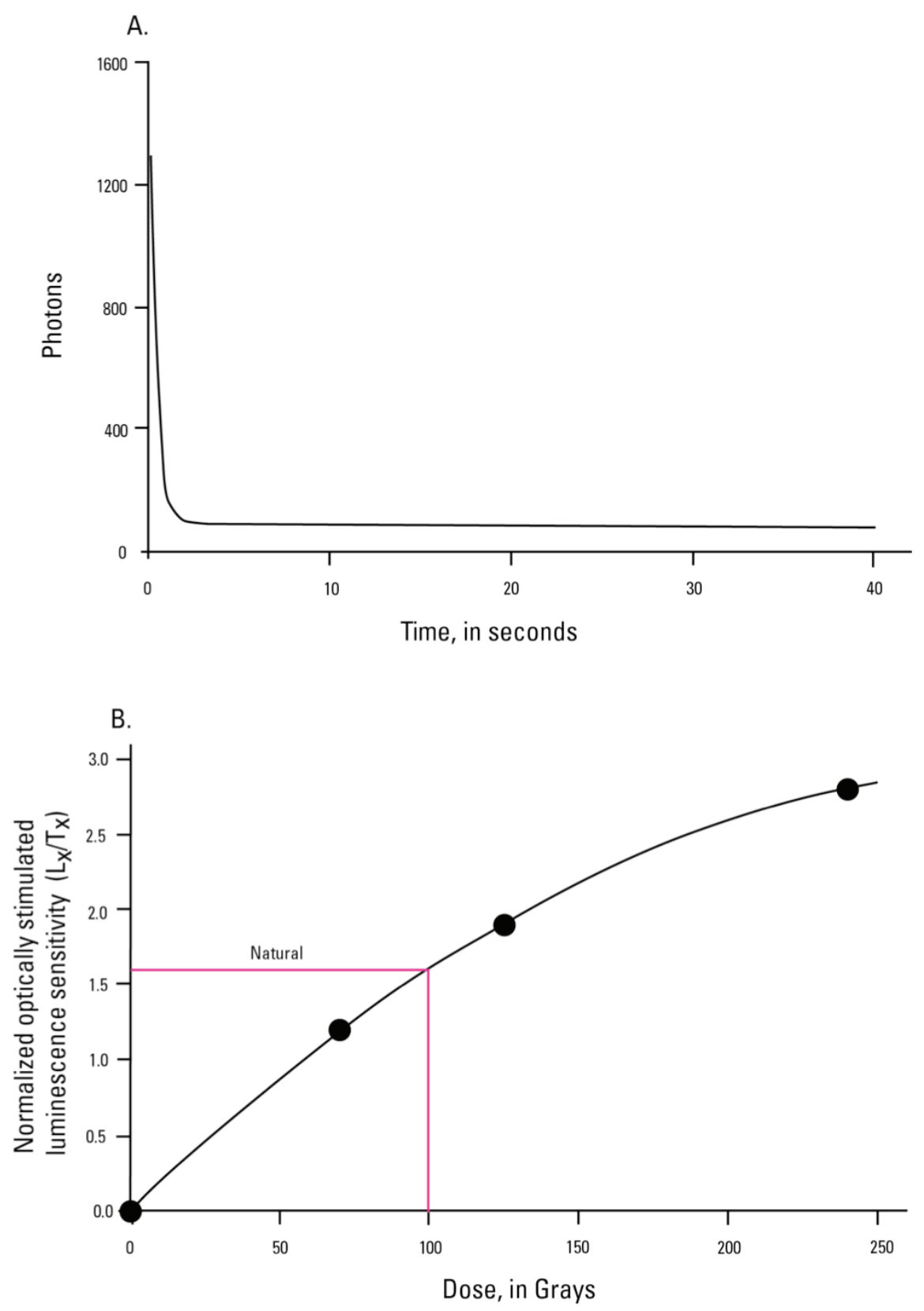

Figure 65. A. Optically stimulated luminescence (OSL) decay curve for LBCC-15C $(22.7 \mathrm{~m})$ showing the quartz signal as measured with blue-light wavelength emitting diodes. Time is measured in seconds (s) and OSL is measured in photon counts for a total time of $40 \mathrm{~s}$. B. LBCC-15C growth curve, with the natural plotted on the $Y$ axis. Regeneration proceeded "optimally", with a recycle that duplicates the first measurement; circles indicate increases in response to increasing beta radiation. Fit is to an exponential and linear function. Dose is measured in Grays (Gy, absorbed radiation) and OSL is measured in unitless normalized OSL sensitivity measurements (Lx/Tx).

Elemental data analyses did not indicate large dose rates that were likely to cause the creation of large amounts of unstable luminescence in a short amount of time (Aitken, 1998) (table 20), and closely track other elemental data collected for the other wells (tables 6, 9, 13, and 16). The IRSL curves were fitted with a single saturating exponential function, but probably still underestimate the value of the equivalent dose when attempting to project further than $300 \mathrm{~Gy}$ (or 


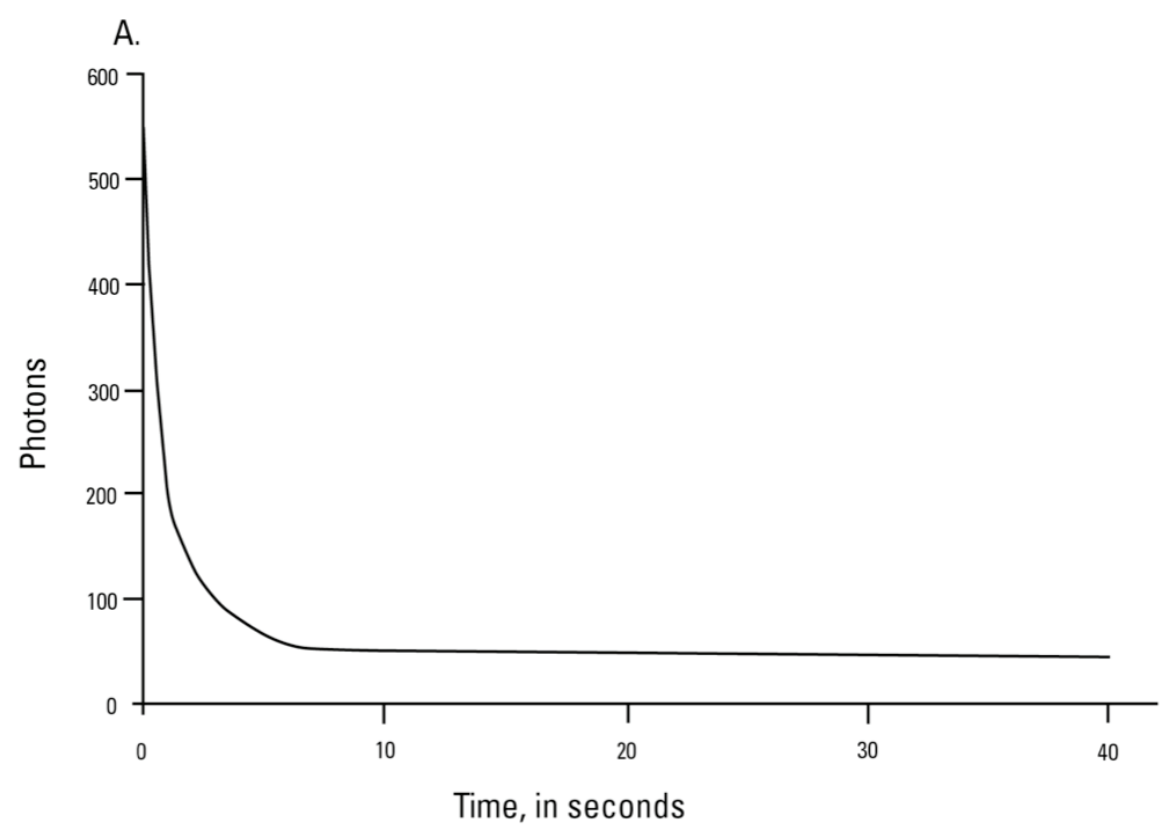

B.

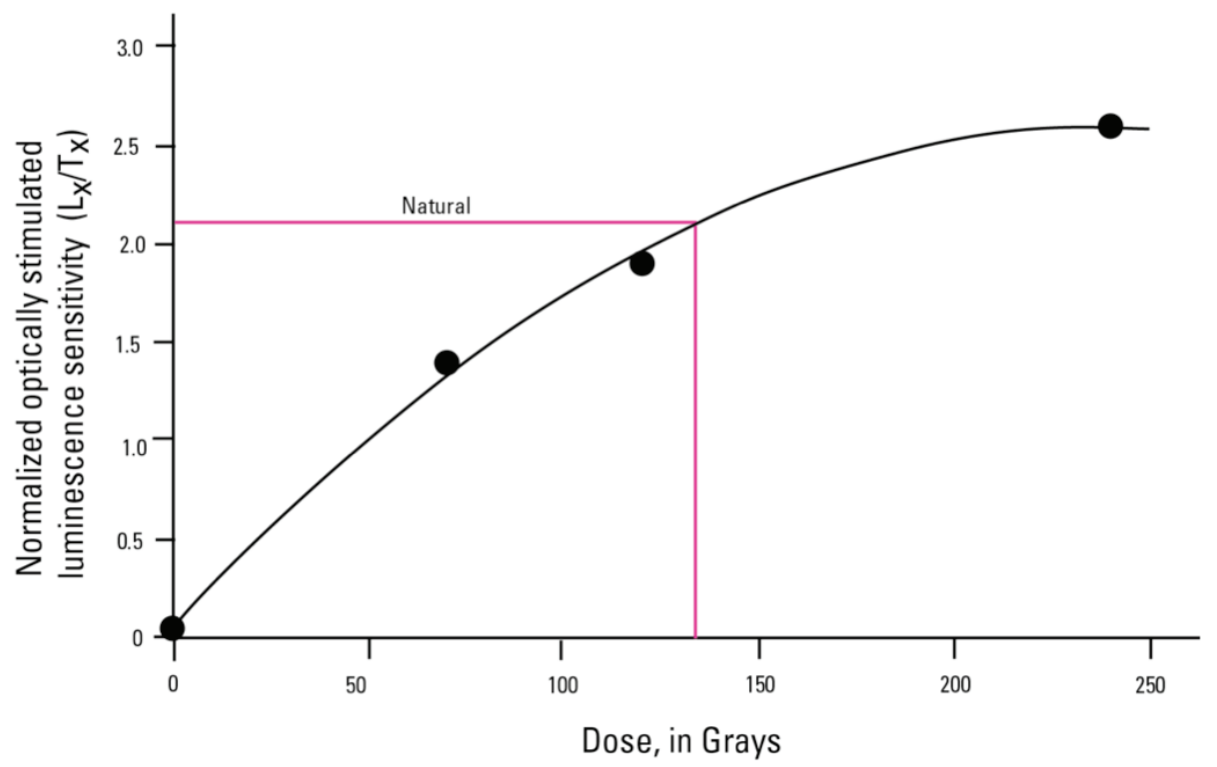

Figure 66. A. OSL decay curve for LBCC-52C $(105.0 \mathrm{~m})$ showing the quartz signal as measured with bluelight wavelength emitting diodes. Time is measured in seconds (s), and optically stimulated luminescence (OSL) is measured in photon counts for a total time of $40 \mathrm{~s}$. B. LBCC-52C growth curve, with the natural plotted on the $Y$ axis. Regeneration proceeded "optimally", with a recycle that duplicates the first measurement; circles indicate increases in response to increasing beta radiation. Fit is to an exponential function. Dose is measured in Grays (Gy, absorbed radiation) and OSL is measured in unitless normalized OSL sensitivity measurements (Lx/Tx).

for samples older/deeper than LBCC-52C). At ages greater than $100 \mathrm{ka}$, it is not possible to accurately date these sediments using OSL, and it is more than likely that the feldspar age for LBCC-52C $(105 \mathrm{~m})$ is also an underestimate, given our experiences with other samples at depth.

The magnetic anomaly correlated with the Laschamp event (40 ka) seen in LBCC from 3.9 to $5.2 \mathrm{~m}$ does not agree with the OSL ages obtained from a sample at $5.6 \mathrm{~m}$ (LBCC-4). The OSL 


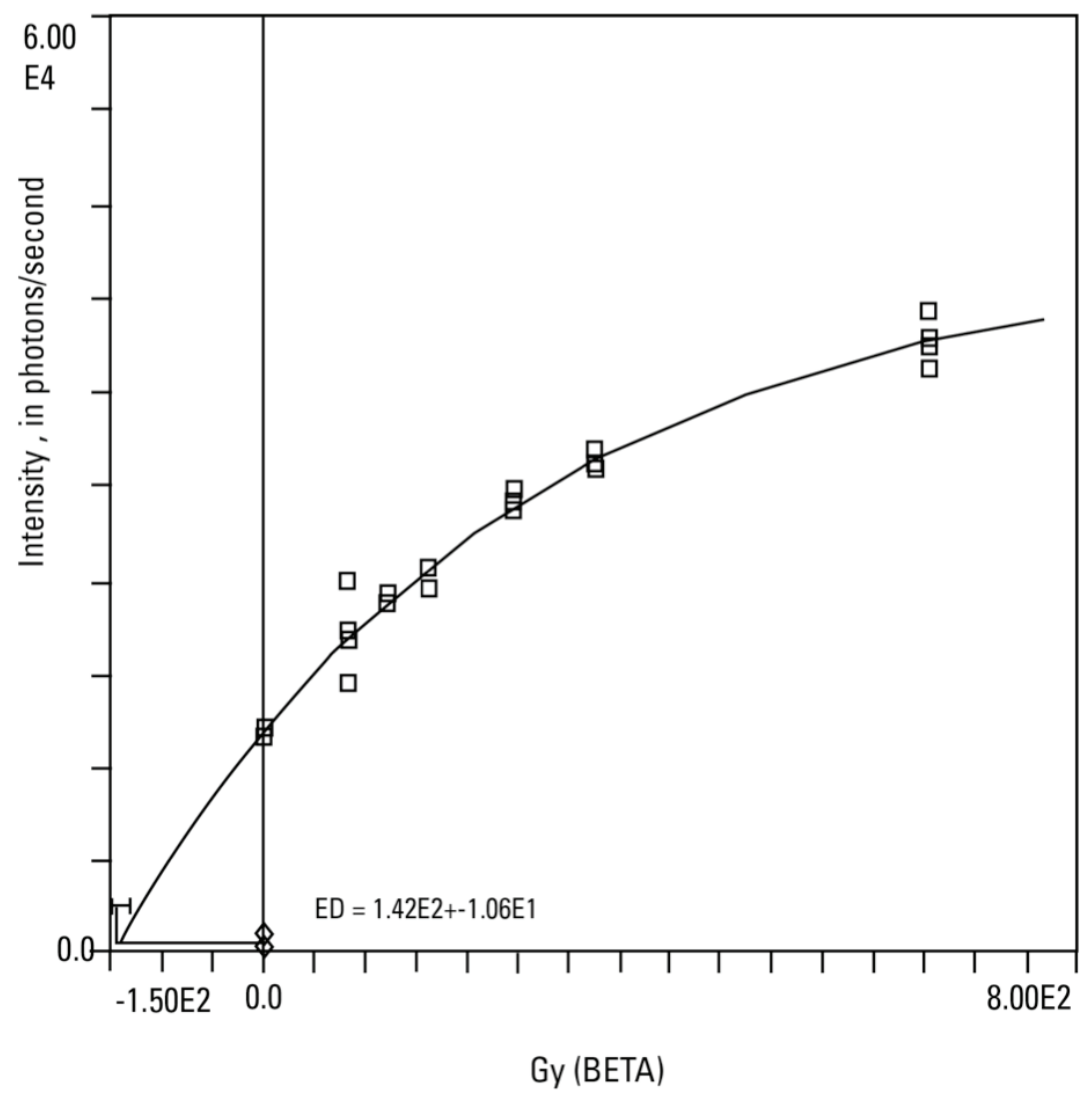

Figure 67. IRSL growth curve for a multi-aliquot additive dose method (MAAD) of sample at 22.7 (LBCC 15). Bleaches are denoted with diamonds, naturals sit on vertical axis, and increasing beta radiated aliquots (six sets of four) are shown on an exponential fit line. The $X$ axis shows the measured equivalent dose in Grays (Gy) when compared to calibrated Grays generated by exposure to a beta source. The $Y$ axis shows the intensity of light emitted from the aliquots and is measured in photons/second.

ages of 20-26 ka for LBCC-4 (table 19) do not match any known excursions, and it is puzzling that both the IRSL-OSL and quartz OSL ages would record much younger ages if the Laschamp event is indeed recorded at $5 \mathrm{~m}$. The second magnetic anomaly, noted at $21.7 \mathrm{~m}$ in LBCC, was correlated with the Blake event $(\sim 117 \mathrm{ka})$, but also does not agree with the OSL ages from a sample at $22.7 \mathrm{~m}$ (LBCC-15; 28-33 ka). This observation is even more vexing because a positive correlation between a TL age and the Blake event is recorded in LWEB. However, the last appearance of the macrofossil Chione $(\geq 116 \mathrm{ka})$ in LBCC that occurs at about the same level $(20.4 \mathrm{~m})$ is more compatible with the paleomagnetic interpretation than the OSL ages. The OSL ages are much younger than either the paleomagnetic or macrofossil evidence but passed all the tests within the luminescence dating laboratory. The young evidence of OSL ages cannot be confirmed at this time and should be treated as an alternate hypothesis to sediment deposition until the matter can be resolved.

\section{Tephrochronology}

A distinct tephra layer was found in LBCC, and instrumental analyses of individual volcanic glass shards and a bulk volcanic glass sample were done, resulting in a definitive age call for the tephra. The volcanic glass at $378 \mathrm{~m}$ (LBCC 108, C-1, 45-51 cm) is composed of colorless, angular, isotropic, predominantly solid, platy, bubble wall (bw), or bubble-wall junction (bwj) 
Table 19. Feldspar infrared stimulated luminescence (IRSL) and quartz optically stimulated luminescence (OSL) ages for the Long Beach City College core site and monitoring well (LBCC), Long Beach, California.

[\%, percent; ka, thousands of years; Gy, Grays; >, greater than; -, no data]

\begin{tabular}{|c|c|c|c|c|c|c|c|c|}
\hline $\begin{array}{c}\text { Sample } \\
\text { information } \\
\text { core depth }(\mathrm{m}) \text { : } \\
\text { material }\end{array}$ & $\begin{array}{c}\text { Moisture } \\
(\%)^{a}\end{array}$ & $\begin{array}{l}\text { IRSL dose } \\
\text { rate } \\
\text { (Gy/ka) }\end{array}$ & $\begin{array}{c}\text { Equivalent } \\
\text { dose } \\
\text { (Gy) }\end{array}$ & $\begin{array}{l}\text { IRSL age } \\
\qquad(k a)^{b}\end{array}$ & $\mathrm{nc}^{\mathrm{c}}$ & $\begin{array}{l}\text { Blue dose rate } \\
\qquad \text { (Gy/ka) }\end{array}$ & $\begin{array}{c}\text { Equivalent } \\
\text { dose } \\
\text { (Gy) }\end{array}$ & $\begin{array}{l}\text { Blue age } \\
\qquad(k a)^{d}\end{array}$ \\
\hline $\begin{array}{l}\text { LBCC-4 } \\
\text { 5.6: Sand }\end{array}$ & $18(26)$ & $4.13 \pm 0.08$ & $\begin{array}{l}108 \pm 1.63 \\
- \\
\end{array}$ & $\begin{array}{l}26.2 \pm 1.25 \\
-\quad \\
\end{array}$ & $35(40)$ & $2.96 \pm 0.06$ & $59.8 \pm 5.32$ & $20.2 \pm 3.67$ \\
\hline $\begin{array}{l}\text { LBCC-15 } \\
\text { 22.7: Sand }\end{array}$ & $29(40)$ & $4.31 \pm 0.08$ & $\begin{array}{l}135 \pm 0.50 \\
141 \pm 2.07\end{array}$ & $\begin{array}{l}31.4 \pm 1.20 \\
32.6 \pm 1.47\end{array}$ & $20(25)$ & $3.04 \pm 0.05$ & $84.7 \pm 5.06$ & $27.9 \pm 3.48$ \\
\hline $\begin{array}{l}\text { LBCC-52 } \\
\text { 105: Silt }\end{array}$ & $29(55)$ & $3.49 \pm 0.08$ & $\begin{array}{l}266.2 \pm 3.22 \\
-\quad\end{array}$ & $\begin{array}{l}76.3 \pm 4.10 \\
-\end{array}$ & $24(30)$ & $2.47 \pm 0.06$ & $110 \pm 6.61$ & $44.7 \pm 5.79$ \\
\hline
\end{tabular}

${ }^{a}$ Field moisture, possible saturated moisture in parentheses; ages based on 20-40 percent moisture content through time.

${ }^{b}$ Silt fraction (4-11 micron size) for IRSL as multiple aliquot additive dose technique.

${ }^{c}$ Number of replicated equivalent dose estimates used to calculate the mean. Figures in parentheses indicate total number of measurements made, including failed runs with unusable data.

${ }^{\mathrm{d}}$ Lab used fine sand grains (125-90 micron size) for quartz OSL as single aliquot regeneration technique. Fitted to a linear regression. Errors on ages, equivalent dose and dose rate data at one sigma were calculated before rounding.

Table 20. Elemental concentrations and associated dosimetry for Long Beach City College core site and monitoring well (LBCC), Long Beach, California, optically stimulated luminescence (OSL) samples.

$\left[\%\right.$, percent; ppm, parts per million; $\mathrm{m}$, meter; $\mathrm{D}_{\mathrm{r}}$, dose rate; K, Potassium; $\mathrm{U}$, Uranium; Th, Thorium; Rb, Rubidium; - , no data]

\begin{tabular}{|c|c|c|c|c|c|c|c|c|c|c|c|c|}
\hline $\begin{array}{l}\text { Sample } \\
\text { number }\end{array}$ & $(\%)$ & (ppm) & (ppm) & Depth & Water & $\begin{array}{c}D_{r} \\
\text { fine } \\
\text { grain }\end{array}$ & $\begin{array}{c}\mathrm{D}_{\mathrm{r}} \\
\text { coarse } \\
\text { grain }^{\mathrm{a}}\end{array}$ & $\begin{array}{c}D_{r} \\
\text { for } K\end{array}$ & $\begin{array}{c}D_{r} \\
\text { for } U\end{array}$ & $\begin{array}{c}D_{r} \\
\text { for } T h\end{array}$ & $\begin{array}{c}D_{r} \\
\text { for } R b\end{array}$ & $\begin{array}{c}D_{r} \\
\text { for } \\
\text { cosmic } \\
\text { ray }\end{array}$ \\
\hline LBCC-4C & 2.30 & 1.89 & 9.96 & 5.56 & 20 & 4.13 & 2.96 & 1.824 & 0.374 & 0.622 & 0.037 & 0.103 \\
\hline LBCC-15C & 2.59 & 2.15 & 12.7 & 22.7 & 30 & 4.31 & 3.04 & 1.870 & 0.388 & 0.721 & 0.038 & 0.025 \\
\hline LBCC-52C & 2.28 & 2.35 & 9.83 & 105 & 40 & 3.49 & 2.47 & 1.511 & 0.390 & 0.515 & 0.030 & 0.002 \\
\hline
\end{tabular}

${ }^{a}$ Coarse grains used for quartz OSL have the alpha component and about $10 \%$ beta component of the dosimetry etched away before analyses.

shards. Many of the bw and bwj shards in this sample are distinctive because they are spherical glass bubbles; they resemble minute, spherical, glass "fishing floats." Nearly all of the tephra samples analyzed in the Tephra Lab containing bw and bwj shards consist of fractured or exploded fragments. Volcanic glass samples containing abundant, whole bubble-glass shards are rare. Scanning electron micrographs (SEMs) of bw, bwj, and whole bwj glass shards are shown in figure 68. Also noted in the glass fraction of this sample were small subpopulations of ribbed, webby/frothy, vesiculated shards. The vesicle shards were observed to be poorly to superhydrated, equant to irregular bubble types.

Additional commonly observed sample components in the sample at $378 \mathrm{~m}$ are highly altered, devitrified, or heavily coated grains. Minor amounts of plagioclase feldspar, biotite, magnetite, quartz, hornblende, lithic, and plant fragments also are present. 

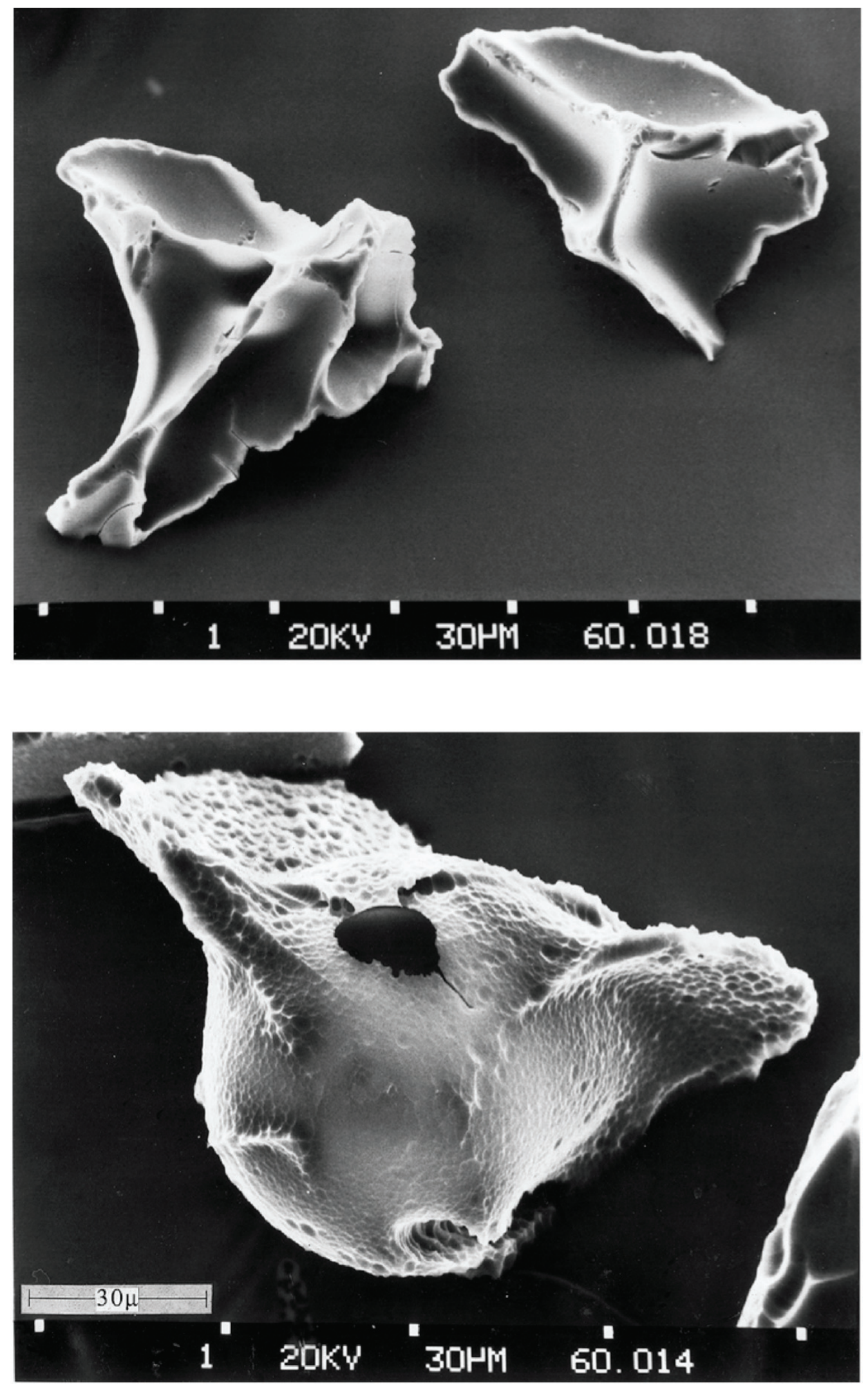

Figure 68. Scanning electron microscope pictures of bubble-wall junction shards and glass-encased spherical bubble walls on flanks from Lava Creek B ash collected from Long Beach City College core site and monitoring well, Long Beach, California. 


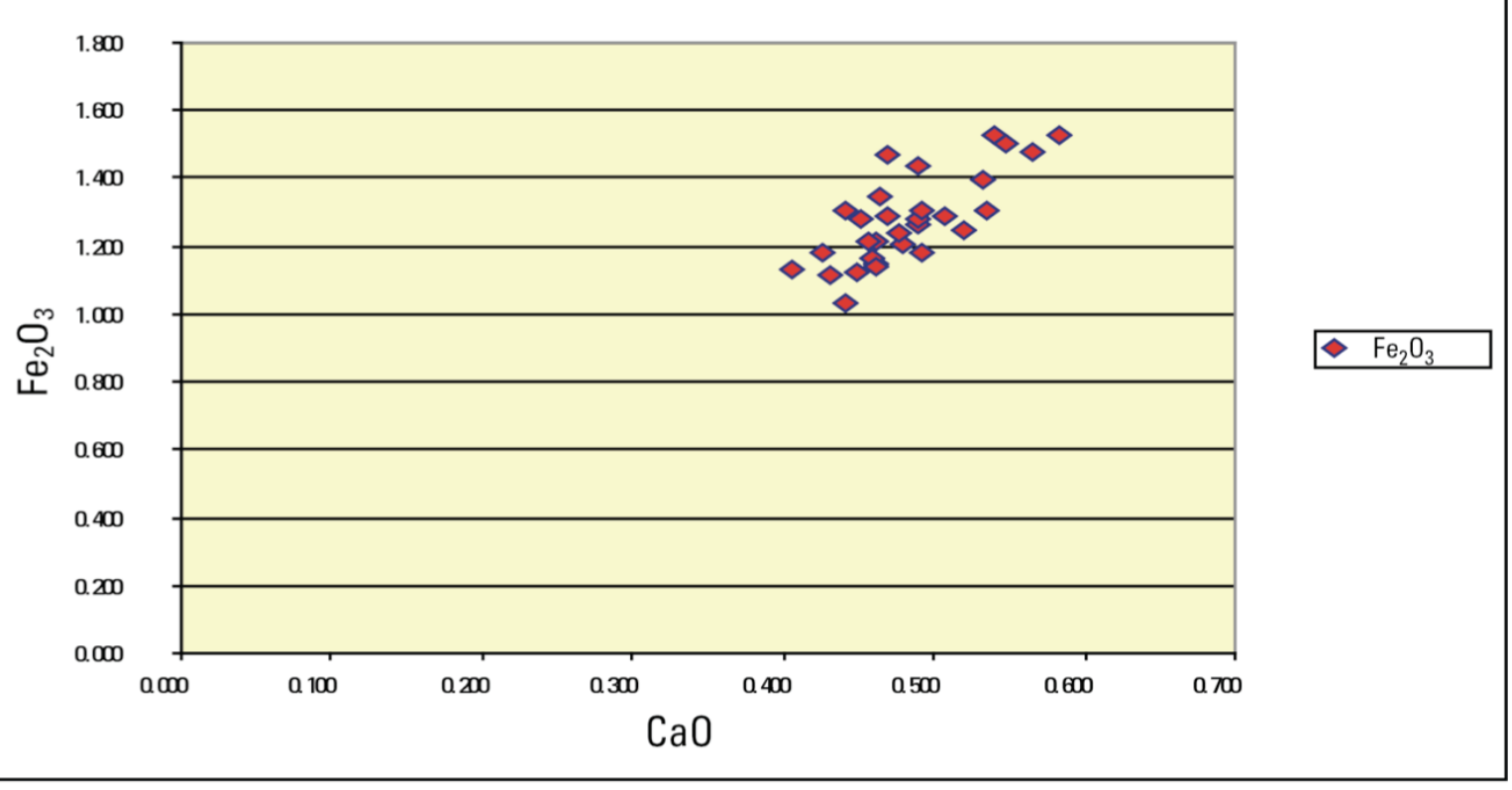

Figure 69. $\mathrm{Fe}_{2} \mathrm{O}_{3}$ versus $\mathrm{CaO}$ scatter-plot showing graphic geochemical fingerprint of sample at $378 \mathrm{~m}$ (LBCC 108, C-1, $45-51 \mathrm{~cm}$ ), a rhyolitic volcanic glass with intermediate and low concentrations, respectively, of $\mathrm{Fe}_{2} \mathrm{O}_{3}$ and $\mathrm{CaO}$.

The above shard morphology also can be used to describe the typical physical characteristics of volcanic glass shards in Lava Creek B ash samples from Death Valley, California (Knott, 1998; Knott and others, 1999; Machette and others, 2001). The mineral assemblages also are similar.

The unnormalized electron microprobe data of single and mean glass-shard compositions for the sample at $378 \mathrm{~m}$ are shown in table 21. In general, $\mathrm{CaO}$ and $\mathrm{Fe}_{2} \mathrm{O}_{3}$ are the most useful major oxides for the identification and correlation of unknown, chemically distinctive ash samples to recognized, geochronically or stratigraphically constrained tephra layers (Sarna-Wojcicki and Davis, 1991). $\mathrm{A} \mathrm{Fe}_{2} \mathrm{O}_{3}$ versus $\mathrm{CaO}$ scatter-plot (fig. 69) illustrates the chemical fingerprint of LBCC 108, C-1, 45-51 cm (378 m).

To obtain chemical correlations for the sample at $378 \mathrm{~m}$ (LBCC 108, C-1), electronmicroprobe data were recalculated (to 100 percent, on a fluid-free basis) and analyzed by similarity coefficients. The results are numerous correlations to tephra layers previously "fingerprinted," identified, and dated as the Lava Creek B ash (table 22). The age of this ash bed is $0.639 \pm 0.002$ $\mathrm{Ma}$, based on ${ }^{40} \mathrm{Ar} /{ }^{39} \mathrm{Ar}$ dating (Lanphere and others, 2002). The eruptive source of the widespread Lava Creek B ash is in the Yellowstone area of northwestern Wyoming (Sarna-Wojcicki and Davis, 1991; Sarna-Wojcicki and others, 1997). Geochemical data from Instrumental Neutron Activation analysis (INAA) of the sample at $378 \mathrm{~m}$ confirm the identification of this rhyolitic volcanic-glass sample as the middle Pleistocene Lava Creek B ash.

Closer examination of the "best matches"/similarity coefficient list also shows that many of the strong ( $>0.95$ similarity coefficient) correlations are to well defined Lava Creek B ash samples (JRK-DV) from the Death Valley, Calif., area. The JRK-DV samples originally were collected and extensively studied by Knott (1998) and Knott and others (1999). The best match for LBCC 108, C-1, 45-51 cm (378 m) is JRK-DV-70 (fig. 70; table 22). The relative locations of LBCC 108C 
Table 21. Electron microprobe analytical data for LBCC108, C-1 (378 m), Long Beach City College core site and monitoring well, Long Bach, California.

[Single shard and mean chemical compositions (oxide concentrations are in weight-percent oxide), and individual and mean weight percent totals (original oxide totals indicate degree of hydration of volcanic shards). $\mathrm{Na}_{2} 0$, sodium oxide; $\mathrm{MgO}$, magnesium oxide; $\mathrm{Al}_{2} \mathrm{O}_{3}$, aluminum oxide; $\mathrm{SiO}_{2}$, silicon dioxide; $\mathrm{K}_{2} \mathrm{O}$, potassium oxide; $\mathrm{CaO}$, calcium oxide; $\mathrm{TiO}_{2}$, titanium oxide; $\mathrm{MnO}$, manganese oxide; $\mathrm{FeO}$, ferrous oxide]

\begin{tabular}{|c|c|c|c|c|c|c|c|c|c|c|}
\hline No. & $\mathrm{Na}_{2} \mathrm{O}$ & $\mathrm{MgO}$ & $\mathrm{Al}_{2} \mathrm{O}_{3}$ & $\mathrm{SiO}_{2}$ & $\mathrm{~K}_{2} \mathrm{O}$ & $\mathrm{CaO}$ & $\mathrm{TiO}_{2}$ & $\mathrm{MnO}$ & $\mathrm{FeO}$ & Total \\
\hline 21 & 2.820 & 0.023 & 11.327 & 71.961 & 5.135 & 0.451 & 0.058 & 0.051 & 1.282 & 93.108 \\
\hline 22 & 2.776 & 0.023 & 11.521 & 71.765 & 5.287 & 0.425 & 0.088 & 0.049 & 1.179 & 93.113 \\
\hline 23 & 2.878 & 0.012 & 11.305 & 70.929 & 5.111 & 0.441 & 0.054 & 0.033 & 1.030 & 91.793 \\
\hline 24 & 2.687 & 0.015 & 11.502 & 71.045 & 5.117 & 0.540 & 0.118 & 0.016 & 1.524 & 92.564 \\
\hline 25 & 2.986 & 0.023 & 11.482 & 71.664 & 5.136 & 0.407 & 0.072 & 0.013 & 1.134 & 92.917 \\
\hline 114 & 3.032 & 0.035 & 11.524 & 71.284 & 4.786 & 0.461 & 0.078 & 0.004 & 1.145 & 92.349 \\
\hline 115 & 2.946 & 0.033 & 11.513 & 71.310 & 4.976 & 0.468 & 0.096 & 0.038 & 1.284 & 92.664 \\
\hline 116 & 2.761 & 0.033 & 11.689 & 71.866 & 5.062 & 0.430 & 0.064 & 0.013 & 1.113 & 93.031 \\
\hline 117 & 2.880 & 0.022 & 11.367 & 71.129 & 4.874 & 0.479 & 0.096 & 0.037 & 1.206 & 92.090 \\
\hline 118 & 3.121 & 0.022 & 11.606 & 71.034 & 4.764 & 0.508 & 0.078 & 0.016 & 1.292 & 92.441 \\
\hline 119 & 3.074 & 0.034 & 11.642 & 71.897 & 4.964 & 0.442 & 0.096 & 0.030 & 1.304 & 93.483 \\
\hline 120 & 3.043 & 0.026 & 11.598 & 71.173 & 4.782 & 0.489 & 0.080 & 0.017 & 1.438 & 92.646 \\
\hline 121 & 2.805 & 0.031 & 11.392 & 71.062 & 4.931 & 0.534 & 0.128 & 0.015 & 1.305 & 92.203 \\
\hline 122 & 3.058 & 0.033 & 11.662 & 71.256 & 5.049 & 0.489 & 0.092 & 0.040 & 1.266 & 92.945 \\
\hline 123 & 2.902 & 0.038 & 11.601 & 71.121 & 4.997 & 0.463 & 0.085 & 0.024 & 1.344 & 92.575 \\
\hline 124 & 2.810 & 0.022 & 11.513 & 70.987 & 5.100 & 0.461 & 0.034 & 0.048 & 1.213 & 92.188 \\
\hline 125 & 2.714 & 0.025 & 11.367 & 71.304 & 5.189 & 0.533 & 0.117 & 0.033 & 1.395 & 92.677 \\
\hline 126 & 3.028 & 0.011 & 11.423 & 72.132 & 4.941 & 0.519 & 0.074 & 0.043 & 1.249 & 93.420 \\
\hline 127 & 3.153 & 0.027 & 11.592 & 70.894 & 4.735 & 0.549 & 0.170 & 0.048 & 1.504 & 92.672 \\
\hline 128 & 2.995 & 0.013 & 11.434 & 70.605 & 5.058 & 0.565 & 0.118 & 0.000 & 1.475 & 92.263 \\
\hline 129 & 3.027 & 0.041 & 11.577 & 70.579 & 4.677 & 0.584 & 0.113 & 0.029 & 1.531 & 92.158 \\
\hline 130 & 2.797 & 0.013 & 11.571 & 70.759 & 4.934 & 0.458 & 0.088 & 0.021 & 1.168 & 91.809 \\
\hline 131 & 2.997 & 0.019 & 11.644 & 72.105 & 4.941 & 0.492 & 0.102 & 0.026 & 1.182 & 93.508 \\
\hline 132 & 2.889 & 0.024 & 11.623 & 71.298 & 4.944 & 0.457 & 0.118 & 0.037 & 1.212 & 92.602 \\
\hline 133 & 3.012 & 0.031 & 11.520 & 71.000 & 5.019 & 0.461 & 0.102 & 0.033 & 1.143 & 92.321 \\
\hline 134 & 2.978 & 0.014 & 11.627 & 71.190 & 4.891 & 0.489 & 0.086 & 0.006 & 1.283 & 92.564 \\
\hline 135 & 3.052 & 0.018 & 11.471 & 71.113 & 4.659 & 0.491 & 0.095 & 0.027 & 1.304 & 92.230 \\
\hline 136 & 3.032 & 0.022 & 11.621 & 71.890 & 4.593 & 0.448 & 0.002 & 0.044 & 1.127 & 92.779 \\
\hline 137 & 2.645 & 0.015 & 11.602 & 71.194 & 5.181 & 0.469 & 0.096 & 0.044 & 1.472 & 92.718 \\
\hline 138 & 2.824 & 0.016 & 11.647 & 71.812 & 5.354 & 0.478 & 0.092 & 0.012 & 1.237 & 93.472 \\
\hline Mean & 2.924 & 0.024 & 11.532 & 71.312 & 4.973 & 0.483 & 0.090 & 0.028 & 1.278 & 92.643 \\
\hline Std Dev. & 0.135 & 0.008 & 0.106 & 0.436 & 0.185 & 0.043 & 0.030 & 0.015 & 0.133 & 0.472 \\
\hline Range & 0.508 & 0.030 & 0.384 & 1.553 & 0.761 & 0.177 & 0.168 & 0.051 & 0.501 & 1.715 \\
\hline Minimum & 2.645 & 0.011 & 11.310 & 70.580 & 4.593 & 0.407 & 0.002 & 0.000 & 1.030 & 91.793 \\
\hline Maximum & 3.153 & 0.041 & 11.690 & 72.130 & 5.354 & 0.584 & 0.170 & 0.051 & 1.531 & 93.508 \\
\hline Count & 30 & 30 & 30 & 30 & 30 & 30 & 30 & 30 & 30 & 30 \\
\hline $\begin{array}{l}\text { Confidence } \\
\text { Level } 95.0 \%\end{array}$ & 0.05 & 0.003 & 0.04 & 0.163 & 0.07 & 0.02 & 0.01 & 0.01 & 0.05 & 0.176 \\
\hline
\end{tabular}

(378 m) and JRK-DV-70 and the areal distribution of the Lava Creek B ash are shown in figure 71. The correlation to JRK-DV-70 is especially significant because at the outcrop; this sample is underlain and chronostratigraphically constrained by the Bishop ash. The age of the Bishop Tuff is $0.759 \pm 0.002 \mathrm{Ma}$, based on ${ }^{40} \mathrm{Ar} /{ }^{39} \mathrm{Ar}$ analysis of sanidine feldspar crystals (Sarna-Wojcicki and 
Table 22. Similarity coefficient list with normalized geochemical data including six major and three minor oxides for LBCC 108, C-1 (378 m), Long Beach City College core site and monitoring well, Long Beach, California, and comparative data of closest $(>0.9363$ similarity coefficient) chemical correlations.

[Reference samples with asterisks have been identified as the Lava Creek B ash. The best correlation is to JRK-DV-70, a chronostratigraphically constrained tephra layer from Death Valley, California. JRK samples were originally collected and studied by $\mathrm{Knott}(1998,1999)$. $\mathrm{Na}_{2} \mathrm{O}$, sodium oxide; $\mathrm{MgO}$, magnesium oxide; $\mathrm{Al}_{2} \mathrm{O}_{3}$, aluminum oxide; $\mathrm{SiO}_{2}$, silicon dioxide; $\mathrm{K}_{2} \mathrm{O}$, potassium oxide; $\mathrm{CaO}$, calcium oxide; $\mathrm{TiO}_{2}$, titanium oxide; $\mathrm{MnO}$, manganese oxide; $\mathrm{FeO}$, ferrous oxide]

\begin{tabular}{|c|c|c|c|c|c|c|c|c|c|c|c|c|c|}
\hline No. & Sample number & Date & $\mathrm{SiO}_{2}$ & $\mathrm{Al}_{2} \mathrm{O}_{3}$ & $\mathrm{Fe}_{2} \mathrm{O}_{3}$ & $\mathrm{MgO}$ & $\mathrm{MnO}$ & $\mathrm{CaO}$ & $\mathrm{TiO}_{2}$ & $\mathrm{Na}_{2} \mathrm{O}$ & $\mathrm{K}_{2} \mathrm{O}$ & Total & $\begin{array}{l}\text { Similarity } \\
\text { coefficient }\end{array}$ \\
\hline 5000 & LBCC 108C-1 & $3 / 2003$ & 76.86 & 12.43 & 1.53 & 0.03 & 0.03 & 0.52 & 0.10 & 3.15 & 5.36 & 100.10 & 1.0000 \\
\hline 3654 & $\begin{array}{l}\text { JRK-DV-70 } \\
\text { T338-6 }\end{array}$ & $3 / 1996$ & 76.77 & 12.19 & 1.57 & 0.03 & 0.03 & 0.52 & 0.10 & 3.45 & 5.34 & 100.00 & $0.9848^{*}$ \\
\hline 3647 & $\begin{array}{l}\text { JRK-DV-56 } \\
\text { T338-1 }\end{array}$ & $3 / 1996$ & 76.88 & 12.09 & 1.53 & 0.03 & 0.03 & 0.53 & 0.10 & 3.52 & 5.29 & 100.00 & $0.9817 *$ \\
\hline 632 & $\begin{array}{l}\text { TULELAKE- } \\
329, \text { T61-9(2) }\end{array}$ & 9/1983 & $77 / 04$ & 12.03 & 1.54 & 0.03 & 0.03 & 0.52 & 0.10 & 3.49 & 5.21 & 99.99 & $0.9815^{*}$ \\
\hline 3686 & $\begin{array}{l}\text { JRK-DV-78 \#2 } \\
\text { T339-10 }\end{array}$ & $11 / 1996$ & 76.59 & 12.48 & 1.53 & 0.03 & 0.03 & 0.53 & 0.11 & 3.38 & 5.33 & 100.01 & $0.9788^{*}$ \\
\hline 2768 & \#4078 T251-4 & $2 / 1998$ & 76.64 & 12.22 & 1.65 & 0.03 & 0.03 & 0.55 & 0.10 & 3.51 & 5.27 & 100.00 & $0.9704 *$ \\
\hline 3684 & $\begin{array}{l}\text { JRK-DV-77 \#2 } \\
\text { T339-9 }\end{array}$ & $11 / 1996$ & 76.50 & 12.51 & 1.56 & 0.03 & 0.03 & 0.54 & 0.12 & 3.39 & 5.32 & 100.00 & $0.9653 *$ \\
\hline 991 & $\mathrm{RC}-12$ & & 76.67 & 12.53 & 1.59 & 0.03 & 0.03 & 0.52 & 0.11 & 3.61 & 4.91 & 100.00 & $0.9611^{*}$ \\
\hline 2857 & BL-3499 T263-3 & $7 / 1992$ & 76.81 & 12.35 & 1.49 & 0.03 & 0.03 & 0.52 & 0.11 & 3.72 & 4.93 & 99.99 & $0.9603 *$ \\
\hline 4676 & L2000ISI & $1 / 2001$ & 76.87 & 12.29 & 1.50 & 0.03 & 0.04 & 0.52 & 0.10 & 3.43 & 5.22 & 100.00 & $0.9568^{*}$ \\
\hline 989 & RC-9 & $3 / 1900$ & 76.72 & 12.54 & 1.52 & 0.03 & 0.03 & 0.52 & 0.12 & 3.61 & 4.91 & 100.00 & $0.9561 *$ \\
\hline 4878 & $\begin{array}{l}\text { RK-SVR6_POP2 } \\
\text { T476-6 }\end{array}$ & $4 / 2002$ & 76.88 & 12.14 & 1.45 & 0.03 & 0.03 & 0.52 & 0.11 & 3.83 & 5.00 & 99.99 & $0.9543 *$ \\
\hline 2075 & $\begin{array}{l}\text { CDH-D88-23 } \\
\text { T172-5 }\end{array}$ & 9/1988 & 76.90 & 12.36 & 1.54 & 0.03 & 0.03 & 0.53 & 0.13 & 3.50 & 4.99 & 100.01 & $0.9521 *$ \\
\hline 3685 & $\begin{array}{l}\text { JRK-DV-78 } \\
\text { T339-10 }\end{array}$ & $11 / 1996$ & 77.24 & 12.13 & 1.49 & 0.02 & 0.03 & 0.52 & 0.10 & 3.32 & 5.15 & 100.00 & $0.9468 *$ \\
\hline 2750 & BUR-281.9 LoFe & & 77.09 & 12.19 & 1.58 & 0.02 & 0.03 & 0.52 & 0.10 & 2.95 & 5.53 & 100.01 & $0.9465^{*}$ \\
\hline 3683 & $\begin{array}{l}\text { JRK-DV-77 } \\
\text { T339-9 }\end{array}$ & $11 / 1996$ & 77.14 & 12.18 & 1.49 & 0.02 & 0.03 & 0.51 & 0.10 & 3.34 & 5.18 & 99.99 & $0.9452 *$ \\
\hline 3646 & $\begin{array}{l}\text { JRK-DV-55 } \\
\text { T337-10 }\end{array}$ & $3 / 1996$ & 76.92 & 12.13 & 1.52 & 0.02 & 0.03 & 0.53 & 0.10 & 3.48 & 5.26 & 99.99 & $0.9448 *$ \\
\hline 392 & $\begin{array}{l}\text { TEC0-30G T17- } \\
14\end{array}$ & & 76.75 & 12.66 & 1.72 & 0.03 & 0.03 & 0.55 & 0.13 & 2.78 & 5.36 & 100.01 & $0.9408 *$ \\
\hline 4120 & Ak594 t377 & $1 / 1998$ & 76.63 & 12.38 & 1.53 & 0.02 & 0.03 & 0.52 & 0.10 & 3.74 & 5.05 & 100.00 & $0.9382 *$ \\
\hline 448 & $66 \mathrm{~W} 4 \mathrm{~T} 5-6$ & & 76.91 & 12.26 & 1.43 & 0.04 & 0.03 & 0.58 & 0.11 & 3.22 & 5.42 & 100.00 & $0.9381 *$ \\
\hline 4576 & PC-HD-1 T436-9 & $3 / 2000$ & 77.04 & 12.40 & 1.60 & 0.03 & 0.04 & 0.55 & 0.10 & 3.51 & 4.73 & 100.00 & $0.9363 *$ \\
\hline 3645 & $\begin{array}{l}\text { JRK-DV-54 } \\
\text { T337-9 }\end{array}$ & $1 / 1900$ & 76.81 & 12.23 & 1.53 & 0.02 & 0.03 & 0.53 & 0.11 & 3.49 & 5.26 & 100.01 & $0.9360 *$ \\
\hline
\end{tabular}

Pringle, 1992; Sarna-Wojcicki and others, 2000). The eruptive source of the Bishop Tuff and ash beds is the Long Valley Caldera in California.

For comparison of the geochemical fingerprints, a $\mathrm{Fe}_{2} \mathrm{O}_{3}$ versus $\mathrm{CaO}$ scatter-plot of LBCC 108, C-1, 45-51 cm (378 m) was superimposed over that of "type" Lava Creek B ash sample JRKDV-70 (fig. 71). Note how closely the two fingerprints overlap and that there are few outliers. The composite scatter-plot is additional evidence that these two volcanic-glass samples are chemically well matched. 


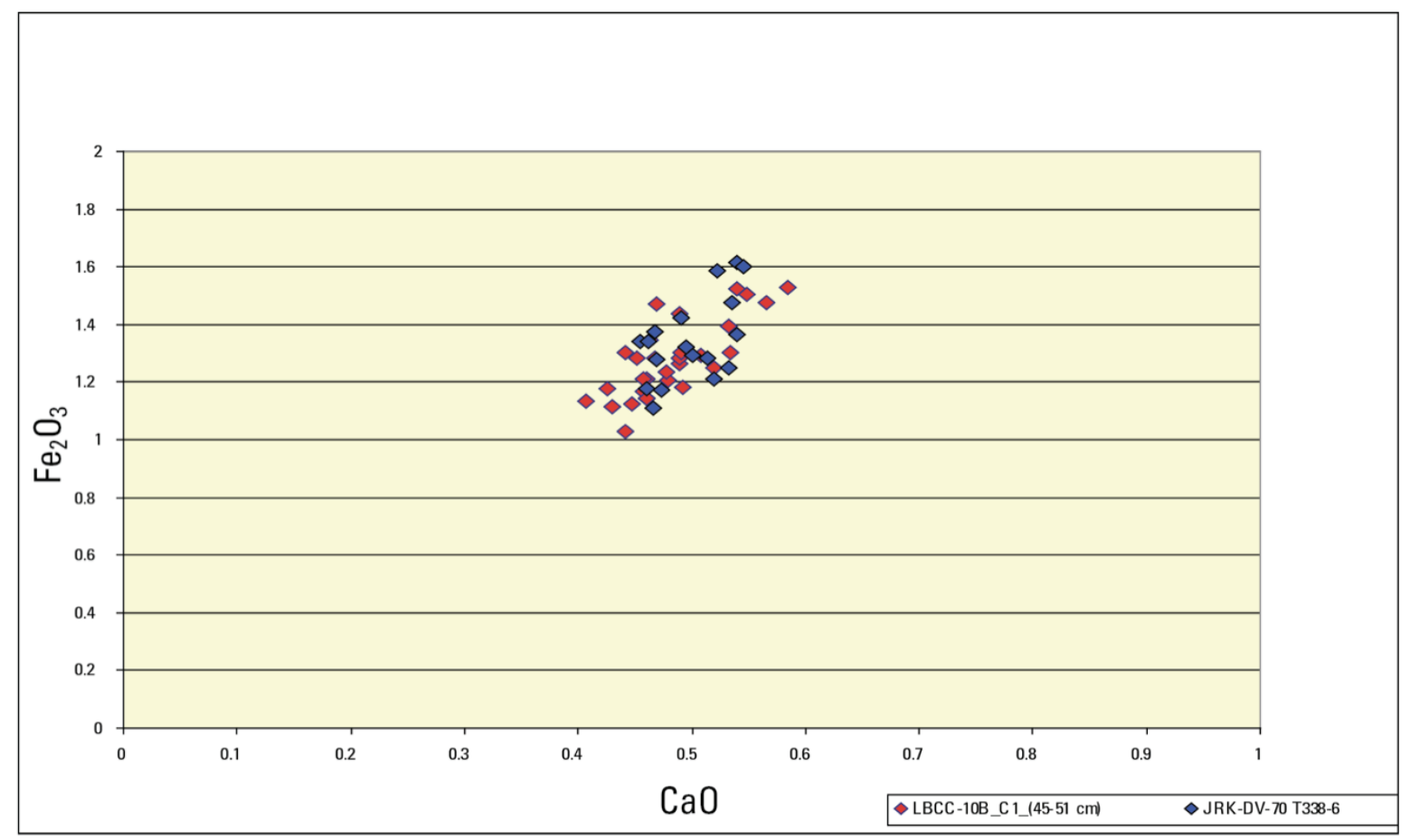

Figure 70. Composite $\mathrm{Fe}_{2} \mathrm{O}_{3}$ versus $\mathrm{CaO}$ scatter-plot of sample at $378 \mathrm{~m}$ (LBCC 108, C-1, $45-51 \mathrm{~cm}$ ) and JRK-DV-70 illustrating good overlap of analyzed points and few outliers.

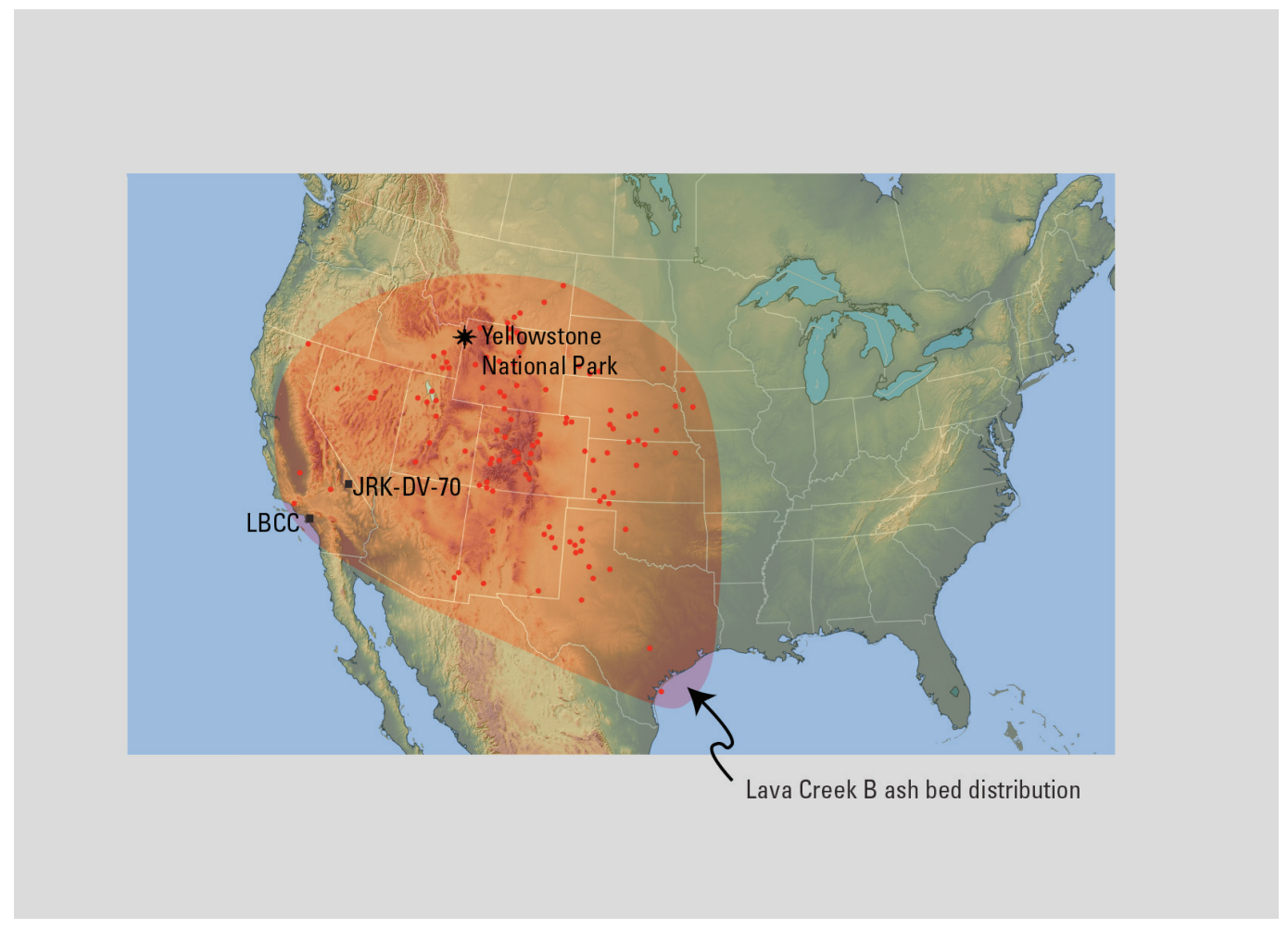

Figure 71. Map showing relative locations of sample at $378 \mathrm{~m}$ (LBCC 108, C-1, 45-51 cm) and JRK-DV-70, areal distribution of $\left(639 \pm 2 \mathrm{ka},{ }^{40} \mathrm{Ar} / 39 \mathrm{Ar}\right)$ Lava Creek B ash deposits, and eruptive source (star) in the Yellowstone area of Wyoming and Idaho. 


\section{Paleoecology}

\section{Benthic Foraminifers}

Bathymetric analyses of the benthic foraminifers in LBCH are illustrated in figure 72. Faunas in LBCH indicated that the questionable Venturian interval was deposited at upper middle bathyal depths which shallowed to upper bathyal in the Wheelerian and early Hallian. A dramatic shallowing of water depths, occurred in the Hallian as the Hallian faunas indicate water depths were less than $50 \mathrm{~m}$. Oxygen conditions throughout LBCC are primarily oxic to suboxic. Dysoxic species appear in nine samples, but not in abundance. Infaunal species dominate the microfauna in this well, suggesting low-oxygen bottom-water conditions.

The biofacies analysis indicates that the questionable Venturian faunas at the base of LBCC were deposited at upper middle bathyal depths $(500-1,500 \mathrm{~m})$. This interpretation is, however, based on three species that occur in the upper and lower samples of this interval. The intervening samples contain very few specimens. Water depths probably were within the shallow part of the upper middle bathyal biofacies. Transported specimens are from the outer neritic and (or) bank biofacies; there is no evidence of inner neritic species.

Biofacies analysis of the Wheelerian interval indicates deposition occurred in the upper middle bathyal biofacies (500-1,500 m) in the lower Wheelerian interval between 396.8 and 284.4 $\mathrm{m}$ (Mf11146-Mf11130), but shallowed to the upper bathyal biofacies (150-500 $\mathrm{m}$ ) in the upper Wheelerian interval above $284.4 \mathrm{~m}$ (Mf11130). Borderland biofacies analysis indicates that the lower Wheelerian contains an upper slope fauna $(85-450 \mathrm{~m})$ and a lower slope fauna $(400-950 \mathrm{~m})$, whereas upper Wheelerian was deposited at bank depths $(50-200 \mathrm{~m})$. The distribution of these faunas indicates that deposition of the lower Wheelerian at water depths of 500--950 m and the upper Wheelerian occurred at depths of 150-200 m. Uvigerina peregrina is moderately abundant from 379.6 to $358.4 \mathrm{~m}$ (Mf11144-Mf11141) and 291.7 to 282.7 m (Mf11135-Mf11129), suggesting the presence of an oxygen-deficient water mass.

Deposition during the early Hallian occurred at upper bathyal depths (150-500 m). The abundance of cassidulinids in the assemblages indicates that deposition occurred in the borderland bank biofacies (50-200 m). The occurrence of Praeglobobulimina affinis suggests lower oxygen conditions. Benthic foraminifers indicate a rapid decrease in water depth between 171.4 and 149.1 $\mathrm{m}$ (Mf11110-Mf11109). Although $22 \mathrm{~m}$ of sediment occur between these two samples the rapid increase in water depth suggests an unconformity or hiatus also may be present. Paleoecological analyses of the Hallian faunas indicate that this interval was deposited in the inner neritic biofacies at depths of less than $50 \mathrm{~m}$ (fig. 72).

\section{Macrofossils}

Macrofossils indicate littoral to sublittoral depths, from the base of the sampled interval up to $142.6 \mathrm{~m}$, after which littoral to inner sublittoral depths are indicated. Occasional intervals with indeterminate fragments are encountered throughout the well. Important environmental interpretations are illustrated in figure 73.

Megafossils are rare from 354 to $250 \mathrm{~m}$ (shaker samples 1,160-820). Species encountered indicate littoral-to-sublittoral water depths and the occurrence of Chione? at $250 \mathrm{~m}$ (shaker 820) implies warmer water temperatures, similar to today off Long Beach or warmer. Faunas consistent with littoral-to-sublittoral water depths continue up to $<207 \mathrm{~m}$ (shaker 680). The occurrence of the bivalve Nutricola cymata and a fragment of a large thick pectinid was collected at $<204 \mathrm{~m}$ (shaker 670), which is questionably referred to the genus Patinopecten. These specimens indicate water depths of 16-90 m (Coan and others, 2000) and cooler water temperatures than those found off Long Beach today. The appearance of a single valve, questionably identified as Tivela stultorum 


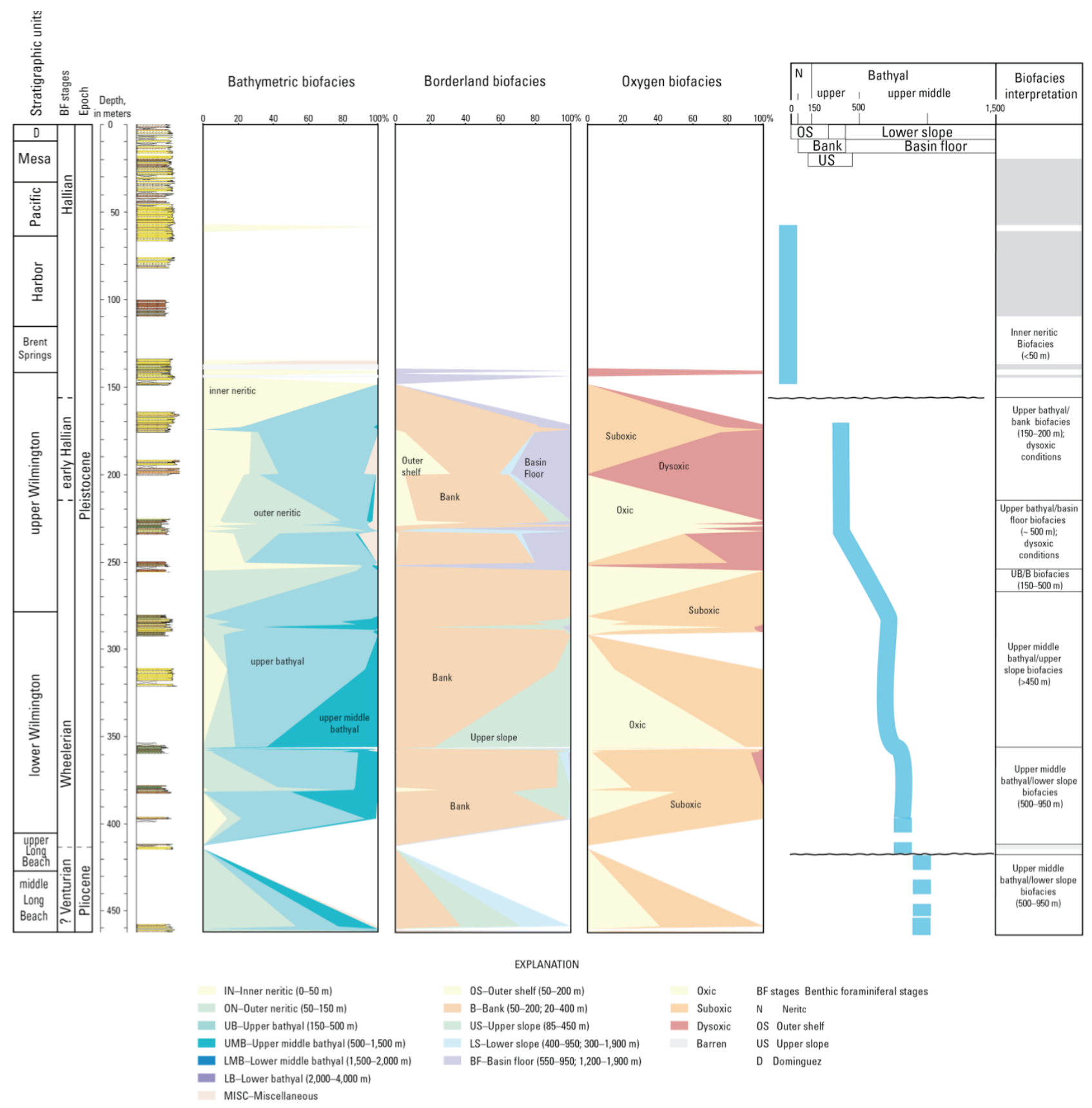

Figure 72. Paleoecological benthic foraminiferal biofacies analysis of Long Beach City College core site and monitoring well, Long Beach, California. The three biofacies analyses discussed in the text, are based on the abundance of benthic foraminifers in the samples. The bathymetric curve represents the most probable depth at which the samples were deposited. Stratigraphic units are identified in the left column, and lithologies are indicated on the stratigraphic column by color (clay, green; silt, brown; sand, yellow) (Ponti and others, 2007). [Reduced-size figure is shown here for continuity; full-size figure is included on plate 18.]

(193.9 m, LBCC 75, C-1, $36 \mathrm{~cm}$ ), slightly higher in the well, indicates littoral to shallow, sublittoral water depths and sandy beaches exposed to strong surf at water depths (Coan and others, 2000). Between $<192 \mathrm{~m}$ (shaker 630) and $144.6 \mathrm{~m}$ (LBCC62, C-1, $133.5 \mathrm{~cm}$ ), samples contain few, commonly fragmented fossils that do not allow detailed ecologic interpretation. 


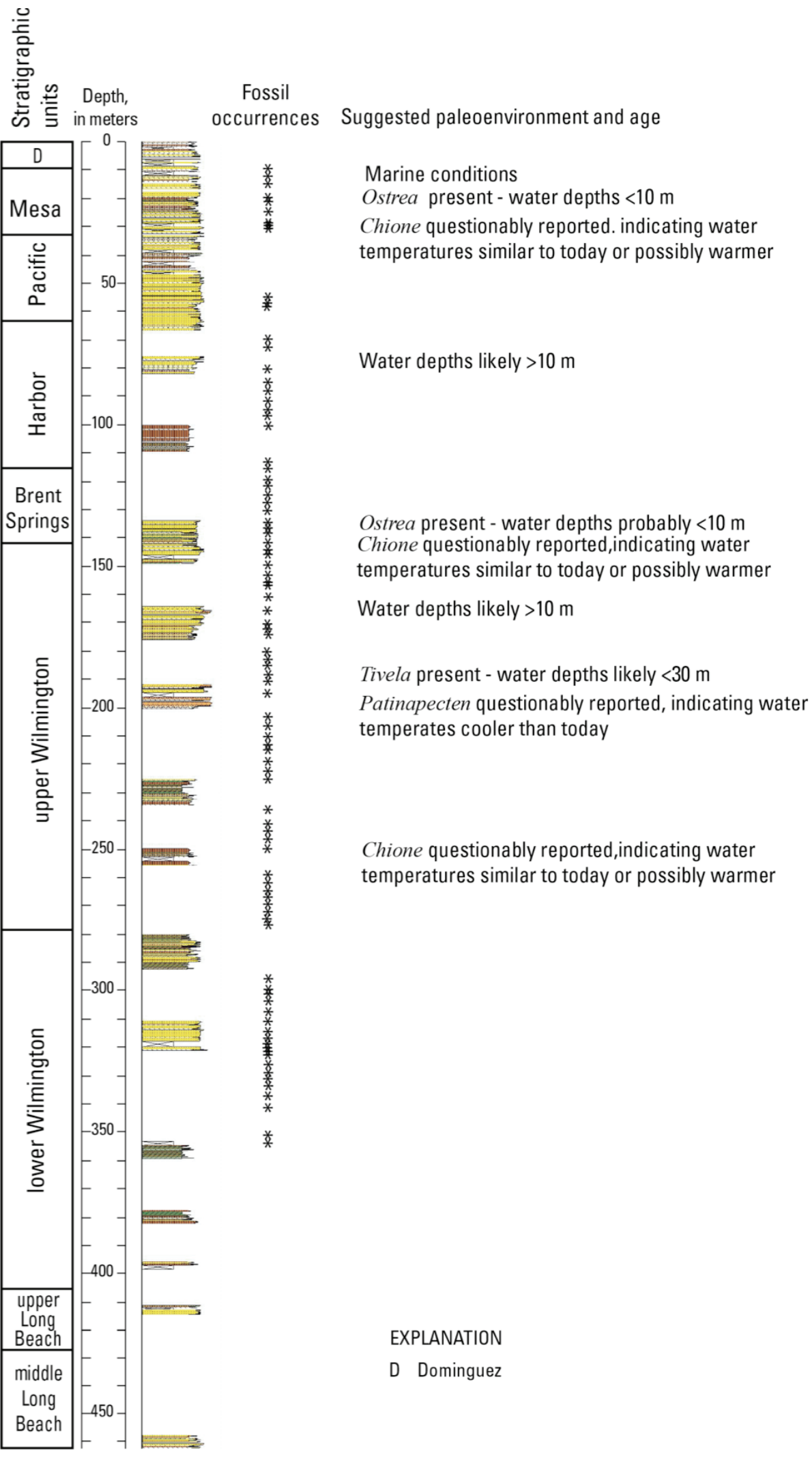

Figure 73. Distribution and paleoecologic interpretation of macrofossils from the Long Beach City College core site and monitoring well, Long Beach, California. Blank intervals represent no core recovery. Stratigraphic units are identified in the left column, and lithologies are indicated on the stratigraphic column by color (clay, green; silt, brown; sand, yellow) (Ponti and others, 2007). 
Littoral/adlittoral to possibly outer sublittoral depths are indicated between 144.4 and 142.4 m (LBCC62, C-1, 96-115 cm, LBCC62, C-1, 43-56 cm, and LBCC61, C-1, 68-75 cm). Greater water depths are suggested based on the occurrence of Lirobittium cf. L. lomaense, which typically is found at depths from 30-100 m (McLean and Gosliner, 1996). Further support comes from the occurrence of the bivalve genera Nutricola and Parvilucina, and the gastropods genera Alvinia, Lirobittium, Micranellum, and Turbonilla, which can be found in the adlittoral zone, but are much more common at deeper depths. The occurrence of Chione in this same interval indicates water temperatures similar to, or warmer than, those found off Long Beach today.

Shallower water depths are suggested for the overlying interval from approximately 137 to $<125 \mathrm{~m}$ (LBCC57, C-1, 127-133 cm, shaker 410). A single valve identified as Rochefortia cf. $R$. grippi was found at $\sim 137 \mathrm{~m}$ (LBCC57, C-1, 127-133 cm), which today occurs at water depths deeper than $10 \mathrm{~m}$. If correctly identified, this would be its first reported fossil occurrence. Donax gouldii occurs between 134.5 and $<128 \mathrm{~m}$ (LBCC56, C-1, $39.5 \mathrm{~cm}$, shaker 420) and indeterminate Donax and possibly Anomia occur at $<125 \mathrm{~m}$ (shaker 410). These taxa are characteristic of, but not restricted to, littoral to adlittoral depths (Coan and others, 2000).

Shaker samples recovered from to $<125$ to $<85 \mathrm{~m}$ (shaker $410-280$ ) contain species indicating deeper, inner sublittoral to possibly the shallower portion of the outer sublittoral (continental-shelf depth, which is somewhat arbitrarily assigned a maximum depth of about $100 \mathrm{~m}$ here) water depths. The bivalve genus Nuculana and gastropod genera Lirobittium, Mitrella, Nassarius, and Turritella are not restricted to this depth zone (of Valentine, 1961), but commonly live deeper than littoral depths off California. No extralimital taxa are present in this part of the well, and water temperatures are presumed to be similar to those off Long Beach today.

Between about 73 and $15 \mathrm{~m}$ (shaker 240 to shaker 45-50) a small fauna characterized by the bivalves Donax gouldii and Ostrea conchaphila, and the scaphopod Dentalium neohexagonum is interpreted as occurring in sand at littoral to inner sublittoral water depths. The upper part of the well $(<30-10.7 \mathrm{~m}$ ) was deposited at littoral to inner-sublittoral water depths along an open coast, with moderate wave exposure. The shallowest megafossil sample encountered in this well at 10.7 m (LBCC8, C-1, 98-100 cm) contains only indeterminate shell fragments. Although not environmentally diagnostic, the shell fragments are consistent with marine conditions.

\section{Long Beach City College Core Site and Monitoring Well Summary}

LBCC ranges from Pleistocene to Holocene in age (fig. 74). Paleomagnetism identifies the Brunhes Normal Polarity Chron and the Olduvai Subchron as well as the Laschamp and Blake events. OSL dates in the upper part of LBCC identify sediments ranging in age from 20.2 to 76.3 ka. A discrete volcanic-ash layer (sample LBCC $108 \mathrm{C}-1,45-51 \mathrm{~cm}$ ) is located at $\sim 378 \mathrm{~m}$ depth in the lower part of the well. Tephrochronologic analyses of the volcanic glass shards confirm that the sample is the Lava Creek B ash. This ash has a numerical age of $639 \pm 2 \mathrm{ka}$, based on ${ }^{40} \mathrm{Ar} /{ }^{39} \mathrm{Ar}$ analysis of sanidine feldspar grains (Lanphere and others, 2002). The Lava Creek B ash occurs in the middle part of the lower Wilmington unit in a normally polarized section of LBCC. Benthic foraminiferal assemblages identify the Pleistocene Stages. Macrofossils at 142-144 m indicate an age of $400-300 \mathrm{ka}$ and, at $20 \mathrm{~m}$, an age of $\geq 116 \mathrm{ka}$.

Pleistocene benthic foraminiferal assemblages in LBCC indicate the presence of the questionable Venturian, Wheelerian, early Hallian, and Hallian stages (fig. 74). The questionable Venturian interval occurs at from 462.1 to $457.6 \mathrm{~m}$ (Mf1 1576-Mf11573) and contains a fauna similar to that in the overlying Wheelerian interval, except for the presence of Gyroidina altiformis and Oridorsalis umbonatus. An unconformity is inferred at $417.9 \mathrm{~m}$, which separates the Venturian and Wheelerian faunas. The Wheelerian Stage is recognized from 396.8 to $226.2 \mathrm{~m}$ (Mf11146Mf11116). Cassidulina tortuosa, C. limbata, and Uvigerina juncea are common to abundant in this 


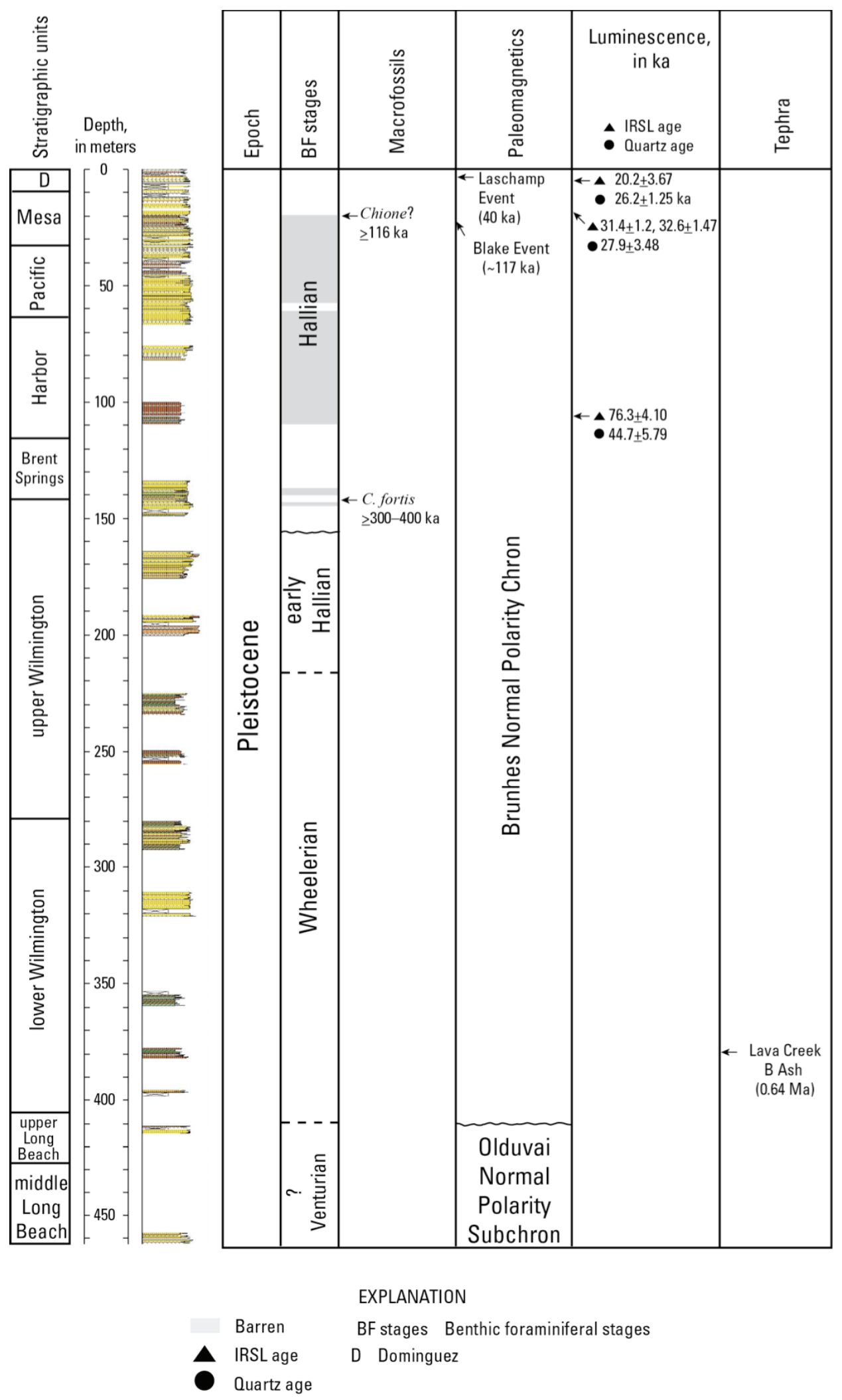

Figure 74. Summary of geochronology of Long Beach City College based on the microfossils, macrofossils, paleomagnetics, luminescence, and radiocarbon. Stratigraphic units are identified in the left column, and lithologies are indicated on the stratigraphic column by color (clay, green; silt, brown; sand, yellow) (Ponti and others, 2007). 
interval. Early Hallian faunas occur between 200.0 and 171.4 m (Mf11115-Mf11110). Cassidulina tortuosa and $C$. limbata dominate much of this interval. A rapid decrease in water depth occurs between 171.4 and $149.1 \mathrm{~m}$, suggesting an unconformity or hiatus. The Hallian Stage $(148-0 \mathrm{~m})$ is only sparsely fossiliferous and contains diagnostic shallow-water species.

Magnetic inclination, intensity of remanent magnetization, and magnetic susceptibility were measured in LBCC to a depth of $461.2 \mathrm{~m}$. Inclinations are predominantly of normal polarity, with the exception of two short reversed-polarity intervals within the Mesa and Pacific units. The tentative correlations are the Laschamp event $(40 \mathrm{ka})$ at $3.9-5.2 \mathrm{~m}$ and the Blake event $(\sim 117 \mathrm{ka})$ at $21.7 \mathrm{~m}$. The last appearance of the macrofossil Chione $(\geq 116 \mathrm{ka})$ at $20 \mathrm{~m}$ supports the correlation of the Blake event. However, OSL ages of 26-20 ka from a sample at 5.6 $\mathrm{m}$ and 36-28 $\mathrm{ka}$ at 22.7 $\mathrm{m}$ disagree with these correlations. This discrepancy is unresolved. The lower Wilmington and younger units were deposited during the Brunhes Normal Polarity Chron $(<0.781 \mathrm{Ma})$, as confirmed by the Lava Creek B ash at $378 \mathrm{~m}$ depth. A major unconformity inferred at $417.9 \mathrm{~m}$ represents a time gap of approximately one million years, because no reversed polarity inclinations were found below this depth and the foraminifers indicate early Pleistocene ages below the unconformity.

Paleoecological analysis of LBCC indicates water depths decreased gradually up section from upper middle bathyal/lower slope biofacies $(500-950 \mathrm{~m})$ to littoral, possibly inner sublittoral depths ( $\sim 9 \mathrm{~m}$ ) (fig. 75). Benthic foraminifers indicate deposition shallowed from upper middle bathyal/lower slope depths (500-950 m) during the Venturian at the base of the well to upper middle bathyal/upper slope depths $( \pm 450 \mathrm{~m})$ and upper bathyal/bank biofacies $(150-200 \mathrm{~m})$ during the Wheelerian and early Hallian between 396.8 and $171.4 \mathrm{~m}$. An unconformity between 171.4 and $149.1 \mathrm{~m}$ is indicated by a rapid decrease in water depth from upper bathyal to inner neritic depths $(150-500 \mathrm{~m}$ to $<50 \mathrm{~m})$. Macrofaunas indicate water depths decreases to shallow, warm marine waters, and possibly a sand beach by $13 \mathrm{~m}$. 


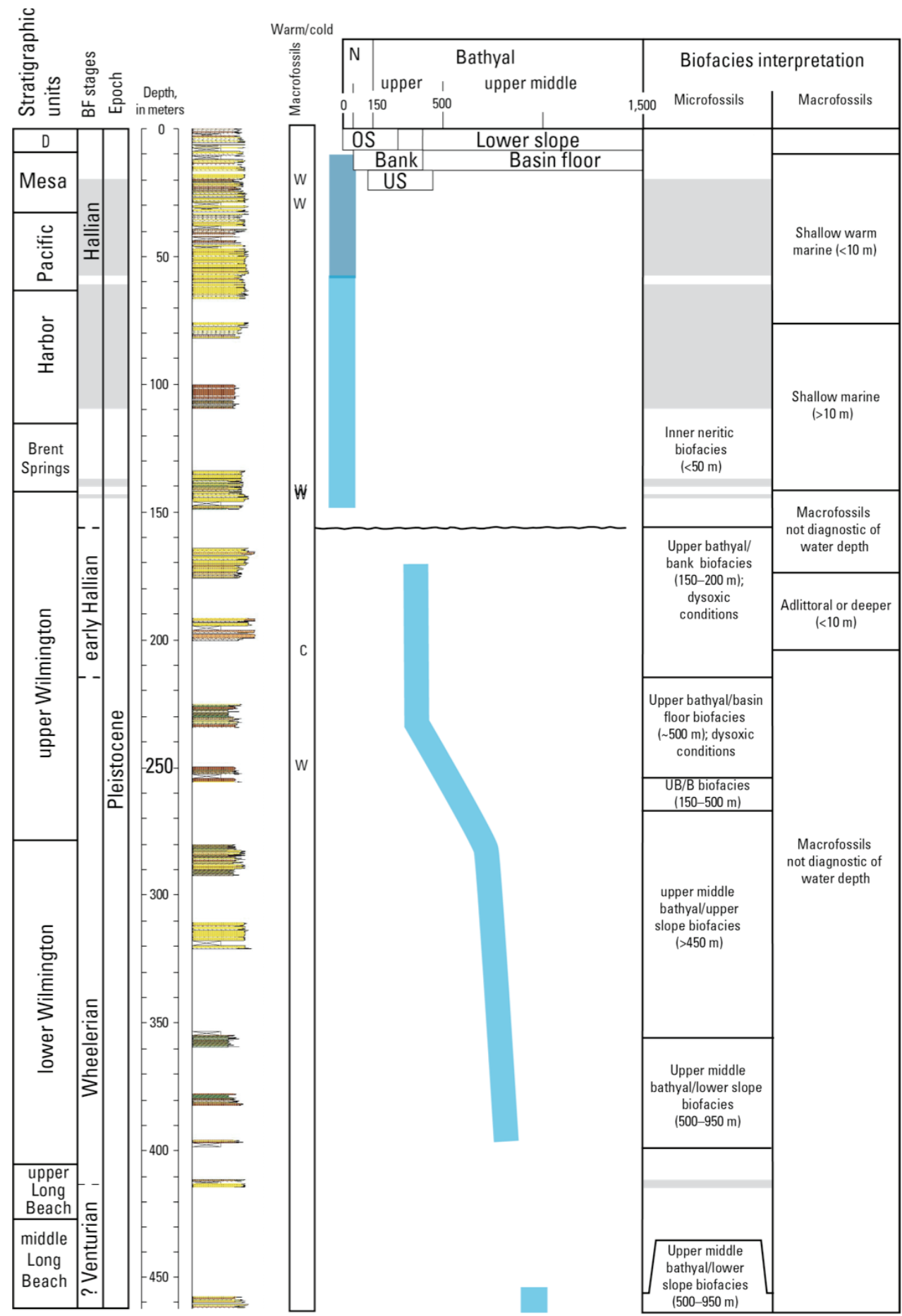

EXPLANATION
D Dominguez
BF stages Benthic foraminiferal stages
$\mathrm{N}$ Neritic
OS Outer shelf
US Upper slope

Figure 75. Summary of paleoecologic interpretations of Long Beach City College core site and monitoring well, Long Beach, California, based on benthic foraminifers and macrofossils. Stratigraphic units are identified in the left column, and lithologies are indicated on the stratigraphic column by color (clay, green; silt, brown; sand, yellow) (Ponti and others, 2007). 


\section{Chapter 7-Long Beach Water Treatment Plant Core Site and Monitoring Well, Long Beach, California}

\section{Introduction}

Long Beach Water Treatment Plant core site and water monitoring well (LBWT) is located on the south side of East Spring Street, approximately $180 \mathrm{~m}$ east of the intersection of Redondo Avenue and Spring Streets, on the Long Beach Water Treatment Plant (lat 33⒋'37.6"N; long $118^{\circ} 08^{\prime} 57.1^{\prime \prime W}$ ) in Long Beach, California (fig. 1). Total depth of the well is $472.4 \mathrm{~m}$ (table 1). The biostratigraphic, chronostratigraphic, and paleoecologic data collected at LBWT are summarized in this chapter. Core samples taken from LBWT were examined for benthic foraminifers (Kristin McDougall) and paleomagnetics (John Hillhouse). The lower Wilmington (472.4-317.0 m), upper Wilmington (317.0-129.5 m), Bent Spring (129.5-106.7 m), Harbor (106.7-44.2 m), Pacific (44.2--13.7 m), and Mesa (13.7-0 m) units were identified in this well (Ponti, oral commun., 2008).

\section{Biostratigraphy}

\section{Benthic Foraminifers}

Benthic foraminifers were analyzed from 70 samples from LBWT. Coring and sampling were not continuous in this well, and more than half of the microfossil samples are barren (40 of the 70 samples). The fossiliferous samples generally contain less than 100 specimens and, therefore, are not useful for statistical analysis. Like the barren samples, these low abundance samples are dispersed throughout the well (plate 13, fig. 76). Using criteria established for the Pliocene and Pleistocene of the Los Angeles Basin (fig. 4), benthic foraminifers diagnostic of the Pleistocene Wheelerian, early Hallian, and Hallian Stages are recognized (fig. 77).

Pleistocene Wheelerian Stage benthic foraminifers occur from 471.1 to $399.9 \mathrm{~m}$ (Mf10943Mf10939). Diagnostic species include Epistominella pacifica (471.1-399.9 m, Mf10943-Mf10939) and Cibicides mckannai suppressa (471.1-469.9 m, Mf10943-Mf10942). The last abundant appearance of Epistominella pacifica occurs at $399.9 \mathrm{~m}$ (Mf10939) marking the top of the Wheelerian Stage. An interval which contains nondiagnostic assemblages and barren samples occurs above 397.2-360.1 m (Mf10938-Mf10931).

Beginning at $358.62 \mathrm{~m}$ (Mf10930), Cassidulina tortuosa, C. limbata, and Uvigerina juncea appear and become common to abundant upsection to $200.04 \mathrm{~m}$ (Mf10902). These species indicate the early Hallian. A second interval of barren or nondiagnostic assemblages occurs between 199.3 and 110.02 $\mathrm{m}$ (Mf10901-Mf10896). Overlying this interval at 108.2-27.1 $\mathrm{m}$ are common to abundant occurrences of Ammonia beccarii, Elphidiella hannai, and various Elphidium species, which indicate the Hallian Stage.

\section{Geochronology}

\section{Paleomagnetism}

Funding constraints dictated an intermittent coring program at LBWT, which left substantial gaps in the paleomagnetic record (fig. 78). Fifty-five samples were collected for paleomagnetic study beginning at a depth of $471 \mathrm{~m}$ and extending to a depth of $26 \mathrm{~m}$. However, the cores represent only one-third of the stratigraphic column. Alternating-field treatments were applied in the range of 10-50 mT. In general, the quality of the line fits to the demagnetization data was good, as indicated by MADs of less than $10^{\circ}$ from 75 percent of the specimens (appendix III, 


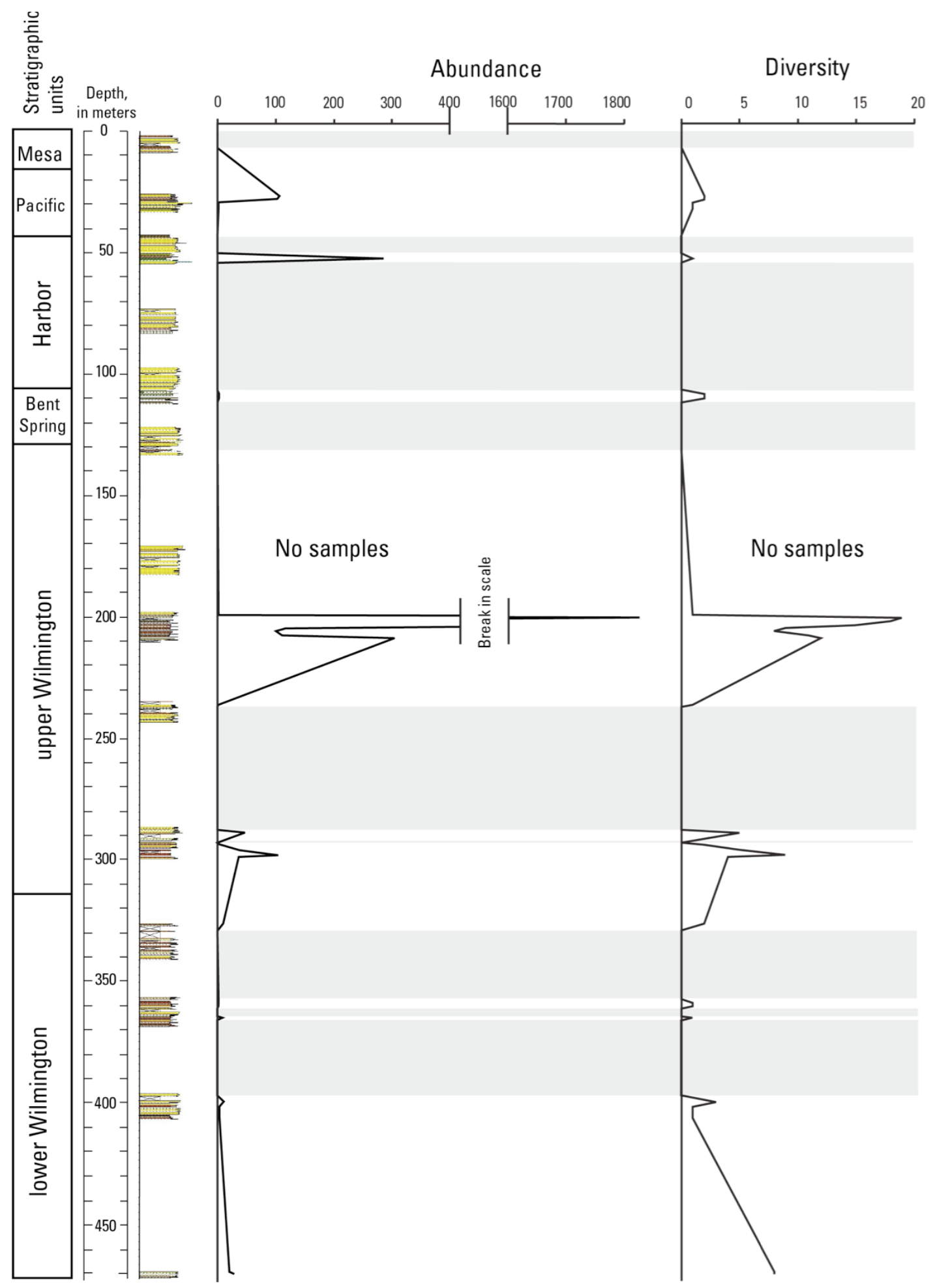

EXPLANATION

Barren

Figure 76. Abundance and diversity of the foraminiferal fauna in Long Beach Water Treatment Plant core site and monitoring well, Long Beach, California. Abundance of the foraminifers is based on the number of foraminiferal specimens present in the sample. Diversity is the number of species identified in the sample. Stratigraphic units are identified in the left column, and lithologies are indicated on the stratigraphic column by color (clay, green; silt, brown; sand, yellow) (Ponti and others, 2007). 

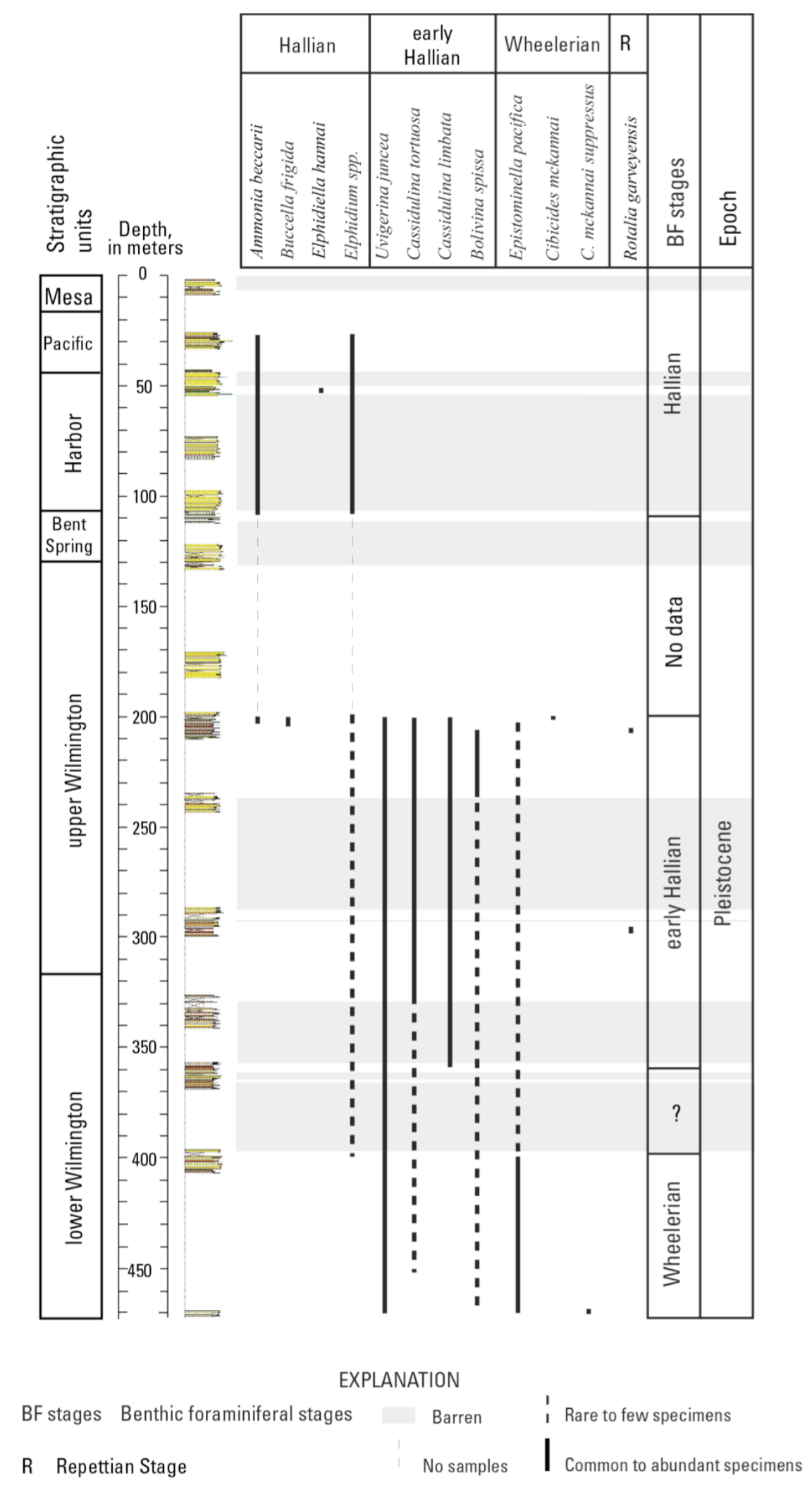

Figure 77. Stratigraphic distribution of age-diagnostic benthic foraminifers in Long Beach Water Treatment Plant core site and monitoring well, Long Beach, California. Abundances are given in plate 13. Stratigraphic units are identified in the left column, and lithologies are indicated on the stratigraphic column by color (clay, green; silt, brown; sand, yellow) (Ponti and others, 2007). 


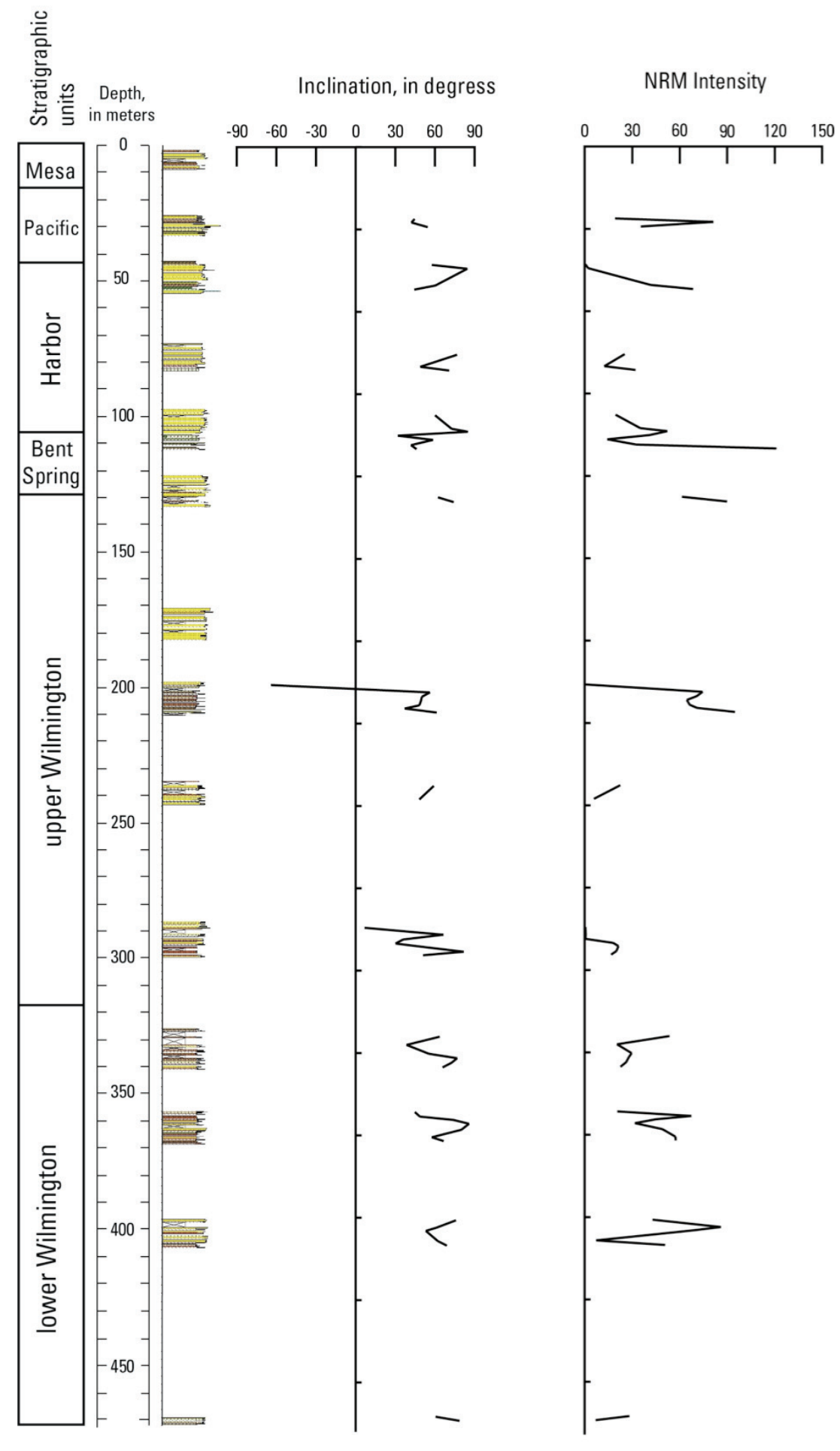

Figure 78. Remanent-magnetization (inclination and intensity) properties of the Long Beach Water Treatment Plant core site and monitoring well, Long Beach, California. Inclination is measured in degrees. Intensity is depicted with a logarithmic scale, where 0.0 equals 1 milliAmpere/m. Magnetic susceptibility also is given with a logarithmic scale, where 0.0 equals 10-6 Sl. Stratigraphic units are identified in the left column, and lithologies are indicated on the stratigraphic column by color (clay, green; silt, brown; sand, yellow) (Ponti and others, 2007). 
table 23). All but one specimen have positive inclinations (normal polarity) after alternating-field treatment. Reliability of the magnetization direction with reversed polarity $(199.10 \mathrm{~m})$ is questionable owing to its weak magnetization and poor line-fit quality (MAD is $17.3^{\circ}$ ).

Dominantly, normally polarized results from LBWT show no evidence that the well penetrated the Matuyama-Brunhes boundary (0.78 Ma). Substantial gaps in the core sampling leave the paleomagnetic record incomplete and prevent correlation of the inclination curve with other wells from the Long Beach coring program.

Table 23. Paleomagnetic results from the Long Beach Water Treatment core site and monitoring well (LBWT), Long Beach, California. [Title of table is included here for continuity; complete table is in appendix III.]

\section{Paleoecology}

\section{Benthic Foraminifers}

Bathymetric analysis of LBWT (fig. 79) suggest that deposition occurred in the upper middle bathyal or lower slope biofacies with water depths of 500-950 m during the Wheelerian interval, 471.1-399.9 m (Mf10943-Mf10939). Present in this interval are Epistominella pacifica and Gyroidina sp. Conditions are dysoxic, as indicated by Nonionella stella.

The early Hallian interval, 364.8-200.0 m (Mf10934-Mf10902), was deposited in the upper bathyal/lower slope biofacies with water depths of 400-500 m. The upper bathyal biofacies is suggested by presence of Cassidulina tortuosa, Praeglobobulimina affinis, Trifarina angulosa, $T$. carinata, and Uvigerina peregrina. These species, and Epistominella pacifica, Bolivina spissa, and Loxostomum bradyi, are indicative of the lower slope biofacies. With the exception of Epistominella pacifica, these species also are indicative of dysoxic and suboxic conditions. The abundance of Nonionella stella throughout this interval indicates strongly dysoxic conditions. Strong dysoxia may be responsible for the numerous barren samples.

The Hallian and early Hallian may be separated by an unconformity as in other wells, but with only two sparsely fossiliferous samples between the oldest Hallian sample (Mf10895, 110.02 $\mathrm{m}$ ) and the youngest early Hallian sample (Mf10902, 200.04 m), it is impossible to recognize based on microfossils. However, a dramatic change in water depth is suggested for the Hallian Stage (108.2-27.1 m, Mf10895-Mf10876). During this interval, deposition occurred at inner neritic depths of less than $50 \mathrm{~m}$ (fig. 79). Benthic foraminiferal faunas are composed of three species: Ammonia beccarii, Elphidiella hannai, and Elphidium sp. Elphidiella hannai occurs only in sample Mf10884 (52.4 m) and indicates colder water temperatures than those found off the southern California coast at present.

\section{Long Beach Water Treatment Plant Core Site and Water Monitoring Well Summary}

LBWT is Pleistocene in age (fig. 80). Paleomagnetic analysis places the entire section in the Brunhes Normal Polarity Chron, but is not able to recognize any excursions. Benthic foraminifers indicate the presence of the Pleistocene Hallian, early Hallian, and Wheelerian Stages. Benthic foraminifers also indicate that deposition occurred in the upper middle bathyal/lower slope biofacies (500-950 m) in the Wheelerian, upper bathyal/bank or basin floor biofacies (400-500 $\mathrm{m}$ ) in the early Hallian, and inner neritic biofacies $(<50 \mathrm{~m})$ in the Hallian (fig. 80). Low dissolvedoxygen conditions were dominant in the Wheelerian and early Hallian Stages. 

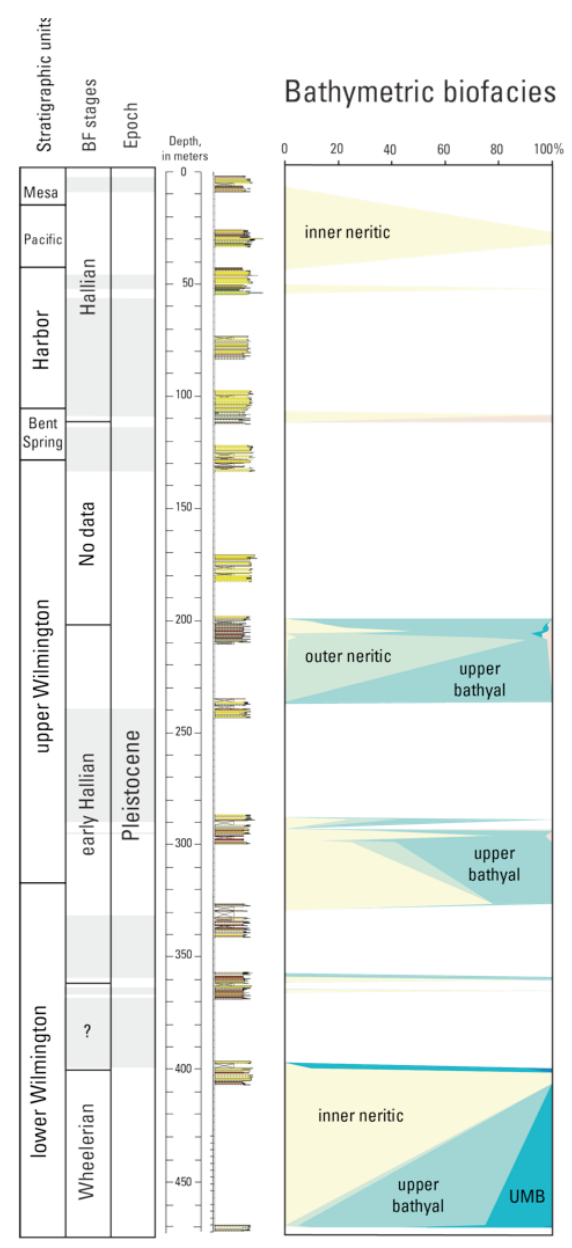

Borderland biofacies
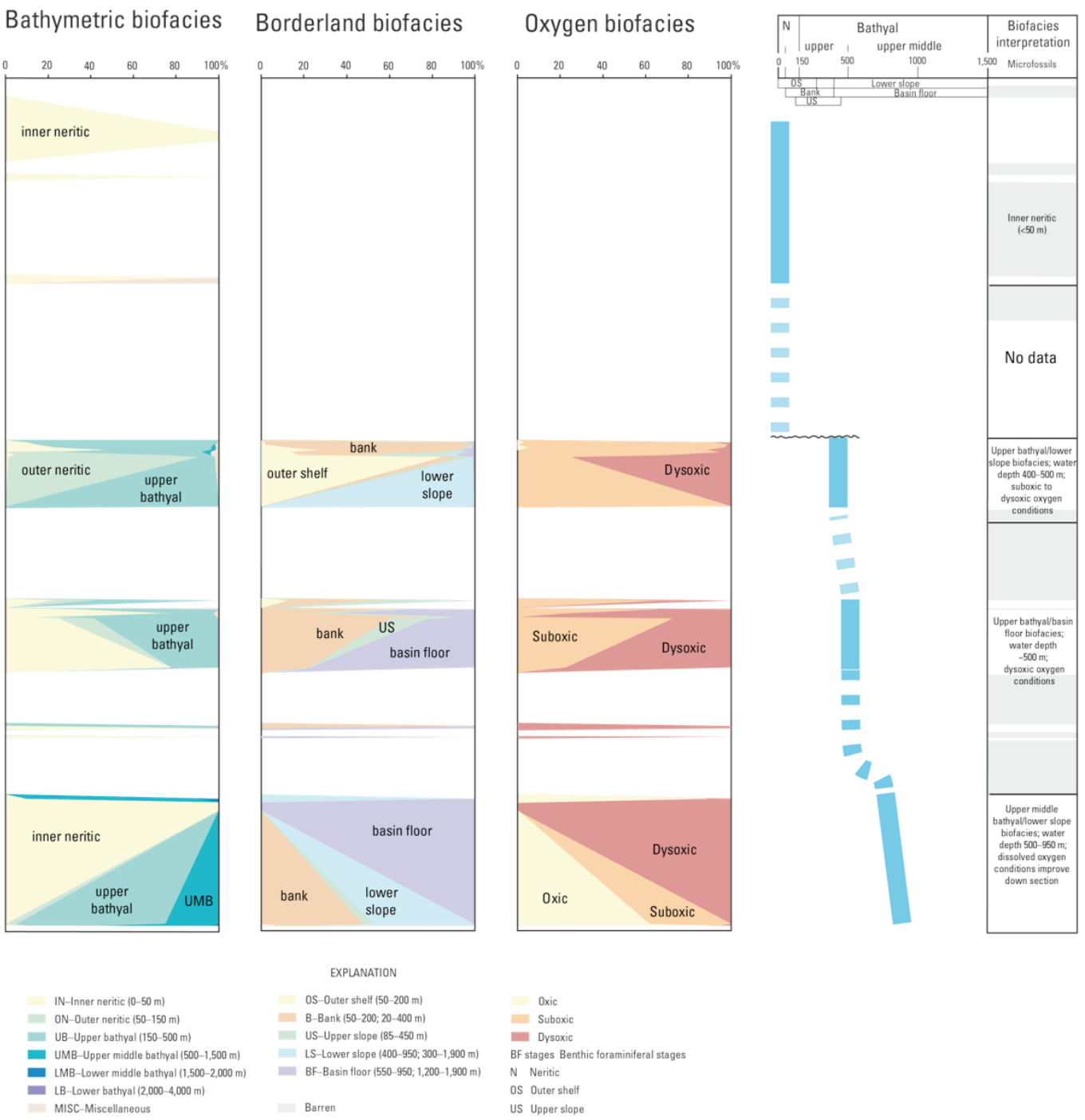

Figure 79. Paleoecological benthic foraminiferal biofacies analysis of Long Beach Water Treatment Plant core site and monitoring well, Long Beach, California. The three biofacies analyses discussed in the text, are based on the abundance of benthic foraminifers in the samples. The bathymetric curve represents the most probable depth at which the samples were deposited. Stratigraphic units are identified in the left column, and lithologies are indicated on the stratigraphic column by color (clay, green; silt, brown; sand, yellow) (Ponti and others, 2007). [Reduced-size figure is shown here for continuity; full-size figure is included on plate 18.] 


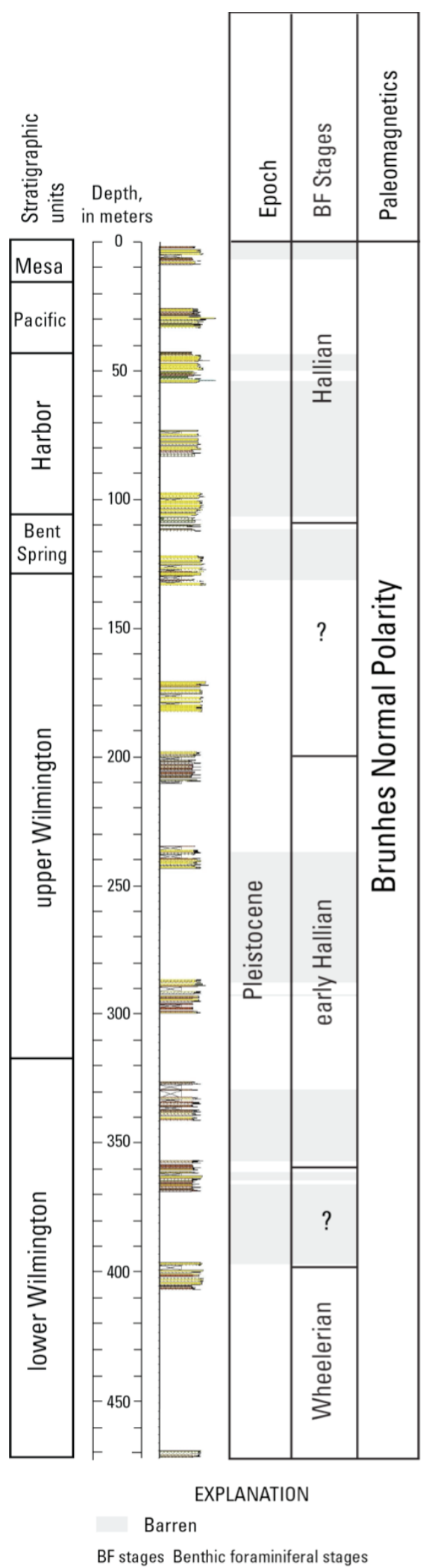

Figure 80. Summary of geochronology of Long Beach Water Treatment Plant core site and monitoring well, Long Beach, California, based on the microfossils and paleomagnetics. Stratigraphic units are identified in the left column, and lithologies are indicated on the stratigraphic column by color (clay, green; silt, brown; sand, yellow) (Ponti and others, 2007). 


\section{Chapter 8-Long Beach Water \# 1 Core Site and Monitoring Well, Long Beach, California}

\section{Introduction}

Long Beach Water \# 1 core site and monitoring well (LBW1), which was drilled in July 1999 , reached a total depth of $456.6 \mathrm{~m}$. The well was cored nearly continuously down to a depth of $155 \mathrm{~m}$, and the lower part of the well (155-454 m) was not cored. The lowest intact sample was taken from a pitcher-barrel sampler at the well bottom $(\sim 455 \mathrm{~m})$. LBW1 is located at lat $33^{\circ} 47^{\prime} 52.8^{\prime \prime} \mathrm{N}$; long $118^{\circ} 05^{\prime} 18.2^{\prime \prime} \mathrm{W}$ (fig. 1). Core samples were examined for benthic foraminifers (Kristin McDougall), macrofossils (Charles Powell, II), and paleomagnetics (John Hillhouse). The lower Wilmington (456.6-349.6 m), upper Wilmington (349.6-231.7 m), Bent Spring (231.7196.6 m), Harbor (196.6-88.4 m), Pacific (88.4-33.5 m), Mesa (33.5-21.9 m), and Dominquez (21.9-0 m) units were recognized in this well (Ponti, oral commun., 2008).

\section{Biostratigraphy}

\section{Benthic Foraminifers}

Of the 19 samples examined for foraminifers, all but two of the samples were barren of foraminifers. Samples Mf10262 (75.25 m) and Mf10264 (76.4 m) contained several specimens of Elphidium subarcticum. This species suggests that the sediments were deposited during the Hallian at shallow inner neritic depths $(<10 \mathrm{~m})$.

\section{Macrofossils}

Twenty-eight samples containing remains of mollusks, arthropods, and echinoids were examined from LBW1 (plate 14). All but eight of the samples were found in situ and represent shell-lag deposits containing mixed death assemblages. Samples with identifiable mollusks are clustered in two intervals, one between 51.2 and $41.4 \mathrm{~m}$, and another between 137.3 and $121.31 \mathrm{~m}$. Between these two intervals, at $79.35 \mathrm{~m}$, a single sample containing identifiable mollusks, indicating marine conditions was encountered.

A number of southern extra-limited species occur in LBW1, including the bivalves Crassinella cf. C. nuculiformis at 129.6-129.8, 50.8-51.1, <47.2, and $<44.2 \mathrm{~m}$; Trachycardium cf. T. panamense at 47.5-47.2 m; Anadara perlabiata at $129.6 \mathrm{~m}$; and Petricolaria congnata? at 129.8-129.6 m); and gastropod Glyptaesopus oldroydi at 49.2-48.8 m. These southern extralimital species are found in the Los Angeles County deposits older than the end of MIS 5e ( $\leq 116 \mathrm{ka})$ (Ponti, 1989; Powell and others, 2000). This indicates a minimum age of $116 \mathrm{ka}$ for the interval below $44.2 \mathrm{~m}$.

\section{Geochronology}

\section{Paleomagnetism}

Sixty-seven paleomagnetic specimens were collected at approximately $1-\mathrm{m}$ intervals from the upper cores, and two specimens were collected from the pitcher barrel. Alternating-field demagnetization was carried to a maximum field of $60 \mathrm{mT}$, although the majority of specimens gave optimum paleomagnetic results after treatments of 10-40 $\mathrm{mT}$. The better determinations of magnetization direction ( $\mathrm{MAD} \leq 10^{\circ}$ ) were obtained from 77 percent of the specimens. Intensity of NRM, inclination, declination (relative to the core split face), and demagnetization treatments are 
listed in appendix III, table 24. All inclinations are positive (normal polarity), although two specimens (105.7 and $37.1 \mathrm{~m}$ ) gave inclinations considerably more shallow than the expected axial-dipole inclination (fig. 81). In both cases, the intensities of magnetization are low, and the high MADs indicate poor determination of the magnetization direction.

Table 24. Paleomagnetic results from the Long Beach Water well \# 1 core site and monitoring well (LBW1), Long Beach, California. [Title of table is included here for continuity; complete table is in appendix III.]

The exclusively normal-polarity record from LBW1 is consistent with deposition of Brunhes age, suggesting that the cored section to $155 \mathrm{~m}$ penetrated sediment no older than $0.78 \mathrm{Ma}$ (fig. 8). The pitcher-barrel sample at the bottom of the well also is normally polarized, although the magnetization direction of this sandy specimen was poorly determined (MAD is $20^{\circ}$ ). Lack of coring in the long interval from 155 to $454 \mathrm{~m}$ precludes magnetostratigraphic correlations in the lower section of the well. Unusually large swings in declination occur in the interval from 23-37 $\mathrm{m}$, where the inclination shallows to $15^{\circ}$ followed by rapid steepening to $81^{\circ}$. A similar feature is found in the LWEB. The LWEB inclination anomaly is a possible correlative to the Blake event $(\sim 117 \mathrm{ka})$, which is a brief geomagnetic reversal known from oceanic drilling in the Mediterranean Sea (Tucholka and others, 1987). Correlation of the Blake event and the LBW1 inclination feature is weakened by the lack of a well-defined magnetization direction at the base of the feature (37.1 $\mathrm{m})$.

\section{Paleoecology}

\section{Macrofossils}

All samples with identifiable mollusks are consistent with continental shelf water depths, somewhat arbitrarily cited here as to about $100 \mathrm{~m}$ and sandy substrate. Data from five collections (129.56-129.75, 121.31-121.43, 50.84-51.05, 47.88-49.23, and 47.24-47.48 m) show bimodal depth ranges suggesting a mixed thanatocoenosis and significant reworking. These collections generally contain one shallow-water restricted mollusk, usually Donax gouldii ( $<5 \mathrm{~m}$; Coan and others, 2000), and commonly several species restricted to deeper water, $>20 \mathrm{~m}$. The Donax gouldii may be reworked as it is a single species, but several different species are commonly restricted to deeper water. In addition, the small, thick valves of Donax could undergo transport and a long period of time at the water-sediment interface without showing significant wear or breakage. The shallowest megafossil sample contains only indeterminate bivalve fragments, occurs at $<6.41 \mathrm{~m}$ (fig. 82), and indicates marine conditions.

The bivalves Anadara perlabiata, Crassinella cf. C. nuculiformis, Petricolaria congnata(?), Trachycardium cf. T. panamense, and gastropod Glyptaesopus oldroydi, are southern extralimital species, which today occur only as far north as northern Baja. Since southern extralimital species are present in both major-sample intervals, temperatures warmer than today are indicated for those intervals.

\section{Long Beach Water \# 1 Core Site and Monitoring Well Summary}

The LBW1 well is Pleistocene in age. Paleomagnetic analysis places the entire section in the Brunhes Normal Polarity Chron, but is not able to recognize any excursions. Benthic foraminifers are rare and indicate deposition occurred in the Hallian. Extralimital southern macrofossils from 44.2 to $155 \mathrm{~m}$ indicate an age of $\geq 116 \mathrm{ka}$. Together these data suggest an age of $\geq 116 \mathrm{ka}$ and $<780 \mathrm{ka}$ for the sampled part of LBW1. 


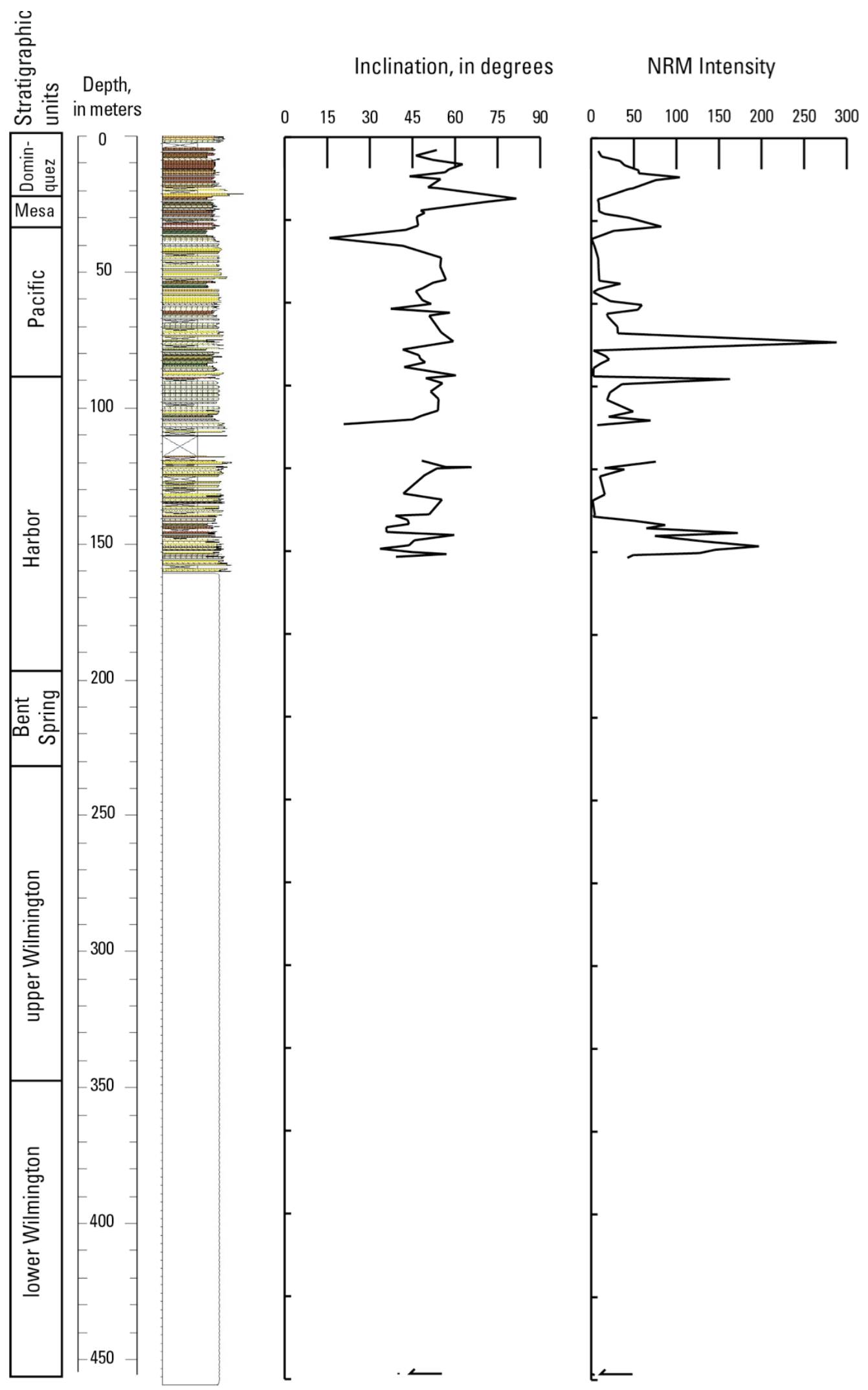

Figure 81. Inclination (in degrees) after alternating-field treatment and intensity of natural remanent magnetization (NRM, in $\mathrm{mA} / \mathrm{m}$ ) of specimens from Long Beach Water \# 1 core site and monitoring well, Long Beach, California. Stratigraphic units are identified in the left column, and lithologies are indicated on the stratigraphic column by color (clay, green; silt, brown; sand, yellow) (Ponti and others, 2007). 


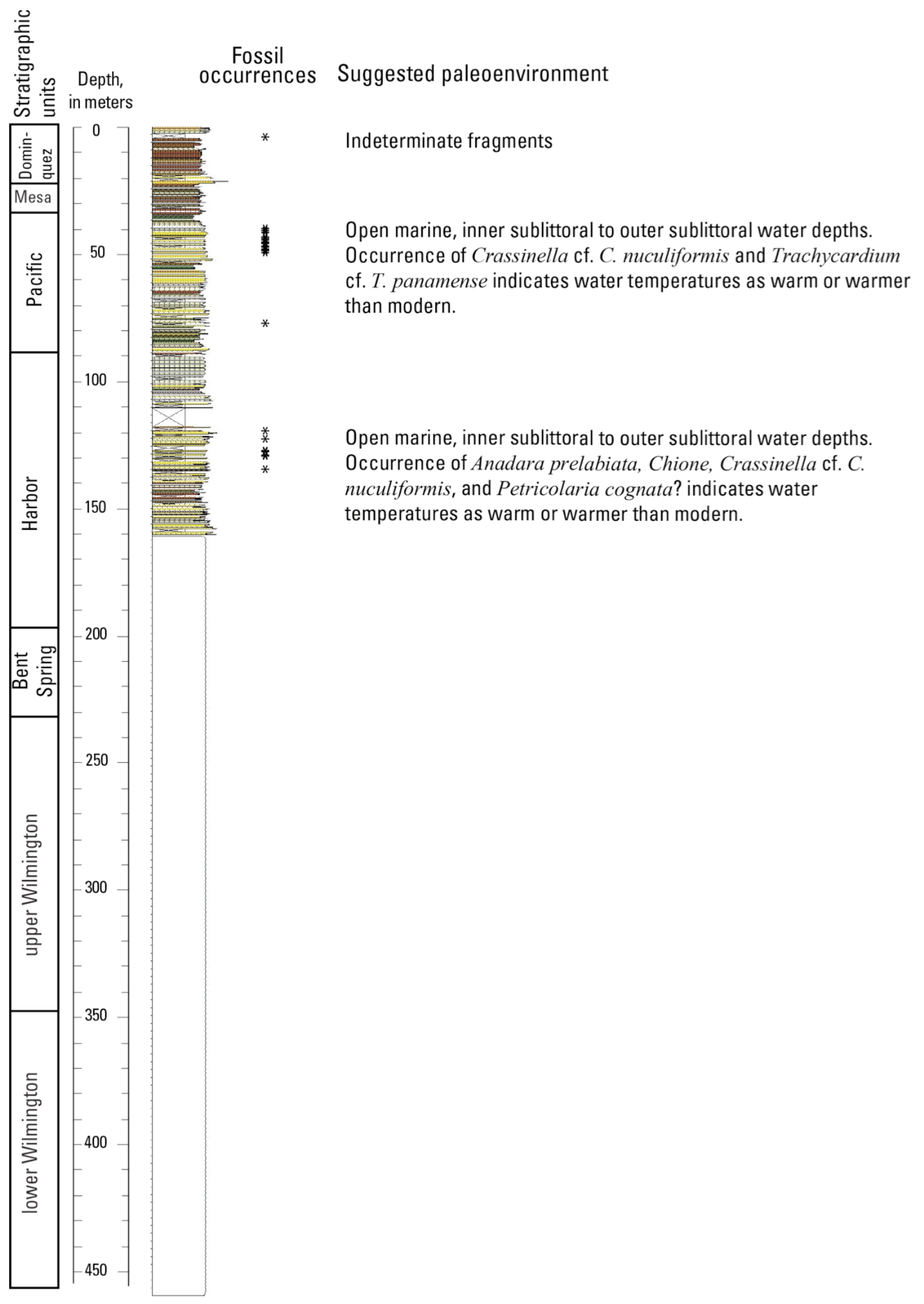

Figure 82. Distribution and paleoecologic interpretation of macrofossil samples in Long Beach Water \# 1 core site and monitoring well, Long Beach, California. Stratigraphic units are identified in the left column, and lithologies are indicated on the stratigraphic column by color (clay, green; silt, brown; sand, yellow) (Ponti and others, 2007). 
All the macrofossils recovered are consistent with a shelf environment, probably at depths shallower than about $100 \mathrm{~m}$, and the few benthic foraminifers present indicate inner neritic depths $(<50 \mathrm{~m})$. The occurrence of southern extralimital species indicate that water temperatures were warmer than they are today. 


\section{Chapter 9-Westchester Core Site and Monitoring Well, Westchester, California}

\section{Introduction}

The Westchester core site and monitoring well (WEST) is located on the southern tip of the Westchester Recreation Center, near the intersection of Lincoln Boulevard and La Tijera Boulevard, Los Angeles, California (lat 335 '20.4"N; long 118 $24^{\prime} 55.0^{\prime \prime} \mathrm{W}$ ) (fig. 1). Total depth of the well is $273.7 \mathrm{~m}$ (table 1). The biostratigraphy, chronostratigraphy, and paleoecologic data collected at WEST are summarized in this chapter. Core samples were examined for benthic foraminifers (Kristin McDougall) and paleomagnetics (John Hillhouse). The upper Long Beach (273.7-233.3 m), lower Wilmington (233.2-190.8 m), upper Wilmington (190.8-143.6 m), Bent Spring (143.6-100.6 m), Harbor (100.6-61.5 m), Pacific (61.6-30.5 m), and Mesa (30.5-0 m) units were recognized in this well (Ponti, oral commun., 2008).

\section{Biostratigraphy}

\section{Benthic Foraminifers}

Benthic foraminifers were analyzed from 115 samples in WEST. The lower 47 samples (272.4-180.2 m, Mf10861-Mf10814) include 12 barren samples and 35 samples with microfossils, whereas the upper 65 samples (175.7-38.4 m, Mf10813-Mf10753) are barren of benthic foraminifers (plate 15, fig. 83). The entire fossiliferous section is assigned to the Pleistocene Wheelerian Stage (fig. 84). This interpretation is based on the presence of age-diagnostic Wheelerian Stage species, such as Epistominella pacifica, Cibicides mckannai, and C. mckannai suppressa. Hallian and early Hallian species (Buccella frigida, Elphidium transluscens, various cassidulinids, and Uvigerina juncea) appear in this interval, but in reduced abundances. Oridorsalis (O. subtenera and $O$. umbonatus) occurs in the stratigraphically oldest samples and indicates that these lower faunas represent the older part of the Wheelerian Stage. No age-diagnostic Pliocene species are observed.

\section{Geochronology}

\section{Paleomagnetics}

The WEST well was cored nearly continuously to a depth of $243 \mathrm{~m}$. Coring was intermittent below $243 \mathrm{~m}$, and two 6-m cores were taken in the depth intervals 256-250 m and 274-268 m. Sampling for paleomagnetism was done at approximately 1.5-m intervals in suitably fine-grained sediments, beginning at a depth of $18.76 \mathrm{~m}$, and the deepest sample was collected at $272.08 \mathrm{~m}$. The results are of high quality with 89 percent of the least-squares line fits giving MADs of $<10^{\circ}$ (appendix III, table 25). Inclinations measured in WEST are dominantly normally polarized, although five horizons (A, $30.8 \mathrm{~m}$; B, $76.6 \mathrm{~m}$; C, $112.9 \mathrm{~m}$; D, $174.5 \mathrm{~m}$, and E, $236.4 \mathrm{~m}$ ) have reversed polarity (fig. 85). Of those five inclination excursions, only A, the uppermost anomaly, has poor quality (MAD is $17.7^{\circ}$ ) and very weak magnetization. The lack of a substantial zone of reversed polarity in WEST implies that the drilling did not penetrate beyond the Matuyama-Brunhes boundary $(0.78 \mathrm{Ma})$.

Table 25. Paleomagnetic results from the Westchester core site and monitoring well (WEST), Westchester, California. [Title of table is included here for continuity; complete table is in appendix III.] 

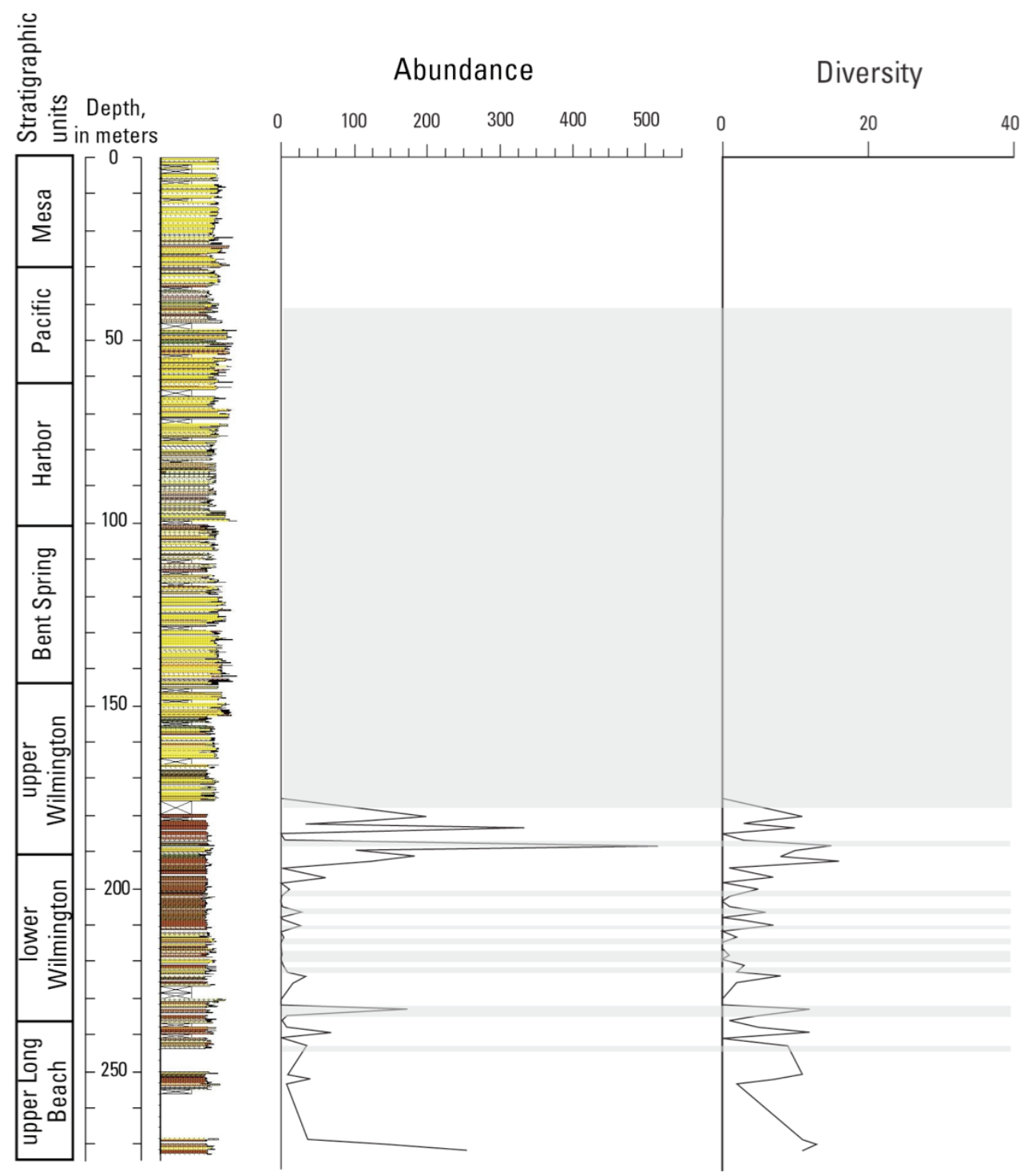

EXPLANATION

Barren

Figure 83. Abundance and diversity of the foraminiferal fauna in Westchester core site and monitoring well, Westchester, California. Abundance of the foraminifers is based on the number of foraminiferal specimens present in the sample. Diversity is the number of species identified in the sample. Stratigraphic units are identified in the left column, and lithologies are indicated on the stratigraphic column by color (clay, green; silt, brown; sand, yellow) ( D. Ponti, oral commun., 2007).

\section{Paleoecology}

\section{Benthic Foraminifers}

Abundance and diversity are typically low in the WEST well (fig. 83) making statistical analysis of WEST difficult. Only 10 of the 35 fossiliferous samples contained more than 100 specimens. Bathymetric analysis of the fossiliferous Wheelerian part of WEST suggests that at 272.4-252.3 m (Mf10861-Mf10856) sediments were deposited in the upper middle bathyal or lower slope biofacies at water depths of 500-950 (fig. 86). Dissolved-oxygen conditions 


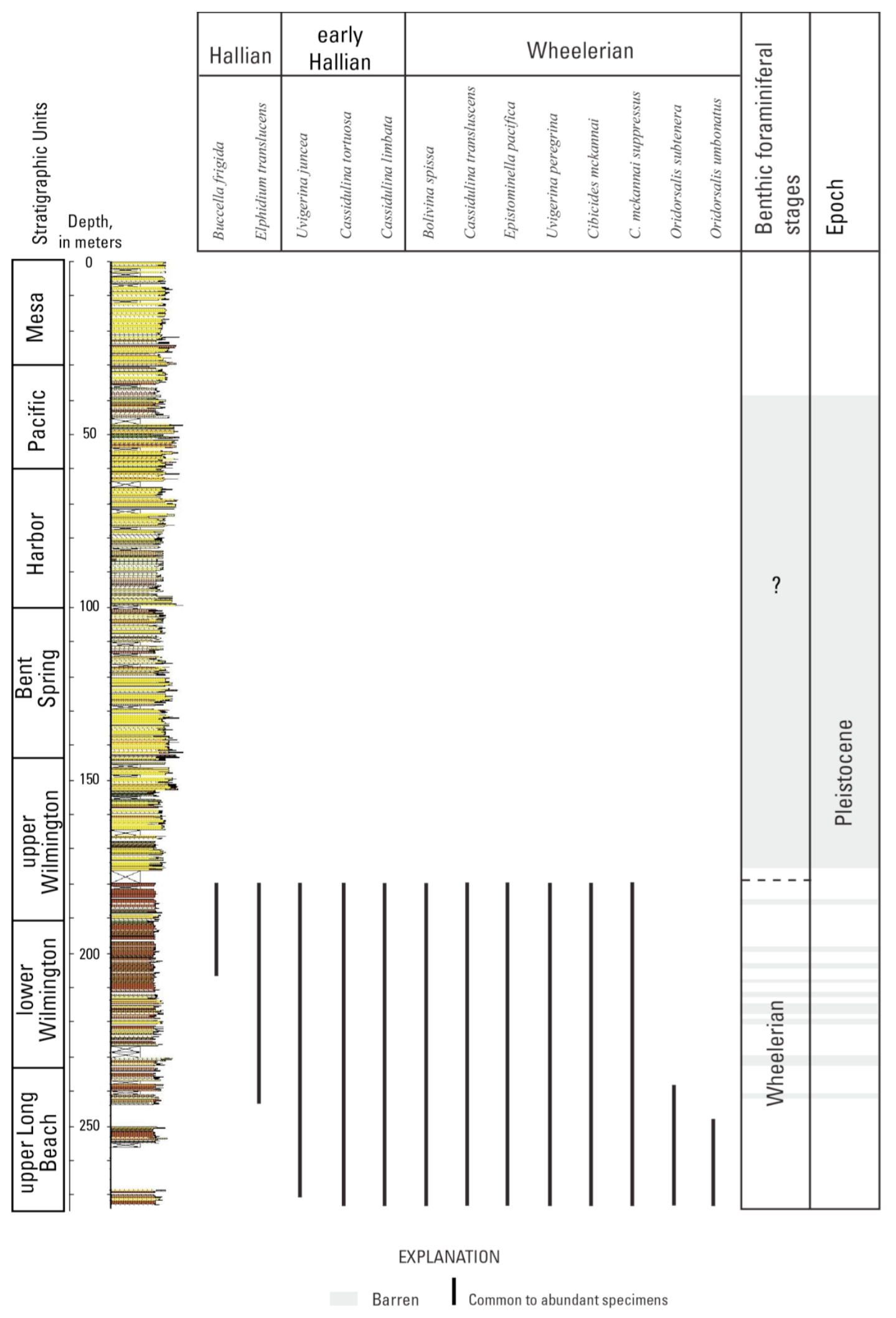

Figure 84. Stratigraphic distribution of age-diagnostic benthic foraminifers in the Westchester core site and monitoring well, Westchester, California. Abundances are given in plate 15. Stratigraphic units are identified in the left column, and lithologies are indicated on the stratigraphic column by color (clay, green; silt, brown; sand, yellow) (D. Ponti, oral commun., 2007). 


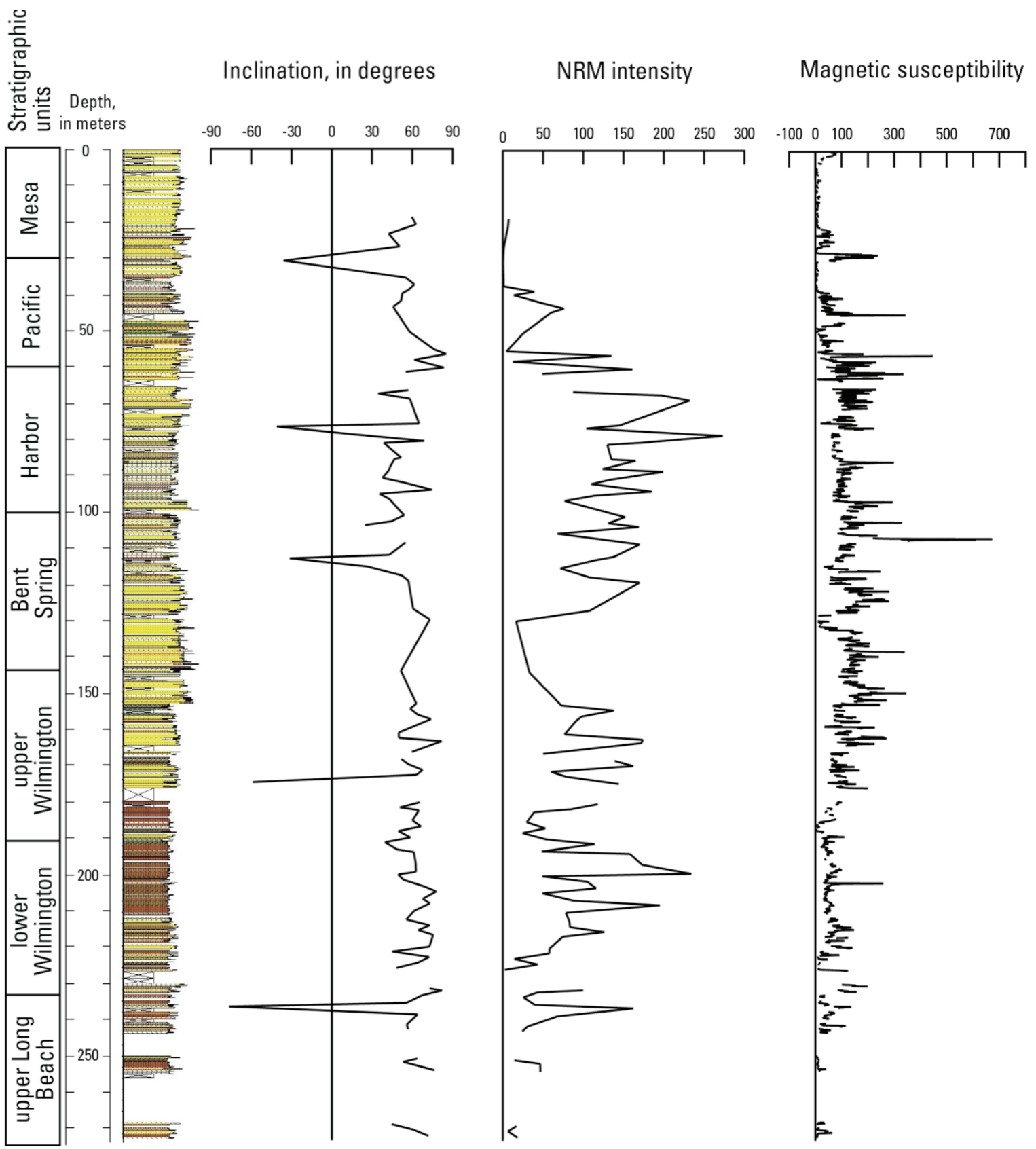

Figure 85. Remanent-magnetization (inclination and intensity) properties and magnetic susceptibility of the Westchester core site and monitoring well, Westchester, California. Inclination is measured in degrees. Intensity is depicted with a logarithmic scale, where 0.0 equals 1 milliAmpere/m. Magnetic susceptibility also is given with a logarithmic scale, where 0.0 equals $10-6 \mathrm{SI}$. Stratigraphic units are identified in the left column, and lithologies are indicated on the stratigraphic column by color (clay, green; silt, brown; sand, yellow) (Ponti and others, 2007).

throughout this interval were dysoxic. Water depths decreased from upper middle bathyal/lower slope biofacies to upper bathyal/bank biofacies by $180.2 \mathrm{~m}$ (Mf10814). Assemblages in the interval from 196.9 to $180.2 \mathrm{~m}$ (Mf10825-Mf10814) were at water depths of 150-200 m. Bottom waters were well oxygenated. Common in these samples are various cassidulinids, Cibicides mckannai, $C$. mckannai suppressa, and Uvigerina juncea, which are characteristic of banks and upper bathyal biofacies. 


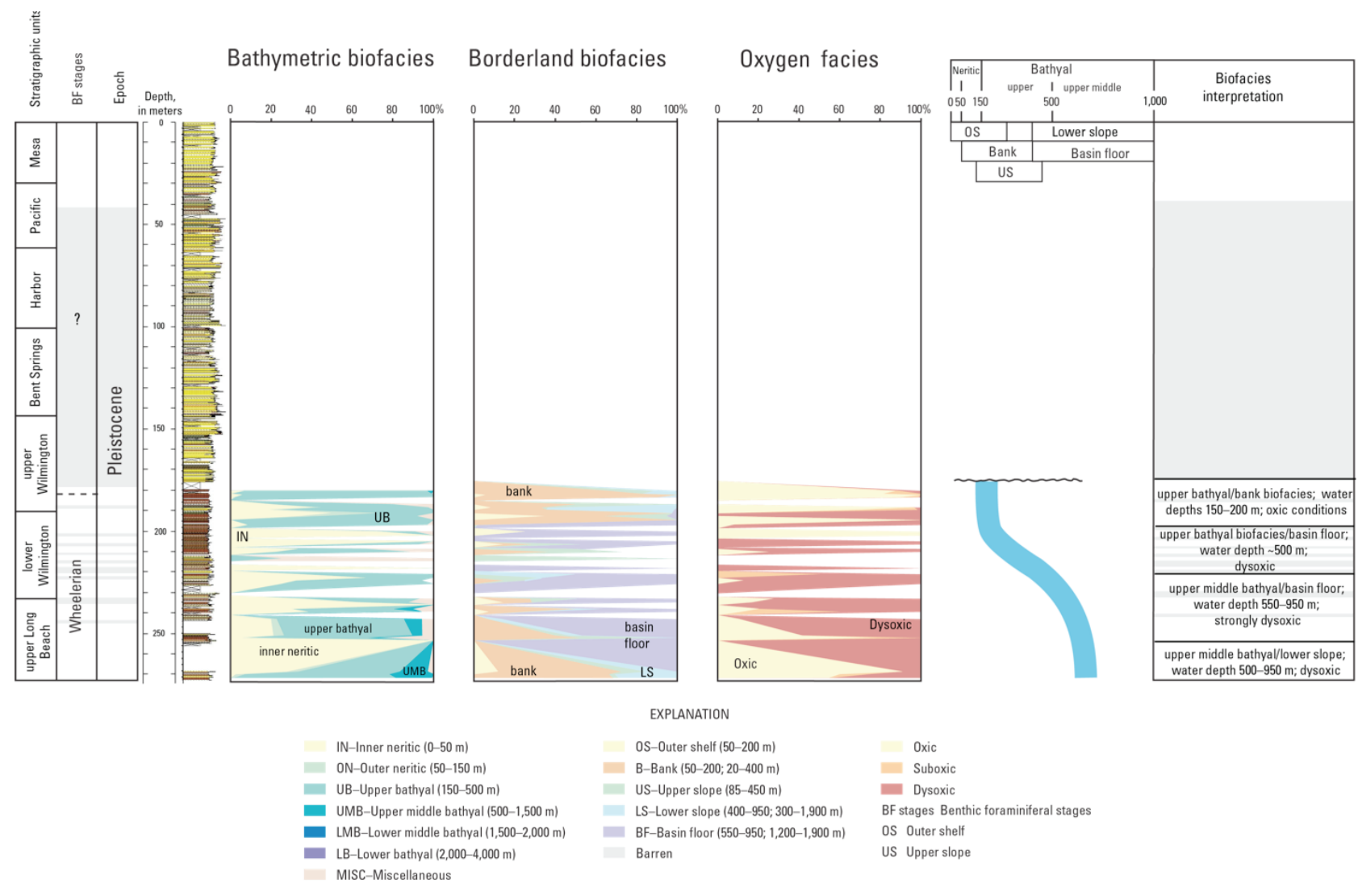

Figure 86. Paleoecological benthic foraminiferal biofacies analysis of the Westchester core site and monitoring well, Westchester, California. The three biofacies analyses discussed in the text, are based on the abundance of benthic foraminifers in the samples. The bathymetric curve represents the most probable depth at which the samples were deposited. Stratigraphic units are identified in the left column, and lithologies are indicated on the stratigraphic column by color (clay, green; silt, brown; sand, yellow) (D. Ponti, oral commun., 2007). [Reduced-size figure is shown here for continuity; full-size figure is included on plate 18.]

\section{Westchester Core Site and Monitoring Well Summary}

WEST is Pleistocene in age (fig. 87). Paleomagnetic analysis places the entire section in the Brunhes Normal Polarity Chron $(\leq 0.78 \mathrm{Ma})$. Five thin reversed-polarity intervals were detected but were not correlated. Benthic foraminifers indicate the presence of the Pleistocene Wheelerian Stage in the lower part of the well. Benthic foraminiferal faunas at the base of the well indicate deposition occurred in the upper middle bathyal/lower slope biofacies $(500-950 \mathrm{~m})$ but water depths decrease to the upper bathyal biofacies (150-200 m) and oxic conditions upsection (fig. 86). 


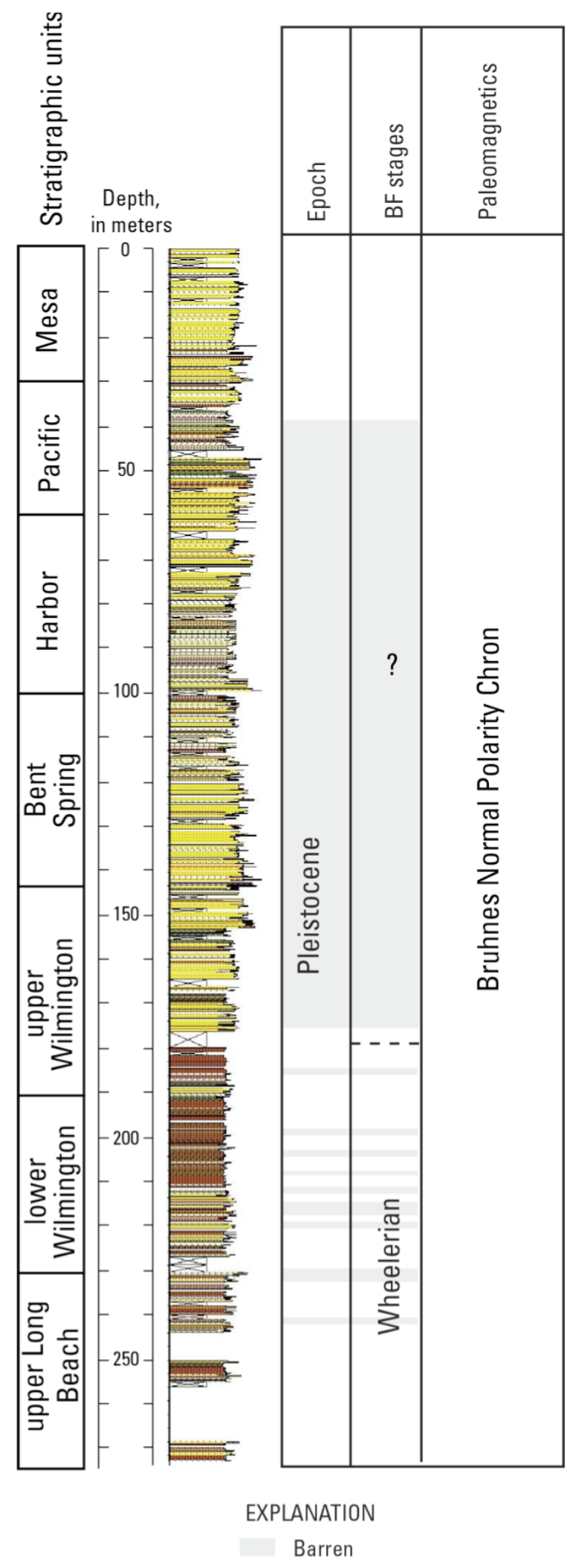

BF stages Benthic foraminiferal stages

Figure 87. Summary of geochronology of the Westchester core site and monitoring well, Westchester, California, based on the microfossils and paleomagnetics. Stratigraphic units are identified in the left column, and lithologies are indicated on the stratigraphic column by color (clay, green; silt, brown; sand, yellow) (D. Ponti, oral commun., 2007). 


\section{Chapter 10-Correlation, Summary, and Conclusions}

\section{Introduction}

The correlation established by Ponti and others (2007) was based on sequence stratigraphic units and preliminary biostratigraphic, chronostratigraphic, and paleoecologic interpretations of five key wells (LBPF, LBPC, LBCH, LWEB, and LBCC). The previous chapters provide data, analyses, and interpretation of the primary wells, as well as three additional wells examined during the FOQUS-LA drilling program. This chapter summarizes the results of these studies on the FOQUS-LA wells and the correlation of the key wells. The chapter concludes by revising our understanding of the sequence stratigraphic units of Ponti and others (2007) and, thus, the evolution of the later Neogene of the Los Angeles Basin.

\section{Biostratigraphy}

Three fossil groups were used to establish the biostratigraphy of the Los Angeles Basin: (1) benthic foraminifers, (2) planktic foraminifers, and (3) macrofossils. Although macrofossil biostratigraphic input was limited, planktic and benthic foraminifers provided more definitive information on the biostratigraphic framework and correlation. Only two wells (LBPF and LBPC) were analyzed for planktic foraminifers; benthic foraminiferal analyses were done on all wells in the study area. Sparse sampling and barren intervals that occurred primarily in the upper part of the wells made analysis of the fossil groups difficult.

\section{Benthic Foraminiferal Biostratigraphic Summary}

The benthic foraminiferal biostratigraphy utilized the California Pliocene and Pleistocene stages defined by Natland $(1952,1957)$ for the Los Angeles and Ventura Basins, which subdivide the Quaternary into four benthic foraminiferal stages. These stages were defined by the first, last, or common occurrences of key species (fig. 45). Since none of the species become extinct, the first and last appearances are based entirely on environmental conditions. However, because the stages were defined in the Los Angeles and Ventura Basins, the zonation works well for the FOQUS-LA wells. Recognition of an early Hallian interval is the only deviation from the original definitions.

The Venturian Stage is defined by changes in the abundance of bolivinids, Cibicides mckannai and the first appearance of Bolivina sinuata, Bulimina pagoda hebespinata, $B$. subaccuminata, Gyroidina, Oridorsalis, and Uvigerina pigmea. Venturian assemblages are identified in LBPF and LBPC, and questionably identified in LBCC. Since variations in abundance of Wheelerian and Venturian species are related to environment, the placement of the Wheelerian/Venturian boundary is difficult. In LBPF, LBPC, and LWEB faunas were questionably assigned to the Wheelerian Stage because species abundances were not clearly representative of either stage.

Wheelerian Stage assemblages are recognized in the FOQUS-LA wells by the last abundant occurrence ( $>5$ percent in this study) of Epistominella pacifica and the appearance of Bolivina argentea, Cibicides mckannai, and Uvigerina peregrina. Species diagnostic of the Wheelerian Stage have UDLs in the upper bathyal and upper slope biofacies and (or) are associated with the transitional or Pacific Intermediate Water masses. Wheelerian assemblages are identified in all the wells (plate 15).

The Hallian Stage in the FOQUS-LA wells is recognized by the presence of the inner neritic species (Ammonia beccarii, Buccella frigida, Elphidiella hannai, and various Elphidium species), whereas the early Hallian Stage is recognized by the last appearance of species from the outer shelf or bank and upper slope biofacies and (or) associated with the surface-water masses 
(Cassidulina transluscens, C. tortuosa, C. limbata, various bolivinids, and Uvigerina juncea). Praeglobobulimina affinis and Trifarina angulosa appear with these species and support the bathymetric interpretation. In the FOQUS-LA wells, early Hallian assemblages are recognized in strata below an unconformity in LBPF and LWEB, are removed by an unconformity in LBPC, and are below probable unconformities in $\mathrm{LBCH}$ and LBCC. Lack of samples complicates the interpretation of $\mathrm{LBCH}$ and LWEB.

The age range of the benthic foraminiferal stages given by Blake (1991) is supported by the study. The base of the Venturian Stage is not observed in this study; however, the oldest Venturian benthic foraminiferal assemblages occur with planktic foraminifers assigned to zone CM7 in LBPF. The base of the Venturian Stage is $>3.2 \mathrm{Ma}$ (minimum age for the base of CM7). The base of the Wheelerian Stage occurs with planktic foraminifers assigned to zones CM2-4 in LBPF and within the upper part of zone CM5 in LBPC. In both wells reworking associated with the unconformity between the lower Wilmington and upper Long Beach units makes zonal assignments difficult. Nevertheless the planktic foraminiferal zones and various datums indicate that the base of the Wheelerian Stage is between the age of the base of zone CM4 (2.0-1.8Ma) and the 2.4 Ma planktic datum observed in LBPC. Recognition of the Olduvai Subchron in sediments assigned to the Wheelerian Stage further limits the age of the base of this Stage to 1.95-1.8 Ma. In LBPF and LBPC, the base of the Hallian (including the early Hallian) always occurs in sediments assigned to the Brunhes Normal Polarity Chron and, therefore, less than $0.78 \mathrm{Ma}$ and in planktic foraminiferal zone CM1, which is in agreement with the 0.8-0.6 Ma age of the base of zone CM1.

\section{Planktic Foraminiferal Biostratigraphic Summary}

Using the standard Neogene planktic foraminiferal zonation scheme based on tropical- and subtropical-marker taxa (Banner and Blow, 1965; Blow, 1969; Stainforth and others, 1975; Kennett and Srinivasen, 1983), samples from LBPC and LBPF are Pleistocene age. By incorporating the zonation proposed by Kennett and others (2000) for ODP Leg 167 sites drilled along the California margin, the Neogene biochronology can be further refined. The CM zonational scheme subdivides the late Neogene into eight zones (CM1-CM8). The boundaries of these zones are based on evolutionary changes within the Neogloboquadrina plexus and FO and LO of other species. Because planktic foraminifer samples in the FOQUS-LA wells were recovered from discontinuous nearshore (or inland) sediments that have been influenced by the cold water California Current, the warm water Southern California Countercurrent, and regional tectonic activity, the minimum and maximum age for FOs and LOs in LBPC and LBPF were used. Any ages derived using this scheme should be extrapolated with caution. Despite these problems, the California Margin zonation scheme was used successfully on these two wells (fig. 88).

Below the intervals containing relatively few to no diagnostic planktic foraminifers in LBPF and LBPC, zones CM1 through CM7 are recognized. Species diagnostic of the zonal boundaries occur in these sections despite the nearshore environment. The discontinuous sediment record of the wells, however, seriously impacts the recognition of several zones. In both wells, boundaries of zones CM2-4 are difficult to recognize. In LBPF, the interval below CM2 contains stratigraphically mixed first and last appearances of species diagnostic of zones CM2 through CM4: LO of Neogloboquadrina kagaensis, FO of Neogloboquadrina inglei, FO of Globigerina umbilicata, FO of Neogloboquadrina pachyderma B, and LO Neogloboquadrina pachyderma C. These occurrences mark the base of CM4, CM3, zone N21, CM2, and CM3, respectively. In LBPC the interval (215.10-265.78 m) below CM2 includes the LO of Neogloboquadrina kagaensis, which marks the base of CM4 but contains no species diagnostic of CM3, thus the interval is assigned to zones CM3-4. In both LBPF and LBPC, unconformities are recognized by other criteria above and below these intervals. 
LBPF

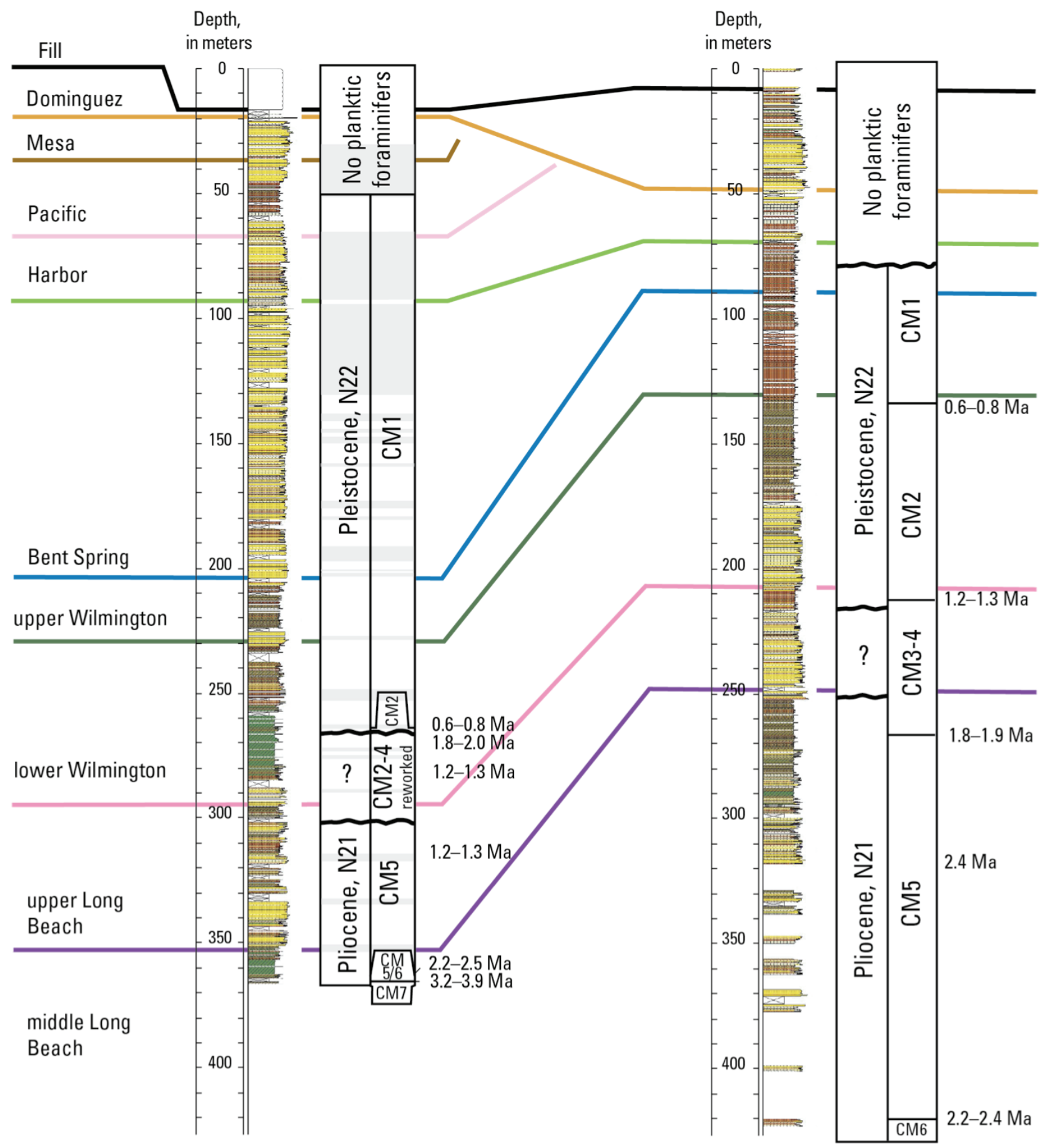

EXPLANATION

Barren

Figure 88. Detailed summary of the planktic foraminiferal-age interpretation of the Long Beach Pier $F$ and Pier $\mathrm{C}$ core site and monitoring wells, Long Beach, California. Stratigraphic units are identified in the left column, and lithologies are indicated on the stratigraphic column by color (clay, green; silt, brown; sand, yellow) (Ponti and others, 2007). 
Corroborating age interpretations are not available in the FOQUS-LA wells. Macrofossil and benthic foraminiferal zonations are not tied to a geochronology. OSL and TL ages, radiocarbon dates, and paleomagnetic excursions are too young to be of use, and there are no definitive paleomagnetic reversals observed in the wells.

\section{Macrofossil Biostratigraphic Summary}

Although no detailed macrofossil biostratigraphy exists for the Pleistocene and Holocene of southern California, and very few species are present in the core samples to accurately date the sediments, several species become locally extinct owing to changes in water temperature and thus provide approximate ages. A principal geographic range end point is near the Los Angeles Basin, so a slight increase or decrease in water temperature allows the species to migrate north or south of the Los Angeles Basin. The bivalves Chione and Donax do not occur in the Los Angeles Basin between MIS 5e and beginning of the Holocene $(\geq 116$ to $\leq 12 \mathrm{ka})$; therefore, the stratigraphically highest occurrence of these species prior to the Holocene in the FOQUS-LA wells indicates an age of $\geq 116 \mathrm{ka}$ and the reappearance of these genera indicates an age of $\leq 12 \mathrm{ka}$. Chione was recognized in LBPC, LBCH, LWEB, and LBCC, whereas Donax was recognized only in LBPC (plate 16) and these age designations are supported by TL/OSL dates and paleomagnetic excursions. Other agediagnostic macrofossils include Patinopecten ( $<300 \mathrm{ka})$ and Calicantharus fortis (300-400 ka). Patinopecten occurs in LBPC near a TL date of $>156 \pm 14 \mathrm{ka}$, and $C$. fortis occurs in LBCC below a TL date of $45 \pm 6$ and $76 \pm 4 \mathrm{ka}$. However, the specimens are poorly preserved and probably reworked, so their presumed age range does not match with TL dates.

\section{Geochronology}

\section{Paleomagnetism Summary}

Magnetic susceptibility of the FOQUS-LA wells varies over three orders of magnitude, from 10-6 to 10-3 in the SI-volume system, and has a mean value of approximately $3 \times 10-5$. Susceptibility is primarily a measure of the concentration of magnetic minerals, most commonly magnetite, in sediment. Intensity of NRM in these wells strongly correlates with susceptibility, ranging over three orders of magnitude from 10-4 to $10-1 \mathrm{~A} / \mathrm{m}$. The magnetization is significantly weak in some intervals, given the abundance of detrital magnetite in the largely granitic upland source areas. Some prominent features that can be correlated between wells are low-intensity values at the Mesa-Pacific and Harbor-Bent Spring unit boundaries.

Inclination logs from the FOQUS-LA wells exhibit no sustained intervals of reversed polarity, suggesting absence of the Matuyama-Brunhes boundary (fig. 8). If no other agediagnostic evidence existed, the inclination record would imply that the entire core represents sediment no older than $0.781 \mathrm{Ma}$. However, planktic foraminifers from samples below the lower Wilmington unit in LBPF and LBPC are late Pliocene or early Pleistocene in age, and are older than 1.8 Ma. An erosional unconformity separates the lower Wilmington from the underlying upper Long Beach unit in LBPF, LBPC, and LBCC and may explain the absence of the MatuyamaBrunhes boundary. The erosional gap would be a hiatus in deposition spanning approximately one million years, representing the interval between the Olduvai Normal Polarity Subchron and the beginning of the Brunhes Normal Polarity Chron. Anomalously low inclinations that were measured near the base of the lower Wilmington, excursion G in LBPF (fig. 89) are perhaps a record of geomagnetic instability during the early stages of the Brunhes Normal Polarity Chron. This correlation is consistent with the stratigraphic position of the Lava Creek B ash (639 $\pm 2 \mathrm{ka})$ in LBCC, lower Wilmington unit. 
Inclination, in degrees

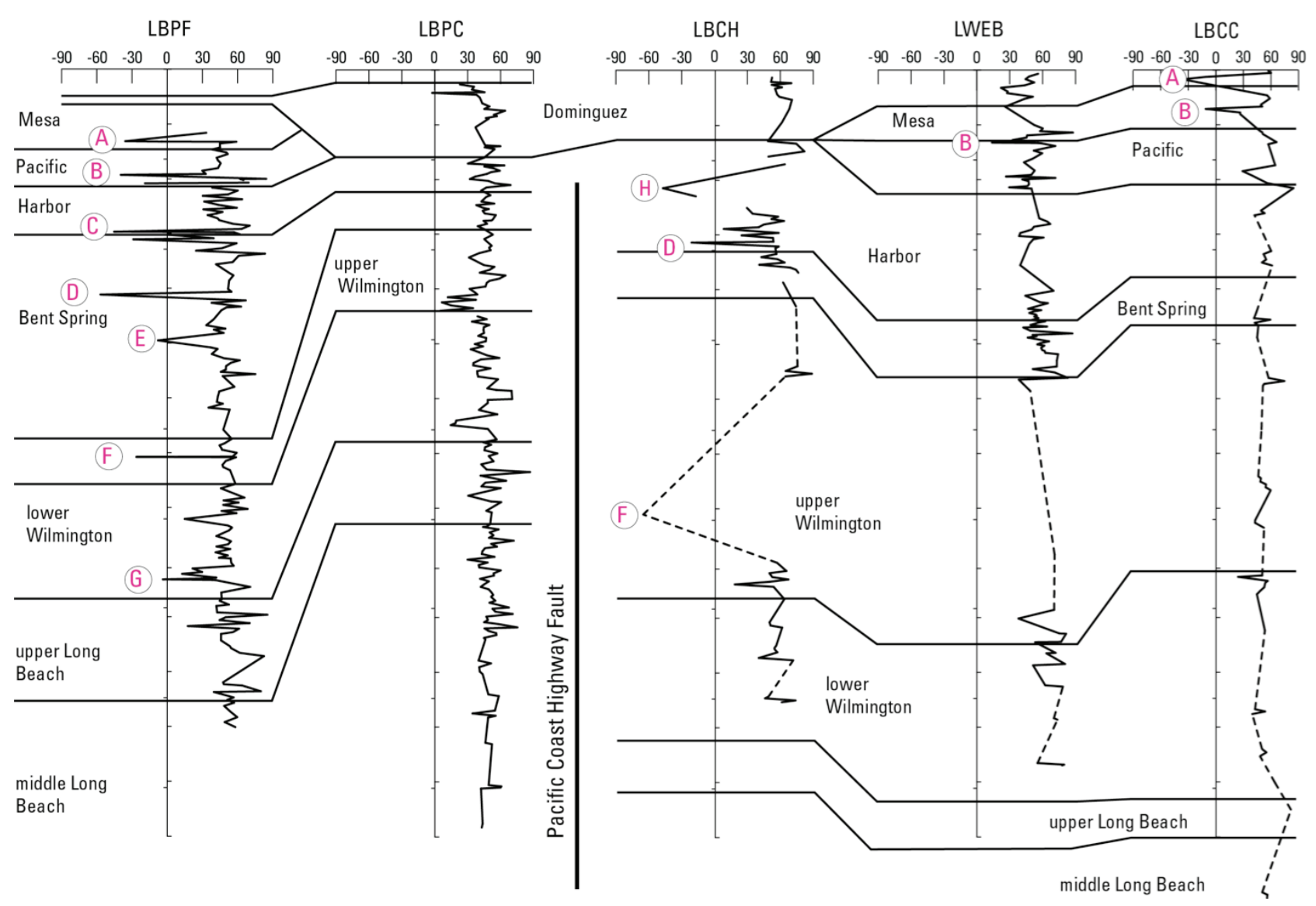

Figure 89. Summary of paleomagnetic inclination data. Major paleomagnetic excursions are labeled from $A$ to H: A, Laschamp Event (40 ka); B, Blake Event (117 ka); C, occurs in friable sandstone of LBPF, not recognized in other core holes; $D$, Pringle Falls Event (200 ka); $E$, found in one sample in LBPF, age not confirmed; $F$, found in one sample in LBPF, age not confirmed; G, possible reversal in LBPF; and H, reversal in LBCH. Sequence stratigraphic units and correlation is from Ponti and others (2007). Depth in meters (50-m interval) is given on the left side and depth in feet (100-ft interval) is given on the right side of the zero inclination line.

A comparison of the inclination logs from the five Long Beach wells (fig. 89) shows predominantly normal polarity broken by several short intervals of reversed or intermediate polarity. Median inclinations for each core are near the expected axial dipole field value, which is $52^{\circ}$ at the mean site latitude. Several inclination anomalies and features (labeled A-H in fig. 89) occur within the same stratigraphic sequences in the wells. The significance of two negativeinclination features in the Dominguez unit are discounted owing to the possibility of artificial disturbance near the surface. The uppermost excursion (A) is a swing to low inclinations in the Mesa unit of LBPF and the Dominguez unit in LBCC. The second excursion (B) is characterized by a swing to negative inclination in LBPF and LBCC and by very low inclinations in LWEB. This feature occurs in the Pacific unit, but is absent in LBPC and LBCH where erosion has removed these units. The third excursion (D) is a swing to very low inclination in the Bent Spring unit of LBPF and just above the Brent Spring-Harbor contact in LBCH. It occurs within an interval of generally decreasing inclination from the Bent Spring upward through the Harbor unit. Excursion $\mathrm{G}$ occurs in LBPF in the lower Wilmington unit. There are several negative-inclination features, particularly in LBPF, exclusive of the features mentioned, but these features were not confirmed in 
other cores. Very few samples were obtained from the upper Wilmington unit in LBCH, LWEB, and LBCC because the poorly consolidated coarse sands were poor targets for paleomagnetism.

Electron-microprobe scans of magnetic separates from LBPC and LBPF consistently show iron-oxide cores surrounded by rims of iron-sulfide. The sulfide rims, up to 20 microns thick, appear in two forms: as a clustering of microspheres on the grain surface and as deep replacement of partially dissolved iron-oxide grains. Comparing results from LBPC and LBPF, we note thicker sulfide rims and a higher degree of etching and dissolution in the LBPC magnetic grains. In both cores, sulfide authigenesis is less developed in the upper and middle Long Beach units relative to alteration in the Harbor, Bent Spring, and lower Wilmington units. Sulfide rims are less than 3 microns thick in the upper and middle Long Beach units. From this limited sampling, the more common type of magnetic grain is titanium-poor magnetite, typical of plutonic rocks. Also present are titanomagnetite grains with ilmenite lamellae, a common constituent of subaerially deposited volcanic rocks, and grains of ilmenohematite from metamorphic rocks.

The ubiquitous presence of authigenic sulfides in the FOQUS-LA wells raises a possibility that the original depositional remanent magnetization has been altered chemically. At the very least, the original magnetization has decreased in intensity as magnetite grains were dissolved and replaced by iron-sulfide. Dissolution could explain very low magnetizations noted in some intervals of the LBPC and LBPF wells. It is reasonable to assume that the smaller magnetite grains that are critical for preserving a stable paleomagnetic signal are severely depleted, given that thick rims of sulfide were observed on the larger grains. Moreover, spurious secondary magnetizations could be present if magnetic species of authigenic iron-sulfide (pyrrhotite or greigite) developed long after deposition.

In marine environments, iron-sulfides form under conditions of low oxygen and high organic carbon (Canfield and Berner, 1987). Bacteria reduce sulfate in seawater to produce $\mathrm{H}_{2} \mathrm{~S}$, which in turn reacts with iron-bearing minerals. Prolonged exposure of magnetite to $\mathrm{H}_{2} \mathrm{~S}$ leads to the formation of pyrite, an iron-sulfide that does not acquire remanent magnetization. However, the sulfidization reaction can progress through intermediate products, such as greigite, a form of ironsulfide that may acquire remnence. The microprobe images show crystal forms consistent with pyrite, but the tests performed to date cannot rule out the presence of greigite or pyrrhotite.

The anomalous negative inclination (excursion A) in the Mesa unit is correlated with the Laschamp event, which is dated at $40 \mathrm{ka}$. This correlation is supported in LBPF by a radiocarbon date $(41 \pm 1.1 \mathrm{ka})$ and TL dates $(35 \pm 2.6 \mathrm{ka}$ and $27 \pm 4.3 \mathrm{ka})$ above the anomaly. The interval of anomalous negative inclinations in the Pacific unit (excursion B, fig. 89) is correlated with the Blake event (fig. 8), a global geomagnetic instability that occurred during MIS 5e ( 117 ka). A TL age from sample LBPF-28C, which is within the zone of anomalous inclination, yielded ages of $93.2 \pm 7.8 \mathrm{ka}$ and $95.9 \pm 19.5 \mathrm{ka}$. The last appearance of the macrofossil Chione in LBPF, just below the anomalous inclination in LBPF, suggests an age of $>116 \mathrm{ka}$. In LWEB, TL dating of sample LWEB-32C and the last appearance of Chione, both below the anomalous inclination yield dates of $123 \mathrm{ka}$ and $>116 \mathrm{ka}$, respectively. In LBCC, the $\geq 116 \mathrm{ka}$ date based on the last appearance of Chione occurs $1 \mathrm{~m}$ above the anomalous inclination.

Excursion D in the Bent Spring unit of LBPF and the Harbor unit of LBCH occurs between horizons dated by TL at $300 \mathrm{ka}$ and $100 \mathrm{ka}$. Excursion D is correlated with the Pringle Falls Event (200 ka), although more corroborative evidence is needed.

\section{Optically Stimulated Luminescence and Thermal Luminescence Summary}

Two techniques were used to date the luminescence samples in the FOQUS-LA wells: (1) a single-aliquot regeneration method (SAR) for sand-sized grains of quartz and (2) the multi-aliquot additive dose method (MAAD) for silt-sized grains in a polymineral mix for IRSL-OSL on 
feldspars, as well as TL. Ages for feldspar (IRSL-OSL) and quartz (blue-light OSL) were compared to TL ages and ages based on other techniques. Except for the very young ages $(<2 \mathrm{ka})$, the feldspar IRSL-OSL ages tended to be at least $5 \mathrm{ka}$ older than the quartz ages. The difference between the two luminescence techniques and minerals increased with age, with the quartz OSL saturating out at around $80 \mathrm{~Gy}$ (approximately equivalent to 35-30 ka). When the IRSL equivalent doses approached 210-250 Gy (approximately 80-70 ka), they, too, began returning age underestimates, suggesting this was the limit of this technique. The TL ages are older than any of the OSL ages but generally track better with the feldspar IRSL-OSL ages. It was not possible to obtain a TL age greater than about $275 \mathrm{ka}$ owing to continued saturation of these systems (ages generally began to return severe underestimates around $170 \mathrm{ka}$ ). As stated before, elemental-data analyses did not indicate large dose rates that were likely to cause the creation of large amounts of unstable luminescence in a short amount of time (Aitken, 1998). Dose rates were generally in the range of 4-3 Gy for the IRSL-OSL and TL, and in the range of 3-2 Gy for the quartz OSL.

Excluding the samples which were considered to be underestimates or overestimates, the quartz OSL, feldspar IRSL-OSL, and TL ages are minimum ages and increase downhole with no stratigraphic reversals noted. In general, when compared to the radiocarbon ages which were obtained in LBPF, LBPC, and LWEB, and the paleomagnetic excursions (fig. 90), these ages showed good correlation.

TL dates are similar to those obtained from paleomagnetic events, except for some correlation problems in LBCH, where a TL date of 274 ka occurs stratigraphically above the Pringle Fall event (200 ka). The Laschamp event (40 ka) is recognized in LBPF stratigraphically below OSL and TL dates ranging in age from 35 to $22 \mathrm{ka}$ and near a radiocarbon age of $41 \mathrm{ka}$. However, in LBCC, this same event occurs stratigraphically above OSL dates of 26-20 ka (no TL dates in this core). The Blake event ( 117 ka) occurs in LBPF, between TL dates of $93 \mathrm{ka}$ (above) and $131 \mathrm{ka}$ (below), in LWEB above a TL date of $123 \mathrm{ka}$ and in LBCC.

Quartz OSL ages obtained on LBPC-33C (43.5 m) match ages obtained from radiocarbon taken on wood from the same core interval. Wood (not charcoal) was discovered at depths of 45.4 and $44.2 \mathrm{~m}$ (both from LBPC-33C). The wood from $44.2 \mathrm{~m}$ was dated at $12 \pm 0.05 \mathrm{ka} \mathrm{cal} \mathrm{BP}$, and the wood from $45.4 \mathrm{~m}$ was dated at $12 \pm 0.04 \mathrm{ka}$ cal BP. Therefore, it seems likely that the two quartz ages (11 and $12 \mathrm{ka}$ ) are reliable indicators of the true depositional ages of the sediment.

OSL and TL ages were compared with radiocarbon ages obtained in LBPF and LWEB. In LBPF, a shell occurring at $\sim 35.5 \mathrm{~m}$ (LBPF-13) yielded a radiocarbon age of $41 \pm 1.13 \mathrm{ka} \mathrm{BP}$, whereas sediment at $36.5 \mathrm{~m}$ (LBPF-13) yielded TL dates of $27 \pm 4$ and $35 \pm 3 \mathrm{ka}$ (IRSL-OSL ages were $31 \pm 1$ and $24 \pm 1 \mathrm{ka}$ ). The luminescence ages are younger than the radiocarbon, but all the older ages overlap around the vicinity of $40 \mathrm{ka}$. In LWEB, radiocarbon dates were obtained from a peat layer at $11.9 \mathrm{~m}$ and a macrofauna (shell?) at $12.1 \mathrm{~m}$, and OSL dates were obtained at $7.3 \mathrm{~m}$ (LWEB-5). The peat was dated to $2.39 \pm 0.04 \mathrm{ka} \mathrm{BP}$, the macroflora was dated at $1.76 \pm 0.04 \mathrm{ka} \mathrm{BP}$, and the OSL ages were $1.48 \pm 0.09 \mathrm{ka}, 1.28 \pm 0.16 \mathrm{ka}$, and $1.60 \pm 0.13 \mathrm{ka}$. There is less overlap of these ages.

The range of OSL and TL dates in the sequence stratigraphic units are Dominguez $<18 \mathrm{ka}$, Mesa 22-41 ka, Pacific 66-160 ka, Harbor 131-275 ka, Bent Spring 282->505 ka, and upper Wilmington $>425 \mathrm{ka}$. These ages differ slightly from the ages given by Ponti and others (2007). Generally, these luminescence dates suggest a greater time span for the units than previously published. Differences in the luminescence ages north and south of the PCH Fault were noted in the Pacific and Harbor units and possibly the Bent Spring unit. South of the fault, ages of the stratigraphic units are younger than north of the fault. The Pacific unit south of the fault has dates ranging from 66 to $95 \mathrm{ka}$ but north of the fault, the unit ranges in age from 160 to $123 \mathrm{ka}$. A similar relation is noted in the Harbor unit. South of the PCH Fault, ages range from 174 to $131 \mathrm{ka}$, 


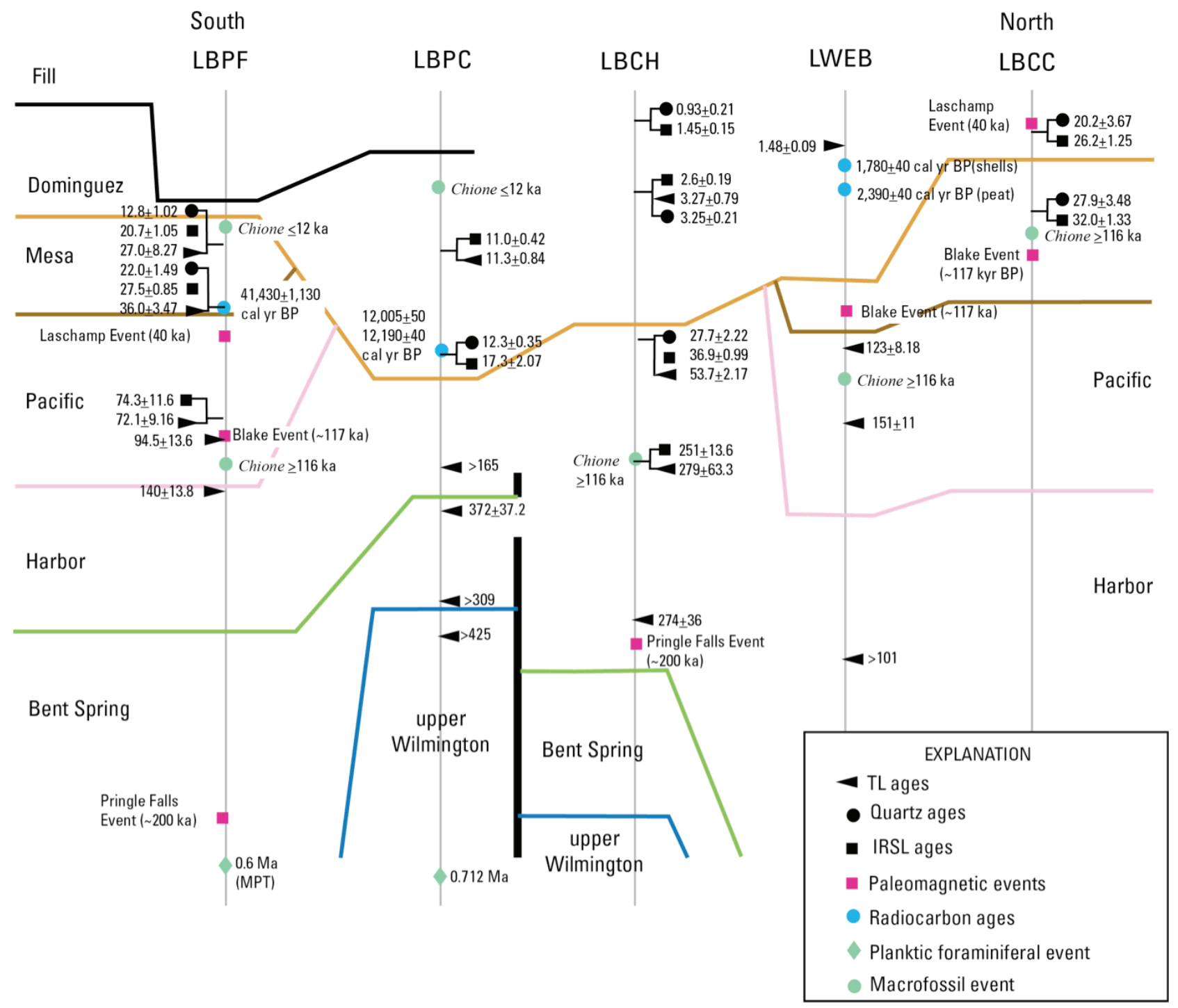

Figure 90. Ages (in ka) obtained as a result of quartz optically stimulated luminescence (OSL), feldspar infrared stimulated luminescence (IRSL), thermal luminescence (TL), and radiocarbon analysis are plotted in each well. Ages considered to be overestimates or underestimates are excluded and only one average is shown for each method. Paleomagnetic events and fossil events in the upper part of the wells also are plotted in this figure. Distribution of the sequence stratigraphic units is from Ponti and others (2007). One TL date (>505 $\pm 90 \mathrm{ka}, \mathrm{LBCH})$, in the Bent Springs unit south of the PCH Fault, occurs stratigraphically lower than the area shown in this figure.

whereas north of the fault ages range from $>101$ to $275 \mathrm{ka}$. South of the fault, TL dates in the Bent Spring unit range from 372 to $282 \mathrm{ka}$. The single date in the Bent Spring unit north of the fault is $>505 \mathrm{ka}$. These age differences suggest that movement on the fault was occurring during deposition of the Bent Spring unit and stopped after deposition of the Pacific unit. This interpretation is consistent with that of the conclusion by Ponti and others (2007) that movement on the fault began during lower Wilmington time and continued at least into Harbor time, with possible movement continuing into Pacific time (ending around 66-65 ka). 


\section{Paleoecology}

Paleoecologic interpretations throughout this study were based on macrofossils, benthic and planktic foraminifers. Macrofossils subdivide the marine environment into four shallow marine biofacies and one deeper marine biofacies (Valentine, 1961) (fig. 5). Macrofossil paleoenvironmental interpretations were useful in shallow marine waters, but the abundance and paleobathymetric models based on benthic foraminifers were more useful in the outer shelf and bathyal environments.

Benthic foraminiferal analysis used two paleobathymetric models to determine for marine environments (figs. 5 and 6). One was developed by Ingle (1980) for use along open margins and the other was developed by Douglas and Heitman (1979) for use in the Southern California borderland basins. The open margin biofacies model is more sensitive to changes in the shelf environments, whereas the borderland basin model is more useful in dealing with foraminiferal distributions in silled basins. The intertidal, adlittoral, and inner sublittoral macrofossil biofacies correspond to the inner neritic biofacies of benthic foraminifers, and the outer sublittoral macrofossil biofacies corresponds to the outer neritic and (or) bank benthic foraminiferal biofacies. The bathyal macrofossil biofacies encompasses the multiple bathyal and abyssal biofacies of benthic foraminifers. Benthic foraminiferal paleoecological analysis also examined the dissolvedoxygen conditions of the bottom waters, recognizing three biofacies: oxic, suboxic, and dysoxic biofacies (fig. 7). Occasionally the abundance of infauna and epifaunal species were determined to support the dissolved-oxygen interpretations.

Planktic foraminiferal paleoecologic reconstructions examined the morphotypes and ratios of the Neogloboquadrina pachyderma plexus as paleotemperature proxies. Other paleoenvironmentally sensitive taxa used to support these ecologic interpretations included additional planktic foraminifers and macrofossils. Benthic foraminiferal faunas respond to the bottom water-masses and, therefore, were not useful in providing support for surface-water mass paleotemperature interpretations. Macrofossils that occupy the surface-water masses in the shallow marine environments were able to provide additional information on the paleoclimate and paleotemperatures.

Paleobathymetric analysis based on macrofossils and benthic foraminifers indicates that water depth in the wells generally shallowed over time (plate 17). In LBPF, LBPC, and LBCC, a regional unconformity occurs between the upper Long Beach and lower Wilmington units (Ponti and others, 2007) and coincides with the change in water depth observed between these units in LBPC and LBCC, but not in LBPF. A change in water depth also is recognized between the middle and upper Long Beach units in LBPF and LBPC. Water depths decrease between the middle Long Beach and the overlying upper Long Beach unit in LBPF and LBPC, but the water depth change across the regional unconformity between upper Long Beach and the lower Wilmington units is variable. A second regional unconformity occurs in the Bent Spring unit in LBPF, LBPC, LBCH, and LBCC. This same unconformity probably is present in the base of the Harbor unit of LWEB, but foraminiferal data is limited and macrofossil data for this interval are based primarily on transported specimens. This unconformity marks a change from outer shelf and upper slope depths $(\sim 150 \mathrm{~m})$ to inner neritic depths $(<50 \mathrm{~m})$.

\section{Age, Correlation, and Paleoecology of the Sequence Stratigraphic Units}

Based primarily on preliminary paleomagnetism and OSL and TL dating, Ponti and others (2007) considered the lower Wilmington through Dominquez sequence stratigraphic units to be younger than $0.78 \mathrm{Ma}$ and separated by a regional unconformity from the upper, middle, and lower Long Beach units (table 2). Emphasis on the planktic foraminiferal ages and integration of analyses by the various disciplines suggests that some of the sequence stratigraphic units above the 
unconformity are older than $0.78 \mathrm{Ma}$. Although initial paleomagnetic interpretations suggested all sediments above the unconformity were deposited during the Brunhes Normal Polarity Chron and, therefore, $\leq 0.78 \mathrm{Ma}$, ages based on foraminiferal assemblages suggest ages $>0.78 \mathrm{Ma}$ and multiple unconformities associated with the sequence stratigraphic units (table 26, fig. 91). In this section, the age and ecology of each unit used to construct figure 91 are discussed. Emphasis is on the five key wells because the three additional wells provide little data.

\section{Middle and Upper Long Beach Units}

Ponti and others (2007) indicated that both the middle and upper Long Beach units were $>2.6 \mathrm{Ma}$ or $\sim 2.0 \mathrm{Ma}$ based on the preliminary magnetic polarity and paleontology. The lower Long Beach unit, which was not sampled in any of the wells, was believed to be $>2.6 \mathrm{Ma}$ and correlated with the Pliocene, Repettian Stage. The middle and upper Long Beach units were sampled in LBPF, LBPC, and LBCC, but neither unit was sampled in LBCH or LWEB. However, in LBCC, microfossil assemblages in the middle Long Beach unit were sparse and provided little information, and samples from the upper Long Beach unit were barren. Macrofossils were not found in either unit in LBCC, and paleomagnetic samples were not definitive. Interpretations of the middle and upper Long Beach units are, therefore, based entirely on samples from LBPF and LBPC. These interpretations suggest that the middle Long Beach unit of LBPF represents older sediments than those recognized in LBPC, that the upper Long Beach unit of LBPF and the middle Long Beach unit of LBPC represent roughly the same time interval, and that the upper Long Beach unit of LBPC is the youngest.

Planktic foraminifers from the middle Long Beach unit in LBPF are assigned to California margin zones CM7, CM6/5, and CM5. The base of zone CM6 occurs between 3.2 and 2.6 Ma, and the base of zone CM5 occurs between 2.5 and 2.2 Ma. Other FO and LO datums in this interval also support these ages. Neogloboquadrina pachyderma coiling morphotypes and tropical species occurring in the middle Long Beach unit of LBPF assigned to zones CM7 and CM6-CM5, indicate warm surface-water conditions. Planktic foraminifers in the middle Long Beach unit assigned to zone CM5 indicate a change to cooler surface-water conditions. Benthic foraminifers from the middle Long Beach unit of LBPF are assigned to the Venturian Stage and indicate that deposition occurred in the lower middle bathyal/lower slope biofacies (1,200-1,900 m). Macrofossils were not recovered from this unit. The polarity of the middle Long Beach unit is normal and was tentatively correlated with the Olduvai Normal Polarity Subchron. This correlation and the paleoclimatic conditions suggests correlation with an early Pleistocene warm (2.0-1.8 Ma) and cold (1.8 to $\sim 1.5$ $\mathrm{Ma}$ ), which is too young based on planktic foraminiferal ages. An alternative interpretation suggests correlation with a Pliocene warm (4.5 to 3.1 Ma; Poore, 2007; Ravelo and others, 2004; Ravelo and Wara, 2004) and the onset of Northern Hemisphere glaciation (2.75 Ma; Lisiecki and Raymo, 2007; Poore, 2007; Ravelo and others, 2004). This correlation implies that the normal polarity indicated for this unit correlates with the Gauss Chron (3.58-2.58 Ma).

Planktic foraminiferal assemblages from the middle Long Beach unit in LBPC are assigned to zones CM6, CM5, and CM3/4. Ages for the zonal boundaries are 2.4-2.2 Ma (CM5/6) and 1.9$1.8 \mathrm{Ma}(\mathrm{CM} 4 / 5)$. Planktic foraminiferal datums occurring in the middle Long Beach sediments assigned to zone CM 5 give an age of 2.4 Ma. Cold surface-water temperatures are indicated for most of this unit, but there is a change to warm surface-water masses near the top. Benthic foraminifers are again assigned to the Venturian Stage and indicate deposition began in the upper middle to lower bathyal/lower slope biofacies (950-1,500 m) and shallowed to upper middle bathyal/lower slope biofacies (500-950 m). Macrofossils indicate deposition occurred on the continental slope. Both benthic foraminifers and macrofossil assemblages include transported shelf assemblages and in the case of the foraminifers, there are reworked Miocene specimens. These 


\section{Table 26. Correlation of sequence stratigraphic units to age criteria for selected Long Beach wells, Long}

Beach, California.

[Formation designations from California Department of Water Resources (1961). Sequence stratigraphic units from Ponti and others (2007). Age estimates, planktic foraminiferal zones, benthic foraminiferal stages, and comments summarized from data in this study. MIS, Marine Isotope Stage; LBPF, Long Beach Pier F core site and monitoring well, Long Beach, California; PF zones, Planktic foraminiferal zones; BF stages, Benthic foraminiferal stages; LBCH, Long Beach Cabrillo High School core site and monitoring well, Long Beach, California; LBCC, Long Beach City College core site and monitoring well, Long Beach, California; LWEB, Long Beach Webster School core site and monitoring well, Long Beach, California]

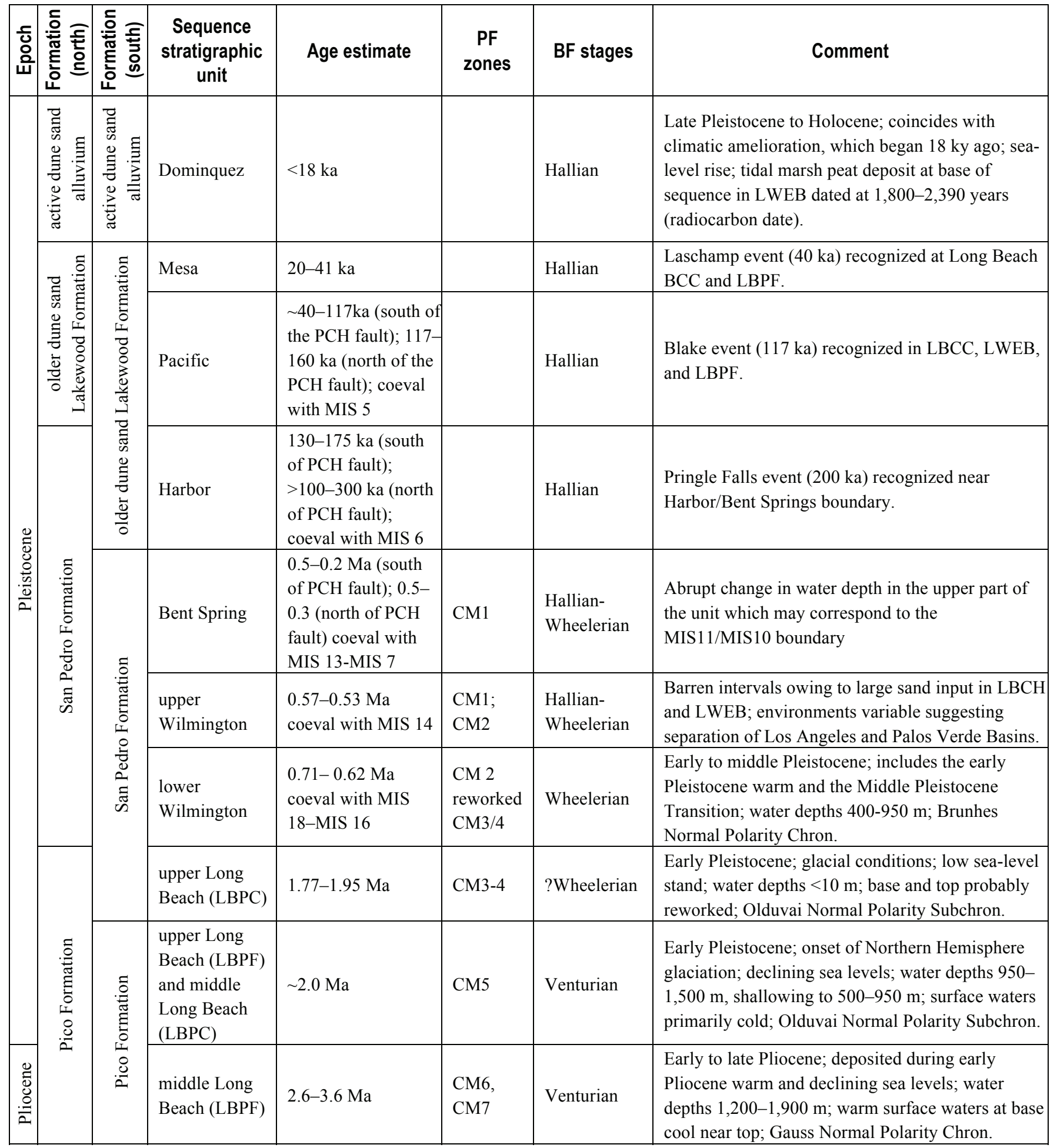




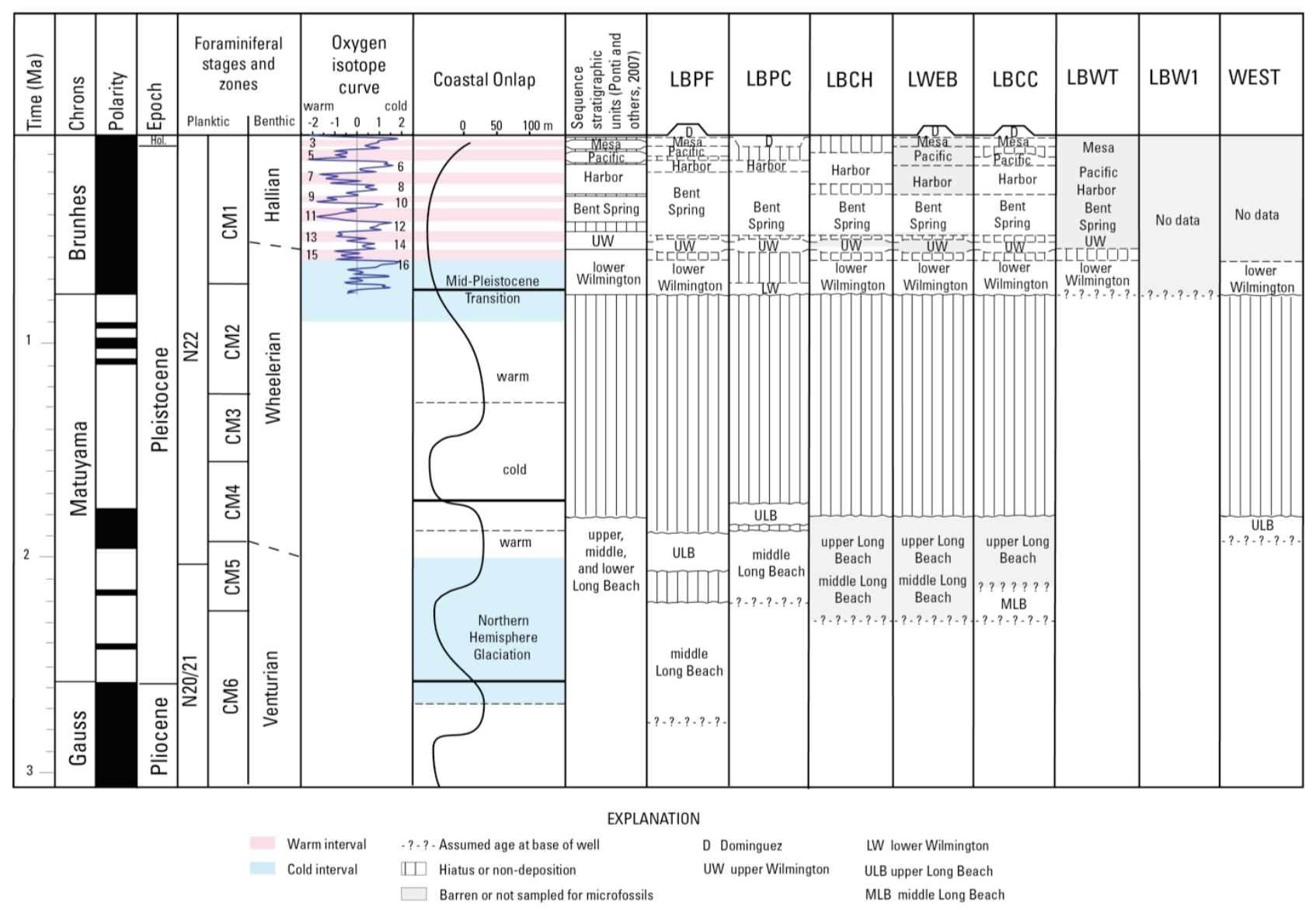

Figure 91. Distribution of the sequence stratigraphic units of Ponti and others (2007) encountered in the FOQUS-LA wells with respect to the chronostratigraphic (Gradstein and Ogg, 2005; Gradstein and others, 2004) and biostratigraphic time scales (Blow, 1969; Kennett and others, 2000; Natland, 1952, 1957; Blake, 1991), marine oxygen-isotope paleoclimate curve, and the coastal onlap curve (Johnson and Bloch, 2005). Planktic foraminiferal CM zone boundaries placed at mean age for the base of the zone (see table 3 for maximum and minimum age ranges). Benthic foraminiferal stage boundaries are dashed and slanted to indicate the minimum and maximum age of the stage boundary. Boundaries of the benthic foraminiferal stages are modified as discussed in the text. Pliocene warm and cold intervals follow Ravelo and others (2004).

ages, datums, and paleoecologic interpretations suggest correlation with Northern Hemisphere glaciation $(2.75$ to $\sim 2.0 \mathrm{Ma})$ and an early Pleistocene warm ( 2 Ma). Paleomagnetic analysis correlates these sediments with the Olduvai Normal Polarity Subchron (1.9-1.8 Ma) and thus overlaps with the ages predicted by the planktic foraminifers, but significantly restricts the age range of this unit in LBPC. The fauna of the middle Long Beach unit indicates younger ages in LBPC compared to its counterpart in LBPF, although seismic-reflection profiles show clearly defined boundaries of the middle Long Beach connecting the two wells stratigraphically.

In LBPF, the upper Long Beach unit is assigned to zone CM5 and the Venturian Stage. The FO of $N$. pachyderma B (1.3-1.2 Ma), which occurs near the top of this unit may be within the zone of reworking and, therefore, may not be a reliable FO. Benthic foraminifers indicate deposition occurred in the upper middle bathyal/lower slope biofacies (500-950 m) and both foraminifers and macrofossils suggest considerable transport of upper slope and shelf assemblages. Planktic foraminifers indicate that except for the uppermost part of the unit, surface waters were 
cold. The upper Long Beach unit in LBPF is therefore correlated with a portion of the Northern Hemisphere glaciation (2.74 to $\sim 2.0 \mathrm{Ma}$ ). The alternating warm and cold surface-water intervals in the upper part of the unit are correlated with an early Pleistocene warm based on planktic foraminiferal ages. Paleomagnetic data, which suggest correlation with the Olduvai Normal Polarity Subchron, coupled with these biostratigraphic and paleoecologic interpretations, indicate that the upper Long Beach unit in LBPF is approximately $2 \mathrm{Ma}$, as suggested by Ponti and others (2007).

In LBPC, foraminifers occurring below and above the shallow-water deposits in the middle of the upper Long Beach unit are questionably assigned to the Wheelerian Stage and zones CM4CM3 and the base of CM2. Both groups indicate considerable reworking and mixing of assemblages that are probably related to the abrupt water-depth changes and associated erosion. Zones CM4-CM3 indicate an age range of 1.8-2.0 Ma (base of CM4) to 1.2-1.3 (base of overlying $\mathrm{CM} 2$ zone). The two microfossil samples assigned to zone CM2 from the top of the upper Long Beach unit are probably from sediment reworked during the transgression that deposited the overlying unit and may be part of the overlying unit. Benthic foraminifers and macrofossils indicate that the lower part of this unit was deposited in the upper bathyal/lower slope biofacies (500-950 m), whereas the middle part was deposited at intertidal ( $\leq 10 \mathrm{~m})$ depths, which increased up section to shelf depths $(<150 \mathrm{~m})$. Benthic foraminifers indicate a return to the upper middle bathyal/lower slope or basin floor biofacies (550-950 m) in the upper most part of the unit. Planktic foraminiferal assemblages indicate cold surface water conditions. Macrofossils also suggest cool surface-water conditions. Based on the biostratigraphy and paleoecology, this unit correlates with an early Pleistocene cold period and low sea-level stand (maximum at $\sim 1.73 \mathrm{Ma}$ ). The normal polarity of these sediments is correlated with the Olduvai Subchron, thus further restricting the age of this unit to $1.95-1.77 \mathrm{Ma}$.

These analyses indicate that the middle and upper Long Beach units of Ponti and others (2007) represent three periods of deposition (fig. 91). The oldest sediments are identified as the middle Long Beach unit in LBPF. These sediments are now interpreted as late Pliocene in age. They were deposited during the latter part of the Pliocene warm during a period of declining sealevels. The next period of deposition is represented by the upper Long Beach unit in LBPF and the middle Long Beach unit of LBPC. These sediments are early Pleistocene in age and were deposited during the onset of Northern Hemisphere glaciation. Sea levels were lower and upper Miocene sediments were exposed locally and reworked in to the sediments near LBPC. The youngest period of deposition is represented by the upper Long Beach unit in LBPC. These sediments also are early Pleistocene in age and were deposited primarily during glacial conditions. Although seismic lines are continuous between the wells and support the presence of only two units, the age and ecology of the faunas suggests that there are three units bounded by unconformities and dramatic changes in sea-level and climate.

The only other well with fossiliferous samples from the upper Long Beach unit was WEST. There are, however, no distinctive faunas present which help clarify the age of this unit. Paleomagnetics indicate the unit in WEST has a normal polarity and probably correlates with the Olduvai Normal Polarity Subchron.

Lower Wilmington Unit

The lower Wilmington unit is separated from the underlying units by a regional unconformity. Ponti and others (2007) interpreted this unit to be $<780$ to $\sim 580 \mathrm{ka}$ in age and coeval with MIS $17+$ to MIS 15 . They interpreted this unit to represent deep marine waters (500-900 m) south of the PCH fault but, outer shelf to middle bathyal depths north of the fault. 
The lower Wilmington unit was encountered in all the wells. In LBPF, planktic foraminifers from the lower Wilmington unit are assigned to zones CM4-2, CM2, and CM1. However, these sediments probably were deposited during zone CM2, and the older assemblages were reworked into the unit from the underlying sediments. The base of CM2 ranges in age from 1.3 to $1.2 \mathrm{Ma}$ and the base of CM1 ranges from 0.8 to $0.6 \mathrm{Ma}$. The FO and LO datums in the interval assigned to CM4-2 are not in stratigraphic order. In LBPC, the lower Wilmington unit is assigned to zone CM2. The CM2/CM1 boundary approximates the lower Wilmington/upper Wilmington boundary in this well. No planktic assemblages were examined in LBCH, LWEB, and LBCC.

Warm surface-water masses dominate the lower part of the lower Wilmington unit in LBPF, but shift to cold surface-water masses in the middle of the unit. The upper cold interval is interpreted as correlating with the Middle Pleistocene Transition (MPT, 0.9-0.6 Ma). The entire lower Wilmington unit in LBPC is interpreted as representing a cold surface-water mass. The higher abundances of warm-water indicators in this interval is probably due to reworking of sediments. Although the MPT is not identified clearly at LBPC, the cold water faunas assigned to CM2 at the base of the unit are thought to represent this transition (fig. 39).

Benthic foraminifers from this unit are assigned to the Wheelerian Stage. In LBPF and LBPC the lower part of the unit is questionably assigned to the Wheelerian Stage because many species present are more common to abundant in the Venturian Stage. This questionable assignment may be due to the regional unconformity and reworking of sediments and faunas above the unconformity. Benthic foraminifers suggest deposition at the base of the unit occurred within the upper middle bathyal/slope biofacies (400-950 m). Water depths gradually shallowed up section, but remain within this depth range. Benthic foraminiferal assemblages at the base of this unit contain Uvigerina peregrina and U. senticosa. The latter species has a limited distribution in the FOQUS-LA wells. Uvigerina senticosa occurs in LBPF and LBPC, just prior to the change to a cold surface-water mass; thus, the presence of this species in LBCH, LWEB, and WEST is believed to indicate a similar change (plate 17). In LBCC, Uvigerina peregrina was identified in the upper part of the lower Wilmington unit, but $U$. senticosa was not recognized in this well, which suggests that the limited sampling missed this assemblage, or the water-mass change does not occur in this interval. In WEST, $U$. senticosa occurs at the boundary between the upper and lower Wilmington units.

No samples were examined from the lower Wilmington unit in LBW1, and only a few samples in LBWT contain benthic foraminifers. In LBWT, the lower Wilmington faunas show the same decrease in water depth observed in other wells north of the PCH Fault, but contain no distinctive features.

The ages and paleoecologic interpretations indicate correlation of the lower Wilmington unit with the MPT (0.9-0.6 Ma). Paleomagnetic interpretation places this entire interval in the Brunhes Normal Polarity Chron, which would restrict the age to $0.78 \mathrm{Ma}$ or younger. The Lava Creek B ash (639 $\pm 2 \mathrm{ka}$ ) occurs in the lower part of the lower Wilmington unit of LBCC. The biostratigraphy, paleoecology, polarity, and Lava Creek B ash restrict the age of the lower Wilmington unit to $\leq 0.78$ to $\geq 0.6 \mathrm{Ma}$. The presence of both warm and cold intervals suggests possible correlation with MIS 18-MIS 16 (0.712-0.621 Ma; Bassinot and others, 1994).

\section{Upper Wilmington unit}

Ponti and others (2007) interpreted the upper Wilmington unit as being deposited during a single high sea-level stand in MIS 13-MIS 14 (580 to $474 \mathrm{ka}$ ). This unit was considered a progradational package consisting of shallow marine $(\leq 50 \mathrm{~m})$, deltaic, and delta and (or) fluvialchannel deposits (Ponti and others, 2007). 
In wells south of the Pacific Coast Highway (PCH) Fault, foraminifers from this unit are assigned to the Wheelerian Stage and zone CM1. In wells north of the PCH Fault, benthic foraminifers in the upper Wilmington unit are diagnostic of the Wheelerian, early Hallian, and Hallian Stages. Planktic foraminifers suggest that the base of the upper Wilmington unit is younger than the base of zone CM1 (0.8-0.6 Ma), but they give no indication of the upper age limit. Planktic foraminifers also suggest surface-water temperatures were cool. There are no agediagnostic macrofossils or TL dates available for this unit. Paleomagnetic interpretations indicate that the upper Wilmington unit correlates with the Brunhes Normal Polarity Chron and is, therefore, $\leq 0.78 \mathrm{Ma}$.

North of the PCH Fault, the age of this unit based on microfossils is not clear. LBCH and LWEB contain large intervals that are barren of fossils or were not sampled for fossils.

Foraminiferal assemblages in LBCH contain benthic foraminifers assigned to the Wheelerian, early Hallian, and Hallian stages. In LWEB, the foraminiferal assemblages are present only at the base of the unit and are assigned to the Wheelerian Stage. In LBCC, benthic foraminifers diagnostic of the Wheelerian and early Hallian Stages are present. Macrofossils indicate that the upper Wilmington unit in LBCC was deposited during a warm interval followed by a cold interval.

The upper Wilmington unit north of the PCH Fault was deposited on the shelf, and the sediments suggest deltaic conditions. Although the sediments are sandy, deposition at LBCC, which is south and east of LBCH and LWEB, occurred in the upper bathyal to upper bathyal biofacies ( $450 \mathrm{~m}$ at base to 200-150 $\mathrm{m}$ at top of unit), despite the sandy sediments encountered in this well. South of the fault deposition occurred at upper middle bathyal/lower slope depths (500$950 \mathrm{~m}$ ). These differences in the biofacies suggest that the PCH Fault was active during deposition of the upper Wilmington unit and that wells were separated into two different basins, with the northern basin being more rapidly filled with sediments than the southern basin. The separation of the Palos Verdes Basin from the Los Angeles Basin previously was thought to have occurred until or just prior to the deposition of the Bent Spring unit (Ponti and others, 2007).

Planktic foraminifers in the upper Wilmington unit at both LBPF and LBPC suggest deposition occurred during a cold interval. Paleoecologic conditions in the other wells cannot be determined. The upper Wilmington unit was deposited in upper middle bathyal/lower slope biofacies (500-950 m) south of the PCH Fault, but north of the fault water depths vary from upper bathyal/bank $(150-500 \mathrm{~m})$ to neritic biofacies $(<100 \mathrm{~m})$. In LBCC, which is located east of LBCH, the upper Wilmington unit was deposited in the upper middle bathyal/upper slope biofacies $(\sim 450$ $\mathrm{m})$ at the base and the upper bathyal/bank biofacies (150-200 m) at the top of the unit.

These analyses and the age of the underlying lower Wilmington unit suggest that the lower boundary of the upper Wilmington unit is close to $0.6 \mathrm{Ma}$ and based on cold climatic conditions in LBPF. LBPC more than likely represents MIS $14(0.57-0.53 \mathrm{Ma})$ and possibly the adjacent warm stages (MIS 15, 0.62-0.57 Ma or MIS13, 0.53-0.47 Ma).

\section{Bent Spring Unit}

Ponti and others (2007) interpreted the Bent Spring unit as representing deposition that occurred between $\sim 300$ and $450 \mathrm{ka}$ and MIS 9 and (or) MIS 11. The unit is primarily a sandy unit of marine origin that was deposited on the shelf and (or) upper slope. The sands in LBPF and seismic data suggest that the Bent Spring unit comprises a delta complex that prograded from the northwest to the southeast along the Palos Verdes Basin axis.

Paleomagnetic and TL ages south of the PCH Fault indicate this unit is 309-200 ka in age, whereas north of the fault the one TL date from this unit is $>505 \mathrm{ka}$. The Pringle Falls event (200 ka) occurs in this unit south of the fault but overlies the unit north of the fault. Wheelerian, early Hallian, and Hallian Stages are recognized in the Bent Spring unit of LBPF. The unit covers the 
same time interval in LBPC, except that the early Hallian has been removed by an unconformity. Planktic foraminifers diagnostic of zone CM1 occur in the unit in both wells south of the fault. North of the fault, the Bent Spring unit thins and contains Hallian (LBCH), early Hallian and Hallian (LBCC), and early Hallian and a barren older interval (LWEB). No Wheelerian benthic foraminiferal faunas are recognized north of the fault.

An abrupt change in water depth occurs within the Bent Spring unit separating bathyal/slope (150-500 m) deposition from neritic/bank $(50-150 \mathrm{~m})$ deposition in all wells, except LWEB. The probable Hallian interval in LWEB was not sampled for microfossils. The macrofossils in LWEB indicate minimum depths and do not indicate any change in water depth in the upper Wilmington, Bent Spring, and Harbor units. The shift from warm MIS 11 to cold MIS 10 is greater than previous shifts and the accompanying drop in sea level may be reflected by the abrupt change from bathyal/slope to neritic/bank deposition observed in the benthic foraminifers. Planktic foraminifers indicate several warm/cold cycles occurred in the deeper water parts of this unit, but very little temperature data is available for the upper shallow water part of the unit.

The boundary between the Bent Spring/upper Wilmington units is younger than the 0.8-0.6 Ma age estimated for the base of zone CM1 and less than the 0.58-0.53 Ma age predicted for the upper Wilmington unit. The upper boundary of the Bent Spring unit is approximately 0.2 Ma south of the PCH Fault based on the presence of the Pringle Falls event near the upper boundary of this unit. Deposition of this unit north of the fault may have ended sooner based on identification of the Pringle Falls event (200 ka), TL dates $(<300->200 \mathrm{ka})$, and the last appearance of the macrofossil, provisionally identified fragments assigned to Calicantharus fortis (400-300 ka) in the overlying Harbor unit. These ages indicate that the Bent Spring unit ranges in age from $<0.5 \mathrm{Ma}$ to $\sim 0.2 \mathrm{Ma}$ south of the fault and from $<0.5 \mathrm{Ma}$ to $\sim 0.3 \mathrm{Ma}$ north of the fault.

\section{Harbor Unit}

Ponti and others (2007) interpreted the Harbor sequence stratigraphic unit as older than MIS 5 and younger than MIS 9, or 300 to $160 \mathrm{ka}$, although no dates were available from this unit in the study area. Subsequently paleomagnetics, TL dates, and macrofossils dates in this unit range from 174 to $130 \mathrm{ka}$ south of the PCH Fault and from 275 to $>100 \mathrm{ka}$ north of the fault. The Pringle Falls event $(200 \mathrm{ka})$ is recognized in this unit north of the fault. Foraminifers are diagnostic of the Hallian Stage and zone CM1 south of the fault, indicating that this unit is less than $0.6 \mathrm{Ma}$ in age. North of the fault, foraminifers diagnostic of the Hallian Stage are present in LBCH and LBCC, but no microfossil samples were taken from the presumed Hallian in LWEB. The age of this unit, north of the PCH Fault is $\pm 275-100$ ka based primarily on macrofossils and TL dates. South of the PCH Fault, sediments assigned to the Harbor unit appear to have a more limited age range (174-130 ka) based on the TL dates.

The Harbor unit constitutes a series of deposits that record a coastal progradation including marine shelf to beach, and possibly fluvial channels and floodplains. In all wells macrofossils and (or) microfossils indicate deposition occurred on the shelf at depths of $50 \mathrm{~m}$ or less.

\section{Pacific Unit}

The Pacific sequence stratigraphic unit was thought to represent the marine high-stand deposits from MIS 5e and c, or between 130 and $110 \mathrm{ka}$ in age (Ponti and others, 2007). The Pacific unit represents shallow marine deposition, which grades upward to tidal flat and fluvial channel and overbank deposits (Ponti and others, 2007).

Paleomagnetic, OSL, and TL dates south of the PCH Fault in LBPF indicate that this unit ranges in age from at least $117-40 \mathrm{ka}$. Rare planktic foraminifers in LBPF indicate that warm climatic conditions prevailed, so correlation with MIS 5 is probable. North of the PCH Fault in 
LWEB and LBCC, the Pacific unit ranges in age from 160 to $28 \mathrm{ka}$, based on paleomagnetics, OSL and TL dates, and macrofossils evidence. The youngest ages are OSL dates from LBCC-15 in which the ages range from 33 to $28 \mathrm{ka}$ (appendix III, table 18). These ages are approximately $2 \mathrm{~m}$ below the last appearance of Chione $(\geq 116 \mathrm{ka})$ and $1 \mathrm{~m}$ below the magnetic anomaly identified as the Blake event $(\sim 117 \mathrm{ka})$. Both the LO of Chione and the Blake event are identified in the upper part of the Pacific unit in LWEB along with OSL and TL dates ranging from 160 to $123 \mathrm{ka}$. The discrepancy between the luminescence ages and the paleomagnetics and macrofossil ages in LBCC cannot be explained at this time. Because the groups agree in LWEB and two of the three groups agree in LBCC, the age of the Pacific unit north of the fault is considered to be 160-117 ka until the resolution of the age discrepancy.

\section{Mesa and Dominguez Units}

The Mesa and Dominguez sequence stratigraphic units were interpreted as representing sediments deposited between 80 to $\sim 30 \mathrm{ka}$ and $<15 \mathrm{ka}$, MIS 5a and 2, respectively (Ponti and others, 2007). The Mesa unit reflects a prograding shoreline, and the Dominguez unit consists of fluvial gravel, which grades upward to marginal marine and estuarine conditions.

Paleomagnetics, OSL, TL, and radiocarbon dates indicate the Mesa unit includes sediments as old as $41.4 \mathrm{ka}$ to as young as $20 \mathrm{ka}$. The Mesa unit was recognized in LBPF, LWEB, and LBCC. The Laschamp event ( $40 \mathrm{ka}$ ) occurs in the Mesa unit near the top of LBCC, but at the base of the Mesa unit in LBPF. The presence of the Laschamp event in LBPF is supported by both radiocarbon, IRSL-OSL, and TL dates, but IRSL-OSL and TL dates in the Mesa unit of LBCC range from 20.2 to $26.2 \mathrm{ka}$, near the Laschamp event (40 ka). This difference is not resolved at this time.

OSL, TL, and radiocarbon dates, as well as macrofossil evidence, indicate that the Dominguez unit is younger than $18 \mathrm{ka}$, and this unit coincides with the climatic amelioration following the last glacial maximum. The Dominguez unit was recognized in all wells except LBCC. OSL and TL dates range from 18.6 to $0.93 \mathrm{ka}$. Radiocarbon dates of 2.39 and $1.78 \mathrm{ka}$ were obtained from LWEB. In LBPC, the macrofossil Chione reappears, indicating an age of $<12 \mathrm{ka}$. Macrofossils and benthic foraminifers, when present, indicate deposition occurred at depths of 20 m or less.

\section{Conclusions}

Synthesis of data from microfossils, macrofossils, paleomagnetism, luminescence, and tephra refines the chronologic and ecologic framework of the Pliocene and younger sequences in the Los Angeles Basin. The ages of the benthic foraminiferal stage boundaries are modified slightly from the chronology proposed by Blake (1991). Based on comparisons with the planktic foraminiferal zones and the paleomagnetic chrons, the Hallian Stage ranges between $\leq 0.6 \mathrm{Ma}$ and the present, except in LBCC where the presence of the Lava Creek B ash suggests that the base of the Hallian Stage is closer to 0.64 Ma. The Wheelerian Stage ranges between $\geq 0.6$ and $1.95 \mathrm{Ma}$, consistent with the $1.88 \mathrm{Ma}$ age suggested by Blake (1991). The base of the Venturian Stage probably occurs closer to 3.6 Ma rather than the $\geq 2.5 \mathrm{Ma}$ suggested by (Blake, 1991). The other modification to the benthic foraminiferal stages is the recognition of early Hallian. The early Hallian is defined as the first downhole appearance of outer shelf or bank and upper slope species and represents a paleoecologic change. This change is widespread and appears to mark a regional event that occurred between MIS 11 and MIS $10(\sim 36 \mathrm{ka})$. The planktic foraminiferal CM zonation proposed by Kucera and Kennett (2000) was used successfully on two of the FOQUS-LA wells, despite problems posed by erosional discontinuities in nearshore sections. The paleomagnetic zonation was faced with numerous problems related to the discontinuous sections and 
unconformities. The combined interaction between fossils and magnetostratigraphy did, however, provide a more refined understanding of the basin chronology. Luminescence dates were useful in the younger part of the sections (OSL to $\sim 80 \mathrm{ka}$ and TL to $\sim 175 \mathrm{ka}$ ), where the other disciplines could not distinguish smaller age changes.

The ages of the sequence stratigraphic units, as defined in Ponti and others (2007), are modified to reflect the improved chronologies and ecologic interpretations presented here (table 26). These modifications indicate that there are three older sequence stratigraphic units and that the Pleistocene units are older than predicted (fig. 91). A regional unconformity that separates the early Pleistocene units from the later Pleistocene units is approximately 1 million years in duration. The Los Angeles Basin was separated into two smaller sub-basins (Palos Verdes and Los Angeles) during the deposition of the upper Wilmington unit based on paleoecological and age differences between the wells north and south of the PCH Fault. Shallow-water deposition began earlier in the northern basin. By the time the Mesa unit was deposited, the entire area was acting as a single basin. 


\section{Acknowledgments}

The authors wish to thank Daniel Ponti and the entire FOQUS-LA crew for their assistance, discussions, and efforts to understand the late Neogene development of the Los Angeles Basin. We especially would like to thank Mary McGann and Brian Edwards for reviewing this manuscript and providing insightful suggestions. We also thank all the scientists and technicians that worked on these cores, either at the drill sites or in the laboratories, for their valuable help. 


\section{References Cited}

Abbott, R.T., 1974, American seashells: New York, Van Norstrand Reinold, 663 p.

Addicott, W.O., 1965, Some western American Cenozoic gastropods of the genus Nassarius: U.S. Geological Survey Professional Paper 503B, p. B1-B24.

Addicott, W.O., 1966, Late Pleistocene marine paleoecology and zoogeography in central California: U.S. Geological Survey Professional Paper 523C, p. C1-C21.

Addicott, W.O., 1969, Late Pliocene mollusks from San Francisco Peninsula and their paleogeographic significance: California Academy of Sciences Proceedings, v. 37, no. 3, p. 57-93.

Addicott, W.O., 1976, Molluscan paleontology of the lower Miocene Clallam Formation, northwestern Washington: U.S. Geological Survey Professional Paper 976, 44 p.

Addicott, W.O., Poore, R.Z., Barron, J.A., Gower, H.D., and McDougall, K., 1978, Neogene biostratigraphy of the Indian Creek-Shell Creek area, northern La Panza Range, California, in Addicott, W.O., ed., Neogene biostratigraphy of selected areas in the California Coast Ranges: U.S. Geological Survey Open-File Report 78-446, p. 49-67.

Addicott, W.O., and Vedder, J.G., 1963, Paleotemperatures inferences from late Miocene mollusks in the San Luis Obispo-Bakersfield area, California: U.S. Geological Survey Professional Paper 475C, p. C63-C68.

Adegoke, O.S., 1969, Stratigraphy and paleontology of the marine Neogene formation of the Coalinga region, California: University of California Publications in Geological Sciences, v. 80, $241 \mathrm{p}$.

Aitken, M.J., 1985, Thermoluminescence Dating: Academic Press, London, 359 p.

Aitken, M.J., 1998, An introduction to optical dating: Oxford and New York, Oxford University Press, $267 \mathrm{p}$.

Allen, J.E., 1945, Geology of the San Juan Bautista Quadrangle, California: Berkeley, Calif., University of California, Ph.D. dissertation, $94 \mathrm{p}$.

Arnold, R., 1903, The paleontology and stratigraphy of the marine Pliocene and Pleistocene of San Pedro, California: Memoirs of the California Academy of Sciences Memoirs, v. 3, 419 p.

Arnold, R., 1906, Tertiary and Quaternary pectens of California: U.S. Geological Survey Professional Paper 47, 264 p.

Arnold, R., 1908, Description of new Cretaceous and Tertiary fossils from the Santa Cruz Mountains, California: Proceedings of the U.S. National Museum Proceedings, v. 34, no. 1617, p. 345-402.

Arnold, R., 1909, Paleontology of the Coalinga district, Fresno and Kings Counties, California: U.S. Geological Survey Bulletin 396, 173 p.

Ashley, G.H., 1895 [1896], The Neogene stratigraphy of the Santa Cruz Mountains of California: California Academy of Sciences, Second Series, v. 6, p. 273-367 [reprinted by Stanford University Publications, Geology and Paleontology, v. 1, p. 18-367].

Bandy, O.L., 1953, Ecology and paleoecology of some California Foraminifera, pt. 1-Frequency distribution of recent Foraminifera off California: Journal of Paleontology, v. 27, no. 2, p. 161-182.

Bandy, O.L., 1961, Distribution of Foraminifera, radiolaria and diatoms in sediments of the Gulf of California: Micropaleontology, v. 7, no. 1, p. 1-26. 
Banerjee, D., Botter-Jensen, L., and Murray, A.S., 2000, Estimation of the quartz equivalent dose in retrospective dosimetry using the single-aliquot regenerative-dose protocol: Applied Radiation and Isotopes, v. 52, p. 831-844.

Banner, F.T., and Blow, W.H., 1965, Progress in the planktonic foraminiferal biostratigraphy of the Neogene: Nature, v. 208, p. 1164-1166.

Barbat, W.F., and Johnson, F.L., 1934, Stratigraphy and Foraminifera of the Reef Ridge Shale, upper Miocene, California: Journal of Paleontology, v. 8, no. 1, p. 3-17.

Bartsch, P., 1917, A monograph of west American melanellid mollusks: United States National Museum Proceedings, v. 52, no. 2207, p. 295-356.

Bassinot, F.C., Labeyrie, L.D., Vincent, E., Quidelleu, X., Shackleton, N.J., and Lancelot, Y., 1994, The astronomical theory of climate and the age of the Brunhes-Matuyama magnetic reversal: Earth and Planetary Science Letters, v. 126, p. 91-108.

Bedrossian, T.L., 1974, Fossils of the "Merced" Formation, Sebastopol region: California Geology, v. 27, no. 8, p. 175-182.

Behrens, D., 1991, Pacific coast nudibranchs (2d ed.): Monterey, Calif., Sea Challengers, 107 p.

Berger, G.W., 1988, Dating Quaternary events by luminescence, in Easterbrook, D.J., ed., Dating Quaternary sediments: Geological Association of America Special Paper 227, p. 13-50.

Berger, G.W., 1990, Regression and error analysis for a saturating-exponential-plus-linear model: Ancient TL, v. 8, no. 3, p. 23-25.

Berggren, W.A., Kent, D.V., Swisher, C.C., III, and Aubry, M.-P., 1995, A revised Cenozoic geochronology and chronostratigraphy, in Berggren, W.A., Kent, D.V., Aubry, M.-P., and Hardenbol, J., 1995, Geochronology time scales and global stratigraphic correlation: Society of Economic Paleontologists and Mineralogists, Special Publication, no. 54, p. 129-212.

Bernard, F.R., 1983, Catalogue of the living Bivalvia of the eastern Pacific Ocean-Bering Strait to Cape Horn: Canadian Special Publication of Fisheries and Aquatic Sciences, no. 61, 102 p.

Blackie, G.W., and Yeats, R.S., 1976, Magnetic-reversal stratigraphy of Pliocene-Pleistocene producing section of Saticoy oil field, Ventura Basin, California: American Association of Petroleum Geologists Bulletin, v. 60, no. 11, p. 1985-1991.

Blake, G.H., 1976, The distribution of benthic Foraminifera in the outer borderland and its relationship to Pleistocene marl: Los Angeles, University of Southern California, master's thesis, $143 \mathrm{p}$.

Blake, G.H., 1991, Review of the Neogene biostratigraphy and stratigraphy of the Los Angeles Basin and implications for basin evolution, in Biddle, K.T., ed., Active margin basins: Tulsa, Okla., American Association of Petroleum Geologists, p. 135-184.

Blow, W.H., 1959, Age, correlation and biostratigraphy of the upper Tokuyo (San Lorenzo) and Pozo formations, Eastern Falcon, Venezuela: Bulletin of American Paleontologists, v. 39, p. 67-252.

Blow, W.H., 1969, Late middle Eocene to recent planktic foraminiferal biostratigraphy, in Brönnimann, P., and Renz, H.H., eds., Proceedings of the First International Conference Planktonic Microfossils, 1967: E.J. Brill, Leiden, v. 1, p. 199-422.

Boellstorff, J., and Steineck, P.L., 1975, The stratigraphic significance of fission-trace ages on volcanic ashes in the marine late Cenozoic of southern California: Earth and Planetary Science Letters, v. 27, no. 2, p. 143-154.

Boersma, A., 1984, Handbook of common Tertiary Uvigerina: Stony Point, N.Y., Microclimates Press, 207 p. 
Brady, H.B., 1881, Notes on some of the reticularian Rhizapoda of the Challenger expedition: Quarterly Journal Microscope Sciences, n.s. v. 21, p. 37-71.

Brady, 1884, Report on the scientific results of the voyage of the H.M.S. Challenger during the years 1873-1876: Zoology, v. 9, p. 696, pl. 103, figs. 13-14.

Bukry, D., 1973, Low-latitude coccolith biostratigraphic zonation, in Edgar, N.T., Saunders, J.B., and others, eds., Initial reports of the Deep Sea Drilling Project: Washington, D.C., U.S. Government Printing Office, v. 15, p. 685-703.

Bukry, D., 1975, Coccolith and silicoflagellate stratigraphy, northwestern Pacific Ocean, Deep Sea Drilling Project leg 32, in Larson, R.L., Moberly, R., and others, eds., Initial reports of the Deep Sea Drilling Project: Washington, D.C., U.S. Government Printing Office, v. 32, p. 677-701.

Burch, J.Q., ed., 1944-46, Distributional list of the west American marine mollusks from San Diego, California, to the Polar Sea: Conchological Club of Southern California Minutes, no. 4662 , unnumbered pages.

California Department of Water Resources, 1961, Planned utilization of the ground water basins of the coastal plain of Los Angeles County-Appendix A, ground water geology: California Department of Water Resources Bulletin 104, 191 p.

Cande, S.C., and Kent, D.V., 1995, Revised calibration of the geomagnetic polarity timescale for the Late Cretaceous and Cenozoic: Journal of Geophysical Research, v. 100, p. 6093-6095.

Canfield, D.E., and Berner, R.A., 1987, Dissolution and pyritization of magnetite in anoxic marine sediments: Geochimica et Cosmochimica Acta, v. 51, p. 645-659.

Cannariato, K.G., and Kennett, J.P., 1999, Climatically related millennial-scale fluctuations in strength of California margin oxygen-minimum zone during the past 60 k.y.: Geology, v. 27, no. 11, p. 975-978.

Clark, A., 1931, The cool-water Timms Point Pleistocene horizon at San Pedro, California: San Diego Society of Natural History Transactions, v. 7, no. 4, p. 25-42.

Clark, B.L., 1915, Fauna of the San Pablo Group of middle California: University of California Publications, Department of Geology Bulletin, v. 8, no. 22, p. 385-572.

Coan, E.V., Scott, P.V., and Bernard, F.R., 2000, Bivalve seashells of western North AmericaMarine bivalve mollusks from arctic Alaska, to Baja California: Santa Barbara Museum of Natural History, Monographs, v. 2, 764 p.

Cooper, J.G., 1888, Catalogue of California fossils-Annual Report of the State Mineralogists: Sacramento, California State Office, p. 221-308.

Coryell, H.N., and Mossman, R.W., 1942, Foraminifera from the Charco Azul Formation, Pliocene of Panama: Journal of Paleontology, v. 16, p. 233-246.

Culver, S.J., and Buzas, M.A., 1986, Distribution of recent benthic Foraminifera off the North American Pacific Coast from California, to Baja: Smithsonian Contributions to the Marine Sciences, no. 28, 634 p.

Cummings, J.C., Touring, R.M., and Brabb, E.E., 1962, Geology of the northern Santa Cruz Mountains, California, in Bowen, O.E., Jr., ed., Geologic guide to the gas and oil fields of northern California: California Division of Mines and Geology Bulletin 181, p. 179-220.

Cushman, J.A., 1918, Some Pliocene and Miocene Foraminifera of the coastal plain of the United States: U.S. Geological Survey Bulletin, v. 676, 100 p.

Cushman, J.A. 1920, Results of the Hudson Bay expedition, 1920; Part I-The Foraminifera: Canadian Biological Board, Contribution to Canadian Biology, no. 9, p. 3-13.

Cushman, J.A., 1923, The Foraminifera of the Atlantic Ocean, Part IV_-Lagenidae: U.S. National Museum Bulletin, v. 104, 228 p. 
Cushman, J.A., 1925, Some Textulariidae from the Miocene of California: Cushman Laboratory for Foraminiferal Research, Contributions, v. 1, pt. 2, p. 29-35.

Cushman, J.A., 1926, Some Pliocene bolivinas from California: Cushman Laboratory for Foraminiferal Research, Contributions, v. 2, pt. 2, p. 40-47.

Cushman, J.A., 1927, Recent Foraminifera from the West coast of America: Bulletin, Scripps Institution of Oceanography, Technical Series, v. 1, no. 10, p. 119-188.

Cushman, J.A., 1930, The Foraminifera of the Atlantic Ocean; Part VII-Nonionidae, Camerinidae, Peneroplidae, and Alveolinellidae: U.S. National Museum Bulletin, no. 104, 79 p.

Cushman, J.A., 1933, Some new recent Foraminifera from the tropical Pacific: Cushman Laboratory of Foraminiferal Research, Contributions, v. 9, pt. 4, p. 77-95.

Cushman, J.A., 1944, Foraminifera from the shallow water of the New England Coast: Cushman Laboratory for Foraminiferal Research, Special Publication, no. 12, 37 p.

Cushman, J.A., and Edwards, P.G., 1937, The described America Eocene species of Uvigerina: Cushman Laboratory for Foraminiferal Research, Contributions, v. 13, pt. 3, p. 74-87.

Cushman, J.A., and Hughes, D.D., 1925, Some later Cassidulinas of California: Cushman Laboratory for Foraminiferal Research, Contributions, v. 1, pt. 1, p. 11-17.

Cushman, J.A., and McCulloch, I., 1942, Some Virgulininae in the collections of the Allan Hancock Foundation: Allan Hancock Pacific Expedition Reports, v. 6, no. 4, p. 179-230.

Cushman, J.A., and Moyer, D.A., 1930, Some recent Foraminifera from off San Pedro, California: Cushman Laboratory for Foraminiferal Research, Contributions, v. 6, pt. 3, p. 49-62.

Cushman, J.A., and Parker, F.P., 1938, Notes on Pliocene and Pleistocene species of Bulimina and Buliminella: Cushman Laboratory for Foraminiferal Research, Contributions, v. 14, pt. 3, p. 5361.

Cushman, J.A., Stewart, R.E., and Stewart, K.C., 1930, Tertiary Foraminifera from Humboldt County, California: San Diego Society of Natural History Transactions, v. 6, p. 42-94.

Cushman, J.A., and Todd, R., 1941, Notes on the species of Uvigerina and Angulogerina described from the Pliocene and Pleistocene: Cushman Laboratory for Foraminiferal Research, Contributions, v. 17, p. 53-86.

Cushman, J.A., and Todd, R., 1944, The genus Spiroloculina and its species: Cushman Laboratory for Foraminiferal Research, Special Publication, no. 11, 82 p.

Cushman, J.A., and Valentine, W.W., 1930, Shallow water Foraminifera from the Channel Islands off southern California: Stanford University, Calif., Contributions to the Department of Geology, v. 1, no. 1, 51 p.

Dall, W.H., 1885, Comments, in Orcutt, C.R., Notes on the mollusks of the vicinity of San Diego, California and Todos Santos Bay, Lower California: U.S. National Museum, Proceedings, v. 8, no. 536, p. 534-552.

Dall, W.H., 1921, Summary of the marine shell-bearing mollusks of the northwest coast of America, from San Diego, California, to the Polar Sea, mostly contained in the collections of the United States National Museum, with illustrations of hitherto unfigured species: U.S. National Museum Bulletin, 112, 217 p.

Darling, D.F., Wade, C.M., Stewart, I.A., Kroon, D., Dingle, R. Brown, A.J.L., 2000, Molecular evidence for genetic mixing of Arctic and Antacrctic subpolar populations of planktonic foraminifers: Nature, v. 405, no. 6781, p. 43-47.

Darling, K.F., Kucera, M., Kroon, D., and Wade, C.M., 2006, A resolution for the coiling direction paradox in Neogloboquadrina pachyderma: Paleoceanography, v. 21, no. 2, p. PA2011. 
Dawson, G.M., 1870, On Foraminifera from the Gulf and River St. Lawrence: Canadian Naturalist, n.s., v. 5, p. 171-179.

Deméré, T.A., 1981, A newly recognized late Pleistocene marine fauna from the city of San Diego, San Diego County, California, in Abbott, P.L., and O'Dunn, S., eds., Geologic investigations of the coastal plain, San Diego County, California: San Diego Association of Geologists, field trip, p. $1-10$.

Dibblee, T.W., Jr., 1966, Geology of the central Santa Ynez Mountains, Santa Barbara County, California: California Division of Mines and Geology Bulletin, no. 186, 99 p.

Douglas, R.G., 1981, Paleoecology of continental margin basins: a modern case history from the borderland of southern California-Depositional systems of active continental margin basins, short course notes: Los Angeles, Calif., Pacific Section, Society of Economic Paleontologists and Mineralogist, p. 121-156.

Douglas, R.G., and Heitman, H.L., 1979, Slope and basin benthic Foraminifera of the California borderland, in Doyle, L.J., and Pilkey, O.H., eds, Geology of continental slopes: Society of Economic Paleontologists and Mineralogists, Special Publication, no. 27, p. 231-246.

Duller, G.A.T., Botter-Jensen, L., Mejdahl, V., 1999, An automated iterative method for determining palaeodoses using the SARA method: Quaternary Geochronology, v. 18, p. 293301.

Durham, D.L., 1974, Geology of the southern Salinas Valley area, California: U.S. Geological Survey Professional Paper 819, 111 p.

Durham, J.W., 1950, Megascopic paleontology and marine stratigraphy, in 1940 E.W. Scripps Cruise to the Gulf of California, part II: Geological Society of America Memoir 43, p. 1-216.

Durham, D.L., and Addicott, W.O., 1965, Pancho Rico Formation, Salinas Valley, California: U.S. Geological Survey Professional Paper 524A, p. A1-A22.

Durham, D.L., and Yerkes, R.F., 1964, Geology and oil resources of the eastern Puente Hills area, southern California: U.S. Geological Survey Professional Paper 420B, p. B1-B62.

Dushane, H., 1979, The family Epitoniidae (Mollusca: Gastropoda) in the northeastern Pacific: The Veliger, v. 22, no. 2, p. 91-134.

Eldridge G.H., and Arnold, R., 1907, The Santa Clara, Puente Hills, and Los Angeles oil districts: U.S. Geological Survey Bulletin 309, 266 p.

Emerson, W.K., and Addicott, W.O., 1953, A Pleistocene invertebrate fauna from the southwest corner of San Diego County, California: Transactions of the San Diego Society of Natural History, v. 11, no. 17, p. 429-443.

Evans, J.W., 1967, Relationship between Penitella penita (Conrad, 1837) and other organisms of the rocky shore: The Veliger, v. 10, no. 2, p. 148-149.

Fahy, N.E., 1974, Origin of Lake Merced, California: Geology, v. 27, no. 8, p. 171-174.

Feyling-Hanssen, R.W., 1972, The foraminifer Elphidium excavatum (Terquem) and its variant forms: Micropaleontology, v. 18, no. 3, p. 337-354.

Finger, K.L., 1990, Atlas of California Neogene Foraminifera: Cushman Foundation for Foraminiferal Research, Special Publication, no. 28, 271 p.

Fornaciari, E., 2000, Calcareous nannofossil biostratigraphy of the California margin, in Lyle, M., Koizumi, I., Richter, C., and Moore, T.C., Jr., eds., Proceedings of the Ocean Drilling Program: Scientific Results, v. 167, p. 3-40.

Galloway, J.J., and Wissler, S.G.,1927, Pleistocene Foraminifera from the Lomita Quarry, Palos Verdes Hills, California: Journal of Paleontology, v. 1, no. 3, p. 35-87. 
Gibbard, P.L., Head, M.J., Walker, J.C., and the Subcommission on Quaternary Stratigraphy, 2010, Formal ratification of the Quaternary System/Period and the Pleistocene Series/Epoch with a base at 2.58 Ma: Journal of Quaternary Science, v. 25, p. 96-102.

Gorsline, D.S., and Emery, K.O., 1959, Turbidity-current deposits in San Pedro and Santa Monica basins off southern California: Geological Society of America Bulletin, v. 70, no. 3, p. 279-289.

Gradstein F.M., and Ogg, J.G., 2005, Time scale, in Selley, R.C., Cocks, L.R.M., and Pilmer, I.R., eds., Encyclopedia of geology: United Kingdom, Elsevier Academic Press, v. 5, p. 503-520.

Gradstein, F.M., Ogg, J.G., and 38 others, 2004, A geologic time scale 2004: Cambridge, Cambridge University Press, 589 p.

Grant, U.S., IV, and Gale, H.R., 1931, Catalogue of the marine Pliocene and Pleistocene Mollusca of California and adjacent regions: San Diego Society of Natural History Memoir, v. 1, 1036 p.

Groves, L.T., 1991, Paleontology and biostratigraphy of the Plio-Pleistocene lower Saugus Formation, Santa Susana Mountains, southern California: Northridge, Calif., California State University, master's thesis, $384 \mathrm{p}$.

Guibert, P., Vartanian, E., Bechtel, F., and Schvoerer, M., 1996, Non linear approach of TL response to dose: polynomial approximation: Ancient TL, v. 14, no. 2, p. 7-15.

Guyodo, Y., and Valet, J-P., 1999, Global changes in intensity of the Earth's magnetic field during the past 800 kyr: Nature, v. 399, no. 6733, p. 249-252.

Hall, C.A., Jr., 1958, Geology and paleontology of the Pleasanton area, Alameda and Contra Costa Counties, California: University of California Publications in Geological Sciences, v. 34, no. 1, p. 1-90.

Hall, C.A., Jr., 1960, Displaced Miocene molluscan provinces along the San Andreas fault, California: University of California Publications in Geological Sciences, v. 34, no. 6, p. 281-308.

Hertlein, L.G., and Grant, U.S., IV, 1972, The geology and paleontology of the marine Pliocene of San Diego, California (Paleontology: Pelecypoda): San Diego Society of Natural History Memoir 2, pt. 2B, 409 p.

Hillhouse, J.W., 1977, A method for the removal of rotational remnant magnetization acquired during alternating field demagnetization: Geophysical Journal of the Royal Astronomical Society, v. 50, p. 29-34.

Hoots, H.W., 1930, Geology of the eastern part of the Santa Monica Mountains, Los Angeles County, California: U.S. Geological Survey Professional Paper 165C, p. 83-134.

Howard, P.J., 1935, Report on Buena Vista Hills, a portion of the Midway-Sunset oil field: California Oil Fields, v. 20, no. 4, p. 5-22.

Howe, H.V., 1922, Faunal and stratigraphic relationships of the Empire Formation, Coos Bay, Oregon: University of California Publications, Department of Geological Sciences Bulletin, v. 14 , no. 3, p. 85-114.

Huntley, D.J., and Lamothe, M., 2001, Ubiquity of anomalous fading in K-feldspars and the measurement and correlation for it in optical dating: Canadian Journal of Earth Sciences, v. 38, no. 7, p. 1093-1106.

Imbrie, J., Hays, J.D., Martinson, D.G., McIntyre, A., Mix, A.C., Morley, J.J., Pisias, N.G., Prell, W.L., and Shackleton, N.J., 1984, The orbital theory of Pleistocene climate: support from a revised chronology of the marine ${ }^{18} \mathrm{O}$ record, in Berger, A., Imbrie, J. Hays, J., Kukla, G., and Saltzman, B., eds., Milankovich and climate, pt. 1: Plenum Reidel, Dordrecht, p. 269-305.

Ingle, J.C., Jr., 1967, Foraminiferal biofacies variation and the Miocene-Pliocene boundary in southern California: Bulletin of American Paleontology, v. 52, no. 236, p. 217-394. 
Ingle, J.C., Jr., 1973a, Neogene Foraminifera from the northeastern Pacific Ocean, leg 18, Deep Sea Drilling Project, in Kulm, L.D., von Huene, R., and others, 1973, Initial reports of the Deep Sea Drilling Project, v. 18, p. 517-567.

Ingle, J.C., Jr., 1973b, Summary comments on Neogene biostratigraphy, physical stratigraphy, and paleo-oceanography in the marginal northeastern Pacific Ocean, in Kulm, L.D., von Huene, R., and others, 1973, Initial reports of the Deep Sea Drilling Project, v. 18, p. 949-960.

Ingle, J.C., Jr., 1980, Cenozoic paleobathymetry and depositional history of selected sequences within the Southern California Borderland: Cushman Foundation for Foraminiferal Research, Special Publication, no. 19, p. 163-195.

Ingle, J.C., Jr., and Keller, G., 1980, Benthic foraminiferal biofacies of western Pacific margin between $40^{\circ} \mathrm{S}$ and $32^{\circ} \mathrm{N}$, in Field, M.E., Douglas, R.G., Bouma, A.H., and others, eds., Quaternary depositional environments of the Pacific Coast: Pacific Coast Paleogeography Symposium 4, Pacific Section, Society of Economic Paleontologists and Mineralogist, Los Angeles, California, p. 341-355.

Jordan, E.K., 1936, The Pleistocene fauna of Magdalena Bay, Lower California: Stanford University, Calif., Contributions from the Department of Geology, v. 1, no. 4, p. 107-173.

Johnson, C., and Bloch, R.B., 2005, Tertiary sequences of the central San Joaquin Basin, California-Age control and eustatic versus tectonic forcing factors: Pacific Section, AAPG Miscellaneous Publication series, MP\#49, 1 sheet.

Kanakoff, G.P., and Emerson, W.K., 1959, Late Pleistocene invertebrates of the Newport Bay area, California: Los Angeles County Museum Contribution in Science, no. 31, 47 p.

Keen, A.M., 1937, Nomenclatural units of the pelecypod family Cardiidae: Museum Royal History Belgigue, B, v. 13, no. 7, 22 p.

Keen, A.M., 1971, Sea shells of tropical west America; Marine mollusks from Baja California, to Peru: Stanford, Calif., Stanford University Press, 1,064 p.

Keller, Gerta, 1978, Late Neogene planktonic foraminiferal biostratigraphy and paleoceanography of the northeastern Pacific; evidence from DSDP Sites 173 and 310 at the North Pacific Front: Journal of Foraminiferal Research, v. 8, no. 4, p. 332-349.

Kennedy, G.L., and Browne, I.D., 2007, Paleontology and geochronology of the middle and upper Pleistocene marine record in the downtown San Diego area, San Diego County, southern California: Western Society of Malacologists Annual Report, no. 36, p. 13-34.

Kennedy, G.L., Lajoie, K.R., and Wehmiller, J.F., 1982, Aminostratigraphy and faunal correlations of late Quaternary marine terraces, Pacific coast, USA: Nature, v. 299, no. 5883, p. 545-547.

Kennett, J.P., 1968, Latitudinal variation in Globigerina pachyderma (Ehrenberg) in surface sediments of the southwest Pacific Ocean: Micropaleontology, v. 14, no. 3, p. 305-318.

Kennett, J.P., 1973, Middle and late Cenozoic planktonic foraminiferal Biostratigraphy of the southwest Pacific - DSDP Leg 21, in Burns, R.E., and others, Initial reports of the Deep Sea Drilling Project, v. 21, p. 575-640.

Kennett, J.P., Rozo-Vera, G.A., and Machain Castillo, M.L., 2000, Latest Neogene planktonic foraminiferal biostratigraphy of the California margin, in Lyle, M., Koizumi, I., Richter, C., and Moore, T.C., Jr., eds., Proceedings of the Ocean Drilling Program: Scientific Results, v. 167, p. 41-62.

Kennett, J.P., and Srinivasan, M.S., 1980, Surface ultrastructure variation in Neogloboquadrina pachyderma (Ehrenberg) - Phenotypic variation and phylogeny in the Late Cenozoic, in Sliter, W.V., ed., Studies in marine micropaleontology-A memorial volume to Orville L. Bandy: Cushman Foundation Foraminiferal Research Special Publication, no. 19, p. 134-162. 
Kennett, J.P., and Srinivasan, M.S., 1983, Neogene planktonic Foraminifera-A phylogenetic atlas: Stroudsburg, Penn., Hutchinson Ross Publishing Company, 265 p.

Kern, J.P., 1973, Early Pliocene marine climate and environments of the eastern Ventura Basin, southern California: University of California Publications in Geological Sciences, v. 96, 117 p.

Kern, J.P., and Wicander, E.R., 1974, Origin of a bathymetrically displaced marine invertebrate fauna in the upper part of the Capistrano formation (lower Pliocene), southern California: Journal of Paleontology, v. 48, no. 3, p. 494-505.

Kirschvink, J.L., 1980, The least-squares line and plane and the analysis of palaeomagnetic data: Geophysical Journal of the Royal Astronomical Society, v. 62, p. 699-718.

Kleinpell, R.M., 1938, Miocene stratigraphy of California: Tulsa, Okla., American Association of Petroleum Geologists, 450 p.

Knott, J.R., 1998, Late Cenozoic tephrochronology, stratigraphy, geomorphology, and neotectonics of the western Black Mountains piedmont, Death Valley, California; Implications for the spatial and temporal evolution of the Death Valley fault zone: Riverside, University of California, Ph.D. dissertation, $407 \mathrm{p}$.

Knott, J.R., Sarna-Wojcicki, A.M., Meyer, C.E., Tinsley, J.C., III, Wells, S.G., and Wan, Elmira, 1999, Late Cenozoic stratigraphy and tephrochronology of the western Black Mountains piedmont, Death Valley, California-Implications for the tectonic development of Death Valley, in Wright, L.A., and Troxel, B.W., eds., Cenozoic basins of the Death Valley region: Geological Society of America Special Paper 333, p. 345-366.

Kucera, M., and Kennett, J.P., 2000, Biochronology and evolutionary implications of late Neogene California margin planktonic foraminiferal events: Marine Micropaleontology, v. 40, no. 1-2, p. 67-81.

Kucera, M., and Kennett, J.P., 2002, Causes and consequences of a middle Pleistocene origin of the modern planktonic foraminifera Neogloboquadrina pachyderma sinistral: Geology, v. 30, no. 6, p. 539-542.

Lagoe, M.B., 1987, Chronostratigraphic significance of late Cenozoic planktic foraminifera from the Wheeler Canyon and Balcom Canyon sections, Ventura Basin, California, in Davis, T.L., and Namson, J.S. eds., Structural evolution of the western Transverse Ranges: Los Angeles, Calif., Pacific Section, Society of Economic Paleontologists and Mineralogist, Book 48A, p. 17-28.

Lagoe, M.B., and Thompson, P.R., 1988, Chronostratigraphic significance of late Cenozoic planktonic foraminifera from the Ventura Basin-Potential for improving tectonic and depositional interpretation: Journal of Foraminiferal Research, v. 18, no. 3, p. 250-266.

Lajoie, K.R., Ponti, D.J., Powell, C.L., II, Mathieson, S.A., and Sarna-Wojcicki, A.M., 1991, Emergent marine strandlines and associated sediments, coastal California-A record of Quaternary sea-level fluctuations, vertical tectonic movements, climatic changes, and coastal processes, in Morrison, R.B., ed., Quaternary geology of the Pacific margin; Quaternary nonglacial geology conterminous U.S. (volume K-2) - The geology of North America: Boulder, Colo., The Geological Society of America, p. 190-213.

Lankford, R.R., and Phleger, F.B., 1973, Foraminifera from the near shore turbulent zone, western North America: Journal of Foraminiferal Research, v. 3, no. 3, p. 101-132.

Lanphere, M.A., Champion, D.E., Christiansen, R.L., Izett, G.A., and Obradovich, J.D., 2002, Revised ages for the tuffs of Yellowstone Plateau volcanic field; assignment of the Huckleberry Ridge Tuff to a new magnetic polarity event: Geological Society of America Bulletin, v. 114, no. 5, p. 559-568. 
Leslie, B.W., Lund, S.P., and Hammond, D.E., 1990a, Rock magnetic evidence for the dissolution and authigenic growth of magnetic minerals within anoxic marine sediments of the California continental borderland: Journal of Geophysical Research, v. 95 (B4), p. 4437-4452.

Leslie, B.W., Hammond, D.E., Berelson, W.M., and Lund, S.P., 1990b, Diagenesis in anoxic sediments from the California continental borderland and its influence on iron, sulfur, and magnetite behavior: Journal of Geophysical Research, v. 95 (B4), p. 4453-4470.

Lisiecki, L.E., and Raymo, M.E., 2007, Plio-Pleistocene climate evolution-Trends and transitions in glacial cycle dynamics: Quaternary Science Reviews, v. 26, no. 1-2, p. 56-69.

Loeblich A.R., and Tappan, H., 1953, Studies of Arctic Foraminifera: Smithsonian Miscellaneous Collections, v. 121, no. 7, 142 p.

Loel, W., and Corey, W.H., 1932, The Vaqueros Formation, lower Miocene of California; I, Paleontology: University of California Publications in Geological Sciences, v. 22, no. 3, p. 31410.

Lyle, M., Koizumi, I., Delaney, M.L., and Barron, J.A., 2000, Sedimentary record of the California Current system, middle Miocene to Holocene: a synthesis of leg 167 results, in Lyle, M., Koizumi, I., Richter, C., and Moore, T.C., Jr., eds., Proceedings of the Ocean Drilling Program, Scientific Results, v. 167, p. 341-367.

Machette, M.N., Johnson, M.L., and Slate, J.L., 2001, Quaternary and late Pliocene geology of the Death Valley region-Recent observations on tectonics, stratigraphy, and lake cycles, Pacific Cell, Friends of the Pleistocene Field Trip, Feb. 17-19: U.S. Geological Survey Open-File Report 01-51, 246 p.

Marincovich, L.N., Jr., 1976, Late Pleistocene molluscan faunas from upper terraces of the Palos Verdes Hills, California: Natural History Museum of Los Angeles County Contributions in Science, no. 281, 28 p.

Marincovich, L.N., Jr., 1977, Cenozoic Naticidae (Mollusca: Gastropoda) of the northeastern Pacific: Bulletins of American Paleontology, v. 70, p. 169-494.

Martin, B., 1916, The Pliocene of middle and northern California: University of California Publications, Bulletin of the Department of Geology, v. 9, no. 15, p. 215-259.

Martin, L., 1952, Some Pliocene Foraminifera from a portion of the Los Angeles Basin, California: Cushman Foundation for Foraminiferal Research, Contributions, v. 3, p. 107-141.

Martini, E., 1971, Standard Tertiary and Quaternary calcareous nannoplankton zonation, in Farinacci, A., ed., Proceedings of the Second Planktonic Conference: Rome, Edizioni Teconscienza, p. 739-785.

Mason, H.L., 1934, Pleistocene flora of the Tomales Formation: Carnegie Institute of Washington Publication no. 415, p. 81-179.

McLean, J.H., 1978, Marine shells of southern California: Los Angeles County Museum of Natural History, Science Series 24, (rev. ed.), 104 p.

McLean, J.H., 2007, Gastropoda — Shelled Gastropoda, in Carlton, J.T., ed., The Light and Smith manual-Intertidal invertebrates from central California, to Oregon (4th ed.): Berkeley, University of California Press, p. 713-753.

McLean, J.H., and Gosliner, T.M., 1996, The Gastropoda, in Taxonomic atlas of the benthic fauna of the Santa Maria Basin and western Santa Barbara Channel, v. 9, The Mollusca, pt. 2, The Gastropoda, 228 p.

Meade, R.F., 1967, Molluscan paleoecology of the Fernando Group of the southern Ventura Basin: Los Angeles, University of California, Ph.D. dissertation, 154 p. 
Merriam, C.W., 1941, Fossil turritellas from the Pacific coast region of North America: University of California Publications, Bulletin of the Department of Geological Sciences Bulletin, v. 26, no. $1,214 \mathrm{p}$.

Merrill, R.T., and McFadden, P.L., 2005, The use of magnetic field excursions in stratigraphy: Quaternary Research, v. 63, no. 3, p. 232-237.

Merrill, R.T., McElhinny, M.W., and McFadden, P.L., 1998, The magnetic field of the Earth: New York, Academic Press, International Geophysics Series, v. 63, 531 p.

Millard, H.T., and Maat, P.B., 1994, Thermoluminescence dating procedures in use at the U.S. Geological Survey, Denver, Colorado: U.S. Geological Survey Open-File Report 94-249, 112 p.

Minch, J.C., Gastil, G., Fink, W., Robinson, J., and James, A.H., 1976, Geology of the Vizcaino Peninsula, in Howell, D.G., ed., Aspects of the geologic history of the California continental borderland: American Association of Petroleum Geologists, Pacific Section, Miscellaneous Publication 24, p. 136-195.

Montagu, G., 1803, Testacea Britannica or natural history of British shells, marine, land and freshwater, including the most minute, J.S. Hollis, Romsey, England, 183 p.

Moody, C.L., 1916, Fauna of the Fernando of Los Angeles: University of California Publications, Department of the Geology Bulletin, v. 10, no. 4, p. 39-62.

Moore, E.J., 1983, Tertiary marine pelecypods of California and Baja California-Nuculidae through Malleidae: U.S. Geological Survey Professional Paper 1228A, p. A1-A108.

Moore, E.J., 1987, Tertiary marine pelecypods of California and Baja California-Plicatulidae to Ostreidae: U.S. Geological Survey Professional Paper 1228C, 53 p.

Moore, E.J., 2002, Family Pharidae, in Tertiary marine pelecypods of California and Baja California; Chapter F: Chintimini Press, July 2003, at http://members.peak.org/ chintimp/Tertiary.pelecypods.htm, $4 \mathrm{p}$.

Murray, A.S., and Wintle, A.G., 2000, Luminescence dating of quartz using an improved singlealiquot regenerative-dose protocol: Radiation Measurements, v. 32, no. 1, p. 57-73.

Natland, M.L., 1938, New species of Foraminifera from off the west coast of North America and from the later Tertiary of the Los Angeles Basin: Scripps Institution of Oceanography Bulletin, Technical Series, v. 4, p. 137-164.

Natland, M.L., 1952, Pleistocene and Pliocene stratigraphy of southern California: Los Angeles, University of California, Ph.D. dissertation, 165 p.

Natland, M.L., ed., 1957, Paleoecology of west coast Tertiary sediments, Treatise on Marine Ecology and Paleoecology: Geological Society of America Memoir 67, v. 2, p. 543-572.

Nomland, J.O., 1917a, The Etchegoin Pliocene of middle California: University of California Publications, Department of Geology Bulletin, v. 10, no. 14, p. 191-254.

Nomland, J.O., 1917b, Fauna of the Santa Margarita beds in the north Coalinga region of California: University of California Publications, Department of Geology Bulletin, v. 10, no. 18, p. 293-326.

Ogg, J.G., and Smith, A.G., 2004, The geomagnetic polarity time scale, in Gradstein, F.M., Ogg, J.G., and Smith, A.G., eds., A geologic time scale: Cambridge, Mass., Cambridge University Press, p. 63-86.

Oldroyd, T.S., 1914, A remarkably rich pocket of fossil drift from the Pleistocene, California: The Nautilus, v. 28, no. 7, p. 80-82.

Oldroyd, T.S., 1925, The fossils of the lower San Pedro fauna of the Nob Hill cut, San Pedro, California: Proceedings of the U.S. National Museum Proceedings, v. 65, art. 22, p. 1-39. 
Olsson, A.A., 1961, Mollusks of the tropical eastern Pacific particularly from the southern half of the Panamic-Pacific faunal province (Panama to Peru) - Panamic-Pacific Pelecypoda: Ithaca, New York, Paleontological Research Institution, 574 p.

Opdyke, N.D., and Channell, J.E.T., 1996, Magnetic stratigraphy: San Diego, Calif., Academic Press, $346 \mathrm{p}$.

d'Orbigny, A.D., 1826, Tableau methodique de la classe des Cephalopodes: Paris, Annales des Sciences Naturelles, ser. 1, v. 7, p. 96-314.

d'Orbigny, A.D., 1846, Foraminiferes fossiles du bassin tertiaire de Vienne (Autriche) (Due fossilen Foramniferen des tertiaeren Beckens von Wien): Gide et Comp., 312 p.

Perry, F.A., 1993, Fossil invertebrates and geology of the marine cliffs at Capitola, California: Santa Cruz, Calif., Santa Cruz City Museum, 30 p.

Phleger, F.B., 1964, Patterns of living benthonic Foraminifera, Gulf of California-Marine geology of the Gulf of California: Tulsa, Okla., American Association of Petroleum Geology, Memoir 3, p. 377-394.

Phleger, F.B., and Parker, F.L., 1951, Ecology of Foraminifera, northwestern Gulf of Mexico; Part II-Foraminifera species: Geological Society of America Memoirs, v. 46, p. 1-64.

Poland, J.F., Piper, A.N., and others, 1956, Ground water geology of the coastal zone, Long Beach, California: U.S. Geological Survey Water Supply Paper 1109, 162 p.

Ponti, D.J., 1989, Aminostratigraphy and chronostratigraphy of Pleistocene marine sediments, southwestern Los Angeles Basin, California: Boulder, University of Colorado, Ph.D. dissertation, 409 p.

Ponti, D.J., Ehman, K.D., Edwards, B.D., Tinsley, J.C., III, Hildenbrand, T., Hillhouse, J.W., Hanson, R.T., McDougall, K., Powell, C.L., II, Wan, E., Land, M., Mahan, S., and SarnaWojcicki, A.M., 2007, A 3-dimensional model of water-bearing sequences in the Dominguez Gap region, Long Beach, California: U.S. Geological Survey Open-File Report 2007-1013, 43 p. Poore, R.Z., 2007, Pliocene environments, in Elias, S.A., ed., Encyclopedia of Quaternary science, v. 3: Amsterdam, Netherlands, Elsevier, p. 1948-1958.

Powell, C.L., II, 1986, Stratigraphy and bivalve molluscan paleontology of the Neogene Imperial Formation in Riverside County, California: San Jose, Calif., San Jose State University, master's thesis, $325 \mathrm{p}$.

Powell, C.L., II, 1998, The Purisima Formation and related rocks (upper Miocene-Pliocene), greater San Francisco Bay area, central California-Review of literature and U.S. Geological Survey collections (now housed at the Museum of Paleontology, University of California, Berkeley): U.S. Geological Survey Open-File Report 89-594, 101 p., (Also available at http://wrgis.wr.usgs.gov/open-file/of98-594/index.html.)

Powell, C.L., II, Allen, J.R., and Holland, P.J., 2004, Invertebrate paleontology of the Wilson Grove Formation (late Miocene to late Pliocene), Sonoma and Marin Counties, California, with some observations on its stratigraphy, thickness, and structure: U.S. Geological Survey OpenFile Report 2004-1017, 106 p. (Also available at http://pubs.usgs.gov/of/2004/1017/)

Powell, C.L., II, Barron, J.A., Sarna-Wojcicki, A.M., Clark, J.C., Perry, F.A., Brabb, E.E., and Fleck, R.J., 2007, Age, stratigraphy, and correlation of the late Neogene Purisima Formation, central California Coast Ranges: U.S. Geological Survey Professional Paper 1740, 32 p. (Also available at http://pubs.usgs.gov/pp/2007/1740/.)

Powell, C.L., II, Lajoie, K., and Ponti, D., 2000, A preliminary chronostratigraphy based on molluscan biogeography for the late Quaternary of southern California: Western Society of Malacologists Annual Report, v. 32, p. 23-36. 
Powell, C.L., II, and Ponti, D.J., 2007, Paleontologic and stratigraphic reevaluation of Dead Man Island, formerly in San Pedro Bay, California, in Brown, A.R., Shlemon, R.J., and Cooper, J.D., eds., Geology and paleontology of Palos Verdes Hills, California-A 60th anniversary revisit to commemorate the 1946 publication of U.S. Geological Survey Professional Paper 207: Pacific Section SEPM, book 103, p. 101-120.

Powell, C.L., II, and Stevens, D., 2000, Significance of macrofossils from the "San Pedro"

Formation, Coyote Hills, Orange County, southern California: Western Society of Malacologists Annual Report, v. 32, p. 36-41.

Prescott, J., and Hutton, J., 1988, Cosmic ray and gamma ray dosimetry for TL and ESR: Nuclear

Tracks and Radiation Measurements, Part D, v. 14, p. 223-227.

Preston, H.M., 1931, Report on Fruitvale oil field: California Oil Fields, v. 16, no. 4, p. 5-24.

Ravelo, A.C., Andreason, D.H., Lyle, M., Lyle. A.O., and Wara, M.W., 2004, Regional climate shifts caused by gradual global cooling in the Pliocene epoch: Nature, v. 429, no. 6989, p. 263267.

Ravelo, A.C., Lyle, M., Koizumi, I., Caulet, J.P., Fornaciari, E., Hayashida, A., Heider, F., Hood, J., Hovan, S., Janecek, T., Janik, A., Stax, R., Yamamoto, M., and the ODP Leg 167 Shipboard Scientific Party, 1997, Pliocene carbonate accumulation along the California margin: Paleoceanography, v. 12, no. 6, p. 729-741.

Ravelo, A.C., and Wara, M.W., 2004, The role of the tropical oceans on global climate during a warm period and a major climate transition: Oceanography, v. 17, no. 3, p. 32-41.

Richardson, C.A., McDonald, E.V., and Busacca, A.J., 1997, Luminescence dating of loesses from the northwest United States: Quaternary Science Reviews, v. 16, no. 3-5, p. 403-415.

Reuss, A.E., 1863, Beitirage sur Kenntniss der tertiaren Foraminiferen-Fauna (zweirw Folge): Kaiserliche Akademie Wissenschatten, Mathematisch-Naturwissenschaftiche Classe, Sitzber., Wien, Osterreich. Bd. 48, Abth. 1, p. 36-71.

Robert, H.M., and Wintle, A.G., 2001, Equivalent dose determinations for polymineralic finegrains using the SAR protocol-Application to a Holocene sequence of the Chinese loess plateau: Quaternary Science Reviews, v. 20, no. 5-9, p. 859-863.

Rodda, P.U., 1957, Paleontology and stratigraphy of some marine Pleistocene deposits in northwest Los Angeles Basin, California: American Association of Petroleum Geologists Bulletin, v. 41, no. 11, p. 2475-2492.

Roemer, F.A., 1938, Die Cephalopoden des norddeutschen tertiaren Meeressandes: Stuttgart, Deutschland, Neues Jahrbuch fur Mineralogie, Geognosie, Geologie und Petrefakten-Kunde, p. 381-394.

Rögl, E., and Bolli, H.M., 1973, Holocene to Pleistocene planktonic foraminifera of Leg 15, Site 147 (Cariaco Basin [Trench], Caribbean Sea) and their climatic interpretation, in Edgar, N.T., Saunders, J.B., and others, Initial reports of the Deep Sea Drilling Project, leg 15: U.S. Government Printing Office, Washington, D.C., p. 553-615.

Roth, B., 1979, Late Cenozoic marine invertebrates from northwest California and southwest Oregon: Berkeley, University of California, Ph.D. dissertation, 792 p.

Sarna-Wojcicki, A.M., 2000, Tephrochronology, in Noller, J.S., Sowers, J.M., and Lettis, W.R., eds., Quaternary geochronology: Washington, D.C., American Geophysical Union Reference Shelf 4, p. 357-377.

Sarna-Wojcicki, A.M., Bowman, H.R., Meyer, C.E., Rowe, J.J., Jr., Baedecker, P.A., Asaro, F., and Michael, H., 1984, Chemical analyses, correlations, and ages of upper Pliocene and 
Pleistocene ash layers of east-central and southern California: U.S. Geological Survey Professional Paper 1293, 40 p.

Sarna-Wojcicki, A.M., and Davis, J.O., 1991, Quaternary tephrochronology, in Morrison, R.B., ed., Quaternary nonglacial geology; conterminous U.S.: Boulder, Colo., Geological Society of America, The Geology of North America, v. K-2, p. 93-116.

Sarna-Wojcicki, A.M., Meyer, C.E., and Wan, E., 1997, Age and correlation of tephra layers, position of the Matuyama-Brunhes chron boundary, and effects of the Bishop Ash eruption on Owens Lake, as determined from drill hole OL-92, southeast California, in Smith, G.I., and Bischoff, J.L., eds., An 800,000-year paleoclimatic record from core OL-92, Owens Lake, southeast California: Geological Society of America Special Paper 317, p. 79-90.

Sarna-Wojcicki, A.M., and Pringle, M.S., 1992, Laser fusion ${ }^{40} \mathrm{Ar} /{ }^{39} \mathrm{Ar}$ ages of the tuff of Taylor Canyon and Bishop Tuff, E. California-W. Nevada: EOS, Transactions, American Geophysical Union, v. 73, no. 43, p. 633.

Sarna-Wojcicki, A.M., Pringle, M.S., and Wijbrans, J., 2000, New ${ }^{40} \mathrm{Ar} /{ }^{39} \mathrm{Ar}$ age of the Bishop Tuff from multiple sites and sediment rate calibration for the Matuyama-Brunhes boundary: Journal of Geophysical Research, v. 105, no. 9B, p. 21,431-21,443.

Schoellhamer, J.E., Vedder, J.G., Yerkes, R.F., and Kinney, D.M., 1981, Geology of the northern Santa Ana Mountains: U.S. Geological Survey Professional Paper 420D, p. D1-D109.

Scaillet, S., Laj, C., Kissel, C., Guillou, H., and Singer, B.S., 2004, Age and structure of the Laschamp geomagnetic excursion: Eos, Transactions, American Geophysical Union, v. 85, no. 47, Supplement, Abstract GP41B-05.

Schmieder, F., Dobeneck, T.V., Bleil, U., 2000, The mid-Pleistocene climate transition as documented in the deep South Atlantic Ocean; initiation, interim state and terminal event: Earth and Planetary Science Letters, v. 179, no. 3-4, p. 539-549.

Schwager, C., 1866, Fossile foraminiferen von Kar-Nicobar: Novara Expedition Geologisch Theil, v. 2, p. 187-268.

Sequenza, G., 1862, Deii terreni Terziarii del distretto di Messina; Parte II - Descriptione dei foraminiferi monotalamici delle marne mioceniche del distretto de Messina T. Capra, p. 66.

Shackleton, N.J., and Opdyke, N.D., 1973, Oxygen isotope and paleomagnetic stratigraphy of equatorial Pacific core V28 238-Oxygen isotope temperatures and ice volumes on a $10^{5}$ and $10^{6}$ year scale: Quaternary Research, v. 3, no. 1, p. 39-55.

Shimek, R.L., 1998, Class Scaphopoda, in Taxonomic atlas of the benthic fauna of the Santa Maria Basin and western Santa Barbara Channel, v. 8, The Mollusca, part 1, The Aplacophora, Polyplacophora, Scaphopoda, Bivalvia and Cephalopoda: Santa Barbara, Calif., Santa Barbara Museum of Natural History, p. 75-96.

Singer, B.S., Hoffman, K.A., Chauvin, A., Coe, R.S., and Pringle, M.S., 1999, Dating transitionally magnetized lavas of the late Matuyama Chron; Toward a new ${ }^{40} \mathrm{Ar} /{ }^{39} \mathrm{Ar}$ timescale of reversals and events: Journal of Geophysical Research, v. 104, no. B1, p. 679-693.

Singhvi, A.K., Bluszcz, A., Bateman, M.D., and Rao, M.S., 2001, Luminescence dating of loesspalaeosol sequences and coversands; methodological aspects and palaeoclimatic implications: Earth-Science Reviews, v. 54, no. 1, p. 193-211.

Singhvi, A.K., Sharma, Y.P., and Agrawal, D.P., 1982, Thermoluminescence dating of sand dunes in Rajasthan, India: Nature, v. 295, no. 5847, p. 313-315.

Smith, P.B., 1963, Quantitative and Qualitative analysis of the family Bolivinidae: U.S. Geological Survey Professional Paper, v. 429-A, 39 p. 
Smith, P.B., 1964, Ecology of benthonic species: U.S. Geological Survey Professional Paper, v. 429-B, 55 p.

Soper, E.K., and Grant, U.S., IV, 1932, Geology and paleontology of a portion of Los Angeles, California: Geological Society of America Bulletin, v. 43, no. 12, p. 1041-1068.

Stainforth, R.M., Lamb, J.L., Luterbacher, H., Beard, J.H., and Jeffords, R.M., 1975, Cenozoic planktonic foraminiferal zonation and characteristics of index forms: University of Kansas Paleontological Contributions, art. 62, 425 p.

Stanton, J.R., Jr., 1966, Megafauna of the upper Miocene Castaic Formation, Los Angeles County, California: Journal of Paleontology, v. 40, no. 1, p. 21-40.

Stewart, R.E., and Stewart, K.C., 1930, Post-Miocene foraminifera from the Ventura Quadrangle, Ventura County, California: Journal of Paleontology, v. 4, no. 1, p. 60-72.

Strong, A.M., 1928, West American Mollusca of the genus Phasianella: Proceedings of the California Academy of Sciences, Fourth Series, v. 17, no. 6, p. 187-203.

Touring, R.M., 1959, Structure and stratigraphy of the La Honda and San Gregorio Quadrangles, San Mateo County, California: Stanford University, Calif., Ph.D. dissertation, 228 p.

Trask, P.D., 1922, The Briones Formation of middle California: University of California Publication, Department Geological Sciences Bulletin, v. 13, no. 5, p. 133-174.

Tucholka, P., Fontugne, M., Guichard, F., and Paterne, M., 1987, The Blake magnetic polarity episode in cores from the Mediterranean Sea: Earth and Planetary Science Letters, v. 86, no. 2-4, p. 320-326.

Uchio, T., 1960, Ecology of living benthonic Foraminifera from the San Diego, California, area: Cushman Foundation for Foraminiferal Research Special Publication, no. 5, 72 p.

Valentine, J.W., 1955, Upwelling and thermally anomalous Pacific Coast Pleistocene molluscan faunas: American Journal of Science, v. 253, no. 8, p. 462-474.

Valentine, J.W., 1956, Upper Pleistocene Mollusca from Potrero Canyon, Pacific Palisades, California: Transactions of the San Diego Society of Natural History, v. 12, no. 2, p. 181-205.

Valentine, J.W., 1958, Late Pleistocene megafauna of Cayucos, California and its zoogeographic significance: Journal of Paleontology, v. 32, no. 4, p. 687-696.

Valentine, J.W.,1961, Paleoecologic molluscan geography of the California Pleistocene: University of California Publications in Geological Sciences, v. 34, p. 309-442.

Valentine, J.W., and Lipps, J.H., 1963, Late Cenozoic rocky-shore assemblages from Anacapa Island, California: Journal of Paleontology, v. 37, no. 6, p. 1292-1302.

Vedder, J.D., 1973, Geologic framework and correlation of Miocene rocks in the Caliente Range, in Sedimentary facies changes in Tertiary rocks - California Transverse and southern Coast Ranges: American Association of Petroleum Geologists, Society of Economic Paleontologists and Mineralogists, and Society of Economic Geologists, Pacific Section, Annual Meeting, 1973, Society of Economic Paleontologists and Mineralogists Trip 2, 60 p.

Wagner, F.J., 1959, Palaeoecology of the marine Pleistocene fauna of southwestern British Columbia: Geological Survey of Canada Bulletin, no. 52, 67 p.

Walker, G., and Jacob, E., 1798, Adams' Essays on the microscope: (2d ed.), London, Dillon and Keating, 712 p.

Wallinga, J., 2002, Optically stimulated luminescence dating of fluvial deposits - A review: Boreas, v. 31, no. 4, p. 303-322.

Walton, W.R., 1955, Ecology of living benthonic foraminifera, Todos Santos Bay, Baja California: Journal of Paleontology, v. 29, no. 6, p. 952-1018. 
Waterfall, L.N., 1929, A contribution to the paleontology of the Fernando Group, Ventura County, California: University of California Publications in the Geological Sciences, v. 18, no. 3, p. 7192.

Weaver, C.E., 1949, Geology of the Coast Ranges immediately north of the San Francisco Bay region, California: Geological Society of America Memoir 35, 242 p.

White, W.R., 1956, Pliocene and Miocene foraminifera from the Capistrano Formation, Orange County, California: Journal of Paleontology, v. 30, no. 2, p. 237-260.

Willet, G., 1937, An upper Pleistocene fauna from the Baldwin Hills, Los Angeles County, California: Transactions of the San Diego Society of Natural History, v. 8, no. 30, p. 379-406.

Williamson, W.C., 1848, On the recent British species of the genus Lagena: Annual Magazine of Natural History, ser. 2, v. 1, p. 1-20.

Williamson, W.C., 1858, On the recent Foraminifera of Great Britain: London, Ray Society, 107 p.

Winterer, E.L., and Durham, D.L., 1962, Geology of southeastern Ventura Basin, Los Angeles County, California: U.S. Geological Survey Professional Paper 334H, 366 p.

Woodring, W.P., and Bramlette, M.N., 1950, Geology and paleontology of the Santa Maria District, California: U.S. Geological Survey Professional Paper 222, 185 p.

Woodring, W.P., Bramlette, M.N., and Kew, W.S.W., 1946, Geology and paleontology of Palos Verdes Hills, California: U.S. Geological Survey Professional Paper 207, 145 p.

Wright, T.L., 1991, Structural geology and tectonic evolution of the Los Angeles basin, California, in Biddle, K.T., Active margin basins: American Association of Petroleum Geologists Memoir 52 , p. 35-134. 


\section{Appendix I-Methods}

\section{Drilling, Coring, and Sampling}

A Christiansen coring tool equipped with 5-ft or 10-ft clear plastic liners (2.5-inch diameter) was used. The bottom part of the liner was blackened with spray paint to protect luminescence samples from ambient light during recovery of the core. Within 12 hours of recovery, the cores were logged and sampled in a mobile laboratory near the drill site. First, whole cores in liners were passed through an automated Geotek MultiSensor Core Logger (MSCL) that measured compression wave velocity (Vp), gamma bulk density, and magnetic susceptibility at $1-\mathrm{cm}$ intervals. Samples for luminescence dating were then cut from the blackened end of the core liner. Next, the cores and liners were split lengthwise for description, photography, and further sampling. After sampling, the cores were placed in refrigerated storage at the mobile laboratory and later transported to a long-term, refrigerated storage facility at the U.S. Geological Survey (USGS), Menlo Park, California.

\section{Microfossils}

Microfossil samples were collected at the drill site and processed in the USGS Micropaleontology Laboratory in Flagstaff, Arizona. The samples were soaked in water, wetsieved using a 250 mesh screen, and dried in a low temperature oven $\left(\leq 40^{\circ} \mathrm{C}\right)$. A statistically significant number of benthic foraminifers (300 specimens) or all specimens if $<300$ present in the sample were examined from the $\geq 150$ micron fraction of the residue. The same procedure was adopted for the planktic foraminifers. The presence of other organic material also was noted. Microfossil slides are on file with the Micropaleontology Laboratory in Flagstaff, Ariz.

\section{Macrofossils}

Macrofossils were found by visual inspection after the core was cut in half. When shells or shell fragments were observed, the working portion of the core containing the fossils was removed; occasionally the archive half of the core also was sampled. Samples were washed through 60 micron and 8 micron mesh screens. The samples were labeled, dried, and examined under a microscope. All identifiable specimens are listed, but the abundance of faunal elements is not noted because most species were represented by fewer than twenty individuals.

Shaker samples (K) refer to material that was carried by drilling fluid up the well and caught on screens that separate the drilling mud from sediments and fossils. Because no casing was used during drilling, these samples represent a mixture of sediment from the entire well wall at the time of collection. Commonly this fauna represents the last coring interval, or about $5 \mathrm{ft}$. These samples were processed in the same manner as the samples from the core.

\section{Paleomagnetism}

The sampling tool for paleomagnetism consisted of a brass tube $(3.0 \mathrm{~cm} / 1.2$ inch diameter $)$ and plastic piston mounted on an aluminum frame. Samples were extracted from the working half of the core by pushing the tube through the split face down to the core liner, then by extruding the sediment plug into a cylindrical plastic container $(16 \mathrm{cc})$. The tool includes a scriber that places a mark on the upward side of the plug along the central axis of the core. This procedure controls the plug orientation for an accurate measurement of magnetic inclination because the well axis is assumed to be vertical and the bedding is essentially horizontal, although some cross bedding was noted. Although the large volume of the specimen has the advantage of providing more material for the measurement, it has the disadvantage of collecting possibly deformed material near the core 
liner. Inspection of cores indicated that, in the worst cases, drilling-induced deformation extended from the core liner inward about one-third of the core radius. Deformation was manifested as a tilting of fine bedding down toward the core liner. As shown in figure 92, the dimensions are such that as much as 20 percent of the specimen volume could consist of deformed material. However, given that deformation was usually absent, and when observed, rarely exceeded $15^{\circ}$ at the core liner, drilling-induced deformation is not believed to have caused significant errors in the magnetic measurements.

The coring system is not equipped with a compass, so the lack of azimuthal control prevents true magnetic declinations from being determined. A local coordinate system, indexed to the split face of the core, was used consistently for each of the sampled cores, as shown in figure 92.

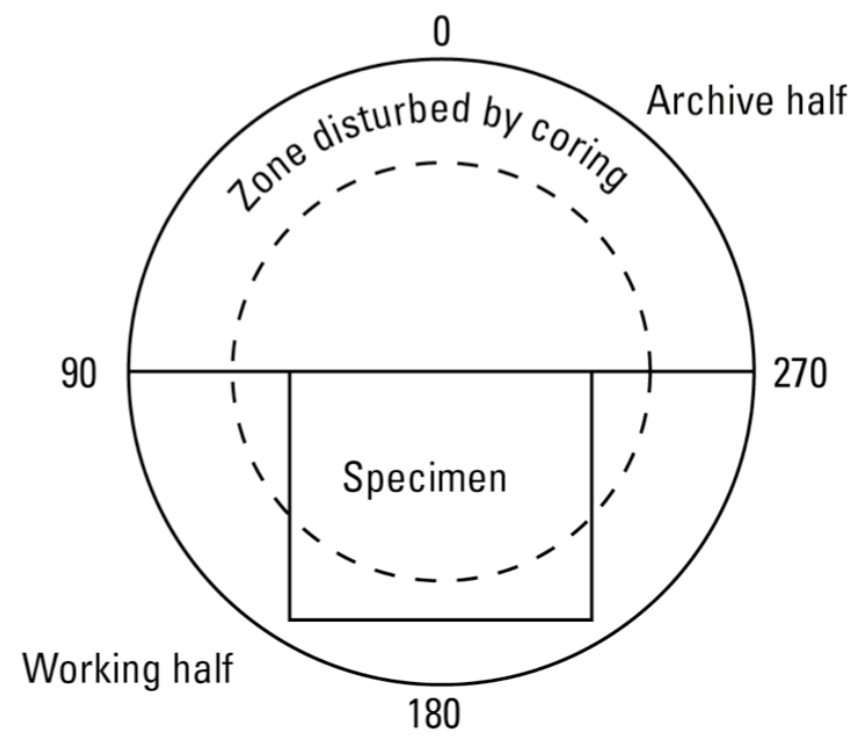

Figure 92. Cross-sectional view of a generalized core, showing location of specimen for paleomagnetic analysis. View is up the core, and the section is perpendicular to the core axis. Numbers (in degrees) indicate azimuths indexed to the split face between the working and archive halves of the core.

The sampling scheme called for one specimen to be taken every $1.5-\mathrm{m}$ length of core, provided suitably firm and fine-grained sediment was present. Friable sand and gravel were considered unsuitable for paleomagnetic analysis because the coring process easily disturbed them and they are more susceptible to induction and remagnetization effects.

All measurements of remanent magnetization were performed with a superconductingsensor magnetometer at the USGS Rock Magnetics Laboratory in Menlo Park, Calif. Each specimen was treated in alternating fields (AF) to remove spurious components of magnetization that were imparted by the recent geomagnetic field, or by stray fields during coring. The cleaning procedure involved a regimen of demagnetization steps in peak AFs progressing from 50 oersteds to 600 oersteds $(5-60 \mathrm{mT})$, resulting in a sequence of 5 to 8 measurements. The AF device employs a three-axis tumbler mounted inside a coil driven at 60 Hertz. Some specimens, particularly the fine sands, acquired an artifact of the treatment called "rotational remanent magnetization." When necessary, a double-demagnetization procedure (Hillhouse, 1977) was used to remove this artifact.

Vector diagrams that depict projections of the magnetic directions in the horizontal and vertical planes were then analyzed for each specimen. For demagnetization steps that demonstrated stabilization of the magnetic direction, a least-squares line was fit to the data according to the 
method of Kirschvink (1980). The analysis yields a best-fit magnetic direction from the demagnetization treatment plus the "maximum angle of deviation" (MAD), a measure of the colinearity of the data. MADs of $10^{\circ}$ or less indicate results of high quality in studies of unconsolidated sediment (Kirschvink, 1980).

\section{Optically Stimulated Luminescence and Thermoluminescence}

Luminescence dating works on the principle that common minerals, such as quartz and feldspar, contain impurities, some of which can act as traps for free electrons. Luminescence is created by ionizing radiation freeing electrons, which wander through the crystal lattice until they encounter a "trapped hole" or recombine, and become trapped at electron traps. These are lattice defects (impurities) with negative charge deficits. Free electrons are produced when minerals are subjected to alpha, beta, and gamma ionizing radiation from the decay of uranium, thorium, and potassium $\left({ }^{40} \mathrm{~K}\right)$ in the sediment matrix, as well as cosmic-ray radiation. If, for example, a sedimentary deposit is eroded and the mineral grains exposed to sunlight, light-sensitive electron traps will be emptied or "zeroed". After subsequent burial, these traps gradually fill again. The longer the crystal has been exposed to ionizing radiation, the more "traps" can be filled, resulting in an increased luminescence signal, with a practical time limit of 1-800 ka in thermal luminescence (TL) and $0.1->100 \mathrm{ka}$ in optically stimulated luminescence (OSL) (Aitken, 1985, 1998; Berger, 1988).

Methodology and much more detailed reviews of optical dating can be found throughout recent literature (Berger, 1988; Aitken, 1998; Huntley and Lamothe, 2001). To evoke the emission of TL or OSL, additional thermal or optical stimulation, respectively, has to be supplied to the crystal. The intensity of the measured light is related to the number of electrons emitted, hence the time elapsed since they were last exposed to sufficient sunlight or heat. Through lab measurements, the radiation dose that produced the trapped-electron population can be determined with a calculation of the radiation dose rate $\left(D_{r}\right)$, and the time elapsed since burial can be estimated.

The interaction between this radiation and the atoms of minerals results in gradually increasing radiation damage. The intensity of the radiation damage in crystal lattices is a measure of the equivalent dose or $\mathrm{D}_{\mathrm{e}}$, which the mineral has received since formation or last "resetting" by exposure to sunlight or heat greater than $400{ }^{\circ} \mathrm{C}$. $\mathrm{D}_{\mathrm{e}}$ is measured in Gray (Gy), or absorbed radiation energy per unit mass. Once one has "read" the $\mathrm{D}_{\mathrm{e}}$ by means of a TL or OSL measurement, the $\mathrm{D}_{\mathrm{r}}$ is obtained by measuring the ionizing radiation of potassium, uranium, thorium, rubidium, and cosmic rays as dose per unit time or $\mathrm{Gy} / \mathrm{ka}$. The equation for obtaining an age is:

Age $(\mathrm{ka})=\mathrm{D}_{\mathrm{e}}(\mathrm{Gy}) / \mathrm{D}_{\mathrm{r}}(\mathrm{Gy} / \mathrm{ka})$.

Key assumptions are:

(1) Materials have uniform and definable dose rates.

(2) Moisture content of the sample and its environment can be determined.

(3) Depth, altitude, and intensity of cosmic rays on site can be calculated or are known.

(4) The radiation-induced signal has to be thermally or optically reset by the event to be dated. The rate and completeness of "resetting" can be reliably obtained.

(5) The TL or OSL must have been stable during the time span in question. Any spurious "fading" of TL or OSL can be measured and compensated for in age calculations.

(6) The TL and OSL growth characteristics have to follow a mathematical function. 
A sample was collected from each core in the mobile laboratory by cutting the blackened liner $15 \mathrm{~cm}$ above the core bottom. If the upper 1-1.2 $\mathrm{m}$ of sediments were between silt and fine sand size, a luminescence sample was taken. The material in the blackened core liner was wrapped in heavy black photography bags and shipped back to the USGS Luminescence Dating Laboratory in Denver, Colo. In the lab, under subdued sodium vapor lights, about 5-10 $\mathrm{mm}$ of the outer exposed surfaces of the samples were removed and used for determination of the $\mathrm{D}_{\mathrm{r}}$. Sediments used for dosimetry concentrations were air-dried, sealed for four weeks in clear plastic dishes (to allow for radon migration) and counted using gamma spectrometry.

Approximately $100 \mathrm{~g}$ of inner core sediment was used for the $\mathrm{D}_{\mathrm{e}}$ determinations and any extra material (500-600 g) was used for other types of data analyses (moisture values, duplicates, elemental concentrations for dosimetry). Two grain sizes were used for obtaining luminescence data - the 4-11 (silt) and the 90-125 (sand) micron grain sizes. Methods outlined in Millard and Maat (1994), as well as other standard procedures with appropriate modifications (Robert and Wintle, 2001; Singhvi and others, 2001) were used on the sand size. The fine sand-size underwent a heavy liquid treatment (lithium sodium tungstate or LST) to separate the potassium feldspar from the quartz grains while impurities in the quartz fraction were dissolved with a 50 percent hydrofluoric acid treatment for 40 minutes following methods outlined by Duller and others (1999), Banerjee and others (2000), and Murray and Wintle (2000).

\section{Equivalent Dose Analyses and Techniques}

Samples were measured for TL and infrared stimulated luminescence (IRSL) on polymineralic silt-sized grain discs using a multiple-aliquot additive dose technique (Singhvi and others, 1982). These discs were plated using a prescribed amount of methanol/silt slurry and dried in a warming oven to ensure an even coating on each surface. TL was obtained by heating the disc to $500{ }^{\circ} \mathrm{C}$, and the feldspar IRSL was obtained by exposing the disc to 100 seconds of LEDs emitting in the infrared wavelengths. IRSL data was obtained before TL data, using the same discs. The quartz OSL was obtained using a single aliquot regeneration procedure on fine-grained sand (Robert and Wintle, 2001). The sample was loose, that is, not sprayed onto a flat surface with any sort of silicone spray or methanol slurry, but was contained within shallow aluminum cups. Carousel sizes of 10-48 discs were run, depending on time and initial scatter of data in test runs. The ideal number of discs to run to obtain 5-10 percent precision varied, but in most cases was about 20 separate discs or aliquots.

\section{Dosimetry}

Several components are needed for an accurate $\mathrm{D}_{\mathrm{r}}$ : (1) measurement of potassium, uranium (or some equivalent daughter product, such as radium), thorium (or an equivalent), and rubidium (Aitken, 1985, 1998); (2) calculation of moisture content in field at time of collection and saturation potential of the sample sediment; and (3) cosmic ray component calculation. Secular equilibrium in the uranium decay series is assumed, unless comparisons among techniques indicate otherwise. Annual radiation doses in Gy/ka or $10^{-3} \mathrm{~Gy} / \mathrm{yr}$ are taken from Aitken (1985) and adapted as needed.

Gamma ray spectrometry was used to measure concentrations of these elements. Highresolution gamma ray spectrometry (using $\mathrm{NaI}$ detector with extended counting times $>8.5$ hours times four separate count intervals) was carried out on a $600 \mathrm{~g}$ sample to obtain the necessary acceptable homogenous soil sample and accurate counting statistics. Apart from elemental quantification, this technique enables the checking of radioactive equilibrium. Moisture and radon migration are not factors because the bulk sample was dried and sealed for a month and radon was allowed to equilibrate before counting. The program collects gamma spectra and then fits standard 
spectra of potassium, uranium, and thorium together using the least-squares criterion (Berger, 1988). Comparisons between laboratory and literature values for these standards show excellent agreement. Most of the scatter can be attributed to counting statistics or because there was not an optimal amount of sample.

Moisture content through geologic time was estimated, with the understanding that this estimate carries a large uncertainty. Ages are calculated using an approximated field-moisture percentage, unless unusual conditions prevailed at the time of sample collection (that is, sustained rain during a period of time, perched water table, drought, or human disturbance). Water attenuation corrections for each type of radiation are made using moisture-correction factors taken from Aitken (1985). Values for the cosmic doses are taken from Prescott and Hutton (1988) and specific applications in use at the USGS Luminescence Dating Lab from Millard and Maat (1994).

\section{Tephrochronology}

Tephra layers (volcanic ashes and tuffs) are produced by explosive eruptions from volcanoes and can be spread over wide areas almost instantaneously. Correlation of new exposures to dated layers of tephra permits absolute age dating of the stratified sediments, as well as correlation between basins (Sarna-Wojcicki and others, 1984). The USGS Tephrochronology Project geochemical database has a reference collection of $>5,900$ samples of volcanic glass collected from upper Cenozoic (mostly Quaternary) deposits throughout the western conterminous United States and the eastern Pacific Ocean. Numerical and statistical programs (SIMANAL and RATIONAL) described in Sarna-Wojcicki (2000), Sarna-Wojcicki and Davis (1991), and SarnaWojcicki and others $(1984,1997)$ are used to identify the sample and to derive chemical correlations. The resulting best matches, at $>0.95$ similarity coefficient (normalized to 100 percent on a fluid-free basis), along with criteria such as stratigraphic position and sequence, mineralogy, and shard morphology, are considered for a complete and accurate identification. The age determinations for correlated ash layers were acquired from directly dated comagmatic mineral grains, and (or) previously dated or stratigraphically bracketed tephra layers.

The technique used to recover tephra samples from the FOQUS-LA wells depended on whether the deposit was a discrete tephra layer or was composed of disseminated volcanic-glass shards. If a distinct tephra layer was present, then the interior of the deposit was sampled to ensure that the volcanic ash sample contained little or no disturbed, reworked, or highly altered material. Sediment believed to contain disseminated glass shards was "trench sampled". A 6- mm wide, Teflon-coated spatula was used to excavate or trench sample several grams of sediment at $10-\mathrm{cm}$ intervals down the center of a split core.

In the Tephrochronology Laboratory, samples from distinct tephra layers were disaggregated, and wet-sieved through Nitex nylon screens. Each sample was treated with 10 percent hydrochloric acid to remove carbonates, and 8 percent hydrofluoric acid to eliminate hydrated or altered material. The glass shards were separated mechanically from the other sample components using a Frantz Magnetic Separator. Afterward, gravimetric separations using mixtures of acetone and the heavy liquid methylene iodide were done until a nearly 100 percent pure separate of isotropic volcanic-glass shards was obtained.

Smear slides (using 1.515 refractive index oil) were made at each step of the separation process. The smear slides from each stage were examined under plane-polarized light, a gypsum plate, and crossed nichols. The volcanic glass-shard morphology was described, and the percent abundances and condition of shard types, minerals, and other constituents were noted progressively. All notes for processed tephra samples were entered into the USGS Tephrochronology Project laboratory database. The raw samples, processed residues, and analyzed volcanic-glass samples are archived in the Project's reference-sample collection. 
In trench samples, the excavated sediment was homogenized, dried, and conserved in a labeled glass vial or small resealable plastic sample bag. A smear slide of each trench sample also was created. Morphologic descriptions and percent abundance estimates were made for volcanicglass shards (if present). Descriptions and estimated percent abundances also were logged for minerals and other sample constituents (such as lithic grains, altered grains, and microfossils). Trench samples and associated smear slides are housed in the USGS FOQUS-LA sample collection.

Electron Microprobe analyses (EMA) of volcanic-glass samples were done using the JEOL 8900 Electron Microprobe in the USGS Electron Microprobe Laboratory At Stanford University, Stanford, California. To chemically characterize silicic-glass samples, the concentration levels of six major elements (silica, aluminum, calcium, iron, potassium, and sodium) and three minor elements (titanium, manganese, and magnesium) were measured. Electron-microprobe sample mounts are stored in the USGS Tephrochronology Project reference-sample collection. Raw and recalculated geochemical data and tephrochronologic interpretations are archived in the USGS Tephrochronology Project computer databases. 


\section{Appendix II-Taxonomic Notes}

\section{Benthic Foraminiferal Taxonomic Notes}

Ammonia beccarii (Linne) - - Smith, 1964, p. B46

Ecology: Along the East Pacific Margin, A. beccarii has a UDL in the inner neritic biofacies (Ingle, 1980; 20 m off Central America, Smith, 1964).

Astacolus californicus Galloway and Wissler, 1927, p. 46, pl. 8, fig. 4.

Astacolus planulatus Galloway and Wissler, 1927, p. 46, pl. 8, fig. 5.

Astrononion incilis Lankford in Lankford and Phleger, 1973, v. 3, no. 3, p. 115, pl. 3, fig. 11.

Astrononion stellatum Cushman and Edwards, 1937, p. 32, pl. 3, figs. 9-11.

Ecology: Astrononion stellatum is a common species in the bank assemblage of the

offshore basins in the California borderland (Douglas and Heitman, 1979).

Bolivina argentea Cushman, 1926, p. 42, pl. 6, fig. 5.

Range: Pliocene to Holocene (Culver and Buzas, 1986; Martin, 1952; Finger, 1990).

Ecology: Bolivina argentea has a UDL in the upper middle bathyal biofacies (Ingle, 1980) and in the California borderland; the UDL approximates the upper limit of 100 percent southern water (Douglas, 1981).

Bolivina interjuncta Cushman = Bolivina costata d'Orbigny interjuncta Cushman, 1926, p. 41, pl. 6, fig. 3.

Ecology: The UDL of $B$. interjuncta is in the upper bathyal biofacies (Ingle, 1980; Ingle and Keller, 1980). High abundances of $B$. interjuncta have been noted in the upper bathyal oxygen minimum zone along the East Pacific Margin (Ingle and Keller, 1980).

Bolivina marginata Cushman, 1918, p. 48, pl. 10, fig. 1.

Ecology: Bolivina marginata has a UDL in the upper bathyal biofacies, 150-500 $\mathrm{m}$ (Ingle, 1980).

Bolivina minuta Natland, 1938, v. 4, no. 5, p. 146, pl. 5, fig. 10.

Bolivina obliqua Barbat and Johnson, 1934, p. 15, pl. 1, fig. 20.

Ecology: The UDL of B. obliqua along the East Pacific margin is upper bathyal (Ingle, 1980).

Bolivina pacifica Cushman and McCulloch = Bolivina acerosa Cushman pacifica Cushman and McCulloch, 1942, p. 185, pl. 21, figs. 2 and 3.

Ecology: Along the Eastern Pacific Margin, B. pacifica is found in the upper bathyal biofacies associated with the shallow oxygen minimum zone (Smith, 1964; Ingle, 1980; Ingle and Keller, 1980). In the Gulf of California and off Central America, the upper depth limit of B. pacifica is in the inner neritic biofacies where it occurs rarely (36 m, Walton, 1955; 18-37 m, Bandy, 1961; 37 m, Smith, 1964). Common abundances occur on the outer neritic and upper bathyal biofacies (Bandy, 1961; Phleger, 1964).

Bolivina sinuata Galloway and Wissler, 1927, p. 71, pl. 11, fig. 9a-b.

Range: late Miocene (Mohnian Stage) to Holocene (Finger, 1990).

Ecology: The UDL of B. sinuata is in the upper bathyal biofacies (Ingle, 1980).

Bolivina spissa Cushman = Bolivina subadvena Cushman spissa Cushman, 1926, p. 45, pl. 6, fig. 8.

Ecology: Ingle and Keller (1980) give the UDL of B. spissa as the upper bathyal biofacies where high abundances of this species associated with oxygen-rich, low salinity Antarctic Intermediate Water along the East Pacific Margin. High abundances of this species also are found in the low oxygen waters $(>0.5-1.7 \mathrm{ml} / \mathrm{l})$ of the basins in the California borderland 
(Douglas, 1981; Blake, 1991). Bolivina spissa is a dominant species in the lower slope assemblage of both the nearshore and offshore basins of the California continental borderland (Douglas and Heitman, 1979).

Bolivina subadvena Cushman, 1926, p. 44, pl. 6, fig. 6.

Bolivina subadvena serrata Natland, 1938, p. 145, pl. 5, figs. 8 and 9.

Bolivina tongi Cushman filacostata Cushman and McCulloch, 1942, p. 214-215, pl. 27, figs. 7-11.

Bolivina vaughani Natland, 1938, p. 146, pl. 5, fig. 11.

Ecology: The UDL of $B$. vaughani is in the less turbulent outer part of the inner neritic biofacies; its upper depth limit is, however, usually given as in outer neritic biofacies where it tends to be most common, particularly in the warmer tropical surface waters (Ingle, 1980; Ingle and Keller, 1980). This species is particularly abundant in the well-oxygenated waters (5-6 ml/1) of the shelf (Douglas, 1981; Blake, 1991).

Bolivina woodringi Kleinpell, 1938, p. 285, pl. 21, figs. 4 and 5.

Range: late Miocene to Pliocene, Mohnian to "Delmontian" stages (Finger, 1990).

Ecology: Bolivina woodringi has a UDL in the upper middle bathyal biofacies (Ingle, 1980).

Buccella frigida $($ Cushman $)=$ Pulvinulina frigida Cushman, 1920, p. 12 .

Ecology: The UDL of $B$. frigida is in the inner neritic biofacies (Ingle, 1980).

Bulimina denudata Cushman and Parker = Bulimina pagoda Cushman var. denudata Cushman and Parker, 1938, p. 57, pl. 10, figs. 1 and 2.

Ecology: The UDL of $B$. denudata is in the inner neritic biofacies (Ingle and Keller, 1980). $B$. denudata is a dominant species in the outer shelf assemblages of the nearshore basins in the California continental borderland (Douglas and Heitman, 1979).

Bulimina fossa Cushman and Parker, 1938, p. 56, pl. 9, fig. 10.

Bulimina marginata d'Orbigny - - Galloway and Wissler, 1927, p. 73, pl. 11, fig. 17.

Bulimina subaccuminata Cushman, Stewart, and Stewart, 1930, p. 65, pl. 5, figs. 2 and 3a-b.

Range: Pliocene to Holocene (Martin, 1952); Miocene, Saucesian Stage to Holocene (Finger, 1990).

Ecology: The UDL of B. subaccuminata is in the upper middle bathyal biofacies (Ingle, 1980).

Buliminella basispinata Stewart and Stewart = Buliminella curta Cushman basispinata Stewart and Stewart, 1930, p. 63, pl. 8, fig. 6.

Buliminella curta Cushman, 1925, p. 33, pl. 5, fig. 13.

Range: Oligocene, Zemorrian Stage to Holocene (Finger, 1990).

Ecology: The UDL of B. curta is in the outer neritic biofacies (Ingle, 1980). Blake (1991) considers this species an indicator of low oxygen conditions.

Buliminella elegantissima (d'Orbigny) - - Lankford and Phleger, 1973, p. 116, pl. 4, fig. 12.

Range: Oligocene, Zemorrian Stage to Holocene (Finger, 1990).

Ecology: Along the Eastern Pacific Margin, the UDL of $B$. elegantissima is in the inner neritic biofacies (20 m, Walton, 1955; Bandy, 1961; Phleger, 1964; Smith, 1964; Ingle, 1980).

Cancris auricula (Fitchel and Moll) - - Walton, 1955, p. 1004, pl. 102, figs. 25 and 26.

Cassidulina californica Cushman and Hughes, 1925, p. 12, pl. 2, fig. 1.

Ecology: The UDL of C. californica (Islandiella californica of some authors) is in the upper bathyal biofacies but may be transitional between outer neritic and upper bathyal biofacies (Ingle, 1980). 
Cassidulina delicata Cushman, 1927, p. 168, pl. 6, fig. 5.

Range: late Miocene to Holocene (Finger, 1990).

Ecology: Cassidulina delicata is a cosmopolitan species (Culver and Buzas, 1986), with an upper depth limit that is transitional between upper bathyal and upper middle bathyal biofacies along the Eastern Pacific Margin (Smith, 1964; Ingle, 1980). In the Gulf of California, the UDL of $C$. delicata is in the upper bathyal biofacies (152-244 m, Bandy, 1961). Cassidulina delicata suggests low oxygen conditions (Blake, 1991).

Cassidulina laevigata d'Orbigny carinata Silvestri - - White, 1956, p. 255, pl. 31, fig. 3a,b

Ecology: The UDL of $C$. laevigata carinata is in the upper middle bathyal biofacies (Ingle, 1980).

Cassidulina limbata Cushman and Hughes, 1925, p. 12, pl. 2, fig. 2.

Ecology: The UDL of $C$. limbata is transitional between the outer neritic and upper bathyal biofacies along the Eastern Pacific Margin (Ingle, 1980). In the Gulf of California, the UDL is also in the upper bathyal biofacies (152-244 $\mathrm{m}$ ) although rare specimens are found in the inner neritic biofacies (Walton, 1955; Bandy, 1961).

Cassidulina lomitensis Galloway and Wissler, 1927, p. 79, pl. 12, fig. 10.

Ecology: The UDL of $C$. lomitensis is transitional between the outer neritic and the upper bathyal biofacies (Ingle, 1980).

Cassidulina minuta Cushman, 1933, p. 92, pl. 10, fig. 3.

Ecology: The UDL of $C$. minuta is in the outer neritic biofacies along the Eastern Pacific

Margin (Smith, 1964; Ingle, 1980). In the Gulf of California, rare specimens of C. minuta have been found in the beach and inner neritic faunas (Bandy, 1961), and it dominates faunas in the outer neritic (37-73 m) and upper bathyal (152-244 m) biofacies (Bandy, 1961).

Cassidulina transluscens Cushman and Hughes, 1925, p. 15, pl. 2, fig. 5.

Ecology: The UDL of $C$. transluscens is transitional between the outer shelf and upper bathyal biofacies (Ingle, 1980).

Cassidulina tortuosa Cushman and Hughes, 1925, p. 14, pl. 2, fig. 4.

Ecology: The UDL of $C$. tortuosa is transitional between the outer neritic and upper bathyal biofacies (Ingle, 1980). Cassidulina tortuosa is a dominant species in the bank assemblage of the offshore basins of the California continental borderland (Douglas and Heitman, 1979).

Cassidulinoides bradyi (Norman) - - Natland, 1952, pl. 18, fig. 3a,b.

Chilostomella grandis Cushman - - Martin, 1952, p. 127, pl. 21, figs. 1a-c.

Chilostomella ovoidea Reuss - Kleinpell, 1938, p. 338, pl. 22, fig. 8; pl. 31, fig. 4.

Ecology: C. ovoidea occurs in the upper middle bathyal biofacies in anaerobic bottom conditions (Ingle, 1980).

Cibicides conoideus Galloway and Wissler, 1927, p. 63, pl. 10, fig. 7.

Cibicides fletcheri Galloway and Wissler, 1927, p. 64, pl. 10, figs. 8 and 9.

Ecology: C. fletcheri has a UDL in the inner neritic biofacies along the Eastern Pacific Margin (Lankford and Phleger, 1973; Ingle, 1980). In the Gulf of California, abnormal specimens of $C$. fletcheri are recorded from the lagoons whereas normal specimens are recorded in abundance from the inner neritic biofacies (Walton, 1955; Bandy, 1961).

Cibicides lobatulus (d'Orbigny) - - Bandy, 1953, p. 176, pl. 22, fig. 4.

Ecology: The UDL of $C$. lobatulus is in the inner neritic biofacies in the Gulf of California (18-37 m, Bandy, 1961) and along the East Pacific Margin (0-50 m, Ingle, 1980). 
Cibicides mckannai Galloway and Wissler, 1927, p. 65, pl. 10, figs. 5 and 6.

Range: Middle Miocene to Holocene (Finger, 1990).

Ecology: The UDL of C. mckannai is in the upper bathyal biofacies (Ingle, 1980).

Cibicides mckannai Galloway and Wissler suppressus Martin, 1952, p. 123, pl. 20, fig. 3a-c. Cyclogyra involvens (Reuss) - - Loeblich and Tappan, 1953, p. 49, pl. 7, figs. 4 and 5.

Dentalina baggi Galloway and Wissler, 1927, p. 49, pl. 8, figs. 14 and 15.

Dentalina decepta (Bagg) - - Galloway and Wissler, 1927, p. 49, pl. 8, figs. 12 and 13.

Dentalina soluta Reuss - - Natland, 1952, pl. 3, figs. 12-14 and 15a,b.

Dyocibicides perforata Cushman and Valentine, 1930, p. 31, pl. 10, fig. 3.

Ecology: Along the East Pacific Margin, D. perforatus has a UDL in the inner neritic biofacies (Lankford and Phleger, 1973).

Ehrenbergina compressa Cushman - - Uchio, 1960, pl. 9, figs. 28-31.

Elphidiella hannai (Cushman and Grant) - - Natland, 1952, pl. 7, fig. 6a,b.

Ecology: Along the East Pacific Margin, E. hannai is common from Point Conception,

California, north, with rare occurrences in the Santa Barbara Basin of southern California

(Culver and Buzas, 1986). E. hannai migrated south during cooler periods in the late

Neogene when the California Current moved south of its present position (Blake, 1991).

Elphidium clavatum Cushman = Elphidium incertum (Williamson) clavatum Cushman, 1930, p.

20.

Elphidium excavatum alba Feyling-Hanssen, 1972, p. 340-341, pl. 3, figs. 1-9.

Elphidium frigidum Cushman - - Loeblich and Tappan, 1953, p. 99, pl. 18, figs. 4-9.

Elphidium incertum (Williamson) - - Loeblich and Tappan, 1953, p. 100-102.

Elphidium orbiculare (Brady) - - Loeblich and Tappan, 1953, p. 102-103, pl. 19, figs. 1-4.

Elphidium spinatum Cushman and Valentine, 1930, p. 21, pl. 6, figs. 1 and 2.

Elphidium subarcticum Cushman, 1944, p. 27, pl. 3, figs. 34 and 35.

Elphidium transluscens Natland, 1938, p. 144, pl. 5, figs. 3 and 4.

Ecology: The UDL of E. transluscens is in the inner neritic biofacies (Ingle, 1980).

Epistominella exiqua Brady, 1884, p. 696, pl. 103, figs. 13 and 14.

Epistominella pacifica (Cushman) - - Martin, 1952, p. 136, pl. 24, fig. 8a-b.

Ecology: The UDL of E. pacifica is in the upper middle bathyal biofacies (Ingle, 1980). E. pacifica commonly is found associated with cool, high salinity, oxygen-rich water (Ingle and Keller, 1980).

Epistominella smithi (Stewart and Stewart) - - White, 1956, p. 257, pl. 32, fig. 1a-c.

Range: Miocene to Pliocene (Finger, 1990).

Ecology: The UDL of E. smithi is transitional between the upper bathyal and upper middle bathyal biofacies (Ingle, 1980). Epistominella smithi is a dominant species in the group II, lower slope assemblages of both the nearshore and offshore basins of the California continental borderland (Douglas and Heitman, 1979) and suggests low oxygen conditions (Blake, 1981).

Eponides sp. - - This designation includes specimens assigned to Eponides sp. 5, Eponides cf. E. rosaformis Cushman and Kleinpell of Natland (1952, pl. 15, figs. 1a-c), and Eponides sp. B of Natland (1952).

Fissurina exsculpta (Brady) = Lagena exsculpta Brady, 1881, p. 61.

Fissurina marginata $($ Montagu $)=$ Vermiculum marginatum Montagu, 1803, p. 524. 
Fissurina orbignyana Sequenza, 1862, p. 66, pl. 2, figs. 25 and 26.

Gaudryina arenaria Galloway and Wissler, 1927, p. 68, pl. 11, fig. 5.

Ecology: Along the Eastern Pacific Margin and in the Gulf of California, the UDL of $G$.

arenaria is in the outer neritic biofacies (Bandy, 1961; Ingle, 1980).

Gaudryina grammostomata Galloway and Wissler, 1927, p. 69, pl. 11, fig. 6.

Gavelinopsis campanulata (Galloway and Wissler) - - Lankford and Phleger, 1973, p. 120, pl. 5, fig. 13.

Globobulimina pacifica Cushman, 1927, v. 3, p. 67, pl. 14, fig. 12.

Ecology: Along the East Pacific Margin, G. pacifica has a UDL that is transitional between outer neritic and upper bathyal biofacies (Ingle, 1980). G. pacifica is a dominant species in the upper slope assemblages of the nearshore basins of the California continental borderland (Douglas and Heitman, 1979).

Glandulina laevigata (d'Orbigny) - - White, 1956, p. 246, pl. 27, figs. 4 and 5a,b.

Ecology: Glandulina laevigata ovata has a UDL in the upper middle bathyal biofacies (Ingle, 1980).

Globocassidulina globosa (Hantken) = Cassidulina globosa Hantken - - Phleger and Parker, 1951, p. 27, pl. 14, figs. 11-13.

Ecology: Along the East Pacific Margin, the UDL of G. globosa is in the outer shelf biofacies, but is more frequently found in the upper bathyal biofacies (Ingle, 1980). Globocassidulina globosa is a dominant species in the bank assemblages of both the nearshore and offshore basins of the California continental borderland (Douglas and Heitman, 1979).

Globulina globosa (von Muster) = Polymorphina globosa von Munster in Roemer, 1938, p. 386, pl. 3, fig. 33 .

Guttulina austriaca d'Orbigny = Polymorphina (Guttulina) austriaca d'Orbigny - Galloway and Wissler, 1927, p. 57, pl. 9, fig. 9.

Guttulina laevigata (d'Orbigny = Polymorphina (Guttuline) laevigata d'Orbigny, 1826, p. 26.

Gyroidina altiformis Stewart and Stewart = Martin, 1952, p. 125, pl. 19, fig. 8a-b.

Range: Oligocene (Zemorrian) to Holocene (Finger, 1990).

Ecology: The UDL of G. altiformis is in the upper bathyal biofacies (Ingle, 1980), although Smith (1964) finds the UDL in the lower middle bathyal biofacies off Central America.

Gyroidina multilocula Coryell and Mossman = Gyroidina soldanii d'Orbigny multilocula Coryell and Mossman, 1942, p. 237, pl. 36, fig. 20.

Hanzawaia nitidula (Bandy) = Cibicidina basiloba (Cushman) var. nitidula Bandy, 1953, p. 178, pl. 22, fig. 3.

Ecology: The UDL of $H$. nitidula is in the outer neritic biofacies in the California borderland (Ingle, 1980), and in the deep inner neritic (18-37 m) and outer neritic (37-73 $\mathrm{m}$ ) biofacies in the Gulf of California (Bandy, 1961). It is most common in the tropical surface-water masses (Walton, 1955; Bandy, 1961; Phleger, 1964; Lankford and Phleger, 1973).

Hoeglundina elegans (d'Orbigny) - - Bandy, 1953, p. 177, pl. 23, fig. 9.

Ecology: Along the East Pacific margin, H. elegans is found primarily in the California borderland (Culver and Buzas, 1986), and it is a common species in the group II, lower slope assemblages of the offshore basins of the California continental borderland (Douglas and Heitman, 1979). The UDL of H. elegans is in the upper bathyal biofacies (Smith, 1964; Ingle, 1980). 
Karreriella milleri Natland, 1938, p. 140, pl. 3, figs. 11 and 12.

Lagena acuticosta Reuss - - Martin, 1952, p. 120, pl. 17, fig. 13a-b.

Lagena alcocki White, 1956, p. 246, pl. 27, fig. 7a-b.

Lagena costata $($ Williamson $)=$ Entosolenia costata Williamson, 1858, p. 9, pl. 1, fig. 18.

Lagena elongata (Ehrenberg) - - Martin, 1952, p. 121, pl. 18, fig. 2a-b.

Lagena flatulenta Loeblich and Tappan, 1953, p. 60, pl. 11, figs. 9 and 10.

Lagena hexagona (Williamson) - - Martin, 1952, p. 121, pl. 18, figs. 2a-b.

Lagena hispida Reuss, 1863, p. 335, pl. 6, figs. 77-79.

Lagena laevis $($ Montagu $)=$ Vermiculum laeve Montagu, 1803, p. 524.

Lagena scalariformis $($ Williamson $)=$ Entosolenia squamosa (Montagu) scalariformis Williamson, 1858, p. 13, pl. 1, fig. 30.

Lagena semistriata Williamson = Lagena striata $($ Monatgu $)$ var semistriata Williamson, 1848, p.

14, pl. 1, figs. 9-10.

Lagena striata (d'Orbigny) - - Martin, 1952, p. 121, pl. 18, fig. 6a-b.

Lagena sulcata $($ Walker and Jacob $)=$ Serpula sulcata Walker and Jacob, 1798, p. 634, pl. 14, fig. 5.

Lagena vulgaris Williamson - - Martin, 1952, p. 122, pl. 18, fig. 9a-b.

Lenticulina cushmani (Galloway and Wissler) = Robulus cushmani Galloway and Wissler, 1927, p. 51, pl. 8, fig. 11.

Ecology: Off Central America, the UDL of L. cushmani is in the outer neritic biofacies (approximately $50 \mathrm{~m}$, Smith, 1964). Blake (1976) considers this species a warm-water indicator that is restricted to areas south of the California borderland, except during warm interglacial periods when it migrates into the borderland.

Lenticulina peregrina (Schwager) - - Cushman, 1923, p. 113.

Lenticulina smileyi (Kleinpell) - - Finger, 1990, p. 158-159, figs. 1-8.

Loxostomum bradyi (Asano) = Bolivina bradyi Asano - Smith, 1963, p. A23, pl. 31, figs. 1 and 2 .

Loxostomum pseudobeyrichi $($ Cushman $)=$ Bolivina pseudobeyrichi Cushman, 1926, p. 45.

Ecology: Loxostomum pseudobeyrichi is a dominant species in the lower slope assemblage of the nearshore basins and the basin floor assemblage of the offshore basins of the California continental borderland (Douglas and Heitman, 1979).

Marginulina grandis (Galloway and Wissler) = Hemicristerllaria grandus Galloway and Wissler, 1927, p. 47, pl. 8, fig. 6.

Melonis barleeanus (Williamson) - - Finger, 1990, p. 166-167, plate-figs. 1-8.

Range: middle Miocene, Luisian Stage to Holocene (Finger, 1990).

Ecology: The UDL of M. barleeanus is transitional between the upper middle bathyal to lower middle bathyal biofacies (Ingle, 1980).

Milionella californica Rhumbler - - Lankford and Phleger, 1973, p. 123, pl. 2, fig. 8.

Ecology: M. californica tends to prefer rocky to coarse sand bottoms and depths of $0-30 \mathrm{~m}$ (Lankford and Phleger, 1973).

Nonionella basispinata Cushman and Moyer - - Bandy, 1953, p. 177, pl. 21, fig. 9 and 13.

Ecology: The UDL of N. basispinata is in the inner neritic biofacies (Ingle, 1980; Ingle and Keller, 1980) and it is a dominant species in the outer shelf assemblages of the nearshore basins of the California continental borderland (Douglas and Heitman, 1979).

Nonionella labradorica $($ Dawson $)=$ Nonionina labradorica Dawson, 1870, p. 191, fig. 4 . 
Nonionella miocenica Cushman, 1926, p. 64.

Range: Oligocene to Holocene (Finger, 1990).

Ecology: The UDL of $N$. miocenica is in the inner neritic biofacies (Ingle, 1980).

Nonionella stella Cushman and Moyer = Nonionella miocenica Cushman stella Cushman and Moyer, 1930, p. 56, pl. 7, fig. 17.

Ecology: The UDL of N. stella is in the inner neritic biofacies along the East Pacific Margin and Gulf of California (Walton, 1955; Bandy, 1961; Lankford and Phleger, 1973; Ingle, 1980; Ingle and Keller, 1980). In nearshore basins of the California continental borderland, $N$. stella is a dominant species in the outer shelf assemblages (Douglas and Heitman, 1979). Ingle and Keller (1980) associate this species with the shallow oxygenminimum zone.

Oolina globosa $($ Montagu $)=$ Vermiculum globosum Montagu, 1803, p. 523 .

Oolina striatopunctata (Parker and Jones) - - Loeblich and Tappan, 1953, p. 74-75, pl. 12, figs. $2-5$.

Oridorsalis subtenera (Galloway and Wissler) = Rotalia subtenera Galloway and Wissler, 1927, $\mathrm{p}$. 60 , pl. 10, fig. 4.

Oridorsalis umbonatus (Reuss) = Eponides umbonatus (Reuss) - - Phleger and Parker, 1951, p. 22, pl. 11, figs. 10a,b, 13a,b, and 14a,b.

Ecology: Ingle (1980) gives the UDL of $O$. umbonatus as upper bathyal in the Paleogene and as upper middle bathyal in the Neogene along the East Pacific Margin.

Planulina exorna Phleger and Parker, 1951, p. 32, pl. 18, figs. 5-7.

Planulina ornata (d'Orbigny) - - Natland, 1952, pl. 20, figs. 2a,b, and 3.

Ecology: Along the East Pacific Margin, $P$. ornata has a UDL in the outer neritic biofacies (50 m, Bandy, 1961; Smith, 1964; Ingle, 1980).

Polymorphina biserialis Galloway and Wissler, 1927, p. 53, pl. 9, fig. 4.

Polymorphina doanei Galloway and Wissler, 1927, p. 54, pl. 9, fig. 8.

Praeglobobulimina affinis (d'Orbigny) = Bulimina affinis d'Orbigny - - White, 1956, p. 253, pl. 30, fig. $4 a, b$.

Praeglobobulimina ovata (d'Orbigny) = Bulimina ovata d'Orbigny, 1846, p. 185, pl. 11, figs. 13-14.

Ecology: Praeglobobulimina ovata has a UDL in the upper bathyal biofacies (Ingle, 1980).

Poroeponides cribrorepandus Asano and Uchio - - Lankford and Phleger, 1973, p. 125, pl. 4, fig. 25.

Pullenia bulloides (d'Orbigny) = Nonionina bulloides d'Orbigny, 1846, p. 107, pl. 5, figs. 9 and 10.

Pullenia salisburyi Stewart and Stewart, 1930, p. 72, pl. 8, fig. 2.

Ecology: Along the East Pacific Margin, P. salisburyi has a UDL transitional between the outer neritic biofacies (Ingle, 1980) and the upper bathyal biofacies (Smith, 1964). In the California borderland, this species frequently is found in the bank assemblages of the nearshore basins (Culver and Buzas, 1986; Douglas and Heitman, 1979).

Pyrgo murrhina $($ Schwager $)=$ Biloculina murrhina Schwager, 1866, p. 203, pl. 4, fig. 15.

Pyrgo rotalaria Loeblich and Tappan 1953, p. 47, pl. 6, figs. 5 and 6.

Quinqueloculina akneriana d'Orbigny - - Natland, 1952, pl. 3, fig. 3a-c.

Quinqueloculina granulosa Natland, 1938, p. 141, pl. 4, fig. 1. 
Quinqueloculina lamarkiana d'Orbigny - - Lankford and Phleger, 1973, p. 126, pl. 1, fig. 23. Ecology: In the Gulf of California, Q. lamarkiana is found rarely in lagoons and is a dominate species in the inner neritic biofacies (0-37 m, Bandy, 1961; Phleger, 1964). Along the East Pacific Margin, Q. lamarkiana has a UDL in the inner neritic biofacies (Lankford and Phleger, 1973).

Rectobolivina hancocki (Cushman and McCulloch) - - Smith, 1964, p. 39, pl. 3, fig. 3.

Robertinoides charlottensis $($ Cushman $)=$ Cassidulina charlottensis Cushman, 1925, p. 41, pl. 6, figs. 6 and 7.

Quinqueloculina sp. of Walton, 1955, p. 1012, pl. 100, figs. 19 and 20.

Rosalina columbiensis (Cushman) - - Lankford and Phleger, 1973, p. 127, pl. 5, figs. 10-12.

Ecology: Rosalina columbiensis dominants the inner neritic biofacies (Ingle and Keller,

1980) and the bank assemblages of the offshore basins of the California continental

borderland (Douglas and Heitman, 1979). Off Central America, the UDL of $R$.

columbiensis is near the inner neritic/outer neritic biofacies boundary (50 m, Smith, 1964;

Lankford and Phleger, 1973).

Rosalina hitchcockae Galloway and Wissler, 1927, p. 62, pl. 10, fig. 2.

Rosalina lomaensis Bandy, 1953, p. 179, pl. 22, fig. 3.

Rosalina versiformis Bandy, 1953, p. 179, pl. 22, fig. 5

Rotalia garveyensis Natland, 1938, p. 147, pl. 6, fig. 6.

Range: late Miocene, upper Delmontian Stage (Kleinpell, 1938) to the base of the

Pleistocene, Repettian Stage (Natland, 1952).

Sigmoilina elliptica Galloway and Wissler, 1927, p. 39, pl. 7, fig. 2.

Sigmoilina tenuis (Czjeck) - - Phleger and Parker, 1951, p. 8, pl. 4, fig. 7.

Ecology: The UDL of $S$. tenuis is in the upper middle bathyal biofacies (Ingle, 1980).

Sigmomorphina frondiculariformis (Galloway and Wissler) = Polymorphina frondiculariformis Galloway and Wissler, 1927, p. 55, pl. 9, fig. 6.

Siphotextularia flintii (Cushman) - - Martin, 1952, p. 117, pl. 17, fig. 1a-c.

Range: Repettian Stage, Pliocene (Natland, 1952).

Spirillina vivipara Ehrenberg - - Galloway and Wissler, 1927, p. 37, pl. 7, fig. 1.

Spiroloculina dentata Cushman and Todd, 1944, p. 71, pl. 9, figs. 33 and 34.

Textularia conica d'Orbigny - - Bandy, 1961, p.17.

Ecology: Textularia conica has a UDL in the inner neritic biofacies (Bandy, 1961).

Trifarina angulosa (Williamson) - - Lankford and Phleger, 1973, p. 129, pl. 3, figs. 29 and 30.

Trifarina carinata Cushman, 1927, p. 159, pl. 4, fig. 3.

Ecology: The UDL of Trifarina carinata is transitional between the outer neritic and upper bathyal biofacies (Ingle, 1980).

Trifarina semitrigona (Galloway and Wissler) = Uvigerina semitrigona Galloway and Wissler, 1927, p. 77, pl. 11, fig. 21.

Triloculina inornata d'Orbigny - - Lankford and Phleger, 1973, p. 130, pl. 3, fig. 19.

Triloculina trihedra Loeblich and Tappan, 1953, p. 45, pl. 4, fig. 10.

Uvigerina juncea Cushman and Todd, 1941, p. 78, pl. 20, figs. 4-11.

Ecology: The UDL of $U$. juncea is transitional between the outer neritic and upper bathyal biofacies (Ingle, 1980). U. juncea is a dominant species in the upper shelf assemblages of the nearshore basins of the California continental borderland (Douglas and Heitman, 1979). Abundant $U$. juncea occur at low oxygen values of 1.0-2.0 $\mathrm{ml} / 1$; the highest abundances 
occur when the oxygen content is about $1.0 \mathrm{ml} / 1$ (Douglas, 1981). This species tends to prefer organic carbon values of \pm 1 percent of the total sediment (Douglas, 1981).

Uvigerina peregrina Cushman, 1923, p. 166, pl. 42, figs. 7-10.

Ecology: The UDL of $U$. peregrina is in the upper bathyal biofacies (Ingle, 1980). Douglas and Heitman (1979) have noted this species in the lower slope assemblage of both the nearshore and offshore basins.

Uvigerina senticosa Cushman adiposa White, 1956, p. 259, pl. 32, fig. 9a-b.

Ecology: Variants of $U$. senticosa are found in the lower bathyal biofacies (Ingle, 1980).

Vaginulina robusta Galloway and Wissler, 1927, p. 48, pl. 8, fig. 9.

Valvulineria araucana (d'Orbigny) - - White, 1956, p. 247, pl. 28, fig. 3a-c.

Ecology: The UDL of $V$. araucana is in the upper middle bathyal biofacies (Ingle, 1980).

Valvulineria oblonga (d'Orbigny) = Valvulina oblonga d'Orbigny - - Smith, 1964, p. 44-45, pl. 5, fig. $4 a, b$.

\section{Planktic Foraminiferal Taxonomic Notes}

Globigerina bulloides d'Orbigny - - Kennett and Srinivasan, 1983, p. 36, pl. 6, figs. 4-6.

Globigerina clarkei Rögl and Bolli, 1973, p. 563, pl. 4, figs. 13-15.

Globigerina falconensis Blow, 1959, p. 177, pl. 9, fig. 40a-c.

Globigerina quinqueloba Natland - - Kennett and Srinivasan, 1983, p. 32, pl. 5, figs. 4-6.

Globigerina umbilicata Orr and Zaitzeff - - Kennett and Srinivasan, 1983, p. 38, pl. 6, figs. 7-9.

Globigerinella calida (Parker) - - Kennett and Srinivasan, 1983, p. 240, pl. 60, figs. 7-9.

Globigerinella obesa (Bolli) - - Kennett and Srinivasan, 1983, p. 234-236, pl. 59, figs. 2-5.

Globigerinita (Ga.) glutinata (Egger) - - Kennett and Srinivasan, 1983, p. 224, pl. 56, figs. 1, 3-5.

Globigerinita parkerae (Bermudez) - - Kennett and Srinivasan, 1983, p. 226, pl. 57, figs. 1-3.

Globigerinita uvula (Ehrenberg) - - Kennett and Srinivasan, 1983, p. 224, pl. 56, figs. 6-8.

Globigerinoides obliquus Bolli - - Kennett and Srinivasan, 1983, p. 56, pl. 11, fig. 7-9.

Globigerinoides ruber (d'Orbigny) - - Kennett and Srinivasan, 1983, p. 78, pl. 10, fig. 6; pl. 17,

figs. 1-3.

Globorotalia crassaformis (Galloway and Wissler) - - Kennett and Srinivasan, 1983, p. 146, pl. 34, figs. $6-8$.

Globorotalia hirsuta (d'Orbigny) - - Kennett and Srinivasan, 1983, p. 138, pl. 32, figs. 7-9.

Globorotalia inflata d'Orbigny - - Kennett and Srinivasan, 1983, p. 118, p1. 27, figs. 7-9. - -

Kennett and others, 2000, p. 57, pl. 2, figs. 10-15.

Globorotalia menardii (Parker, Jones, and Brady) - - Kennett and Srinivasan, 1983, p. 124, pl. 28, fig. 2; pl. 29, figs. 1-3.

Globorotalia puncticulata (Deshayes) - - Kennett and Srinivasan, 1983, p. 116, pl. 27, figs. 4-6 - Kennett and others, 2000, p. 57, pl. 2, figs. 8 and 9.

Globorotalia scitula (Brady) - - Kennett and Srinivasan, 1983, p. 134, pl. 31, figs. 1 and 3-5.

Globorotalia tosaensis Takayanagi and Saito - - Kennett and Srinivasan, 1983, p. 148, pl. 34, fig.

1; pl. 35, figs. 1-3.

Globorotalia truncatuloides (d'Orbigny) - - Kennett and Srinivasan, 1983, p. 148, pl. 34, fig. 2; pl. 35, figs. 4-6. 
Globorotalia anfracta Parker - - Kennett and Srinivasan, 1983, p. 164, pl. 39, fig. 2, 4; pl. 40, figs. 7-9.

Neogloboquadrina asanoi (Maiya, Saito, and Sato) - - Kennett and others, 2000, p. 55, pl. 1, figs. 19-22; pl. 2, figs. 1-3.

Neogloboquadrina kagaensis (Maiya, Saito, and Sato) - - Kennett and others, 2000, p. 55, pl. 1, figs. 15-18.

Neogloboquadrina dutertrei (d'Orbigny) - - Kennett and Srinivasan, 1983, p. 198, pl. 48, figs. 7-9. - - Kennett and others, 2000, p. 55, pl. 2, figs. 4 and 5.

Neogloboquadrina humerosa praehumerosa Natori - - Kennett and others, 2000, p. 56, pl. 1, figs. $1-3$.

Neogloboquadrina pachyderma (Ehrenberg) C of Kennett and others, 2000, p. 57, pl. 1, figs. 6-8.

Neogloboquadrina pachyderma (Ehrenberg) B of Kennett and others, 2000, p. 56-57, pl. 1, figs. 11-14.

Neogloboquadrina pachyderma (Ehrenberg) A of Kennett and others 2000, p. 56, pl. 1, figs. 4, 5, 9, and 10. = Neogloboquadrina inglei Kucera and Kennett, 2000, p. 80, pl. 1, figs. 1-13).

Neogloboquadrina pachyderma pachyderma (Ehrenberg) - - Kennett and others, 2000, p. 56, pl. 1, figs. $1-3$.

Orbulina suturalis Brönnimann - - Kennett and Srinivasan, 1983, p. 86, pl. 20, figs. 1-3.

Orbulina. universa d'Orbigny - - Kennett and Srinivasan, 1983, p. 86, pl. 18, fig. 2; pl. 20, figs. 4-6.

Pulleniatina obliquiloculata (Parker and Jones) - - Kennett and Srinivasan, 1983, p. 202, pl. 49, fig. 2; pl. 50, figs. 6-9.

Spharoideinellopsis seminulina (Schwager) - - Kennett and Srinivasan, 1983, p. 206, pl. 51, figs.1, and 6-8.

\section{Macrofossil Taxonomic Notes}

[Species are arranged in alphabetical order by genus]

Acila castrensis (Hinds)

Range: Late Miocene to Holocene (Arnold, 1909; Kern and Wicander, 1974; Moore, 1983;

Groves, 1991; Powell, 1998; Powell and others, 2007; Coan and others, 2000).

Ecology: Kamchatka and the northeastern Bering Sea, Alaska, to Las Cruces, Mexico, at depths of 5-400 $\mathrm{m}$ (Coan and others, 2000).

Adontorhina cyclia Berry

Range: late Pliocene to Holocene (Vedder in Kern and Wicarder, 1974; Coan and others, 2000).

Ecology: Eastern Pacific from the Navarin Basin, Bering Sea to Isla Guadalupe, Mexico, and in the western Pacific from Sakhalin Island to the southern Kurile Island, at depths of 12-3,000 $\mathrm{m}$ on sand and mud (Coan and others, 2000).

Acila castrensis (Hinds)

Range: Miocene to Holocene (Addicott, 1976; Moore, 1983; Groves, 1991; Coan and others, 2000).

Ecology: Kamchatka and the northeastern Bering Sea to Las Cruces, Mexico, at depths of 5-400 m (Coan and others, 2000). 
Acteocina culcitella (Gould)

Range: Middle Pleistocene to Holocene (Arnold, 1903; Clark, 1931; Jordan, 1936;

Marincovich, 1976; Mason, 1934; Rodda, 1957; Valentine and Lipps, 1963; Wagner, 1959; McLean, 1978).

Ecology: Kodiak Island, Alaska, to Laguna San Ignacio, Mexico, on sand and mudflats in bays, also on soft bottoms off shore (McLean, 1978).

Acteocina harpa (Dall)

Range: Middle Pleistocene to Holocene (Arnold, 1903; Oldroyd, 1925; Abbott, 1974).

Ecology: Forrester Island, Alaska, to San Diego, California, from the intertidal zone to 100 m (Abbott, 1974).

Adontorhina cyclia Berry

Range: Late Pliocene to Holocene (Vedder in Kern and Wicarder, 1974; Coan and others, 2000).

Ecology: Eastern Pacific from the Navarin Basin, Bering Sea to Isla Guadalupe, Mexico, and in the western Pacific from Sakhalin Island to the southern Kurile Island, at depths of $12-3,000 \mathrm{~m}$ in sand and mud (Coan and others, 2000).

Alia carinata (Hinds)

Range: Late Pliocene to Holocene (Hoots, 1930; Grant and Gale, 1931; Soper and Grant, 1932; Dibblee, 1966; Meade, 1967; Kern, 1973; McLean, 1978).

Ecology: Forrester Island, Alaska, to Baja California Sur, Mexico, near surf grass and algae at low water to sublittoral depths (McLean, 1978).

Alia tuberosa (Carpenter)

Range: Middle Miocene to Holocene (Clark, 1915; Grant and Gale, 1931; Addicott and

Vedder, 1963; Schoellhamer and others, 1981; McLean, 2007).

Ecology: Newport, Oregon, to Bahia San Lucas, Mexico in sand and gravel at low tide and in beach drift (Keen, 1937; McLean, 2007).

Alvinia oldroydae (Bartsch)

Range: Pleistocene to Holocene (herein; McLean, 1978).

Ecology: Monterey Bay, California, to Asuncion Island, Mexico (McLean, 1978).

Alvinia tumida Carpenter

Range: Pleistocene to Holocene (herein; McLean and Gosliner, 1996).

Ecology: Santa Maria Basin, California, to Panama, on soft bottoms between 20 and $90 \mathrm{~m}$

(McLean and Gosliner, 1996).

Amiantis callosa (Conrad)

Range: Miocene to Holocene (Grant and Gale, 1931; Coan and others, 2000).

Ecology: Santa Barbara, California, to Bahía Santa Maria, Mexico, at water depths from the littoral zone to $20 \mathrm{~m}$ (Coan and others, 2000).

Amphissa reticulata Dall

Range: Early Pleistocene to Holocene (Powell and Stevens, 2000; McLean and Gosliner, 1996).

Ecology: Kenai Peninsula, Alaska, to Isla San Benito, Mexico, on soft bottoms between 30 and $300 \mathrm{~m}$ (McLean and Gosliner, 1996).

Anomia peruviana (d'Orbigny)

Range: Miocene to Holocene (Moore, 1987; Powell, 1986).

Ecology: Monterey, California, but is generally not found north of San Pedro, California, to Paita, Peru, in water depths between the intertidal zone and $120 \mathrm{~m}$ (Olsson 1961; Coan and others, 2000). 
Antalis pretiosum Sowerby

Range: Late Pliocene to Holocene (Waterfall, 1929; Burch, 1944-46).

Ecology: Forrester Island, Alaska, to San Diego, California, in water depths between 18 and $183 \mathrm{~m}$ also recorded from 18.2 to $146.3 \mathrm{~m}$, with one aberrant lot from $560 \mathrm{~m}$ (Burch, 1944-46).

Antiplanes catalensis (Raymond)

Range: Pleistocene to Holocene (Powell, 1998; McLean and Gosliner, 1996)

Ecology: Queen Charlotte Sound, Canada, to San Diego, California, on soft bottoms between 90 and $270 \mathrm{~m}$ (McLean and Gosliner, 1996).

Argopecten ventricosus (Sowerby)

Range: Miocene to Holocene (Winterer and Durham, 1962; Olsson, 1961).

Ecology: Santa Barbara, California, to Bayovar, Peru (Olsson, 1961), from the intertidal zone to $55 \mathrm{~m}$, usually on mud and sand in bays and lagoons (Coan and others, 2000). This species is an extralimital warm-water species in the Los Angeles Basin Holocene (Powell and others, 2000).

Astyris gauspata (Gould)

Range: Miocene, probably late Miocene to Holocene (Howe, 1922; Grant and Gale, 1931; Powell and others, 2004; McLean and Gosliner, 1996).

Ecology: Bechevin Bay, Alaska, to Punta San Pablo, Mexico, on soft bottoms from 30 to $200 \mathrm{~m}$ (McLean and Gosliner, 1996).

Axinopsida serricata (Carpenter)

Range: Late Pliocene to Holocene (Kern and Wicander, 1974).

Ecology: Point Barrow, Alaska, to Punta San Pablo, Mexico, between the low intertidal zone and $275 \mathrm{~m}$ in mud (Coan and others, 2000).

Balcis micans (Carpenter)

Range: Pliocene to Holocene (Woodring and Bramlette, 1950; Bartsch, 1917).

Ecology: Kodiak Island, Alaska, to Punta Abreojos, Mexico, in water from 30 to $100 \mathrm{~m}$ deep (Bartsch, 1917; Dall, 1921; McLean and Gosliner, 1996).

Boreotrophon raymondi (Moody)

Range: Pliocene to Holocene (Moody, 1916; McLean and Gosliner, 1996).

Ecology: Queen Charlotte Sound, Canada, to San Clemente Island, California, in water from 80 to $440 \mathrm{~m}$ on soft bottoms to depths of greater than $300 \mathrm{~m}$ off southern California (McLean and Gosliner, 1996).

Caesia fossatus (Gould)

Range: Questionably Pliocene to Holocene (Woodring and Bramlette, 1950; McLean, 1978).

Ecology: Vancouver Island, Canada, to Bahía San Ignacio, Mexico, in bays and lagoons and on sandy bottoms offshore to depths of about $20 \mathrm{~m}$ (McLean, 1978).

Caesia perpinguis (Hinds)

Range: Middle Pleistocene to Holocene (Arnold, 1903; Emerson and Addicott, 1953;

Jordan, 1936; Kanakoff and Emerson, 1959; Mason, 1934; Rodda, 1957; Valentine, 1956, 1958; Weaver, 1949; Willett, 1937; Woodring and others, 1946; McLean and Gosliner, 1996).

Ecology: Point Reyes, California, to Cedros Island, Mexico, on soft bottoms to $60 \mathrm{~m}$ (McLean and Gosliner, 1996). 


\section{Caesia rhinetes Berry}

Range: Pleistocene to Holocene (herein; McLean and Gosliner, 1996).

Ecology: Humboldt County, California, to Bahia Blanca, Mexico, on soft bottoms from 10-91 m (McLean and Gosliner, 1996).

Cardiomya pectinata (Carpenter)

Range: Pliocene to Holocene (Hertlein and Grant, 1972; Coan and others, 2000).

Ecology: Prince William Sound, Alaska, to Isla la Plata, Ecuador, in water depths between 5 and 1,000 $\mathrm{m}$ (Coan and others, 2000).

Calicantharus fortis (Carpenter)

Range: Late Miocene to late Pleistocene (Groves, 1991).

Callianax baetica (Carpenter)

Range: Pliocene to Holocene (Woodring and Bramlette, 1950; McLean, 1978).

Ecology: Kodiak Island, Alaska, to Bahía San Lucas, Mexico, in lagoons exposed at low tide and offshore on sandy bottoms in shallow water (McLean, 1978).

Callianax biplicata (Sowerby)

Range: Late Miocene to Holocene (Addicott and Vedder, 1963; Addicott and others, 1978; McLean, 1978).

Ecology: Vancouver Island, Canada, to Bahía Magdelena, Mexico, in shallow water offshore along exposed sandy beaches (McLean, 1978).

Calliostoma canaliculatum (Lightfoot)

Range: Early Pleistocene to Holocene (Powell and Stevens, 2000; McLean, 1978).

Ecology: Sitka, Alaska, to Camalú, Mexico, on subtidal rocky bottoms (McLean, 1978).

Cerithidea californica (Haldeman)

Range: Middle Pleistocene to Holocene (Waterfall, 1929; McLean, 1978).

Ecology: Bolinas Bay, California, to Bahía San Ignacio, Mexico, on mud at high tidal levels in back bays and estuaries (McLean, 1978).

\section{Chione}

Comment: In the late Pleistocene of Los Angeles County, Chione is not found in deposits between MIS 5e or $\geq 116 \mathrm{ka}$ and the Holocene, or $\leq 12 \mathrm{ka}$ (Powell and others, 2000).

Ecology: The genus Chione does not occur north of Point Conception, California, in the modern northeastern Pacific Ocean (Coan and others, 2000).

Chione californiensis (Broderip)

Range: Late Pliocene to Holocene (Durham, 1950; Kanakoff and Emerson, 1959; Deméré, 1981; Coan and others, 2000).

Ecology: San Francisco Bay, California (usually not found north of Santa Barbara, California) to Acapulco, Mexico, from the intertidal zone to $50 \mathrm{~m}$, especially on sandy mud flats in bays (Coan and others, 2000).

Chione undatella (Sowerby)

Range: late Pliocene to Holocene (Durham, 1950; Coan and others, 2000).

Ecology: Goleta, California, to Paita, Peru, in water between the intertidal zone and $40 \mathrm{~m}$, on mud flats or sand in exposed areas (Coan and others, 2000).

Chlamys hastata (Sowerby)

Range: Late Miocene to Holocene (Nomland, 1917b: Addicott and Vedder, 1963; Coan and others, 2000).

Ecology: Kenai Peninsula, Alaska, to San Diego, California, in water between the intertidal zone and $160 \mathrm{~m}$ (Coan and others, 2000). 
Compsomyax subdiaphana (Carpenter)

Range: Late Miocene to Holocene (Howe, 1922; Addicott, 1969; Hertlein and Grant, 1972; Coan and others, 2000).

Ecology: Cook Inlet and Prince William Sound, Alaska, to Puertecitos, Mexico, on soft mud at 2 to $500 \mathrm{~m}$ (Coan and others, 2000).

Conus californicus Reeve

Range: Late Miocene to Holocene (Stanton, 1966; McLean, 1978).

Ecology: Farallon Islands, California, to Bahía Magdalena, Mexico, on rocky and sandy bottoms from low water to $30 \mathrm{~m}$ (McLean, 1978).

Crassadoma gigantea (Gray)

Range: Miocene to Holocene (Arnold, 1906; Nomland, 1917b; Adegoke, 1969; Vedder, 1973; Durham, 1974; McLean, 1978).

Ecology: Queen Charlotte Island, Canada, to Point Abreojos, Mexico (McLean, 1978),

common at low tide and in the sublittoral zone on pilings in bays and along the outer coast.

Crenella decussata (Montagu)

Range: Late Miocene to Holocene (Powell, 1986; Olsson, 1961).

Ecology: Circumboreal distribution; eastern Pacific it occurs from the Beaufort Sea,

Alaska, to northern Peru (Olsson, 1961), in water depths between the intertidal zone and $200 \mathrm{~m}$ (Coan and others, 2000).

Crepidula norrisiarum Williamson

Range: Late Pleistocene to Holocene (Kanakoff and Emerson, 1959; McLean, 1978).

Ecology: Cayucos, California, to southern Baja California Sur, Mexico on shells, particularly Norrisia norrisi (Sowerby) from the intertidal zone to $35 \mathrm{~m}$ (McLean, 1978).

Crepidula perforans (Valenciennes)

Range: Late Pleistocene to Holocene (Kennedy and Browne, 2007; McLean, 1978).

Ecology: Vancouver Island, Canada, to Baja California, Mexico (McLean, 1978).

Crepidula onyx Sowerby

Range: Miocene to Holocene (Martin, 1916; Bedrossian, 1974; McLean, 1978).

Ecology: Southern California, to Peru in bays and lagoons, common elsewhere at low tide to sublittoral depths on shells and rock (McLean, 1978).

Crepidula perforans (Valenciennes)

Range: Late Pleistocene to Holocene (Kanakoff and Emerson, 1959; McLean, 1978).

Ecology: Vancouver Island, Canada, to Baja California, Mexico (McLean, 1978).

Crepipatella dorsata (Broderip) [syn. Verticumbo charybdis Berry]

Range: Middle Pleistocene to Holocene (Woodring and others, 1946; McLean and Gosliner, 1996).

Ecology: Bering Sea to San Diego, California at water depths between 100 and 2,100 m, commonly attached to shells or other hard substrate (Dall, 1921; McLean and Gosliner, 1996).

Crucibulum spinosum (Sowerby)

Range: Early Pleistocene to Holocene (Powell and Stevens, 2000; McLean, 1978).

Ecology: San Pedro, California, to Chile, on shell rubble in shallow bays at low water (McLean, 1978). 
Cryptonatica affinis (Gmelin)

Range: Early Miocene to Holocene (Marincovich, 1977).

Ecology: Circumpolar; northeastern Pacific Ocean, it occurs from the Arctic Ocean to San

Diego, California, in water depths from 0 to $400 \mathrm{~m}$, (80-400 m off southern California)

(McLean and Gosliner, 1996).

Cylichna diegensis (Dall)

Range: Late Pleistocene to Holocene (Jordan, 1936; McLean and Gosliner, 1996).

Ecology: Santa Monica, California, to Baja California, Mexico (Abbott, 1974). No depth

records have been published, but the type was collected between 98 and 191 fathoms

(180-350 m; Gosliner in McLean and Gosliner, 1996).

Cryptomya californica (Conrad)

Range: Miocene to Holocene (Grant and Gale, 1931; Coan and others, 2000).

Ecology: Montague Island, Alaska, to Bayovar, Peru in water depths between the intertidal zone and $80 \mathrm{~m}$, usually in fine sand (Coan and others, 2000).

Cyathodonta pedroana Dall

Range: Pliocene to Holocene (Durham and Yerkes, 1964; Coan and others, 2000).

Ecology: Monterey Bay, California, to Bahía Magdalena, Mexico, in water from 9 to $114 \mathrm{~m}$ (Coan and others, 2000).

Dentalium neohexagonum Pilsbry and Sharp

Range: Pliocene to Holocene (Eldridge and Arnold, 1907; Moody, 1916; Soper and Grant, 1932; Woodring and Bramlette, 1950; Winterer and Durham, 1962; Kern, 1973; Kern and Wicander, 1974; McLean, 1978).

Ecology: Monterey Bay, California, to Baja California, Mexico, at depths of 9-180 m (McLean, 1978).

Dentalium vallicolens Raymond

Range: Pleistocene to Holocene (herein Shimeck, 1998).

Ecology: Straits of Juan de Fuca, Washington, to the Gulf of California, Mexico, in water depths from 20 to $290 \mathrm{~m}$ (Shimeck, 1998).

Donax californica (Carpenter)

Range: Pleistocene to Holocene (Grant and Gale, 1931; Coan and others, 2000).

Ecology: Morro Bay, California, to Puerto Pizarro, Peru, in the low intertidal and subtidal zone in sand or sandy mud of bays and protected outer coasts (Coan and others, 2000).

Donax gouldii Dall

Range: Pliocene to Holocene (Hertlein and Grant, 1972; Coan and others, 2000).

Ecology: Santa Cruz County, California (but sporadic north of Point Conception), to southern Baja California, Mexico, on exposed sandy beach at water depths from the intertidal zone to $5 \mathrm{~m}$ along the open coast (Coan and others, 2000).

Epitonium indianorum (Carpenter)

Range: Pliocene to Holocene (DuShane, 1979).

Ecology: Forrester Island, Alaska, to Bahia Todos Santos, Mexico, in water depths from the intertidal zone to $120 \mathrm{~m}$, but usually below $30 \mathrm{~m}$ in southern California on soft and rocky bottoms (McLean and Gosliner, 1996).

Epitonium sawinae (Dall)

Range: Pliocene to Holocene (DuShane, 1979).

Ecology: British Columbia, Canada, to Bahia Magdalena, Mexico, on soft bottoms (McLean and Gosliner, 1996) in water from 18 to $360 \mathrm{~m}$ deep (DuShane, 1979). 
Fusinus barbarensis (Trask)

Range: Pliocene to Holocene (Grant and Gale, 1931; McLean and Gosliner, 1996).

Ecology: Monterey Bay, California, to Gorda Bank, off Cabo San Lucas, Mexico, on soft bottoms from 50 to $350 \mathrm{~m}$ (McLean and Gosliner, 1996).

Gadila aberrans (Whiteaves)

Range: Middle Pleistocene to Holocene (Powell and Ponti, 2007; McLean and Gosliner, 1996).

Ecology: Prince William Sound, Alaska, to southern California, from a depth range of 25-274 m (Shimek, 1998).

Glycymeris septentrionalis (Middendorff)

Range: Middle Miocene to Holocene (Groves, 1991).

Ecology: Cook Inlet, Alaska, to Rocas Alijos, Mexico, in water depths from the intertidal zone to $400 \mathrm{~m}$ (Coan and others, 2000).

Granulina margaritula (Carpenter)

Range: Pleistocene to Holocene (herein McLean, 2007).

Ecology: Gravel of tide pools and on the undersurfaces of medium-sized rocks in the low intertidal (McLean, 2007).

Hiatella arctica (Linnaeus)

Range: Late Oligocene/early Miocene to Holocene (Coan and others, 2000).

Ecology: Eastern Pacific Ocean from Barrow, Alaska, to Chile, at water depths between the intertidal zone and 1,190 $\mathrm{m}$ (Coan and others, 2000).

Hima mendicus (Gould)

Range: Pliocene to Holocene (Woodring and Bramlette, 1950; McLean, 1978);

questionable Miocene occurrences (Cooper, 1888; Clark, 1915; Howe, 1922).

Ecology: Kodiak Island, Alaska, to Isla Asuncion, Mexico, in bays, along the open coast from the intertidal zone to $30 \mathrm{~m}$ (McLean, 1978)

Irusella lamellifera (Conrad)

Range: Late Pliocene to Holocene (Woodring and Bramlette, 1950; Coan and others, 2000). Ecology: Coos Bay, Oregon (Evans, 1967), or Shelter Cove, California, to Isla San Martin, Baja California Sur, Mexico, in water depths from the littoral zone to $100 \mathrm{~m}$, where it commonly nestles in rock crevices (Coan and others, 2000).

Juliacorbula luteola (Carpenter)

Range: Questionably Miocene; Pliocene to Holocene (Coan and others, 2000).

Ecology: Monterey Bay, California, to Cabo San Lucas, Mexico, in the low intertidal zone to $60 \mathrm{~m}$ (Coan and others, 2000).

Kellia laperousii (Deshayes)

Range: Late Pliocene to Holocene (Woodring and Bramlette, 1950; Hertlein and Grant, 1972; Coan and others, 2000).

Ecology: Eastern Pacific from Prince William Sound, Alaska, to Zorritos, Peru, in the littoral zone to $20 \mathrm{~m}$ (Coan and others, 2000).

Lacuna unifasciata Carpenter

Range: Pleistocene to Holocene (Grant and Gale, 1931; McLean, 1978).

Ecology: Monterey, California, to Bahia Magdalena, Mexico, on eel grass and algae at low tide and in the sublittoral under kelp (McLean, 1978). 
Laevicardium substriatum (Conrad)

Range: Pleistocene to Holocene (Grant and Gale, 1931; Coan and others, 2000), with a doubtful occurrence in the Pliocene (Coan and others, 2000).

Ecology: Mugo Lagoon, southern California, to southern Baja California, Mexico (McLean, 1978), in water depths from the intertidal zone to $40 \mathrm{~m}$ on sand bottoms or sloping banks at low tide in bays and offshore (Coan and others, 2000).

Leptopecten latiauratus (Conrad)

Range: Pliocene to Holocene (Minch and others, 1976; Coan and others, 2000).

Ecology: Point Reyes, California, to Cabo San Lucas, Mexico, in intertidal pools to $250 \mathrm{~m}$ (Coan and others, 2000).

Lirobittium lomaense (Bartsch)

Range: Pleistocene to Holocene (herein McLean and Gosliner, 1996).

Ecology: Santa Cruz Island to San Diego, California, on soft bottoms at 30-100 m (McLean and Gosliner, 1996).

Lirobittium paganicum (Dall)

Range: Pleistocene to Holocene (herein McLean and Gosliner, 1996).

Ecology: Point Piños to Dana Point, California, at water depths of 360-650 m (McLean in McLean and Gosliner, 1996).

Lirobittium rugatum (Carpenter)

Range: Middle Pleistocene to Holocene (Grant and Gale, 1931; McLean and Gosliner, 1996).

Ecology: Point Piños, California, to Isla San Benito, Mexico, on soft bottoms in water depths from 30 to $500 \mathrm{~m}$ (McLean and Gosliner, 1996).

Littorina planaxis Philippi

Range: Middle Pleistocene to Holocene (Powell and Ponti, 2007; McLean, 1978).

Ecology: Puget Sound, Washington, to Bahía Magdalena, Mexico, on rocky reefs in the splash zone (McLean, 1978).

Lucinoma annulatum (Reeve)

Range: Late Miocene to Holocene (Roth, 1979; Coan and others, 2000).

Ecology: Kodiak Island and Prince William Sound, Alaska, to Guaymas, Mexico. This species also occurs on Isla Monserrat and in the western Pacific from Hokkaido to Kyushu, Japan, from the intertidal zone to $665 \mathrm{~m}$ (Coan and others, 2000).

Lucinisca nuttalli (Conrad)

Range: Late Miocene to Holocene (Nomland, 1917b; Preston, 1931; Hall, 1960; Addicott and Vedder, 1963; Adegoke, 1969; Coan and others, 2000).

Ecology: Monterey Bay, California, to Playa Novillero, Mexico, in water from 10 to $75 \mathrm{~m}$, usually on sand or sandy mud, although permanent populations probably do not occur north of Point Conception, California (Coan and others, 2000).

Lyonsia californica Conrad

Range: Pliocene to Holocene (Coan and others, 2000).

Ecology: Prince William Sounds, Alaska, to Acapulco, Mexico, at water depths between the intertidal zone and $100 \mathrm{~m}$ (Coan and others, 2000).

Macoma nasuta (Conrad)

Range: Oligocene to Holocene (Loel and Corey, 1932; Coan and others, 2000).

Ecology: Eastern Pacific from Montague Island, Alaska, to Punta Rompiente, Mexico, in water depths from the littoral zone to $50 \mathrm{~m}$, commonly in exposed to sheltered situations on sand and (or) silt (Coan and others, 2000). 
Macoma yoldiformis Carpenter

Range: Possibly late Miocene/Pliocene to Holocene (Touring, 1959; Cummings and others, 1962; Powell and others, 2007; Coan and others, 2000).

Ecology: Sitka, Alaska, to Bahía San Bartolomé, Mexico, from the intertidal zone to $100 \mathrm{~m}$ in bays and protected foreshores on sand or mud (Coan and others, 2000).

Melampus olivaceus Carpenter

Range: Pliocene to Holocene (Dall, 1885; McLean, 1978).

Ecology: Mugu Lagoon, California, to Mazatlan, Mexico, in lagoons and back bays at the drift line of the highest tides under debris (McLean, 1978).

Micranellum crebricincium (Carpenter)

Range: Pliocene to Holocene (Arnold, 1903; Oldroyd, 1925; Grant and Gale, 1931;

Woodring and Bramlette, 1950; Valentine and Lipps, 1963; McLean and Gosliner, 1996). Ecology: Kachemak Bay, Alaska, to Punta Abreojos, Mexico, on many different kinds of substrates, including gravel near rocks and fine particles from 10 to $200 \mathrm{~m}$ (McLean and Gosliner, 1996).

Mitrella tuberosa (Carpenter)

Range: Middle Miocene to Holocene (Schoellhamer and others, 1981; McLean, 1978).

Ecology: Forrester Island, Alaska, to Baja California Sur, Mexico, chiefly sublittoral and not uncommon in gravel under kelp (McLean, 1978).

Mysella pedroana Dall

Range: Pleistocene to Holocene (herein Coan and others, 2000).

Ecology: San Francisco, California, to Rosarito Beach, Mexico, from the intertidal zone to $30 \mathrm{~m}$ (Coan and others, 2000).

Nassarius is used here for indeterminate taxa previously assigned to this genus. Many of the California species are now referred to the genera (formerly subgenera) Hima or Caesia (of Addicott, 1965) following McLean (2007). Species names used in this study include Nassarius fossatus (Gould), Nassarius mendicus (Gould), Nassarius perpinguis (Hinds), and Nassarius rhinetes Berry.

Nassarius tegula (Reeve)

Range: Middle Pleistocene? to Holocene (Waterfall, 1929; McLean, 1978).

Ecology: Santa Barbara, California, to San Ignacio Lagoon, Mexico, on sandy mudflats in bays and lagoons at low tide (McLean, 1978).

Neverita reclusiana (Deshayes)

Range: Late Eocene to Holocene (Marincovich, 1977).

Ecology: Crescent City, California, to Isla las Tres Marias, Mexico, at water depths

between the littoral zone and $50 \mathrm{~m}$ (Marincovich, 1977).

Nodiscala spongiosa (Carpenter)

Range: Pliocene to Holocene (DuShane, 1979).

Ecology: Monterey, California, to the Gulf of California, Mexico, and in the Galapagos

Islands, in water depths between 18 and $72 \mathrm{~m}$, on rocks and gravel (DuShane, 1979).

Nucula exigua Sowerby

Range: Late Miocene/early Pliocene to Holocene (Arnold, 1908; Addicott, 1969; Kern, 1973; Moore, 1983; Powell, 1998)

Ecology: Eastern Pacific from the northeastern Bering Sea, Alaska, to Punta San Pablo, Mexico, at water depths from 5 to $400 \mathrm{~m}$ (Coan and others, 2000). 
Nuculana taphria (Dall)

Range: Oligocene to Holocene (Moore, 1983; Winterer and Durham, 1962; Coan and others, 2000).

Ecology: Fort Bragg, California, to Cedros Island, Mexico, in water depths between 10 and $100 \mathrm{~m}$ (Coan and others, 2000).

Nutricola cymata (Dall) [syn. Nutricola stephenae Hertlein and Grant]

Range: Questionably late Miocene/Pliocene to Holocene (Woodring and others, 1946;

Powell, 1998; Coan and others, 2000).

Ecology: Santa Rosa Island, California, to Isla Guadalupe and Rocas Alijos, Mexico, in water depths from 16 to $90 \mathrm{~m}$ (Coan and others, 2000).

Nutricola lordi (Baird)

Range: Late Miocene/early Pliocene to Holocene (Nomland, 1917a; Coan and others, 2000).

Ecology: Southeast Bering Sea and Cook Inlet, Alaska, to Punta Regueña, Mexico, from the littoral zone to $22 \mathrm{~m}$ (Coan and others, 2000).

Nutricola ovalis (Dall)

Range: Middle Pliocene to Holocene (Hertlein and Grant, 1972; Coan and others, 2000).

Ecology: Fort Bragg, California, to Punta Rompiente, Mexico, in 20-150 m (Coan and others, 2000).

Nutricola tantilla (Gould) [syn. N. tantilla var. californica Arnold]

Range: Late Miocene/early Pliocene to Holocene (Woodring and others, 1946; Powell, 1998; Coan and others, 2000).

Ecology: Prince William Sound, Alaska, to Isla Cedros, Mexico, in the littoral zone to 120 $\mathrm{m}$ (Coan and others, 2000).

Ocenebrina foveolata (Hinds)

Range: Early Pliocene to Holocene (Kern, 1973; McLean, 1978).

Ecology: Monterey Bay, California, to Bahía Magdelena, Mexico (McLean, 1978).

Ostrea conchaphila Carpenter

Range: Pliocene to Holocene (Howard, 1935; Adegoke, 1969; Minch and others, 1976;

Moore, 1987; Coan and others, 2000).

Ecology: Sitka, Alaska, to Panama in the intertidal zone to $10 \mathrm{~m}$ (Coan and others, 2000).

Pandora bilirata Conrad

Range: Pliocene to Holocene (Coan and others, 2000).

Ecology: Eastern Pacific from Kukak Bay and Prince William Sound, Alaska, to the Gulf of California, and in the western Pacific from the Kurile Islands to Honshu, Japan, in the subtidal zone to $250 \mathrm{~m}$ (Coan and others, 2000).

Panope abrupta (Conrad)

Range: Questionably Oligocene (Arnold, 1906); late Miocene to Holocene (Nomland, 1917b; Coan and others, 2000) .

Ecology: Circum-Pacific from Kodiak Island, Alaska, to Newport Bay, California, in water depths from the low intertidal zone to $100 \mathrm{~m}$ (Coan and others, 2000).

Parvilucina approximata (Dall)

Range: Pliocene to Holocene (Durham, 1950; Coan and others, 2000).

Ecology: Santa Barbara, California, to Panama in waters between the intertidal zone and greater than 1,000 m (Coan and others, 2000). 
Parvilucina tenuisculpta (Carpenter)

Range: Miocene to Holocene (Clark, 1915; Weaver, 1949; Hall, 1958; Coan and others, 2000).

Ecology: Kodiak Island, Alaska, to Isla Cedros, Mexico, in water depths from the intertidal zone to $300 \mathrm{~m}$ (Coan and others, 2000).

\section{Patinopecten}

Comments: The genus is common in the Tertiary of California, but all species became extinct by the end of the Pliocene except for P. caurinus (Gould). Middle and late Pleistocene occurrences of $P$. caurinus (Gould) in the southern California Bight are thought to represent cooler water conditions than those that exist in southern California today. Ecology: Eastern Pacific from Amlia Island and Unalaska Island, Alaska, to Point Sur, California, in water depths from 10 to $200 \mathrm{~m}$ (Coan and others, 2000).

Petricola carditoides (Conrad)

Range: Late Miocene/early Pliocene to Holocene (Nomland, 1917a; Coan and others, 2000).

Ecology: Sitka, Alaska, to Punta Pequeña, Mexico, in water depths from the littoral zone to $46 \mathrm{~m}$, commonly nesting in empty pholad holes and other cavities (Coan and others, 2000).

Protothaca staminea (Conrad)

Range: Miocene to Holocene (Coan and others, 2000).

Ecology: Attu Island, Alaska, to Bahia Santa Maria, Mexico, in water from the intertidal zone to $10 \mathrm{~m}$ (Coan and others, 2000).

Protothaca tenerrima (Carpenter)

Range: Late Miocene to Holocene (Ashley, 1895 [1896]; Arnold, 1908; Martin, 1916;

Allen, 1945; Cummings and others, 1962; Perry, 1993; Powell, 1998; Coan and others, 2000).

Ecology: Baranof Island, Alaska, to Bahía Thurloe, Mexico, in the littoral zone to $30 \mathrm{~m}$ (Coan and others, 2000).

Rictaxis punctocaelatus (Carpenter)

Range: Pliocene to Holocene (Woodring and Bramlette, 1950; Powell, 1998; McLean and Gosliner, 1996).

Ecology: Ketchikan, Alaska, to Bahía Magdalena, Mexico, at water depths from the littoral zone to $100 \mathrm{~m}$ (Behrens, 1991; McLean and Gosliner, 1996).

Rochefortia grippi Dall

Range: Pleistocene to Holocene (herein Coan and others, 2000).

Ecology: Esperanza Inlet, Vancouver Island, Canada, to San Diego, California, in water depths between 10 and $120 \mathrm{~m}$ (Coan and others, 2000).

Rochefortia tumida (Carpenter)

Range: Late Pleistocene to Holocene (Grant and Gale, 1931).

Ecology: Beaufort Sea, Alaska, to San Diego, California and Gulf of California at Puerto

Peñasco, Mexico, in water depths from the littoral zone to $973 \mathrm{~m}$ (Coan and others, 2000).

Scabrotrophon cerritensis (Arnold)

Range: Middle Pleistocene to Holocene (Arnold, 1903; McLean and Gosliner, 1996).

Ecology: Santa Rosa Island to San Diego, California, at water depths between 110 and 270 m on rocky bottoms (McLean and Gosliner, 1996). 
Semibittium cf. S. attenuatum Carpenter

Range: middle Pleistocene to Holocene (Woodring and others, 1946; McLean, 1978).

Ecology: Ketchikan, Alaska, to Isla San Geronimo, Mexico, common at low water and in sublittoral zones near rocks (McLean, 1978).

Siliqua lucida (Conrad)

Range: Late Miocene to Holocene (Moore, 2002; Coan and others, 2000).

Ecology: Bodega Harbor, California, to Boca de Soledad, Mexico, in water depths from the low intertidal zone to $50 \mathrm{~m}$ in mud and sand on exposed foreshores (Coan and others, 2000).

Simomactra falcata (Gould)

Range: Middle Miocene to Holocene (Trask, 1922; Weaver, 1949; Hall, 1960; Coan and others, 2000).

Ecology: Queen Charlotte Island, Canada, to Isla San Martin, Mexico, on sandy substrate from the low intertidal zone to about $50 \mathrm{~m}$ (Coan and others, 2000).

Siphonodentalium quadrifissatum (Pilsbry and Sharp)

Range: Late Pleistocene to Holocene (Kanakoff and Emerson, 1959; Keen, 1971).

Ecology: Monterey Bay, California, to Baja California, Mexico, from 4 to $365 \mathrm{~m}$ (Keen, 1971).

Solen rostriformis Dunker

Range: Pliocene to Holocene (Eldridge and Arnold, 1907; Fahy, 1974; Hertlein and Grant, 1972; Coan and others, 2000).

Ecology: Santa Barbara, California, to Mazatlán, Mexico, in the low intertidal zone to 50 $\mathrm{m}$, generally in mud (Coan and others, 2000).

Solen sicarius Gould

Range: Oligocene to Holocene (Arnold, 1906; Coan and others, 2000).

Ecology: Queen Charlotte Islands, Canada, to Bahía San Quintin, Mexico, on sand and mud in sheltered bays from the mid- to lower littoral zone (Coan and others, 2000).

Tellina bodegensis (Hinds)

Range: Late Miocene/early Pliocene to Holocene (Nomland, 1917a; Adegoke, 1969; Coan and others, 2000).

Ecology: Sitka, Alaska, to Bahía Magdalena, Mexico, in water depths from the littoral zone to $100 \mathrm{~m}$ (Coan and others, 2000).

Tellina cadieni Valentich Scott and Coan

Range: Pleistocene to Holocene (herein Coan and others, 2000).

Ecology: Morro Bay to San Diego, California in water depths from the littoral zone to 305

m (Coan and others, 2000).

Tellina carpenteri Dall

Range: Pliocene to Holocene (Hertlein and Grant, 1972).

Ecology: Sitka, Alaska, to Panama, in the intertidal zone to $823 \mathrm{~m}$ (Coan and others, 2000).

Tellina idae Dall

Range: Questionably Miocene; late Pliocene to Holocene (Durham and Addicott, 1965;

Coan and others, 2000).

Ecology: Santa Barbara to San Diego, California, from the littoral zone to $100 \mathrm{~m}$ on sand (Coan and others, 2000). 
Terebra danai Berry

Range: Pleistocene, upper Bent Spring Amino Acid Zone (MIS 9, 300 ka) to Holocene (Ponti, 1989; McLean, 1978).

Ecology: San Pedro, California, to Baja California Sur, Mexico, offshore on sandy bottoms (McLean, 1978).

Thyasira flexuosa (Montagu)

Range: Pleistocene to Holocene (herein Coan and others, 2000).

Ecology: Beaufort Sea, Alaska, to Point Loma, California, in the eastern Pacific Ocean in 20-3,000 $\mathrm{m}$ on fine mud (Coan and others, 2000).

Tivela stultorum (Mawe)

Range: Late Pliocene (Hertlein and Grant, 1972)

Ecology: Stinson Beach, California, to Bahia Magdalena, Mexico, in the intertidal zone to $30 \mathrm{~m}$ on sandy beaches exposed to strong surf (Coan and others, 2000).

Tresus nuttallii (Conrad)

Range: Miocene (Arnold, 1906; Clark, 1915; Nomland, 1917b; Addicott and others, 1978; Coan and others, 2000).

Ecology: Kodiak Island, Alaska, to Bahía Magdalena, Mexico, in the middle intertidal zone to $80 \mathrm{~m}$, in mud of protected bays and foreshores (Coan and others, 2000).

Tricola pulloides (Carpenter)

Range: Late Pleistocene to Holocene (Jordan, 1936; Wooding and others, 1946; Burch, 1944-46).

Ecology: Puget Sound, Washington, to Bahía San Lucas, Mexico, on the open coast at low tide and in the shallow sublittoral, in eelgrass or gravel (McLean, 1978), in water depths between 0 and $46 \mathrm{~m}$ (0-25 fathoms) (Burch, 1944-46).

Tricola rubrilineata (Strong)

Range: probable middle Pleistocene to Holocene (Strong, 1928; Woodring and others, 1946; McLean, 1978).

Ecology: Los Angeles County, California, to Isla San Marin, Mexico, in gravel near eelgrass roots and in the sublittoral under kelp (McLean, 1978)

Truncatella californica Pfeiffer

Range: Pleistocene to Holocene (herein McLean, 1978).

Ecology: Santa Barbara, California, and Bahia Magdalena, Mexico, in large numbers under rocky rubble above the high tide line on the open coast (McLean, 1978).

Turritella cooperi Carpenter

Range: Late Miocene to Holocene (Merriam, 1941; Durham, 1974; McLean, 1978).

Ecology: Monterey Bay, California, and Cedros Island, Mexico, offshore on sand or mud bottoms (McLean, 1978).

Volvulella cylindrica (Carpenter)

Range: Late Pleistocene to Holocene (Arnold, 1903; Oldroyd, 1914; Grant and Gale, 1931; McLean and Gosliner, 1996).

Ecology: Santa Cruz, California, to Bahia Todos Santos, Mexico, in water depths between 90 and 345 m (Abbott, 1974; McLean and Gosliner, 1996).

Volvulella panamica Dall

Range: Plesitocene to Holocene (herein McLean and Gosliner, 1996).

Ecology: Santa Maria Basin, California, to Panama, at water depths between 90 and $197 \mathrm{~m}$ (Abbott, 1974; McLean and Gosliner, 1996). 


\section{Appendix III-Paleomagnetic Tables}

Table 4. Paleomagnetic results from Long Beach Pier F core site and monitoring well (LBPF), Long Beach, California.

[Inclination of remanent magnetization after alternating-field treatment of samples from LBPF. RML Id, Rock Magnetism Laboratory identification number; Decl (relativity), declination relative to the split face of the core; $\mathrm{N}$, normal; R, reversed; I, indeterminate polarity of magnetization; Oe , oersteds; mT, millitesla; AF Demag, range of demagnetization steps in Oe used in calculation of inclination (100 Oe=10 mT); MAD, maximum angular deviation (in degrees) from principal-component analysis (Kirschvink, 1980)]

\begin{tabular}{|c|c|c|c|c|c|c|c|c|}
\hline $\begin{array}{c}\text { Core } \\
\text { number }\end{array}$ & $\begin{array}{l}\text { Depth, in } \\
\text { meters }\end{array}$ & $\begin{array}{l}\text { Depth, in } \\
\text { feet }\end{array}$ & $\begin{array}{l}\text { RML } \\
\text { Id }\end{array}$ & Polarity & $\begin{array}{l}\text { Inclination, in } \\
\text { degrees }\end{array}$ & $\begin{array}{c}\text { Decl } \\
\text { (relativity) }\end{array}$ & $\begin{array}{l}\text { AF Demag } \\
(0 \mathrm{e})\end{array}$ & MAD \\
\hline $13 / 1$ & 35.46 & 116.34 & $1 \mathrm{H} 090$ & $\mathrm{~N}$ & 33.30 & 2.10 & $100-300$ & 18.70 \\
\hline $16 / 1$ & 40.12 & 131.63 & 6J663 & $\mathrm{R}$ & (35.70) & 85.10 & $350-450$ & 20.90 \\
\hline $16 / 1$ & 40.36 & 132.41 & 1H092 & 1 & $(4.60)$ & 185.60 & $150-400$ & 5.70 \\
\hline $16 / 1$ & 40.47 & 132.78 & 6J662 & $\mathrm{N}$ & 58.90 & 140.66 & $100-300$ & 7.60 \\
\hline $17 / 1$ & 41.36 & 135.70 & $1 \mathrm{H} 091$ & $\mathrm{~N}$ & 44.90 & 152.40 & $150-300$ & 11.80 \\
\hline $18 / 1$ & 43.63 & 143.14 & $1 \mathrm{H} 093$ & $\mathrm{~N}$ & 45.00 & 33.90 & $100-200$ & 25.40 \\
\hline $19 / 1$ & 44.72 & 146.72 & $1 \mathrm{H} 094$ & $\mathrm{~N}$ & 38.40 & 269.30 & $150-300$ & 6.60 \\
\hline $20 / 1$ & 46.41 & 152.26 & $1 \mathrm{H} 095$ & $\mathrm{~N}$ & 50.50 & 12.00 & $150-300$ & 2.10 \\
\hline $21 / 1$ & 47.32 & 155.25 & $1 \mathrm{H} 096$ & $\mathrm{~N}$ & 51.60 & 54.20 & $100-300$ & 3.80 \\
\hline $22 / 1$ & 49.32 & 161.81 & $1 \mathrm{H} 097$ & $\mathrm{~N}$ & 42.20 & 137.70 & $150-400$ & 3.50 \\
\hline $23 / 1$ & 50.65 & 166.17 & 1H098 & $\mathrm{N}$ & 43.10 & 352.70 & $150-300$ & 1.60 \\
\hline $24 / 1$ & 52.35 & 171.75 & $1 \mathrm{H} 099$ & $\mathrm{~N}$ & 45.60 & 141.90 & $150-400$ & 1.40 \\
\hline $26 / 1$ & 55.13 & 180.87 & $1 \mathrm{H} 100$ & $\mathrm{~N}$ & 43.30 & 53.40 & $150-300$ & 4.10 \\
\hline $27 / 1$ & 56.54 & 185.50 & 1H101 & $\mathrm{N}$ & 29.90 & 190.70 & $150-400$ & 5.00 \\
\hline $28 / 1$ & 58.38 & 191.54 & 6J650 & $\mathrm{N}$ & 32.90 & 78.10 & $200-400$ & 7.40 \\
\hline $28 / 1$ & 58.67 & 192.49 & 1H102 & 1 & $(14.30)$ & 344.80 & $150-400$ & 17.40 \\
\hline $28 / 1$ & 58.84 & 193.04 & 6J651 & $\mathrm{R}$ & $(39.50)$ & 104.50 & 150-200 & 5.50 \\
\hline $30 / 1$ & 61.09 & 200.43 & 6J652 & $\mathrm{N}$ & 84.30 & 6.33 & $100-400$ & 9.50 \\
\hline $30 / 1$ & 61.25 & 200.95 & $1 \mathrm{H} 103$ & $\mathrm{~N}$ & 62.40 & 191.70 & $150-300$ & 7.70 \\
\hline $30 / 1$ & 61.79 & 202.72 & 6J653 & $\mathrm{N}$ & 65.00 & 331.60 & $150-400$ & 28.60 \\
\hline $31 / 1$ & 62.78 & 205.97 & 6J654 & & & & & \\
\hline $31 / 1$ & 63.23 & 207.45 & 6J655 & $\mathrm{N}$ & 69.40 & 112.90 & $100-400$ & 10.60 \\
\hline $31 / 2$ & 63.60 & 208.66 & 1H104 & 1 & $(18.90)$ & 191.60 & $150-300$ & 41.10 \\
\hline $32 / 1$ & 64.26 & 210.83 & 6J656 & & & & & \\
\hline $32 / 1$ & 65.25 & 214.07 & 1H105 & $\mathrm{N}$ & 46.40 & 94.40 & $100-300$ & 3.60 \\
\hline $33 / 1$ & 65.96 & 216.40 & 1H106 & $\mathrm{N}$ & 38.40 & 130.90 & $150-300$ & 2.60 \\
\hline $34 / 1$ & 67.62 & 221.85 & 1H107 & $\mathrm{N}$ & 60.10 & 63.80 & $150-300$ & 6.50 \\
\hline $36 / 1$ & 69.74 & 228.81 & 1H108 & $\mathrm{N}$ & 52.00 & 163.60 & $200-400$ & 1.60 \\
\hline $37 / 1$ & 70.56 & 231.50 & 1H109 & $\mathrm{N}$ & 30.40 & 118.20 & $100-300$ & 1.20 \\
\hline $38 / 1$ & 72.46 & 237.73 & $1 \mathrm{H} 110$ & $\mathrm{~N}$ & 63.80 & 161.40 & 100-200 & 7.10 \\
\hline $39 / 1$ & 73.72 & 241.86 & $1 \mathrm{H} 111$ & $\mathrm{~N}$ & 31.60 & 179.90 & $150-400$ & 16.80 \\
\hline $40 / 1$ & 75.57 & 247.93 & 1H112 & $\mathrm{N}$ & 43.50 & 86.30 & $100-300$ & 6.50 \\
\hline $41 / 1$ & 77.22 & 253.35 & $1 \mathrm{H} 113$ & $\mathrm{~N}$ & 59.30 & 208.30 & $100-200$ & 14.70 \\
\hline $42 / 1$ & 78.09 & 256.20 & 1H114 & $\mathrm{N}$ & 30.90 & 324.60 & $100-300$ & 1.30 \\
\hline $43 / 1$ & 79.52 & 260.89 & $1 \mathrm{H} 115$ & $\mathrm{~N}$ & 47.10 & 115.50 & $100-300$ & 3.70 \\
\hline $44 / 1$ & 80.45 & 263.94 & $1 \mathrm{H} 116$ & $\mathrm{~N}$ & 41.90 & 167.50 & $200-400$ & 5.40 \\
\hline $45 / 1$ & 81.29 & 266.70 & $1 \mathrm{H} 117$ & $\mathrm{~N}$ & 34.50 & 116.20 & $100-300$ & 7.60 \\
\hline
\end{tabular}




\begin{tabular}{|c|c|c|c|c|c|c|c|c|}
\hline $46 / 1$ & 83.03 & 272.41 & 1H118 & $\mathrm{N}$ & 42.90 & 117.50 & $100-300$ & 1.60 \\
\hline $47 / 1$ & 84.15 & 276.08 & $1 \mathrm{H} 119$ & $\mathrm{~N}$ & 44.50 & 113.90 & $150-300$ & 3.10 \\
\hline $48 / 1$ & 86.19 & 282.78 & $1 \mathrm{H} 120$ & $\mathrm{~N}$ & 56.50 & 343.90 & $150-300$ & 9.50 \\
\hline $49 / 1$ & 87.12 & 285.83 & $1 \mathrm{H} 121$ & $\mathrm{~N}$ & 70.30 & 1.70 & $100-300$ & 11.50 \\
\hline $50 / 1$ & 89.00 & 291.99 & $1 \mathrm{H} 122$ & $\mathrm{~N}$ & 63.30 & 40.21 & $100-300$ & 4.20 \\
\hline $51 / 1$ & 90.54 & 297.05 & $1 \mathrm{H} 123$ & $\mathrm{R}$ & $(45.20)$ & 58.60 & $100-300$ & 11.40 \\
\hline $51 / 1$ & 90.81 & 297.93 & 6J660 & $\mathrm{N}$ & 56.80 & 174.20 & $200-400$ & 11.40 \\
\hline $52 / 1$ & 91.99 & 301.80 & 6J661 & $\mathrm{N}$ & 61.80 & 85.10 & $100-300$ & 17.30 \\
\hline $52 / 1$ & 92.20 & 302.49 & $1 \mathrm{H} 124$ & $\mathrm{I}$ & 0.80 & 12.00 & $150-400$ & 16.80 \\
\hline $53 / 1$ & 94.16 & 308.92 & $1 \mathrm{H} 125$ & $\mathrm{~N}$ & 39.50 & 353.30 & $150-400$ & 5.90 \\
\hline $54 / 1$ & 94.76 & 310.89 & $1 \mathrm{H} 126$ & $\mathrm{R}$ & $(28.90)$ & 344.40 & $100-200$ & 9.20 \\
\hline $55 / 1$ & 96.96 & 318.11 & $1 \mathrm{H} 127$ & $\mathrm{~N}$ & 59.10 & 91.60 & $150-300$ & 7.50 \\
\hline $57 / 1$ & 99.75 & 327.26 & $1 \mathrm{H} 128$ & $\mathrm{~N}$ & 46.50 & 245.70 & $100-300$ & 13.30 \\
\hline $58 / 1$ & 101.11 & 331.73 & $1 \mathrm{H} 129$ & $\mathrm{~N}$ & 24.60 & 183.30 & $100-400$ & 21.40 \\
\hline $59 / 1$ & 102.76 & 337.14 & $1 \mathrm{H} 130$ & $\mathrm{~N}$ & 83.30 & 145.80 & $100-300$ & 17.30 \\
\hline $60 / 1$ & 103.93 & 340.98 & $1 \mathrm{H} 131$ & $\mathrm{~N}$ & 60.90 & 21.50 & $100-300$ & 11.10 \\
\hline $62 / 1$ & 107.47 & 352.59 & 1H132 & $\mathrm{N}$ & 55.80 & 52.40 & $100-400$ & 20.10 \\
\hline $63 / 1$ & 108.65 & 356.46 & $1 \mathrm{H} 133$ & $\mathrm{~N}$ & 41.60 & 343.80 & $100-300$ & 12.90 \\
\hline $66 / 1$ & 113.62 & 372.77 & $1 \mathrm{H} 134$ & $\mathrm{~N}$ & 53.20 & 325.00 & $100-300$ & 6.00 \\
\hline $67 / 1$ & 114.81 & 376.67 & $1 \mathrm{H} 135$ & $\mathrm{~N}$ & 56.50 & 123.20 & $100-300$ & 12.90 \\
\hline $69 / 1$ & 117.70 & 386.15 & $1 \mathrm{H} 136$ & $\mathrm{~N}$ & 52.80 & 75.20 & $100-300$ & 5.60 \\
\hline $72 / 1$ & 122.44 & 401.71 & $1 \mathrm{H} 137$ & $\mathrm{~N}$ & 51.90 & 105.40 & $100-300$ & 9.30 \\
\hline $73 / 1$ & 123.97 & 406.73 & $1 \mathrm{H} 138$ & $\mathrm{~N}$ & 54.80 & 82.70 & $100-300$ & 6.50 \\
\hline $74 / 1$ & 125.50 & 411.75 & 6J664 & $\mathrm{R}$ & $(56.80)$ & 356.50 & $150-300$ & 11.10 \\
\hline $74 / 1$ & 125.62 & 412.14 & $1 \mathrm{H} 139$ & $\mathrm{~N}$ & $(54.00)$ & 28.40 & $100-300$ & 27.40 \\
\hline $76 / 1$ & 128.79 & 422.54 & $1 \mathrm{H} 140$ & $\mathrm{~N}$ & 66.90 & 329.30 & $100-300$ & 7.10 \\
\hline $77 / 1$ & 130.14 & 426.97 & $1 \mathrm{H} 141$ & $\mathrm{~N}$ & 37.90 & 194.10 & $100-300$ & 1.80 \\
\hline $78 / 1$ & 132.24 & 433.86 & $1 \mathrm{H} 142$ & $\mathrm{~N}$ & 62.90 & 30.60 & $100-300$ & 16.90 \\
\hline $79 / 1$ & 132.64 & 435.17 & $1 \mathrm{H} 143$ & $\mathrm{~N}$ & 50.70 & 54.40 & $100-300$ & 2.00 \\
\hline $80 / 1$ & 134.25 & 440.45 & $1 \mathrm{H} 144$ & $\mathrm{~N}$ & 46.20 & 122.10 & $100-300$ & 2.50 \\
\hline $83 / 1$ & 139.32 & 457.09 & $1 \mathrm{H} 145$ & $\mathrm{~N}$ & 39.60 & 33.80 & $100-300$ & 2.10 \\
\hline $85 / 1$ & 142.62 & 467.91 & $1 \mathrm{H} 146$ & $\mathrm{~N}$ & 33.30 & 166.50 & $100-300$ & 1.80 \\
\hline $86 / 1$ & 144.48 & 474.02 & $1 \mathrm{H} 147$ & $\mathrm{~N}$ & 49.60 & 301.70 & $100-300$ & 7.90 \\
\hline $87 / 1$ & 145.05 & 475.89 & 1H148 & $\mathrm{N}$ & 39.80 & 50.20 & $100-300$ & 3.60 \\
\hline $88 / 1$ & 146.89 & 481.92 & $1 \mathrm{H} 149$ & $\mathrm{~N}$ & 48.10 & 296.20 & $150-300$ & 2.80 \\
\hline $89 / 1$ & 151.05 & 495.57 & $1 \mathrm{H} 150$ & 1 & $(7.80)$ & 217.90 & $100-300$ & 5.50 \\
\hline $93 / 1$ & 154.94 & 508.33 & $1 \mathrm{H} 151$ & $\mathrm{~N}$ & 37.00 & 259.10 & $150-400$ & 1.30 \\
\hline $94 / 1$ & 155.79 & 511.12 & $1 \mathrm{H} 152$ & $\mathrm{~N}$ & 43.00 & 53.60 & $150-300$ & 1.20 \\
\hline $96 / 1$ & 158.64 & 520.47 & $1 \mathrm{H} 153$ & $\mathrm{~N}$ & 38.00 & 223.30 & $150-300$ & 3.20 \\
\hline $97 / 1$ & 161.00 & 528.22 & $1 \mathrm{H} 154$ & $\mathrm{~N}$ & 48.50 & 155.20 & $150-300$ & 1.00 \\
\hline $98 / 1$ & 162.13 & 531.92 & $1 \mathrm{H} 155$ & $\mathrm{~N}$ & 61.80 & 107.50 & $150-300$ & 9.10 \\
\hline $99 / 1$ & 163.51 & 536.45 & $1 \mathrm{H} 156$ & $\mathrm{~N}$ & 54.40 & 87.40 & $150-300$ & 4.60 \\
\hline $100 / 1$ & 165.34 & 542.45 & 1H157 & $\mathrm{N}$ & 50.20 & 134.00 & $150-300$ & 1.60 \\
\hline $101 / 1$ & 167.26 & 548.75 & $1 \mathrm{H} 158$ & $\mathrm{~N}$ & 50.00 & 177.50 & $150-300$ & 3.50 \\
\hline $102 / 1$ & 168.56 & 553.02 & $1 \mathrm{H} 159$ & $\mathrm{~N}$ & 45.70 & 47.70 & $150-400$ & 4.50 \\
\hline $103 / 1$ & 169.81 & 557.12 & $1 \mathrm{H} 160$ & $\mathrm{~N}$ & 75.10 & 65.20 & $100-200$ & 14.50 \\
\hline $104 / 1$ & 170.88 & 560.63 & $1 \mathrm{H} 161$ & $\mathrm{~N}$ & 47.30 & 55.90 & $150-300$ & 17.10 \\
\hline $108 / 1$ & 176.89 & 580.35 & 1H162 & $\mathrm{N}$ & 57.30 & 197.60 & $100-200$ & 11.10 \\
\hline $109 / 1$ & 179.45 & 588.75 & $1 \mathrm{H} 163$ & $\mathrm{~N}$ & 44.40 & 114.70 & $150-300$ & 4.60 \\
\hline
\end{tabular}




\begin{tabular}{|c|c|c|c|c|c|c|c|c|}
\hline $111 / 1$ & 182.52 & 598.82 & 1H164 & $\mathrm{N}$ & 43.10 & 47.80 & $150-400$ & 4.00 \\
\hline $113 / 1$ & 185.32 & 608.01 & $1 \mathrm{H} 165$ & $\mathrm{~N}$ & 42.40 & 81.90 & $150-400$ & 2.80 \\
\hline $114 / 1$ & 186.32 & 611.29 & 1H167 & $\mathrm{N}$ & 47.40 & 35.30 & $200-400$ & 1.70 \\
\hline $115 / 1$ & 188.48 & 618.37 & 1H168 & $\mathrm{N}$ & 35.30 & 140.20 & $200-400$ & 5.30 \\
\hline $116 / 1$ & 189.58 & 621.98 & 1H169 & $\mathrm{N}$ & 53.20 & 241.40 & $150-300$ & 4.50 \\
\hline $123 / 1$ & 200.75 & 658.63 & $1 \mathrm{H} 170$ & $\mathrm{~N}$ & 47.80 & 131.90 & $100-200$ & 4.70 \\
\hline $127 / 1$ & 205.89 & 675.49 & 1H171 & $\mathrm{N}$ & 55.00 & 146.80 & 150-400 & 9.20 \\
\hline $128 / 1$ & 208.37 & 683.63 & $1 \mathrm{H} 166$ & $\mathrm{~N}$ & 48.90 & 142.30 & $150-400$ & 2.10 \\
\hline $129 / 1$ & 209.45 & 687.17 & $1 \mathrm{H} 172$ & $\mathrm{~N}$ & 44.60 & 69.30 & $150-300$ & 5.20 \\
\hline $130 / 1$ & 211.11 & 692.62 & 1H173 & $\mathrm{N}$ & 46.20 & 65.80 & $150-300$ & 1.80 \\
\hline $131 / 1$ & 211.95 & 695.37 & 1H174 & $\mathrm{N}$ & 46.80 & 212.84 & $200-500$ & 5.40 \\
\hline $132 / 1$ & 213.61 & 700.82 & 1H175 & $\mathrm{N}$ & 59.20 & 263.90 & 150-300 & 8.40 \\
\hline $133 / 1$ & 215.75 & 707.84 & 6J665 & $\mathrm{N}$ & 55.80 & 231.30 & $100-400$ & 11.50 \\
\hline $133 / 1$ & 215.91 & 708.37 & 1H176 & $\mathrm{R}$ & (26.20) & 2.50 & $150-400$ & 9.90 \\
\hline $133 / 1$ & 216.10 & 708.99 & 6J666 & $\mathrm{N}$ & 58.60 & 210.30 & $150-400$ & 6.10 \\
\hline $134 / 1$ & 217.31 & 712.96 & $1 \mathrm{H} 177$ & $\mathrm{~N}$ & 53.80 & 250.90 & $150-300$ & 6.30 \\
\hline $135 / 1$ & 218.12 & 715.62 & 1H178 & $\mathrm{N}$ & 50.00 & 243.80 & 150-400 & 13.90 \\
\hline $136 / 1$ & 220.37 & 723.00 & $1 \mathrm{H} 179$ & $\mathrm{~N}$ & 47.10 & 309.60 & $200-400$ & 4.70 \\
\hline $137 / 1$ & 221.56 & 726.90 & $1 \mathrm{H} 181$ & $\mathrm{~N}$ & 47.70 & 223.40 & $200-500$ & 2.70 \\
\hline $138 / 1$ & 223.37 & 732.84 & 1H180 & $\mathrm{N}$ & 53.60 & 279.70 & $300-500$ & 0.10 \\
\hline $141 / 1$ & 230.95 & 757.71 & 1H182 & $\mathrm{N}$ & 58.20 & 335.20 & $200-400$ & 4.70 \\
\hline $142 / 1$ & 233.42 & 765.81 & $1 \mathrm{H} 183$ & $\mathrm{~N}$ & 45.80 & 196.90 & $200-500$ & 5.60 \\
\hline $144 / 1$ & 238.59 & 782.78 & $1 \mathrm{H} 184$ & $\mathrm{~N}$ & 65.80 & 193.80 & $100-200$ & 2.10 \\
\hline $145 / 1$ & 240.14 & 787.86 & $1 \mathrm{H} 185$ & $\mathrm{~N}$ & 48.10 & 244.10 & $300-500$ & 3.40 \\
\hline $146 / 1$ & 241.33 & 791.77 & $1 \mathrm{H} 186$ & $\mathrm{~N}$ & 60.80 & 231.70 & $200-400$ & 3.90 \\
\hline $147 / 1$ & 242.63 & 796.03 & 1H187 & $\mathrm{N}$ & 47.80 & 65.30 & $300-500$ & 4.00 \\
\hline $148 / 2$ & 244.88 & 803.41 & 1H188 & $\mathrm{N}$ & 68.50 & 300.90 & $100-300$ & 12.60 \\
\hline $149 / 1$ & 246.00 & 807.09 & 1H189 & $\mathrm{N}$ & 46.40 & 106.50 & $150-300$ & 4.90 \\
\hline $150 / 1$ & 247.24 & 811.15 & $1 \mathrm{H} 190$ & $\mathrm{~N}$ & 59.00 & 92.50 & $100-300$ & 9.70 \\
\hline $152 / 1$ & 250.46 & 821.72 & 1H191 & I & 15.00 & 231.30 & $100-200$ & 10.20 \\
\hline $154 / 1$ & 254.08 & 833.60 & $1 \mathrm{H} 192$ & $\mathrm{~N}$ & 51.60 & 79.70 & $100-300$ & 11.10 \\
\hline $155 / 1$ & 255.26 & 837.47 & $1 \mathrm{H} 193$ & $\mathrm{~N}$ & 55.40 & 317.10 & $200-500$ & 8.10 \\
\hline $156 / 1$ & 256.87 & 842.75 & $1 \mathrm{H} 194$ & $\mathrm{~N}$ & 52.60 & 105.50 & $100-300$ & 11.90 \\
\hline $158 / 1$ & 259.99 & 852.99 & $1 \mathrm{H} 195$ & $\mathrm{~N}$ & 42.00 & 183.60 & $300-400$ & 6.60 \\
\hline $159 / 1$ & 261.37 & 857.51 & $1 \mathrm{H} 196$ & $\mathrm{~N}$ & 48.90 & 178.10 & $100-300$ & 7.20 \\
\hline $160 / 1$ & 262.89 & 862.50 & $1 \mathrm{H} 197$ & $\mathrm{~N}$ & 54.40 & 190.30 & $100-300$ & 5.80 \\
\hline $161 / 1$ & 264.60 & 868.11 & 1H198 & $\mathrm{N}$ & 51.80 & 162.70 & $100-300$ & 25.00 \\
\hline $162 / 1$ & 265.79 & 872.01 & 1H199 & $\mathrm{N}$ & 42.10 & 351.90 & $100-300$ & 9.70 \\
\hline $163 / 1$ & 267.21 & 876.67 & $1 \mathrm{H} 200$ & $\mathrm{~N}$ & 53.70 & 89.50 & $100-200$ & 6.70 \\
\hline $164 / 1$ & 269.06 & 882.74 & $1 \mathrm{H} 201$ & $\mathrm{~N}$ & 41.30 & 88.10 & $100-300$ & 8.00 \\
\hline $165 / 1$ & 270.73 & 888.22 & $1 \mathrm{H} 202$ & $\mathrm{~N}$ & 51.60 & 290.50 & $100-300$ & 13.10 \\
\hline $166 / 1$ & 272.08 & 892.65 & $1 \mathrm{H} 203$ & $\mathrm{~N}$ & 44.20 & 195.10 & $100-300$ & 8.90 \\
\hline $167 / 1$ & 272.46 & 893.90 & $1 \mathrm{H} 204$ & $\mathrm{~N}$ & 54.10 & 353.70 & $100-300$ & 13.10 \\
\hline $168 / 1$ & 274.90 & 901.90 & $1 \mathrm{H} 205$ & $\mathrm{~N}$ & 54.60 & 178.70 & $100-300$ & 5.80 \\
\hline $169 / 1$ & 276.59 & 907.45 & $1 \mathrm{H} 206$ & $\mathrm{~N}$ & 56.70 & 64.20 & $100-300$ & 13.90 \\
\hline $170 / 1$ & 278.06 & 912.27 & $1 \mathrm{H} 207$ & $\mathrm{~N}$ & 21.70 & 102.36 & $150-400$ & 1.60 \\
\hline $171 / 1$ & 280.01 & 918.67 & $1 \mathrm{H} 208$ & $\mathrm{~N}$ & 29.70 & 34.50 & $150-500$ & 2.90 \\
\hline $172 / 1$ & 281.02 & 921.98 & $1 \mathrm{H} 209$ & 1 & 12.80 & 45.80 & $300-500$ & 3.90 \\
\hline $173 / 1$ & 283.12 & 928.87 & $1 \mathrm{H} 210$ & $\mathrm{~N}$ & 41.80 & 116.50 & $100-300$ & 6.60 \\
\hline
\end{tabular}




\begin{tabular}{|c|c|c|c|c|c|c|c|c|}
\hline 174/1 & 283.66 & 930.64 & 6J657 & $\mathrm{N}$ & 29.00 & 263.60 & $150-400$ & 1.30 \\
\hline 174/1 & 284.10 & 932.09 & $1 \mathrm{H} 211$ & 1 & $(3.60)$ & 137.50 & $300-500$ & 6.30 \\
\hline $174 / 1$ & 284.43 & 933.17 & 6J658 & $\mathrm{N}$ & 38.00 & 256.60 & $150-400$ & 2.80 \\
\hline $174 / 1$ & 284.53 & 933.50 & 6J659 & $\mathrm{N}$ & 41.30 & 227.30 & $150-400$ & 4.20 \\
\hline 178/1 & 288.31 & 945.90 & $1 \mathrm{H} 212$ & $\mathrm{~N}$ & 70.70 & 8.80 & $150-300$ & 1.60 \\
\hline $181 / 1$ & 291.44 & 956.17 & $1 \mathrm{H} 213$ & $\mathrm{~N}$ & 46.10 & 99.60 & $200-400$ & 1.60 \\
\hline 184/1 & 295.07 & 968.08 & $1 \mathrm{H} 214$ & $\mathrm{~N}$ & 46.50 & 212.20 & $200-400$ & 1.90 \\
\hline $185 / 1$ & 296.07 & 971.36 & $1 \mathrm{H} 215$ & $\mathrm{~N}$ & 44.70 & 37.00 & $300-500$ & 2.10 \\
\hline $186 / 1$ & 298.17 & 978.25 & $1 \mathrm{H} 216$ & $\mathrm{~N}$ & 52.60 & 122.30 & $150-400$ & 18.30 \\
\hline $187 / 1$ & 298.91 & 980.68 & $1 \mathrm{H} 217$ & $\mathrm{~N}$ & 41.90 & 55.60 & $150-300$ & 6.00 \\
\hline $189 / 1$ & 302.48 & 992.39 & $1 \mathrm{H} 218$ & $\mathrm{~N}$ & 42.60 & 242.70 & $150-300$ & 11.20 \\
\hline 190/1 & 303.80 & 996.72 & $1 \mathrm{H} 219$ & $\mathrm{~N}$ & 85.30 & 128.90 & $100-300$ & 5.60 \\
\hline $191 / 1$ & 305.19 & $1,001.28$ & $1 \mathrm{H} 220$ & $\mathrm{~N}$ & 49.90 & 28.60 & $150-400$ & 2.50 \\
\hline $192 / 1$ & 306.77 & $1,006.46$ & $1 \mathrm{H} 221$ & $\mathrm{~N}$ & 44.70 & 125.50 & $100-400$ & 5.10 \\
\hline 193/1 & 308.47 & $1,012.04$ & $1 \mathrm{H} 222$ & $\mathrm{~N}$ & 70.20 & 64.70 & $100-300$ & 9.00 \\
\hline 194/1 & 310.10 & $1,017.39$ & $1 \mathrm{H} 223$ & 1 & 17.60 & 262.60 & 150-300 & 7.10 \\
\hline 195/1 & 311.55 & $1,022.15$ & $1 \mathrm{H} 224$ & $\mathrm{~N}$ & 61.30 & 103.20 & $100-400$ & 5.50 \\
\hline $196 / 1$ & 313.49 & $1,028.51$ & $1 \mathrm{H} 225$ & $\mathrm{~N}$ & 56.00 & 186.70 & $150-300$ & 3.30 \\
\hline $197 / 1$ & 314.49 & $1,031.79$ & $1 \mathrm{H} 226$ & $\mathrm{~N}$ & 45.90 & 126.60 & $200-400$ & 4.80 \\
\hline 199/1 & 318.12 & $1,043.70$ & $1 \mathrm{H} 227$ & $\mathrm{~N}$ & 45.90 & 124.20 & $150-300$ & 10.70 \\
\hline $202 / 1$ & 321.34 & $1,054.27$ & $1 \mathrm{H} 228$ & $\mathrm{~N}$ & 53.50 & 24.90 & $100-300$ & 4.80 \\
\hline $203 / 1$ & 322.38 & $1,057.68$ & $1 \mathrm{H} 229$ & $\mathrm{~N}$ & 54.40 & 237.00 & $100-300$ & 15.90 \\
\hline 205/1 & 325.04 & $1,066.40$ & $1 \mathrm{H} 230$ & $\mathrm{~N}$ & 61.90 & 75.80 & $100-300$ & 9.50 \\
\hline $206 / 1$ & 326.81 & $1,072.21$ & $1 \mathrm{H} 231$ & $\mathrm{~N}$ & 82.50 & 24.60 & $150-400$ & 7.00 \\
\hline 219/1 & 341.44 & $1,120.21$ & $1 \mathrm{H} 232$ & $\mathrm{~N}$ & 47.60 & 124.10 & $150-300$ & 7.70 \\
\hline $220 / 1$ & 342.47 & $1,123.59$ & $1 \mathrm{H} 233$ & $\mathrm{~N}$ & 48.30 & 126.80 & $200-500$ & 4.20 \\
\hline $221 / 1$ & 343.21 & $1,126.02$ & $1 \mathrm{H} 234$ & $\mathrm{~N}$ & 63.90 & 5.20 & $100-300$ & 4.00 \\
\hline 224/1 & 346.41 & $1,136.52$ & $1 \mathrm{H} 235$ & $\mathrm{~N}$ & 79.80 & 56.10 & $200-500$ & 11.70 \\
\hline $225 / 1$ & 346.80 & $1,137.80$ & $1 \mathrm{H} 236$ & $\mathrm{~N}$ & 39.80 & 163.60 & $200-500$ & 8.20 \\
\hline $226 / 1$ & 349.86 & $1,147.83$ & $1 \mathrm{H} 238$ & $\mathrm{~N}$ & 56.60 & 179.50 & $100-300$ & 6.60 \\
\hline $227 / 1$ & 351.20 & $1,152.23$ & $1 \mathrm{H} 237$ & $\mathrm{~N}$ & 51.30 & 295.90 & $100-300$ & 5.90 \\
\hline $228 / 1$ & 352.79 & $1,157.45$ & $1 \mathrm{H} 239$ & $\mathrm{~N}$ & 57.00 & 180.70 & $100-200$ & 5.30 \\
\hline 229/1 & 354.54 & $1,163.19$ & $1 \mathrm{H} 240$ & $\mathrm{~N}$ & 48.50 & 41.90 & $100-300$ & 3.90 \\
\hline $232 / 1$ & 357.60 & $1,173.23$ & $1 \mathrm{H} 241$ & $\mathrm{~N}$ & 53.60 & 67.40 & $100-300$ & 4.10 \\
\hline $234 / 1$ & 360.83 & $1,183.83$ & $1 \mathrm{H} 242$ & $\mathrm{~N}$ & 59.70 & 200.90 & $100-300$ & 4.70 \\
\hline $236 / 1$ & 363.58 & $1,192.85$ & $1 \mathrm{H} 243$ & $\mathrm{~N}$ & 49.00 & 312.80 & $100-300$ & 9.30 \\
\hline $238 / 1$ & 366.36 & $1,201.97$ & $1 \mathrm{H} 244$ & $\mathrm{~N}$ & 58.10 & 202.20 & $200-500$ & 6.90 \\
\hline
\end{tabular}


Table 7. Paleomagnetic results from Long Beach Pier $\mathrm{C}$ core site and monitoring well (LBPC), Long Beach, California.

[Inclination of remanent magnetization after alternating-field treatment of samples from LBPC. RML Id, Rock Magnetism Laboratory identification number; Decl (relativity), declination relative to split face of core; N, normal; $\mathrm{R}$, reversed; I, indeterminate polarity of magnetization; Oe, oersteds; mT, millitesla; AF Demag, range of demagnetization steps in Oe used in calculation of inclination $(100 \mathrm{Oe}=10 \mathrm{mT})$; MAD, maximum angular deviation (in degrees) from principal-component analysis (Kirschvink, 1980); *, single demagnetization step, no line-fit result; **, lost sample]

\begin{tabular}{|c|c|c|c|c|c|c|c|c|c|}
\hline $\begin{array}{c}\text { Core } \\
\text { number }\end{array}$ & $\begin{array}{l}\text { Depth, in } \\
\text { meters }\end{array}$ & $\begin{array}{l}\text { Depth, in } \\
\text { feet }\end{array}$ & RML Id & Polarity & $\begin{array}{l}\text { Inclination, in } \\
\text { degrees }\end{array}$ & $\begin{array}{c}\text { Decl } \\
\text { (relativity) }\end{array}$ & $\begin{array}{l}\text { AF Demag } \\
\text { (Oe) }\end{array}$ & $\begin{array}{l}\text { Intensity NRM } \\
(\mathbf{m A} \mathbf{A} / \mathbf{m})\end{array}$ & MAD \\
\hline $2 / 1$ & 8.09 & 26.53 & 0H182 & $\mathrm{N}$ & 23.00 & 175.40 & $100-300$ & 41.40 & 3.20 \\
\hline $3 / 1$ & 9.34 & 30.64 & 0H183 & $\mathrm{N}$ & 35.80 & 24.60 & $150-400$ & 44.30 & 1.90 \\
\hline $4 / 1$ & 11.01 & 36.12 & 0H184 & $\mathrm{N}$ & 33.90 & 166.00 & $100-300$ & 64.30 & 2.50 \\
\hline $5 / 1$ & 12.44 & 40.80 & 0H185 & $\mathrm{N}$ & 45.40 & 109.50 & $100-400$ & 22.00 & 5.90 \\
\hline $5 / 1$ & 12.80 & 41.99 & 0H186 & I & -2.20 & 75.60 & $100-300$ & 50.40 & 1.00 \\
\hline $6 / 1$ & 13.82 & 45.35 & 0H187 & $\mathrm{N}$ & 38.10 & 195.40 & $150-400$ & 8.23 & 9.70 \\
\hline $7 / 1$ & 15.44 & 50.64 & 0H188 & $\mathrm{N}$ & 41.10 & 97.30 & $150-400$ & 21.20 & 4.50 \\
\hline $9 / 1$ & 18.64 & 61.17 & 0H189 & $\mathrm{N}$ & 43.40 & 193.50 & $150-300$ & 64.10 & 3.00 \\
\hline $10 / 1$ & 20.36 & 66.81 & 0H190 & $\mathrm{N}$ & 50.00 & 140.40 & $100-300$ & 48.70 & 0.80 \\
\hline $11 / 1$ & 21.78 & 71.46 & 0H191 & $\mathrm{N}$ & 45.20 & 248.00 & $100-300$ & 63.90 & 14.80 \\
\hline $12 / 1$ & 22.75 & 74.64 & 0H192 & $\mathrm{N}$ & 64.10 & 227.90 & $50-300$ & 22.40 & 7.60 \\
\hline $13 / 1$ & 25.05 & 82.18 & 0H193 & $\mathrm{N}$ & 53.90 & 316.70 & $150-300$ & 73.30 & 3.10 \\
\hline $14 / 1$ & 25.79 & 84.61 & 0H194 & $\mathrm{N}$ & 56.70 & 306.00 & $100-300$ & 30.30 & 1.30 \\
\hline $14 / 1$ & 26.85 & 88.10 & 0H195 & $\mathrm{N}$ & 46.70 & 273.90 & $100-300$ & 69.50 & 1.80 \\
\hline $15 / 1$ & 27.22 & 89.31 & 0H196 & $\mathrm{N}$ & 49.20 & 1.20 & $100-300$ & 64.90 & 2.80 \\
\hline $20 / 1$ & 31.99 & 104.96 & 0H197 & $\mathrm{N}$ & 37.10 & 40.70 & $100-300$ & 7.77 & 32.10 \\
\hline $32 / 1$ & 42.04 & 137.92 & 0H198 & $\mathrm{N}$ & 46.00 & 115.60 & $100-300$ & 52.80 & 1.90 \\
\hline $33 / 1$ & 42.55 & 139.60 & 0H199 & $\mathrm{N}$ & 59.80 & 195.10 & $300^{*}$ & 34.90 & \\
\hline $33 / 1$ & 43.17 & 141.65 & $0 \mathrm{H} 200$ & $\mathrm{~N}$ & 45.60 & 178.00 & $150-300$ & 95.20 & 1.20 \\
\hline $34 / 1$ & 44.18 & 144.95 & 0H201 & $\mathrm{N}$ & 54.60 & 219.70 & $100-300$ & 20.70 & 5.60 \\
\hline $39 / 1$ & 49.00 & 160.77 & 0H202 & $\mathrm{N}$ & 44.90 & 59.50 & $150-400$ & 3.10 & 12.20 \\
\hline $41 / 1$ & 52.25 & 171.41 & 0H203 & $\mathrm{N}$ & 30.30 & 349.80 & $100-200$ & 0.32 & 15.80 \\
\hline $42 / 1$ & 53.26 & 174.75 & 0H204 & $\mathrm{N}$ & 63.50 & 135.20 & $100-300$ & 0.47 & 8.60 \\
\hline $42 / 1$ & 53.83 & 176.61 & 0H205 & $\mathrm{N}$ & 45.30 & 71.60 & $100-200$ & 0.30 & 27.50 \\
\hline $43 / 1$ & 54.96 & 180.30 & 0H206 & $\mathrm{N}$ & 53.90 & 359.70 & $150-300$ & 18.70 & 8.60 \\
\hline $44 / 1$ & 56.24 & 184.52 & 0H207 & $\mathrm{N}$ & 59.30 & 331.70 & $100-300$ & 24.60 & 5.90 \\
\hline $45 / 1$ & 57.06 & 187.19 & 0H208 & $\mathrm{N}$ & 51.20 & 53.10 & $100-200$ & 43.00 & 10.70 \\
\hline $46 / 1$ & 58.03 & 190.38 & 0H209 & $\mathrm{N}$ & 47.50 & 314.80 & $100-300$ & 26.30 & 6.80 \\
\hline $47 / 1$ & 59.54 & 195.35 & $0 \mathrm{H} 210$ & $\mathrm{~N}$ & 36.80 & 25.90 & $100-300$ & 34.60 & 10.40 \\
\hline $48 / 1$ & 60.89 & 199.77 & 0H211 & $\mathrm{N}$ & 32.10 & 7.50 & $100-300$ & 16.20 & 14.70 \\
\hline $48 / 1$ & 61.92 & 203.14 & $0 \mathrm{H} 212$ & $\mathrm{~N}$ & 48.90 & 104.70 & $150-300$ & 33.80 & 2.90 \\
\hline $49 / 1$ & 62.56 & 205.26 & $0 \mathrm{H} 213$ & $\mathrm{~N}$ & 51.60 & 185.80 & $150-400$ & 57.00 & 1.20 \\
\hline $49 / 1$ & 63.27 & 207.59 & $0 \mathrm{H} 214$ & $\mathrm{~N}$ & 54.90 & 289.50 & $150-300$ & 30.80 & 3.20 \\
\hline $50 / 1$ & 64.21 & 210.66 & $0 \mathrm{H} 215$ & $\mathrm{~N}$ & 69.10 & 96.30 & $150-300$ & 70.40 & 3.70 \\
\hline $51 / 1$ & 65.58 & 215.16 & $0 \mathrm{H} 216$ & $\mathrm{~N}$ & 47.20 & 253.50 & $200-500$ & 23.70 & 2.00 \\
\hline $52 / 1$ & 67.35 & 220.95 & 0H217 & $\mathrm{N}$ & 42.30 & 9.60 & $150-400$ & 0.75 & 16.50 \\
\hline $53 / 1$ & 68.75 & 225.57 & 0H218 & $\mathrm{N}$ & 47.30 & 335.30 & $150-300$ & 2.28 & 8.70 \\
\hline $54 / 1$ & 69.93 & 229.42 & 0H219 & $\mathrm{N}$ & 50.80 & 262.50 & $200-400$ & 7.42 & 5.60 \\
\hline $54 / 1$ & 70.84 & 232.43 & $0 \mathrm{H} 220$ & $\mathrm{~N}$ & 47.00 & 291.80 & $150-300$ & 55.40 & 2.30 \\
\hline $56 / 1$ & 73.43 & 240.90 & $0 \mathrm{H} 221$ & $\mathrm{~N}$ & 42.50 & 192.30 & $150-300$ & 36.50 & 2.00 \\
\hline $57 / 1$ & 74.58 & 244.69 & 0H222 & $\mathrm{N}$ & 54.20 & 13.10 & $150-300$ & 37.10 & 1.40 \\
\hline $57 / 1$ & 75.42 & 247.43 & $0 \mathrm{H} 223$ & $\mathrm{~N}$ & 38.00 & 83.20 & $200-500$ & 23.60 & 9.20 \\
\hline $58 / 1$ & 76.97 & 252.53 & 0H224 & $\mathrm{N}$ & 44.20 & 149.00 & $200-400$ & 60.10 & 4.50 \\
\hline $59 / 1$ & 77.62 & 254.67 & $0 \mathrm{H} 225$ & $\mathrm{~N}$ & 49.30 & 189.20 & $150-300$ & 33.40 & 2.00 \\
\hline $59 / 1$ & 78.56 & 257.75 & $0 \mathrm{H} 226$ & $\mathrm{~N}$ & 43.70 & 234.70 & $100-400$ & 45.60 & 2.60 \\
\hline
\end{tabular}




\begin{tabular}{|c|c|c|c|c|c|c|c|c|c|}
\hline $60 / 1$ & 80.08 & 262.72 & 0H227 & $\mathrm{N}$ & 45.60 & 245.20 & $200-400$ & 22.90 & 3.30 \\
\hline $61 / 1$ & 80.98 & 265.67 & 0H228 & $\mathrm{N}$ & 55.70 & 214.40 & $100-200$ & 22.60 & 0.80 \\
\hline $63 / 1$ & 83.64 & 274.41 & 0H229 & $\mathrm{N}$ & 52.70 & 260.30 & $200-500$ & 6.96 & 5.30 \\
\hline $63 / 1$ & 84.03 & 275.69 & $0 \mathrm{H} 231$ & $\mathrm{~N}$ & 51.50 & 303.30 & $100-300$ & 18.10 & 10.90 \\
\hline $63 / 1$ & 84.18 & 276.19 & $0 \mathrm{H} 230$ & $\mathrm{~N}$ & 44.50 & 42.90 & $100-300$ & 16.60 & 10.10 \\
\hline $64 / 1$ & 85.85 & 281.66 & $0 \mathrm{H} 232$ & $\mathrm{~N}$ & 47.70 & 71.80 & $150-400$ & 20.10 & 2.90 \\
\hline $65 / 1$ & 87.20 & 286.08 & 0H233 & $\mathrm{N}$ & 39.30 & 228.90 & $100-300$ & 19.70 & 6.40 \\
\hline $66 / 1$ & 88.88 & 291.59 & $0 \mathrm{H} 234$ & $\mathrm{~N}$ & 45.20 & 70.10 & $150-500$ & 46.70 & 2.40 \\
\hline $68 / 1$ & 91.89 & 301.46 & $0 \mathrm{H} 235$ & $\mathrm{~N}$ & 53.10 & 5.80 & $150-300$ & 55.70 & 4.40 \\
\hline $70 / 1$ & 94.37 & 309.60 & 0H237 & $\mathrm{N}$ & 45.10 & 99.30 & $200-500$ & 29.50 & 8.50 \\
\hline $73 / 1$ & 98.12 & 321.90 & 0H238 & $\mathrm{N}$ & 52.00 & 345.20 & $200-500$ & 10.80 & 4.80 \\
\hline $74 / 1$ & 99.14 & 325.25 & $0 \mathrm{H} 236$ & $\mathrm{~N}$ & 49.50 & 317.70 & $200-500$ & 30.90 & 4.30 \\
\hline $75 / 1$ & 100.63 & 330.14 & 0H239 & $\mathrm{N}$ & 51.00 & 41.80 & $200-500$ & 2.40 & 6.20 \\
\hline $76 / 1$ & 102.26 & 335.51 & $0 \mathrm{H} 240$ & $\mathrm{~N}$ & 40.40 & 82.40 & $100-400$ & 2.46 & 15.00 \\
\hline $77 / 1$ & 104.63 & 343.29 & $0 \mathrm{H} 241$ & $\mathrm{~N}$ & 31.20 & 253.60 & $100-400$ & 2.50 & 8.80 \\
\hline $81 / 1$ & 108.90 & 357.28 & 0H242 & $\mathrm{N}$ & 44.90 & 87.00 & $100-300$ & 0.83 & 24.00 \\
\hline $82 / 1$ & 109.86 & 360.43 & $0 \mathrm{H} 243$ & $\mathrm{~N}$ & 54.50 & 74.80 & $100-300$ & 4.58 & 15.30 \\
\hline $83 / 1$ & 111.54 & 365.95 & 0H244 & $\mathrm{N}$ & 49.90 & 125.60 & $50-150$ & 10.80 & 4.00 \\
\hline $84 / 1$ & 113.13 & 371.17 & 0H245 & $\mathrm{N}$ & 41.10 & 16.10 & $50-150$ & 12.10 & 5.50 \\
\hline $85 / 1$ & 114.67 & 376.21 & 0H246 & $\mathrm{N}$ & 64.50 & 309.90 & $150-300$ & 0.67 & 18.90 \\
\hline $86 / 1$ & 116.49 & 382.18 & $0 \mathrm{H} 247$ & $\mathrm{~N}$ & 58.80 & 16.50 & $150-400$ & 4.61 & 7.70 \\
\hline $87 / 1$ & 117.67 & 386.05 & 0H248 & $\mathrm{N}$ & 50.00 & 185.00 & $200-400$ & 7.22 & 3.30 \\
\hline $88 / 1$ & 118.77 & 389.67 & 0H249 & $\mathrm{N}$ & 47.50 & 142.70 & $150-400$ & 6.80 & 4.40 \\
\hline $89 / 1$ & 120.86 & 396.52 & $0 \mathrm{H} 250$ & $\mathrm{~N}$ & 46.30 & 187.10 & $100-300$ & 1.11 & 11.00 \\
\hline $90 / 1$ & 122.13 & 400.70 & $0 \mathrm{H} 251$ & $\mathrm{~N}$ & 31.80 & 159.10 & $150-300$ & 1.12 & 30.10 \\
\hline $91 / 1$ & 124.32 & 407.88 & $0 \mathrm{H} 253$ & $\mathrm{~N}$ & 37.10 & 81.50 & $150-400$ & 1.51 & 9.20 \\
\hline $92 / 1$ & 125.34 & 411.23 & $0 \mathrm{H} 252$ & $\mathrm{~N}$ & 38.90 & 101.50 & $150-400$ & 1.44 & 31.90 \\
\hline $93 / 1$ & 126.85 & 416.19 & $0 \mathrm{H} 254$ & $\mathrm{I}$ & 11.90 & 351.50 & $100-300$ & 0.55 & 21.40 \\
\hline $94 / 1$ & 128.26 & 420.80 & $0 \mathrm{H} 255$ & $\mathrm{~N}$ & 37.50 & 13.60 & $100-400$ & 0.31 & 17.90 \\
\hline $95 / 1$ & 129.68 & 425.47 & $0 \mathrm{H} 256$ & $\mathrm{I}$ & 6.60 & 3.60 & $150-300$ & 0.43 & 20.40 \\
\hline $96 / 1$ & 131.41 & 431.15 & 0H257 & $\mathrm{I}$ & 15.00 & 5.20 & $150-300$ & 0.31 & 4.50 \\
\hline $97 / 1$ & 132.92 & 436.10 & $0 \mathrm{H} 258$ & $\mathrm{~N}$ & 34.90 & 340.50 & $150-300$ & 1.05 & 23.50 \\
\hline $98 / 1$ & 134.38 & 440.87 & 0H259 & $\mathrm{I}$ & 5.30 & 358.90 & $150-300$ & 0.60 & 16.50 \\
\hline $99 / 1$ & 136.12 & 446.58 & $0 \mathrm{H} 260 * *$ & & & & & & \\
\hline $100 / 1$ & 137.51 & 451.14 & 0H261 & $\mathrm{N}$ & 39.10 & 232.90 & $150-300$ & 1.60 & 5.80 \\
\hline $101 / 1$ & 139.08 & 456.31 & $0 \mathrm{H} 262$ & $\mathrm{~N}$ & 47.40 & 237.70 & $100-200$ & 2.00 & 6.80 \\
\hline $102 / 1$ & 140.42 & 460.69 & $0 \mathrm{H} 263$ & $\mathrm{~N}$ & 34.00 & 15.60 & $150-400$ & 1.11 & 15.60 \\
\hline $103 / 1$ & 142.31 & 466.89 & 0H264 & $\mathrm{N}$ & 49.80 & 262.40 & $150-300$ & 1.34 & 12.50 \\
\hline $104 / 1$ & 143.56 & 470.99 & 0H365 & $\mathrm{N}$ & 44.80 & 203.50 & $150-300$ & 1.79 & 7.00 \\
\hline $105 / 1$ & 145.15 & 476.20 & $0 \mathrm{H} 366$ & $\mathrm{~N}$ & 44.50 & 339.10 & $150-400$ & 1.66 & 11.20 \\
\hline $106 / 1$ & 146.76 & 481.51 & 0H367 & $\mathrm{N}$ & 45.00 & 21.90 & $150-400$ & 1.99 & 11.10 \\
\hline $107 / 1$ & 148.42 & 486.94 & 0H368 & $\mathrm{N}$ & 39.70 & 199.50 & $150-400$ & 38.20 & 1.80 \\
\hline $108 / 1$ & 149.51 & 490.52 & $0 \mathrm{H} 369$ & $\mathrm{~N}$ & 46.90 & 44.40 & $150-400$ & 30.30 & 1.70 \\
\hline $109 / 1$ & 151.39 & 496.69 & $0 \mathrm{H} 370$ & $\mathrm{~N}$ & 46.60 & 248.70 & $150-300$ & 172.00 & 2.70 \\
\hline $110 / 1$ & 152.96 & 501.85 & 0H371 & $\mathrm{N}$ & 36.60 & 314.40 & $150-400$ & 34.90 & 5.50 \\
\hline $111 / 1$ & 154.26 & 506.10 & 0H372 & $\mathrm{N}$ & 44.00 & 299.90 & $100-300$ & 20.60 & 4.80 \\
\hline $112 / 1$ & 155.87 & 511.40 & 0H373 & $\mathrm{N}$ & 32.90 & 256.80 & $100-300$ & 16.30 & 3.50 \\
\hline $113 / 1$ & 157.66 & 517.27 & 0H374 & $\mathrm{N}$ & 41.00 & 187.80 & $100-300$ & 17.00 & 4.20 \\
\hline $114 / 1$ & 159.27 & 522.53 & 0H375 & $\mathrm{N}$ & 47.80 & 252.00 & $100-300$ & 29.30 & 2.80 \\
\hline $115 / 1$ & 160.73 & 527.32 & 0H376 & $\mathrm{N}$ & 58.90 & 24.30 & $150-300$ & 22.70 & 7.10 \\
\hline $116 / 1$ & 161.53 & 529.94 & 0H377 & $\mathrm{N}$ & 42.20 & 337.20 & $150-400$ & 86.30 & 1.90 \\
\hline $117 / 1$ & 163.56 & 536.63 & 0H378 & $\mathrm{N}$ & 35.30 & 210.20 & $200-400$ & 73.80 & 1.40 \\
\hline $118 / 1$ & 164.84 & 540.82 & 0H379 & $\mathrm{N}$ & 35.10 & 88.00 & $150-300$ & 38.80 & 3.80 \\
\hline $119 / 1$ & 166.54 & 546.38 & $0 \mathrm{H} 380$ & $\mathrm{~N}$ & 50.80 & 29.80 & $200-400$ & 61.50 & 2.90 \\
\hline $120 / 1$ & 168.09 & 551.46 & 0H381 & $\mathrm{N}$ & 38.70 & 135.50 & $100-300$ & 32.20 & 2.00 \\
\hline $121 / 1$ & 169.72 & 556.81 & 0H382 & $\mathrm{N}$ & 39.00 & 266.90 & $150-400$ & 66.00 & 3.30 \\
\hline
\end{tabular}




\begin{tabular}{|c|c|c|c|c|c|c|c|c|c|}
\hline $122 / 1$ & 171.08 & 561.30 & 0H383 & $\mathrm{N}$ & 39.60 & 162.20 & $150-300$ & 13.20 & 11.70 \\
\hline $123 / 1$ & 172.60 & 566.28 & 0H384 & $\mathrm{N}$ & 57.70 & 235.90 & $150-300$ & 2.50 & 9.10 \\
\hline $128 / 1$ & 177.71 & 583.04 & $0 \mathrm{H} 385$ & $\mathrm{~N}$ & 47.90 & 224.70 & $150-400$ & 0.92 & 19.80 \\
\hline $129 / 1$ & 178.60 & 585.97 & 0H386 & $\mathrm{N}$ & 56.20 & 166.30 & $100-300$ & 20.00 & 12.90 \\
\hline $130 / 1$ & 179.07 & 587.50 & 0H387 & $\mathrm{N}$ & 70.10 & 58.90 & $150-300$ & 1.07 & 27.00 \\
\hline $135 / 1$ & 183.65 & 602.54 & 0H388 & $\mathrm{N}$ & 70.60 & 52.00 & $150-400$ & 1.25 & 34.40 \\
\hline $136 / 1$ & 184.12 & 604.08 & 0H389 & $\mathrm{N}$ & 48.30 & 299.90 & $100-300$ & 1.96 & 9.80 \\
\hline $137 / 1$ & 185.84 & 609.72 & 0H390 & $\mathrm{N}$ & 48.40 & 195.10 & $150-300$ & 1.98 & 7.00 \\
\hline $139 / 1$ & 189.74 & 622.51 & 0H391 & $\mathrm{N}$ & 40.30 & 357.40 & $100-300$ & 16.80 & 14.80 \\
\hline $141 / 1$ & 192.16 & 630.46 & 0H392 & $\mathrm{N}$ & 57.00 & 172.60 & $100-300$ & 6.86 & 9.80 \\
\hline $143 / 1$ & 195.66 & 641.92 & 0H393 & $\mathrm{I}$ & 19.60 & 334.00 & $100-300$ & 21.30 & 46.10 \\
\hline $144 / 1$ & 197.12 & 646.72 & 0H394 & $\mathrm{I}$ & 18.90 & 194.80 & $150-400$ & 0.95 & 17.00 \\
\hline $145 / 1$ & 198.22 & 650.33 & 0H395 & $\mathrm{I}$ & 14.60 & 339.90 & $150-300$ & 0.87 & 28.70 \\
\hline $146 / 1$ & 200.33 & 657.25 & 0H396 & $\mathrm{N}$ & 48.50 & 352.80 & $100-300$ & 2.02 & 10.70 \\
\hline $150 / 1$ & 206.21 & 676.53 & 0H397 & $\mathrm{N}$ & 56.50 & 165.80 & $150-400$ & 4.06 & 7.10 \\
\hline $151 / 1$ & 207.79 & 681.74 & 0H398 & $\mathrm{N}$ & 44.30 & 40.00 & $200-400$ & 6.19 & 2.90 \\
\hline $152 / 1$ & 209.11 & 686.05 & 0H399 & $\mathrm{N}$ & 51.40 & 118.50 & $200-400$ & 11.60 & 3.80 \\
\hline $153 / 1$ & 210.56 & 690.80 & 0H400 & $\mathrm{N}$ & 45.90 & 218.10 & $150-400$ & 47.40 & 1.90 \\
\hline $154 / 1$ & 212.22 & 696.27 & 0H401 & $\mathrm{N}$ & 45.40 & 112.70 & $150-300$ & 22.20 & 5.10 \\
\hline $155 / 1$ & 214.01 & 702.12 & 0H402 & $\mathrm{N}$ & 57.10 & 176.10 & $150-300$ & 2.55 & 6.30 \\
\hline $156 / 1$ & 215.44 & 706.84 & 0H403 & $\mathrm{N}$ & 49.20 & 324.70 & $150-400$ & 7.46 & 2.60 \\
\hline $158 / 1$ & 218.43 & 716.62 & 0H404 & $\mathrm{N}$ & 53.70 & 119.50 & $100-300$ & 1.56 & 20.50 \\
\hline $159 / 1$ & 220.07 & 722.00 & 0H405 & $\mathrm{N}$ & 42.40 & 182.40 & $100-300$ & 9.14 & 9.70 \\
\hline $161 / 1$ & 223.01 & 731.67 & 0H406 & $\mathrm{N}$ & 47.40 & 199.40 & $150-300$ & 1.97 & 11.50 \\
\hline $162 / 1$ & 224.39 & 736.20 & 0H407 & $\mathrm{N}$ & 86.90 & 163.30 & $150-400$ & 3.54 & 6.40 \\
\hline $163 / 1$ & 226.38 & 742.72 & 0H408 & $\mathrm{N}$ & 41.80 & 325.10 & $200-400$ & 7.11 & 6.60 \\
\hline $164 / 1$ & 227.05 & 744.92 & 0H409 & $\mathrm{N}$ & 47.00 & 76.80 & $150-400$ & 1.30 & 28.20 \\
\hline $165 / 1$ & 229.25 & 752.12 & 0H410 & $\mathrm{N}$ & 65.10 & 348.80 & $200-400$ & 1.42 & 1.50 \\
\hline $166 / 1$ & 230.33 & 755.69 & 0H411 & $\mathrm{N}$ & 46.10 & 200.60 & $100-300$ & 2.34 & 28.50 \\
\hline $167 / 1$ & 232.42 & 762.53 & 0H412 & $\mathrm{N}$ & 42.50 & 90.50 & $100-400$ & 1.41 & 21.90 \\
\hline $168 / 1$ & 233.34 & 765.56 & 0H413 & $\mathrm{N}$ & 60.10 & 128.80 & $100-300$ & 0.63 & 30.00 \\
\hline $171 / 1$ & 237.58 & 779.46 & 0H414 & $\mathrm{N}$ & 30.60 & 211.20 & $100-200$ & 6.27 & 12.50 \\
\hline $173 / 1$ & 240.80 & 790.01 & 0H415 & $\mathrm{N}$ & 51.30 & 211.70 & $100-200$ & 10.70 & 5.90 \\
\hline $173 / 1$ & 241.15 & 791.18 & 0H416 & $\mathrm{N}$ & 60.60 & 224.20 & $100-200$ & 15.30 & 12.00 \\
\hline $176 / 1$ & 246.01 & 807.13 & 0H418 & $\mathrm{N}$ & 47.00 & 116.00 & $100-300$ & 5.22 & 10.40 \\
\hline $177 / 1$ & 246.93 & 810.13 & 0H417 & $\mathrm{N}$ & 51.90 & 42.70 & $100-300$ & 5.80 & 11.00 \\
\hline $182 / 1$ & 253.44 & 831.48 & 0H419 & $\mathrm{N}$ & 50.60 & 189.00 & $150-300$ & 0.81 & 4.70 \\
\hline $183 / 1$ & 254.86 & 836.15 & 0H420 & $\mathrm{N}$ & 47.30 & 225.80 & $150-300$ & 1.09 & 5.70 \\
\hline $183 / 1$ & 255.04 & 836.74 & 0H421 & $\mathrm{N}$ & 44.10 & 240.30 & $150-300$ & 0.71 & 4.40 \\
\hline $184 / 1$ & 256.38 & 841.14 & 0H422 & $\mathrm{N}$ & 58.20 & 275.90 & $150-300$ & 0.81 & 7.50 \\
\hline $185 / 1$ & 258.07 & 846.67 & $0 \mathrm{H} 423$ & $\mathrm{~N}$ & 50.10 & 234.70 & $150-300$ & 0.83 & 6.40 \\
\hline $186 / 1$ & 259.68 & 851.96 & $0 \mathrm{H} 424$ & $\mathrm{~N}$ & 53.70 & 176.60 & $150-300$ & 1.72 & 5.20 \\
\hline $187 / 1$ & 261.09 & 856.59 & 0H425 & $\mathrm{N}$ & 49.50 & 73.80 & $150-300$ & 1.26 & 6.10 \\
\hline $188 / 1$ & 262.71 & 861.90 & $0 \mathrm{H} 426$ & $\mathrm{~N}$ & 72.00 & 23.20 & $150-300$ & 2.46 & 12.00 \\
\hline $189 / 1$ & 264.43 & 867.56 & 0H427 & $\mathrm{N}$ & 51.40 & 197.50 & $200-300$ & 3.08 & 0.70 \\
\hline $190 / 1$ & 266.01 & 872.75 & 0H428 & $\mathrm{N}$ & 56.80 & 228.90 & $150-400$ & 1.21 & 23.20 \\
\hline $191 / 1$ & 266.85 & 875.49 & 0H429 & $\mathrm{N}$ & 45.80 & 323.10 & $150-400$ & 1.07 & 8.70 \\
\hline $192 / 1$ & 268.70 & 881.56 & 0H430 & $\mathrm{N}$ & 43.40 & 40.50 & $100-300$ & 1.49 & 12.80 \\
\hline $193 / 1$ & 270.11 & 886.18 & 0H431 & $\mathrm{N}$ & 43.00 & 354.80 & $150-300$ & 1.98 & 7.30 \\
\hline $194 / 1$ & 271.72 & 891.48 & 0H432 & $\mathrm{N}$ & 54.50 & 320.40 & $150-400$ & 1.44 & 8.00 \\
\hline $195 / 1$ & 273.25 & 896.48 & 0H433 & $\mathrm{N}$ & 30.00 & 35.40 & $100-300$ & 2.13 & 19.90 \\
\hline $196 / 1$ & 274.87 & 901.82 & 0H434 & $\mathrm{N}$ & 48.20 & 316.00 & $200-400$ & 3.51 & 5.70 \\
\hline $197 / 1$ & 276.27 & 906.40 & 0H435 & $\mathrm{N}$ & 40.10 & 148.90 & $150-400$ & 2.90 & 5.30 \\
\hline 198/1 & 277.58 & 910.71 & 0H436 & $\mathrm{N}$ & 40.60 & 216.40 & $200-400$ & 3.36 & 13.30 \\
\hline $199 / 1$ & 279.27 & 916.25 & 0H437 & $\mathrm{N}$ & 60.10 & 359.70 & $150-300$ & 6.03 & 3.60 \\
\hline $200 / 1$ & 280.94 & 921.73 & 0H438 & $\mathrm{N}$ & 53.70 & 357.10 & $200-500$ & 14.50 & 5.20 \\
\hline
\end{tabular}




\begin{tabular}{|c|c|c|c|c|c|c|c|c|c|}
\hline $201 / 1$ & 282.14 & 925.65 & 0H439 & $\mathrm{N}$ & 54.00 & 353.20 & $100-400$ & 4.68 & 5.10 \\
\hline $202 / 1$ & 283.96 & 931.64 & $0 \mathrm{H} 440$ & $\mathrm{~N}$ & 41.40 & 87.80 & $150-400$ & 2.16 & 8.80 \\
\hline 203/1 & 285.35 & 936.18 & 0H441 & $\mathrm{N}$ & 49.40 & 296.60 & $150-300$ & 2.97 & 5.80 \\
\hline $204 / 1$ & 287.01 & 941.62 & 0H442 & $\mathrm{N}$ & 45.20 & 295.20 & $200-400$ & 17.60 & 3.40 \\
\hline $205 / 1$ & 288.49 & 946.49 & 0H443 & $\mathrm{N}$ & 41.90 & 280.10 & $200-400$ & 5.79 & 9.20 \\
\hline $206 / 1$ & 289.80 & 950.80 & 0H444 & $\mathrm{N}$ & 49.20 & 267.00 & $300-500$ & 30.70 & 5.10 \\
\hline $207 / 1$ & 291.47 & 956.28 & 0H445 & $\mathrm{N}$ & 51.70 & 336.20 & $200-500$ & 10.20 & 5.70 \\
\hline $208 / 1$ & 293.02 & 961.36 & 0H446 & $\mathrm{N}$ & 53.40 & 333.80 & $150-400$ & 10.50 & 1.60 \\
\hline $209 / 1$ & 293.98 & 964.49 & 0H447 & $\mathrm{N}$ & 51.30 & 346.10 & $150-400$ & 12.50 & 2.40 \\
\hline $210 / 1$ & 296.21 & 971.83 & 0H448 & $\mathrm{N}$ & 55.30 & 173.10 & $150-400$ & 6.94 & 7.40 \\
\hline $211 / 1$ & 297.31 & 975.43 & 0H449 & $\mathrm{N}$ & 50.00 & 335.30 & $200-500$ & 18.10 & 2.00 \\
\hline $213 / 1$ & 299.98 & 984.18 & 0H450 & $\mathrm{N}$ & 67.50 & 179.30 & $150-300$ & 17.20 & 4.80 \\
\hline $214 / 1$ & 300.64 & 986.36 & $0 \mathrm{H} 453$ & $\mathrm{~N}$ & 52.60 & 261.20 & $150-400$ & 1.81 & 14.30 \\
\hline $215 / 1$ & 302.33 & 991.89 & 0H455 & $\mathrm{N}$ & 55.40 & 16.40 & $150-300$ & 6.46 & 5.70 \\
\hline $216 / 1$ & 303.57 & 995.97 & 0H456 & $\mathrm{N}$ & 71.10 & 244.40 & $150-300$ & 3.78 & 3.00 \\
\hline $217 / 1$ & 305.05 & 1000.82 & $1 \mathrm{H} 001$ & $\mathrm{~N}$ & 47.10 & 126.30 & $150-400$ & 29.30 & 8.40 \\
\hline $218 / 1$ & 306.94 & 1007.03 & $1 \mathrm{H} 002$ & $\mathrm{~N}$ & 48.60 & 170.70 & $200-400$ & 60.90 & 6.20 \\
\hline $219 / 1$ & 308.19 & 1011.13 & $1 \mathrm{H} 003$ & $\mathrm{~N}$ & 45.00 & 170.10 & $150-400$ & 57.30 & 5.00 \\
\hline $219 / 2$ & 309.15 & 1014.28 & 0H454 & $\mathrm{N}$ & 57.40 & 143.70 & $150-400$ & 3.53 & 8.10 \\
\hline $220 / 1$ & 311.07 & 1020.57 & 0H457 & $\mathrm{N}$ & 75.30 & 118.80 & $150-400$ & 10.30 & 14.60 \\
\hline $220 / 1$ & 311.63 & 1022.41 & 0H458 & $\mathrm{N}$ & 45.40 & 17.90 & $150-400$ & 1.48 & 9.10 \\
\hline $220 / 2$ & 313.06 & 1027.09 & $1 \mathrm{H} 004$ & $\mathrm{~N}$ & 49.20 & 151.00 & $150-400$ & 133.00 & 2.60 \\
\hline $221 / 1$ & 314.30 & 1031.18 & $1 \mathrm{H} 005$ & $\mathrm{~N}$ & 56.10 & 40.90 & $150-400$ & 26.30 & 2.70 \\
\hline $221 / 2$ & 315.33 & 1034.54 & 0H459 & $\mathrm{N}$ & 56.30 & 290.30 & $150-400$ & 15.10 & 6.30 \\
\hline $222 / 2$ & 316.92 & 1039.76 & 0H451 & $\mathrm{N}$ & 44.90 & 16.60 & $150-400$ & 66.80 & 2.20 \\
\hline $222 / 2$ & 317.89 & 1042.95 & 0H452 & $\mathrm{N}$ & 46.20 & 67.50 & $200-500$ & 33.30 & 3.10 \\
\hline $223 / 1$ & 329.56 & 1081.23 & $1 \mathrm{H} 006$ & $\mathrm{~N}$ & 40.00 & 153.60 & $150-400$ & 14.70 & 5.20 \\
\hline $223 / 2$ & 331.15 & 1086.45 & $1 \mathrm{H} 007$ & $\mathrm{~N}$ & 51.30 & 309.80 & $100-400$ & 34.60 & 6.40 \\
\hline $224 / 2$ & 333.26 & 1093.36 & $1 \mathrm{H} 008$ & $\mathrm{~N}$ & 40.60 & 48.60 & $100-300$ & 2.25 & 8.30 \\
\hline $225 / 1$ & 335.65 & 1101.20 & $1 \mathrm{H} 009$ & $\mathrm{~N}$ & 41.00 & 2.90 & $150-300$ & 36.70 & 2.60 \\
\hline $225 / 2$ & 337.15 & 1106.13 & $1 \mathrm{H} 011$ & $\mathrm{~N}$ & 43.70 & 40.30 & $150-300$ & 32.90 & 2.80 \\
\hline $227 / 1$ & 348.47 & 1143.26 & $1 \mathrm{H} 012$ & $\mathrm{~N}$ & 48.90 & 42.10 & $200-500$ & 0.49 & 9.80 \\
\hline $227 / 2$ & 349.42 & 1146.38 & $1 \mathrm{H} 010$ & $\mathrm{~N}$ & 58.40 & 96.90 & $50-150$ & 13.00 & 5.50 \\
\hline $228 / 1$ & 357.49 & 1172.88 & $1 \mathrm{H} 013$ & $\mathrm{~N}$ & 54.90 & 204.50 & $100-200$ & 2.64 & 7.90 \\
\hline $228 / 2$ & 359.11 & 1178.18 & $1 \mathrm{H} 014$ & $\mathrm{~N}$ & 34.50 & 129.70 & $100-200$ & 1.62 & 15.50 \\
\hline $229 / 1$ & 360.37 & 1182.33 & $1 \mathrm{H} 015$ & $\mathrm{~N}$ & 55.50 & 1.70 & $100-200$ & 10.60 & 5.20 \\
\hline $229 / 2$ & 361.36 & 1185.56 & $1 \mathrm{H} 016$ & $\mathrm{~N}$ & 48.70 & 289.90 & $150-300$ & 58.80 & 2.00 \\
\hline $232 / 1$ & 375.45 & 1231.78 & $1 \mathrm{H} 017$ & $\mathrm{~N}$ & 46.20 & 78.30 & $100-200$ & 2.09 & 7.80 \\
\hline $232 / 2$ & 376.27 & 1234.48 & $1 \mathrm{H} 018$ & $\mathrm{~N}$ & 52.20 & 254.10 & $100-200$ & 1.61 & 6.90 \\
\hline $233 / 1$ & 399.08 & 1309.33 & $1 \mathrm{H} 027$ & $\mathrm{~N}$ & 49.20 & 293.90 & $100-200$ & 3.17 & 19.60 \\
\hline $233 / 2$ & 399.78 & 1311.62 & $1 \mathrm{H} 024$ & $\mathrm{~N}$ & 60.70 & 110.60 & $100-200$ & 13.20 & 9.60 \\
\hline $233 / 2$ & 400.45 & 1313.81 & $1 \mathrm{H} 025$ & $\mathrm{~N}$ & 60.00 & 74.90 & $100-200$ & 20.20 & 7.50 \\
\hline $233 / 2$ & 401.01 & 1315.66 & $1 \mathrm{H} 026$ & $\mathrm{~N}$ & 42.20 & 69.00 & $200-400$ & 11.60 & 15.30 \\
\hline $234 / 1$ & 420.58 & 1379.85 & $1 \mathrm{H} 028$ & $\mathrm{~N}$ & 43.70 & 268.40 & $100-200$ & 6.98 & 1.20 \\
\hline $234 / 2$ & 422.76 & 1387.01 & $1 \mathrm{H} 029$ & $\mathrm{~N}$ & 42.90 & 20.50 & $200-400$ & 15.80 & 4.60 \\
\hline Resample & 0.00 & & & & & & & & \\
\hline $93 \mathrm{C} / 1$ & 126.24 & 414.17 & $5 \mathrm{H} 001$ & $\mathrm{~N}$ & 27.90 & 139.10 & $300-400$ & 1.08 & 15.90 \\
\hline $93 \mathrm{C} / 1$ & 127.35 & 417.82 & $5 \mathrm{H} 002$ & $\mathrm{~N}$ & 58.10 & 193.40 & $250-400$ & 0.48 & 14.30 \\
\hline $94 \mathrm{C} / 1$ & 128.09 & 420.25 & $5 \mathrm{H} 003$ & $\mathrm{~N}$ & 58.00 & 124.80 & $200-350$ & 0.56 & 32.00 \\
\hline $94 \mathrm{C} / 1$ & 128.67 & 422.15 & $5 \mathrm{H} 004$ & $\mathrm{~N}$ & 54.40 & 294.10 & $150-300$ & 0.45 & 16.30 \\
\hline $94 \mathrm{C} / 1$ & 129.02 & 423.31 & $5 \mathrm{H} 005$ & $\mathrm{~N}$ & 40.20 & 357.70 & $250-400$ & 0.67 & 25.90 \\
\hline $95 \mathrm{C} / 1$ & 129.36 & 424.41 & $5 \mathrm{H} 006$ & $\mathrm{~N}$ & 53.50 & 19.80 & $200-400$ & 0.88 & 14.20 \\
\hline $95 \mathrm{C} / 1$ & 129.94 & 426.31 & $5 \mathrm{H} 007$ & $\mathrm{~N}$ & 49.00 & 20.20 & $150-300$ & 0.77 & 10.00 \\
\hline $95 \mathrm{C} / 1$ & 130.40 & 427.83 & 5H008 & $\mathrm{N}$ & 42.70 & 129.60 & $250-400$ & 0.61 & 16.30 \\
\hline $96 \mathrm{C} / 1$ & 130.86 & 429.33 & $5 \mathrm{H} 009$ & $\mathrm{~N}$ & 45.60 & 275.40 & $150-300$ & 0.82 & 9.80 \\
\hline $96 \mathrm{C} / 1$ & 131.20 & 430.46 & $5 \mathrm{H} 010$ & $\mathrm{~N}$ & 45.70 & 211.80 & $200-350$ & 1.12 & 8.50 \\
\hline
\end{tabular}




\begin{tabular}{|c|c|c|c|c|c|c|c|c|c|}
\hline $96 \mathrm{C} / 1$ & 131.79 & 432.38 & $5 \mathrm{H} 011$ & $\mathrm{~N}$ & 40.90 & 150.70 & $150-250$ & 0.84 & 22.10 \\
\hline $96 \mathrm{C} / 1$ & 132.09 & 433.36 & $5 \mathrm{H} 012$ & $\mathrm{~N}$ & 32.30 & 111.00 & $150-350$ & 0.74 & 8.90 \\
\hline $97 \mathrm{C} / 1$ & 132.47 & 434.62 & $5 \mathrm{H} 013$ & $\mathrm{~N}$ & 52.90 & 206.00 & $150-300$ & 1.22 & 11.80 \\
\hline $97 \mathrm{C} / 1$ & 133.18 & 436.93 & $5 \mathrm{H} 014$ & $\mathrm{~N}$ & 61.30 & 101.90 & $150-300$ & 0.92 & 18.80 \\
\hline $97 \mathrm{C} / 1$ & 133.45 & 437.82 & $5 \mathrm{H} 015$ & $\mathrm{~N}$ & 44.50 & 126.40 & $150-400$ & 0.53 & 27.60 \\
\hline $98 \mathrm{C} / 1$ & 133.91 & 439.33 & $5 \mathrm{H} 016$ & $\mathrm{~N}$ & 46.50 & 154.50 & $150-350$ & 1.08 & 10.20 \\
\hline $98 \mathrm{C} / 1$ & 134.17 & 440.19 & $5 \mathrm{H} 017$ & $\mathrm{~N}$ & 52.30 & 129.20 & $150-350$ & 0.78 & 16.80 \\
\hline $98 \mathrm{C} / 1$ & 134.88 & 442.51 & $5 \mathrm{H} 018$ & $\mathrm{~N}$ & 46.50 & 151.80 & $150-300$ & 0.86 & 8.00 \\
\hline $98 \mathrm{C} / 1$ & 135.14 & 443.37 & $5 \mathrm{H} 019$ & $\mathrm{~N}$ & 31.50 & 287.20 & $150-300$ & 0.62 & 7.50 \\
\hline $99 \mathrm{C} / 1$ & 135.45 & 444.40 & $5 \mathrm{H} 020$ & $\mathrm{~N}$ & 45.90 & 356.20 & $150-300$ & 1.45 & 10.20 \\
\hline $99 \mathrm{C} / 1$ & 135.75 & 445.38 & $5 \mathrm{H} 021$ & I & 15.60 & 309.50 & $150-350$ & 1.38 & 0.00 \\
\hline $99 \mathrm{C} / 1$ & 136.08 & 446.45 & $5 \mathrm{H} 022$ & $\mathrm{~N}$ & 51.30 & 259.70 & $150-300$ & 1.74 & 9.10 \\
\hline $99 \mathrm{C} / 1$ & 136.52 & 447.89 & $5 \mathrm{H} 023$ & $\mathrm{~N}$ & 32.70 & 166.00 & $150-300$ & 1.54 & 8.90 \\
\hline
\end{tabular}


Table 10. Intensity of remanent magnetization and magnetic susceptibility of Long Beach Cabrillo High School core site and monitoring well (LBCH), Long Beach, California, samples.

[RML Id, Rock Magnetism Laboratory identification number; Jnrm, intensity of natural remanent magnetization $(\mathrm{mA} / \mathrm{m}) ; \mathrm{J} 15$, intensity of magnetization after alternating-field treatments of $15 \mathrm{mT}$; J30, intensity of magnetization after alternating-field treatments of $30 \mathrm{mT}$; K, magnetic susceptibility (10-6 SI)]

\begin{tabular}{|c|c|c|c|c|c|c|c|c|c|c|c|}
\hline $\begin{array}{c}\text { Core } \\
\text { number }\end{array}$ & $\begin{array}{l}\text { Depth, } \\
\text { in } \\
\text { meters }\end{array}$ & $\begin{array}{l}\text { Depth, } \\
\text { in feet }\end{array}$ & $\begin{array}{c}\text { RML } \\
\text { Id }\end{array}$ & $\begin{array}{c}\text { Jnrm } \\
(\mathbf{m A} / \mathbf{m})\end{array}$ & LogJnrm & $\begin{array}{c}\mathrm{J15} \\
(\mathrm{mA} / \mathrm{m})\end{array}$ & J15/Jnrm & $\begin{array}{c}\mathbf{J 3 0} \\
(\mathbf{m A} / \mathbf{m})\end{array}$ & J30/Jnrm & $\begin{array}{c}\mathrm{K} \\
10 \mathrm{E}-6 \\
\text { SI }\end{array}$ & $\mathbf{J n r m} / \mathbf{K}$ \\
\hline $4 / 1$ & 4.04 & 13.25 & $2 \mathrm{H} 072$ & 57.80 & 1.76 & 28.00 & 0.48 & 17.90 & 0.31 & 31 & 1.86 \\
\hline $7 / 1$ & 6.48 & 21.26 & $2 \mathrm{H} 073$ & 1.02 & 0.01 & 0.66 & 0.64 & 0.33 & 0.33 & 4 & 0.26 \\
\hline $8 / 1$ & 7.17 & 23.52 & $2 \mathrm{H} 074$ & 22.40 & 1.35 & 3.36 & 0.15 & & 0.00 & 26 & 0.86 \\
\hline $9 / 1$ & 8.12 & 26.64 & $2 \mathrm{H} 075$ & 122.00 & 2.09 & 41.40 & 0.34 & 24.70 & 0.20 & 31 & 3.94 \\
\hline $11 / 1$ & 9.48 & 31.10 & $2 \mathrm{H} 076$ & 35.20 & 1.55 & 17.50 & 0.50 & 1.02 & 0.03 & 23 & 1.53 \\
\hline $12 / 1$ & 10.30 & 33.79 & $2 \mathrm{H} 077$ & 84.40 & 1.93 & 31.10 & 0.37 & 12.80 & 0.15 & 43 & 1.96 \\
\hline $15 / 1$ & 13.45 & 44.13 & $2 \mathrm{H} 078$ & 145.00 & 2.16 & 45.60 & 0.31 & 23.70 & 0.16 & 66 & 2.20 \\
\hline $17 / 1$ & 14.81 & 48.59 & $2 \mathrm{H} 079$ & 168.00 & 2.23 & 37.60 & 0.22 & 16.10 & 0.10 & 140 & 1.20 \\
\hline $19 / 1$ & 16.48 & 54.07 & $2 \mathrm{H} 080$ & 106.00 & 2.03 & 31.90 & 0.30 & & 0.00 & 66 & 1.61 \\
\hline $25 / 1$ & 21.66 & 71.06 & $2 \mathrm{H} 081$ & 90.30 & 1.96 & 8.58 & 0.10 & 4.52 & 0.05 & 145 & 0.62 \\
\hline $33 / 1$ & 29.01 & 95.18 & $2 \mathrm{H} 082$ & 13.60 & 1.13 & & 0.00 & 6.31 & 0.46 & 37 & 0.37 \\
\hline $41 / 1$ & 39.57 & 129.82 & $2 \mathrm{H} 083$ & 1.39 & 0.14 & 0.51 & 0.37 & & 0.00 & 21 & 0.07 \\
\hline $42 / 1$ & 40.95 & 134.35 & $2 \mathrm{H} 084$ & 9.67 & 0.99 & 1.30 & 0.13 & 0.56 & 0.06 & 13 & 0.74 \\
\hline $45 / 1$ & 45.27 & 148.52 & $2 \mathrm{H} 085$ & 96.00 & 1.98 & 4.32 & 0.05 & & 0.00 & 89 & 1.08 \\
\hline $47 / 1$ & 48.14 & 157.94 & $2 \mathrm{H} 086$ & 19.80 & 1.30 & 1.54 & 0.08 & 0.35 & 0.02 & 13 & 1.52 \\
\hline $49 / 1$ & 50.93 & 167.09 & $2 \mathrm{H} 087$ & 38.50 & 1.59 & 2.81 & 0.07 & 0.79 & 0.02 & 41 & 0.94 \\
\hline $50 / 1$ & 52.45 & 172.08 & $2 \mathrm{H} 088$ & 7.27 & 0.86 & 0.95 & 0.13 & 0.52 & 0.07 & 8 & 0.91 \\
\hline $60 / 1$ & 65.81 & 215.91 & $2 \mathrm{H} 089$ & 3.04 & 0.48 & 1.38 & 0.45 & 0.67 & 0.22 & 3 & 1.01 \\
\hline $63 / 1$ & 70.33 & 230.74 & $2 \mathrm{H} 090$ & 0.62 & -0.21 & 0.24 & 0.39 & & 0.00 & 3 & 0.21 \\
\hline $64 / 1$ & 71.69 & 235.20 & $2 \mathrm{H} 091$ & 0.70 & -0.15 & & 0.00 & 0.15 & 0.21 & 1 & 0.70 \\
\hline $68 / 1$ & 76.65 & 251.48 & $2 \mathrm{H} 092$ & 1.33 & 0.12 & 0.35 & 0.26 & 0.27 & 0.20 & 4 & 0.33 \\
\hline $70 / 1$ & 80.02 & 262.53 & $2 \mathrm{H} 093$ & 1.52 & 0.18 & 0.37 & 0.24 & 0.48 & 0.32 & 13 & 0.12 \\
\hline $71 / 1$ & 81.68 & 267.98 & 2H141 & 12.30 & 1.09 & 1.35 & 0.11 & 0.89 & 0.07 & 36 & 0.34 \\
\hline $72 / 1$ & 82.99 & 272.28 & $2 \mathrm{H} 095$ & 158.00 & 2.20 & 1.25 & 0.01 & & 0.00 & 17 & 9.29 \\
\hline $73 / 1$ & 84.07 & 275.82 & $2 \mathrm{H} 096$ & 5.61 & 0.75 & 0.82 & 0.15 & & 0.00 & 7 & 0.80 \\
\hline $74 / 1$ & 86.08 & 282.41 & $2 \mathrm{H} 097$ & 1.86 & 0.27 & 0.87 & 0.47 & & 0.00 & 5 & 0.37 \\
\hline $75 / 1$ & 87.59 & 287.37 & $2 \mathrm{H} 098$ & 3.89 & 0.59 & 1.18 & 0.30 & 0.53 & 0.14 & 8 & 0.49 \\
\hline $76 / 1$ & 88.53 & 290.45 & $2 \mathrm{H} 099$ & 0.59 & -0.23 & 0.48 & 0.80 & 0.27 & 0.46 & 5 & 0.12 \\
\hline $77 / 1$ & 90.74 & 297.70 & $2 \mathrm{H} 100$ & 0.87 & -0.06 & 0.48 & 0.55 & 0.21 & 0.24 & 2 & 0.44 \\
\hline $78 / 1$ & 92.11 & 302.20 & $2 \mathrm{H} 101$ & 2.10 & 0.32 & 0.51 & 0.24 & 0.46 & 0.22 & 10 & 0.21 \\
\hline $79 / 1$ & 93.56 & 306.96 & $2 \mathrm{H} 102$ & 9.77 & 0.99 & 1.49 & 0.15 & 0.47 & 0.05 & 6 & 1.63 \\
\hline $80 / 1$ & 95.67 & 313.88 & $2 \mathrm{H} 103$ & 1.60 & 0.20 & 0.70 & 0.44 & 0.22 & 0.14 & 10 & 0.16 \\
\hline $81 / 1$ & 96.14 & 315.42 & $2 \mathrm{H} 104$ & 5.09 & 0.71 & 0.59 & 0.12 & 0.15 & 0.03 & 9 & 0.57 \\
\hline $82 / 1$ & 98.30 & 322.51 & $2 \mathrm{H} 105$ & 3.50 & 0.54 & 0.86 & 0.25 & & 0.00 & 22 & 0.16 \\
\hline $83 / 1$ & 99.32 & 325.85 & $2 \mathrm{H} 106$ & 10.30 & 1.01 & 1.08 & 0.10 & & 0.00 & 21 & 0.49 \\
\hline $85 / 1$ & 102.49 & 336.25 & $2 \mathrm{H} 107$ & 0.63 & -0.20 & 0.30 & 0.48 & 0.17 & 0.27 & 5 & 0.13 \\
\hline $86 / 1$ & 104.24 & 341.99 & $2 \mathrm{H} 108$ & 3.85 & 0.59 & 1.41 & 0.37 & 0.62 & 0.16 & 8 & 0.48 \\
\hline $87 / 1$ & 105.40 & 345.80 & 2H109 & 4.40 & 0.64 & 0.99 & 0.22 & & 0.00 & 7 & 0.63 \\
\hline $88 / 1$ & 107.29 & 352.00 & $2 \mathrm{H} 110$ & 1.94 & 0.29 & 0.89 & 0.46 & 0.33 & 0.17 & 7 & 0.28 \\
\hline $89 / 1$ & 108.50 & 355.97 & $2 \mathrm{H} 094$ & 2.80 & 0.45 & 1.05 & 0.38 & & 0.00 & 3 & 0.93 \\
\hline $90 / 1$ & 110.09 & 361.19 & $2 \mathrm{H} 111$ & 13.20 & 1.12 & 1.38 & 0.10 & & 0.00 & 17 & 0.78 \\
\hline $91 / 1$ & 111.26 & 365.03 & $2 \mathrm{H} 112$ & 36.90 & 1.57 & 3.30 & 0.09 & & 0.00 & 35 & 1.05 \\
\hline $92 / 1$ & 113.10 & 371.06 & $2 \mathrm{H} 113$ & 48.40 & 1.68 & 4.70 & 0.10 & & 0.00 & 72 & 0.67 \\
\hline $95 / 1$ & 116.34 & 381.69 & $2 \mathrm{H} 114$ & 24.60 & 1.39 & & 0.00 & 0.47 & 0.02 & 28 & 0.88 \\
\hline $96 / 1$ & 118.28 & 388.06 & $2 \mathrm{H} 115$ & 10.20 & 1.01 & 1.13 & 0.11 & & 0.00 & 29 & 0.35 \\
\hline
\end{tabular}




\begin{tabular}{|c|c|c|c|c|c|c|c|c|c|c|c|}
\hline $105 / 1$ & 131.90 & 432.74 & 2H116 & 100.00 & 2.00 & 1.82 & 0.02 & 1.12 & 0.01 & 13 & 7.69 \\
\hline $121 / 1$ & 165.16 & 541.86 & $2 \mathrm{H} 117$ & 19.40 & 1.29 & 1.08 & 0.06 & & 0.00 & 7 & 2.77 \\
\hline $123 / 1$ & 167.79 & 550.49 & 2H118 & 31.30 & 1.50 & & 0.00 & 0.56 & 0.02 & 14 & 2.24 \\
\hline $124 / 1$ & 169.32 & 555.51 & $2 \mathrm{H} 119$ & 34.70 & 1.54 & 2.08 & 0.06 & & 0.00 & 19 & 1.83 \\
\hline $125 / 1$ & 170.82 & 560.43 & $2 \mathrm{H} 120$ & 28.60 & 1.46 & 1.54 & 0.05 & & 0.00 & 20 & 1.43 \\
\hline $153 / 1$ & 247.90 & 813.32 & $2 \mathrm{H} 121$ & 10.70 & 1.03 & 1.06 & 0.10 & & 0.00 & 16 & 0.67 \\
\hline $158 / 1$ & 274.82 & 901.64 & $2 \mathrm{H} 122$ & 9.33 & 0.97 & 0.79 & 0.08 & & 0.00 & 10 & 0.93 \\
\hline $161 / 1$ & 279.39 & 916.63 & $2 \mathrm{H} 123$ & 4.72 & 0.67 & 0.61 & 0.13 & 0.26 & 0.05 & 15 & 0.31 \\
\hline $162 / 1$ & 280.61 & 920.64 & $2 \mathrm{H} 124$ & 7.21 & 0.86 & 0.46 & 0.06 & & 0.00 & 10 & 0.72 \\
\hline $163 / 2$ & 282.80 & 927.82 & $2 \mathrm{H} 125$ & 9.03 & 0.96 & 0.92 & 0.10 & & 0.00 & 12 & 0.75 \\
\hline $164 / 1$ & 284.14 & 932.22 & $2 \mathrm{H} 126$ & 20.90 & 1.32 & 0.90 & 0.04 & 0.09 & 0.00 & 17 & 1.23 \\
\hline $165 / 1$ & 285.44 & 936.48 & $2 \mathrm{H} 127$ & 7.71 & 0.89 & 0.83 & 0.11 & & 0.00 & 6 & 1.29 \\
\hline $166 / 1$ & 286.88 & 941.21 & $2 \mathrm{H} 128$ & 7.60 & 0.88 & 0.74 & 0.10 & & 0.00 & 11 & 0.69 \\
\hline $167 / 1$ & 288.22 & 945.60 & $2 \mathrm{H} 129$ & 2.89 & 0.46 & 0.66 & 0.23 & 0.25 & 0.08 & 8 & 0.36 \\
\hline $171 / 1$ & 295.08 & 968.11 & $2 \mathrm{H} 130$ & 3.71 & 0.57 & 0.72 & 0.20 & & 0.00 & 5 & 0.74 \\
\hline $172 / 1$ & 308.07 & 1010.73 & $2 \mathrm{H} 131$ & 1.43 & 0.16 & 0.59 & 0.41 & 0.17 & 0.12 & 3 & 0.48 \\
\hline $173 / 1$ & 309.82 & 1016.47 & $2 \mathrm{H} 132$ & 60.40 & 1.78 & & 0.00 & 40.70 & 0.67 & 16 & 3.78 \\
\hline $174 / 1$ & 310.98 & 1020.28 & $2 \mathrm{H} 133$ & 31.90 & 1.50 & & 0.00 & 21.60 & 0.68 & 14 & 2.28 \\
\hline $176 / 1$ & 321.05 & 1053.31 & $2 \mathrm{H} 134$ & 90.10 & 1.95 & 58.30 & 0.65 & 28.00 & 0.31 & 43 & 2.10 \\
\hline $177 / 1$ & 322.57 & 1058.30 & $2 \mathrm{H} 135$ & 36.90 & 1.57 & 16.40 & 0.44 & 7.91 & 0.21 & 33 & 1.12 \\
\hline $178 / 1$ & 323.29 & 1060.66 & $2 \mathrm{H} 136$ & 60.60 & 1.78 & 21.70 & 0.36 & 9.76 & 0.16 & 39 & 1.55 \\
\hline $179 / 1$ & 324.80 & 1065.62 & $2 \mathrm{H} 137$ & 63.30 & 1.80 & 8.31 & 0.13 & 2.78 & 0.04 & 36 & 1.76 \\
\hline $181 / 1$ & 327.91 & 1075.82 & $2 \mathrm{H} 138$ & 39.60 & 1.60 & 11.80 & 0.30 & 5.13 & 0.13 & 48 & 0.83 \\
\hline $182 / 1$ & 329.22 & 1080.12 & 2H139 & 1.31 & 0.12 & 0.67 & 0.51 & 0.28 & 0.22 & 40 & 0.03 \\
\hline $186 / 1$ & 349.48 & 1146.59 & $2 \mathrm{H} 140$ & 50.00 & 1.70 & 12.00 & 0.24 & 5.33 & 0.11 & 55 & 0.91 \\
\hline $187 / 1$ & 350.47 & 1149.84 & $2 \mathrm{H} 142$ & 0.78 & -0.11 & 0.28 & 0.36 & 0.09 & 0.11 & 7 & 0.11 \\
\hline $188 / 1$ & 351.63 & 1153.64 & $2 \mathrm{H} 143$ & 26.10 & 1.42 & 7.61 & 0.29 & 2.55 & 0.10 & 38 & 0.69 \\
\hline $189 / 1$ & 352.64 & 1156.96 & $2 \mathrm{H} 144$ & 4.00 & 0.60 & 0.72 & 0.18 & 0.25 & 0.06 & 16 & 0.25 \\
\hline
\end{tabular}


Table 11. Paleomagnetic results for Long Beach Cabrillo High School core site and monitoring well (LBCH), Long Beach, California.

[Inclination of remanent magnetization after alternating-field treatment of samples from LBCH. RML Id, Rock Magnetism Laboratory identification number; Decl (relativity), declination relative to split face of core; N, normal; $\mathrm{R}$, reversed; I, indeterminate polarity of magnetization; Oe, oersteds; mT, millitesla; AF Demag, range of demagnetization steps in Oe used in calculation of inclination (100 Oe=10 mT); MAD, maximum angular deviation (in degrees) from principal-component analysis (Kirschvink, 1980)]

\begin{tabular}{|c|c|c|c|c|c|c|c|c|c|}
\hline $\begin{array}{c}\text { Core } \\
\text { number }\end{array}$ & $\begin{array}{c}\text { Depth, in } \\
\text { meters }\end{array}$ & $\begin{array}{l}\text { Depth, in } \\
\text { feet }\end{array}$ & $\begin{array}{c}\text { RML } \\
\text { Id }\end{array}$ & Polarity & $\begin{array}{c}\text { Inclination, in } \\
\text { degrees }\end{array}$ & $\begin{array}{c}\text { Decl } \\
\text { (relativity) }\end{array}$ & $\begin{array}{c}\text { AF Demag } \\
\text { (Oe) }\end{array}$ & MAD & Comment \\
\hline $4 / 1$ & 4.04 & 13.25 & $2 \mathrm{H} 072$ & $\mathrm{~N}$ & 52.50 & 178.70 & $150-300$ & 1.70 & \\
\hline $7 / 1$ & 6.48 & 21.26 & $2 \mathrm{H} 073$ & $\mathrm{~N}$ & 51.60 & 133.50 & $150-300$ & 4.80 & \\
\hline $8 / 1$ & 7.17 & 23.52 & $2 \mathrm{H} 074$ & $\mathrm{~N}$ & 70.00 & 297.30 & $100-200$ & 7.00 & \\
\hline $9 / 1$ & 8.12 & 26.64 & $2 \mathrm{H} 075$ & $\mathrm{~N}$ & 52.20 & 11.80 & $150-300$ & 0.90 & \\
\hline $11 / 1$ & 9.48 & 31.10 & $2 \mathrm{H} 076$ & $\mathrm{~N}$ & 61.50 & 277.10 & $150-300$ & 2.10 & \\
\hline $12 / 1$ & 10.30 & 33.79 & $2 \mathrm{H} 077$ & $\mathrm{~N}$ & 55.30 & 15.30 & $150-300$ & 7.20 & \\
\hline $15 / 1$ & 13.45 & 44.13 & $2 \mathrm{H} 078$ & $\mathrm{~N}$ & 57.10 & 170.40 & $100-300$ & 13.90 & \\
\hline $17 / 1$ & 14.81 & 48.59 & $2 \mathrm{H} 079$ & $\mathrm{~N}$ & 59.20 & 350.40 & $100-300$ & 6.40 & \\
\hline $19 / 1$ & 16.48 & 54.07 & $2 \mathrm{H} 080$ & $\mathrm{~N}$ & 70.60 & 24.40 & $100-300$ & 6.00 & \\
\hline $25 / 1$ & 21.66 & 71.06 & $2 \mathrm{H} 081$ & $\mathrm{~N}$ & 68.20 & 319.50 & $100-300$ & 10.70 & \\
\hline $33 / 1$ & 29.01 & 95.18 & $2 \mathrm{H} 082$ & $\mathrm{~N}$ & 61.60 & 10.80 & $200-400$ & 4.20 & \\
\hline $41 / 1$ & 39.57 & 129.82 & $2 \mathrm{H} 083$ & $\mathrm{~N}$ & 48.80 & 275.60 & $50-150$ & 5.40 & \\
\hline $42 / 1$ & 40.95 & 134.35 & $2 \mathrm{H} 084$ & $\mathrm{~N}$ & 74.60 & 194.70 & $100-300$ & 13.00 & \\
\hline $45 / 1$ & 45.27 & 148.52 & $2 \mathrm{H} 085$ & $\mathrm{~N}$ & 82.00 & 88.90 & $100-200$ & 6.30 & \\
\hline $47 / 1$ & 48.14 & 157.94 & $2 \mathrm{H} 086$ & $\mathrm{~N}$ & 49.20 & 287.90 & $100-300$ & 9.30 & \\
\hline $49 / 1$ & 50.93 & 167.09 & $2 \mathrm{H} 087$ & & & & & & Unstable \\
\hline $50 / 1$ & 52.45 & 172.08 & $2 \mathrm{H} 088$ & $\mathrm{~N}$ & 64.10 & 39.20 & $100-300$ & 19.00 & \\
\hline $60 / 1$ & 65.81 & 215.91 & $2 \mathrm{H} 089$ & $\mathrm{R}$ & -47.00 & 287.80 & $150-300$ & 6.00 & \\
\hline $63 / 1$ & 70.33 & 230.74 & $2 \mathrm{H} 090$ & I & -17.00 & 294.80 & $100-200$ & 14.10 & \\
\hline $64 / 1$ & 71.69 & 235.20 & $2 \mathrm{H} 091$ & & & & & & Unstable \\
\hline $68 / 1$ & 76.65 & 251.48 & $2 \mathrm{H} 092$ & $\mathrm{~N}$ & 29.40 & 336.90 & $150-300$ & 27.80 & \\
\hline $70 / 1$ & 80.02 & 262.53 & $2 \mathrm{H} 093$ & $\mathrm{~N}$ & 34.80 & 16.50 & $50-150$ & 30.10 & \\
\hline $71 / 1$ & 81.68 & 267.98 & $2 \mathrm{H} 141$ & $\mathrm{~N}$ & 58.00 & 270.40 & $150-300$ & 5.50 & \\
\hline $72 / 1$ & 82.99 & 272.28 & $2 \mathrm{H} 095$ & $\mathrm{~N}$ & 52.00 & 199.70 & $100-200$ & 14.20 & \\
\hline $73 / 1$ & 84.07 & 275.82 & $2 \mathrm{H} 096$ & $\mathrm{~N}$ & 63.40 & 156.70 & $100-200$ & 14.50 & \\
\hline $74 / 1$ & 86.08 & 282.41 & $2 \mathrm{H} 097$ & $\mathrm{~N}$ & 44.90 & 207.10 & $100-200$ & 13.00 & \\
\hline $75 / 1$ & 87.59 & 287.37 & $2 \mathrm{H} 098$ & $\mathrm{~N}$ & 40.20 & 210.30 & $150-300$ & 18.30 & \\
\hline $76 / 1$ & 88.53 & 290.45 & $2 \mathrm{H} 099$ & $\mathrm{I}$ & 8.50 & 180.40 & $200-400$ & 26.90 & \\
\hline $77 / 1$ & 90.74 & 297.70 & $2 \mathrm{H} 100$ & $\mathrm{~N}$ & 58.50 & 233.90 & $150-300$ & 14.70 & \\
\hline $78 / 1$ & 92.11 & 302.20 & $2 \mathrm{H} 101$ & $\mathrm{~N}$ & 24.80 & 257.60 & $50-150$ & 18.50 & \\
\hline $79 / 1$ & 93.56 & 306.96 & $2 \mathrm{H} 102$ & $\mathrm{~N}$ & 53.43 & 46.20 & $100-300$ & 8.40 & \\
\hline $80 / 1$ & 95.67 & 313.88 & $2 \mathrm{H} 103$ & $\mathrm{~N}$ & 53.80 & 70.00 & $100-300$ & 7.60 & \\
\hline $81 / 1$ & 96.14 & 315.42 & $2 \mathrm{H} 104$ & $\mathrm{R}$ & -20.80 & 240.10 & $100-300$ & 10.60 & \\
\hline $82 / 1$ & 98.30 & 322.51 & $2 \mathrm{H} 105$ & $\mathrm{~N}$ & 58.60 & 310.90 & $100-200$ & 20.40 & \\
\hline $83 / 1$ & 99.32 & 325.85 & $2 \mathrm{H} 106$ & $\mathrm{~N}$ & 55.50 & 74.20 & $100-200$ & 6.70 & \\
\hline $85 / 1$ & 102.49 & 336.25 & $2 \mathrm{H} 107$ & $\mathrm{~N}$ & 56.50 & 32.70 & $150-300$ & 14.50 & \\
\hline $86 / 1$ & 104.24 & 341.99 & $2 \mathrm{H} 108$ & $\mathrm{~N}$ & 42.70 & 143.90 & $100-300$ & 5.50 & \\
\hline $87 / 1$ & 105.40 & 345.80 & $2 \mathrm{H} 109$ & $\mathrm{~N}$ & 57.50 & 22.80 & $100-200$ & 7.10 & \\
\hline $88 / 1$ & 107.29 & 352.00 & $2 \mathrm{H} 110$ & $\mathrm{~N}$ & 64.00 & 117.28 & $100-300$ & 6.30 & \\
\hline $89 / 1$ & 108.50 & 355.97 & $2 \mathrm{H} 094$ & $\mathrm{~N}$ & 40.90 & 75.80 & $100-200$ & 3.90 & \\
\hline $90 / 1$ & 110.09 & 361.19 & $2 \mathrm{H} 111$ & $\mathrm{~N}$ & 69.10 & 308.50 & $100-200$ & 17.00 & \\
\hline
\end{tabular}




\begin{tabular}{|c|c|c|c|c|c|c|c|c|c|}
\hline $91 / 1$ & 111.26 & 365.03 & $2 \mathrm{H} 112$ & $\mathrm{~N}$ & 74.30 & 142.80 & $100-200$ & 11.90 & \\
\hline $92 / 1$ & 113.10 & 371.06 & $2 \mathrm{H} 113$ & $\mathrm{~N}$ & 76.60 & 43.10 & $100-200$ & 8.60 & \\
\hline $95 / 1$ & 116.34 & 381.69 & $2 \mathrm{H} 114$ & & & & & & $\begin{array}{l}\text { Demag error; } \\
\text { no result }\end{array}$ \\
\hline $96 / 1$ & 118.28 & 388.06 & $2 \mathrm{H} 115$ & $\mathrm{~N}$ & 62.50 & 107.90 & $100-200$ & 17.80 & \\
\hline $105 / 1$ & 131.90 & 432.74 & $2 \mathrm{H} 116$ & $\mathrm{~N}$ & 74.40 & 79.40 & $100-200$ & 10.30 & \\
\hline $121 / 1$ & 165.16 & 541.86 & $2 \mathrm{H} 117$ & $\mathrm{~N}$ & 75.70 & 213.60 & $100-200$ & 11.60 & \\
\hline $123 / 1$ & 167.79 & 550.49 & 2H118 & $\mathrm{N}$ & 64.90 & 275.50 & $100-300$ & 21.10 & \\
\hline $124 / 1$ & 169.32 & 555.51 & $2 \mathrm{H} 119$ & $\mathrm{~N}$ & 88.80 & 226.50 & $100-200$ & 8.80 & \\
\hline $125 / 1$ & 170.82 & 560.43 & $2 \mathrm{H} 120$ & $\mathrm{~N}$ & 64.70 & 32.10 & $100-200$ & 13.70 & \\
\hline $153 / 1$ & 247.90 & 813.32 & $2 \mathrm{H} 121$ & $\mathrm{R}$ & -65.00 & 208.00 & $100-200$ & 16.20 & \\
\hline $158 / 1$ & 274.82 & 901.64 & $2 \mathrm{H} 122$ & $\mathrm{~N}$ & 57.10 & 11.80 & $100-200$ & 4.00 & \\
\hline $161 / 1$ & 279.39 & 916.63 & $2 \mathrm{H} 123$ & $\mathrm{~N}$ & 65.60 & 334.90 & $100-300$ & 16.90 & \\
\hline $162 / 1$ & 280.61 & 920.64 & $2 \mathrm{H} 124$ & $\mathrm{~N}$ & 50.10 & 65.20 & $100-200$ & 17.80 & \\
\hline $163 / 2$ & 282.80 & 927.82 & $2 \mathrm{H} 125$ & $\mathrm{~N}$ & 52.70 & 50.10 & $100-200$ & 5.10 & \\
\hline $164 / 1$ & 284.14 & 932.22 & $2 \mathrm{H} 126$ & $\mathrm{~N}$ & 67.40 & 66.50 & $100-200$ & 12.60 & \\
\hline $165 / 1$ & 285.44 & 936.48 & $2 \mathrm{H} 127$ & $\mathrm{~N}$ & 49.90 & 99.80 & $100-200$ & 15.40 & \\
\hline $166 / 1$ & 286.88 & 941.21 & $2 \mathrm{H} 128$ & $\mathrm{I}$ & 18.60 & 171.80 & $100-200$ & 7.90 & \\
\hline $167 / 1$ & 288.22 & 945.60 & $2 \mathrm{H} 129$ & $\mathrm{~N}$ & 53.90 & 110.00 & $100-200$ & 8.60 & \\
\hline $171 / 1$ & 295.08 & 968.11 & $2 \mathrm{H} 130$ & $\mathrm{~N}$ & 63.70 & 22.20 & $100-200$ & 4.90 & \\
\hline $172 / 1$ & 308.07 & 1010.73 & $2 \mathrm{H} 131$ & $\mathrm{~N}$ & 50.20 & 26.90 & $150-300$ & 9.50 & \\
\hline $173 / 1$ & 309.82 & 1016.47 & $2 \mathrm{H} 132$ & $\mathrm{~N}$ & 51.10 & 168.50 & $200-500$ & 7.50 & \\
\hline $174 / 1$ & 310.98 & 1020.28 & $2 \mathrm{H} 133$ & $\mathrm{~N}$ & 61.70 & 91.60 & $300-500$ & 7.60 & \\
\hline $176 / 1$ & 321.05 & 1053.31 & $2 \mathrm{H} 134$ & $\mathrm{~N}$ & 56.30 & 209.40 & $200-400$ & 5.60 & \\
\hline $177 / 1$ & 322.57 & 1058.30 & $2 \mathrm{H} 135$ & $\mathrm{~N}$ & 54.50 & 308.90 & $100-300$ & 3.10 & \\
\hline $178 / 1$ & 323.29 & 1060.66 & $2 \mathrm{H} 136$ & $\mathrm{~N}$ & 55.10 & 300.70 & $100-300$ & 1.50 & \\
\hline $179 / 1$ & 324.80 & 1065.62 & $2 \mathrm{H} 137$ & $\mathrm{~N}$ & 57.40 & 3.60 & $100-300$ & 6.30 & \\
\hline $181 / 1$ & 327.91 & 1075.82 & $2 \mathrm{H} 138$ & $\mathrm{~N}$ & 40.40 & 131.80 & $100-200$ & 2.80 & \\
\hline $182 / 1$ & 329.22 & 1080.12 & $2 \mathrm{H} 139$ & $\mathrm{~N}$ & 71.80 & 66.80 & $100-300$ & 14.20 & \\
\hline $186 / 1$ & 349.48 & 1146.59 & $2 \mathrm{H} 140$ & $\mathrm{~N}$ & 49.30 & 270.40 & $150-300$ & 5.50 & \\
\hline $187 / 1$ & 350.47 & 1149.84 & $2 \mathrm{H} 142$ & $\mathrm{~N}$ & 46.10 & 278.60 & $100-300$ & 9.30 & \\
\hline $188 / 1$ & 351.63 & 1153.64 & $2 \mathrm{H} 143$ & $\mathrm{~N}$ & 73.80 & 241.60 & $100-300$ & 5.60 & \\
\hline $189 / 1$ & 352.64 & 1156.96 & $2 \mathrm{H} 144$ & $\mathrm{~N}$ & 61.30 & 149.30 & $100-300$ & 13.50 & \\
\hline
\end{tabular}


Table 14. Paleomagnetic results for the Long Beach Webster School (LWEB), Long Beach, California.

[Inclination of remanent magnetization after alternating-field treatment of samples from LWEB. RML Id, Rock Magnetism Laboratory identification number; Decl (relativity), declination relative to split face of core; N, normal; $\mathrm{R}$, reversed; I, indeterminate polarity of magnetization; Oe, oersteds; $\mathrm{mT}$, millitesla; AF Demag, range of demagnetization steps in Oe used in calculation of inclination (100 Oe=10 $\mathrm{mT})$; MAD, maximum angular deviation (in degrees) from principal-component analysis (Kirschvink, 1980)]

\begin{tabular}{|c|c|c|c|c|c|c|c|c|}
\hline $\begin{array}{c}\text { Core } \\
\text { number }\end{array}$ & $\begin{array}{l}\text { Depth, in } \\
\text { feet }\end{array}$ & $\begin{array}{l}\text { Depth, in } \\
\text { meters }\end{array}$ & $\begin{array}{c}\text { RML } \\
\text { Id }\end{array}$ & Polarity & $\begin{array}{l}\text { Inclination, in } \\
\text { degrees }\end{array}$ & $\begin{array}{l}\text { Declination } \\
\text { (relativity) }\end{array}$ & $\begin{array}{l}\text { AF Demag } \\
\text { (Oe) }\end{array}$ & MAD \\
\hline $2 / 1$ & 6.71 & 2.05 & $0 \mathrm{H} 045$ & $\mathrm{~N}$ & 55.90 & 41.90 & $100-300$ & 11.80 \\
\hline $3 / 1$ & 11.72 & 3.57 & $0 \mathrm{H} 046$ & $\mathrm{~N}$ & 47.70 & 217.50 & $100-300$ & 9.50 \\
\hline $4 / 1$ & 16.64 & 5.07 & 0H047 & $\mathrm{N}$ & 44.40 & 40.40 & $100-300$ & 4.00 \\
\hline $5 / 1$ & 22.57 & 6.88 & 0H048 & $\mathrm{N}$ & 52.30 & 321.10 & $100-300$ & 4.70 \\
\hline $6 / 1$ & 27.84 & 8.49 & 0H049 & $\mathrm{N}$ & 43.80 & 175.10 & $100-300$ & 19.70 \\
\hline $7 / 1$ & 32.39 & 9.87 & $0 \mathrm{H} 050$ & $\mathrm{~N}$ & 22.00 & 9.30 & $200-400$ & 23.20 \\
\hline $8 / 1$ & 39.31 & 11.98 & 0H051 & $\mathrm{N}$ & 28.20 & 224.40 & $100-300$ & 1.30 \\
\hline $9 / 1$ & 42.18 & 12.86 & 0H052 & $\mathrm{N}$ & 27.70 & 88.80 & $100-400$ & 2.30 \\
\hline $10 / 1$ & 48.77 & 14.87 & 0H053 & $\mathrm{N}$ & 51.10 & 21.50 & $100-300$ & 3.00 \\
\hline $11 / 1$ & 52.61 & 16.04 & 0H054 & $\mathrm{N}$ & 43.60 & 210.80 & $100-300$ & 6.80 \\
\hline $14 / 1$ & 67.03 & 20.43 & 0H055 & $\mathrm{N}$ & 25.90 & 12.20 & $150-600$ & 2.60 \\
\hline $22 / 1$ & 100.54 & 30.64 & 0H056 & $\mathrm{N}$ & 52.40 & 207.40 & $50-100$ & 0.70 \\
\hline $24 / 1$ & 106.79 & 32.55 & 0H058 & $\mathrm{N}$ & 60.20 & 220.00 & $150-400$ & 3.40 \\
\hline $25 / 1$ & 109.81 & 33.47 & 0H059 & $\mathrm{N}$ & 58.90 & 213.40 & $100-300$ & 1.50 \\
\hline $26 / 1$ & 111.89 & 34.10 & 0H060 & $\mathrm{N}$ & 57.60 & 146.70 & 100-200 & 27.20 \\
\hline $27 / 1$ & 114.40 & 34.87 & 0H061 & $\mathrm{N}$ & 87.60 & 317.50 & 100-200 & 8.10 \\
\hline $28 / 1$ & 119.57 & 36.44 & 0H062 & $\mathrm{N}$ & 45.90 & 170.90 & $150-400$ & 3.80 \\
\hline $29 / 1$ & 123.48 & 37.64 & 0H057 & $\mathrm{N}$ & 45.30 & 308.80 & $100-300$ & 2.30 \\
\hline $30 / 2$ & 128.07 & 39.04 & 0H063 & $\mathrm{N}$ & 32.70 & 310.20 & $100-600$ & 8.00 \\
\hline $30 / 2$ & 130.15 & 39.67 & 0H064 & $\mathrm{N}$ & 52.80 & 293.80 & $150-600$ & 10.00 \\
\hline $31 / 1$ & 132.04 & 40.25 & 1H019 & $\mathrm{N}$ & 32.90 & 36.40 & $150-400$ & 3.00 \\
\hline $31 / 1$ & 132.53 & 40.40 & $1 \mathrm{H} 020$ & $\mathrm{~N}$ & 31.00 & 46.40 & $200-600$ & 1.50 \\
\hline $31 / 1$ & 132.61 & 40.42 & 0H065 & $\mathrm{I}$ & 13.90 & 42.50 & $150-600$ & 2.50 \\
\hline $31 / 1$ & 133.00 & 40.54 & $1 \mathrm{H} 021$ & $\mathrm{~N}$ & 26.00 & 100.30 & $150-400$ & 22.60 \\
\hline $31 / 1$ & 133.46 & 40.68 & $1 \mathrm{H} 022$ & $\mathrm{~N}$ & 55.60 & 138.90 & $150-400$ & 12.60 \\
\hline $31 / 1$ & 133.96 & 40.83 & $1 \mathrm{H} 023$ & $\mathrm{~N}$ & 58.60 & 88.90 & $300-400$ & 11.00 \\
\hline $32 / 1$ & 138.88 & 42.33 & 0H066 & $\mathrm{N}$ & 71.50 & 63.40 & $150-400$ & 17.50 \\
\hline $34 / 1$ & 147.38 & 44.92 & 0H067 & $\mathrm{N}$ & 52.00 & 158.20 & 100-200 & 12.60 \\
\hline $35 / 1$ & 152.25 & 46.41 & 0H068 & $\mathrm{N}$ & 59.60 & 236.70 & $100-300$ & 10.50 \\
\hline $37 / 1$ & 162.38 & 49.49 & 0H069 & $\mathrm{N}$ & 50.80 & 26.00 & $100-300$ & 2.60 \\
\hline $39 / 1$ & 168.80 & 51.45 & 0H070 & $\mathrm{N}$ & 43.00 & 210.50 & $100-300$ & 3.40 \\
\hline $43 / 1$ & 183.87 & 56.04 & 0H071 & $\mathrm{N}$ & 52.80 & 197.00 & $150-300$ & 17.60 \\
\hline $45 / 2$ & 191.83 & 58.47 & 0H072 & $\mathrm{N}$ & 49.70 & 7.40 & $150-400$ & 7.90 \\
\hline $45 / 2$ & 194.85 & 59.39 & OH073 & $\mathrm{N}$ & 26.70 & 295.90 & $100-300$ & 9.30 \\
\hline $46 / 1$ & 196.23 & 59.81 & 0H074 & $\mathrm{N}$ & 57.90 & 262.20 & $50-150$ & 6.80 \\
\hline $46 / 2$ & 197.43 & 60.18 & 0H075 & $\mathrm{N}$ & 71.60 & 199.60 & $100-200$ & 13.60 \\
\hline $46 / 2$ & 200.18 & 61.01 & 0H076 & $\mathrm{N}$ & 41.50 & 13.10 & $100-300$ & 9.00 \\
\hline $47 / 2$ & 203.47 & 62.02 & 0H077 & $\mathrm{N}$ & 47.20 & 143.50 & $150-300$ & 19.60 \\
\hline $48 / 1$ & 208.64 & 63.59 & 0H078 & $\mathrm{N}$ & 47.60 & 243.20 & $100-300$ & 3.00 \\
\hline $49 / 1$ & 212.41 & 64.74 & 0H079 & $\mathrm{N}$ & 46.30 & 159.90 & $100-300$ & 1.90 \\
\hline $49 / 1$ & 214.69 & 65.44 & 0H080 & $\mathrm{N}$ & 29.60 & 178.70 & $150-300$ & 2.70 \\
\hline $50 / 1$ & 217.00 & 66.14 & 0H081 & $\mathrm{N}$ & 49.90 & 275.90 & $200-400$ & 11.10 \\
\hline
\end{tabular}




\begin{tabular}{|c|c|c|c|c|c|c|c|c|}
\hline $64 / 1$ & 271.34 & 82.70 & 0H083 & $\mathrm{N}$ & 56.90 & 152.90 & $100-200$ & 9.40 \\
\hline $66 / 1$ & 277.28 & 84.51 & 0H084 & $\mathrm{N}$ & 64.20 & 354.10 & $100-200$ & 13.00 \\
\hline $68 / 1$ & 281.82 & 85.90 & 0H085 & $\mathrm{N}$ & 67.00 & 86.80 & $100-300$ & 13.60 \\
\hline $70 / 1$ & 286.75 & 87.40 & 0H086 & $\mathrm{N}$ & 52.20 & 344.30 & $100-200$ & 7.40 \\
\hline $72 / 1$ & 292.09 & 89.03 & 0H087 & $\mathrm{N}$ & 50.00 & 349.60 & $150-300$ & 3.90 \\
\hline $74 / 1$ & 298.23 & 90.90 & 0H082 & $\mathrm{N}$ & 39.70 & 214.00 & $100-300$ & 3.30 \\
\hline $76 / 1$ & 303.85 & 92.61 & 0H088 & $\mathrm{N}$ & 38.60 & 319.70 & $150-300$ & 2.10 \\
\hline $77 / 1$ & 306.57 & 93.44 & 0H089 & $\mathrm{N}$ & 60.80 & 8.00 & $50-300$ & 2.40 \\
\hline $78 / 1$ & 309.71 & 94.40 & 0H090 & $\mathrm{N}$ & 51.50 & 113.00 & $150-400$ & 3.40 \\
\hline $80 / 1$ & 318.44 & 97.06 & 0H091 & $\mathrm{N}$ & 47.70 & 96.20 & $150-400$ & 2.40 \\
\hline $94 / 1$ & 357.26 & 108.89 & 0H092 & $\mathrm{N}$ & 39.60 & 89.00 & $150-400$ & 6.00 \\
\hline $107 / 1$ & 404.14 & 123.18 & 0H093 & $\mathrm{N}$ & 70.00 & 67.20 & $100-300$ & 14.70 \\
\hline $110 / 1$ & 413.07 & 125.90 & 0H094 & $\mathrm{N}$ & 44.30 & 189.20 & $150-300$ & 13.80 \\
\hline $114 / 1$ & 424.91 & 129.51 & 0H095 & $\mathrm{N}$ & 57.70 & 38.70 & $100-300$ & 7.80 \\
\hline $115 / 1$ & 426.66 & 130.05 & 0H096 & $\mathrm{N}$ & 64.80 & 59.90 & $50-300$ & 9.70 \\
\hline $119 / 1$ & 436.92 & 133.17 & 0H097 & $\mathrm{N}$ & 46.80 & 217.90 & $150-300$ & 24.90 \\
\hline $120 / 1$ & 439.48 & 133.95 & 0H098 & $\mathrm{N}$ & 58.70 & 331.30 & $100-300$ & 12.90 \\
\hline $121 / 1$ & 442.13 & 134.76 & 0H099 & $\mathrm{N}$ & 51.30 & 155.60 & $150-300$ & 8.70 \\
\hline $122 / 1$ & 444.63 & 135.52 & 0H100 & $\mathrm{N}$ & 47.90 & 320.70 & NRM & \\
\hline $123 / 1$ & 447.63 & 136.44 & 0H101 & $\mathrm{N}$ & 53.90 & 303.50 & $100-300$ & 4.30 \\
\hline $124 / 1$ & 450.14 & 137.20 & 0H102 & $\mathrm{N}$ & 54.80 & 170.80 & $100-400$ & 5.30 \\
\hline $125 / 1$ & 451.43 & 137.60 & 0H103 & $\mathrm{N}$ & 52.50 & 221.30 & $150-400$ & 2.90 \\
\hline $126 / 1$ & 454.02 & 138.39 & 0H104 & $\mathrm{N}$ & 56.10 & 300.90 & $150-400$ & 3.70 \\
\hline $127 / 1$ & 457.77 & 139.53 & 0H105 & $\mathrm{N}$ & 50.10 & 173.50 & $100-300$ & 6.40 \\
\hline $128 / 1$ & 459.91 & 140.18 & 0H106 & $\mathrm{N}$ & 62.30 & 198.20 & $150-300$ & 6.60 \\
\hline $129 / 1$ & 462.33 & 140.92 & 0H107 & $\mathrm{N}$ & 56.10 & 109.70 & $200-400$ & 25.30 \\
\hline $131 / 1$ & 466.74 & 142.26 & 0H108 & $\mathrm{N}$ & 49.00 & 187.30 & $100-400$ & 8.60 \\
\hline $132 / 1$ & 469.53 & 143.11 & 0H109 & $\mathrm{N}$ & 64.00 & 50.70 & $150-400$ & 1.30 \\
\hline $133 / 1$ & 471.31 & 143.66 & 0H110 & $\mathrm{N}$ & 42.50 & 171.20 & $150-400$ & 2.10 \\
\hline $134 / 1$ & 477.12 & 145.43 & 0H111 & $\mathrm{N}$ & 48.90 & 145.80 & $100-300$ & 9.90 \\
\hline $135 / 1$ & 482.13 & 146.95 & 0H112 & $\mathrm{N}$ & 87.10 & 306.20 & $100-300$ & 7.20 \\
\hline $136 / 1$ & 484.87 & 147.79 & 0H113 & $\mathrm{N}$ & 50.90 & 191.70 & $150-300$ & 13.30 \\
\hline $137 / 1$ & 487.16 & 148.49 & 0H114 & $\mathrm{N}$ & 54.40 & 46.10 & $150-400$ & 7.60 \\
\hline $137 / 1$ & 489.72 & 149.27 & 0H115 & $\mathrm{N}$ & 46.50 & 340.00 & $150-300$ & 7.30 \\
\hline $140 / 1$ & 496.61 & 151.37 & 0H116 & $\mathrm{N}$ & 65.90 & 252.20 & $100-300$ & 10.30 \\
\hline $141 / 1$ & 499.83 & 152.35 & 0H117 & $\mathrm{N}$ & 58.10 & 304.30 & $150-400$ & 4.70 \\
\hline $142 / 1$ & 502.18 & 153.06 & 0H118 & $\mathrm{N}$ & 55.20 & 280.80 & $150-400$ & 7.10 \\
\hline $143 / 1$ & 504.46 & 153.76 & 0H119 & $\mathrm{N}$ & 61.60 & 31.10 & $150-400$ & 4.90 \\
\hline $144 / 1$ & 508.36 & 154.95 & 0H120 & $\mathrm{N}$ & 58.60 & 249.30 & $150-400$ & 4.60 \\
\hline $145 / 1$ & 512.59 & 156.24 & 0H121 & $\mathrm{N}$ & 59.70 & 260.40 & $100-300$ & 4.50 \\
\hline $146 / 1$ & 514.16 & 156.72 & 0H122 & $\mathrm{N}$ & 61.80 & 334.20 & $100-400$ & 5.40 \\
\hline $146 / 1$ & 517.68 & 157.79 & 0H123 & $\mathrm{N}$ & 62.50 & 321.60 & $100-300$ & 6.10 \\
\hline $147 / 1$ & 520.11 & 158.53 & $0 \mathrm{H} 124$ & $\mathrm{~N}$ & 74.10 & 293.30 & $100-200$ & 5.80 \\
\hline $150 / 1$ & 531.72 & 162.07 & 0H125 & $\mathrm{N}$ & 73.00 & 331.30 & $100-200$ & 8.00 \\
\hline $154 / 1$ & 542.65 & 165.40 & 0H126 & $\mathrm{N}$ & 72.90 & 152.40 & $100-300$ & 6.10 \\
\hline $156 / 1$ & 547.31 & 166.82 & 0H127 & $\mathrm{N}$ & 51.10 & 146.80 & $100-200$ & 23.00 \\
\hline $157 / 1$ & 553.49 & 168.70 & 0H128 & $\mathrm{N}$ & 70.90 & 12.60 & $100-200$ & 18.50 \\
\hline $159 / 1$ & 563.38 & 171.72 & 0H129 & $\mathrm{N}$ & 82.90 & 182.30 & $150-400$ & 1.80 \\
\hline $160 / 1$ & 566.69 & 172.73 & 0H130 & $\mathrm{N}$ & 38.30 & 178.00 & $150-400$ & 0.90 \\
\hline
\end{tabular}




\begin{tabular}{|c|c|c|c|c|c|c|c|c|}
\hline $164 / 1$ & 587.51 & 179.07 & 0H131 & $\mathrm{N}$ & 48.80 & 265.20 & $300-400$ & 17.90 \\
\hline $225 / 1$ & 886.80 & 270.30 & 0H132 & $\mathrm{N}$ & 70.90 & 273.50 & $100-300$ & 19.00 \\
\hline $240 / 1$ & 988.13 & 301.18 & 0H133 & $\mathrm{N}$ & 70.50 & 27.60 & $100-300$ & 19.70 \\
\hline $241 / 1$ & 1004.04 & 306.03 & 0H134 & $\mathrm{N}$ & 38.00 & 0.90 & $100-300$ & 21.30 \\
\hline $243 / 1$ & 1031.49 & 314.40 & 0H135 & $\mathrm{N}$ & 75.50 & 42.80 & $100-300$ & 7.60 \\
\hline $243 / 1$ & 1031.95 & 314.54 & 0H136 & $\mathrm{N}$ & 81.40 & 255.50 & $100-300$ & 2.20 \\
\hline $244 / 1$ & 1046.87 & 319.09 & 0H137 & $\mathrm{N}$ & 76.80 & 202.90 & $150-400$ & 10.50 \\
\hline $244 / 1$ & 1047.43 & 319.26 & 0H138 & $\mathrm{N}$ & 53.20 & 331.50 & $50-200$ & 18.10 \\
\hline $245 / 1$ & 1066.98 & 325.22 & 0H139 & $\mathrm{N}$ & 71.90 & 307.10 & $100-400$ & 13.80 \\
\hline $245 / 1$ & 1067.71 & 325.44 & 0H140 & $\mathrm{N}$ & 63.40 & 92.30 & $100-400$ & 10.20 \\
\hline $246 / 1$ & 1087.35 & 331.42 & 0H141 & $\mathrm{N}$ & 80.50 & 78.50 & $100-400$ & 8.40 \\
\hline $246 / 1$ & 1089.71 & 332.14 & 0H142 & $\mathrm{N}$ & 51.30 & 37.10 & $150-400$ & 9.90 \\
\hline $247 / 1$ & 1126.36 & 343.31 & 0H143 & $\mathrm{N}$ & 62.40 & 138.70 & $100-400$ & 16.60 \\
\hline $247 / 1$ & 1128.76 & 344.05 & 0H144 & $\mathrm{N}$ & 78.50 & 12.30 & $200-400$ & 7.20 \\
\hline $248 / 1$ & 1186.46 & 361.63 & 0H145 & $\mathrm{N}$ & 70.30 & 58.30 & $150-300$ & 14.30 \\
\hline $248 / 1$ & 1189.31 & 362.50 & 0H146 & $\mathrm{N}$ & 73.50 & 355.50 & $150-300$ & 7.60 \\
\hline $249 / 1$ & 1268.69 & 386.70 & 0H147 & $\mathrm{N}$ & 55.40 & 198.10 & $100-200$ & 7.90 \\
\hline $250 / 1$ & 1271.62 & 387.59 & 0H148 & $\mathrm{N}$ & 79.60 & 93.60 & $100-300$ & 3.90 \\
\hline $250 / 1$ & 1272.94 & 387.99 & 0H149 & $\mathrm{N}$ & 77.80 & 336.90 & $100-300$ & 4.30 \\
\hline
\end{tabular}


Table 17. Intensity of remanent magnetization and magnetic susceptibility of the Long Beach City College core site and monitoring well (LBCC) samples.

[RML Id, Rock Magnetism Laboratory identification number; Jnrm, intensity of natural remanent magnetization $(\mathrm{mA} / \mathrm{m}) ; \mathrm{J} 15$, intensity of magnetization after alternating-field treatments of $15 \mathrm{mT}$; J30, intensity of magnetization after alternating-field treatments of $30 \mathrm{mT}$; K, magnetic susceptibility (10-6 SI)]

\begin{tabular}{|c|c|c|c|c|c|c|c|c|c|c|}
\hline $\begin{array}{c}\text { Core } \\
\text { number }\end{array}$ & $\begin{array}{l}\text { Depth, in } \\
\text { meters }\end{array}$ & $\begin{array}{l}\text { Depth, } \\
\text { in feet }\end{array}$ & $\begin{array}{l}\text { RML } \\
\text { Id }\end{array}$ & $\underset{(\mathrm{mA} / \mathrm{m})}{\mathrm{Jnrm}}$ & LogJnrm & $\begin{array}{c}\mathrm{J} 15 \\
(\mathrm{~mA} / \mathrm{m})\end{array}$ & J15/Jnrm & $\begin{array}{c}\mathbf{J 3 0} \\
(\mathbf{m A} / \mathbf{m})\end{array}$ & J30/Jnrm & $\begin{array}{c}K \\
10 \mathrm{E}-6 \\
\text { SI } \\
\end{array}$ \\
\hline $1 / 1$ & 0.41 & 1.35 & $3 \mathrm{H} 001$ & 53.1 & 1.725094521 & 18.3 & 0.344632768 & 8.88 & 0.167231638 & 36 \\
\hline $2 / 1$ & 1.67 & 5.48 & $3 \mathrm{H} 002$ & 53.2 & 1.725911632 & 17.7 & 0.332706767 & 9.92 & 0.186466165 & 27 \\
\hline $3 / 1$ & 3.87 & 12.70 & $3 \mathrm{H} 003$ & 20.0 & 1.301029996 & 7.20 & 0.36 & 4.25 & 0.2125 & 18 \\
\hline $4 / 1$ & 5.21 & 17.09 & $3 \mathrm{H} 004$ & 29.1 & 1.463892989 & 9.84 & 0.33814433 & 5.87 & 0.201718213 & 21 \\
\hline $10 / 1$ & 14.13 & 46.36 & $3 \mathrm{H} 005$ & 21.2 & 1.326335861 & 7.45 & 0.351415094 & 4.84 & 0.228301887 & 15 \\
\hline $11 / 1$ & 15.9 & 52.17 & $3 \mathrm{H} 006$ & 29.2 & 1.465382851 & 5.79 & 0.198287671 & 3.61 & 0.123630137 & 32 \\
\hline $13 / 1$ & 19.4 & 63.65 & $3 \mathrm{H} 007$ & 14.5 & 1.161368002 & 2.86 & 0.197241379 & 1.42 & 0.097931034 & 29 \\
\hline $14 / 1$ & 20.39 & 66.90 & $3 \mathrm{H} 008$ & 0.334 & $\begin{array}{c}- \\
0.476253533 \\
\end{array}$ & 0.150 & 0.449101796 & 0.103 & 0.308383234 & 4 \\
\hline $15 / 1$ & 21.7 & 71.19 & $3 \mathrm{H} 009$ & 25.5 & 1.40654018 & 18.9 & 0.741176471 & 6.10 & 0.239215686 & 8 \\
\hline $16 / 1$ & 23.67 & 77.66 & $3 \mathrm{H} 010$ & 3.06 & 0.485721426 & & 0 & 2.20 & 0.718954248 & 4 \\
\hline $17 / 1$ & 24.6 & 80.71 & $3 \mathrm{H} 011$ & 0.785 & $\begin{array}{c}- \\
0.105130343 \\
\end{array}$ & 0.581 & 0.740127389 & 0.523 & 0.666242038 & 4 \\
\hline $23 / 1$ & 33.97 & 111.45 & $3 \mathrm{H} 012$ & 4.47 & 0.650307523 & 4.00 & 0.894854586 & 3.71 & 0.829977629 & 7 \\
\hline $24 / 1$ & 34.76 & 114.04 & $3 \mathrm{H} 013$ & 50.8 & 1.705863712 & 8.61 & 0.169488189 & 4.58 & 0.09015748 & 32 \\
\hline $25 / 1$ & 35.71 & 117.16 & $3 \mathrm{H} 014$ & 24.3 & 1.385606274 & 7.57 & 0.311522634 & 3.47 & 0.142798354 & 32 \\
\hline $28 / 1$ & 40.21 & 131.92 & $3 \mathrm{H} 015$ & 17.6 & 1.245512668 & & 0 & 10.2 & 0.579545455 & 17 \\
\hline $29 / 1$ & 41.36 & 135.70 & $3 \mathrm{H} 016$ & 17.6 & 1.245512668 & 13.7 & 0.778409091 & 10.1 & 0.573863636 & 12 \\
\hline $36 / 1$ & 53.08 & 174.15 & $3 \mathrm{H} 017$ & 23.7 & 1.374748346 & & 0 & 0.249 & 0.010506329 & 30 \\
\hline $38 / 1$ & 56.37 & 184.94 & $3 \mathrm{H} 018$ & 1.16 & 0.064457989 & 0.972 & 0.837931034 & 0.400 & 0.344827586 & 1 \\
\hline $40 / 1$ & 58.79 & 192.88 & $3 \mathrm{H} 019$ & 24.6 & 1.390935107 & 2.47 & 0.100406504 & 0.828 & 0.033658537 & 23 \\
\hline $43 / 1$ & 63.05 & 206.86 & $3 \mathrm{H} 020$ & 13.4 & 1.127104798 & 1.34 & 0.1 & & 0 & 30 \\
\hline $45 / 1$ & 65.81 & 215.91 & $3 \mathrm{H} 021$ & 15.9 & 1.201397124 & 1.09 & 0.068553459 & & 0 & 10 \\
\hline $47 / 1$ & 78.39 & 257.19 & $3 \mathrm{H} 022$ & 3.05 & 0.484299839 & 0.562 & 0.184262295 & & 0 & 6 \\
\hline $48 / 1$ & 79.81 & 261.84 & $3 \mathrm{H} 023$ & 6.72 & 0.827369273 & 0.813 & 0.120982143 & 0.467 & 0.069494048 & 13 \\
\hline $49 / 1$ & 80.96 & 265.62 & $3 \mathrm{H} 024$ & 4.01 & 0.603144373 & 0.783 & 0.195261845 & 0.328 & 0.081795511 & 9 \\
\hline $50 / 1$ & 100.88 & 330.97 & $3 \mathrm{H} 025$ & 63.9 & 1.805500858 & 7.68 & 0.120187793 & 2.71 & 0.042410016 & 40 \\
\hline $51 / 1$ & 102.57 & 336.52 & $3 \mathrm{H} 026$ & 64.6 & 1.810232518 & 17.7 & 0.273993808 & & 0 & 47 \\
\hline $52 / 1$ & 104.04 & 341.34 & $3 \mathrm{H} 027$ & 46.0 & 1.662757832 & 17.3 & 0.376086957 & & 0 & 42 \\
\hline $53 / 1$ & 105.6 & 346.46 & $3 \mathrm{H} 028$ & 57.9 & 1.762678564 & 16.7 & 0.288428325 & & 0 & 46 \\
\hline $54 / 1$ & 107.28 & 351.97 & $3 \mathrm{H} 029$ & 115 & 2.06069784 & 26.2 & 0.227826087 & & 0 & 44 \\
\hline $55 / 1$ & 108.93 & 357.38 & $3 \mathrm{H} 030$ & 65.3 & 1.814913181 & 19.7 & 0.301684533 & 5.79 & 0.088667688 & 47 \\
\hline $56 / 1$ & 135.05 & 443.08 & $3 \mathrm{H} 031$ & 1.70 & 0.230448921 & 0.841 & 0.494705882 & 0.468 & 0.275294118 & 1 \\
\hline $58 / 1$ & 138.31 & 453.77 & $3 \mathrm{H} 032$ & 7.30 & 0.86332286 & 6.74 & 0.923287671 & 5.14 & 0.704109589 & 12 \\
\hline $59 / 1$ & 139.1 & 456.36 & $3 \mathrm{H} 033$ & 62.8 & 1.797959644 & 45.4 & 0.722929936 & 23.8 & 0.378980892 & 73 \\
\hline $60 / 1$ & 140.83 & 462.04 & $3 \mathrm{H} 034$ & 3.08 & 0.488550717 & 0.671 & 0.217857143 & 0.270 & 0.087662338 & 7 \\
\hline $61 / 1$ & 142.32 & 466.93 & $3 \mathrm{H} 035 \mathrm{~A}$ & 0.699 & $\begin{array}{c}- \\
0.155522824 \\
\end{array}$ & 0.398 & 0.569384835 & 0.177 & 0.253218884 & 5 \\
\hline $65 / 1$ & 148.99 & 488.81 & $3 \mathrm{H} 035 \mathrm{~B}$ & 0.726 & $\begin{array}{c}- \\
0.139063379 \\
\end{array}$ & 0.348 & 0.479338843 & 0.180 & 0.247933884 & 8 \\
\hline $70 / 1$ & 171.57 & 562.89 & $3 \mathrm{H} 035$ & 6.12 & 0.786751422 & 0.803 & 0.13120915 & 0.236 & 0.038562092 & 6 \\
\hline $71 / 1$ & 173.3 & 568.57 & $3 \mathrm{H} 036$ & 6.22 & 0.793790385 & 0.999 & 0.160610932 & 0.128 & 0.020578778 & 5 \\
\hline $72 / 1$ & 174.87 & 573.72 & $3 \mathrm{H} 037$ & 2.01 & 0.303196057 & 0.780 & 0.388059701 & 0.253 & 0.125870647 & 9 \\
\hline $73 / 1$ & 175.9 & 577.10 & $3 \mathrm{H} 038$ & 23.4 & 1.369215857 & 1.42 & 0.060683761 & 0.854 & 0.036495726 & 24 \\
\hline $79 / 1$ & 200.09 & 656.46 & $3 \mathrm{H} 039$ & 2.12 & 0.326335861 & 0.894 & 0.421698113 & 0.208 & 0.098113208 & 8 \\
\hline
\end{tabular}




\begin{tabular}{|c|c|c|c|c|c|c|c|c|c|c|}
\hline $80 / 1$ & 226.32 & 742.52 & $3 \mathrm{H} 040$ & 61.6 & 1.789580712 & 47.3 & 0.767857143 & 38.100 & 0.618506494 & 46 \\
\hline $81 / 1$ & 227.45 & 746.23 & $3 \mathrm{H} 041$ & 52.0 & 1.716003344 & & 0 & 34.2 & 0.657692308 & 37 \\
\hline $82 / 1$ & 229.34 & 752.43 & $3 \mathrm{H} 042$ & 148 & 2.170261715 & 135 & 0.912162162 & 114.000 & 0.77027027 & 49 \\
\hline $83 / 1$ & 230.89 & 757.51 & $3 \mathrm{H} 043$ & 49.0 & 1.69019608 & & 0 & 25.0 & 0.510204082 & 46 \\
\hline $84 / 1$ & 232.48 & 762.73 & $3 \mathrm{H} 044$ & 69.1 & 1.839478047 & 35.2 & 0.509406657 & 25.7 & 0.371924747 & 72 \\
\hline $85 / 1$ & 234.07 & 767.95 & $3 \mathrm{H} 045$ & 94.7 & 1.976349979 & 22.0 & 0.232312566 & 15.2 & 0.160506864 & 51 \\
\hline $86 / 1$ & 250.87 & 823.06 & $3 \mathrm{H} 046$ & 66.0 & 1.819543936 & & 0 & 13.4 & 0.203030303 & 68 \\
\hline $87 / 1$ & 252.26 & 827.62 & $3 \mathrm{H} 047$ & 108.0 & 2.033423755 & & 0 & 17.3 & 0.160185185 & 68 \\
\hline $89 / 1$ & 255.06 & 836.81 & $3 \mathrm{H} 048$ & 55.0 & 1.740362689 & 15.6 & 0.283636364 & 5.81 & 0.105636364 & 60 \\
\hline $90 / 1$ & 281.57 & 923.79 & 3H049 & 11.2 & 1.049218023 & 1.83 & 0.163392857 & 0.859 & 0.076696429 & 27 \\
\hline $91 / 1$ & 282.36 & 926.38 & $3 \mathrm{H} 050$ & 27.1 & 1.432969291 & 7.86 & 0.2900369 & 2.63 & 0.09704797 & 38 \\
\hline $92 / 1$ & 284.59 & 933.69 & $3 \mathrm{H} 051$ & 34.5 & 1.537819095 & 10.9 & 0.315942029 & 3.8 & 0.110144928 & 53 \\
\hline $93 / 1$ & 285.63 & 937.11 & $3 \mathrm{H} 052$ & 70.5 & 1.848189117 & 18.8 & 0.2666666667 & 12.1 & 0.171631206 & 65 \\
\hline $95 / 1$ & 288.17 & 945.44 & $3 \mathrm{H} 053$ & 30.2 & 1.480006943 & 5.41 & 0.179139073 & & 0 & 55 \\
\hline $96 / 1$ & 290.16 & 951.97 & $3 \mathrm{H} 054$ & 29.1 & 1.463892989 & 10.4 & 0.357388316 & 3.51 & 0.120618557 & 49 \\
\hline $97 / 1$ & 292.09 & 958.30 & $3 \mathrm{H} 055$ & 66.5 & 1.822821645 & 27.8 & 0.418045113 & 11.8 & 0.177443609 & 51 \\
\hline $98 / 1$ & 312.26 & 1024.48 & $3 \mathrm{H} 056$ & 29.4 & 1.46834733 & 4.76 & 0.161904762 & 2.07 & 0.070408163 & 57 \\
\hline $105 / 1$ & 356.09 & 1168.27 & $3 \mathrm{H} 057$ & 1.49 & 0.173186268 & 0.888 & 0.595973154 & 0.439 & 0.294630872 & 7 \\
\hline $106 / 1$ & 357.36 & 1172.44 & $3 \mathrm{H} 058$ & 2.06 & 0.31386722 & 1.18 & 0.572815534 & 0.504 & 0.244660194 & 5 \\
\hline $107 / 1$ & 358.8 & 1177.17 & $3 \mathrm{H} 059$ & 1.43 & 0.155336037 & 0.778 & 0.544055944 & 0.385 & 0.269230769 & 7 \\
\hline $108 / 1$ & 378.1 & 1240.49 & $3 \mathrm{H} 060$ & 113 & 2.053078443 & 85.9 & 0.760176991 & 62.6 & 0.553982301 & 40 \\
\hline $108 / 1$ & 378.79 & 1242.75 & $3 \mathrm{H} 061$ & 172 & 2.235528447 & 125 & 0.726744186 & 98.4 & 0.572093023 & 44 \\
\hline $109 / 1$ & 380.12 & 1247.11 & $3 \mathrm{H} 062$ & 132 & 2.120573931 & 63.5 & 0.481060606 & 34.5 & 0.261363636 & 61 \\
\hline $110 / 1$ & 382.25 & 1254.10 & $3 \mathrm{H} 063$ & 92.3 & 1.965201701 & 57.9 & 0.627302275 & 38.4 & 0.41603467 & 57 \\
\hline $111 / 1$ & 396.99 & 1302.46 & $3 \mathrm{H} 064$ & 14.6 & 1.164352856 & 2.68 & 0.183561644 & 0.809 & 0.055410959 & 26 \\
\hline $113 / 1$ & 412.12 & 1352.10 & $3 \mathrm{H} 065$ & 47.1 & 1.673020907 & 12.7 & 0.269639066 & 5.23 & 0.11104034 & \\
\hline $115 / 1$ & 458.1 & 1502.95 & $3 \mathrm{H} 066$ & 51.5 & 1.711807229 & 24.4 & 0.473786408 & 12.8 & 0.248543689 & \\
\hline $116 / 1$ & 459.27 & 1506.79 & $3 \mathrm{H} 067$ & 94.3 & 1.974511693 & 53.3 & 0.565217391 & 27.5 & 0.291622481 & \\
\hline $116 / 1$ & 459.49 & 1507.51 & $3 \mathrm{H} 068$ & 80.4 & 1.905256049 & 26.8 & 0.333333333 & 12.9 & 0.160447761 & \\
\hline $117 / 2$ & 461.19 & 1513.09 & $3 \mathrm{H} 069$ & 60.2 & 1.779596491 & 19.8 & 0.328903654 & 9.52 & 0.158139535 & \\
\hline
\end{tabular}


Table 18. Paleomagnetic results from the Long Beach City College core site and monitoring well (LBCC), Long Beach, California.

[Inclination of remanent magnetization after alternating-field treatment of samples from LBCC. RML Id, Rock Magnetism Laboratory identification number; Decl (relativity), declination relative to split face of core; N, normal; $\mathrm{R}$, reversed; I, indeterminate polarity of magnetization; Oe, oersteds; mT, millitesla; AF Demag, range of demagnetization steps in Oe used in calculation of inclination $(100 \mathrm{Oe}=10 \mathrm{mT})$; MAD, maximum angular deviation (in degrees) from principal-component analysis (Kirschvink, 1980)]

\begin{tabular}{|c|c|c|c|c|c|c|c|c|}
\hline $\begin{array}{c}\text { Core } \\
\text { number }\end{array}$ & $\begin{array}{l}\text { Depth, in } \\
\text { feet }\end{array}$ & $\begin{array}{l}\text { Depth, in } \\
\text { meters }\end{array}$ & $\begin{array}{l}\text { RML } \\
\text { Id }\end{array}$ & Polarity & $\begin{array}{l}\text { Inclination, in } \\
\text { degrees }\end{array}$ & $\begin{array}{l}\text { Declination } \\
\text { (relativity) }\end{array}$ & $\begin{array}{l}\text { AF Demag } \\
\quad(\mathrm{Oe})\end{array}$ & MAD \\
\hline $1 / 1$ & 1.35 & 0.41 & $3 \mathrm{H} 001$ & $\mathrm{~N}$ & 57.00 & 13.20 & $150-400$ & 10.60 \\
\hline $2 / 1$ & 5.48 & 1.67 & $3 \mathrm{H} 002$ & $\mathrm{~N}$ & 60.10 & 268.80 & $100-300$ & 4.60 \\
\hline $3 / 1$ & 12.70 & 3.87 & $3 \mathrm{H} 003$ & I & -11.10 & 66.70 & $100-300$ & 5.90 \\
\hline $4 / 1$ & 17.09 & 5.21 & $3 \mathrm{H} 004$ & $\mathrm{R}$ & -36.40 & 252.10 & $150-300$ & 28.40 \\
\hline $10 / 1$ & 46.36 & 14.13 & $3 \mathrm{H} 005$ & $\mathrm{~N}$ & 55.90 & 219.30 & $100-300$ & 3.70 \\
\hline $11 / 1$ & 52.17 & 15.90 & 3H006 & $\mathrm{N}$ & 59.00 & 244.50 & $150-300$ & 2.30 \\
\hline $13 / 1$ & 63.65 & 19.40 & $3 \mathrm{H} 007$ & $\mathrm{~N}$ & 48.90 & 254.80 & $100-300$ & 15.90 \\
\hline $14 / 1$ & 66.90 & 20.39 & $3 \mathrm{H} 008$ & $\mathrm{~N}$ & 50.60 & 46.30 & $100-300$ & 4.70 \\
\hline $15 / 1$ & 71.19 & 21.70 & $3 \mathrm{H} 009$ & I & -11.00 & 278.60 & $100-300$ & 2.50 \\
\hline $16 / 1$ & 77.66 & 23.67 & $3 \mathrm{H} 010$ & $\mathrm{~N}$ & 26.60 & 28.00 & $200-500$ & 4.50 \\
\hline $17 / 1$ & 80.71 & 24.60 & $3 \mathrm{H} 011$ & $\mathrm{~N}$ & 26.70 & 64.50 & $150-500$ & 11.80 \\
\hline $23 / 1$ & 111.45 & 33.97 & $3 \mathrm{H} 012$ & $\mathrm{~N}$ & 48.10 & 221.70 & $300-600$ & 6.20 \\
\hline $24 / 1$ & 114.04 & 34.76 & $3 \mathrm{H} 013$ & $\mathrm{~N}$ & 50.70 & 18.20 & $150-300$ & 3.10 \\
\hline $25 / 1$ & 117.16 & 35.71 & $3 \mathrm{H} 014$ & $\mathrm{~N}$ & 51.30 & 296.00 & $100-300$ & 8.40 \\
\hline $28 / 1$ & 131.92 & 40.21 & $3 \mathrm{H} 015$ & $\mathrm{~N}$ & 66.20 & 104.10 & $200-500$ & 10.80 \\
\hline $29 / 1$ & 135.70 & 41.36 & $3 \mathrm{H} 016$ & $\mathrm{~N}$ & 57.20 & 106.90 & $150-500$ & 6.20 \\
\hline $36 / 1$ & 174.15 & 53.08 & $3 \mathrm{H} 017$ & $\mathrm{~N}$ & 64.70 & 45.30 & $100-300$ & 12.70 \\
\hline $38 / 1$ & 184.94 & 56.37 & $3 \mathrm{H} 018$ & $\mathrm{~N}$ & 29.30 & 79.60 & $150-400$ & 8.90 \\
\hline $40 / 1$ & 192.88 & 58.79 & $3 \mathrm{H} 019$ & $\mathrm{~N}$ & 39.50 & 62.70 & $100-300$ & 5.70 \\
\hline $43 / 1$ & 206.86 & 63.05 & $3 \mathrm{H} 020$ & $\mathrm{~N}$ & 56.00 & 354.40 & $100-200$ & 11.40 \\
\hline $45 / 1$ & 215.91 & 65.81 & $3 \mathrm{H} 021$ & $\mathrm{~N}$ & 84.60 & 336.30 & $100-200$ & 5.80 \\
\hline $47 / 1$ & 257.19 & 78.39 & $3 \mathrm{H} 022$ & $\mathrm{~N}$ & 49.00 & 6.60 & $100-200$ & 10.90 \\
\hline $48 / 1$ & 261.84 & 79.81 & $3 \mathrm{H} 023$ & $\mathrm{~N}$ & 53.20 & 311.40 & $100-300$ & 15.30 \\
\hline $49 / 1$ & 265.62 & 80.96 & $3 \mathrm{H} 024$ & $\mathrm{~N}$ & 42.30 & 210.60 & $150-300$ & 21.60 \\
\hline $50 / 1$ & 330.97 & 100.88 & $3 \mathrm{H} 025$ & $\mathrm{~N}$ & 60.30 & 113.00 & $150-300$ & 6.00 \\
\hline $51 / 1$ & 336.52 & 102.57 & $3 \mathrm{H} 026$ & $\mathrm{~N}$ & 52.10 & 314.30 & $100-200$ & 2.30 \\
\hline $52 / 1$ & 341.34 & 104.04 & $3 \mathrm{H} 027$ & $\mathrm{~N}$ & 53.50 & 49.40 & $100-200$ & 1.40 \\
\hline $53 / 1$ & 346.46 & 105.60 & $3 \mathrm{H} 028$ & $\mathrm{~N}$ & 54.90 & 8.20 & $100-200$ & 3.00 \\
\hline $54 / 1$ & 351.97 & 107.28 & $3 \mathrm{H} 029$ & $\mathrm{~N}$ & 50.20 & 337.90 & $100-200$ & 2.70 \\
\hline $55 / 1$ & 357.38 & 108.93 & $3 \mathrm{H} 030$ & $\mathrm{~N}$ & 61.30 & 308.50 & $100-300$ & 4.60 \\
\hline $56 / 1$ & 443.08 & 135.05 & $3 \mathrm{H} 031$ & $\mathrm{~N}$ & 44.20 & 65.70 & $150-500$ & 13.00 \\
\hline $58 / 1$ & 453.77 & 138.31 & $3 \mathrm{H} 032$ & $\mathrm{~N}$ & 41.70 & 14.20 & $300-600$ & 9.90 \\
\hline $59 / 1$ & 456.36 & 139.10 & $3 \mathrm{H} 033$ & $\mathrm{~N}$ & 59.30 & 344.90 & $150-400$ & 2.30 \\
\hline $60 / 1$ & 462.04 & 140.83 & 3H034 & $\mathrm{N}$ & 42.40 & 80.50 & $100-300$ & 20.20 \\
\hline $61 / 1$ & 466.93 & 142.32 & $3 \mathrm{H} 035 \mathrm{~A}$ & $\mathrm{~N}$ & 46.40 & 78.60 & $150-300$ & 5.00 \\
\hline $65 / 1$ & 488.81 & 148.99 & $3 \mathrm{H} 035 \mathrm{~B}$ & $\mathrm{~N}$ & 45.10 & 245.80 & $100-400$ & 10.50 \\
\hline $70 / 1$ & 562.89 & 171.57 & $3 \mathrm{H} 035$ & $\mathrm{~N}$ & 57.50 & 154.30 & $100-300$ & 8.70 \\
\hline $71 / 1$ & 568.57 & 173.30 & $3 \mathrm{H} 036$ & $\mathrm{~N}$ & 74.60 & 190.50 & $100-300$ & 8.10 \\
\hline $72 / 1$ & 573.72 & 174.87 & $3 \mathrm{H} 037$ & $\mathrm{~N}$ & 52.70 & 259.50 & $100-300$ & 5.40 \\
\hline $73 / 1$ & 577.10 & 175.90 & $3 \mathrm{H} 038$ & $\mathrm{~N}$ & 51.30 & 42.10 & $100-300$ & 22.30 \\
\hline
\end{tabular}




\begin{tabular}{|c|c|c|c|c|c|c|c|c|}
\hline $79 / 1$ & 656.46 & 200.09 & $3 \mathrm{H} 039$ & $\mathrm{~N}$ & 49.80 & 178.10 & $100-300$ & 6.70 \\
\hline $80 / 1$ & 742.52 & 226.32 & $3 \mathrm{H} 040$ & $\mathrm{~N}$ & 46.30 & 140.50 & $150-500$ & 4.60 \\
\hline $81 / 1$ & 746.23 & 227.45 & $3 \mathrm{H} 041$ & $\mathrm{~N}$ & 49.10 & 245.60 & $300-600$ & 13.80 \\
\hline $82 / 1$ & 752.43 & 229.34 & $3 \mathrm{H} 042$ & $\mathrm{~N}$ & 48.60 & 254.88 & $300-600$ & 11.00 \\
\hline $83 / 1$ & 757.51 & 230.89 & $3 \mathrm{H} 043$ & $\mathrm{~N}$ & 54.80 & 264.10 & $300-500$ & 8.90 \\
\hline $84 / 1$ & 762.73 & 232.48 & $3 \mathrm{H} 044$ & $\mathrm{~N}$ & 54.30 & 133.90 & $150-500$ & 5.40 \\
\hline $85 / 1$ & 767.95 & 234.07 & $3 \mathrm{H} 045$ & $\mathrm{~N}$ & 59.80 & 286.00 & $150-400$ & 5.00 \\
\hline $86 / 1$ & 823.06 & 250.87 & $3 \mathrm{H} 046$ & $\mathrm{~N}$ & 42.90 & 158.60 & $100-300$ & 1.20 \\
\hline $87 / 1$ & 827.62 & 252.26 & $3 \mathrm{H} 047$ & $\mathrm{~N}$ & 42.80 & 269.40 & $100-300$ & 2.40 \\
\hline $89 / 1$ & 836.81 & 255.06 & $3 \mathrm{H} 048$ & $\mathrm{~N}$ & 52.60 & 350.00 & $100-300$ & 2.20 \\
\hline $90 / 1$ & 923.79 & 281.57 & $3 \mathrm{H} 049$ & $\mathrm{~N}$ & 50.60 & 347.40 & $100-300$ & 9.00 \\
\hline $91 / 1$ & 926.38 & 282.36 & $3 \mathrm{H} 050$ & $\mathrm{~N}$ & 24.40 & 71.40 & $150-300$ & 4.30 \\
\hline $92 / 1$ & 933.69 & 284.59 & $3 \mathrm{H} 051$ & $\mathrm{~N}$ & 56.60 & 131.10 & $100-300$ & 5.30 \\
\hline $93 / 1$ & 937.11 & 285.63 & $3 \mathrm{H} 052$ & $\mathrm{~N}$ & 53.90 & 223.60 & $150-300$ & 6.80 \\
\hline $95 / 1$ & 945.44 & 288.17 & $3 \mathrm{H} 053$ & $\mathrm{~N}$ & 52.80 & 8.60 & $100-200$ & 8.10 \\
\hline $96 / 1$ & 951.97 & 290.16 & $3 \mathrm{H} 054$ & $\mathrm{~N}$ & 48.40 & 194.30 & $150-300$ & 2.10 \\
\hline $97 / 1$ & 958.30 & 292.09 & $3 \mathrm{H} 055$ & $\mathrm{~N}$ & 44.80 & 326.10 & $150-300$ & 1.90 \\
\hline $98 / 1$ & 1024.48 & 312.26 & $3 \mathrm{H} 056$ & $\mathrm{~N}$ & 53.50 & 341.10 & $100-300$ & 7.50 \\
\hline $105 / 1$ & 1168.27 & 356.09 & $3 \mathrm{H} 057$ & $\mathrm{~N}$ & 42.80 & 117.40 & $150-300$ & 4.80 \\
\hline $106 / 1$ & 1172.44 & 357.36 & $3 \mathrm{H} 058$ & $\mathrm{~N}$ & 53.70 & 305.30 & $150-300$ & 1.80 \\
\hline $107 / 1$ & 1177.17 & 358.80 & $3 \mathrm{H} 059$ & $\mathrm{~N}$ & 39.80 & 331.70 & $200-400$ & 7.60 \\
\hline $108 / 1$ & 1240.49 & 378.10 & $3 \mathrm{H} 060$ & $\mathrm{~N}$ & 50.30 & 127.40 & $150-400$ & 2.40 \\
\hline $108 / 1$ & 1242.75 & 378.79 & $3 \mathrm{H} 061$ & $\mathrm{~N}$ & 51.60 & 108.10 & $150-400$ & 4.70 \\
\hline $109 / 1$ & 1247.11 & 380.12 & $3 \mathrm{H} 062$ & $\mathrm{~N}$ & 55.20 & 331.80 & $150-400$ & 4.80 \\
\hline $110 / 1$ & 1254.10 & 382.25 & $3 \mathrm{H} 063$ & $\mathrm{~N}$ & 48.20 & 60.90 & $150-400$ & 1.40 \\
\hline $111 / 1$ & 1302.46 & 396.99 & $3 \mathrm{H} 064$ & $\mathrm{~N}$ & 64.40 & 297.70 & $150-300$ & 5.20 \\
\hline $113 / 1$ & 1352.10 & 412.12 & $3 \mathrm{H} 065$ & $\mathrm{~N}$ & 81.80 & 352.60 & $100-300$ & 12.40 \\
\hline $115 / 1$ & 1502.95 & 458.10 & $3 \mathrm{H} 066$ & $\mathrm{~N}$ & 50.60 & 60.30 & $100-300$ & 1.60 \\
\hline $116 / 1$ & 1506.79 & 459.27 & $3 \mathrm{H} 067$ & $\mathrm{~N}$ & 55.20 & 36.90 & $100-300$ & 1.70 \\
\hline $116 / 1$ & 1507.51 & 459.49 & $3 \mathrm{H} 068$ & $\mathrm{~N}$ & 56.20 & 19.20 & $100-300$ & 1.40 \\
\hline $117 / 2$ & 1513.09 & 461.19 & $3 \mathrm{H} 069$ & $\mathrm{~N}$ & 55.90 & 279.20 & $150-300$ & 2.10 \\
\hline
\end{tabular}


Table 23. Paleomagnetic results from the Long Beach Water Treatment core site and monitoring well (LBWT), Long Beach, California.

[Inclination of remanent magnetization after alternating-field treatment of samples from LBWT. RML Id, Rock Magnetism Laboratory identification number; Decl (relativity), declination relative to split face of core; N, normal; $\mathrm{R}$, reversed; I, indeterminate polarity of magnetization; Oe, oersteds; mT, millitesla; AF Demag, range of demagnetization steps in Oe used in calculation of inclination (100 Oe=10 mT); MAD, maximum angular deviation (in degrees) from principal-component analysis (Kirschvink, 1980)]

\begin{tabular}{|c|c|c|c|c|c|c|c|c|c|}
\hline $\begin{array}{c}\text { Core } \\
\text { number }\end{array}$ & $\begin{array}{l}\text { Depth, in } \\
\text { meters }\end{array}$ & $\begin{array}{l}\text { Depth, in } \\
\text { feet }\end{array}$ & $\begin{array}{l}\text { RML } \\
\text { Id }\end{array}$ & Polarity & $\begin{array}{c}\text { Inclination, in } \\
\text { degrees }\end{array}$ & $\begin{array}{c}\text { Decl } \\
\text { (relativity) }\end{array}$ & $\begin{array}{c}\text { Jnrm } \\
\mathbf{m A} / \mathbf{m}\end{array}$ & $\begin{array}{l}\text { AF Demag } \\
\text { (Oe) }\end{array}$ & MAD \\
\hline $6 \mathrm{C}-1$ & 26.62 & 87.33 & $2 \mathrm{H} 003$ & $\mathrm{~N}$ & 44.6 & 258.1 & 19.2 & $15-30$ & 4.3 \\
\hline $7 \mathrm{C}-1$ & 27.90 & 91.54 & $2 \mathrm{H} 004$ & $\mathrm{~N}$ & 42.2 & 216.0 & 81.3 & $10-40$ & 1.2 \\
\hline $8 \mathrm{C}-1$ & 29.61 & 97.13 & $2 \mathrm{H} 005$ & $\mathrm{~N}$ & 54.5 & 104.7 & 35.4 & $15-30$ & 8.1 \\
\hline $11 \mathrm{C}-1$ & 43.61 & 143.08 & $2 \mathrm{H} 006$ & $\mathrm{~N}$ & 57.6 & 296.7 & 0.450 & $15-30$ & 17.9 \\
\hline $12 \mathrm{C}-1$ & 45.04 & 147.76 & $2 \mathrm{H} 007$ & $\mathrm{~N}$ & 84.5 & 89.4 & 2.21 & $15-40$ & 3.5 \\
\hline $16 \mathrm{C}-1$ & 51.24 & 168.12 & $2 \mathrm{H} 008$ & $\mathrm{~N}$ & 60.3 & 208.1 & 41.6 & $15-30$ & 8.5 \\
\hline $17 \mathrm{C}-1$ & 52.75 & 173.07 & $2 \mathrm{H} 009$ & $\mathrm{~N}$ & 44.4 & 277.0 & 68.5 & $15-30$ & 1.6 \\
\hline $21 \mathrm{C}-1$ & 76.87 & 252.20 & $2 \mathrm{H} 010$ & $\mathrm{~N}$ & 76.7 & 78.6 & 25.2 & $15-30$ & 3.8 \\
\hline $24 \mathrm{C}-1$ & 81.32 & 266.79 & $2 \mathrm{H} 011$ & $\mathrm{~N}$ & 48.9 & 358.5 & 12.4 & $15-30$ & 11.0 \\
\hline $25 \mathrm{C}-1$ & 82.70 & 271.33 & $2 \mathrm{H} 012$ & $\mathrm{~N}$ & 70.8 & 240.1 & 32.1 & $15-30$ & 4.7 \\
\hline $27 \mathrm{C}-1$ & 99.27 & 325.69 & $2 \mathrm{H} 013$ & $\mathrm{~N}$ & 60.1 & 216.1 & 19.5 & $15-30$ & 14.7 \\
\hline $30 \mathrm{C}-1$ & 104.25 & 342.03 & $2 \mathrm{H} 014$ & $\mathrm{~N}$ & 72.6 & 242.3 & 35.1 & $15-30$ & 8.4 \\
\hline $31 \mathrm{C}-1$ & 105.35 & 345.64 & $2 \mathrm{H} 015$ & $\mathrm{~N}$ & 84.9 & 281.6 & 52.1 & $15-30$ & 6.0 \\
\hline $32 \mathrm{C}-1$ & 106.81 & 350.43 & $2 \mathrm{H} 016$ & $\mathrm{~N}$ & 32.0 & 273.5 & 40.9 & $10-20$ & 0.4 \\
\hline $33 \mathrm{C}-1$ & 108.37 & 355.54 & $2 \mathrm{H} 017$ & $\mathrm{~N}$ & 58.5 & 326.1 & 14.3 & $15-30$ & 14.6 \\
\hline $34 \mathrm{C}-1$ & 110.31 & 361.90 & $2 \mathrm{H} 018$ & $\mathrm{~N}$ & 41.9 & 136.7 & 32.4 & $10-20$ & 0.9 \\
\hline $35 \mathrm{C}-1$ & 111.77 & 366.71 & $2 \mathrm{H} 019$ & $\mathrm{~N}$ & 46.0 & 130.8 & 121 & $15-30$ & 1.0 \\
\hline $41 \mathrm{C}-1$ & 129.63 & 425.28 & $2 \mathrm{H} 020$ & $\mathrm{~N}$ & 62.3 & 212.1 & 61.3 & $15-30$ & 1.9 \\
\hline $42 \mathrm{C}-1$ & 131.39 & 431.07 & $2 \mathrm{H} 021$ & $\mathrm{~N}$ & 74.2 & 357.8 & 89.9 & $15-30$ & 3.7 \\
\hline $52 \mathrm{C}-1$ & 199.10 & 653.20 & $2 \mathrm{H} 022$ & $\mathrm{R}$ & -64.1 & 348.7 & 0.307 & $20-40$ & 17.3 \\
\hline $54 \mathrm{C}-1$ & 201.82 & 662.13 & $2 \mathrm{H} 023$ & $\mathrm{~N}$ & 56.2 & 342.8 & 74.5 & $15-30$ & 0.8 \\
\hline $55 \mathrm{C}-1$ & 203.43 & 667.41 & $2 \mathrm{H} 024$ & $\mathrm{~N}$ & 50.1 & 189.9 & 70.8 & $15-30$ & 5.4 \\
\hline $56 \mathrm{C}-1$ & 204.83 & 672.00 & $2 \mathrm{H} 025$ & $\mathrm{~N}$ & 49.5 & 233.7 & 64.6 & $15-30$ & 3.2 \\
\hline $57 \mathrm{C}-1$ & 206.60 & 677.81 & $2 \mathrm{H} 026$ & $\mathrm{~N}$ & 48.2 & 23.0 & 66.3 & $15-30$ & 0.8 \\
\hline $58 \mathrm{C}-1$ & 207.78 & 681.69 & $2 \mathrm{H} 027$ & $\mathrm{~N}$ & 37.1 & 38.9 & 71.0 & $15-30$ & 1.3 \\
\hline $59 \mathrm{C}-1$ & 209.27 & 686.57 & $2 \mathrm{H} 028$ & $\mathrm{~N}$ & 61.3 & 295.3 & 94.9 & $15-30$ & 0.4 \\
\hline $61 \mathrm{C}-1$ & 236.42 & 775.64 & $2 \mathrm{H} 029$ & $\mathrm{~N}$ & 59.1 & 37.5 & 22.4 & $15-30$ & 8.6 \\
\hline $64 \mathrm{C}-1$ & 241.42 & 792.07 & $2 \mathrm{H} 030$ & $\mathrm{~N}$ & 48.2 & 11.6 & 5.87 & $15-30$ & 9.4 \\
\hline $67 \mathrm{C}-1$ & 288.94 & 947.97 & $2 \mathrm{H} 031$ & I & 6.8 & 205.0 & 0.459 & $10-20$ & 20.4 \\
\hline $69 \mathrm{C}-1$ & 291.50 & 956.38 & $2 \mathrm{H} 032$ & $\mathrm{~N}$ & 66.4 & 55.0 & 0.654 & $15-30$ & 19.8 \\
\hline $70 \mathrm{C}-1$ & 293.27 & 962.17 & $2 \mathrm{H} 033$ & $\mathrm{~N}$ & 35.9 & 344.7 & 0.575 & $15-30$ & 20.6 \\
\hline $71 \mathrm{C}-1$ & 294.76 & 967.07 & $2 \mathrm{H} 034$ & $\mathrm{~N}$ & 30.2 & 204.2 & 18.0 & $15-30$ & 4.8 \\
\hline $72 \mathrm{C}-1$ & 295.94 & 970.92 & $2 \mathrm{H} 035$ & $\mathrm{~N}$ & 49.8 & 355.2 & 21.3 & $15-30$ & 5.1 \\
\hline $73 \mathrm{C}-1$ & 297.80 & 977.03 & $2 \mathrm{H} 036$ & $\mathrm{~N}$ & 81.8 & 106.5 & 20.0 & $15-30$ & 9.2 \\
\hline $74 \mathrm{C}-1$ & 299.10 & 981.30 & $2 \mathrm{H} 037$ & $\mathrm{~N}$ & 51.0 & 255.3 & 16.7 & $15-30$ & 22.4 \\
\hline $77 \mathrm{C}-1$ & 329.24 & 1080.18 & $2 \mathrm{H} 038$ & $\mathrm{~N}$ & 63.6 & 210.8 & 53.5 & $15-30$ & 1.3 \\
\hline $79 \mathrm{C}-1$ & 332.28 & 1090.16 & $2 \mathrm{H} 039$ & $\mathrm{~N}$ & 38.5 & 65.7 & 20.4 & $15-30$ & 5.9 \\
\hline $81 \mathrm{C}-1$ & 335.56 & 1100.92 & $2 \mathrm{H} 040$ & $\mathrm{~N}$ & 55.4 & 43.1 & 29.6 & $30-50$ & 1.6 \\
\hline $82 \mathrm{C}-1$ & 337.20 & 1106.30 & $2 \mathrm{H} 041$ & $\mathrm{~N}$ & 76.8 & 275.4 & 27.7 & $15-50$ & 6.0 \\
\hline $83 \mathrm{C}-1$ & 338.89 & 1111.84 & $2 \mathrm{H} 042$ & $\mathrm{~N}$ & 72.6 & 160.7 & 26.2 & $30-50$ & 19.2 \\
\hline
\end{tabular}




\begin{tabular}{|c|c|c|c|c|c|c|c|c|c|}
\hline $84 \mathrm{C}-1$ & 340.60 & 1117.46 & $2 \mathrm{H} 043$ & $\mathrm{~N}$ & 65.8 & 220.2 & 22.6 & $15-30$ & 9.2 \\
\hline $85 \mathrm{C}-1$ & 357.13 & 1171.67 & $2 \mathrm{H} 044$ & $\mathrm{~N}$ & 44.8 & 80.1 & 20.6 & $10-40$ & 1.6 \\
\hline $86 \mathrm{C}-1$ & 358.81 & 1177.20 & $2 \mathrm{H} 045$ & $\mathrm{~N}$ & 48.6 & 75.5 & 67.4 & $30-50$ & 6.0 \\
\hline $87 \mathrm{C}-1$ & 360.03 & 1181.21 & $2 \mathrm{H} 046$ & $\mathrm{~N}$ & 74.0 & 309.5 & 44.9 & $30-50$ & 15.2 \\
\hline $88 \mathrm{C}-1$ & 361.46 & 1185.90 & $2 \mathrm{H} 047$ & $\mathrm{~N}$ & 85.8 & 153.2 & 31.7 & $15-50$ & 4.6 \\
\hline $89 \mathrm{C}-1$ & 363.69 & 1193.20 & $2 \mathrm{H} 048$ & $\mathrm{~N}$ & 80.0 & 121.1 & 49.0 & $20-50$ & 5.2 \\
\hline $91 \mathrm{C}-1$ & 366.46 & 1202.30 & $2 \mathrm{H} 049$ & $\mathrm{~N}$ & 57.6 & 174.0 & 57.2 & $20-50$ & 1.7 \\
\hline $92 \mathrm{C}-1$ & 367.86 & 1206.90 & $2 \mathrm{H} 050$ & $\mathrm{~N}$ & 66.6 & 224.5 & 57.4 & $20-50$ & 1.2 \\
\hline $93 \mathrm{C}-1$ & 397.19 & 1303.12 & $2 \mathrm{H} 051$ & $\mathrm{~N}$ & 75.9 & 98.4 & 42.8 & $30-50$ & 16.7 \\
\hline $95 \mathrm{C}-1$ & 399.91 & 1312.03 & $2 \mathrm{H} 052$ & $\mathrm{~N}$ & 61.2 & 18.5 & 86.0 & $20-50$ & 6.3 \\
\hline $96 \mathrm{C}-1$ & 401.10 & 1315.94 & $2 \mathrm{H} 053$ & $\mathrm{~N}$ & 53.1 & 97.9 & 69.2 & $30-50$ & 12.9 \\
\hline $98 \mathrm{C}-1$ & 404.85 & 1328.26 & $2 \mathrm{H} 054$ & $\mathrm{~N}$ & 62.1 & 204.3 & 7.3 & $5-40$ & 3.4 \\
\hline $99 \mathrm{C}-1$ & 406.55 & 1333.82 & $2 \mathrm{H} 055$ & $\mathrm{~N}$ & 69.0 & 288.0 & 50.7 & $30-50$ & 11.2 \\
\hline $101 \mathrm{C}-1$ & 469.88 & 1541.60 & $2 \mathrm{H} 056$ & $\mathrm{~N}$ & 60.5 & 104.2 & 28.2 & $20-40$ & 7.9 \\
\hline $102 \mathrm{C}-1$ & 471.38 & 1546.53 & $2 \mathrm{H} 057$ & $\mathrm{~N}$ & 78.6 & 225.8 & 6.91 & $5-50$ & 5.9 \\
\hline
\end{tabular}


Table 24. Paleomagnetic results from the Long Beach Water well \# 1 core site and monitoring well (LBW1), Long Beach, California.

[Inclination of remanent magnetization after alternating-field treatment of samples from LBCC. RML Id, Rock Magnetism Laboratory identification number; Decl (relativity), declination relative to split face of core; N, normal; $\mathrm{R}$, reversed; I, indeterminate polarity of magnetization; Oe, oersteds; mT, millitesla; AF Demag, range of demagnetization steps in Oe used in calculation of inclination $(100 \mathrm{Oe}=10 \mathrm{mT})$; MAD, maximum angular deviation (in degrees) from principal-component analysis (Kirschvink, 1980)]

\begin{tabular}{|c|c|c|c|c|c|c|c|c|c|c|}
\hline $\begin{array}{c}\begin{array}{c}\text { Core } \\
\text { number }\end{array} \\
\end{array}$ & $\begin{array}{c}\text { Depth, in } \\
\text { meters }\end{array}$ & $\begin{array}{l}\text { Depth, in } \\
\text { feet }\end{array}$ & $\begin{array}{c}\text { RML } \\
\text { Id }\end{array}$ & Polarity & $\begin{array}{c}\text { Inclination, in } \\
\text { degrees }\end{array}$ & $\begin{array}{c}\text { Decl } \\
\text { (relativity) }\end{array}$ & $\begin{array}{l}\text { Jnrm } \\
\mathbf{m A} / \mathbf{m}\end{array}$ & $\begin{array}{c}\text { AF } \\
\text { Demag } \\
\text { (Oe) }\end{array}$ & MAD & Comment \\
\hline $3 \mathrm{C}-1$ & 4.74 & 15.55 & $9 \mathrm{H} 083$ & $\mathrm{~N}$ & 53.60 & 338.60 & 8.33 & $10-30$ & 4.20 & \\
\hline $4 \mathrm{C}-1$ & 6.78 & 22.24 & $9 \mathrm{H} 084$ & $\mathrm{~N}$ & 46.20 & 305.30 & 12.10 & $10-30$ & 7.60 & \\
\hline $3 \mathrm{C}-1$ & 8.37 & 27.46 & $9 \mathrm{H} 085$ & $\mathrm{~N}$ & 52.20 & 343.90 & 33.80 & $10-30$ & 4.90 & \\
\hline $5 \mathrm{C}-1$ & 9.99 & 32.78 & $9 \mathrm{H} 086$ & $\mathrm{~N}$ & 62.70 & 220.70 & 39.20 & $10-30$ & 4.50 & \\
\hline $7 \mathrm{C}-1$ & 11.86 & 38.91 & $9 \mathrm{H} 087$ & $\mathrm{~N}$ & 57.80 & 254.00 & 55.90 & $15-30$ & 5.80 & \\
\hline $8 \mathrm{C}-1$ & 12.94 & 42.45 & $9 \mathrm{H} 088$ & $\mathrm{~N}$ & 56.50 & 227.30 & 55.60 & $10-30$ & 4.10 & \\
\hline $9 \mathrm{C}-1$ & 14.41 & 47.28 & 9H089 & $\mathrm{N}$ & 44.00 & 329.30 & 104.00 & $10-30$ & 1.20 & \\
\hline $10 \mathrm{C}-1$ & 15.45 & 50.69 & $9 \mathrm{H} 090$ & $\mathrm{~N}$ & 54.90 & 95.30 & 75.60 & $10-30$ & 1.90 & \\
\hline $12 \mathrm{C}-1$ & 18.49 & 60.66 & 9H091 & $\mathrm{N}$ & 50.50 & 309.80 & 48.70 & $10-20$ & 11.80 & \\
\hline $12 \mathrm{C}-1$ & 18.76 & 61.55 & $9 \mathrm{H} 092$ & $\mathrm{~N}$ & 53.80 & 315.10 & 43.60 & $10-30$ & 5.30 & \\
\hline $15 \mathrm{C}-1$ & 22.60 & 74.15 & $9 \mathrm{H} 093$ & $\mathrm{~N}$ & 81.60 & 183.90 & 7.60 & $15-40$ & 6.30 & \\
\hline $16 \mathrm{C}-1$ & 23.71 & 77.79 & 9H094 & $\mathrm{N}$ & 71.90 & 151.50 & 8.90 & $10-30$ & 6.00 & \\
\hline $18 \mathrm{C}-1$ & 26.96 & 88.45 & $9 \mathrm{H} 095$ & $\mathrm{~N}$ & 47.90 & 27.50 & 9.26 & $10-30$ & 1.80 & \\
\hline $19 \mathrm{C}-1$ & 27.88 & 91.47 & $9 \mathrm{H} 096$ & $\mathrm{~N}$ & 49.30 & 158.20 & 15.90 & $10-20$ & 6.00 & \\
\hline $20 \mathrm{C}-1$ & 29.30 & 96.13 & $9 \mathrm{H} 097$ & $\mathrm{~N}$ & 46.50 & 346.10 & 44.30 & $10-30$ & 3.90 & \\
\hline $22 \mathrm{C}-1$ & 32.56 & 106.82 & 9H098 & $\mathrm{N}$ & 47.00 & 282.90 & 82.30 & $10-30$ & 2.70 & \\
\hline $23 \mathrm{C}-1$ & 34.13 & 111.98 & 9H099 & $\mathrm{N}$ & 42.70 & 249.20 & 26.30 & $10-30$ & 1.90 & \\
\hline $25 \mathrm{C}-1$ & 37.13 & 121.82 & $9 \mathrm{H} 102$ & I & 15.80 & 220.80 & 0.48 & $15-25$ & 26.30 & \\
\hline $27 \mathrm{C}-1$ & 39.99 & 131.20 & $9 \mathrm{H} 103$ & $\mathrm{~N}$ & 41.60 & 268.10 & 4.11 & $10-20$ & 17.90 & \\
\hline $30 \mathrm{C}-1$ & 44.36 & 145.54 & $9 \mathrm{H} 104$ & $\mathrm{~N}$ & 55.10 & 63.30 & 8.27 & $10-20$ & 4.50 & \\
\hline $32 \mathrm{C}-1$ & 47.66 & 156.36 & $9 \mathrm{H} 105$ & $\mathrm{~N}$ & 54.80 & 158.60 & 8.60 & $15-25$ & 12.80 & \\
\hline $35 \mathrm{C}-1$ & 52.48 & 172.18 & $9 \mathrm{H} 106$ & $\mathrm{~N}$ & 56.80 & 263.40 & 9.41 & $10-30$ & 6.50 & \\
\hline $36 \mathrm{C}-1$ & 53.57 & 175.75 & $9 \mathrm{H} 107$ & $\mathrm{~N}$ & 52.30 & 274.50 & 34.40 & $10-20$ & 2.20 & \\
\hline $37 \mathrm{C}-1$ & 55.56 & 182.28 & $9 \mathrm{H} 108$ & $\mathrm{~N}$ & 48.70 & 196.00 & 8.64 & $10-60$ & 4.50 & \\
\hline $38 \mathrm{C}-1$ & 56.66 & 185.89 & $9 \mathrm{H} 109$ & $\mathrm{~N}$ & 46.20 & 247.90 & 2.35 & $15-60$ & 3.30 & \\
\hline $40 \mathrm{C}-1$ & 60.00 & 196.85 & 9H110 & $\mathrm{N}$ & 48.50 & 194.40 & 22.40 & $10-30$ & 12.50 & \\
\hline $41 \mathrm{C}-1$ & 61.39 & 201.41 & 9H111 & $\mathrm{N}$ & 51.60 & 357.80 & 59.50 & $10-60$ & 2.60 & \\
\hline $42 \mathrm{C}-1$ & 63.18 & 207.28 & 9H112 & $\mathrm{N}$ & 37.40 & 222.60 & 54.60 & $10-60$ & 2.60 & \\
\hline $43 \mathrm{C}-1$ & 64.62 & 212.01 & $9 \mathrm{H} 113$ & $\mathrm{~N}$ & 58.20 & 119.70 & 18.50 & $15-60$ & 1.80 & \\
\hline $44 \mathrm{C}-1$ & 65.68 & 215.49 & $9 \mathrm{H} 114$ & $\mathrm{~N}$ & 50.90 & 194.50 & 19.40 & $15-60$ & 2.50 & \\
\hline $46 \mathrm{C}-1$ & 69.47 & 227.92 & 9H115 & $\mathrm{N}$ & 53.50 & 113.60 & 30.80 & $10-30$ & 5.10 & \\
\hline $48 \mathrm{C}-1$ & 71.87 & 235.79 & $9 \mathrm{H} 116$ & $\mathrm{~N}$ & 55.10 & 335.00 & 31.20 & $10-20$ & 9.50 & \\
\hline $50 \mathrm{C}-1$ & 75.19 & 246.69 & 9H117 & $\mathrm{N}$ & 59.40 & 296.70 & 288.00 & $20-40$ & 11.10 & \\
\hline $52 \mathrm{C}-1$ & 78.18 & 256.50 & $9 \mathrm{H} 118$ & $\mathrm{~N}$ & 41.60 & 256.30 & 2.62 & $15-30$ & 3.70 & \\
\hline $53 \mathrm{C}-1$ & 80.28 & 263.39 & 9H119 & $\mathrm{N}$ & 47.30 & 289.40 & 17.20 & $15-30$ & 13.70 & \\
\hline $54 \mathrm{C}-1$ & 81.51 & 267.42 & $9 \mathrm{H} 120$ & $\mathrm{~N}$ & 47.70 & 260.90 & 21.00 & $10-30$ & 3.80 & \\
\hline $55 \mathrm{C}-1$ & 82.91 & 272.01 & $9 \mathrm{H} 121$ & $\mathrm{~N}$ & 49.50 & 307.10 & 11.60 & $15-60$ & 2.80 & \\
\hline $56 \mathrm{C}-1$ & 84.63 & 277.66 & $9 \mathrm{H} 122$ & $\mathrm{~N}$ & 42.10 & 231.20 & 2.86 & $10-30$ & 10.90 & \\
\hline $58 \mathrm{C}-1$ & 87.71 & 287.76 & $9 \mathrm{H} 123$ & $\mathrm{~N}$ & 60.30 & 11.80 & 2.38 & $15-20$ & 11.00 & \\
\hline $59 \mathrm{C}-1$ & 88.72 & 291.08 & $9 \mathrm{H} 124$ & $\mathrm{~N}$ & 49.70 & 67.50 & 163.00 & $15-60$ & 4.70 & \\
\hline
\end{tabular}




\begin{tabular}{|c|c|c|c|c|c|c|c|c|c|c|}
\hline $60 \mathrm{C}-1$ & 90.57 & 297.15 & 9H125 & $\mathrm{N}$ & 55.60 & 5.90 & 36.00 & $10-30$ & 7.80 & \\
\hline $62 \mathrm{C}-1$ & 93.64 & 307.22 & 9H126 & $\mathrm{N}$ & 51.40 & 231.20 & 22.00 & $10-20$ & 6.60 & \\
\hline $64 C-1$ & 96.39 & 316.24 & 9H127 & $\mathrm{N}$ & 54.20 & 207.40 & 18.60 & $10-20$ & 13.70 & \\
\hline $67 \mathrm{C}-1$ & 100.65 & 330.22 & $9 \mathrm{H} 128$ & $\mathrm{~N}$ & 54.00 & 9.80 & 49.30 & $10-40$ & 3.80 & \\
\hline $68 \mathrm{C}-1$ & 102.57 & 336.52 & $9 \mathrm{H} 129$ & $\mathrm{~N}$ & 48.20 & 246.80 & 20.50 & $15-60$ & 10.90 & \\
\hline $69 C-1$ & 103.96 & 341.08 & $9 \mathrm{H} 130$ & $\mathrm{~N}$ & 45.00 & 319.90 & 69.60 & $10-20$ & 2.70 & \\
\hline $70 \mathrm{C}-1$ & 105.66 & 346.65 & 9H131 & $\mathrm{N}$ & 20.80 & 183.20 & 7.03 & $10-15$ & 16.40 & \\
\hline $80 \mathrm{C}-1$ & 119.11 & 390.78 & 9H132 & $\mathrm{N}$ & 48.30 & 306.40 & 75.80 & $15-40$ & 9.00 & \\
\hline $82 \mathrm{C}-1$ & 121.44 & 398.43 & 9H133 & $\mathrm{N}$ & 56.70 & 18.70 & 15.80 & $10-40$ & 9.30 & \\
\hline $82 \mathrm{C}-1$ & 121.48 & 398.56 & 9H134 & $\mathrm{N}$ & 65.80 & 27.40 & 17.20 & $10-30$ & 10.60 & \\
\hline $83 \mathrm{C}-1$ & 121.97 & 400.16 & 9H135 & $\mathrm{N}$ & 53.60 & 309.80 & 38.90 & $10-40$ & 1.80 & \\
\hline $86 \mathrm{C}-1$ & 124.53 & 408.56 & 9H136 & $\mathrm{N}$ & 49.20 & 263.60 & 10.20 & $10-15$ & 31.10 & \\
\hline $93 \mathrm{C}-1$ & 131.20 & 430.45 & 9H137 & $\mathrm{N}$ & 41.80 & 344.30 & 15.90 & $10-20$ & 3.10 & \\
\hline $95 \mathrm{C}-1$ & 133.44 & 437.80 & 9H138 & $\mathrm{N}$ & 55.40 & 96.80 & 1.71 & $10-30$ & 14.30 & \\
\hline $99 \mathrm{C}-1$ & 138.88 & 455.64 & 9H139 & $\mathrm{N}$ & 50.90 & 289.10 & 4.31 & $10-30$ & 8.50 & \\
\hline $99 \mathrm{C}-1$ & 139.33 & 457.12 & $9 \mathrm{H} 140$ & $\mathrm{~N}$ & 39.00 & 111.10 & 2.17 & $15-30$ & 7.10 & \\
\hline $100 \mathrm{C}-1$ & 140.92 & 462.34 & 9H141 & $\mathrm{N}$ & 43.30 & 112.00 & 51.70 & $15-30$ & 8.10 & \\
\hline $101 \mathrm{C}-1$ & 142.42 & 467.26 & 9H142 & $\mathrm{N}$ & 43.80 & 4.50 & 86.90 & $10-40$ & 1.80 & \\
\hline $102 \mathrm{C}-1$ & 143.61 & 471.16 & 9H143 & $\mathrm{N}$ & 35.80 & 271.90 & 64.70 & $10-30$ & 1.70 & \\
\hline $103 \mathrm{C}-1$ & 145.36 & 476.90 & 9H144 & $\mathrm{N}$ & 35.90 & 72.20 & 172.00 & $10-30$ & 1.70 & \\
\hline $104 \mathrm{C}-1$ & 146.46 & 480.51 & 9H145 & $\mathrm{N}$ & 59.70 & 55.30 & 74.80 & $10-30$ & 1.90 & \\
\hline $105 \mathrm{C}-1$ & 148.42 & 486.94 & 9H146 & $\mathrm{N}$ & 45.70 & 123.30 & 131.00 & $10-40$ & 3.10 & \\
\hline $106 \mathrm{C}-1$ & 150.27 & 493.01 & $9 \mathrm{H} 147$ & $\mathrm{~N}$ & 43.80 & 2.70 & 197.00 & $10-40$ & 0.80 & \\
\hline $107 \mathrm{C}-1$ & 151.52 & 497.11 & 9H148 & $\mathrm{N}$ & 33.60 & 123.80 & 146.00 & $10-40$ & 2.60 & \\
\hline $108 \mathrm{C}-1$ & 152.77 & 501.21 & 9H149 & $\mathrm{N}$ & 45.00 & 299.90 & 127.00 & $10-30$ & 1.80 & \\
\hline $108 \mathrm{C}-1$ & 153.49 & 503.58 & $9 \mathrm{H} 150$ & $\mathrm{~N}$ & 57.00 & 178.80 & 49.30 & $10-30$ & 2.00 & \\
\hline $109 \mathrm{C}-1$ & 154.50 & 506.89 & $9 \mathrm{H} 151$ & $\mathrm{~N}$ & 39.20 & 43.80 & 42.50 & $10-40$ & 2.70 & \\
\hline $113 \mathrm{P}-1$ & 454.91 & 1492.50 & 0H001 & & & & 1.39 & & & Unstable \\
\hline $113 \mathrm{P}-1$ & 455.45 & 1494.26 & 0H004 & $\mathrm{N}$ & 40.10 & 63.00 & 3.87 & $15-30$ & 20.00 & \\
\hline
\end{tabular}


Table 25. Paleomagnetic results from the Westchester core site and monitoring well (WEST), Long Beach, California.

[Inclination of remanent magnetization after alternating-field treatment of samples from WEST. RML Id, Rock Magnetism Laboratory identification number; Decl (relativity), declination relative to split face of core; N, normal; $\mathrm{R}$, reversed; I, indeterminate polarity of magnetization; Oe, oersteds; mT, millitesla; AF Demag, range of demagnetization steps in Oe used in calculation of inclination (100 Oe=10 mT); MAD, maximum angular deviation (in degrees) from principal-component analysis (Kirschvink, 1980)]

\begin{tabular}{|c|c|c|c|c|c|c|c|c|c|c|}
\hline $\begin{array}{l}\text { Core } \\
\text { number }\end{array}$ & $\begin{array}{c}\text { Depth, in } \\
\text { meters }\end{array}$ & $\begin{array}{l}\text { Depth, } \\
\text { in feet }\end{array}$ & $\begin{array}{l}\text { RML } \\
\text { Id }\end{array}$ & Polarity & $\begin{array}{c}\text { Inclination, in } \\
\text { degrees }\end{array}$ & $\begin{array}{c}\text { Decl } \\
\text { (relativity) }\end{array}$ & $\begin{array}{l}\text { Jnrm } \\
\mathbf{m A} A / \mathbf{m}\end{array}$ & $\begin{array}{c}\text { AF } \\
\text { Demag } \\
\text { (Oe) }\end{array}$ & MAD & Comment \\
\hline $13 \mathrm{C}-1$ & 18.76 & 61.54 & $1 \mathrm{H} 245$ & $\mathrm{~N}$ & 59.7 & 261.3 & 7.3 & $10-30$ & 7.5 & \\
\hline $14 \mathrm{C}-1$ & 20.81 & 68.28 & $1 \mathrm{H} 246$ & $\mathrm{~N}$ & 62.7 & 225.8 & 6.5 & $10-30$ & 11.5 & \\
\hline $16 \mathrm{C}-1$ & 23.37 & 76.66 & $1 \mathrm{H} 247$ & $\mathrm{~N}$ & 42.4 & 208.4 & 4.2 & $15-40$ & 9.7 & \\
\hline $18 \mathrm{C}-1$ & 26.88 & 88.18 & $1 \mathrm{H} 248$ & $\mathrm{~N}$ & 50.4 & 35.5 & 1.1 & $10-40$ & 9.3 & \\
\hline $21 \mathrm{C}-1$ & 30.80 & 101.05 & $1 \mathrm{H} 249$ & $\mathrm{R}$ & -36.0 & 252.8 & 0.3 & $30-50$ & 17.7 & \\
\hline $24 \mathrm{C}-1$ & 35.46 & 116.35 & $1 \mathrm{H} 250$ & $\mathrm{~N}$ & 55.0 & 242.9 & 0.9 & $15-40$ & 7.0 & \\
\hline $25 \mathrm{C}-1$ & 37.35 & 122.54 & $1 \mathrm{H} 251$ & $\mathrm{~N}$ & 61.5 & 106.0 & 0.9 & $10-40$ & 9.1 & \\
\hline $26 \mathrm{C}-1$ & 38.86 & 127.48 & $1 \mathrm{H} 252$ & $\mathrm{~N}$ & 57.1 & 181.1 & 39.1 & $20-50$ & 5.9 & \\
\hline $27 \mathrm{C}-1$ & 39.79 & 130.54 & $1 \mathrm{H} 253$ & $\mathrm{~N}$ & 52.5 & 299.9 & 13.6 & $15-30$ & 8.6 & \\
\hline $28 \mathrm{C}-1$ & 41.80 & 137.13 & $1 \mathrm{H} 254$ & $\mathrm{~N}$ & 51.8 & 59.9 & 45.6 & $15-40$ & 4.1 & \\
\hline $29 \mathrm{C}-1$ & 43.49 & 142.67 & $1 \mathrm{H} 255$ & $\mathrm{~N}$ & 45.8 & 45.6 & 76.1 & $10-30$ & 1.9 & \\
\hline $30 \mathrm{C}-1$ & 44.59 & 146.30 & $1 \mathrm{H} 256$ & $\mathrm{~N}$ & 47.6 & 192.3 & 60.0 & $15-30$ & 5.1 & \\
\hline $36 \mathrm{C}-1$ & 50.42 & 165.43 & $1 \mathrm{H} 257$ & $\mathrm{~N}$ & 58.0 & 177.2 & 24.8 & $15-40$ & 1.1 & \\
\hline $39 \mathrm{C}-1$ & 55.30 & 181.44 & $1 \mathrm{H} 258$ & $\mathrm{~N}$ & 76.4 & 94.9 & 4.6 & $20-40$ & 8.8 & \\
\hline $40 \mathrm{C}-1$ & 56.55 & 185.53 & $1 \mathrm{H} 259$ & $\mathrm{~N}$ & 85.2 & 215.0 & 135.0 & $15-30$ & 1.8 & \\
\hline $42 \mathrm{C}-1$ & 58.12 & 190.69 & $1 \mathrm{H} 260$ & $\mathrm{~N}$ & 61.4 & 239.9 & 12.6 & $15-30$ & 15.5 & \\
\hline $43 \mathrm{C}-1$ & 60.29 & 197.80 & $1 \mathrm{H} 261$ & $\mathrm{~N}$ & 83.5 & 274.1 & 161.0 & $5-20$ & 1.4 & \\
\hline $44 \mathrm{C}-1$ & 61.49 & 201.74 & $1 \mathrm{H} 262$ & $\mathrm{~N}$ & 55.1 & 38.1 & 48.8 & $10-30$ & 5.8 & \\
\hline $47 \mathrm{C}-1$ & 66.52 & 218.23 & $1 \mathrm{H} 263 \mathrm{~A}$ & $\mathrm{~N}$ & 57.1 & 307.7 & 87.4 & $15-30$ & 8.6 & \\
\hline $48 \mathrm{C}-1$ & 67.41 & 221.16 & $1 \mathrm{H} 264$ & $\mathrm{~N}$ & 34.6 & 249.0 & 197.0 & 30 & & Single step \\
\hline $49 \mathrm{C}-1$ & 68.82 & 225.78 & $1 \mathrm{H} 265$ & $\mathrm{~N}$ & 58.1 & 56.5 & 232.0 & $10-30$ & 11.3 & \\
\hline $53 \mathrm{C}-1$ & 75.73 & 248.45 & $1 \mathrm{H} 266$ & $\mathrm{~N}$ & 65.0 & 161.4 & 145.0 & $10-30$ & 8.0 & \\
\hline $54 \mathrm{C}-1$ & 76.55 & 251.15 & $1 \mathrm{H} 267$ & $\mathrm{R}$ & -40.9 & 14.3 & 104.0 & $10-20$ & 4.7 & \\
\hline $55 \mathrm{C}-1$ & 78.60 & 257.89 & $1 \mathrm{H} 268$ & $\mathrm{I}$ & 13.9 & 276.9 & 273.0 & $10-30$ & 2.1 & \\
\hline $57 \mathrm{C}-1$ & 80.47 & 264.02 & $1 \mathrm{H} 269$ & $\mathrm{~N}$ & 68.8 & 62.9 & 172.0 & $10-30$ & 5.5 & \\
\hline $58 \mathrm{C}-1$ & 81.03 & 265.85 & $1 \mathrm{H} 270$ & $\mathrm{~N}$ & 38.8 & 233.7 & 130.0 & $10-30$ & 1.4 & \\
\hline $60 \mathrm{C}-1$ & 85.08 & 279.15 & $1 \mathrm{H} 271$ & $\mathrm{~N}$ & 51.6 & 307.0 & 135.0 & $10-30$ & 2.8 & \\
\hline $61 \mathrm{C}-1$ & 85.45 & 280.36 & $1 \mathrm{H} 272$ & $\mathrm{~N}$ & 46.8 & 308.7 & 165.0 & $10-30$ & 2.4 & \\
\hline $62 \mathrm{C}-1$ & 87.72 & 287.80 & $1 \mathrm{H} 273$ & $\mathrm{~N}$ & 43.3 & 7.4 & 124.0 & $10-30$ & 5.2 & \\
\hline $63 \mathrm{C}-1$ & 88.49 & 290.33 & $1 \mathrm{H} 274$ & $\mathrm{~N}$ & 42.7 & 292.1 & 199.0 & $15-30$ & 1.7 & \\
\hline $64 \mathrm{C}-1$ & 90.70 & 297.56 & $1 \mathrm{H} 275$ & $\mathrm{~N}$ & 37.8 & 317.1 & 133.0 & $10-30$ & 2.7 & \\
\hline $65 \mathrm{C}-1$ & 91.87 & 301.41 & $1 \mathrm{H} 276$ & $\mathrm{~N}$ & 52.7 & 154.0 & 110.0 & $15-30$ & 4.8 & \\
\hline $66 \mathrm{C}-1$ & 93.95 & 308.22 & $1 \mathrm{H} 277$ & $\mathrm{~N}$ & 74.6 & 283.0 & 185.0 & $15-30$ & 3.0 & \\
\hline $67 \mathrm{C}-1$ & 95.07 & 311.90 & $1 \mathrm{H} 278$ & $\mathrm{~N}$ & 35.6 & 259.1 & 114.0 & $30-50$ & 2.6 & \\
\hline $68 \mathrm{C}-2$ & 96.51 & 316.64 & $1 \mathrm{H} 279$ & $\mathrm{~N}$ & 42.9 & 293.3 & 77.0 & $20-40$ & 3.4 & \\
\hline $71 \mathrm{C}-1$ & 100.98 & 331.30 & $1 \mathrm{H} 280$ & $\mathrm{~N}$ & 53.9 & 0.0 & 152.0 & $20-40$ & 7.2 & \\
\hline $72 \mathrm{C}-1$ & 102.66 & 336.80 & $1 \mathrm{H} 281$ & $\mathrm{~N}$ & 44.5 & 245.2 & 131.0 & $15-40$ & 5.3 & \\
\hline $73 \mathrm{C}-1$ & 103.68 & 340.16 & $1 \mathrm{H} 282$ & $\mathrm{~N}$ & 24.7 & 330.9 & 169.0 & $15-40$ & 4.1 & \\
\hline $74 \mathrm{C}-1$ & 105.56 & 346.31 & $1 \mathrm{H} 283$ & & & & 67.9 & & & $\begin{array}{c}\text { Demag } \\
\text { error }\end{array}$ \\
\hline
\end{tabular}




\begin{tabular}{|c|c|c|c|c|c|c|c|c|c|}
\hline $76 \mathrm{C}-1$ & 108.47 & 355.87 & $1 \mathrm{H} 284$ & $\mathrm{~N}$ & 54.9 & 293.8 & 170.0 & $15-30$ & 6.9 \\
\hline $78 \mathrm{C}-1$ & 111.94 & 367.26 & $1 \mathrm{H} 285$ & $\mathrm{~N}$ & 42.8 & 30.4 & 138.0 & $15-30$ & 4.4 \\
\hline $79 \mathrm{C}-1$ & 112.86 & 370.26 & $1 \mathrm{H} 286$ & $\mathrm{R}$ & -31.4 & 103.8 & 115.0 & $15-30$ & 3.4 \\
\hline $80 \mathrm{C}-1$ & 115.12 & 377.70 & $1 \mathrm{H} 287$ & $\mathrm{~N}$ & 26.4 & 257.4 & 71.7 & $10-30$ & 5.5 \\
\hline $82 \mathrm{C}-1$ & 117.58 & 385.77 & $1 \mathrm{H} 288$ & $\mathrm{~N}$ & 52.2 & 208.6 & 108.0 & $10-30$ & 3.3 \\
\hline $83 \mathrm{C}-1$ & 119.03 & 390.51 & $1 \mathrm{H} 289$ & $\mathrm{~N}$ & 57.1 & 193.8 & 170.0 & $15-40$ & 19.8 \\
\hline $88 \mathrm{C}-1$ & 126.80 & 416.00 & $1 \mathrm{H} 290$ & $\mathrm{~N}$ & 60.6 & 237.4 & 108.0 & $15-30$ & 1.0 \\
\hline $90 \mathrm{C}-1$ & 129.71 & 425.55 & $1 \mathrm{H} 291$ & $\mathrm{~N}$ & 73.0 & 168.3 & 16.5 & $15-30$ & 14.8 \\
\hline $101 \mathrm{C}-1$ & 143.86 & 471.98 & $1 \mathrm{H} 292$ & $\mathrm{~N}$ & 51.5 & 94.3 & 33.1 & $10-30$ & 11.3 \\
\hline $107 \mathrm{C}-1$ & 152.91 & 501.67 & $1 \mathrm{H} 293$ & $\mathrm{~N}$ & 63.0 & 340.4 & 72.9 & $15-30$ & 7.5 \\
\hline $108 \mathrm{C}-1$ & 154.29 & 506.21 & $1 \mathrm{H} 294$ & $\mathrm{~N}$ & 58.4 & 29.0 & 138.0 & $15-40$ & 6.5 \\
\hline $109 \mathrm{C}-1$ & 155.95 & 511.64 & $1 \mathrm{H} 295$ & $\mathrm{~N}$ & 64.0 & 173.9 & 98.0 & $15-30$ & 1.8 \\
\hline $110 \mathrm{C}-1$ & 157.18 & 515.67 & $1 \mathrm{H} 296$ & $\mathrm{~N}$ & 73.9 & 158.5 & 90.9 & $15-30$ & 4.2 \\
\hline $112 \mathrm{C}-1$ & 160.88 & 527.81 & $1 \mathrm{H} 297$ & $\mathrm{~N}$ & 49.9 & 349.8 & 76.9 & $15-40$ & 3.6 \\
\hline $113 \mathrm{C}-1$ & 162.35 & 532.66 & $1 \mathrm{H} 298$ & $\mathrm{~N}$ & 50.0 & 131.2 & 174.0 & $15-30$ & 6.3 \\
\hline $114 \mathrm{C}-1$ & 163.27 & 535.66 & $1 \mathrm{H} 299$ & $\mathrm{~N}$ & 81.8 & 274.6 & 172.0 & $15-30$ & 5.8 \\
\hline $116 \mathrm{C}-1$ & 166.23 & 545.39 & $1 \mathrm{H} 300$ & $\mathrm{~N}$ & 59.7 & 44.4 & 50.0 & $15-30$ & 3.0 \\
\hline $117 \mathrm{C}-1$ & 168.17 & 551.74 & $1 \mathrm{H} 301$ & $\mathrm{~N}$ & 51.9 & 55.8 & 139.0 & $15-40$ & 4.4 \\
\hline $118 \mathrm{C}-1$ & 169.59 & 556.41 & $1 \mathrm{H} 302$ & $\mathrm{~N}$ & 56.9 & 222.3 & 162.0 & $15-30$ & 5.5 \\
\hline $119 \mathrm{C}-1$ & 171.20 & 561.67 & $1 \mathrm{H} 303$ & $\mathrm{~N}$ & 67.6 & 278.5 & 59.9 & $15-30$ & 4.1 \\
\hline $120 \mathrm{C}-1$ & 172.53 & 566.05 & $1 \mathrm{H} 304$ & $\mathrm{~N}$ & 63.2 & 67.3 & 79.0 & $15-30$ & 6.1 \\
\hline $121 \mathrm{C}-1$ & 174.52 & 572.56 & $1 \mathrm{H} 305$ & $\mathrm{R}$ & -58.9 & 280.8 & 144.0 & $15-40$ & 5.0 \\
\hline $125 \mathrm{C}-1$ & 180.12 & 590.93 & $1 \mathrm{H} 306$ & $\mathrm{~N}$ & 65.6 & 72.1 & 118.0 & $10-30$ & 5.1 \\
\hline $127 \mathrm{C}-1$ & 181.53 & 595.57 & $1 \mathrm{H} 307$ & $\mathrm{~N}$ & 50.8 & 15.6 & 84.6 & $15-30$ & 3.6 \\
\hline $128 \mathrm{C}-1$ & 182.31 & 598.12 & 1H308 & $\mathrm{N}$ & 64.9 & 209.9 & 38.8 & $15-30$ & 2.7 \\
\hline $130 \mathrm{C}-1$ & 185.09 & 607.26 & 1H309 & $\mathrm{N}$ & 60.1 & 133.7 & 29.7 & $15-30$ & 10.4 \\
\hline $131 \mathrm{C}-1$ & 186.79 & 612.82 & $1 \mathrm{H} 310$ & $\mathrm{~N}$ & 66.4 & 58.9 & 52.7 & $15-30$ & 1.2 \\
\hline $132 \mathrm{C}-1$ & 188.05 & 616.95 & $1 \mathrm{H} 311$ & $\mathrm{~N}$ & 49.7 & 71.2 & 24.5 & $15-30$ & 8.6 \\
\hline $133 \mathrm{C}-1$ & 189.81 & 622.72 & $1 \mathrm{H} 312$ & $\mathrm{~N}$ & 58.6 & 312.7 & 53.7 & $15-30$ & 1.9 \\
\hline $134 \mathrm{C}-1$ & 191.13 & 627.08 & $1 \mathrm{H} 313$ & $\mathrm{~N}$ & 39.6 & 337.8 & 114.0 & $15-40$ & 3.2 \\
\hline $135 \mathrm{C}-1$ & 193.13 & 633.62 & $1 \mathrm{H} 314$ & $\mathrm{~N}$ & 48.7 & 60.3 & 48.3 & $15-30$ & 9.1 \\
\hline $136 \mathrm{C}-1$ & 193.82 & 635.89 & $1 \mathrm{H} 315$ & $\mathrm{~N}$ & 61.1 & 223.6 & 158.0 & $15-40$ & 2.0 \\
\hline $138 \mathrm{C}-1$ & 196.82 & 645.72 & $1 \mathrm{H} 316$ & $\mathrm{~N}$ & 62.5 & 136.1 & 173.0 & $15-40$ & 3.1 \\
\hline $139 \mathrm{C}-1$ & 199.28 & 653.81 & $1 \mathrm{H} 317$ & $\mathrm{~N}$ & 62.7 & 291.7 & 234.0 & $15-30$ & 2.9 \\
\hline $140 \mathrm{C}-1$ & 199.99 & 656.15 & 1H318 & $\mathrm{N}$ & 49.5 & 45.2 & 49.1 & $10-30$ & 7.7 \\
\hline $141 \mathrm{C}-1$ & 201.49 & 661.05 & $1 \mathrm{H} 319$ & $\mathrm{~N}$ & 53.4 & 118.9 & 105.0 & $15-40$ & 2.1 \\
\hline $142 \mathrm{C}-1$ & 203.30 & 666.98 & $1 \mathrm{H} 320$ & $\mathrm{~N}$ & 68.7 & 72.5 & 116.0 & $10-30$ & 2.6 \\
\hline $143 \mathrm{C}-1$ & 204.69 & 671.54 & $1 \mathrm{H} 321$ & $\mathrm{~N}$ & 77.8 & 29.9 & 49.1 & $15-30$ & 8.7 \\
\hline $144 \mathrm{C}-1$ & 206.74 & 678.28 & $1 \mathrm{H} 322$ & $\mathrm{~N}$ & 67.8 & 211.9 & 88.1 & $15-40$ & 1.1 \\
\hline $145 \mathrm{C}-1$ & 207.98 & 682.36 & $1 \mathrm{H} 323$ & $\mathrm{~N}$ & 73.0 & 44.3 & 195.0 & $15-40$ & 2.8 \\
\hline $146 \mathrm{C}-2$ & 210.04 & 689.12 & $1 \mathrm{H} 324$ & $\mathrm{~N}$ & 61.3 & 281.6 & 78.5 & $15-40$ & 3.6 \\
\hline $147 \mathrm{C}-1$ & 212.44 & 696.97 & $1 \mathrm{H} 325$ & $\mathrm{~N}$ & 55.6 & 77.6 & 82.8 & $15-30$ & 10.4 \\
\hline $149 \mathrm{C}-1$ & 214.01 & 702.12 & $1 \mathrm{H} 326$ & $\mathrm{~N}$ & 73.0 & 104.3 & 83.6 & $15-30$ & 7.1 \\
\hline $150 \mathrm{C}-1$ & 215.36 & 706.57 & $1 \mathrm{H} 327$ & $\mathrm{~N}$ & 64.4 & 77.7 & 126.0 & $15-30$ & 6.8 \\
\hline $151 \mathrm{C}-1$ & 216.65 & 710.80 & $1 \mathrm{H} 328$ & $\mathrm{~N}$ & 75.5 & 46.4 & 74.7 & $10-20$ & 2.3 \\
\hline $153 \mathrm{C}-1$ & 219.92 & 721.51 & $1 \mathrm{H} 329$ & $\mathrm{~N}$ & 72.7 & 63.6 & 57.9 & $10-30$ & 5.2 \\
\hline $154 \mathrm{C}-1$ & 221.27 & 725.94 & $1 \mathrm{H} 330$ & $\mathrm{~N}$ & 45.0 & 25.9 & 57.8 & $15-30$ & 7.5 \\
\hline $155 \mathrm{C}-1$ & 222.78 & 730.89 & $1 \mathrm{H} 332$ & $\mathrm{~N}$ & 72.5 & 329.7 & 14.5 & $15-40$ & 4.1 \\
\hline $156 \mathrm{C}-1$ & 224.31 & 735.92 & $1 \mathrm{H} 333$ & $\mathrm{~N}$ & 64.2 & 341.6 & 43.3 & $15-40$ & 2.2 \\
\hline
\end{tabular}




\begin{tabular}{|c|c|c|c|c|c|c|c|c|c|}
\hline $157 \mathrm{C}-1$ & 225.77 & 740.72 & 1H335 & $\mathrm{N}$ & 48.2 & 78.9 & 2.4 & $15-30$ & 16.0 \\
\hline $161 \mathrm{C}-1$ & 231.46 & 759.37 & $1 \mathrm{H} 336$ & $\mathrm{~N}$ & 72.9 & 62.6 & 99.9 & $15-30$ & 8.1 \\
\hline $162 \mathrm{C}-1$ & 232.01 & 761.18 & $1 \mathrm{H} 337$ & $\mathrm{~N}$ & 82.1 & 155.9 & 42.9 & $15-30$ & 10.8 \\
\hline $163 \mathrm{C}-1$ & 233.34 & 765.56 & $1 \mathrm{H} 331$ & $\mathrm{~N}$ & 67.1 & 241.7 & 25.5 & $15-30$ & 8.5 \\
\hline $164 \mathrm{C}-1$ & 235.42 & 772.38 & 1H338 & $\mathrm{N}$ & 55.6 & 95.9 & 39.4 & $15-40$ & 3.0 \\
\hline $165 \mathrm{C}-1$ & 236.44 & 775.72 & 1H339 & $\mathrm{R}$ & -76.5 & 101.3 & 162.0 & $15-30$ & 4.5 \\
\hline $166 \mathrm{C}-1$ & 238.58 & 782.74 & $1 \mathrm{H} 340$ & $\mathrm{~N}$ & 63.9 & 132.1 & 68.1 & $10-30$ & 6.2 \\
\hline $168 \mathrm{C}-1$ & 241.41 & 792.02 & $1 \mathrm{H} 341$ & $\mathrm{~N}$ & 55.9 & 82.5 & 30.8 & $15-40$ & 6.3 \\
\hline $169 \mathrm{C}-1$ & 242.72 & 796.31 & $1 \mathrm{H} 334$ & $\mathrm{~N}$ & 56.9 & 282.7 & 24.2 & $20-40$ & 4.0 \\
\hline $170 \mathrm{C}-2$ & 250.76 & 822.69 & 1H342 & $\mathrm{N}$ & 63.8 & 180.7 & 14.4 & $20-40$ & 2.0 \\
\hline $171 \mathrm{C}-1$ & 251.69 & 825.76 & $1 \mathrm{H} 343$ & $\mathrm{~N}$ & 53.2 & 266.7 & 46.4 & $20-40$ & 5.3 \\
\hline $172 \mathrm{C}-1$ & 253.95 & 833.18 & $1 \mathrm{H} 344$ & $\mathrm{~N}$ & 76.4 & 289.7 & 46.7 & $15-40$ & 0.6 \\
\hline $174 \mathrm{C}-1$ & 268.85 & 882.07 & $1 \mathrm{H} 345$ & $\mathrm{~N}$ & 44.7 & 341.6 & 16.9 & $15-40$ & 4.1 \\
\hline $175 \mathrm{C}-1$ & 270.29 & 886.77 & $1 \mathrm{H} 346$ & $\mathrm{~N}$ & 60.1 & 324.0 & 6.5 & $15-40$ & 6.2 \\
\hline $175 \mathrm{C}-2$ & 272.08 & 892.64 & $1 \mathrm{H} 347$ & $\mathrm{~N}$ & 71.9 & 37.5 & 18.2 & $20-40$ & 2.0 \\
\hline
\end{tabular}

